\title{
ACCIDENT PROGRESSION ANALYSIS \\ P-300
}

April 2016

United States

Nuclear Regulatory Commission

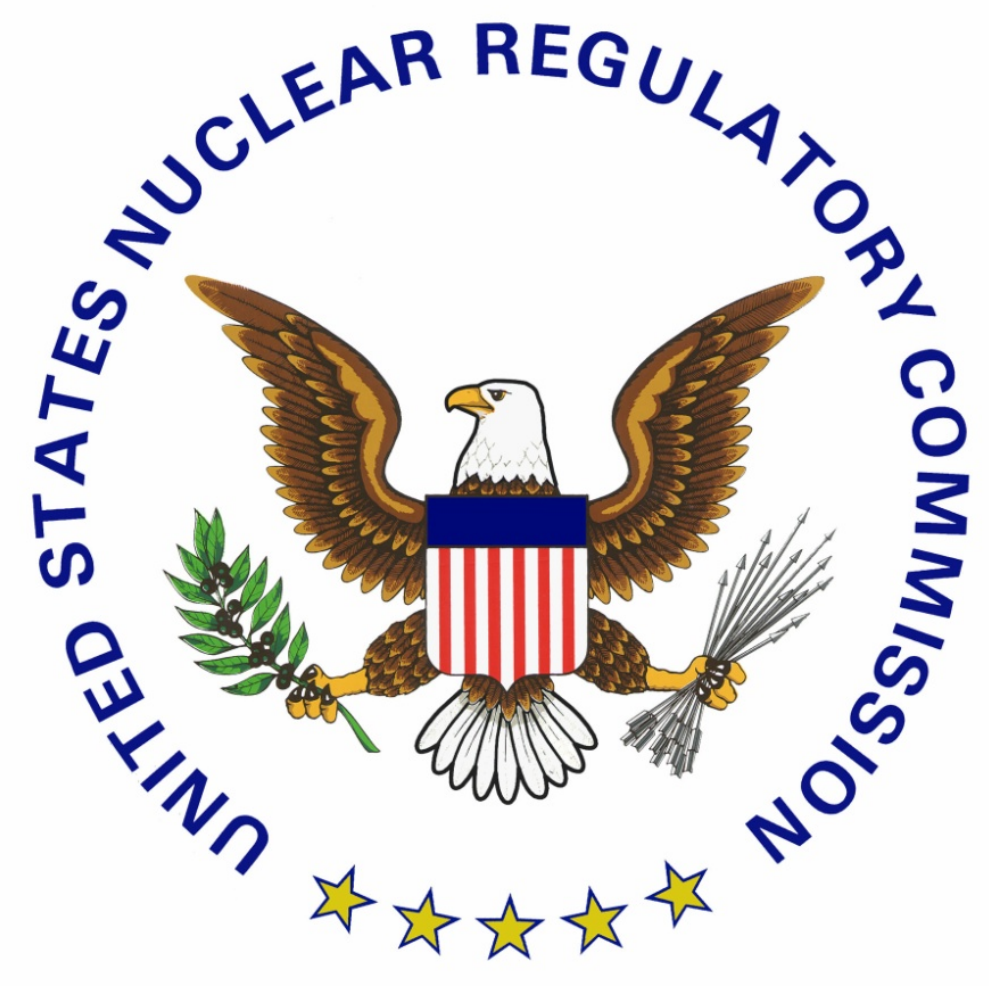

TII Iaho National Laboratory 


\section{DISCLAIMER NOTICE}

This report was prepared as an account of work sponsored by an agency of the United States Government. Neither the United States Government nor any agency thereof, or any of their employees, makes any warranty, expressed or implied, or assumes any legal liability of responsibility for any third party's use, or the results of such use, or any information, apparatus, product or process disclosed in this report, or represents that its use by such third party would not infringe privately owned rights. 


\section{Accident Progression Analysis (P-300)}

\section{Course Presented by}

Shawn St Germain, INL Shawn.StGermain@inl.gov 208-526-9575

Douglas Akers, INL Douglas.Akers@inl.gov 208-526-6118 


\section{Course Objective}

- To understand the basics of severe accident progression, from the onset of core damage to the release of a radioactive source term to the environment

- Onset of core damage (for PWRs) often defined as the uncovering of the top of active fuel (TAF)

- Temperature criteria also used

- Two phases: core degradation and containment challenge

- In-vessel and ex-vessel

- Release to the environment often characterized in terms of Large Early Release Frequency (LERF) 


\section{Course Outline}

1. Risk-Informed Regulation and Review of PRA Basic concepts

2. Overview of Level-1/2/3 PRA

3. LWR Containment Designs

4. Phenomena Affecting Vessel Integrity

5. Phenomena Affecting Containment Integrity

6. Containment Event Tree Development

7. Phenomenological Modeling Capabilities

8. Radionuclide Release and Transport

9. Level-2 PRA Integration and Quantification

10. Example Level-2 Analysis

11. NUREG/CR-6595

12. Review

13. Exam 


\section{Annotated Bibliography}

- WASH-1400, Reactor Safety Study: An Assessment of Accident Risks in U.S. Commercial Nuclear Power Plants, October 1975

- Original Level-2 analysis.

- NUREG/CR-4551, Volumes 1 - 7, Evaluation of Severe Accident Risks, Dates: varied (1990 - 1993)

- Most comprehensive Level-2 analysis, developed Accident Progression Event Tree (APET) method of modeling containment performance (i.e., event tree with 75 - 125 top events).

- NUREG/CR-6595, Rev.1, An Approach for Estimating the Frequencies of Various Containment Failure Modes and Bypass Events, September 2004.

- Developed simple LERF models to support Reg. Guide 1.174.

- NUREG-1560, Volumes 1, 2 \& 3, Individual Plant Examination Program: Perspectives on Reactor Safety and Plant Performance, December 1997

- Extracted and summarizes highlights and insights from the collective IPE results (75 IPEs covering 108 NPP units), including containment performance issues. 


\section{Annotated Bibliography (cont.)}

- NUREG/CR-6338, Resolution of the Direct Containment Heating Issue for All Westinghouse Plants With Large Dry Containments or Subatmospheric Containments, February 1996

- Comprehensive analysis of all referenced plants, includes PWR containment design details extracted from IPEs, including fragility curves.

- NUREG/CR-6475, Resolution of the Direct Containment Heating Issue for Combustion Engineering Plants and Babcock \& Wilcox Plants, November 1998.

- Comprehensive analysis of all referenced plants, includes PWR containment design details extracted from IPEs, including fragility curves.

- NUREG/CR-5423, The Probability of Liner Failure in a Mark-I Containment, August 1991.

- Detailed analysis of issue, benefited from a public workshop and an extensive peer review process. 


\section{Annotated Bibliography (cont.)}

- EPRI NP-6260-M, Criteria and Guidelines for Predicting Concrete Containment Leakage, April 1989.

- EPRI developed method for predicting containment failure mechanisms and leakage locations.

- NUREG-1037, Draft Report for Comment, Containment Performance Working Group Report, May 1985.

- Analyzed potential leakage of containment penetrations as a result of conditions beyond design basis.

- IDCOR T-10.1, Containment Structural Capacity of Light Water Nuclear Power Plants, July 1983

- Analyzes ultimate containment capacity of several PWR and BWR containment structures. Appendix B describes the method used to generate containment fragility curves. 


\section{Annotated Bibliography (cont.)}

- NUREG/CR-4242, Survey of Light Water Reactor Containment Systems, Dominant Failure Modes, and Mitigation Opportunities, January 1988

- Detailed descriptions of various containment designs, rest of information somewhat dated.

- NUREG-1570, Risk Assessment of Severe Accident-Induced Steam Generator Tube Rupture, March 1998.

- Latest information available on induced SGTRs.

- NUREG-1150, Severe Accident Risks: An Assessment for Five U.S. Nuclear Power Plants, December 1990.

- Summary report on the five full-scope PRAs performed and documented in the NUREG/CR-4550, Vol. 1-7; and NUREG/CR4551, Vol. 1-7. 


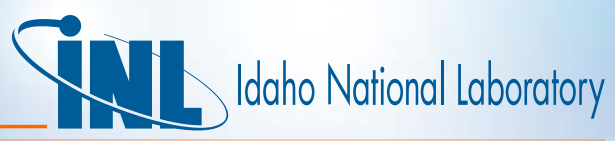

\section{Acronyms}

ACRS Advisory Committee on Reactor Safeguards

ADS Automatic Depressurization System

AFW Auxiliary Feedwater System

AM Accident Management

AP-600 Westinghouse Advanced PWR (600 MWe)

APB Accident Progression Bin

APET Accident Progression Event Tree

ASP Accident Sequence Precursor

AST Accident Source Term

ATWS Anticipated Transient Without SCRAM

B\&W Babcock \& Wilcox

BWR Boiling Water Reactor

CCFP Conditional (on core damage) Containment Failure Probability

$\mathrm{CCl}$ Core Concrete Interaction

CD Core Damage

CDF Core Damage Frequency

CE Combustion Engineering

CET Containment Event Tree

CFD Computational Fluid Dynamics

CFF Containment Failure Frequency

$\mathrm{CHF} \quad$ Critical Heat Flux

$\begin{array}{ll}\text { CHR } & \text { Containment Heat Removal } \\ \text { CRD } & \text { Control Rod Drive } \\ \text { CS } & \text { Cut Set } \\ \text { CSR } & \text { Containment Spray Recirculation } \\ \text { CSS } & \text { Containment Spray System } \\ \text { DCH } & \text { Direct Containment Heating } \\ \text { DW } & \text { Drywell (BWR) } \\ \text { ECCS } & \text { Emergency Core Cooling System } \\ \text { ECI } & \text { Emergency Coolant Injection } \\ \text { ECR } & \text { Emergency Coolant Recirculation } \\ \text { ERVC } & \text { External Reactor Vessel Cooling } \\ \text { FAl } & \text { Fauske Associates, Incorporated } \\ \text { FCI } & \text { Fuel-Coolant Interaction } \\ \text { FEM } & \text { Finite Element Method } \\ \text { FIBS } & \text { Final Bounding State } \\ \text { H2 } & \text { Hydrogen } \\ \text { HPIS } & \text { High Pressure Injection Systems } \\ \text { HPME } & \text { High Pressure Melt Ejection } \\ \text { IPE } & \text { Individual Plant Examination } \\ \text { ISLOCA } & \text { Interfacing System Loss of Coolant Accident } \\ \text { IVR } & \text { In-Vessel Retention }\end{array}$




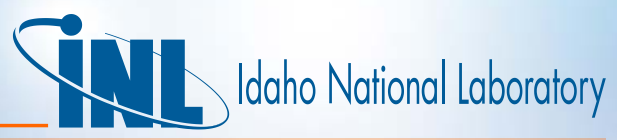

\section{Acronyms (cont.)}

JAERI Japan Atomic Energy Research Institute

KAERI Korea Atomic Energy Research Institute

LERF Large Early Release Frequency

LHF Lower Head Failure

LOCA Loss of Coolant Accident

LPIS Low Pressure Injection System

LWR Light Water Reactor

MAAP Modular Accident Analysis Program

MACCS MELCOR Accident Consequence Code System

$\mathrm{MCCl}$ Molten Core Concrete Interaction

MSSV Main Steam Safety Valve

OECD Organization for Economic Cooperation and Development

OTSG Once-Through Steam Generator

PCS Power Conversion System

PDF Probability Density Function

PDS Plant Damage State

PORV Power (or Pilot) Operated Relief Valves

PST Parametric Source Term

PWR Pressurized Water Reactor

QHO Quantitative Health Objective

RCP Reactor Coolant Pump

$\begin{array}{ll}\text { RCS } & \text { Reactor Coolant system } \\ \text { ROAAM } & \text { Risk Oriented Accident Analysis Methodology } \\ \text { RPS } & \text { Reactor Protection System } \\ \text { RPV } & \text { Reactor Pressure Vessel } \\ \text { RSGPS } & \text { Reactor Safety Goal Policy Statement } \\ \text { RST } & \text { Revised Source Term } \\ \text { RWST } & \text { Refueling Water Storage Tank } \\ \text { SAMG } & \text { Severe Accident Management Guidelines } \\ \text { SBLOCA } & \text { Small Break LOCA } \\ \text { SBO } & \text { Station Blackout } \\ \text { SERG } & \text { Steam Explosion Review Group } \\ \text { SG } & \text { Steam Generator } \\ \text { SGTR } & \text { Steam Generator Tube Rupture } \\ \text { SNL } & \text { Sandia National Laboratory } \\ \text { SRV } & \text { Safety Relief Valve } \\ \text { TAF } & \text { Top of Active Fuel (in reactor core) } \\ \text { TEDE } & \text { Total Effective Dose Equivalent } \\ \text { TMI-2 } & \text { Three Mile Island Unit 2 } \\ \text { UCSB } & \text { University of Santa Barbara } \\ \text { UHI } & \text { Upper Head Injection } \\ \text { VB } & \text { (Reactor Pressure) Vessel Breach } \\ \text { WW } & \text { Wetwell (BWR) }\end{array}$




\begin{tabular}{|c|c|c|c|c|c|c|c|c|c|c|c|c|c|c|c|}
\hline \\
\hline & & & & & & & & & & & & & & & \\
\hline 1 & bar & 14.5 & psi & 100 & $\mathrm{kPa}$ & 0.10 & $\mathrm{MPa}$ & 14.5 & psi & 1.0 & bar & 100.0 & $\mathrm{kPa}$ & 0.10 & $\mathrm{MPa}$ \\
\hline 2 & bar & 29 & psi & 200 & $\mathrm{kPa}$ & 0.20 & $\mathrm{MPa}$ & 100 & psi & 6.9 & bar & 689.7 & $\mathrm{kPa}$ & 0.69 & $\mathrm{MPa}$ \\
\hline 3 & bar & 43.5 & psi & 300 & $\mathrm{kPa}$ & 0.30 & $\mathrm{MPa}$ & 150 & psi & 10.3 & bar & $1,034.5$ & $\mathrm{kPa}$ & 1.03 & $\mathrm{MPa}$ \\
\hline 4 & bar & 58 & psi & 400 & $\mathrm{kPa}$ & 0.40 & $\mathrm{MPa}$ & 200 & psi & 13.8 & bar & 1,379.3 & $\mathrm{kPa}$ & 1.38 & $\mathrm{MPa}$ \\
\hline 5 & bar & 72.5 & psi & 500 & $\mathrm{kPa}$ & 0.50 & $\mathrm{MPa}$ & 250 & psi & 17.2 & bar & $1,724.1$ & $\mathrm{kPa}$ & 1.72 & $\mathrm{MPa}$ \\
\hline 6 & bar & 87 & psi & 600 & $\mathrm{kPa}$ & 0.60 & $\mathrm{MPa}$ & 300 & psi & 20.7 & bar & $2,069.0$ & $\mathrm{kPa}$ & 2.07 & $\mathrm{MPa}$ \\
\hline 7 & bar & 101.5 & psi & 700 & $\mathrm{kPa}$ & 0.70 & $\mathrm{MPa}$ & 350 & psi & 24.1 & bar & $2,413.8$ & $\mathrm{kPa}$ & 2.41 & $\mathrm{MPa}$ \\
\hline 8 & bar & 116 & psi & 800 & $\mathrm{kPa}$ & 0.80 & $\mathrm{MPa}$ & 400 & psi & 27.6 & bar & $2,758.6$ & $\mathrm{kPa}$ & 2.76 & $\mathrm{MPa}$ \\
\hline 9 & bar & 130.5 & psi & 900 & $\mathrm{kPa}$ & 0.90 & $\mathrm{MPa}$ & 450 & psi & 31.0 & bar & $3,103.4$ & $\mathrm{kPa}$ & 3.10 & $\mathrm{MPa}$ \\
\hline 10 & bar & 145 & psi & 1,000 & $\mathrm{kPa}$ & 1.00 & $\mathrm{MPa}$ & 500 & psi & 34.5 & bar & $3,448.3$ & $\mathrm{kPa}$ & 3.45 & $\mathrm{MPa}$ \\
\hline 11 & bar & 159.5 & psi & 1,100 & $\mathrm{kPa}$ & 1.10 & $\mathrm{MPa}$ & 550 & psi & 37.9 & bar & $3,793.1$ & $\mathrm{kPa}$ & 3.79 & $\mathrm{MPa}$ \\
\hline 12 & bar & 174 & psi & 1,200 & $\mathrm{kPa}$ & 1.20 & $\mathrm{MPa}$ & 600 & psi & 41.4 & bar & $4,137.9$ & $\mathrm{kPa}$ & 4.14 & $\mathrm{MPa}$ \\
\hline 13 & bar & 188.5 & psi & 1,300 & $\mathrm{kPa}$ & 1.30 & $\mathrm{MPa}$ & 650 & psi & 44.8 & bar & $4,482.8$ & $\mathrm{kPa}$ & 4.48 & $\mathrm{MPa}$ \\
\hline 14 & bar & 203 & psi & 1,400 & $\mathrm{kPa}$ & 1.40 & $\mathrm{MPa}$ & 700 & psi & 48.3 & bar & $4,827.6$ & $\mathrm{kPa}$ & 4.83 & MPa \\
\hline 15 & bar & 217.5 & psi & 1,500 & $\mathrm{kPa}$ & 1.50 & $\mathrm{MPa}$ & 750 & psi & 51.7 & bar & $5,172.4$ & $\mathrm{kPa}$ & 5.17 & $\mathrm{MPa}$ \\
\hline 16 & bar & 232 & psi & 1,600 & $\mathrm{kPa}$ & 1.60 & $\mathrm{MPa}$ & 800 & psi & 55.2 & bar & $5,517.2$ & $\mathrm{kPa}$ & 5.52 & $\mathrm{MPa}$ \\
\hline 17 & bar & 246.5 & psi & 1,700 & $\mathrm{kPa}$ & 1.70 & $\mathrm{MPa}$ & 850 & psi & 58.6 & bar & $5,862.1$ & $\mathrm{kPa}$ & 5.86 & $\mathrm{MPa}$ \\
\hline 18 & bar & 261 & psi & 1,800 & $\mathrm{kPa}$ & 1.80 & $\mathrm{MPa}$ & 900 & psi & 62.1 & bar & $6,206.9$ & $\mathrm{kPa}$ & 6.21 & $\mathrm{MPa}$ \\
\hline 19 & bar & 275.5 & psi & 1,900 & $\mathrm{kPa}$ & 1.90 & $\mathrm{MPa}$ & 950 & psi & 65.5 & bar & $6,551.7$ & $\mathrm{kPa}$ & 6.55 & $\mathrm{MPa}$ \\
\hline 20 & bar & 290 & psi & 2,000 & $\mathrm{kPa}$ & 2.00 & $\mathrm{MPa}$ & 1000 & psi & 69.0 & bar & $6,896.6$ & $\mathrm{kPa}$ & 6.90 & $\mathrm{MPa}$ \\
\hline 21 & bar & 304.5 & psi & 2,100 & $\mathrm{kPa}$ & 2.10 & $\mathrm{MPa}$ & 1100 & psi & 75.9 & bar & $7,586.2$ & $\mathrm{kPa}$ & 7.59 & $\mathrm{MPa}$ \\
\hline 22 & bar & 319 & psi & 2,200 & $\mathrm{kPa}$ & 2.20 & $\mathrm{MPa}$ & 1200 & psi & 82.8 & bar & $8,275.9$ & $\mathrm{kPa}$ & 8.28 & $\mathrm{MPa}$ \\
\hline 23 & bar & 333.5 & psi & 2,300 & $\mathrm{kPa}$ & 2.30 & $\mathrm{MPa}$ & 1300 & psi & 89.7 & bar & $8,965.5$ & $\mathrm{kPa}$ & 8.97 & MPa \\
\hline 24 & bar & 348 & psi & 2,400 & $\mathrm{kPa}$ & 2.40 & $\mathrm{MPa}$ & 1400 & psi & 96.6 & bar & $9,655.2$ & $\mathrm{kPa}$ & 9.66 & $\mathrm{MPa}$ \\
\hline 25 & bar & 362.5 & psi & 2,500 & $\mathrm{kPa}$ & 2.50 & $\mathrm{MPa}$ & 1500 & psi & 103.4 & bar & $10,344.8$ & $\mathrm{kPa}$ & 10.34 & $\mathrm{MPa}$ \\
\hline 50 & bar & 725 & psi & 5,000 & $\mathrm{kPa}$ & 5.00 & $\mathrm{MPa}$ & 1600 & psi & 110.3 & bar & $11,034.5$ & $\mathrm{kPa}$ & 11.03 & $\mathrm{MPa}$ \\
\hline 75 & bar & 1087.5 & psi & 7,500 & $\mathrm{kPa}$ & 7.50 & $\mathrm{MPa}$ & 1700 & psi & 117.2 & bar & $11,724.1$ & $\mathrm{kPa}$ & 11.72 & $\mathrm{MPa}$ \\
\hline 100 & bar & 1450 & psi & 10,000 & $\mathrm{kPa}$ & 10.00 & $\mathrm{MPa}$ & 1800 & psi & 124.1 & bar & $12,413.8$ & $\mathrm{kPa}$ & 12.41 & $\mathrm{MPa}$ \\
\hline 125 & bar & 1812.5 & psi & 12,500 & $\mathrm{kPa}$ & 12.50 & $\mathrm{MPa}$ & 1900 & psi & 131.0 & bar & $13,103.4$ & $\mathrm{kPa}$ & 13.10 & $\mathrm{MPa}$ \\
\hline 150 & bar & 2175 & psi & 15,000 & $\mathrm{kPa}$ & 15.00 & $\mathrm{MPa}$ & 2000 & psi & 137.9 & bar & $13,793.1$ & $\mathrm{kPa}$ & 13.79 & $\mathrm{MPa}$ \\
\hline 175 & bar & 2537.5 & psi & 17,500 & $\mathrm{kPa}$ & 17.50 & $\mathrm{MPa}$ & 2100 & psi & 144.8 & bar & $14,482.8$ & $\mathrm{kPa}$ & 14.48 & $\mathrm{MPa}$ \\
\hline 200 & bar & 2900 & psi & 20,000 & $\mathrm{kPa}$ & 20.00 & $\mathrm{MPa}$ & 2200 & psi & 151.7 & bar & $15,172.4$ & $\mathrm{kPa}$ & 15.17 & $\mathrm{MPa}$ \\
\hline 225 & bar & 3262.5 & psi & 22,500 & $\mathrm{kPa}$ & 22.50 & $\mathrm{MPa}$ & 2250 & psi & 155.2 & bar & $15,517.2$ & $\mathrm{kPa}$ & 15.52 & $\mathrm{MPa}$ \\
\hline 250 & bar & 3625 & psi & 25,000 & $\mathrm{kPa}$ & 25.00 & $\mathrm{MPa}$ & & & & & & & & \\
\hline
\end{tabular}




\begin{tabular}{|c|c|c|c|c|c|c|c|c|c|c|c|}
\hline \multicolumn{12}{|l|}{ Temperature } \\
\hline & C & 32 & $F$ & 273 & $\mathrm{~K}$ & & $F$ & & $C$ & 273 & $3 \mathrm{~K}$ \\
\hline 100 & C & 212 & & 373 & $\mathrm{~K}$ & 100 & $F$ & & C & 311 & $1 \mathrm{~K}$ \\
\hline 200 & C & 392 & $F$ & 473 & $\mathrm{~K}$ & 200 & $F$ & & C & 366 & $6 \mathrm{~K}$ \\
\hline 300 & C & 572 & $\mathrm{~F}$ & 573 & $\mathrm{~K}$ & 212 & $F$ & 100 & C & 373 & $3 \mathrm{~K}$ \\
\hline 400 & C & 752 & $\mathrm{~F}$ & 673 & $K$ & 300 & $F$ & 149 & C & 422 & $2 \mathrm{~K}$ \\
\hline 500 & C & 932 & $F$ & 773 & $\mathrm{~K}$ & 400 & $F$ & 204 & C & 478 & $3 \mathrm{~K}$ \\
\hline 600 & C & 1112 & $\mathrm{~F}$ & 873 & $\mathrm{~K}$ & 500 & $F$ & 260 & C & 533 & $3 \mathrm{~K}$ \\
\hline 700 & C & 1292 & $\mathrm{~F}$ & 973 & $\mathrm{~K}$ & 600 & $F$ & 316 & C & 589 & $9 \mathrm{~K}$ \\
\hline 800 & C & 1472 & $\mathrm{~F}$ & 1073 & $\mathrm{~K}$ & 700 & $F$ & 371 & C & 644 & $4 \mathrm{~K}$ \\
\hline 900 & C & 1652 & $\mathrm{~F}$ & 1173 & $\mathrm{~K}$ & 800 & $F$ & 427 & C & 700 & $\mathrm{~K}$ \\
\hline 1000 & C & 1832 & $\mathrm{~F}$ & 1273 & $\mathrm{~K}$ & 900 & $F$ & 482 & C & 755 & $5 \mathrm{~K}$ \\
\hline 1100 & C & 2012 & $\mathrm{~F}$ & 1373 & $\mathrm{~K}$ & 1000 & $F$ & 538 & C & 811 & $1 \mathrm{~K}$ \\
\hline 1200 & C & 2192 & $\mathrm{~F}$ & 1473 & $\mathrm{~K}$ & 1100 & $F$ & 593 & C & 866 & $6 \mathrm{~K}$ \\
\hline 1300 & C & 2372 & $\mathrm{~F}$ & 1573 & $K$ & 1200 & $F$ & 649 & C & 922 & \\
\hline 1400 & C & 2552 & $F$ & 1673 & $\mathrm{~K}$ & 1300 & $F$ & 704 & C & 978 & $3 \mathrm{~K}$ \\
\hline 1500 & C & 2732 & $F$ & 1773 & $\mathrm{~K}$ & 1400 & $F$ & 760 & C & 1033 & \\
\hline 1600 & C & 2912 & $F$ & 1873 & $\mathrm{~K}$ & 1500 & $F$ & 816 & C & 1089 & \\
\hline 1700 & C & 3092 & $F$ & 1973 & $\mathrm{~K}$ & 1600 & $F$ & 871 & C & 1144 & \\
\hline 1800 & C & 3272 & $F$ & 2073 & $\mathrm{~K}$ & 1700 & $F$ & 927 & C & 1200 & \\
\hline 1900 & C & 3452 & $F$ & 2173 & $\mathrm{~K}$ & 1800 & $F$ & 982 & C & 1255 & $5 \mathrm{~K}$ \\
\hline 2000 & C & 3632 & $\mathrm{~F}$ & 2273 & $\mathrm{~K}$ & 1900 & $F$ & 1038 & C & 1311 & \\
\hline 2250 & C & 4082 & $F$ & 2523 & $\mathrm{~K}$ & 2000 & $F$ & 1093 & C & 1366 & \\
\hline 2500 & C & 4532 & $\mathrm{~F}$ & 2773 & $\mathrm{~K}$ & 2250 & $\mathrm{~F}$ & 1232 & C & 1505 & \\
\hline 2750 & C & 4982 & $F$ & 3023 & $\mathrm{~K}$ & 2500 & $\mathrm{~F}$ & 1371 & C & 1644 & \\
\hline 3000 & C & 5432 & $F$ & 3273 & $\mathrm{~K}$ & 2750 & $\mathrm{~F}$ & 1510 & C & 1783 & \\
\hline & & & & & & 3000 & $F$ & 1649 & C & 1922 & \\
\hline & & & & & & 3250 & $\mathrm{~F}$ & 1788 & C & 2061 & \\
\hline & & & & & & 3500 & $F$ & 1927 & C & 2200 & \\
\hline & & & & & & 3750 & & 2066 & & 2339 & \\
\hline & & & & & & 4000 & $\mathrm{~F}$ & 2204 & & 2478 & \\
\hline
\end{tabular}




\section{Accident Progression Analysis (P-300)}

1. Risk-Informed Regulatory Background and Review of PRA Basic Concepts 


\section{Session Objectives}

- To understand the motivation for Level-2 PRA

- NRC regulatory philosophy

- PRA Policy Statement

- Reactor Safety Goal Policy Statement

- Regulatory Guide 1.174

- To understand some of the basic PRA concepts

- Risk

- Large Early Release Frequency (LERF) 


\section{PRA Policy Statement}

- The Nuclear Regulatory Commission's (NRC's) policy for implementing risk-informed regulation was expressed in the 1995 policy statement on the use of probabilistic risk assessment (PRA) methods in nuclear regulatory activities. The policy statement states:

- The use of PRA technology should be increased in all regulatory matters to the extent supported by the state-of-the-art in PRA methods and data and in a manner that complements the NRC's deterministic approach and supports the NRC's traditional defense-in-depth philosophy.

- PRA and associated analyses (e.g., sensitivity studies, uncertainty analyses, and importance measures) should be used in regulatory matters, where practical within the bounds of the state-of-the-art, to reduce unnecessary conservatism associated with current regulatory requirements, regulatory guides, license commitments, and staff practices. Where appropriate, PRA should be used to support the proposal of additional regulatory requirements in accordance with 10 CFR 50.109 (Backfit Rule). Appropriate procedures for including PRA in the process for changing regulatory requirements should be developed and followed. It is, of course, understood that the intent of this policy is that existing rules and regulations shall be complied with unless these rules and regulations are revised. 


\section{PRA Policy Statement (Continued)}

- PRA evaluations in support of regulatory decisions should be as realistic as practicable and appropriate supporting data should be publicly available for review.

- The Commission's safety goals for nuclear power plants and subsidiary numerical objectives are to be used with appropriate consideration of uncertainties in making regulatory judgements on the need for proposing and backfitting new generic requirements on nuclear power plants licensees. 


\section{Reactor Safety Goal Policy Statement}

- Originally issued in 1986

- Expressed Commission's policy as:

- ...consequences of nuclear power operations such that individual bear no significant additional risk to life and health.

- Societal risks...from NPP...should be comparable or less than the risks of generating electricity by viable competing technologies and should not be a significant addition to other societal risk. 


\section{RSGPS (continued)}

- Established Quantitative Health Objectives (QHOs)

- Early fatality risk ( $0.1 \%$ of total accident risk) and latent cancer risk (0.1\% from all causes)

- For an individual living in the vicinity of a NPP

- Based on the risk of accidental death in the U.S., this implies a prompt fatality QHO of 5E-7 per year

- Based on the occurrence of cancer fatalities, this implies a latent cancer fatality QHO of 2E-6 per year 


\section{RSGPS (concluded)}

- Update proposed by NRC staff - March 30, 2000 (SECY-00-0077)

- Commission approved (with exceptions) - June 27, 2000

- Emphasize safety goals are "goals" not limits

- Nine issues addressed, including:

- Maintained core damage frequency subsidiary goal of $10^{-4}$ per reactor-year

- Incorporated Large Early Release Frequency (LERF) subsidiary goal of $10^{-5}$ per reactor-year

- Consistent with Reg. Guide 1.174 


\section{Regulatory Guide 1.174}

- An Approach for Using Probabilistic Risk Assessment In Risk-Informed Decisions On Plant-Specific Changes to the Licensing Basis

- Defines the five principles of risk-informed integrated decision-making

- \#4. Proposed increases in CDF or risk are small and consistent with Commission's Safety Goal Policy Statement

- Use of CDF and LERF as bases for PRA acceptance guidelines is an acceptable approach to addressing Principle 4. 


\section{Large Early Release Frequency (LERF)}

- In the context of Reg Guide 1.174, LERF is used as a surrogate for the early fatality $\mathrm{QHO}$

- Defined as: the frequency of those accidents leading to significant, unmitigated releases from containment in a time frame prior to effective evacuation of the close-in population such that there is a potential for early health effects

- No quantitative definition (w.r.t. timing or magnitude)

- By definition, late releases would result in no early fatalities 


\section{RG-1.174 Acceptance Guidelines for Core Damage Frequency}

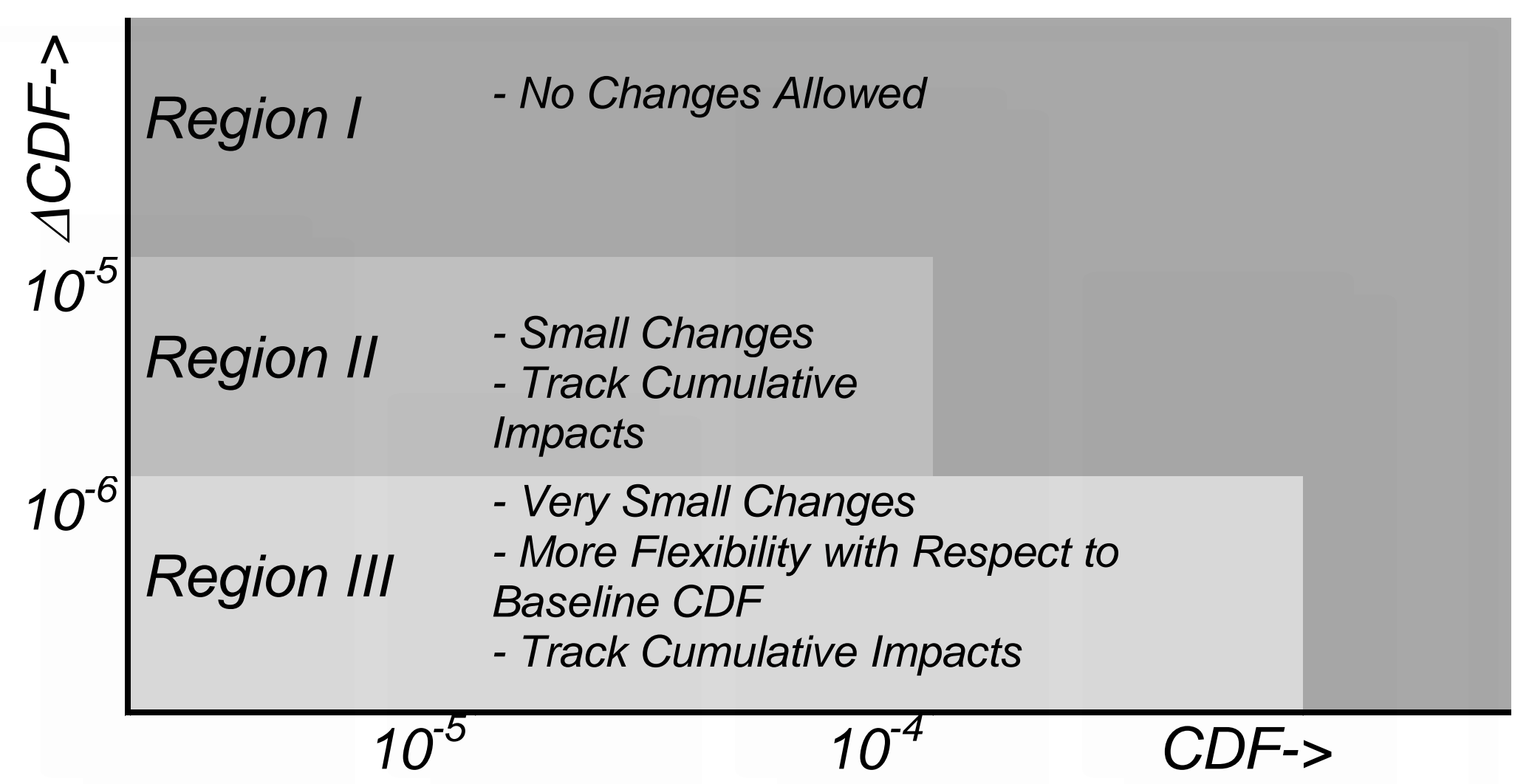




\section{RG-1.174 Acceptance Guidelines for Large Early Release Frequency}

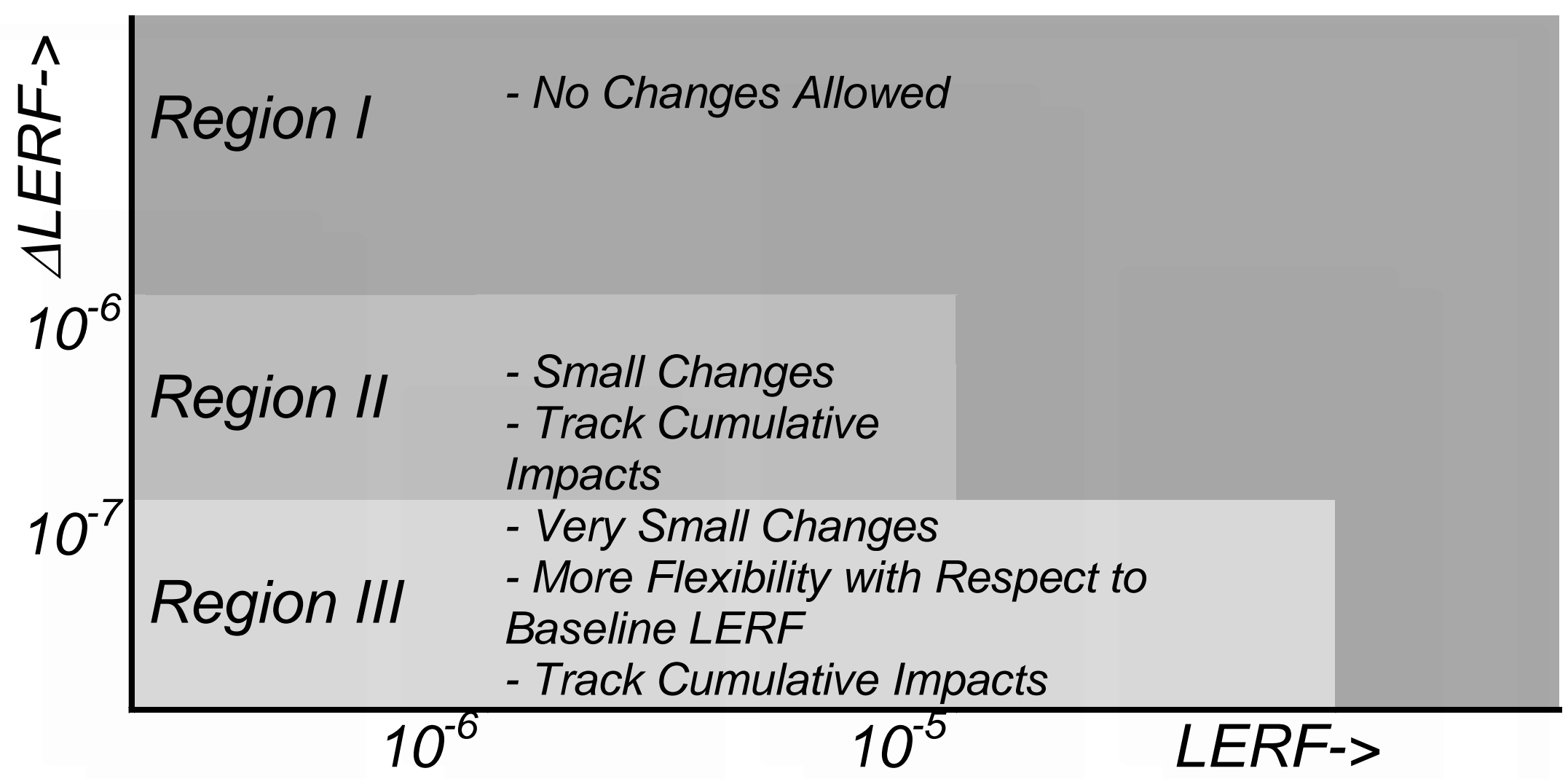




\section{Common PRA Terms}

- Probability - likelihood of the occurrence of a specific event (unitless)

- Frequency - The occurrence rate of an event (typically expressed in number of events per unit of time)

- Conditional probability - probability of an event given the occurrence of another preceding event upon which the succeeding event has some dependence on

- Core damage - beginning of core degradation, (uncovery of top of active fuel, UTAF - common PWR definition, but not universal)

- Plant Damage State (PDS) - Identifies the status of specified plant systems and functions during a core damage event (typically includes information on containment systems)

- Large early release - significant, unmitigated release from containment in a time frame prior to effective evacuation of the close-in population such that there is a potential for early health effects. 


\section{Probabilistic Risk Assessment (PRA) Basic Concepts}

- Risk involves both likelihood and consequences of an event

- PRA attempts to answer three specific questions:

- What can go wrong?

- How likely is it?

- What are the consequences? 


\section{Risk Can be Defined in Different Ways}

- Vector Definition

- Risk Triplet: Risk $=\left\{S_{i}, F_{i}, C_{i}\right\}$,

- where: $S_{i}=$ Accident sequence $i$,

$$
\begin{aligned}
& F_{i}=\text { Frequency of sequence } i, \\
& C_{i}=\text { Consequence of sequence } i .
\end{aligned}
$$

- Scalar Definition

- Risk $=\sum_{\mathrm{i}=1, \mathrm{n}} \mathrm{F}_{\mathrm{i}} \times \mathrm{C}_{\mathrm{i}}$

- Sometimes called aggregated risk 


\section{TII Idaho National laboratory}

\section{Sequence Frequency Quantified by Combining Challenges and Failures}

- Initiating events (IE) challenge plant systems to response to upset conditions

- Plant safety systems are barriers between initiating events and core damage

- Sequence frequency combines IE frequency and safety system failure probabilities (reliabilities)

$\mathrm{CDF}=\lambda \varphi$

where: $\lambda=$ Initiating event frequency

$\varphi=$ Failure probability of safety barriers (systems) 


\section{PRAs Characterized as Level-1, Level-2 or Level-3}

- Level 1: Core damage risk

- Quantifies the frequency of accidents that result in core damage

- Level 2: Radioactive material release risk

- Core damage frequency combined with the conditional probability the containment structure fails to prevent the release

- Level 3: Health consequence risk

- Combines radioactive material release frequency with the health consequences associated with each release 


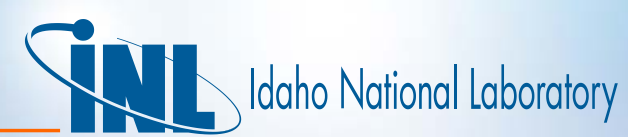

\section{Full Scope PRA Process/Structure}

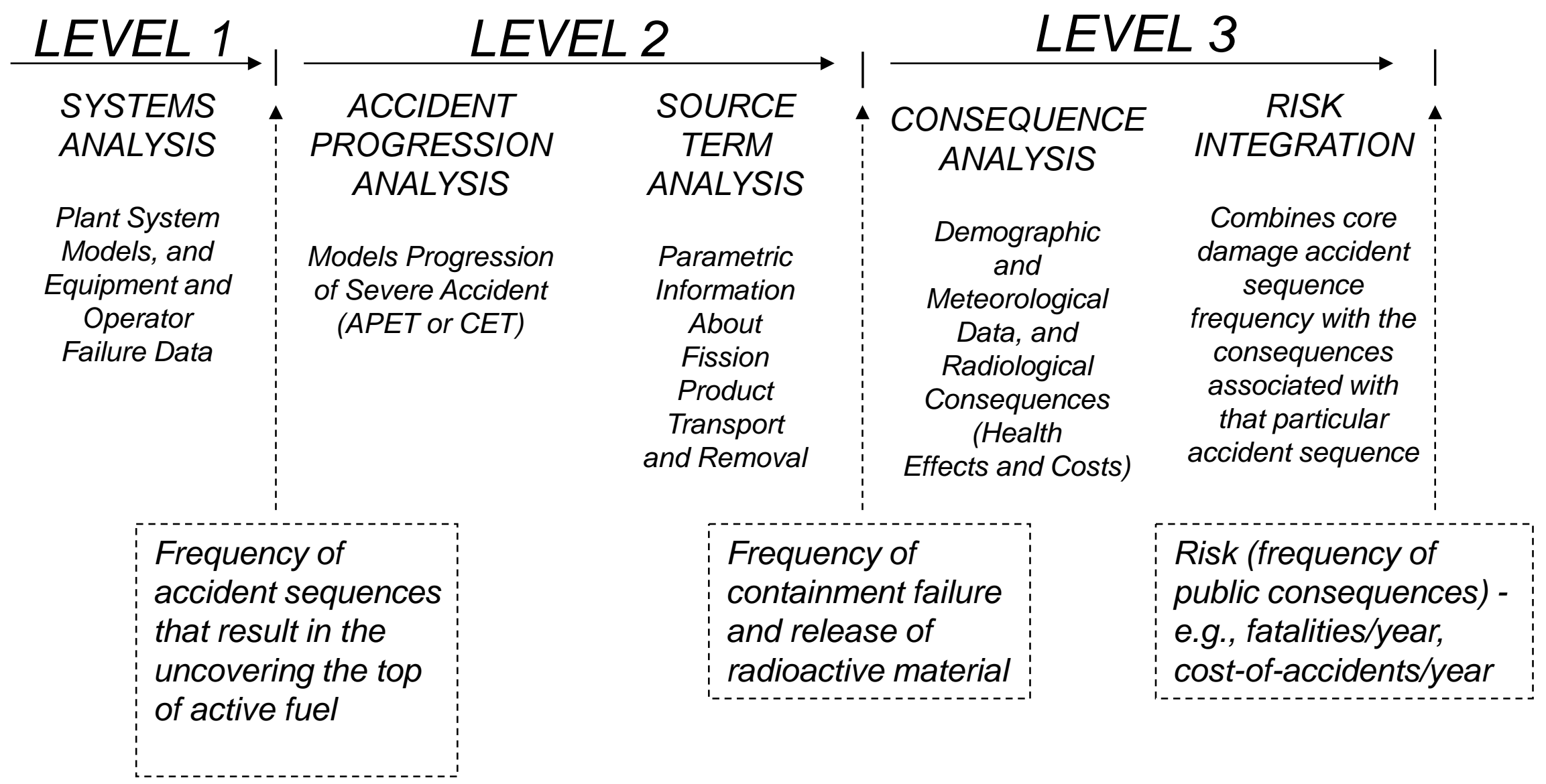




\section{Uncertainty is a Vital and Integral Component in Any PRA}

- RG-1.174 Section 2.2.5 discusses the importance of considering uncertainty in the decision-making process

- Cited in proposed modifications to RSGPS

- Accurate representation of uncertainty in Level-2 results requires reflection of Level-1 uncertainties

- Fully integrated uncertainty analysis usually impractical

- Typically, intermediate (Level-1 output) results generated in the form of histograms on PDS frequencies, which serve as input to Level-2 analysis 


\section{Session Review}

- Why is Level-2 PRA important?

-What are some basic PRA concepts? 


\section{Accident Progression Analysis (P-300)}

2. Overview of PRA 


\section{Session Objectives}

- To understand the PRA framework

- Level-1, Level-2 and Level-3 PRA

- Results of each phase of the PRA 


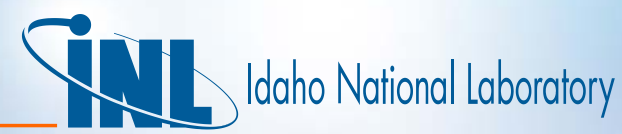

\section{Overview of Level-1/2/3 PRA}

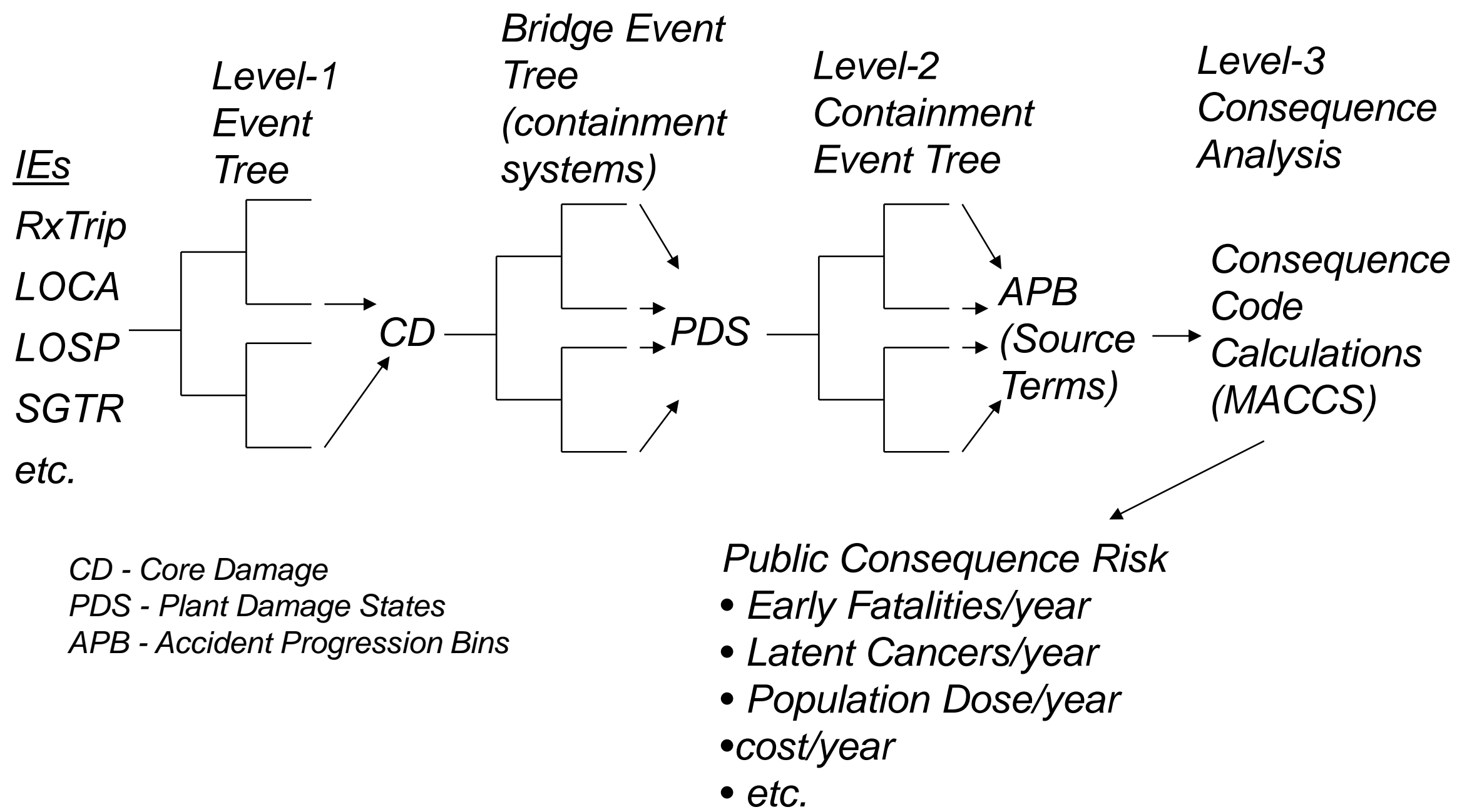




\section{Purpose of Level 1 PRA Analysis}

- Estimate core damage accident risk (frequency)

- Typical definition of core damage: Uncovering of top of active fuel

- Total CD risk (or CD frequency) is sum of the frequencies of the different ways core damage can occur

- Distinctions made among:

- accidents initiated by site-centered events (internal events analysis) during plant power operations

- accidents initiating by offsite-centered events (external events)

- accidents initiated while plant is in a shutdown (non-power producing) state (shutdown/low-power PRA) 


\section{Level 1 PRA Analysis Approach}

- Potential initiating events identified

- Plant response modeled as a sequence of events (system failures)

- Accident Sequence $=$ IE combined with set of system failures that leads to undesired consequence (i.e., CD)

- Integrated analysis of plant system reliability

- Includes consideration of human actions, support system dependencies, common cause failure dependencies

- Core Damage Frequency comprises set of accident sequence frequencies

- Each accident sequence comprises set of accident scenarios (cutsets) 


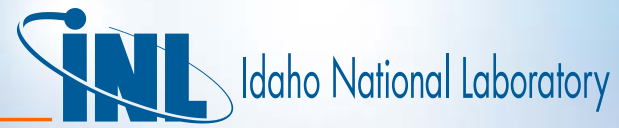

\section{Level-1 PRA (Internal Events Analysis)}

IES

RxTrip

LOCA

LOSP

SGTR

etc.

Plant Systems and Operator

IE Actions (i.e., plant response to IE)

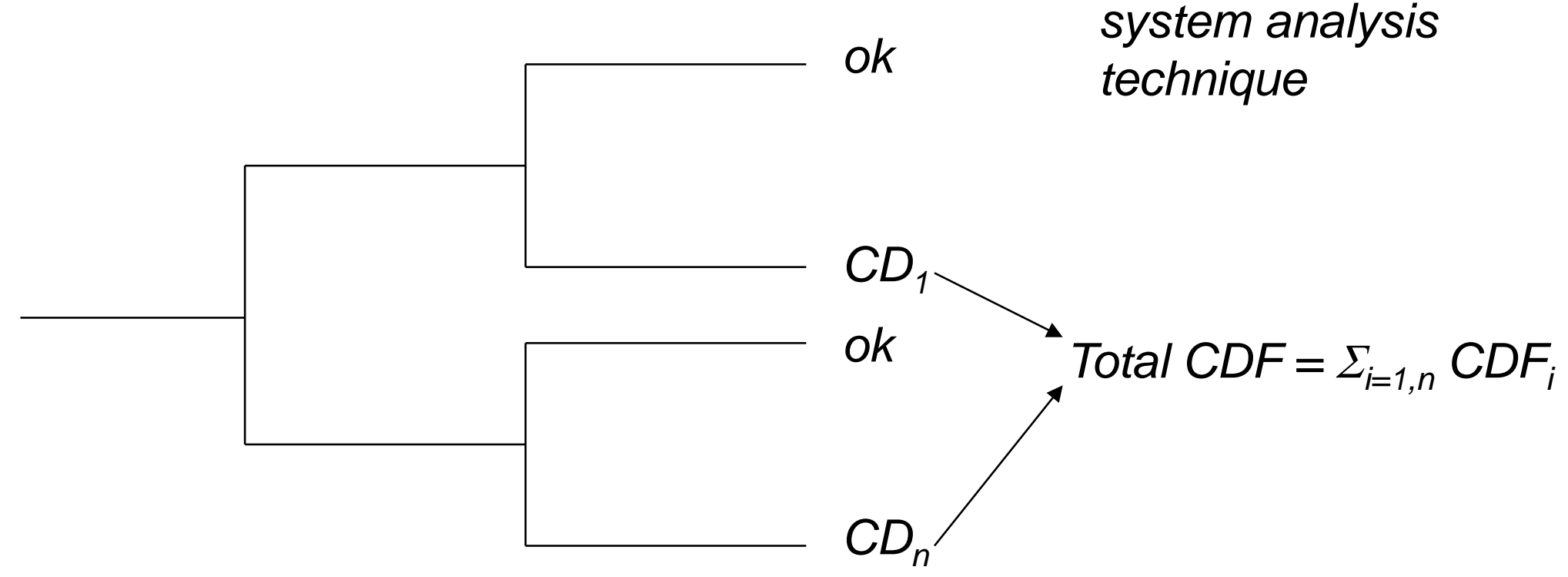

Typically quantified using fault trees or some other detailed system analysis technique 


\section{Purpose of Level-2 PRA Analysis}

- Extend the severe accident analysis beyond the occurrence of core damage

- Core damage accident sequences vary in timing and severity

- Issues addressed in Level-2 include:

- Does fuel damage actually occur? (Remember, Level-1 only analyzes up to the point where CD nominally starts)

- Does accident progress to RPV failure, and how?

- How does the containment respond?

- Is radioactive material released into the environment? 


\section{Level-2 PRA Analysis Approach}

- Characterize challenges to containment resulting from various core damage sequences

- e.g., core degradation produces $\mathrm{H} 2$, which can burn

- Estimate strength of containment

- Identify probable containment failure mode (e.g., failure due to hydrogen detonation or steam explosion, melt through, leakage)

- Describe radioactive source term released into the environment

- Including the energy associated with containment failure and radioactive material release 


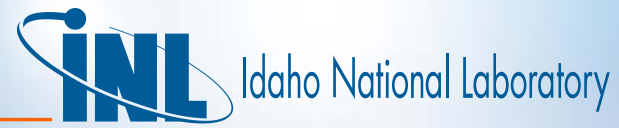

\section{Level-2 PRA (Containment Event Tree)}

Containment Systems and physical phenomena (i.e., containment

$C D$ response to core damage sequence)

Core

Damage

(Plant

Damage

State)
Typically quantified using fault trees (for cont. systems), and detailed code analyses and experimental results (for physical phenomena)

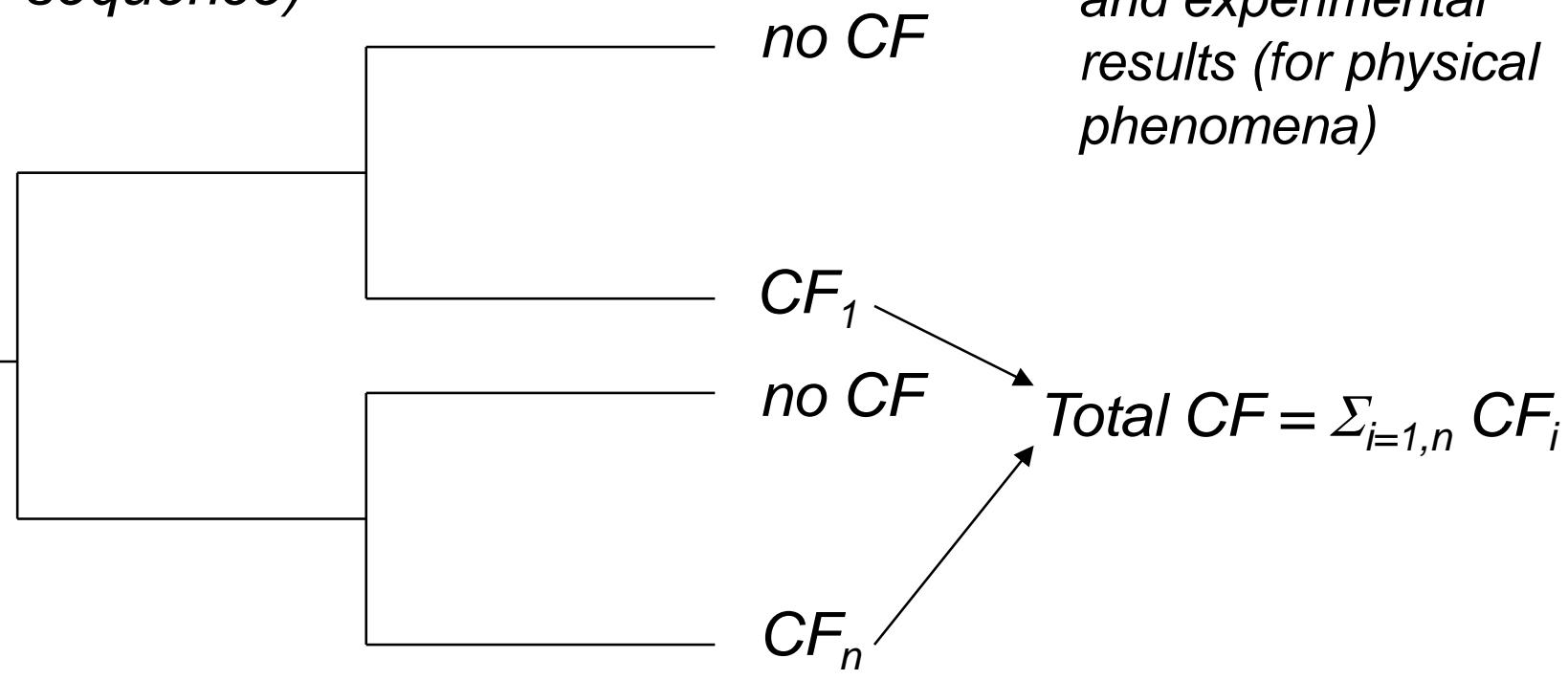

Note that this example focuses on Containment Failure (CF), some Level-2 analyses estimate releases (i.e. source terms) or Large Early Release Frequency (LERF) 


\section{Purpose of Level-3 PRA Analysis}

- Estimate the public consequences (mostly health) of a severe accident

- Person-rem (individual and population), early fatalities, latent cancers, financial cost, etc.

- Site-specific calculation

- Considers local demographics, weather, emergency plan 


\section{Level 3 PRA Analysis Approach}

- Source term information from Level-2 analysis result used as input to Level-3 consequence analysis

- Source term information includes:

- radionuclide composition, energy associated with release, timing and duration of release, etc.

- Source term transport and offsite consequences (both health and economic) modeled using consequence code

- MACCS2 (1998)

- MACCS (1987 - NUREG-1150)

- CRAC2 (1982)

- CRAC (1975 - WASH-1400) 


\section{Level-3 Analysis Combines Source Term Frequencies and Consequences}

Source Terms (for each STG) Demographics Weather data

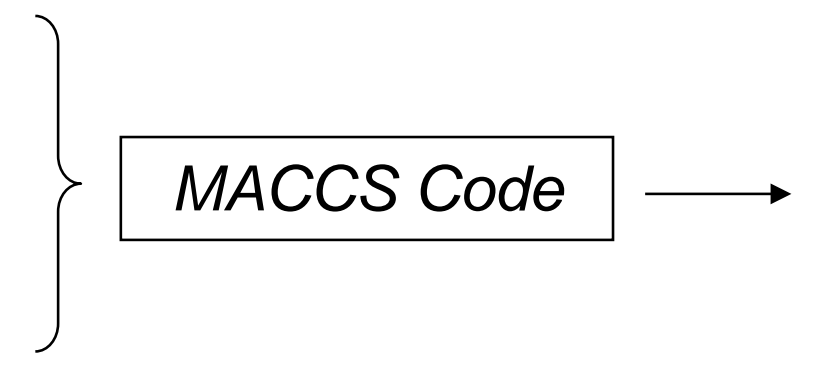

Public Consequences for each Source Term Group

Frequency of each Source Term Group (from Level-2)

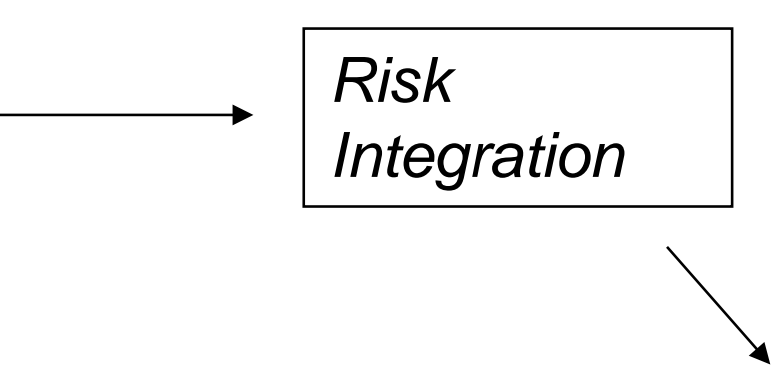

Public Risk (both health and financial) 


\section{Level 1/2/3 PRA Integration Issues}

- Level 1 Accident sequence analysis quantifies core damage frequency

- However, not all CD accident sequences are equal (with respect to potential consequences)

- Containment analysis (Level 2) and consequence analysis (Level 3) usually performed "separate" from CDF analysis

- Different areas of expertise, therefore different analysts

- Because of size and complexity of Level 1/2/3 PRA, difficult to fully integrate analysis, therefore usually performed in pieces or steps

- Special methods used to link accident sequence analysis to containment analysis 


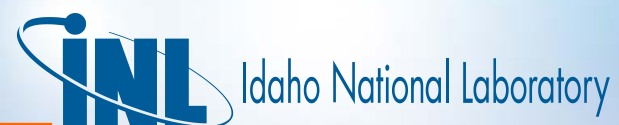

\section{Level-1 Result (CDF) Not Sufficient for Level-2 Analysis}

- Specific details on core damage sequence are needed to model containment response to the severe accident

- Typical Level-1 PRA produces 10,000's of core damage sequences, each of which can comprise 100's of individual scenarios (cut sets)

- Containment systems usually do not impact CDF, therefore often not included in Level-1 systems analyses

- Containment systems analysis must be integrated with Level-1 analysis (need to account for dependencies) 


\section{Dependencies Often Dominate Risk}

- Multiple system failures required for radioactive release to environment

- Failure of multiple systems caused by independent mechanism very incredible probability

- Only by failing multiple barriers (systems) by the same mechanism will the likelihood of the sequence be significant

- Level-2 analysis must account for dependencies between the Level-1 and Level-2 models

- Probabilistic definition of dependency:

$-P(a \mid b) \neq P(a)$ 


\section{Systems Analyses Needs to Include Containment Systems}

- Dependencies between Level-1 modeled systems and containment systems must be considered

- Support system dependencies

- Shared equipment dependencies

- Human action dependencies

- Common cause failure dependencies

- Inclusion of containment systems can be accomplished two ways

- Expand Level-1 event trees

- Bridge trees 


\section{Bridge Event Trees}

- Additional system models and analyses needed before containment analysis can be performed

- "Core Damage" result from Level-1 is not adequate for starting containment analysis

- Some containment systems not relevant to CDF are important for containment response

- Containment system models need to be integrated with Level 1 system analysis (i.e., need to account for dependencies)

- Bridge Event Tree (BET) used to model additional systems/phenomena, linked to Level 1 event trees 


\section{(int}

\section{Plant Damage States (PDS) Framework Used As Input to Level-2 (from Level-1)}

- Output (end states) of BET defined in terms of specific details about $\mathrm{CD}$ accident sequence

- Method utilizes a vector identifier

- Each character position of the vector identifies the status of a particular system or event

- e.g., ACCBABDC

- Vector is "read" by the Level 2 analysis 


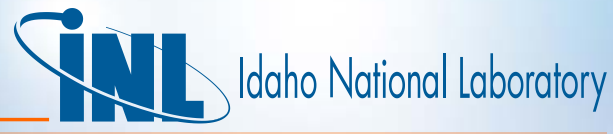

\section{Expanded Systems Analysis Needed to Support Level-2 Model}

Level-1 Event Tree

Bridge Event Tree Appends Containment System Models to Level-1 ET

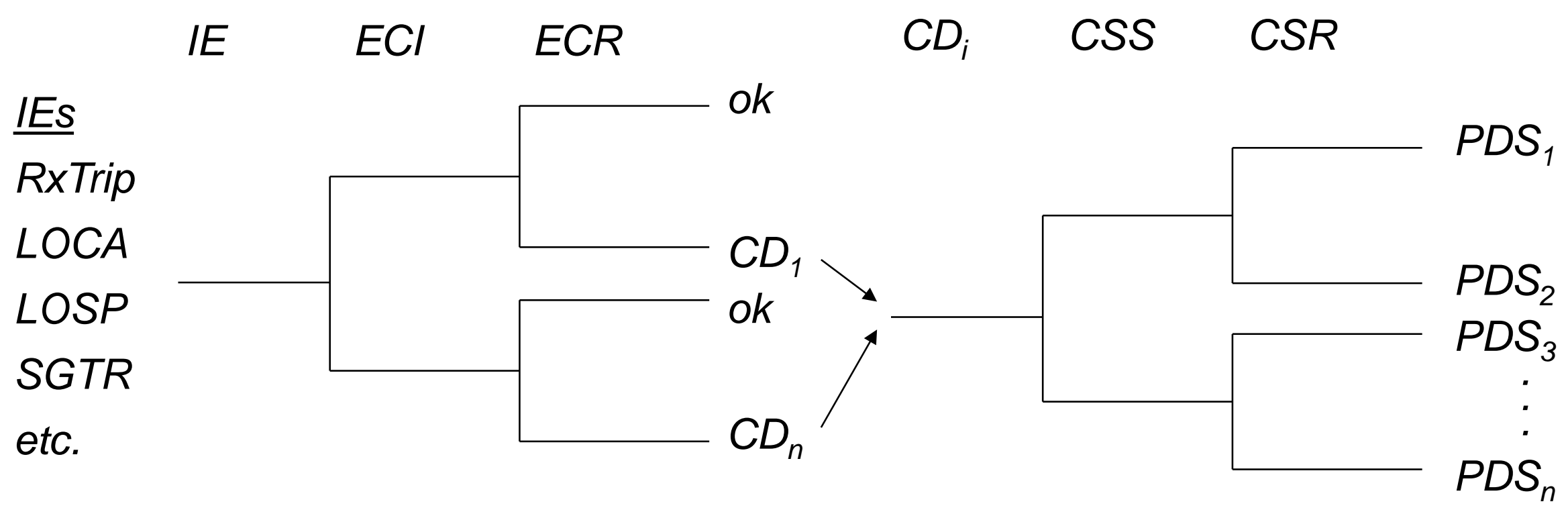




\section{TII Idaho National laboratory}

\section{Each Plant Damage State Represents a Unique Plant Response/Condition}

- Direct link between expanded Level-1 sequence analysis and Level-2 models usually not feasible

- Process includes collapsing the sometimes millions of Level-1 sequences into a manageable number of PDS

- Often referred to as "binning"

- Each unique PDS vector serves as an initiating event for Level-2 analysis

- PDS vector transmits necessary information from Level-1 to Level-2 analyses 


\section{TLI ldaho National laboratory}

\section{Example Plant Damage State (PDS) Vector}

Character

1 Status of RCS at onset of core damage

2 Status of ECCS

3 Status of containment heat removal

$4 \quad$ Status of electric power

$5 \quad$ Status of contents of RWST

6 Status of heat removal from S/Gs

$7 \quad$ Status of cooling for RCP seals

8 Status of containment fan coolers

9
BWR

Status of RPS

Status of electric power

$R P V$ integrity

RPV pressure

Status of HPI

Status of LPI

Status of containment heat removal Status of containment venting

Level of pre-existing leakage from containment

Time to core damage 


\section{Example PDS Scheme - Grand Gulf (NUREG- 1150)}

\begin{tabular}{ll}
$\begin{array}{l}\text { Character } \\
\#\end{array}$ & Description \\
\hline 1 & Initiating event \\
2 & Reactor vessel pressure \\
3 & Status of both high and low pressure injection \\
4 & $\begin{array}{l}\text { Status of containment spray and suppression } \\
\text { pool cooling } \\
5\end{array}$ \\
$\begin{array}{l}\text { Status of containment and containment } \\
\text { systems as start of core damage }\end{array}$ \\
6 & Time of core damage (early or late)
\end{tabular}




\section{PDS Scheme from NUREG-1150 (Grand Gulf)}

\begin{tabular}{|c|c|}
\hline$\# I D$ & Description \\
\hline $1 B 1$ & $\begin{array}{l}\text { Station blackout (SBO) transient has occurred. Offsite power is not recoverable } \\
\text { because there is no emergency DC power. }\end{array}$ \\
\hline B2 & SBO transient has occurred. Offsite power is recoverable. \\
\hline$T 2$ & Loss of PCS transient has occurred. Offsite or onsite power is available. \\
\hline TC & ATWS has occurred. Offsite or onsite power is available. \\
\hline $2 P 1$ & $\begin{array}{l}\text { The reactor vessel (RV) is at high pressure }(H P) \text { at the onset of core damage } \\
(C D) \text { and depressurization is not possible. }\end{array}$ \\
\hline$P 2$ & $\begin{array}{l}\text { The } R V \text { is at } H P \text { at the onset of } C D \text { because the operator failed to depressurize; } \\
\text { depressurization is possible. }\end{array}$ \\
\hline P3 & $\begin{array}{l}\text { The RV could be at HP at the onset of CD. The operator depressurizing the } \\
\text { vessel (which is possible) was not included in the model. }\end{array}$ \\
\hline P4 & The $R V$ is at low pressure ( $L P)$ \\
\hline
\end{tabular}




\section{PDS Scheme from NUREG-1150 (Grand Gulf) - cont.}

\begin{tabular}{|c|c|}
\hline \# ID & Description \\
\hline 311 & Injection to the RV is not available after the onset of $C D$. \\
\hline 12 & Injection with the Firewater system is available before and after the onset of $C D$. \\
\hline 13 & $\begin{array}{l}\text { Injection with the Condensate system is recoverable with the restoration of offsite } \\
\text { power. }\end{array}$ \\
\hline 14 & $\begin{array}{l}\text { Injection with the } L P \text { systems [core spray (LPCS) and coolant injection (LPCI)] is } \\
\text { recoverable with the restoration of offsite power (or RV depressurization). }\end{array}$ \\
\hline 15 & $\begin{array}{l}\text { Injection with both the HP and LP systems is recoverable with the restoration of offsite } \\
\text { power. }\end{array}$ \\
\hline 16 & $\begin{array}{l}\text { Injection with the HP systems (reactor core isolation cooling and control rod drive) and } \\
L P \text { systems (LPCS and LPCI) is recoverable with the restoration of offsite power } \\
\text { (or RV depressurization). }\end{array}$ \\
\hline $\begin{array}{r}\mathrm{H} 1 \\
\mathrm{H} 2 \\
\mathrm{H} 3\end{array}$ & $\begin{array}{l}\text { Containment Spray (CS) is not available at the onset of CD, neither is it recoverable. } \\
\text { At least on train of CS is recoverable with the restoration of offsite power } \\
\text { At least one train of CS is available at the onset of } C D \text {. }\end{array}$ \\
\hline $5 \mathrm{M1}$ & Miscellaneous systems (Venting, SBGT, $\mathrm{Cl}, \mathrm{H} 2 \mathrm{l}$ ) are not available at the onset of CD. \\
\hline M2 & $\begin{array}{l}\text { Miscellaneous systems (Venting, SBGT, } \mathrm{Cl}, \mathrm{H} 2 \mathrm{l} \text { ) are recoverable with the restoration } \\
\text { of offsite power. }\end{array}$ \\
\hline M3 & Miscellaneous systems (Venting, SBGT, $\mathrm{Cl}, \mathrm{H} 2 \mathrm{I}$ ) are available at the onset of $\mathrm{CD}$. \\
\hline $\begin{array}{r}6 S T \\
L T\end{array}$ & $\begin{array}{l}C D \text { occurs in the short term (at } \sim 1 \text { hour). } \\
C D \text { occurs in the long term (at }>12 \text { hours). }\end{array}$ \\
\hline
\end{tabular}




\section{List of PDS from NUREG-1150 (Grand Gulf)}

\begin{tabular}{lll}
\hline PDS & PDS Character Vector & Accident Sequence \\
\hline PDS-1 & B2-P3-I5-H2-M2-ST & T1B-16 \\
& & $T 1 B-17$ \\
& & $T 1 B-21$ \\
\hline$P D S-2$ & $B 2-P 3-I 5-H 1-M 2-S T$ & $T 1 B-16$ \\
& & $T 1 B-17$ \\
& & $T 1 B-21$ \\
\hline$P D S-3$ & $B 2-P 3-I 3-H 1-M 2-S T$ & $T 1 B-16$ \\
& & $T 1 B-17$ \\
& & $T 1 B-21$ \\
\hline$P D S-4$ & $B 2-P 4-I 5-H 2-M 2-L T$ & $T 1 B-14$ \\
\hline$P D S-5$ & $B 2-P 4-I 5-H 1-M 2-L T$ & $T 1 B-14$ \\
\hline$P D S-6$ & $B 2-P 4-I 2-H 1-M 2-L T$ & $T 1 B-14$ \\
\hline$P D S-7$ & $B 1-P 1-I 1-H 1-M 1-S T$ & $T 1 B-16$ \\
& & $T 1 B-17$ \\
& & $T 1 B-21$ \\
\hline$P D S-8$ & $B 1-P 1-I 1-H 1-M 1-L T$ & $T 1 B-13$ \\
\hline$P D S-9$ & $T C-P 2-I 6-H 3-M 3-S T$ & $T C-74$ \\
\hline$P D S-10$ & $T C-P 2-I 4-H 3-M 3-L T$ & $T C-74$ \\
\hline$P D S-11$ & $T 2-P 2-I 5-H 3-M 3-S T$ & $T 2-56$ \\
\hline$P D S-12$ & $T 2-P 2-I 5-H 3-M 3-L T$ & $T 2-56$ \\
\hline
\end{tabular}




\section{Level-2 Analysis Assesses Containment Response to Each PDS}

- Each PDS represents a unique (by design) challenge to containment integrity

- Containment strength (actual, not design) estimated through a detailed engineering evaluation

- Challenge presented by PDS compared to estimated pressure capacity of containment

- Conditional probability of containment failure then calculated

- CET (or APET) provides the framework for this analysis 


\section{TII Idaho National laboratory}

\section{Two General Techniques for Level-2 Modeling}

- Containment Event Trees (CETs)

- Typically displayed in graphical form

- Comprising 8-15 top events (major summary events with underlying detailed models)

- Original example: WASH-1400

- Accident Progression Event Trees (APETs)

- No graphical representation

- All details explicitly modeled

- 75-125 top events, many with multiple (more than 2) branches

- example: NUREG-1150

- Terms often used interchangeably 


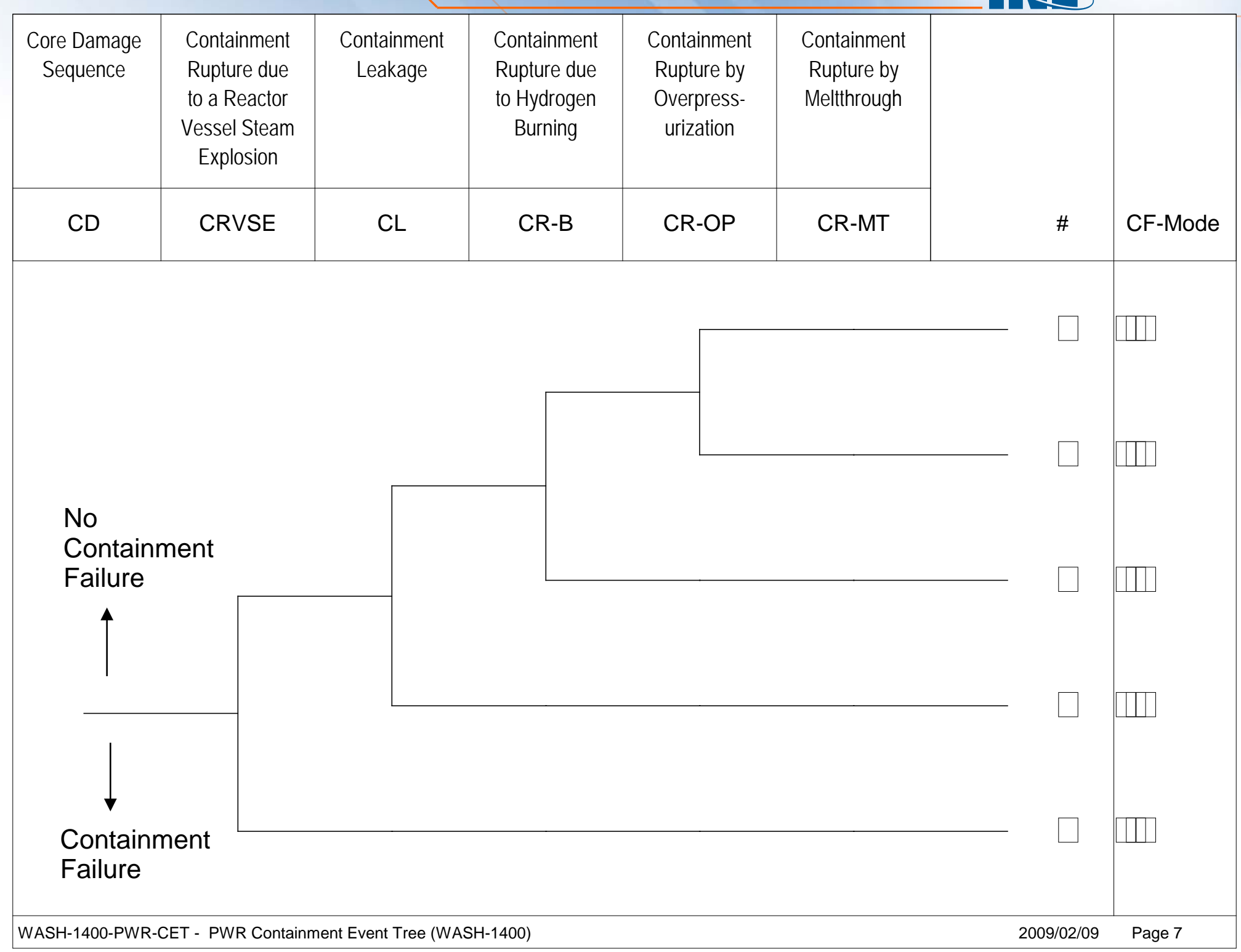




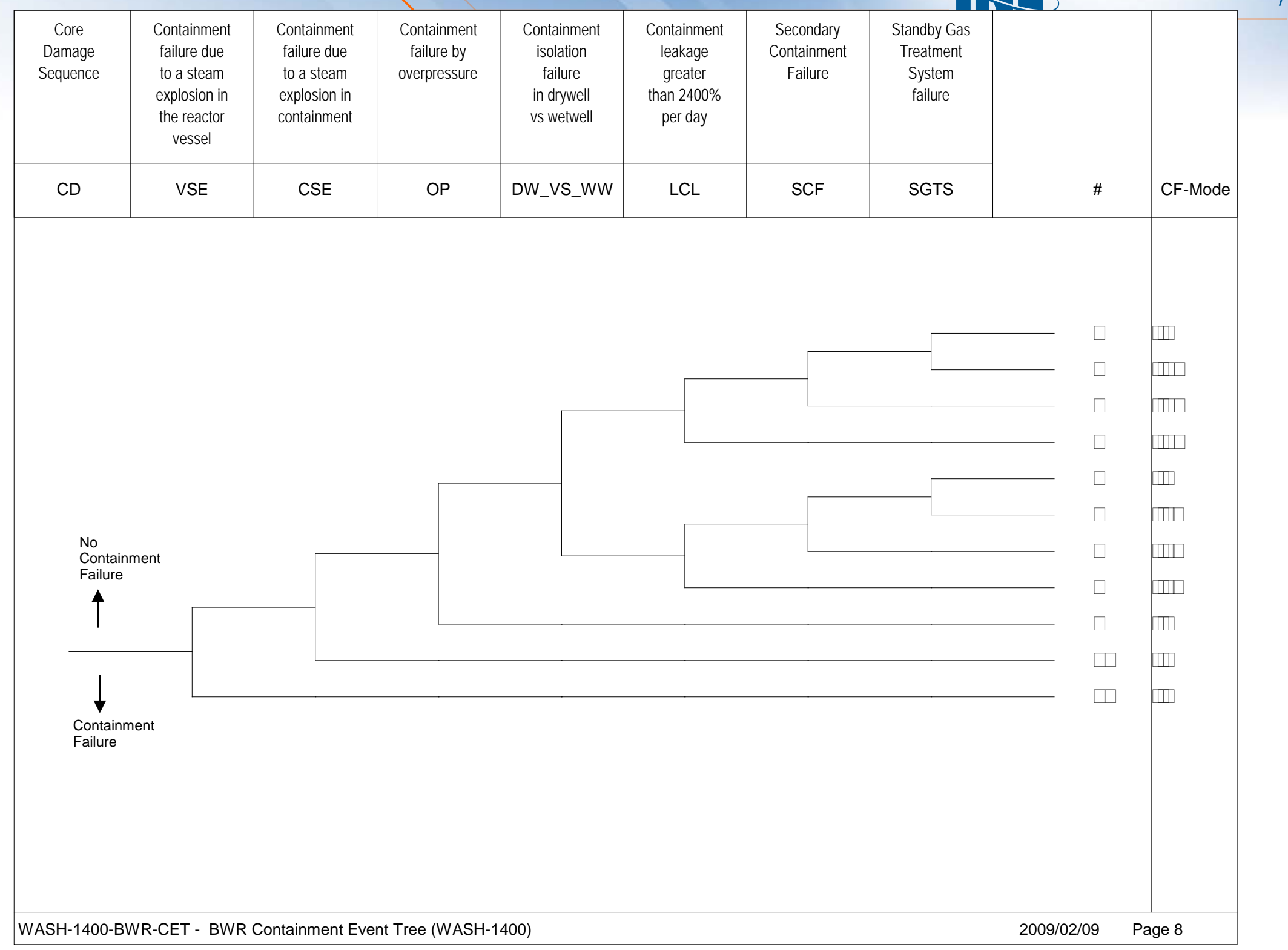




\section{Zion APET from NUREG-1150}

- Zion - PWR with large dry containment

- APET comprises 72 top events questions (most with multiple branches)

- 10 determined by Plant Damage State (from Level-1)

- 5 determined by systems or data analyses

- 14 determined by expert elicitation

- 19 determined from severe accident research

- 21 summary question (i.e., determined by answers to previous questions in the APET)

- 3 determined through internal calculations 


\section{Zion APET - Example Questions}

- Size/location of RCS break when the core uncovers?

- Initial containment leak or isolation failure?

- Temperature-induced hot leg or surge line break?

- Vessel pressure just before vessel breach?

- Amount of Zr oxidized in-vessel during core degradation?

- Adding $\mathrm{H} 2$ produced by core concrete interaction to $\mathrm{H} 2$ already in containment. 


\section{CET/APET Outputs Source Term}

- Containment failure details

- Size of containment failure

- Timing of failure

- Energy associated with failure

- In-containment transport of radioactive material also modeled in CET/APET

- Quality and quantity of radioactive material escaping containment 


\section{Level-3 Analysis Estimates Health Consequences for Each Release Event}

- Output of Level-2 analysis (i.e., details of the radioactive material source term release) provide one input to the Level-3 analysis

- Each source term combined with site-specific information on demographics, weather, emergency planning, etc. to calculate health and economic consequences to the surrounding population

- MACCS code used to perform consequence calculations 


\section{MACCS2 Code Features}

- Atmospheric transport and deposition under time-variant meteorology

- Short- and long-term mitigative actions and exposure pathways

- evacuation, sheltering and relocation of people

- interdiction of milk and crops

- decontamination or interdiction of land and buildings

- Deterministic and stochastic health effects, and economic costs

- Includes Direct (cloudshine, inhalation, groundshine, and skin deposition) and indirect (ingestion) radiation dose pathway 


\section{MACCS2 Available Since 1998}

- Improvements over MACCS include:

- More flexible emergency-response model

- Expanded library of radionuclides

- Semidynamic food-chain model

- Improved phenomenological modeling

- New output options 


\section{Typical Consequence Measures}

- From NUREG-1150 (MACCS)

- Early fatalities

- Total latent cancer fatalities

- Population dose within 50 miles

- Population dose within entire region

- Individual early fatality risk within 1 mile (used for QHO comparison)

- Individual latent cancer fatality risk within 10 miles (used for QHO comparison) 


\section{Session Review}

- PRA structure and outputs

- Level-1 PRA

- Level-2 PRA

- Level-3 PRA 


\title{
Accident Progression Analysis (P-300)
}

\author{
3. LWR Containment Designs
}




\section{Session Objectives}

- To understand the various LWR containment designs

- Features important to severe accident response 


\section{Seven Major Types of LWR Containment Designs}

- Boiling Water Reactors (BWRs)

- Mark I (e.g., Peach Bottom 2 \& 3, Cooper and Fukushima Daiichi 1-5)

- Mark II (e.g., Limerick 1 \& 2, Columbia)

- Mark III (e.g., Clinton, Grand Gulf)

- Pressurized Water Reactors (PWRs)

- Large Dry (e.g., ANO 1 \& 2, Indian Point 2 \& 3)

- Subatmospheric (e.g., Surry $1 \& 2$, Millstone 3)

- Subatmospheric usually grouped with Large Dry

- Ice Condensers (e.g., Sequoyah 1 \& 2, D. C. Cook 1 \& 2)

- AP1000 (e.g. Vogtle 3 \& 4)

- Design variations within each group 


\section{Significantly Larger Number of Dry Containments}

Containment Type

Large dry

- ANO 1 \& 2, Indian Point $2 \& 3$

Subatmospheric

- Surry $1 \& 2$, Millstone 3

Ice Condenser

- Sequoyah 1 \& 2, D.C. Cook 1 \& 2

Mark I

- Peach Bottom 2 \& 3, Cooper

Mark II

- Limerick 1 \& 2, Columbia

Mark III

- Clinton, Grand Gulf
Number

58

7

9

24

8

4 


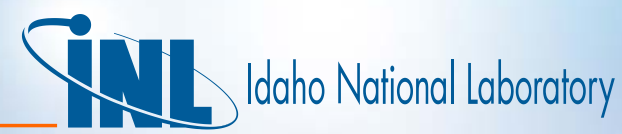

\section{Containment Free Volumes and Design Pressures Differ ${ }_{\text {Containment design pressure (psig) }}$}

$\begin{array}{llllllllllll}0 & 10 & 20 & 30 & 40 & 50 & 60 & 70 & 80 & 90 & 100 & 110\end{array}$

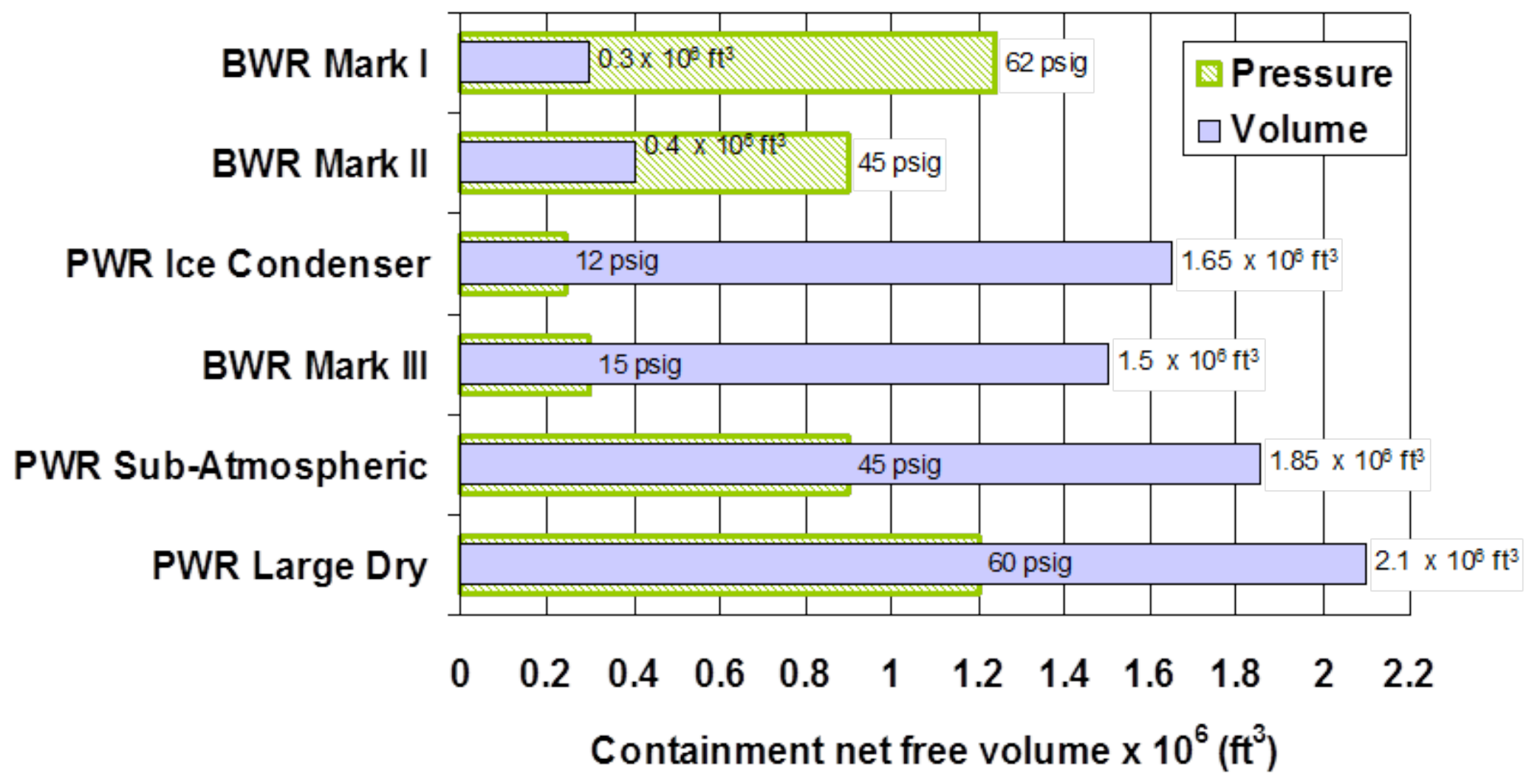




\section{Mark I Design Used in Older BWRs}

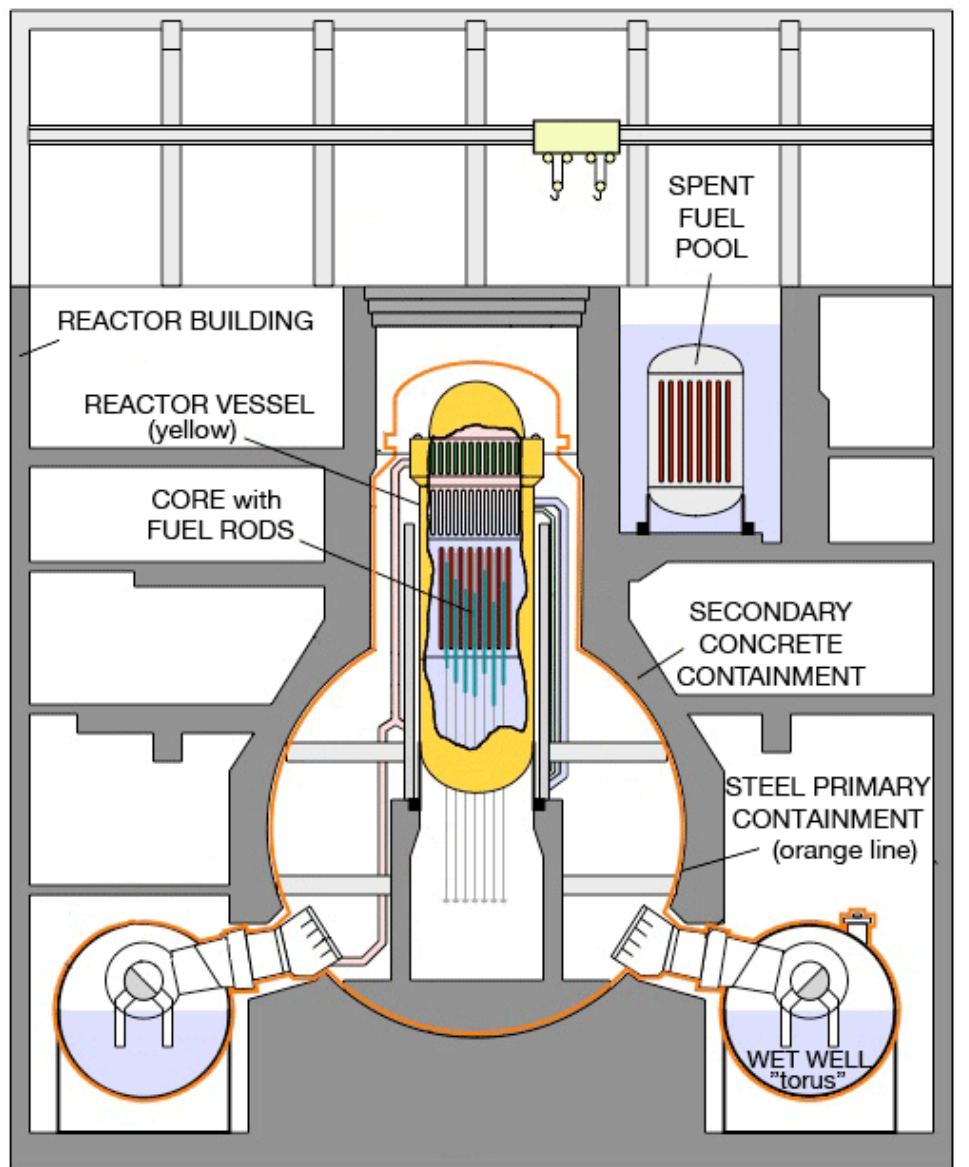

- Two structures/volumes connected by large diameter pipes

- Drywell: reactor vessel and primary system

- Wetwell: torus containing large volume of water used for pressure suppression and heat sink

- Containment atmosphere inerted to prevent hydrogen $(\mathrm{H} 2)$ combustion 


\section{Mark I cutaway}

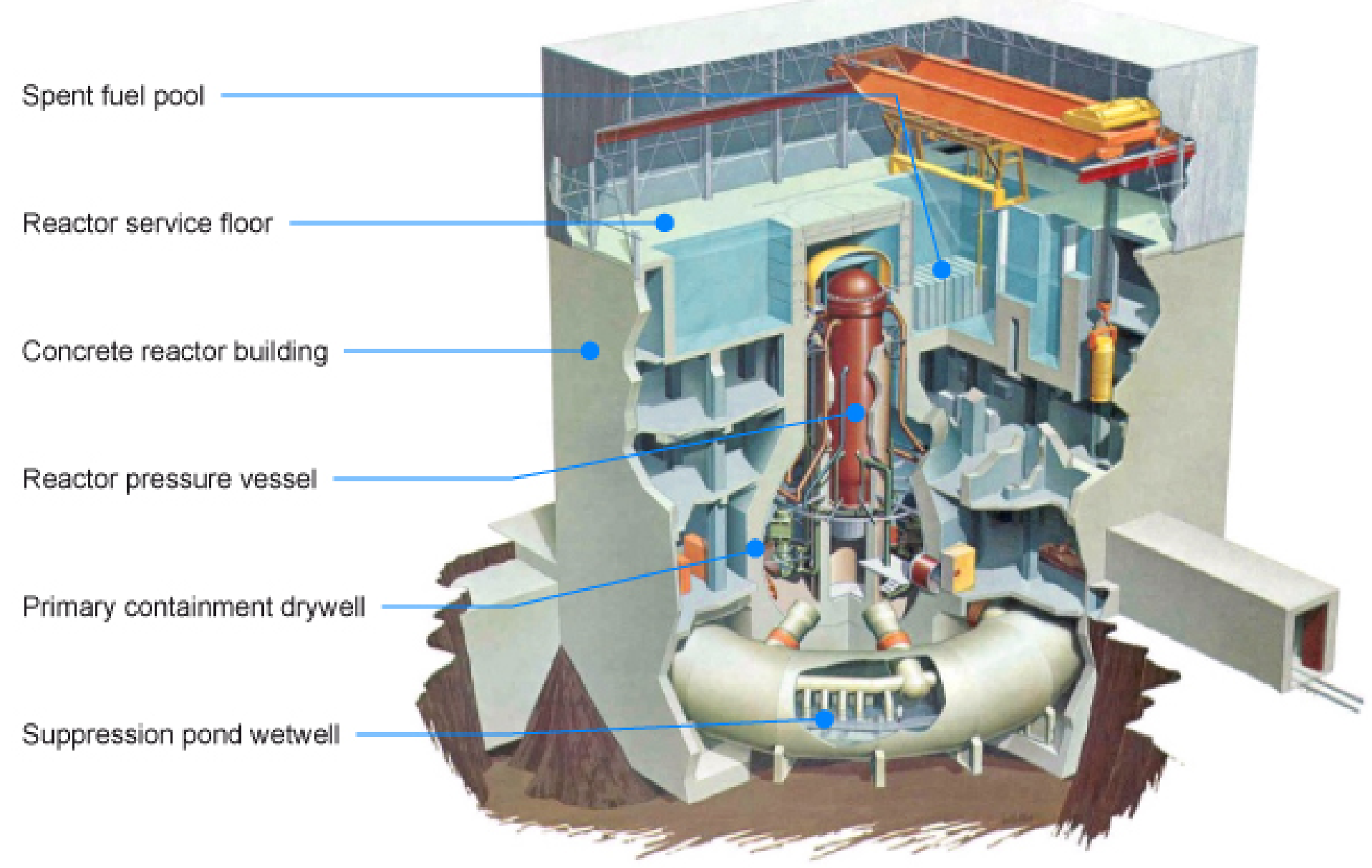




\section{Mark I \\ Containment Heat Removal Relies \\ Primarily on Suppression Pool Water}

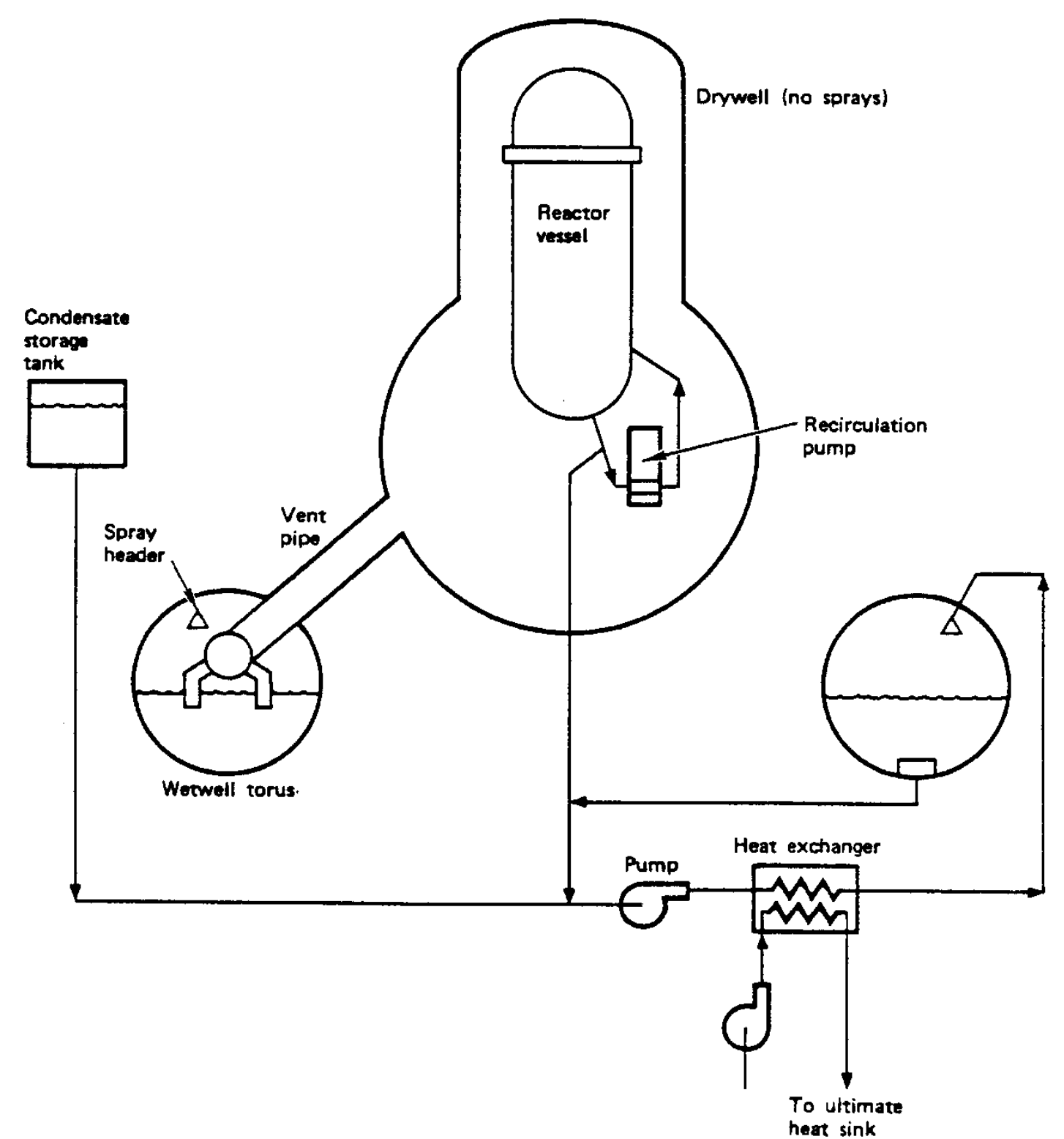




\section{Mark II Design More Unified than Mark I Design}

- Single structure divided into two volumes by concrete floor

- Drywell is directly above wetwell

- Drywell and wetwell connected by vertical pipes

- Reinforced or post-tensioned concrete structures with steel liner (Columbia is exception - free-standing steel)

- Containment atmosphere inerted to prevent H2 combustion 


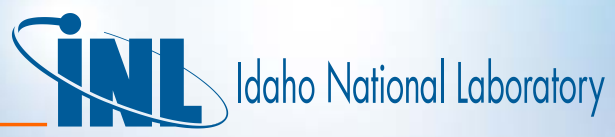

\section{Mark II Design More Unified than Mark I Design (continued)}

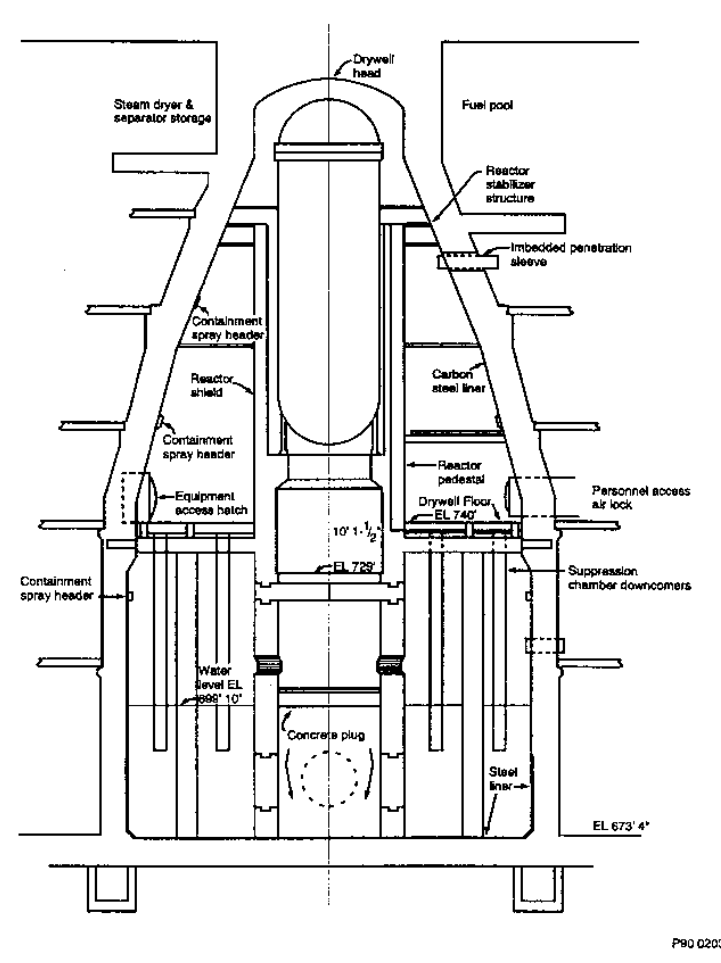

LaSalle Units 1 \& 2

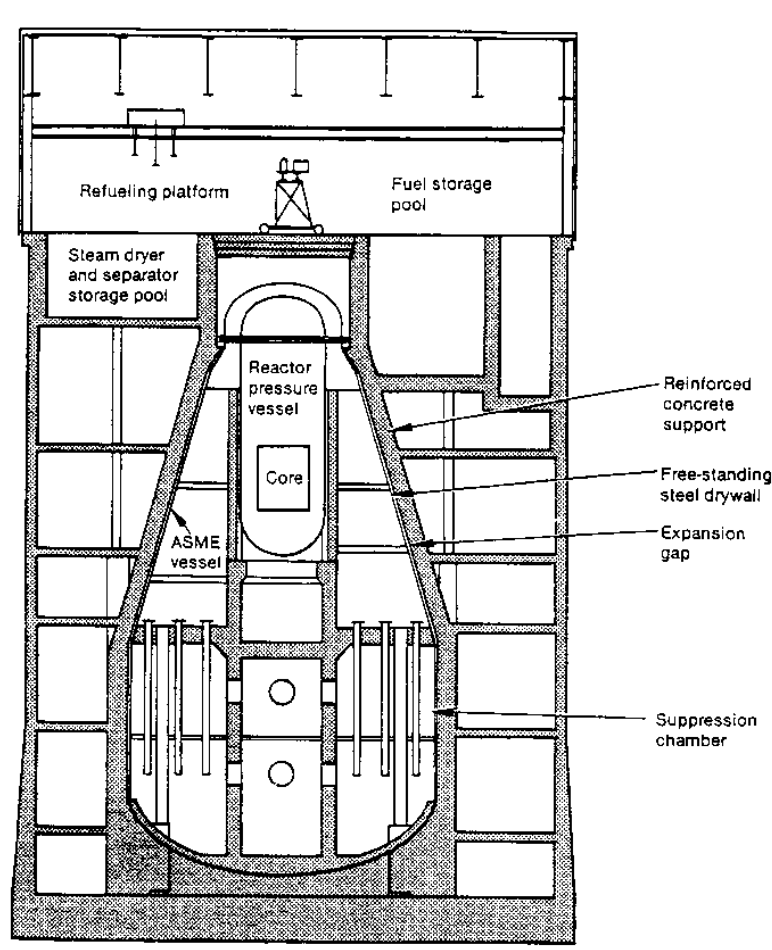

Columbia (WNP-2)

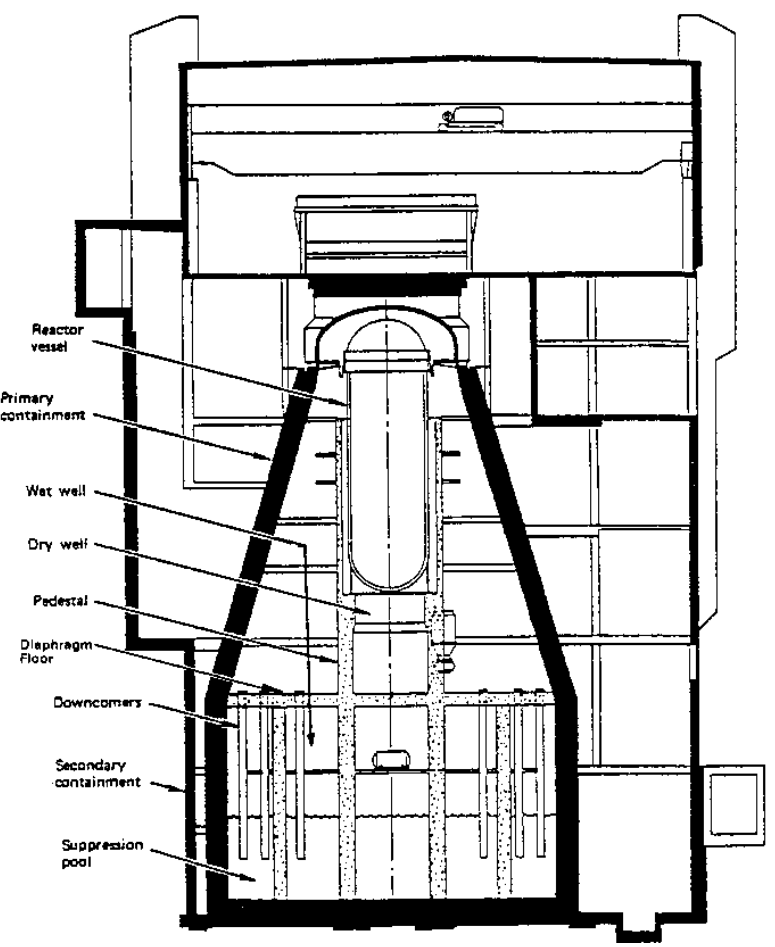

Limerick 1 \& 2 


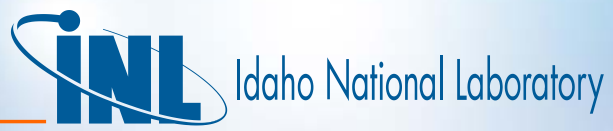

\section{Mark II Design More Unified than Mark I Design (continued)}

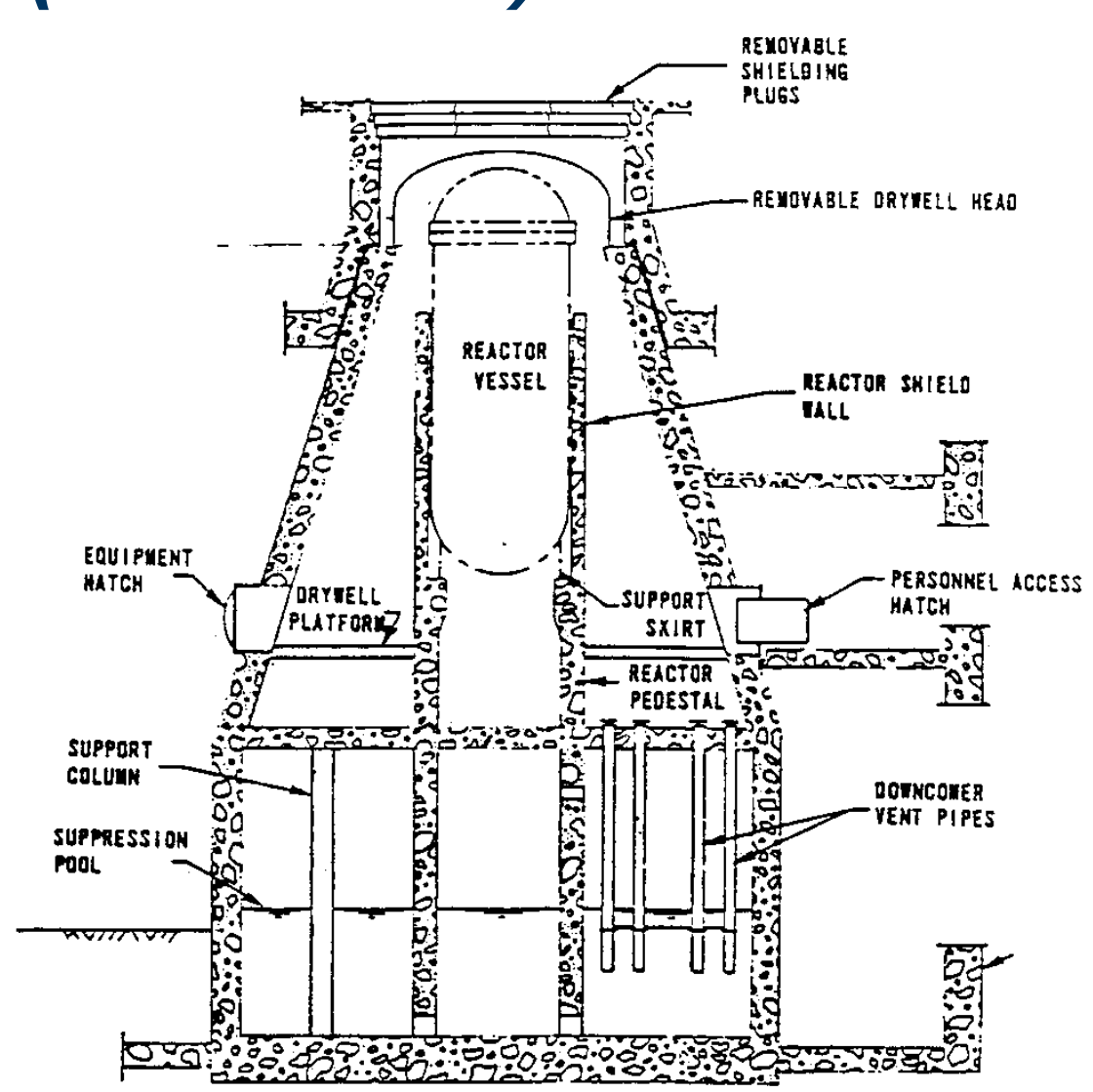

Susquehanna Units $1 \& 2$

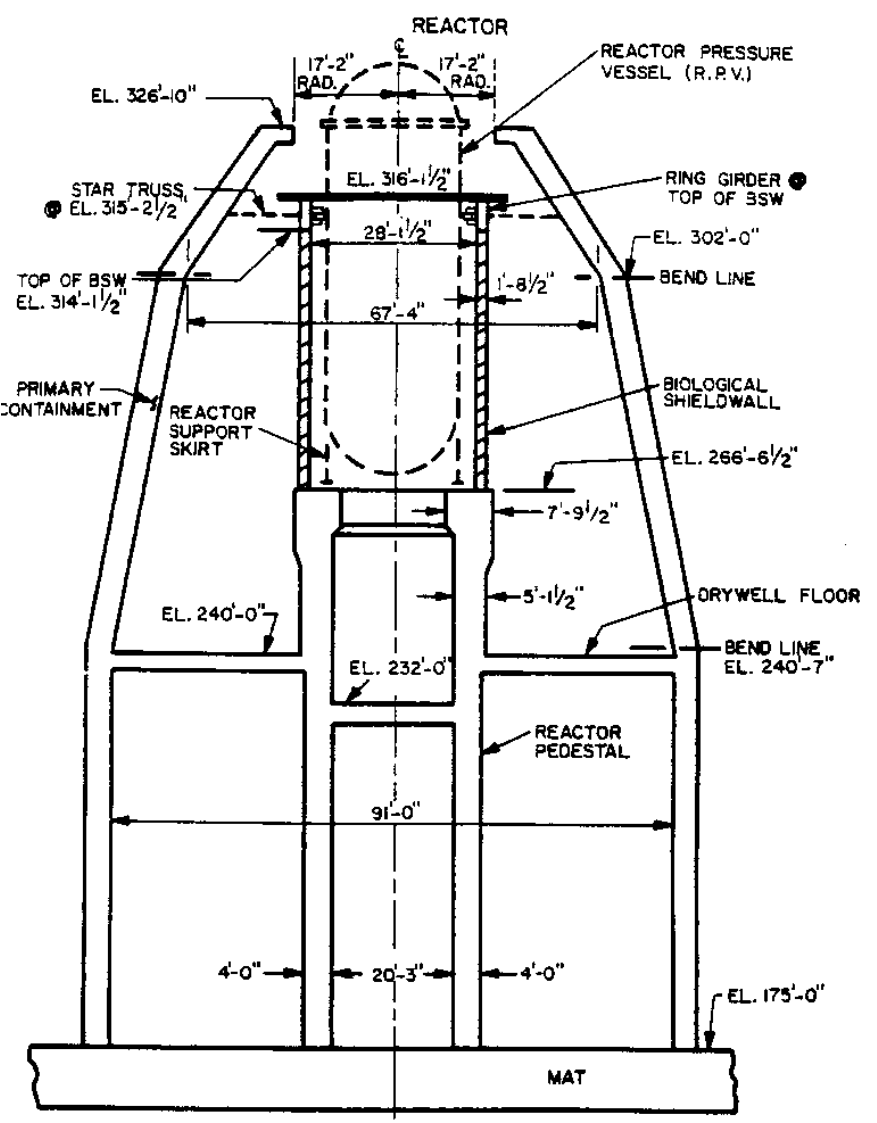

Nine Mile Point 2 


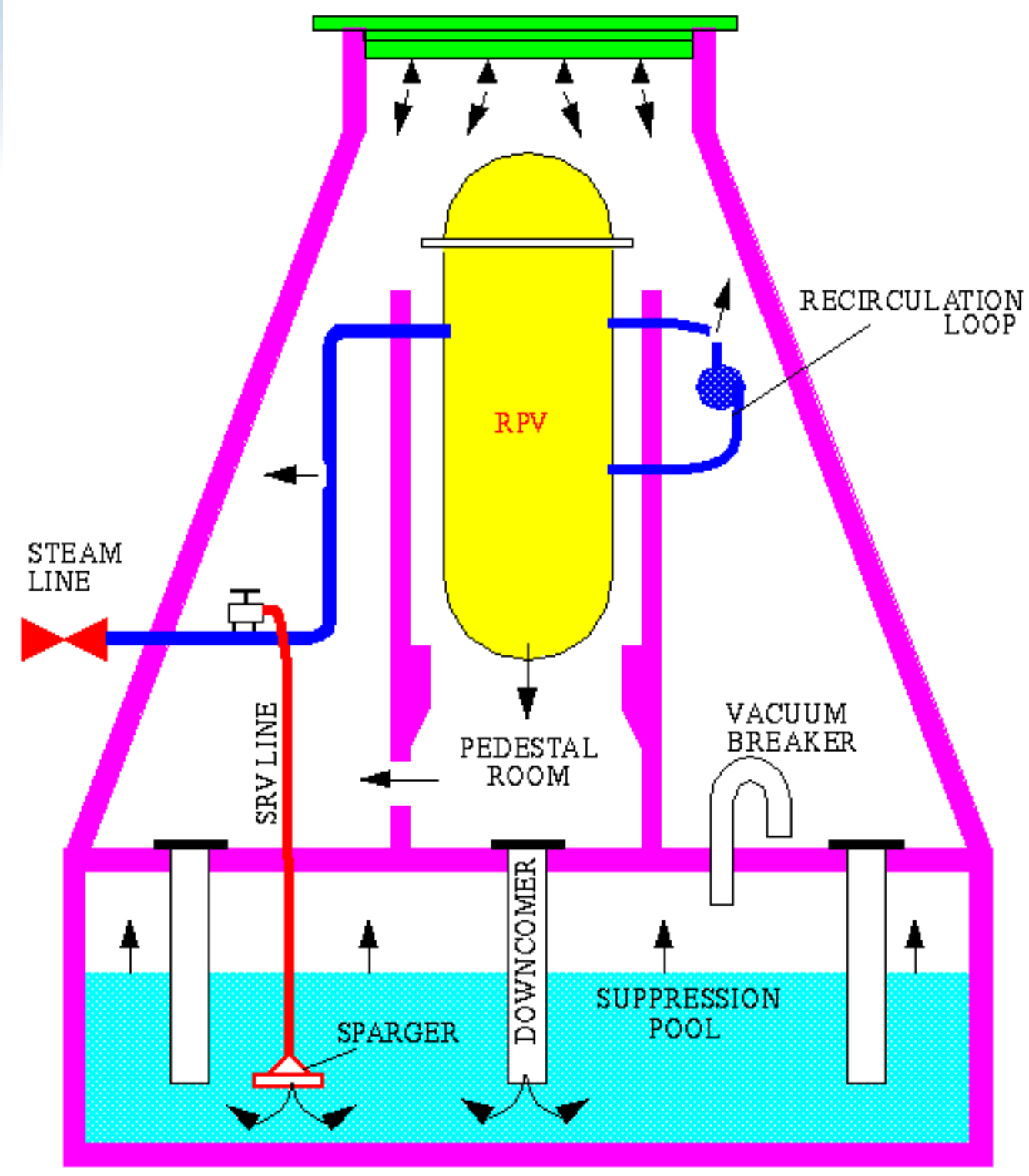




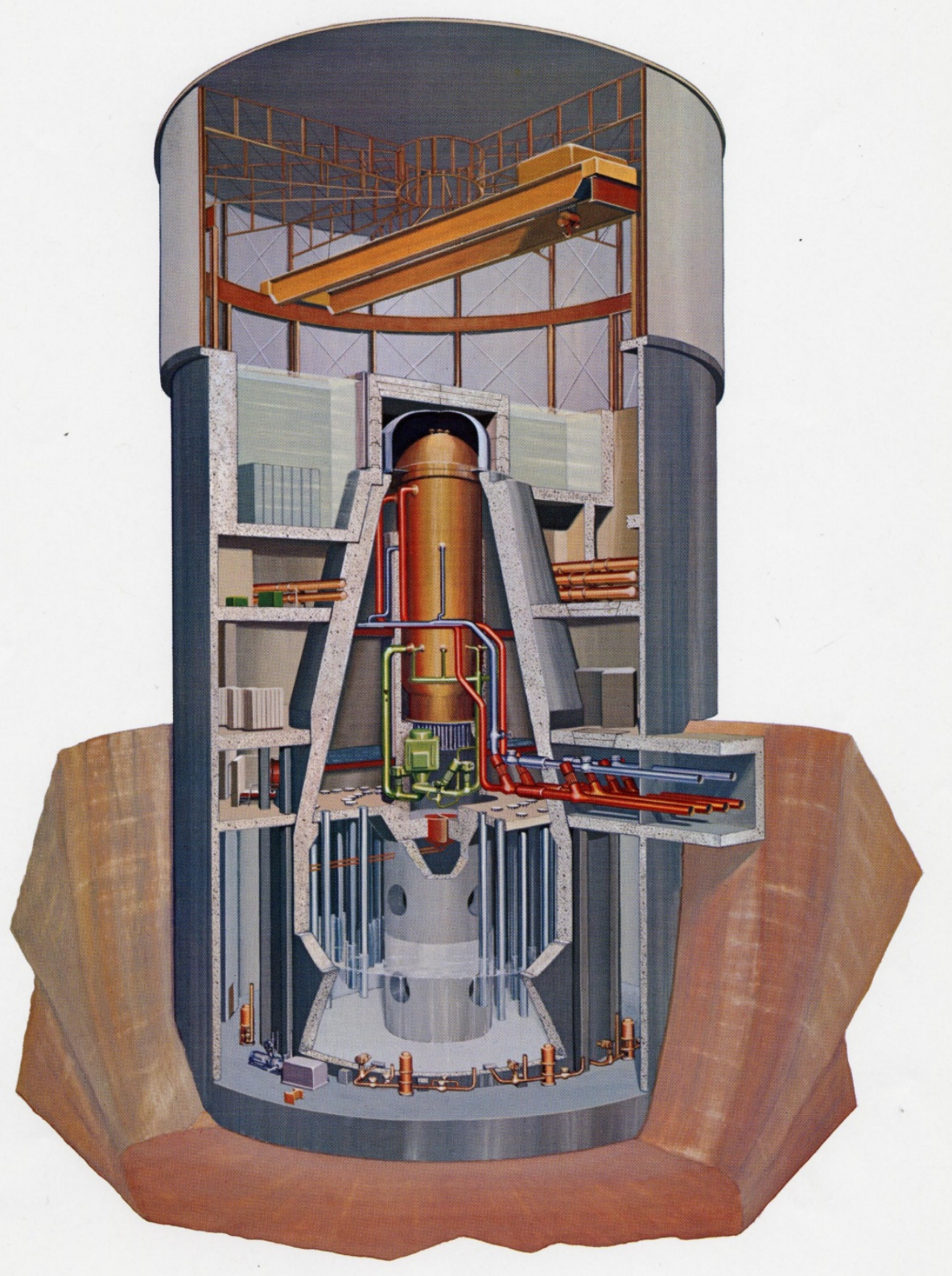




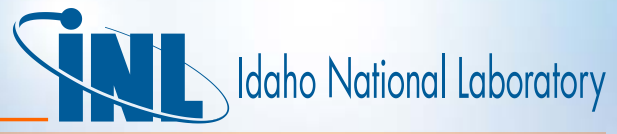

\section{Containment}

\section{Heat Removal}

for Mark II Containment

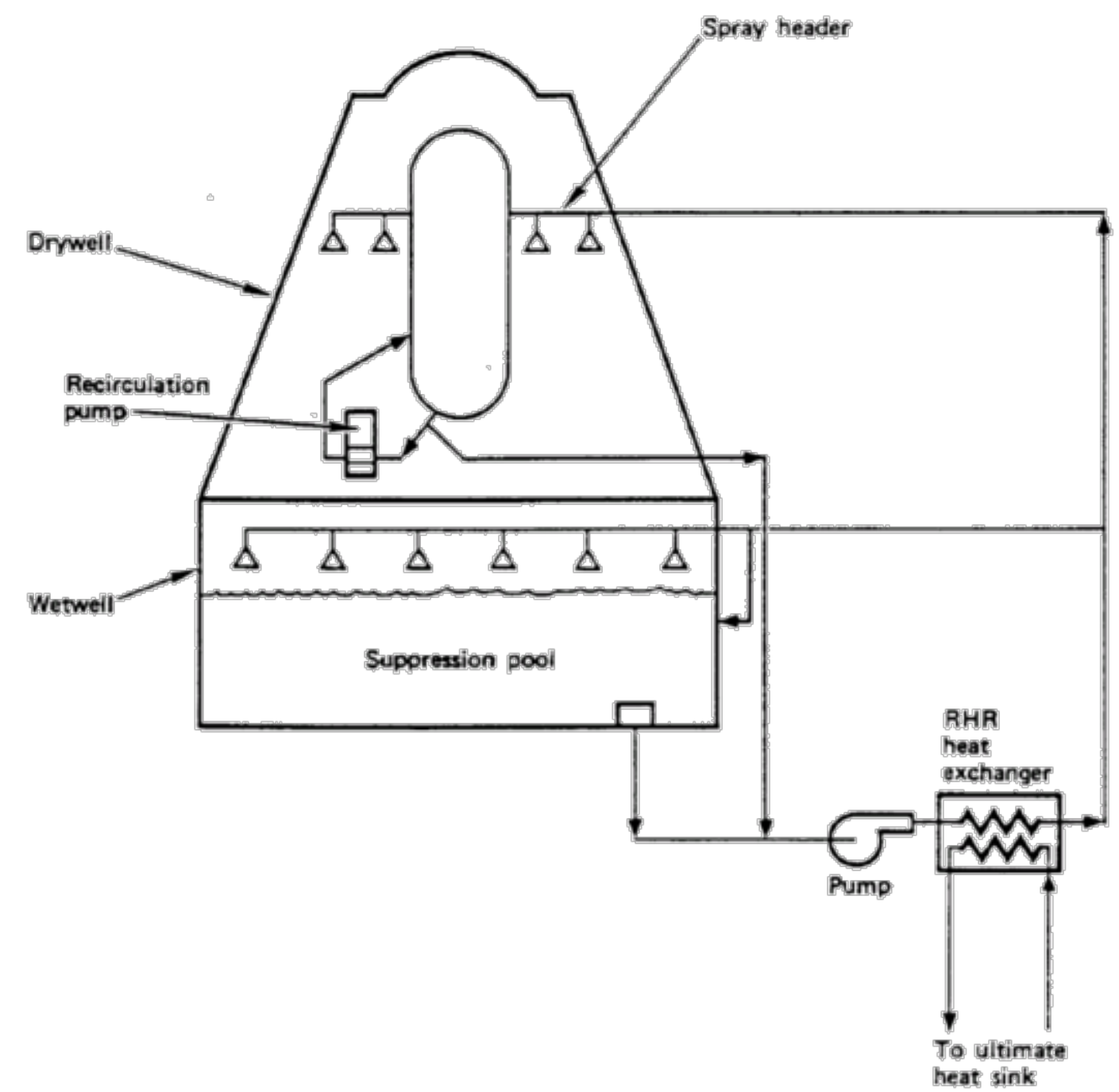




\section{Idaho National Laboratory}

\section{Mark III Dramatically Differs from Mark I and II Designs}

- Two volumes (drywell and wetwell) connected by horizontal vents

- Significantly larger volume than Mark I and Mark II designs

- but lower design pressure

- Containment atmosphere NOT inerted

- relies on hydrogen igniters

- Two types of primary containment designs

- free-standing steel structure (Perry \& River Bend)

- reinforced concrete with steel liner (Clinton \& Grand Gulf) 


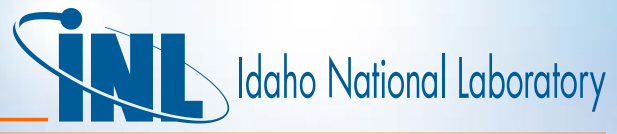

\section{Two Types of Mark III Primary Containments}

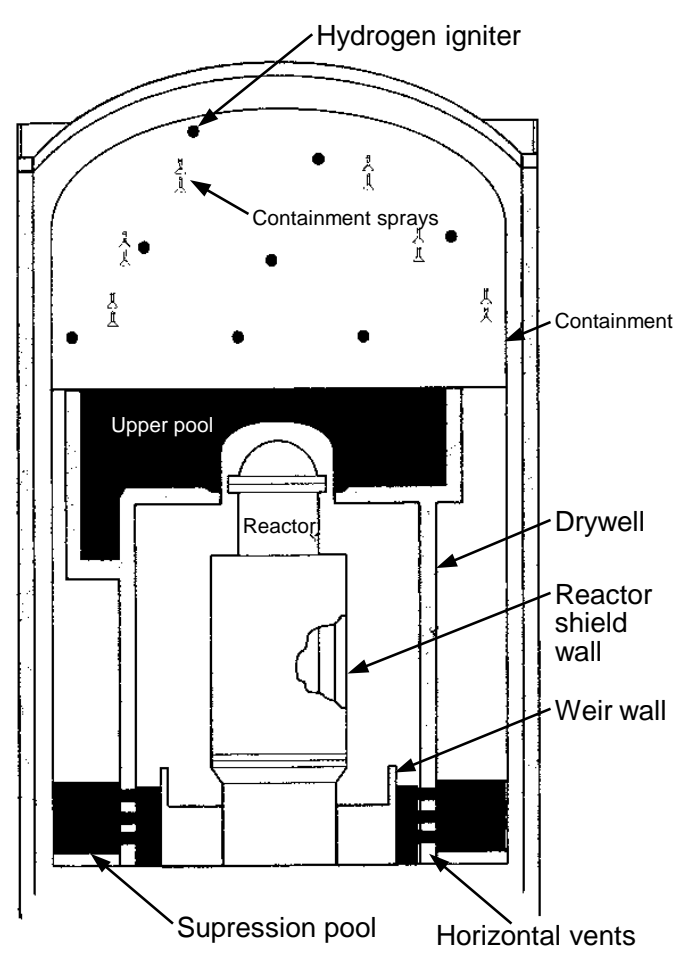

Free standing steel structure

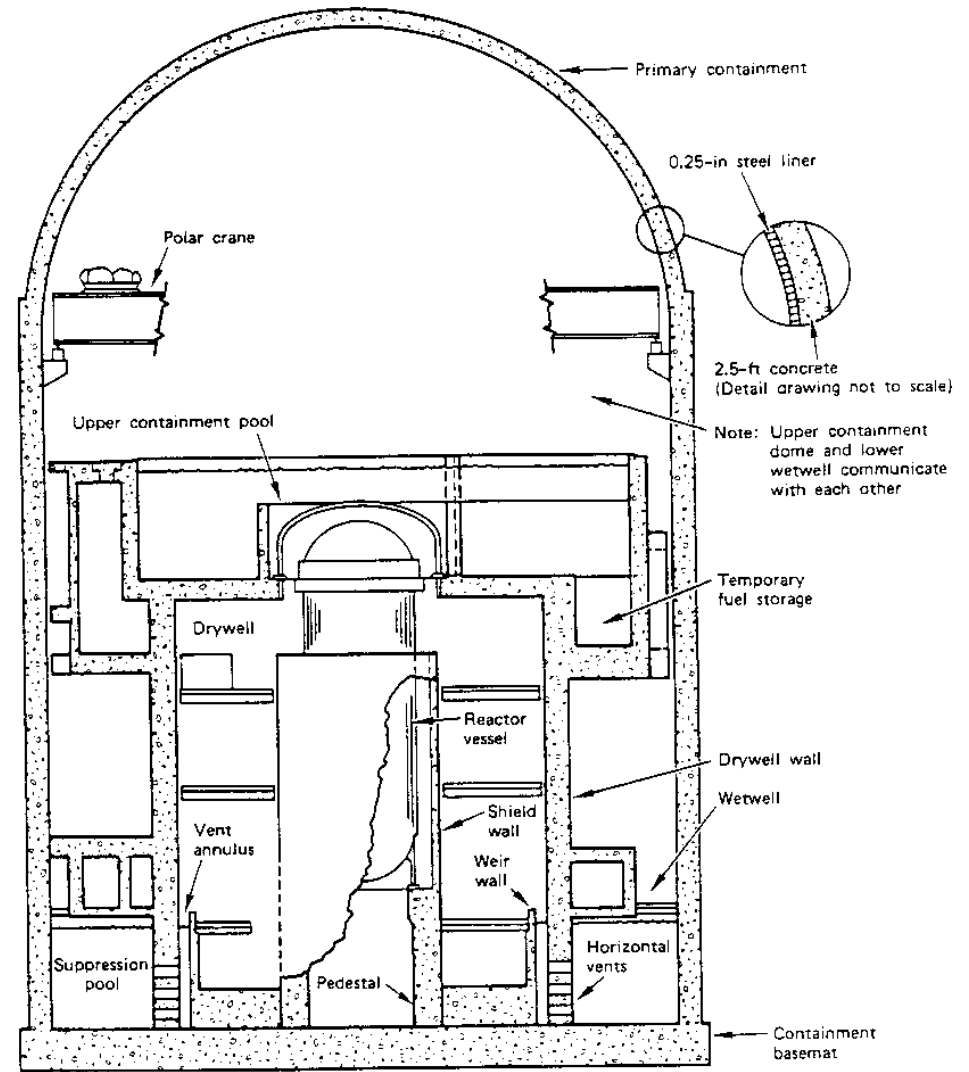

Reinforced concrete 


\section{MARK III CONTAINMENT}

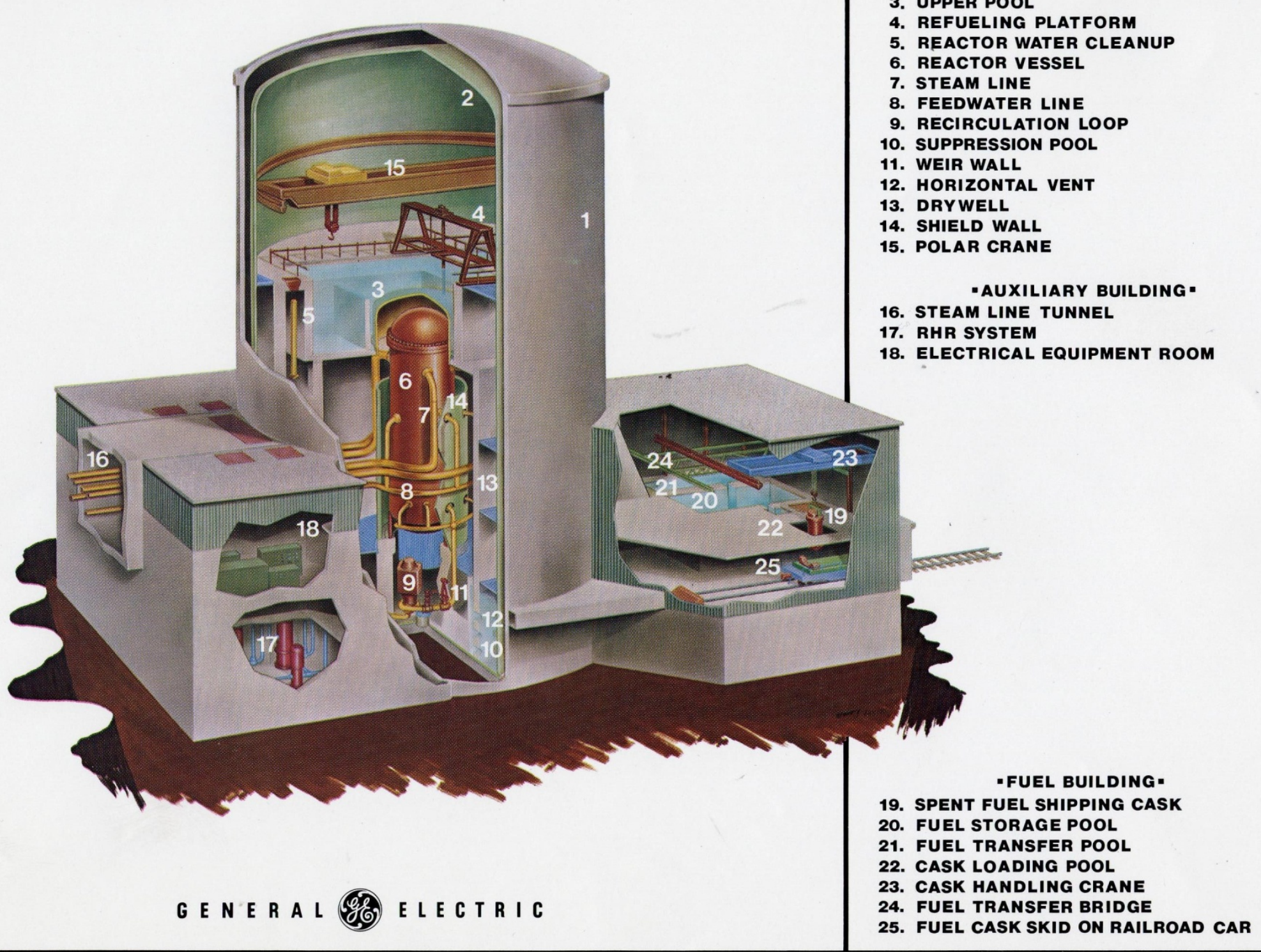

-REACTOR BUILDING.

1. SHIELD BUILDING

2. FREESTANDING STEEL CONTAINMENT

UPPER POOL

4. REFUELING PLATFORM

RECIRCULATION LOOP

12. HORIZONTAL VENT

3. DRY WELL

-AUXILIARY BUILDING.

16. STEAM LINE TUNNEL

18. ELECTRICAL EQUIPMENT ROOM
7. RHR SYSTEM
2. FUEL STORAGE POOL

25. FUEL CASK SKID ON RAILROAD CAR 


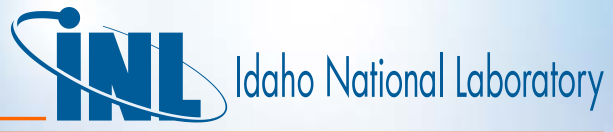

Mark III

Containment

Heat Removal

Accomplished via Sprays and Suppression Pool

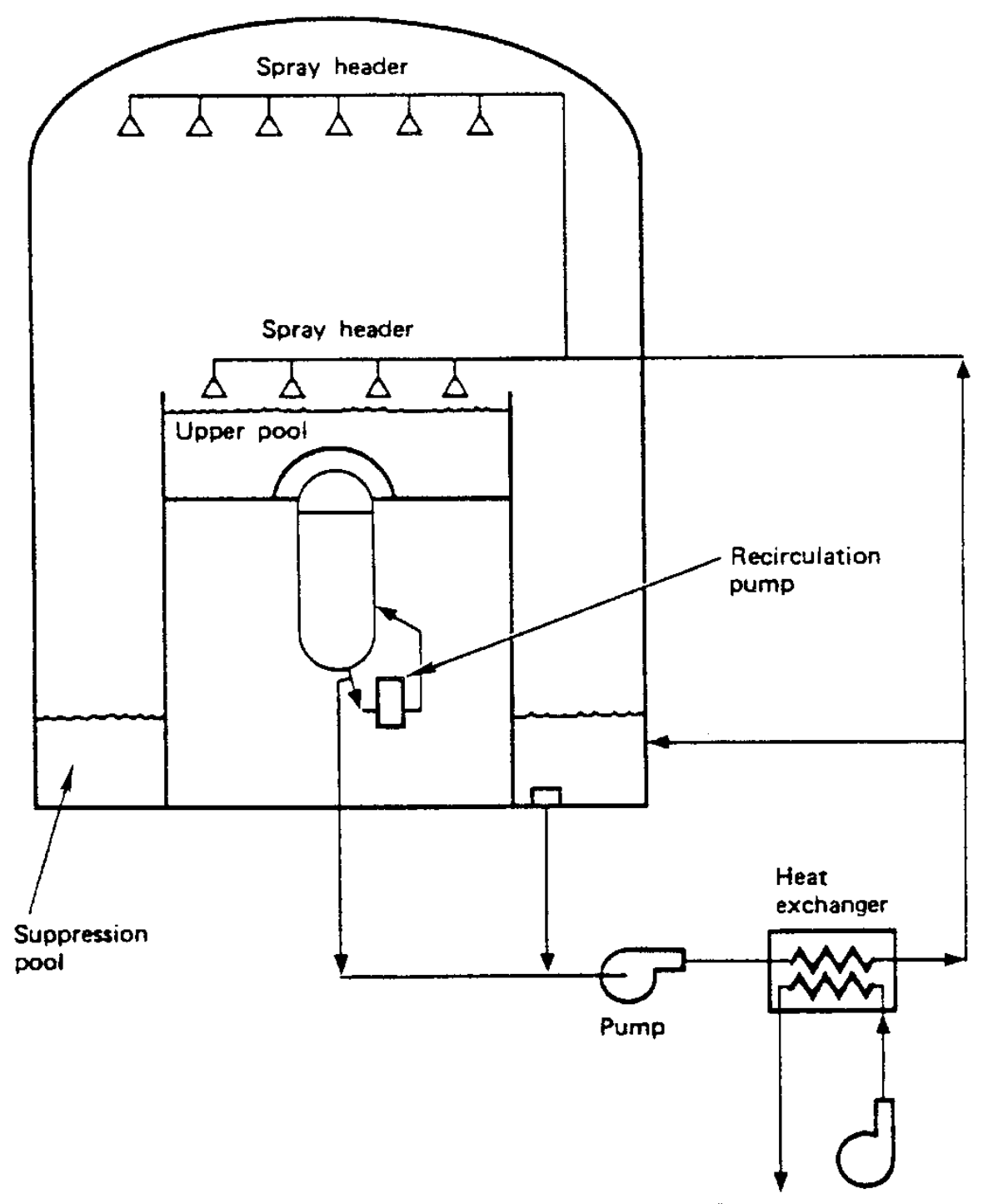

To ultimate

heat sink 


\section{PWR Containment Designs Differ}

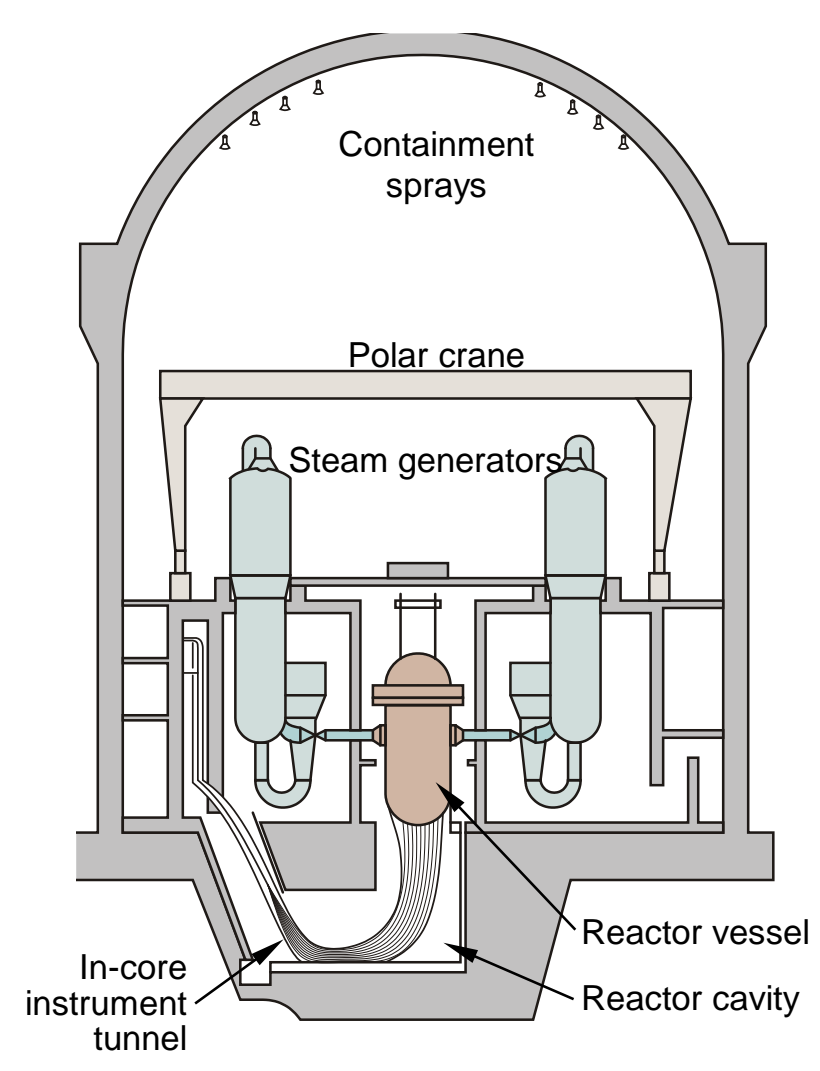

Large dry

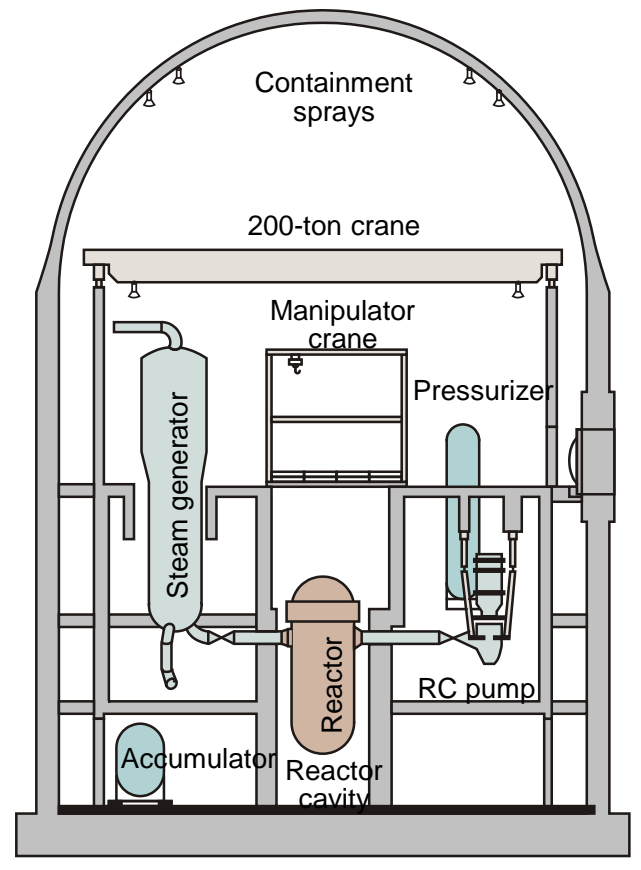

Subatmospheric

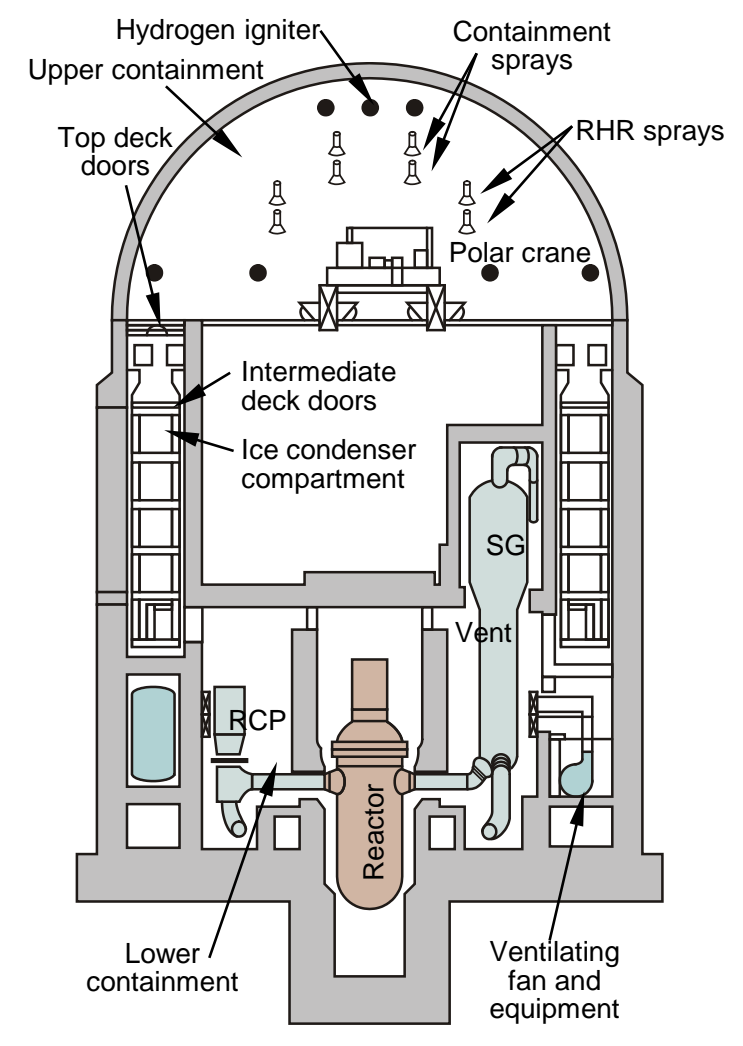

Ice condenser 


\section{TII Idaho National laboratory}

\section{Diverse Types of Large Dry Containments}

- Rely on large internal volume and structural strength (i.e., no passive pressure suppression system)

- greater diversity of designs compared to other types

- Represents largest containment design group

- includes a small subset (about 7) subatmospheric containment designs

- Most use reinforced or post-tensioned concrete with steel liner

- few are of steel construction with reinforced concrete secondary containment 


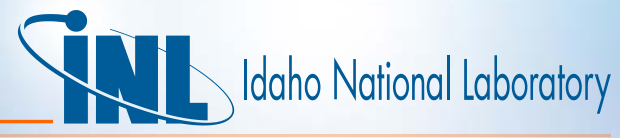

\section{Diverse Types of Large Dry Containments} (continued)

\author{
Large dry reinforced \\ concrete \\ e.g., Diablo Canyon \\ (Most subatmospheric \\ designs are of this type)
}

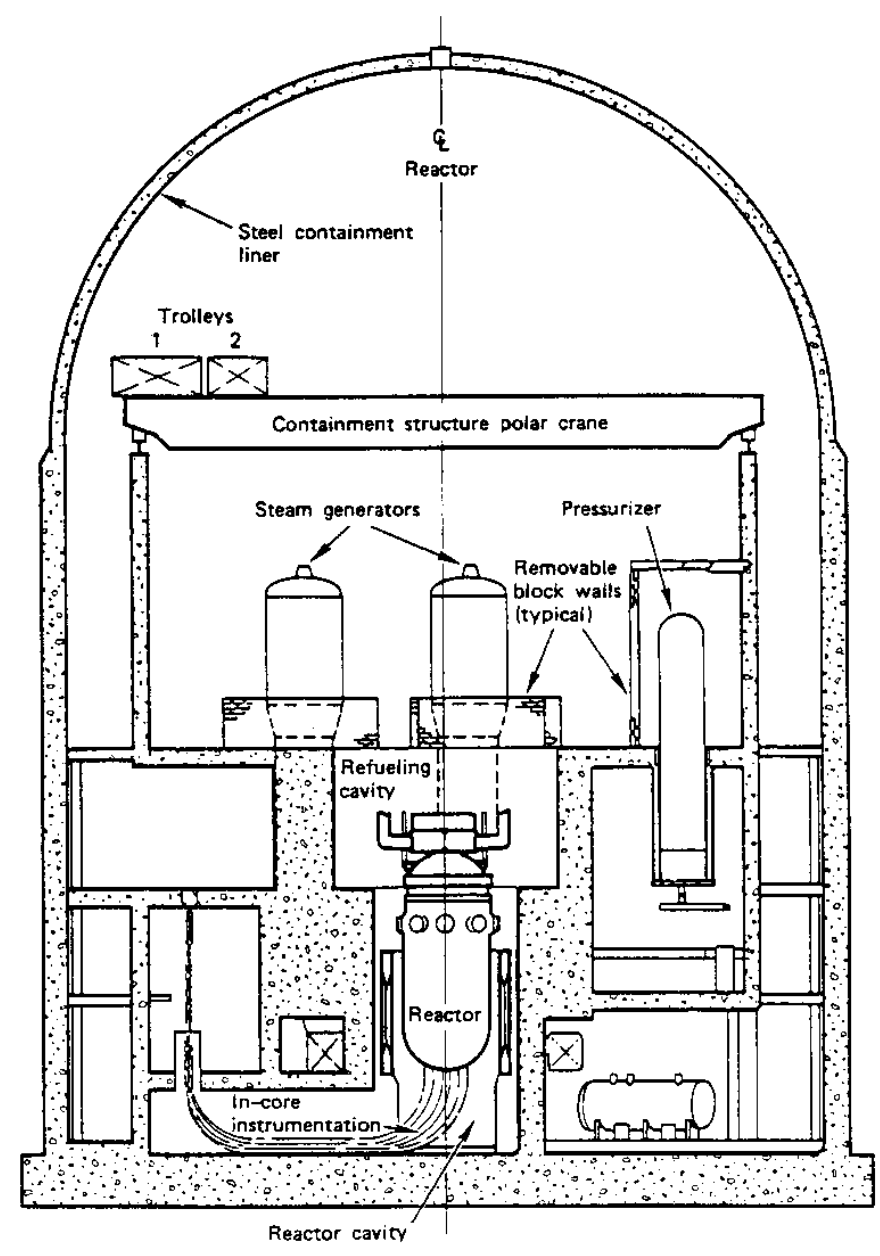




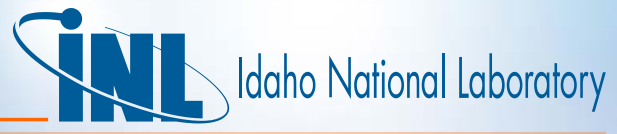

\section{Diverse Types of Large Dry Containments}

(continued)
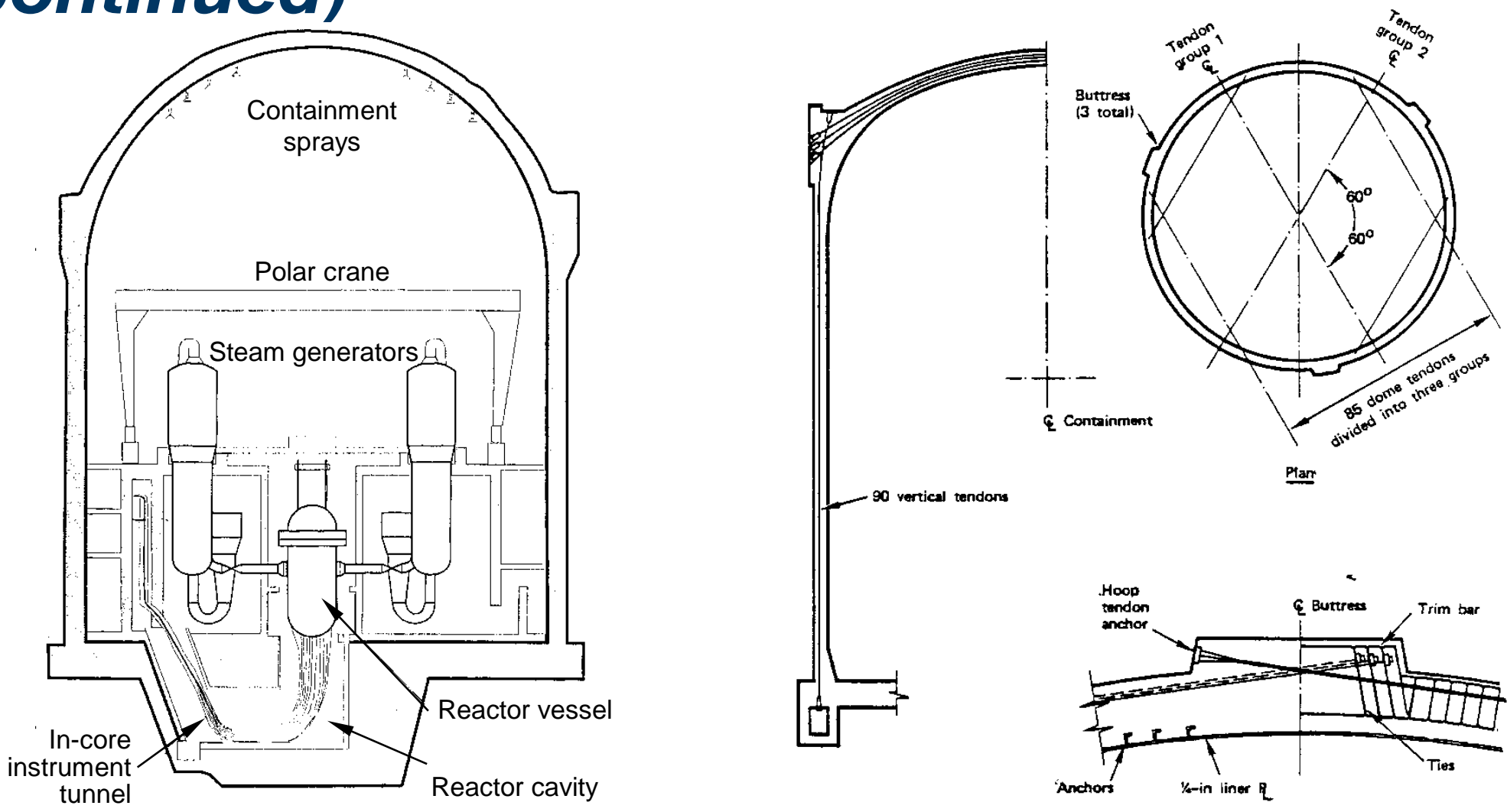

Typical eron section:

Derail of buttress

Large Dry Pre-stressed (or Post-tensioned) Concrete

e.g., Palisades

(This is the most common containment design) 


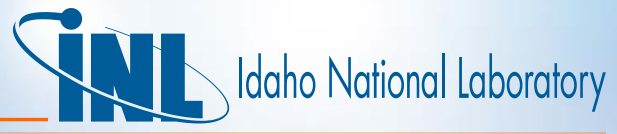

\section{Diverse Types of Large Dry Containments}

(continued)

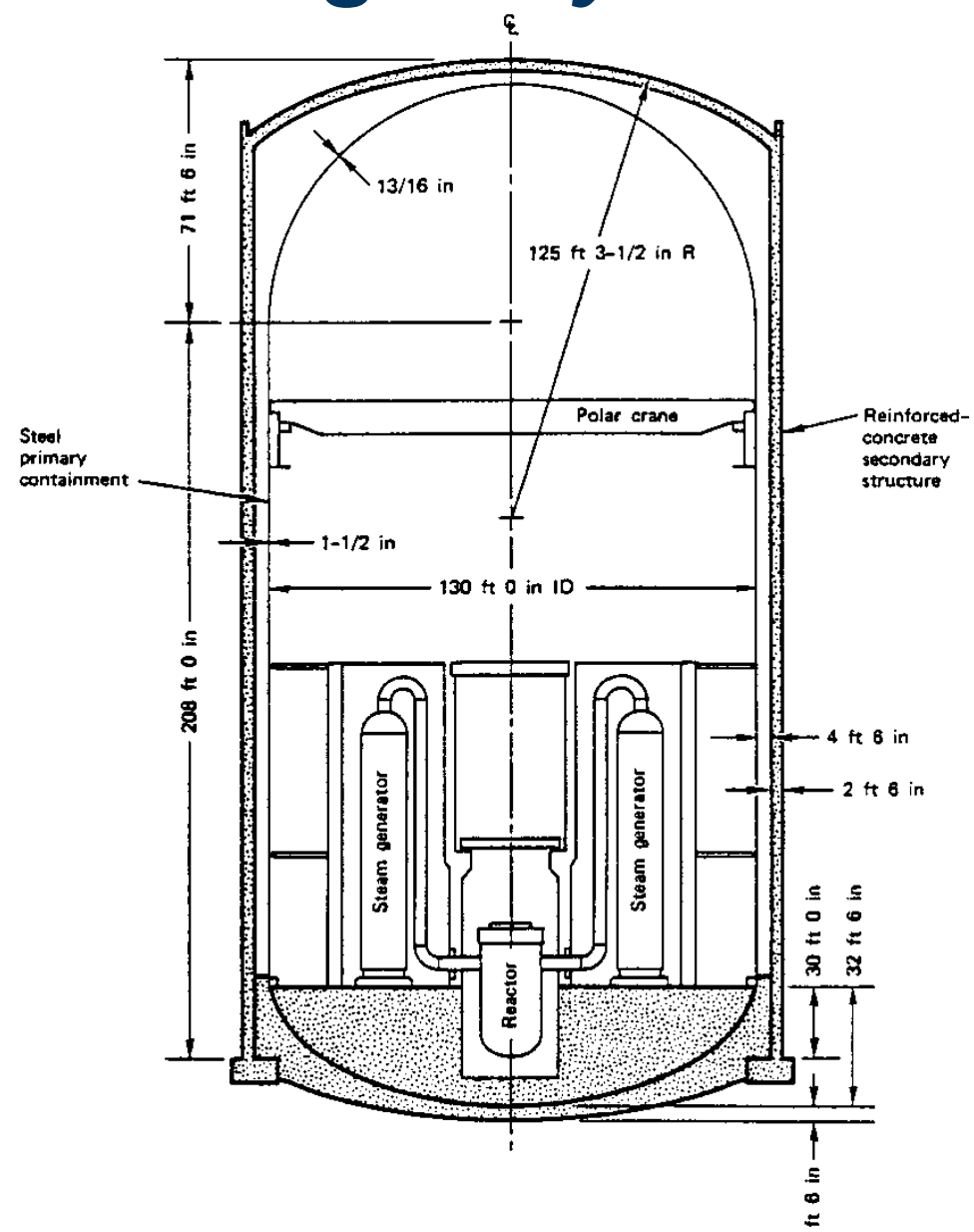

Large dry steel containment with reinforced concrete secondary containment e.g., Davis Besse 


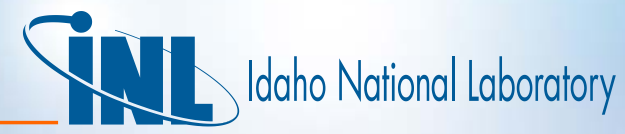

\section{Containment}

Heat Removal for Large Dry Containment Design Uses Sprays and Fans Coolers

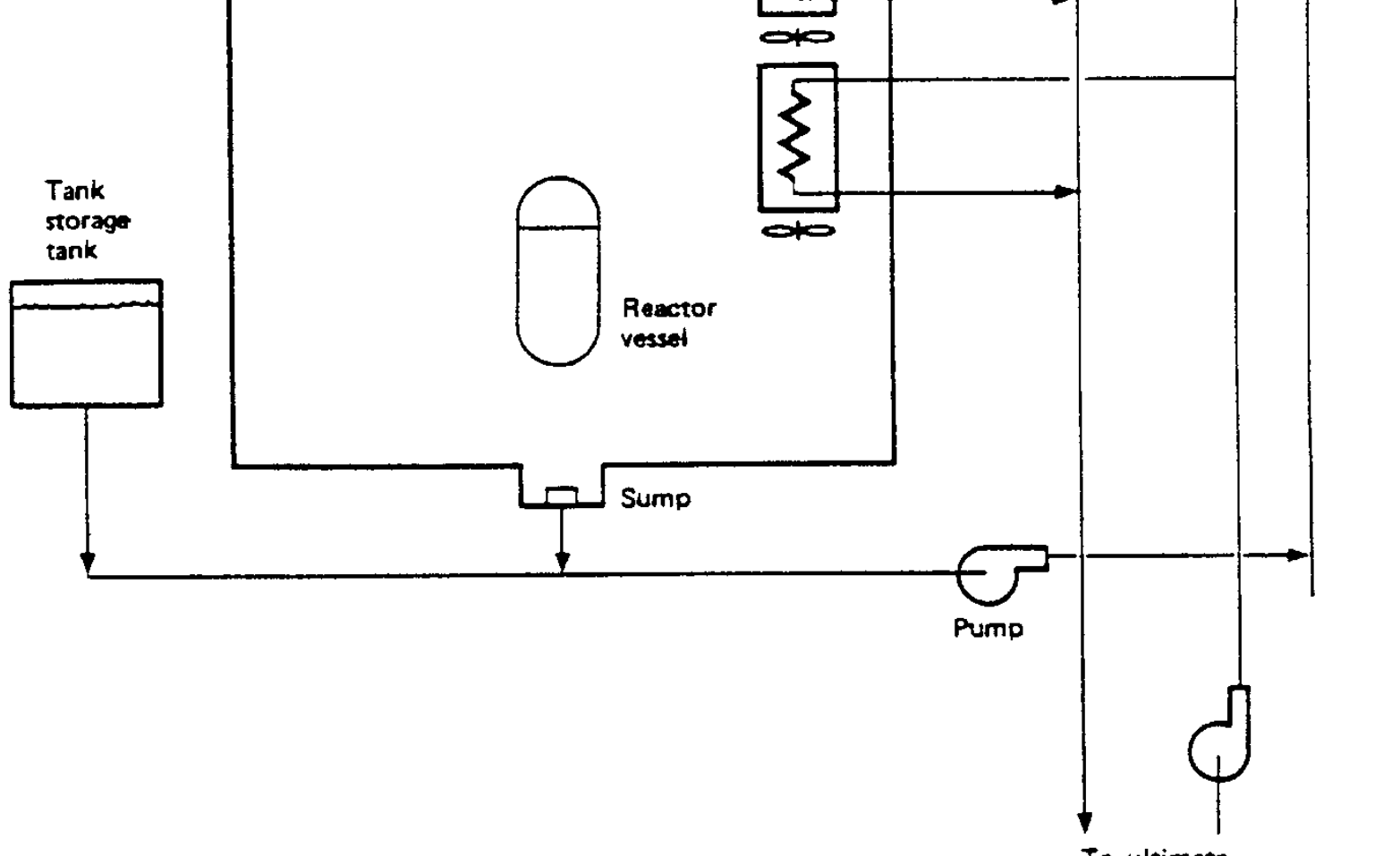




\section{Ice Condenser Containments}

- Three volumes: lower compartment, upper compartment, ice condenser

- Ice condenser connects lower compartment containing RPV and RCS to upper compartment

- Ice condenser holds approximately $2,300,000 \mathrm{lb}$. of borated ice in perforated metal baskets

- Relies on igniters for hydrogen control

- Most have cylindrical steel containment surrounded by concrete secondary containment

- D. C. Cook: concrete containment with steel liner 


\section{Ice Condenser Containments (continued)}

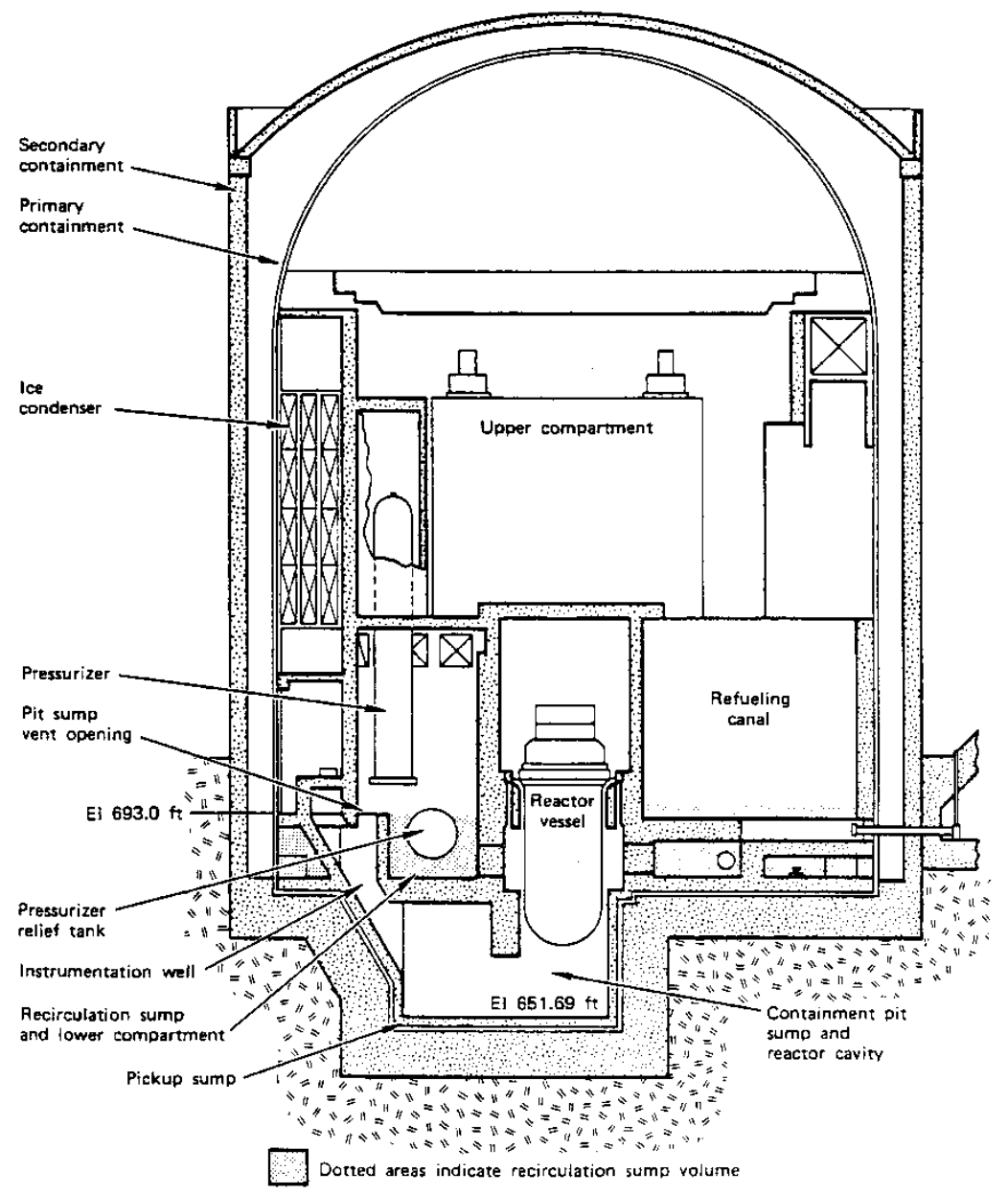

Sequoyah

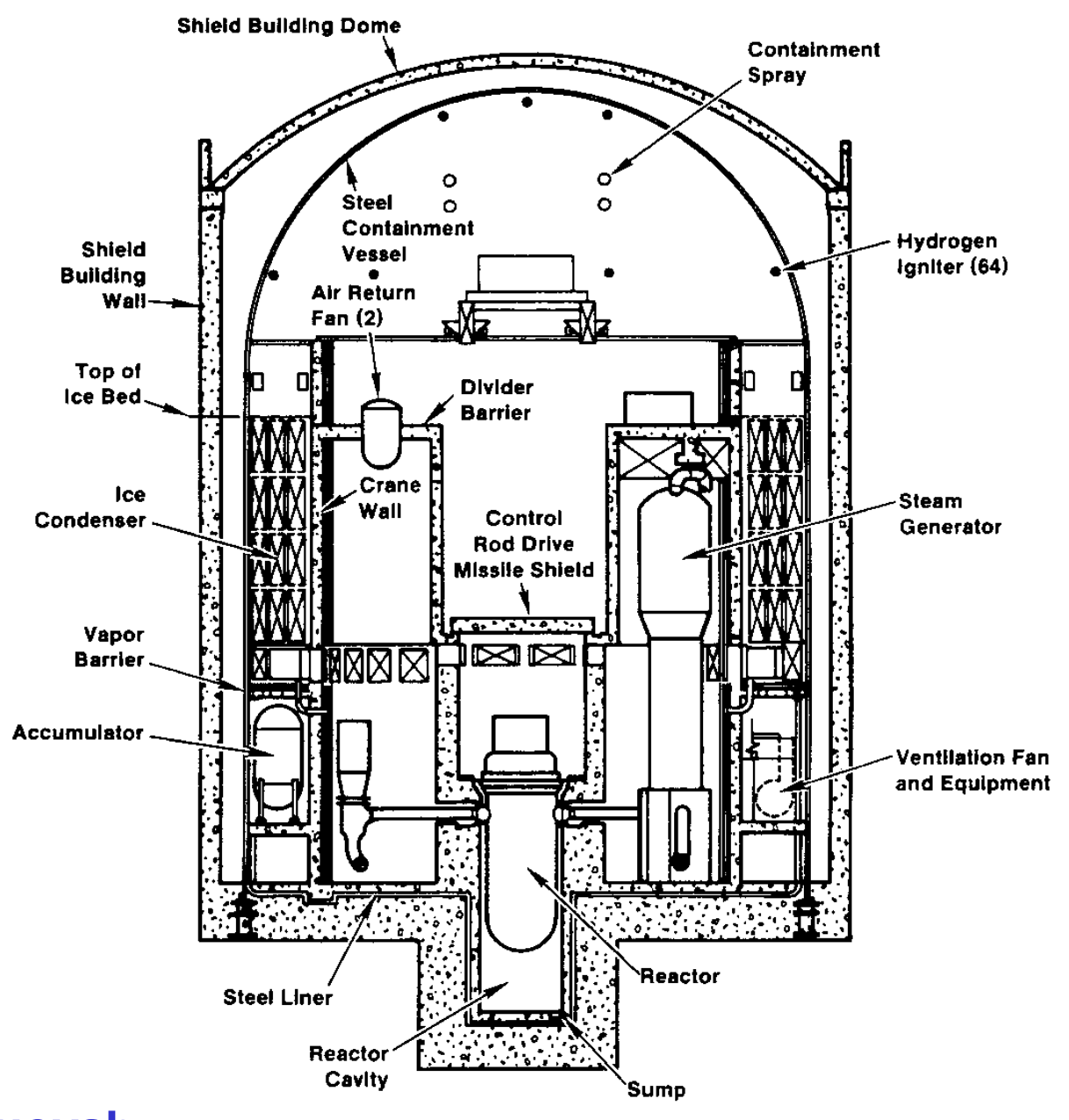




\section{Ice Condenser Containments (continued)}

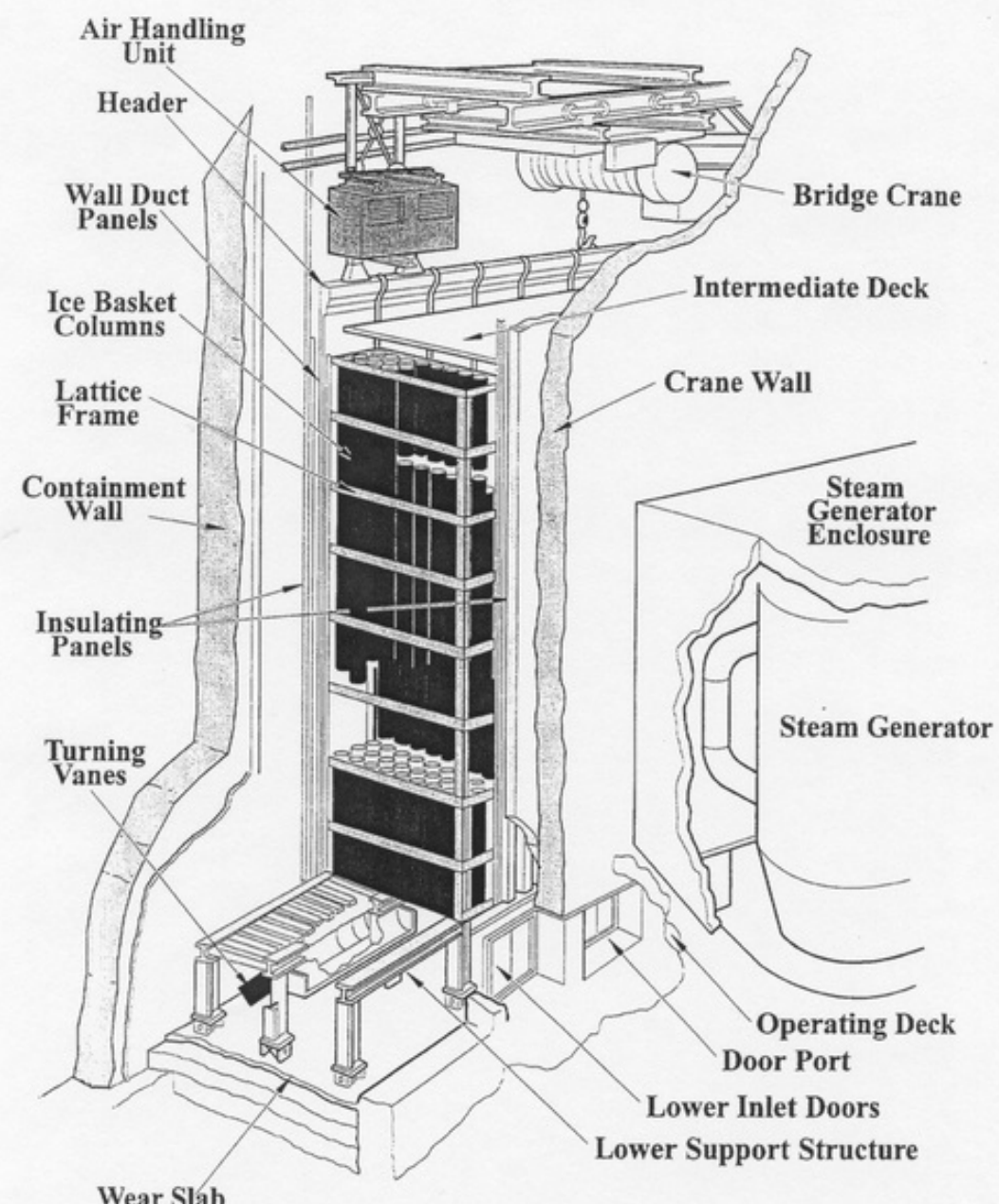

Ice condenser cutaway

Figure 2 


\section{CHR for IC Design Uses Sprays and Ice}

Condensers

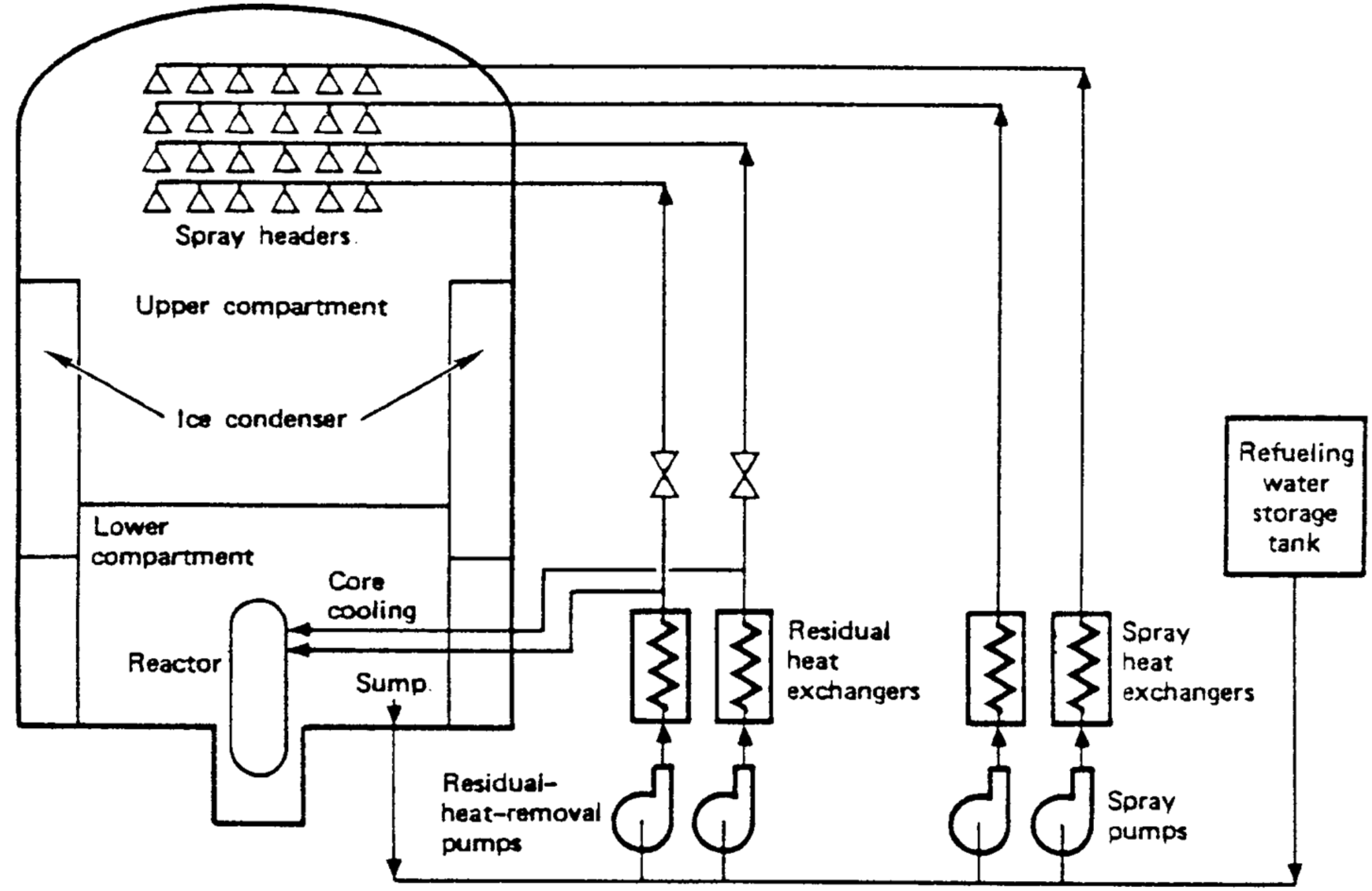




\section{AP1000 Containment Design}

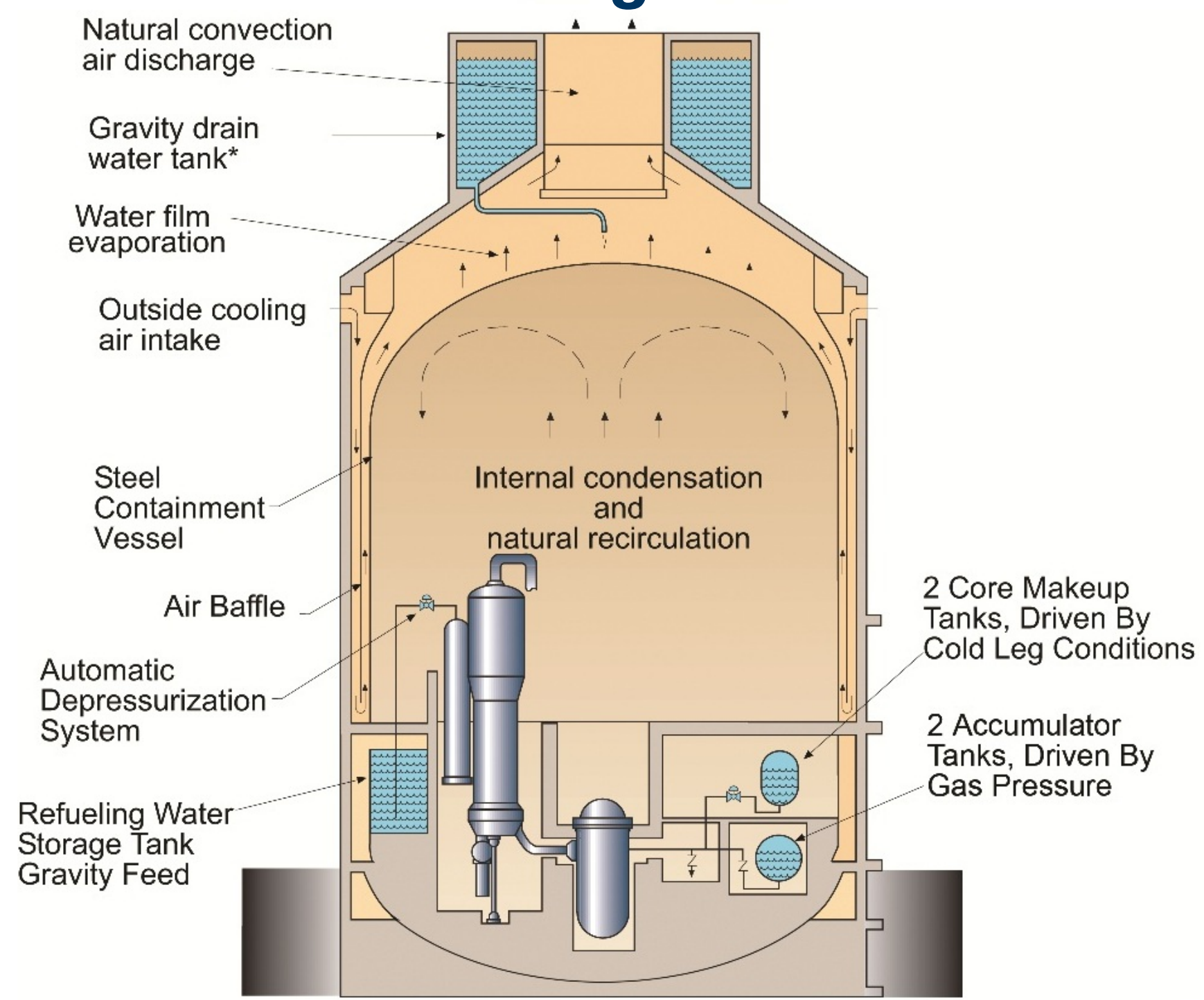




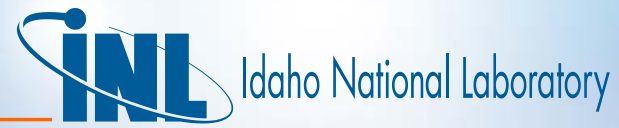

\section{AP1000 Containment Utilizes In-Vessel Core Damage Retention}

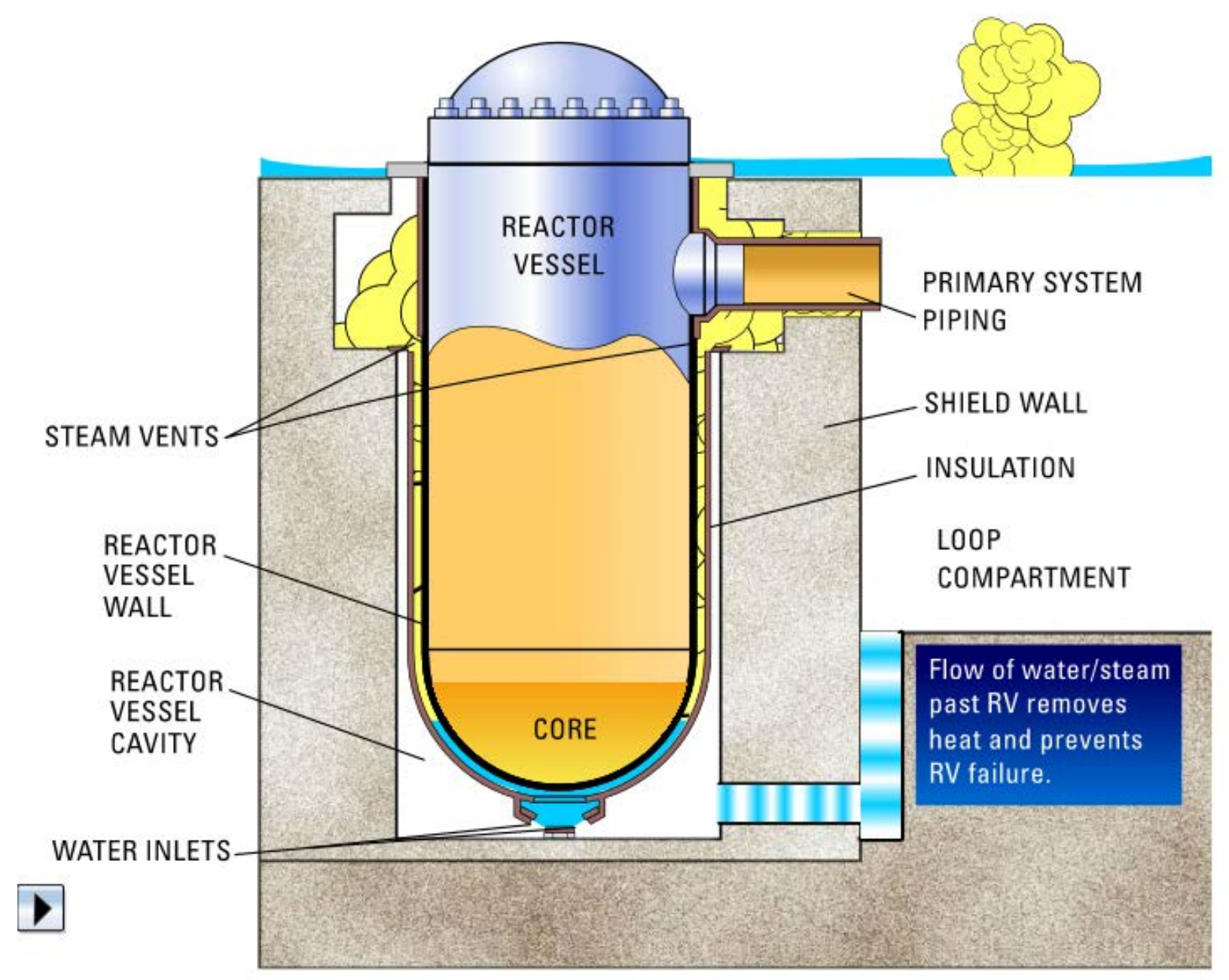




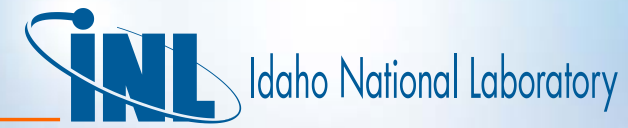

\section{AP1000 Passive Containment Cooling System}

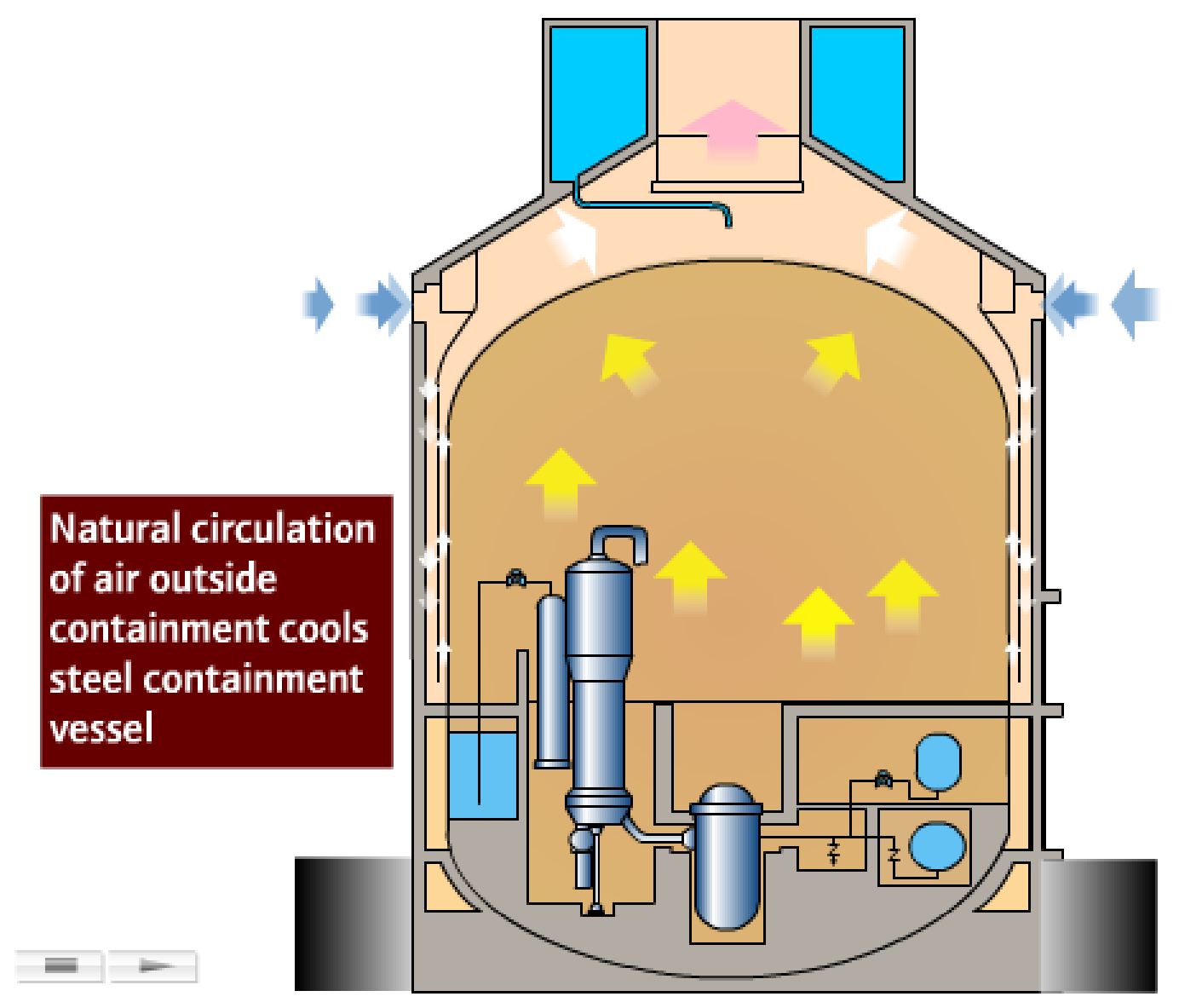




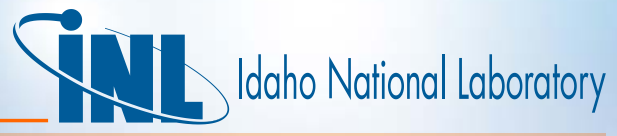

\section{AP1000 Containment Cooling}

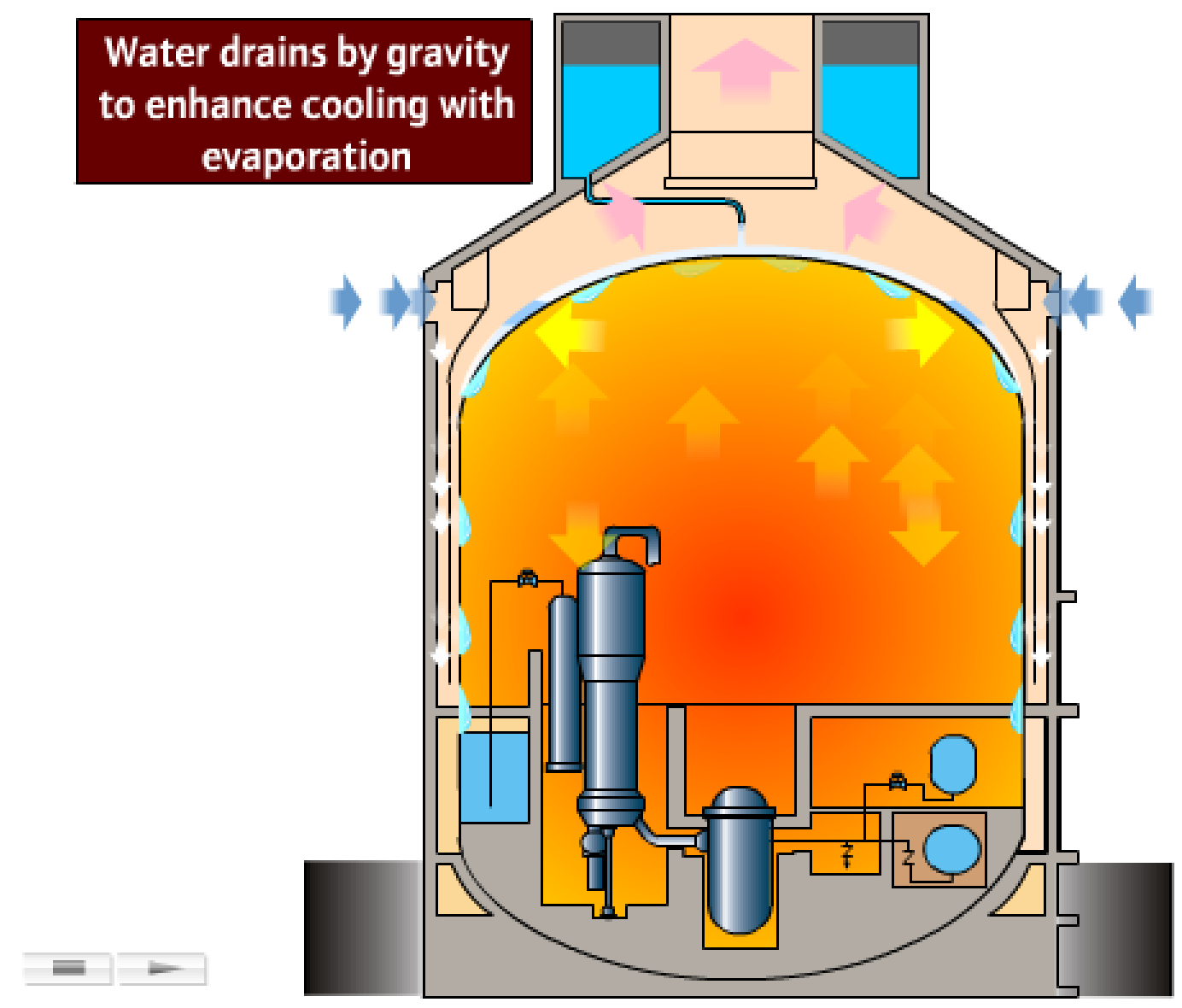




\section{Severe Accidents Pose Several Challenges to Containment Integrity}

- Overpressure

- Dynamic pressure (shock wave)

- Missiles generated by steam explosions

- Melt-through (containment liner or basemat)

- Bypass

- ISLOCA and SGTR

- Isolation failures

- (Note: These will be discussed in detail in Chapter 5) 


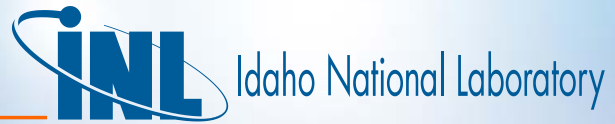

\section{Containment Failure Pressures Significantly Higher than Design Pressures}

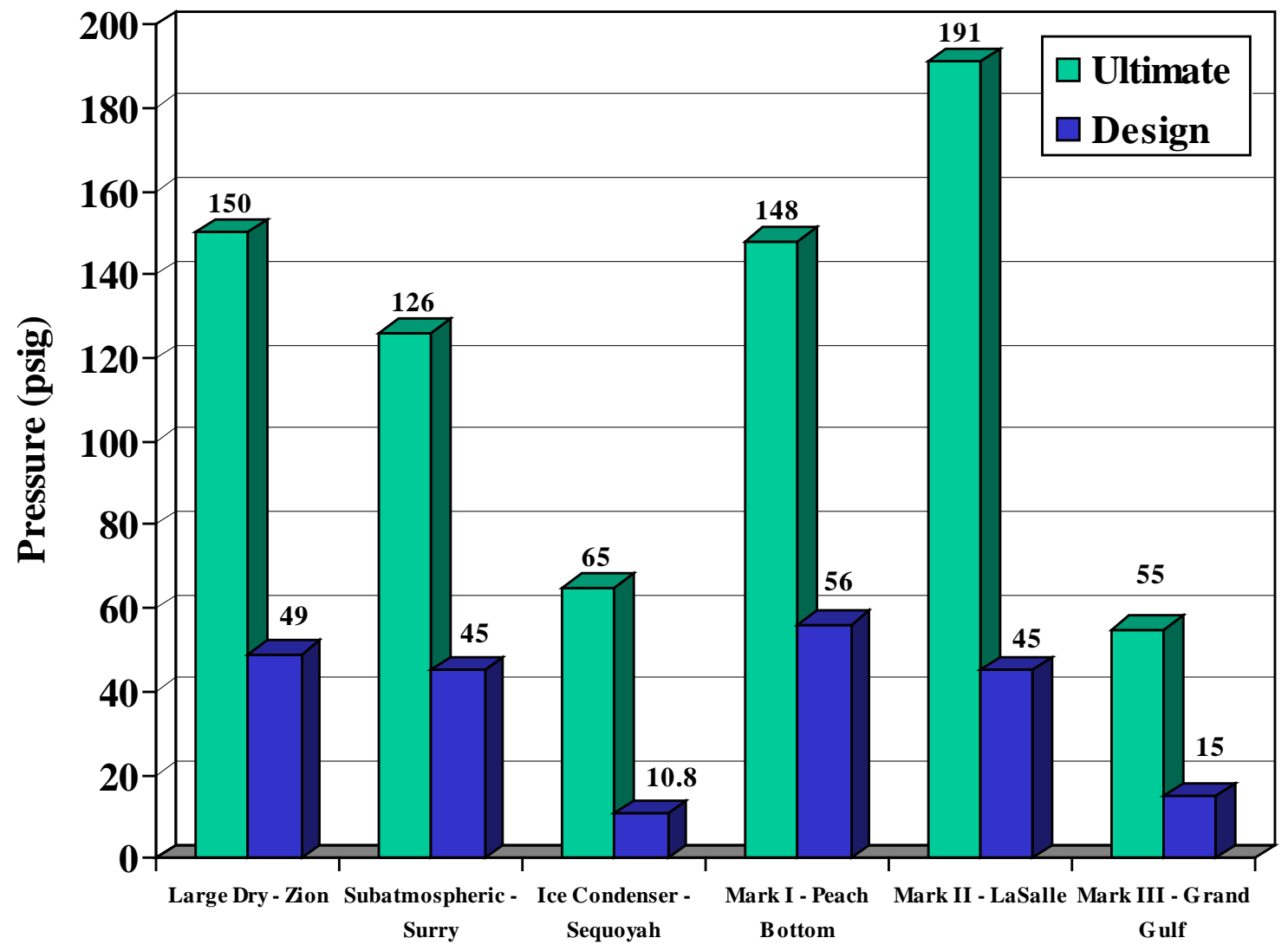




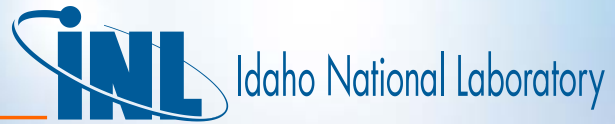

\section{Conditional Probability for Containment Failure for Each Sequence Calculated Probabilistically}

Conditional containment failure

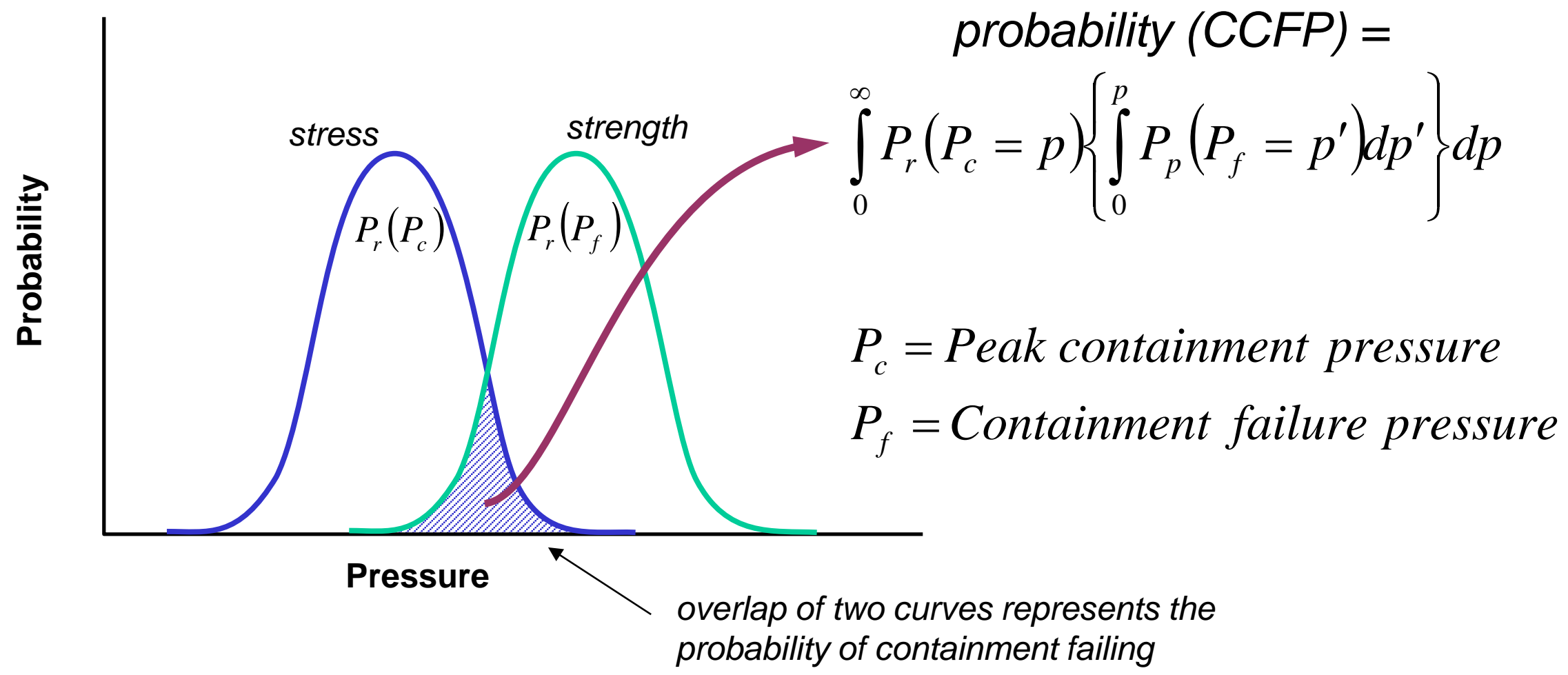




\section{Containment Structural Response and Failure Characterization}

- Objective is to develop a probabilistic description of the internal pressure capacity of the containment structure

- Typically expressed in the form of a fragility curve

- Cumulative probability of failure as a function of internal pressure - Internal pressure assumed to be static and uniform

- Composite fragility curve combines the individual fragility curves for different failure mechanisms

- Mathematical model treats containment pressure capacity as a random variable because of:

- Variability in material properties and manufacturing, and lack of knowledge uncertainties 


\section{Static Uniform Internal Pressures Can Lead to a Number of Different Failure Modes}

- Membrane failure in the hoop direction in the cylinder or dome

- Membrane failure in the meridial direction in the cylinder or dome

- Radial shear failure at cylinder to basemat or dome to cylinder discontinuity

- Bending failure in basemat

- Shear failure in basemat

- Shear failure in the containment shell at penetrations

- Membrane, bending or shear failure in penetrations 


\section{Pressure Fragility Model Similar to Seismic Fragility Model}

- Fragility curve and uncertainty is expressed in terms of median pressure capacity (fragility) times the product of two random variables

- Pressure capacity (fragility) $P$ is given by:

$-\mathrm{P}=\mathrm{P}^{\prime}{ }^{*} \varepsilon_{\mathrm{R}}{ }^{*} \varepsilon_{U}$. Where: $\mathrm{P}^{\prime}=$ median fragility, and

- $\varepsilon_{\mathrm{R}}$ and $\varepsilon_{\mathrm{U}}$ are random variable with unit medians that represent the inherent randomness (variability or aleatory uncertainty) and uncertainty (epistemic uncertainty) in the estimate of ' ${ }^{\prime}$ '

- $\varepsilon_{\mathrm{R}}$ and $\varepsilon_{U}$ are assumed to lognormally distributed with logarithmic standard deviations of $\beta_{\mathrm{R}}$ and $\beta_{\mathrm{U}}$, respectively 


\section{Containment Fragility Curves at Different Confidence}

Levels

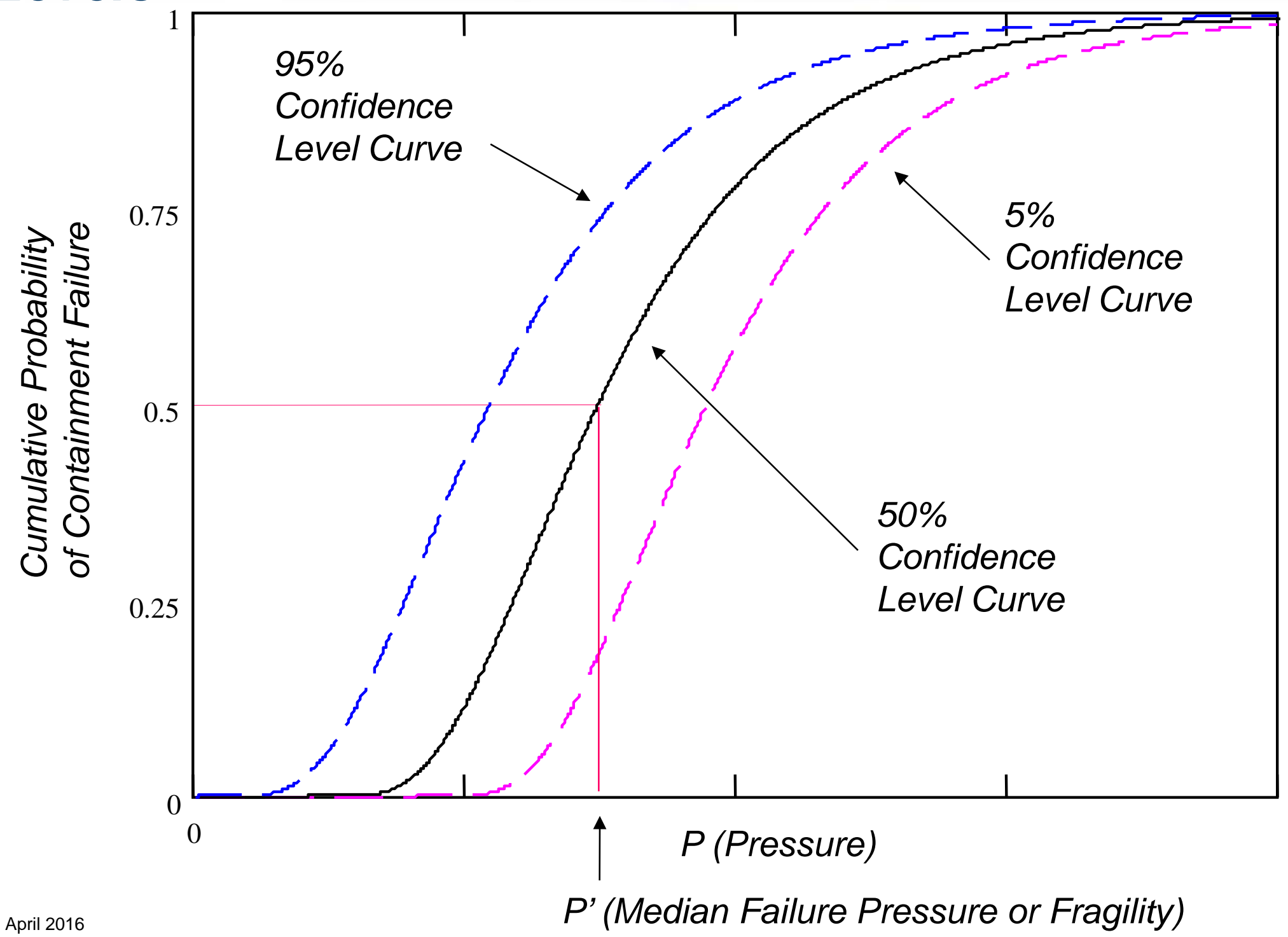




\section{Since Containment Can Fail in Several Ways, Need to Combine Fragilities}

- Referred to as the "Composite Fragility"

- Probability that containment will fail in at least one failure mode at a given internal pressure is:

$\operatorname{PrF}(p)=1-\Pi_{i=1, n}\left[1-\operatorname{PrF}_{i}(p)\right]$

where:

$\operatorname{PrF}_{i}(p)=$ probability of failure mode $i$ at pressure $p$

$\mathrm{n}=$ total number of failure modes

- Note that this formulation assumes independence among the different failure modes

- Assumption of independence in this case, is conservative 


\section{Containment Fragility and Severe Accident Loads are Integrated in CET}

- Plant Damage States (PDS) provide the boundary conditions for the accident progression analysis performed in the containment event tree (CET)

- Phenomena affecting vessel and containment integrity are the topics of the next two sections

- Containment fragility curve establishes the failure criteria for containment integrity

- CET models the progression of the severe accident with respect to the containment failure criteria 


\section{CET Tracks Probabilities or Loads}

- Event tree branch probabilities/values can be either

- Simplistic: track phenomena, then document failure probability estimate

- When DCH happens (given certain conditions), then Containment fails early with probability $=0.1$

- Complex: estimate likelihood of phenomena, incrementally track loads on containment

- DCH happens $20 \%$ of the time, increases containment pressure 100 psi

- Running total of containment pressure then tracked

- Contributions from various phenomena 


\section{Session Review}

- What are the major containment designs?

- What are some of the characteristic features of each? 


\section{Phenomena Affecting Vessel Integrity}

- Introduction

- Reactor Fuels

- Design, RIA and LOCA accidents for PWRS and BWRS

- Failure Modes

- Debris Heat Loads

- Failure Mitigation Measures

- Case Study and Problems

- Study Questions

- References

- Special Summary TMI Damage Implications for Fukushima 


\section{Objectives}

- Define reactor fuels effects on PWR, and BWR Reactors - and RIA and LOCA Behavior

- Identify various vessel failure modes and understand their likelihood in various reactor designs and accident scenarios.

- Describe possible end states for debris that relocates to vessel lower head.

- Discuss various mechanisms or actions that may prevent vessel failure. 


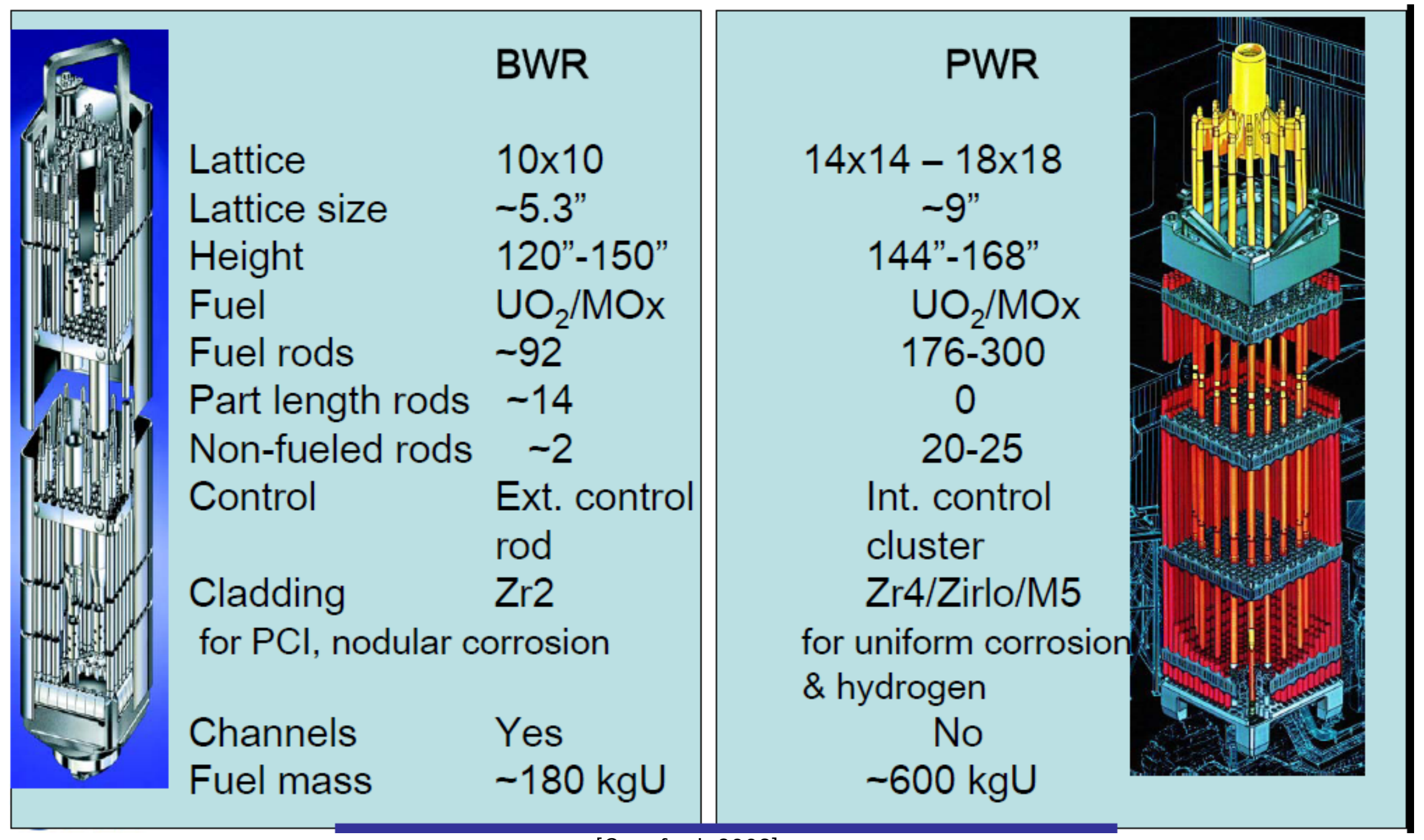

[Crawford, 2009]

4/19/2016 


\section{Key Design Criteria for Fuels -}

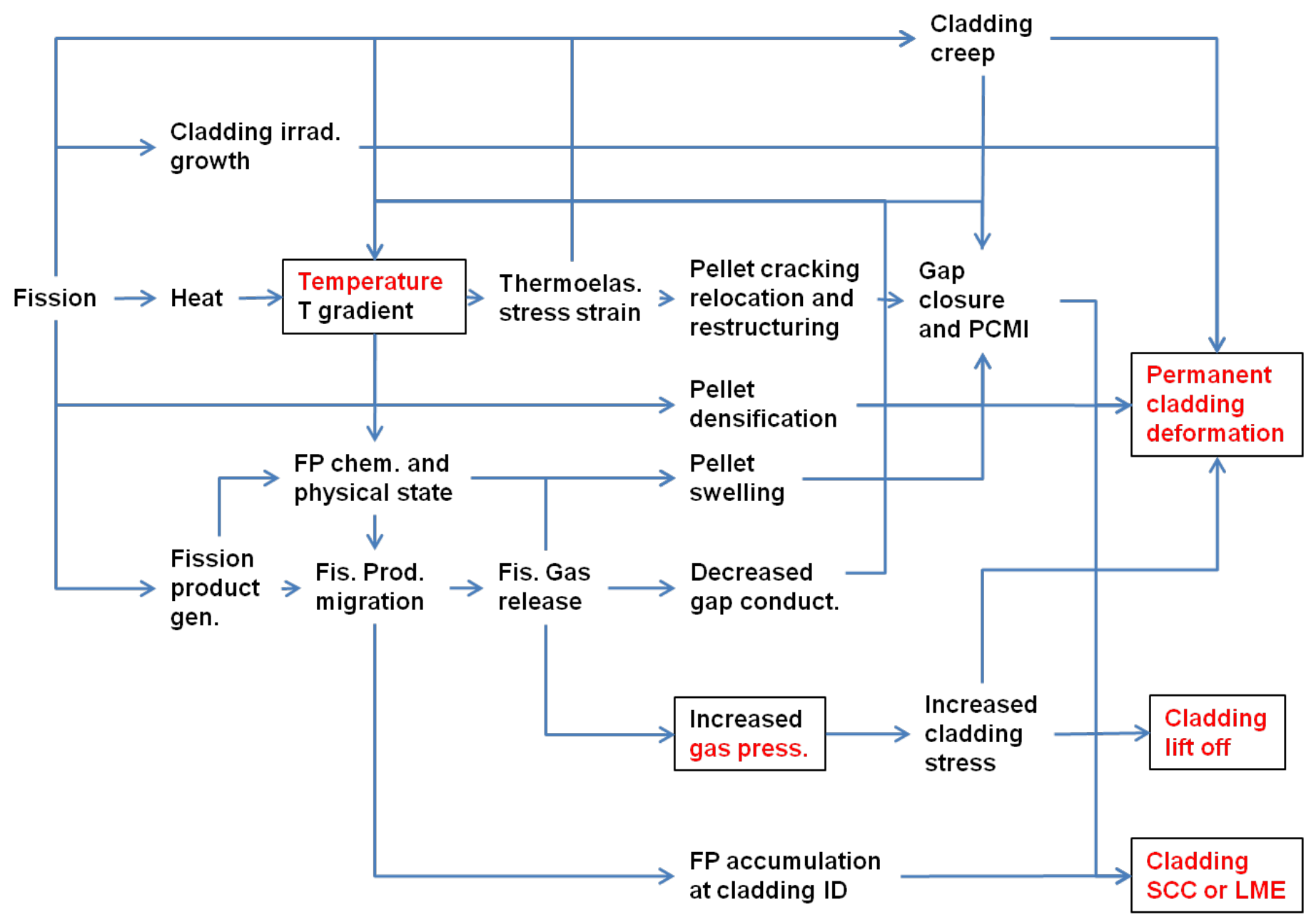

Principal internal, fuel rod processes and their primary interactions (Key design criteria are enclosed with a box and shown in red)

[after Mohr, et al. 1976 - Rudling and Patterson -2012]

Accident Progression Analysis (P-300) 


\section{Fuel Designs Limited Heat Generation Rate and Total Exposure}

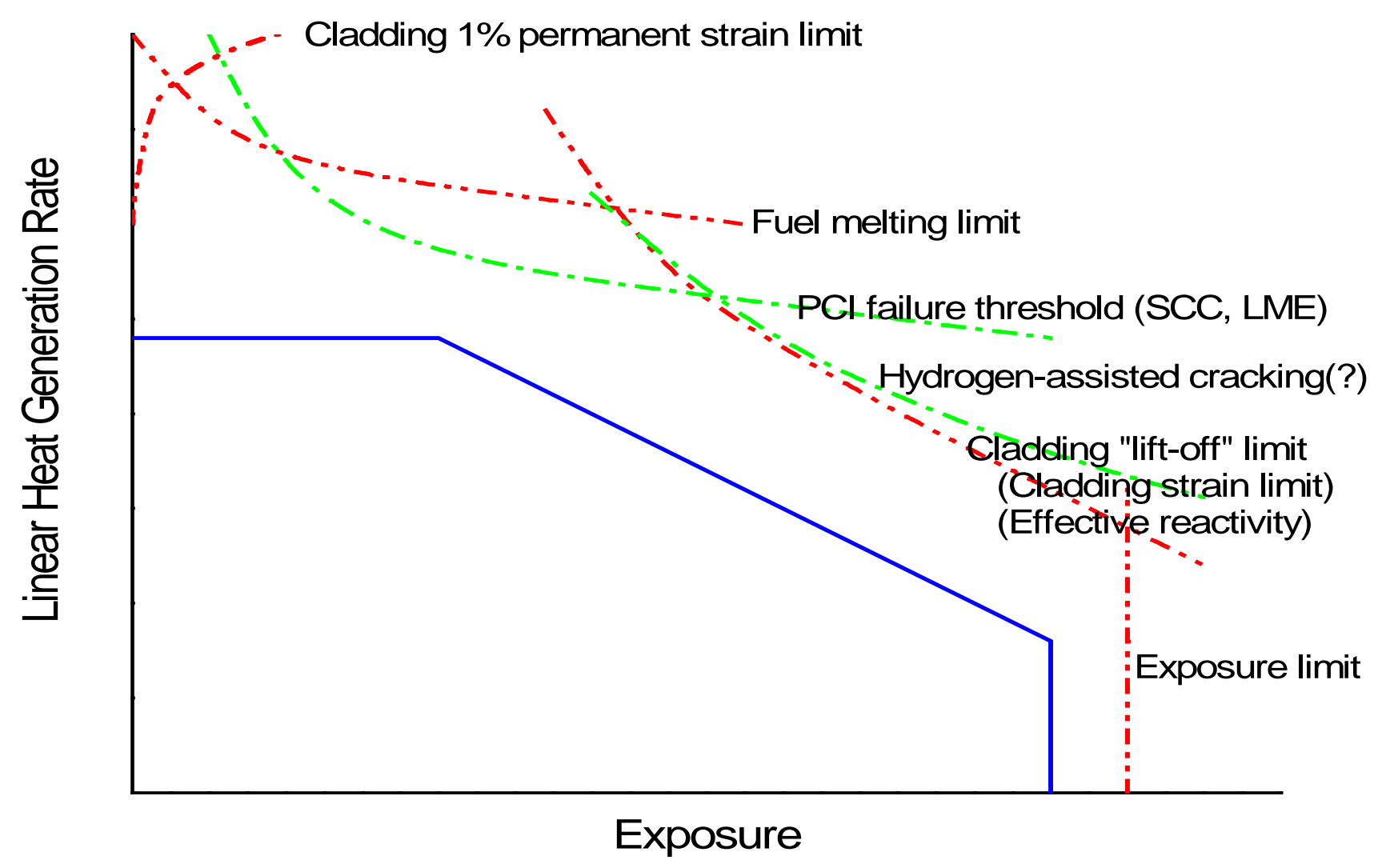

Constraints based on MATPRO/FRAPCON; [Hagrman 1993- Rudling and Patterson 2012] 


\section{UO2 has ideal Fuel Properties Although New Accident Tolerant Fuels are Under Development}

\begin{tabular}{|c|c|c|c|c|}
\hline Property & Uranium & $\mathrm{UO}_{2}$ & UC & UN \\
\hline \multicolumn{5}{|l|}{ A. Chemical } \\
\hline $\begin{array}{l}\text { Free energy of formation at } \\
1000{ }^{\circ} \mathrm{K} \text { (Kcal/mole) }\end{array}$ & - & -218.2 & -25.2 & -47 \\
\hline Corrosion resistance in water & Very poor & Excellent & Very poor & Poor \\
\hline Compatibility with clad materials & $\begin{array}{l}\text { Reacts with } \\
\text { normal clad }\end{array}$ & Excellent & Variable & Variable \\
\hline Thermal stability & $\begin{array}{c}\text { Phase change } \\
\text { at } 665 \text { and } \\
7700^{\circ} \mathrm{C}\end{array}$ & Good & $\begin{array}{l}\text { Good in reducing } \\
\text { atmosphere }\end{array}$ & $\begin{array}{c}\text { Good, decomposes at } \\
2600^{\circ} \mathrm{C}\end{array}$ \\
\hline \multicolumn{5}{|l|}{ B. Physical } \\
\hline Uranium (metal) density $\left(\mathrm{g} / \mathrm{cm}^{3}\right)$ & 19.04 & 9.65 & 12.97 & 13.52 \\
\hline Theoretical Density (T.D.) $\left(\mathrm{g} / \mathrm{cm}^{3}\right)$ & & 10.96 & & \\
\hline Melting point $\left({ }^{\circ} \mathrm{C}\right)$ & 1132 & 2865 & 2850 & 2850 \\
\hline Thermal conductivity $\mathrm{W} / \mathrm{cm} / \mathrm{K}$ & 0.28 at $430^{\circ} \mathrm{C}$ & $\begin{array}{l}0.03 \text { at } \\
1000{ }^{\circ} \mathrm{C}\end{array}$ & 0.25 at $100-700^{\circ} \mathrm{C}$ & 0.2 at $750^{\circ} \mathrm{C}$ \\
\hline
\end{tabular}

after Garzarolli in [Rudling, et al. 2007] 


\section{Primary Fission Sources are Uranium and activation Produce Plutonium}

\begin{tabular}{|c|c|c|c|c|c|}
\hline & $\begin{array}{c}\text { Elastic } \\
\text { Scattering } \\
\sigma(\mathrm{nn})\end{array}$ & $\begin{array}{c}\text { Inelastic } \\
\text { Scattering } \\
\sigma\left(n^{\prime}\right)\end{array}$ & $\begin{array}{c}\text { Radiative } \\
\text { Capture } \\
\sigma(\mathrm{n} \gamma)\end{array}$ & $\begin{array}{c}\text { Fission } \\
\sigma(n f)\end{array}$ & $\begin{array}{c}\text { Average } \\
\text { neutron yield } \\
\text { ( } v \text {-bar) }\end{array}$ \\
\hline Fissile materials & \multicolumn{5}{|c|}{ Average over thermal spectrum (barns) ${ }^{1}$} \\
\hline $235 \mathrm{U}$ & 15.98 & & 86.70 & 504.81 & 2.433 \\
\hline${ }^{239} \mathrm{Pu}$ & 7.90 & & 274.32 & 699.34 & 2.882 \\
\hline${ }^{241} \mathrm{Pu}$ & 12.19 & & 334.11 & 936.65 & 2.946 \\
\hline \multicolumn{6}{|l|}{ Fertile materials } \\
\hline $238 \mathrm{U}$ & 9.37 & & 2.41 & 1.05E-05 & 2.489 \\
\hline${ }^{240} \mathrm{Pu}$ & 1.39 & & 262.65 & 6.13E-02 & 2.784 \\
\hline Fissile materials & \multicolumn{5}{|c|}{ Slowing-down region resonance integrals (barns) ${ }^{2}$} \\
\hline${ }^{235} \mathrm{U}$ & 152.82 & & 131.97 & 271.53 & 2.438 \\
\hline${ }^{239} \mathrm{Pu}$ & 155.87 & & 184.06 & 289.36 & 2.876 \\
\hline${ }^{241} \mathrm{Pu}$ & 148.68 & & 169.13 & 570.66 & 2.933 \\
\hline \multicolumn{6}{|l|}{ Fertile materials } \\
\hline $238 \mathrm{U}$ & 319.06 & & 277.70 & $2.16 \mathrm{E}-03$ & 2.490 \\
\hline $240 \mathrm{Pu}$ & 913.76 & & 8448.70 & 3.74 & 2.785 \\
\hline
\end{tabular}

[Kaye \& Laby 2005] - Rudling and Patterson 2012 
Plutonium is Significant Contributor to Fission by end of Life
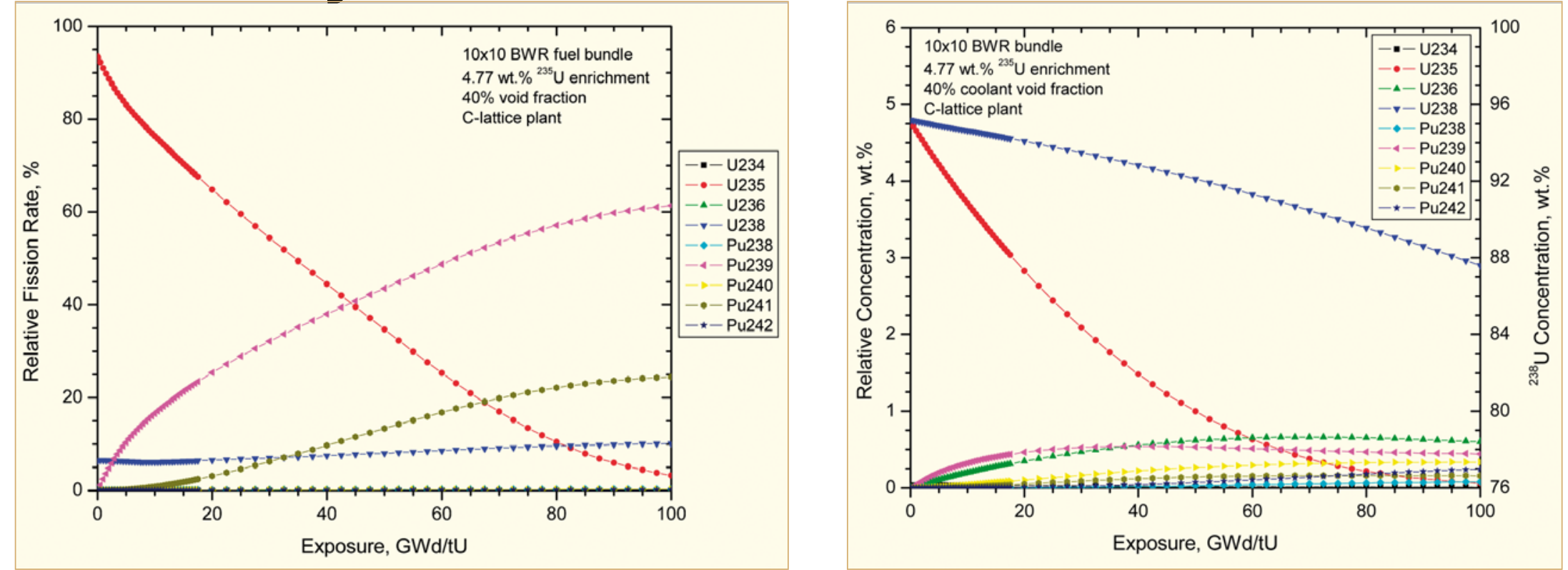

[Lundberg 2010, Rudling and Patterson 2012]

- Relative fission rate changes with exposure

- Plutonium becomes a significant source by mid-life and the dominant source by end of life

- Pu production balanced by loss due to fission

- $\quad(P u$ concentration by EOL typically <1\%) 


\section{Plutonium Content Varies With Void Fraction}

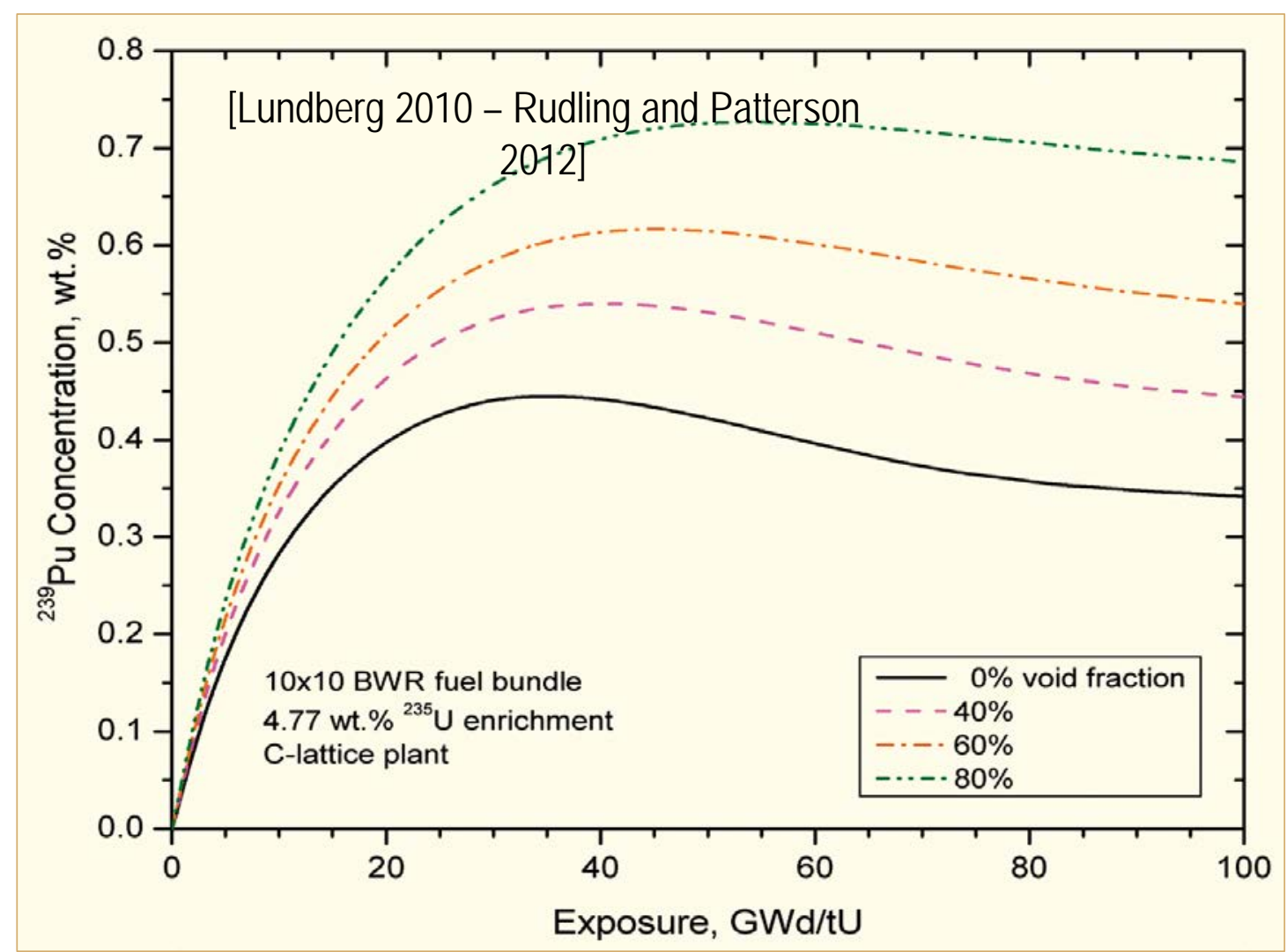

- Plutonium production varies with fuel design and core conditions

- Rate increases with flux of higher energy (epithermal) neutrons

- Production and consumption reach equilibrium for given set of conditions $4 / 19 / 2016$ 


\section{Fuel Chemistry Affects Accident Behavior}

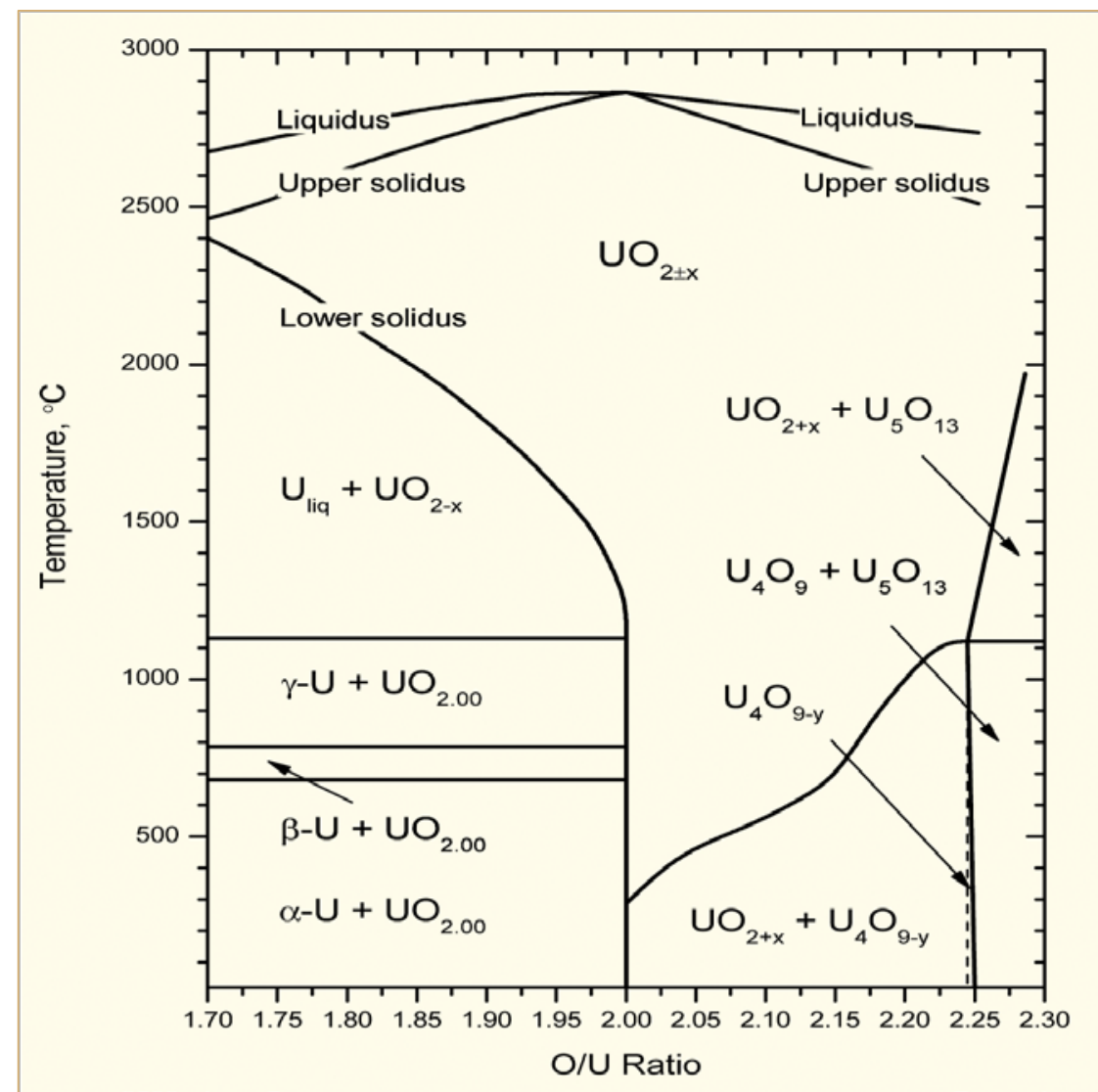

- Fuel fabricated to be nearly stoichiometric; i.e., $\mathrm{UO}_{2.00 \pm}$

- Structure stable to $T_{\text {melt }}$

- Maximum $\mathrm{T}_{\text {melt }}$

- O/M ratio varies slightly during irradiation

- Large deviations from stoichiometry relevant to

- Fabrication

- Defected fuel behavior

- Reprocessing

[Levin \& McMurdie, 1975], [Olander, 1976], [Kim, 2000],

[Guéneau et al, 2002], [Baichi et al, 2006], [Rudling et al, 2007] Rudling and Patterson 2012 


\section{RIA and LOCA - Severe Accident}

- During a Reactivity Initiated Accident and a Loss of Coolant Accident no fuel dispersal is allowed

- RIA -> Severe Accident

- Chernobyl

- LOCA -> Severe Accident

- TMI

- Fukushima 


\section{LWR Design Affects Severe Accident Response}

\begin{tabular}{|l|l|l|}
\hline \multicolumn{2}{|c|}{ Design Feature } & \multicolumn{1}{c|}{ Impact } \\
\hline $\begin{array}{l}\text { Masses } \\
\begin{array}{l}\text { Uranium Dioxide } \\
\text { Zirconium } \\
\text { Steel }\end{array}\end{array}$ & $\begin{array}{l}\text { BWRs have at least 50\% more. } \\
\text { BWRs have at least 100\% -200\%. } \\
\text { BWRs have at least 20\% more. }\end{array}$ & $\begin{array}{l}\text { Potential for larger relocation masses. } \\
\text { Potential for more hydrogen production. } \\
\text { Relocated materials have higher steel } \\
\text { content. }\end{array}$ \\
\hline Power Distribution & $\begin{array}{l}\text { Average power factors in peripheral } \\
\text { regions of BWRs significantly lower. }\end{array}$ & $\begin{array}{l}\text { Significant time lag between heatup in } \\
\text { central and peripheral core regions. }\end{array}$ \\
\hline Coolant Volume & $\begin{array}{l}\text { Much larger volume of coolant } \\
\text { (relative to core structural volume) } \\
\text { beneath BWR core. }\end{array}$ & $\begin{array}{l}\text { Higher potential to quench relocated } \\
\text { materials for longer time periods. }\end{array}$ \\
\hline
\end{tabular}




\section{Reactor Kinetics}

- About $99.4 \%$ of all neutrons are born directly in fission (prompt neutrons), with a very short lifetime. However, approximately $0.64 \%$ of the neutrons are delayed (delayed neutrons) - fraction of delayed neutrons $=\beta$

- In a system reached criticality, just as many neutrons are produced by fission as are lost by absorption and leakage from the reactor in a given time

$-k_{\text {eff }}=$ Rate of neutron production/(Rate of neutron absorption + Rate of neutron leakage) $=1$

- The fractional departure of a system from criticality is often expressed by the reactivity, $\rho$, and defined by:

$$
\rho \equiv \frac{k_{\text {eff }}-1}{k_{\text {eff }}}
$$




\section{Reactor Kinetics}

- The conditions for a reactor power transient like RIA to be of a concern are:

- It must be very fast.

- The reactivity added must be larger than 0.006 .

- However, water reactors are designed so that a power increase will generate negative reactivity feedback

- where a fuel temperature increase gives a fast negative feedback (Doppler effect).

- an increase in the moderator temperature and steam (void) fraction, gives a slower negative feedback.

- A slow reactivity increase may not cause any harm even if it is larger than 0.006 because of the negative feedback mechanisms. 


\section{RIA Kinetics}

- PWR

- The most severe RIA scenario is the control rod ejection accident (CREA).

- The CREA is caused by mechanical failure of a control rod mechanism housing, such that the coolant pressure ejects a control rod assembly completely out of the core.

- Reactivity increase to the core occurs within about $0.1 \mathrm{~s}$ in the worst possible scenario.

- The actual time depends on reactor coolant pressure and the severity of the mechanical failure.

- With respect to reactivity addition, the most severe CREA would occur at hot zero power (HZP) conditions, i.e. at normal coolant temperature and pressure, but with nearly zero reactor power. 


\section{RIA Pulse}

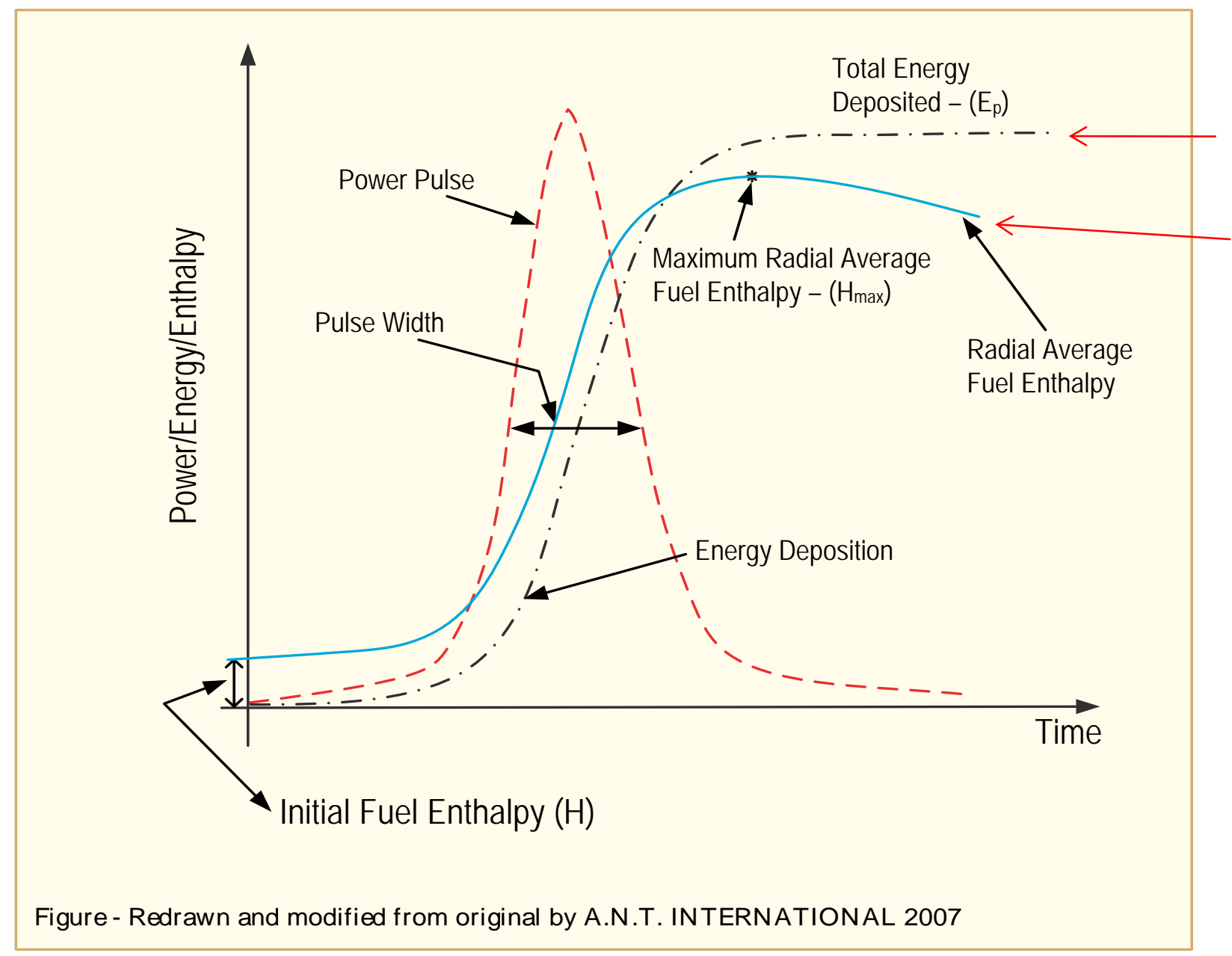

Measured/calculated

Calculate adiabatic energy deposition -delayed neutron fission -heat losses

About 10\% uncertainty in reported values

[Rudling and Patterson

2012\} 


\section{Pulse Characteristics}

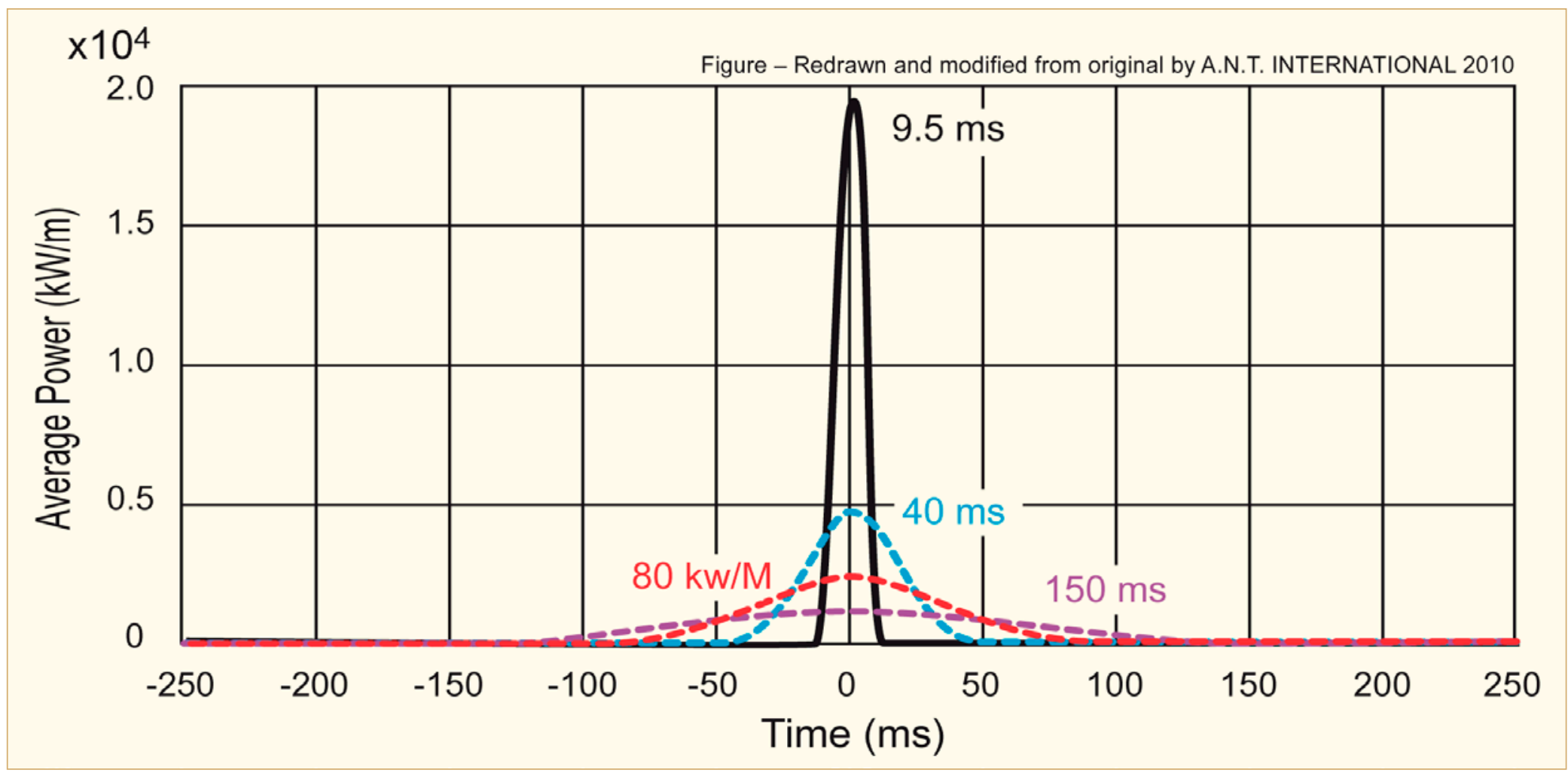

[Rudling and Patterson

2012\} 


\section{RIA}

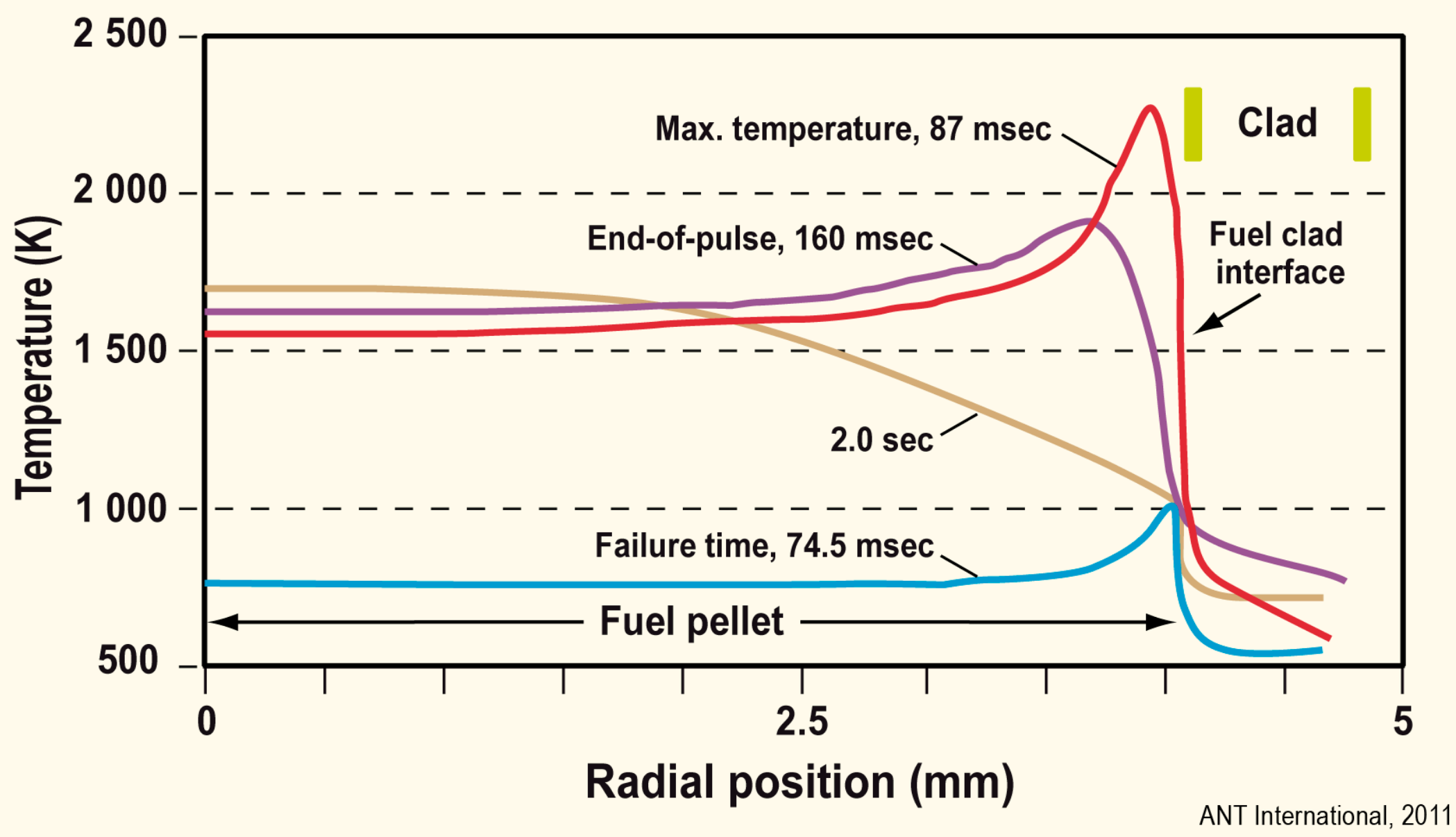

[Rudling and Patterson 2012\} 


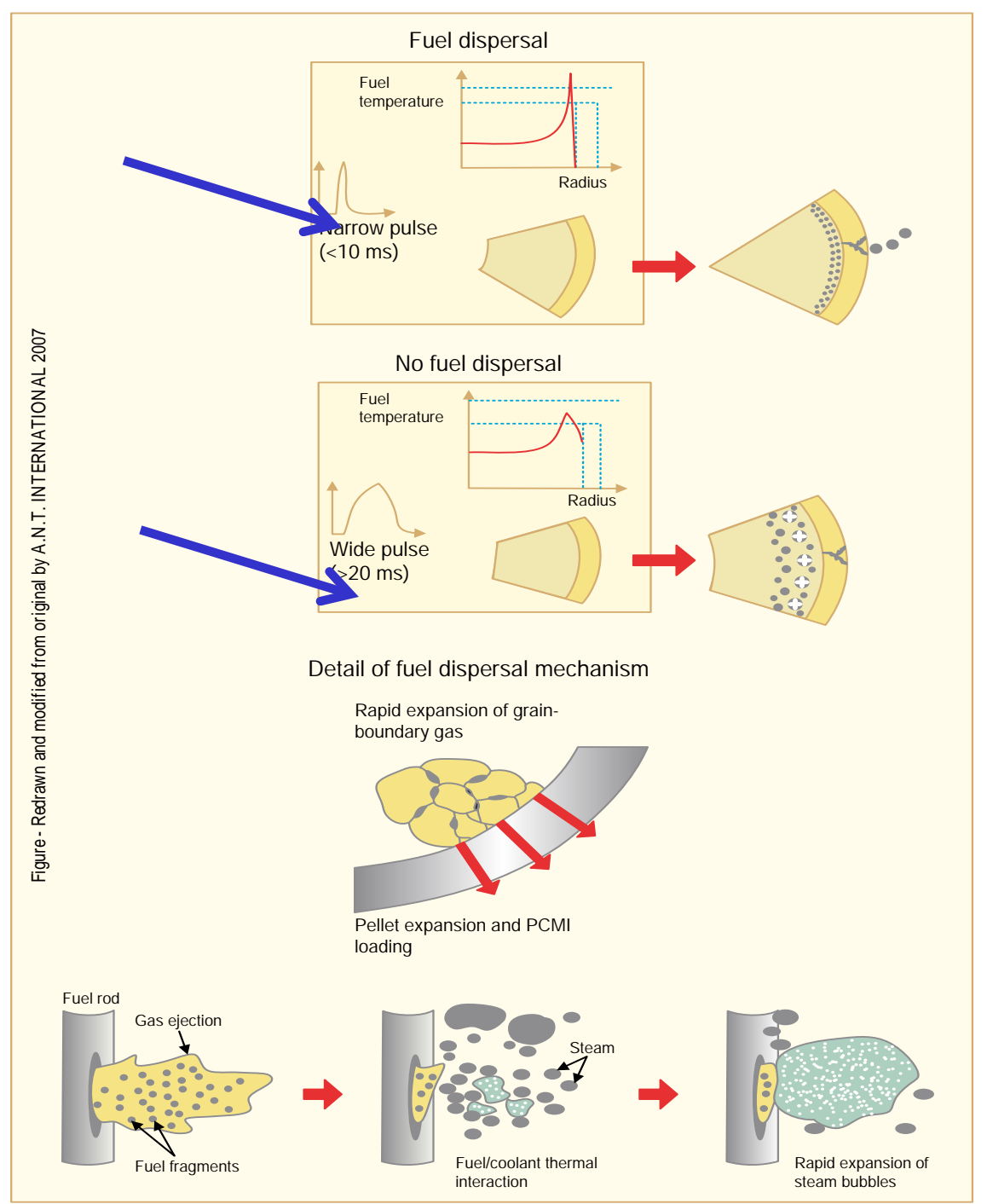




\section{RIA Effect on Fuel}

Figure - Redrawn and modified from original by A.N.T. INTERNATIONAL 2010

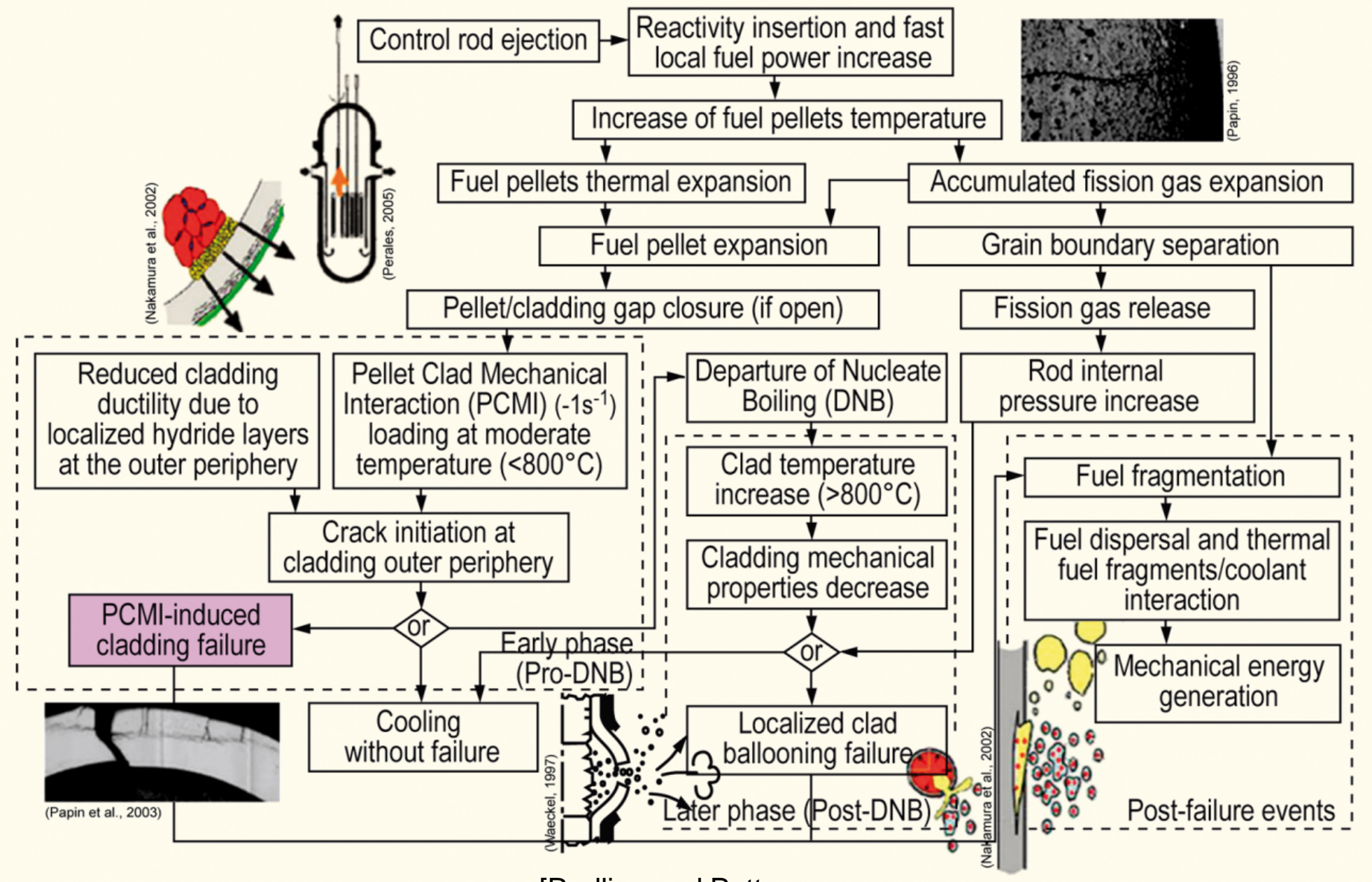

[Rudling and Patterson

2012\}

[Le Saux et al, 2007] 


\section{Clad failure mechanism}

- During a RIA event, the fuel may survive or fail due to:

- Post-DNB fracture of oxidised embrittled cladding at all burnup levels.

- Melting of fuel cladding.

- PCMI failures at higher burnups.

- Post-DNB ballooning and creep burst at higher burnups for fuel rods with an internal overpressure. 


\section{RIA}

- Fuel Failure Modes

- Low Burnups

- Post-DNB failures

- High Burnups

- PCMI

- Creep Rupture

- Fuel Dispersal

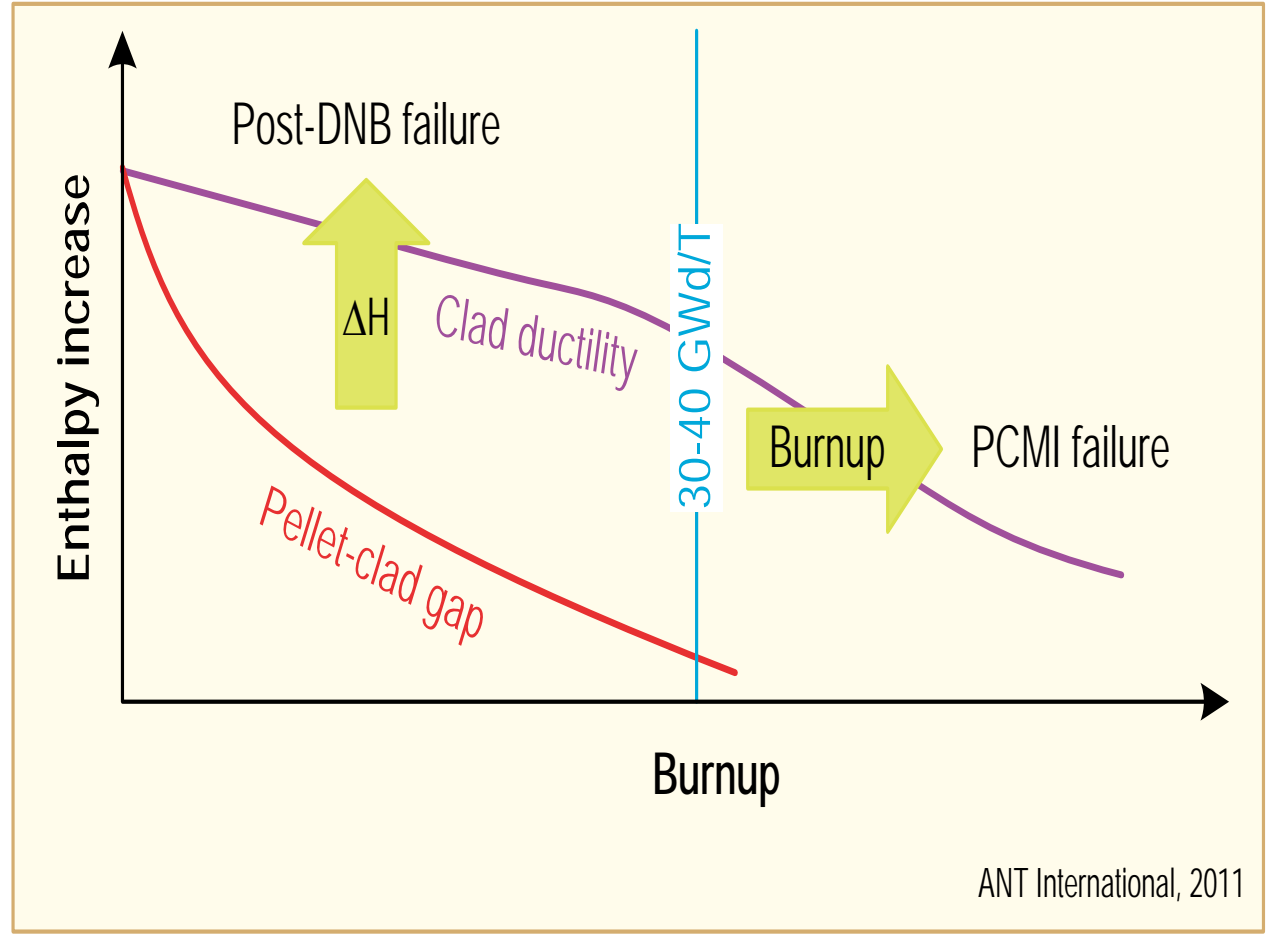

[Rudling and Patterson

2012\} 


\section{PCMI Failure}

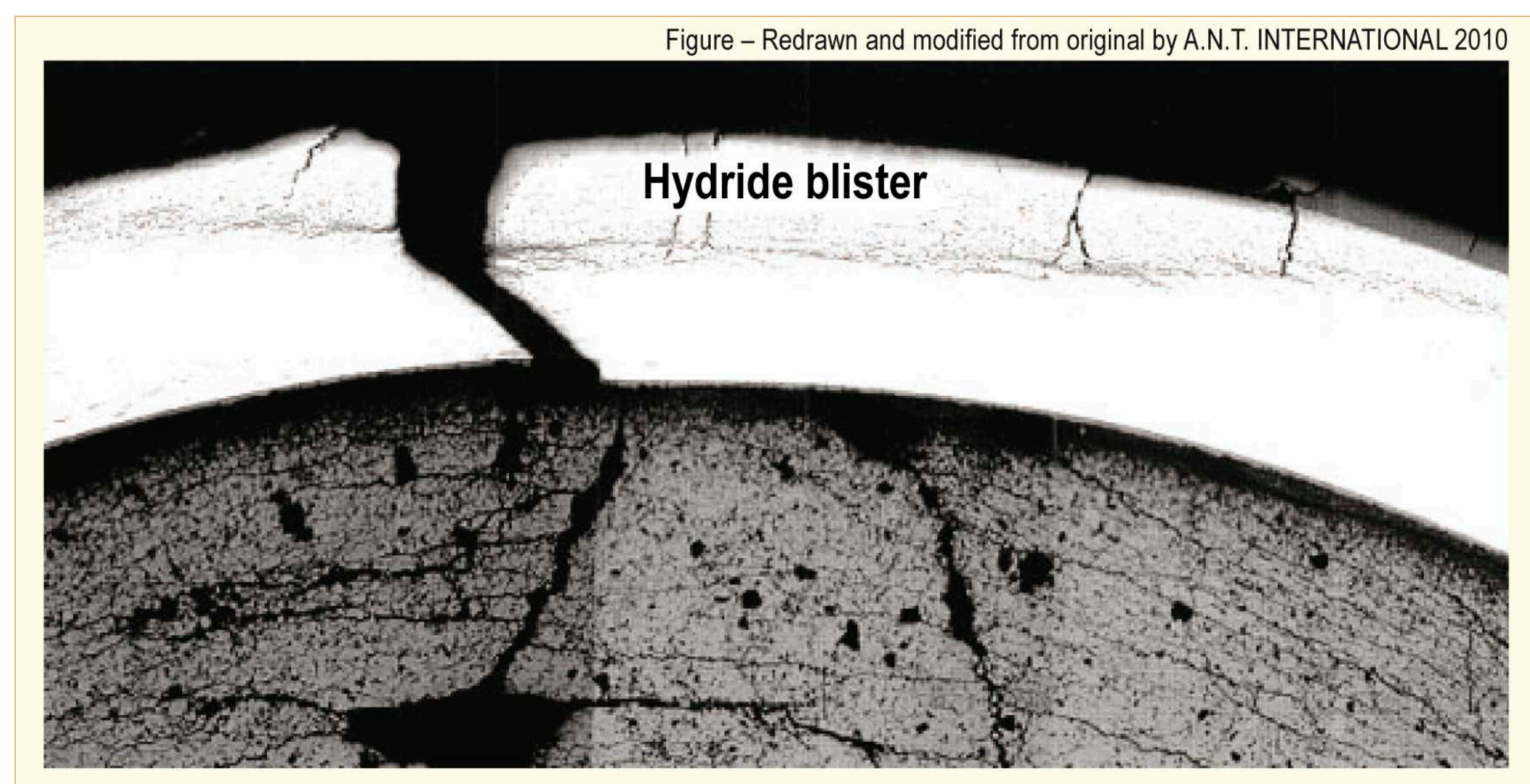

[Rudling and Patterson

2012\}

$4 / 19 / 2016$

Accident Progression Analysis (P-300)

[Papin et al, 2003] and [Garde et al, 1996] 


\section{BWR and PWR RIA Tests}

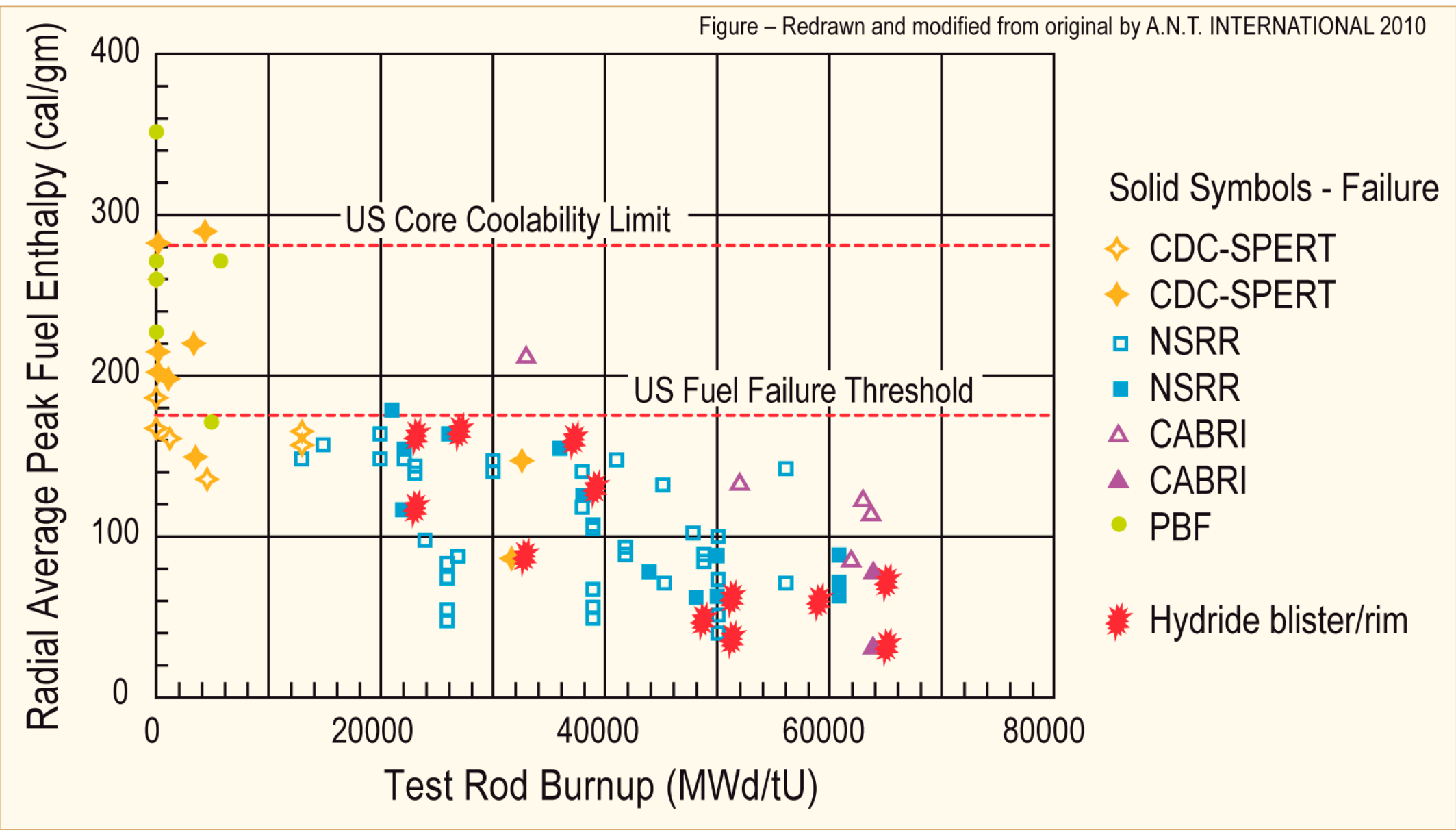

[Rudling and Patterson 2012\} 


\section{Ballooning and Creep Burst Failure}

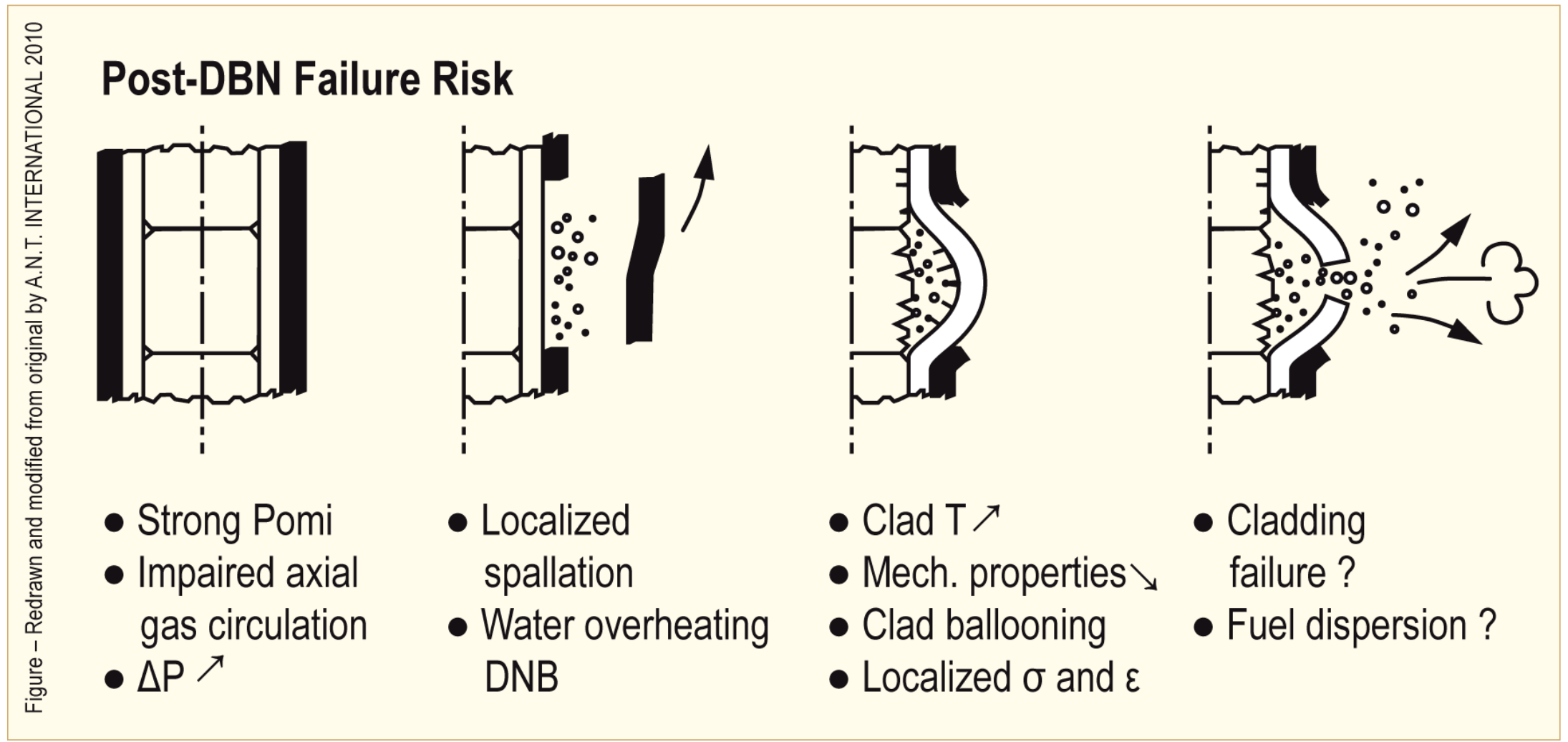

[Rudling and Patterson

2012\} 


\section{Ballooning and Creep Burst Failure in VVER}

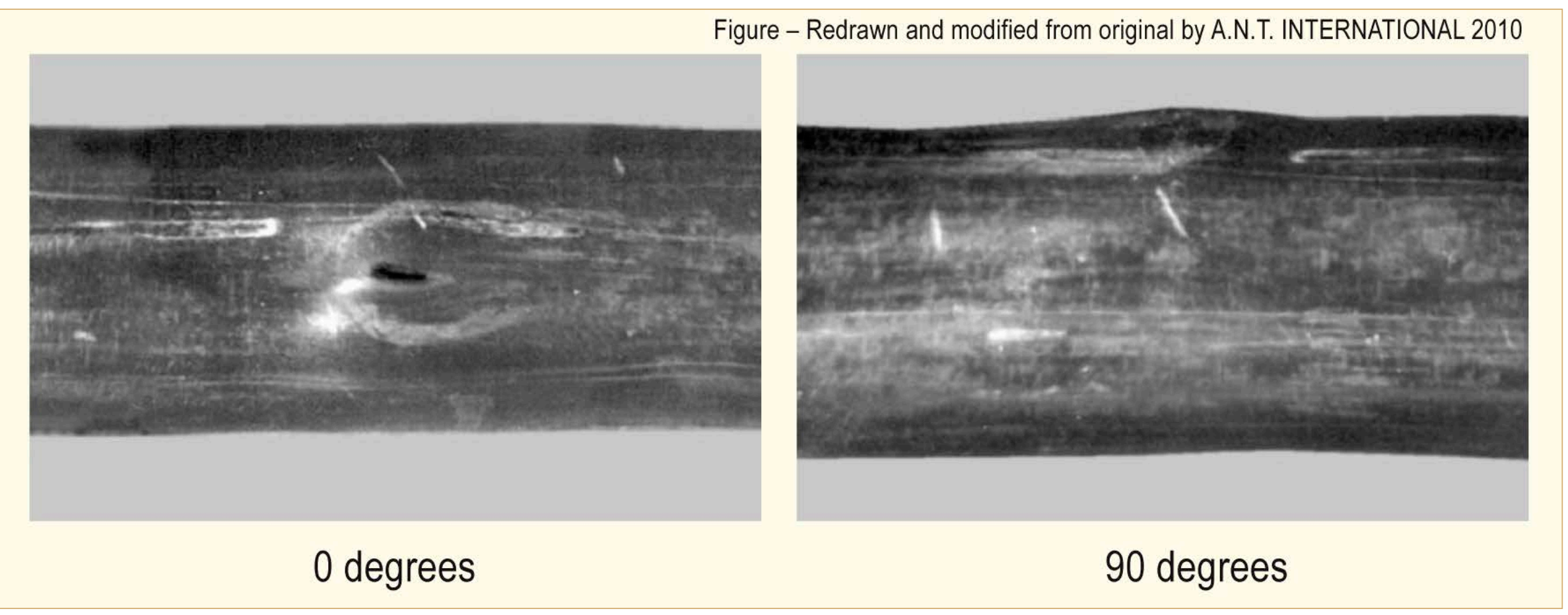

[Rudling and Patterson

2012\} 


\section{RIA Effect on Fuel}

Figure - Redrawn and modified from original by A.N.T. INTERNATIONAL 2010

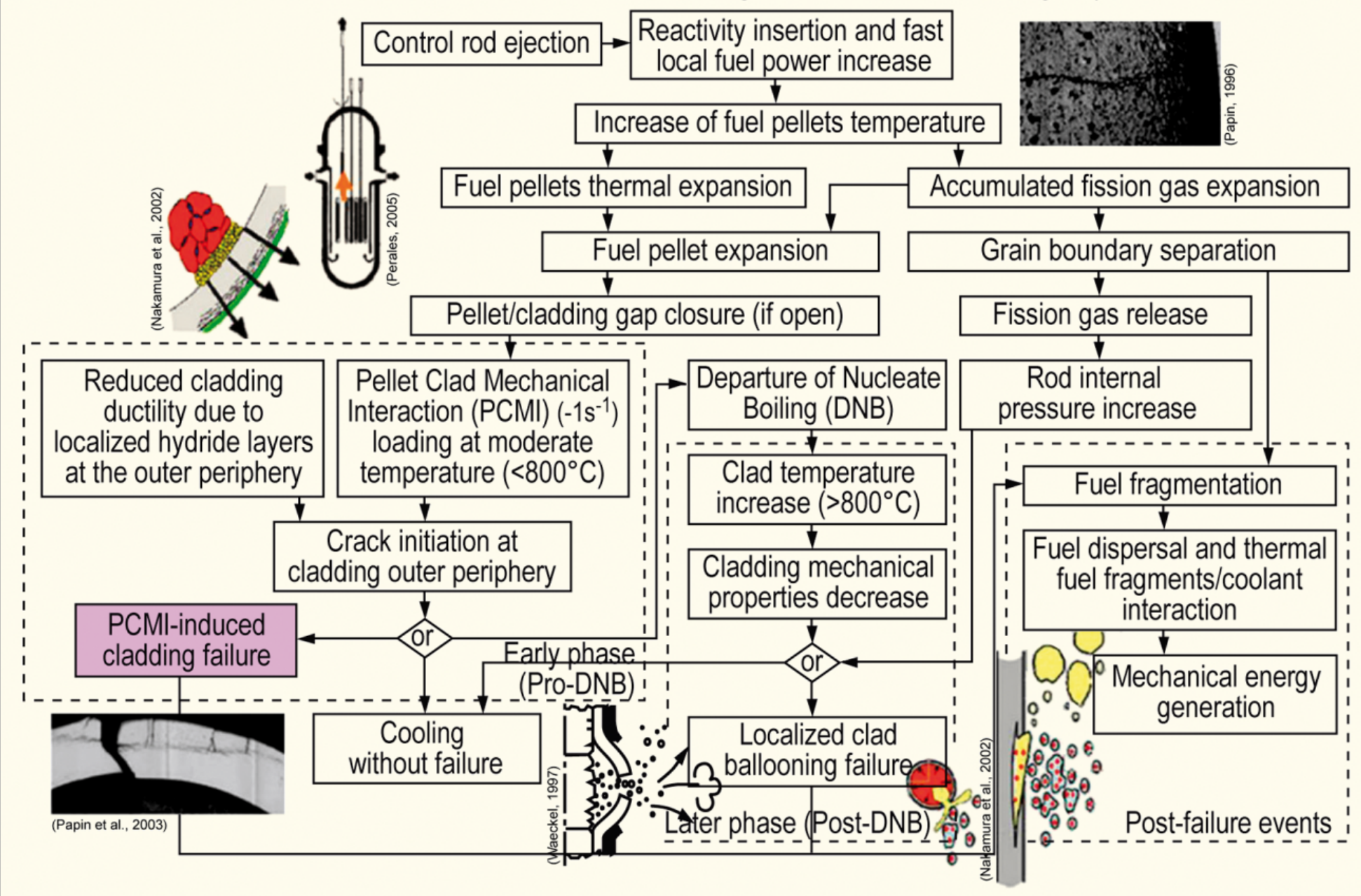




\section{Introduction to LOCA}

Cold-leg break in PWR - blowdown phase

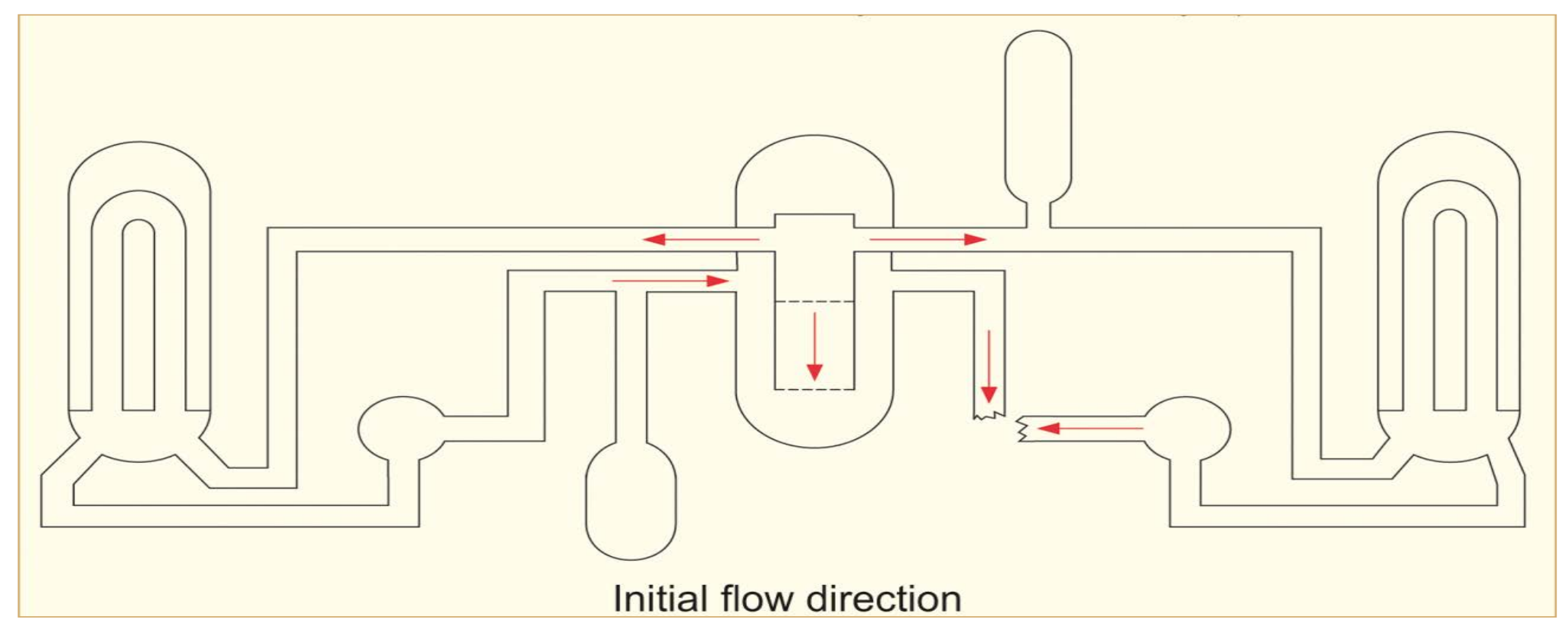

[Rudling and Patterson 2012\} 


\section{Representative Shutdown Response to a LOCA}
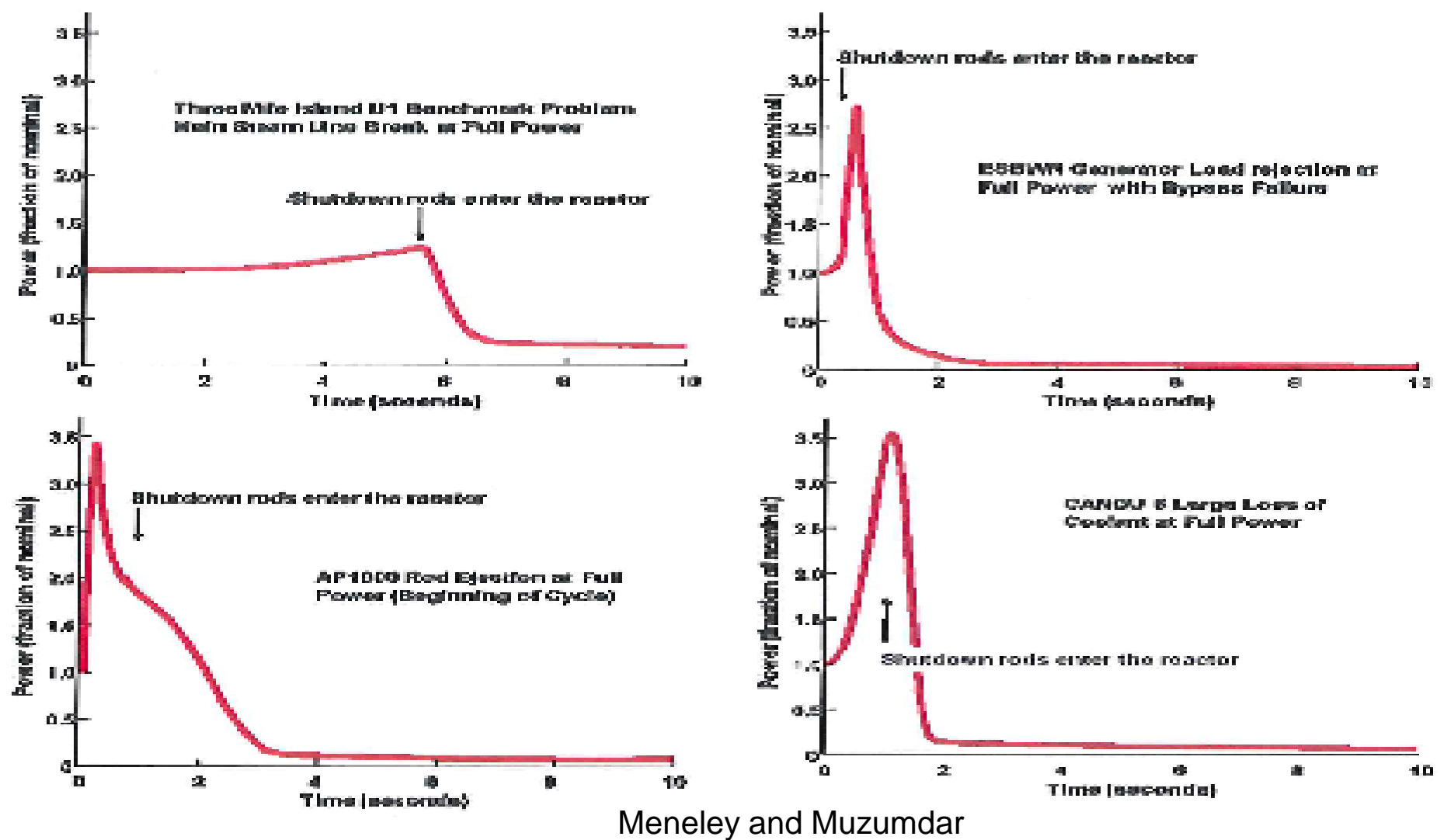


\section{Introduction to LOCA}

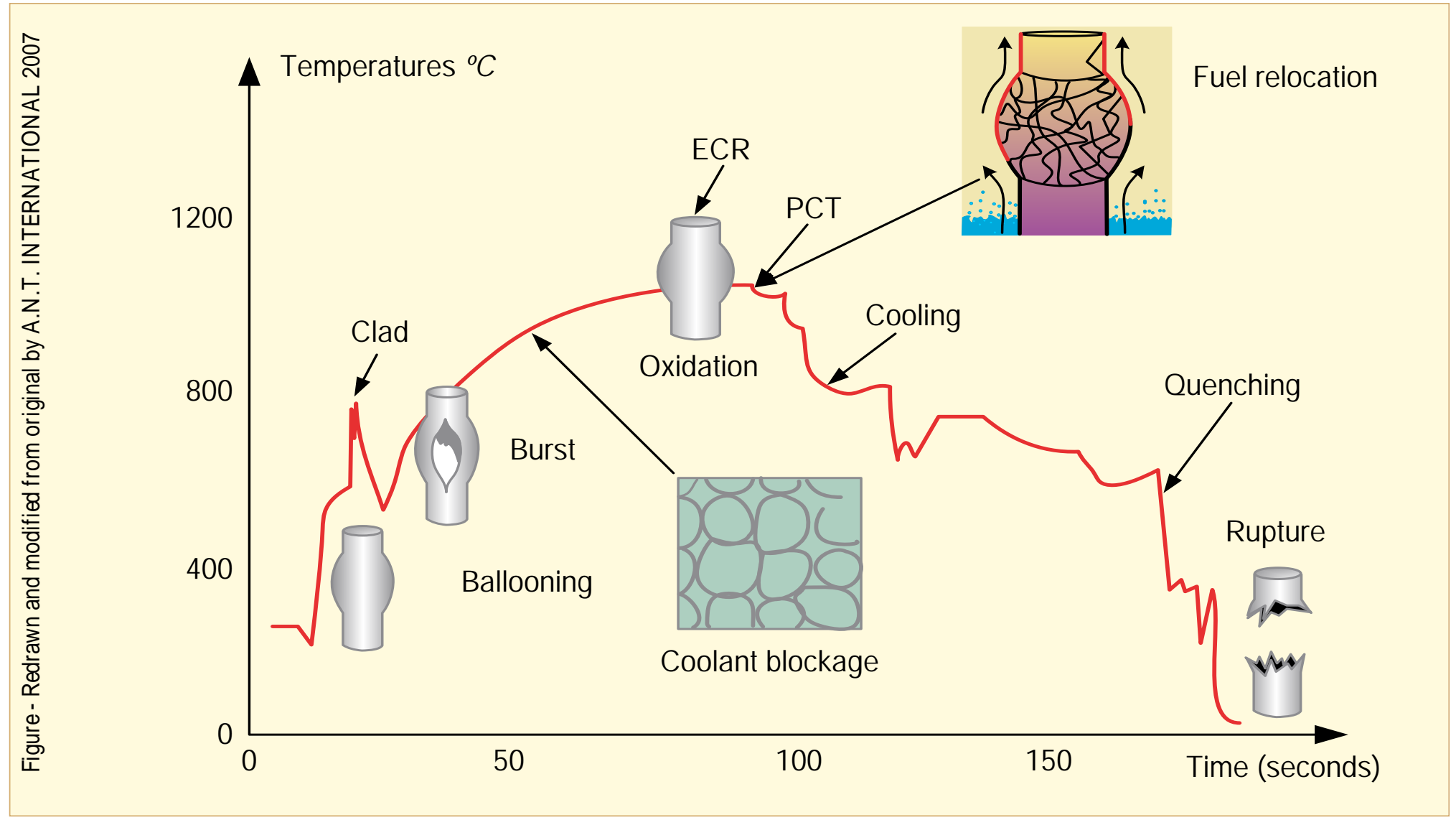

[Rudling and Patterson

2012\} 


\section{LOCA, Decay Heat}

- The removal of the decay heat is a significant reactor safety concern, especially shortly after normal shutdown or following a loss-of-coolant accident.

- Failure to remove decay heat may cause the reactor core temperature to rise to dangerous levels and has caused nuclear accidents, including the nuclear accidents at Three Mile Island and Fukushima I.

- The heat removal is usually achieved through several redundant and diverse systems, from which heat is removed via heat exchangers. 


\section{Decay Heat}

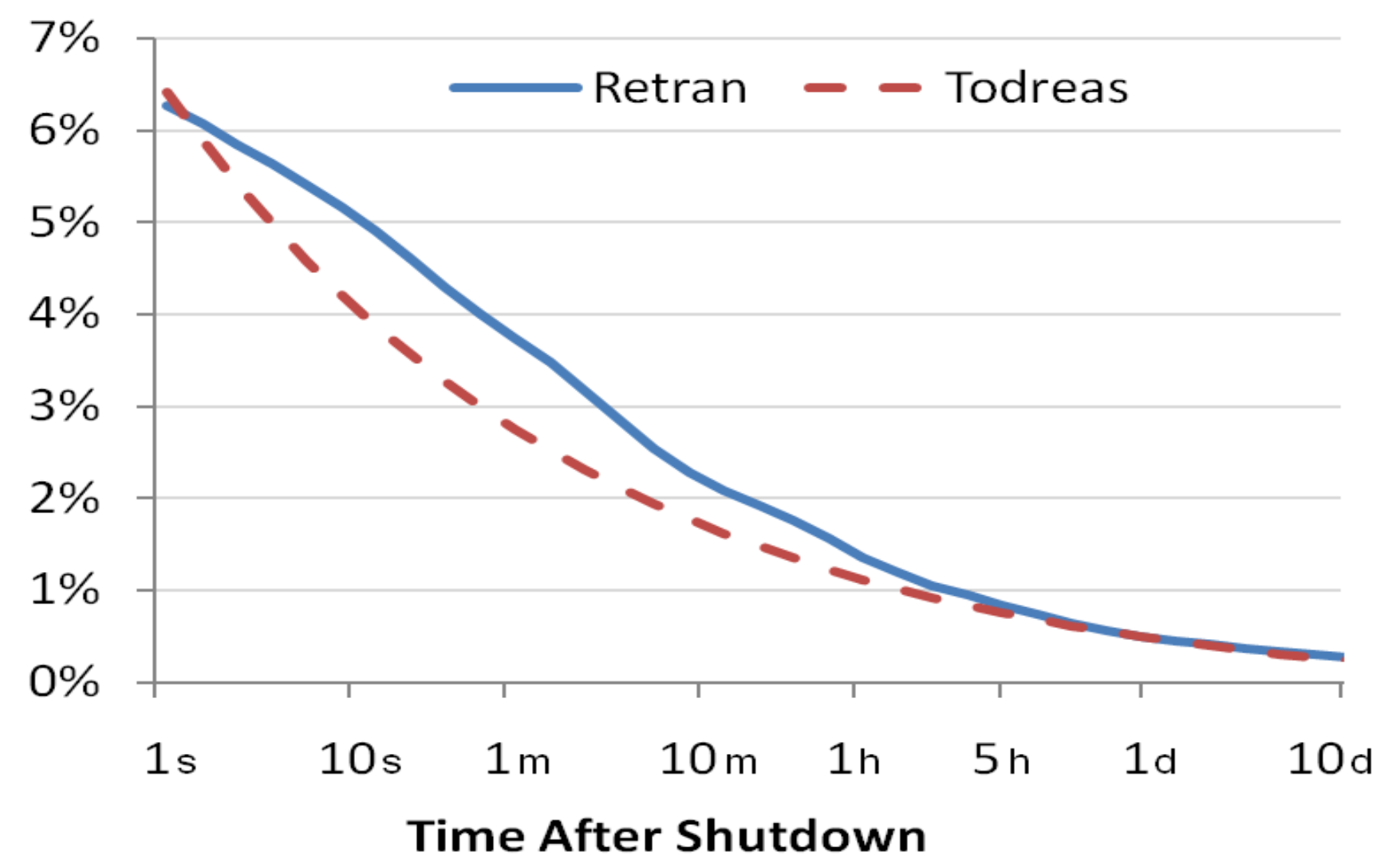

From Wikipedia, the free encyclopedia

[Rudling and Patterson

2012\} 


\section{Fuel Temperature Profile}

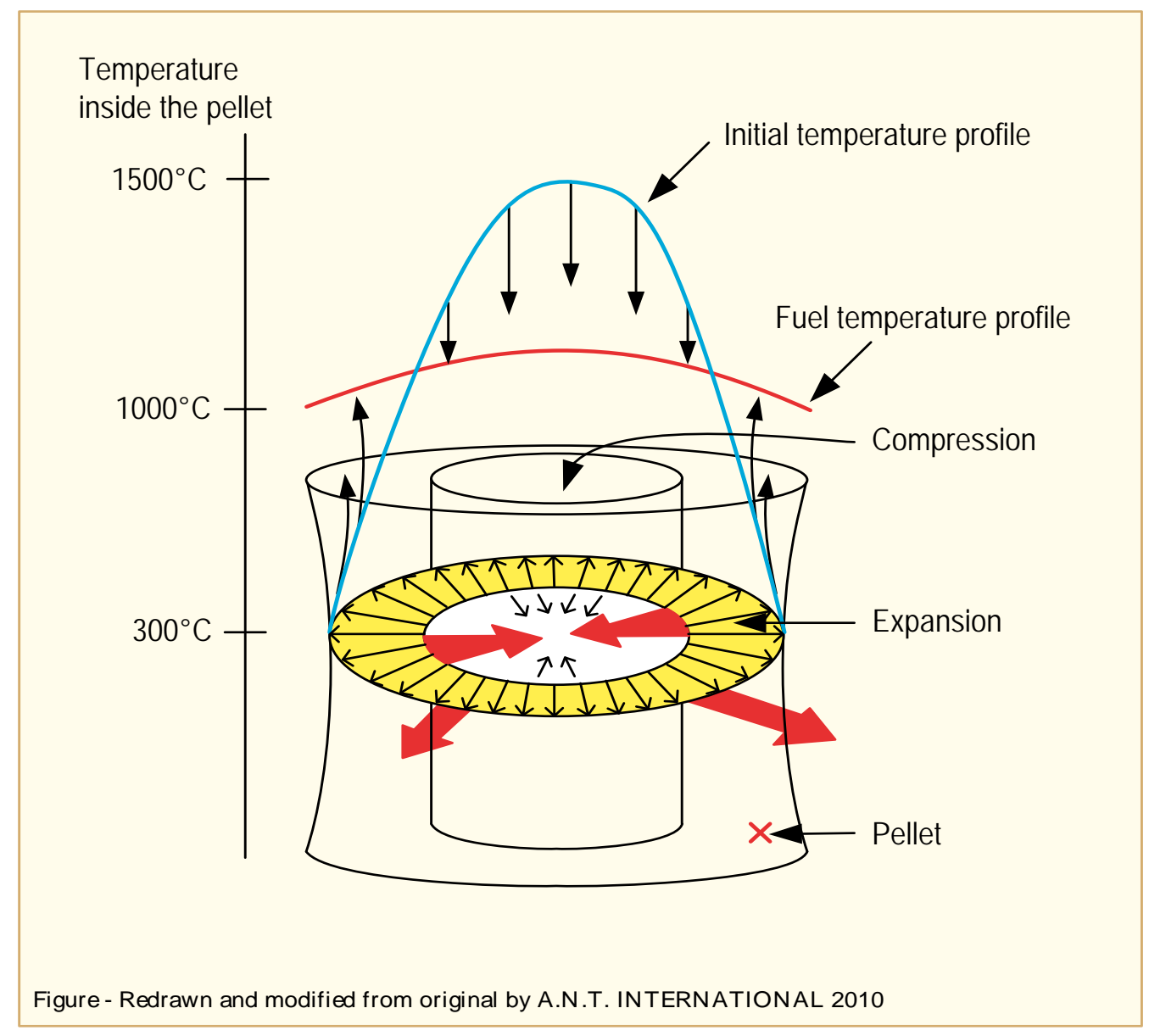

[Rudling and Patterson

[Maillat et al, 2003] 2012\} 


\section{Summary}

- Increased burnup may impact LOCA fuel performance:

- Development of rim zone - high inventory of fission gases, contained mainly in large over-pressurized pores => TFGR may result in fuel dispersal in rods failed through burst.

- Increased rod internal pressure (FGR) and TFGR increase ballooning, more rods failed through burst

- The rod internal pressure at burst (the FGR-prior to the LOCA- and TFGRduring the LOCA- ) constitutes the parts of the source term

- Fuel relocation in ballooned area not a concern

- Pre-LOCA H-pickup

- Increase fraction of rods failed through burst (concern in Germany)

- Less margins to fuel rod fracture through clad embrittlement

- Increase $O$ solubility and diffusivity in the prior-beta $Z r$ phase $=>$ reduce allowable LOCA

- Fuel-clad bonding may increase embrittlement => may reduce allowable LOCA ECR 


\section{Fuel Performance During LOCA}

- During base irradiation and during the LOCA event several changes of the $\mathrm{UO}_{2}$ pellet and within the fuel rod can occur which are significant for LOCA performance. These are:

- FGR from the pellet during base irradiation increases the inner pressure, which affects the ballooning behaviour of the cladding and the probability and time of a burst during LOCA.

- Degradation of the thermal conductivity of the $\mathrm{UO}_{2}$ pellet resulting in increased fuel temperature (at constant rod power) which in turn will increase the FGR.

- A high burnup rim zone is formed at the pellet periphery during the base irradiation at high burnups. This high burnup rim zone has a high inventory of fission gases, contained mainly in large overpressurized pores. During a LOCA the outer rim experiences a temperature increase, e.g. from 400 to $1100^{\circ} \mathrm{C}$, which may lead to a pronounced transient fission gar release TFGR during the LOCA.

- The rod internal pressure at burst (the FGR-prior to the LOCA- and TFGR-during the LOCA- ) constitutes the parts of the source term

- Pellet-Clad Bonding

[Rudling and Patterson

2012\} 


\section{Ballooning and Burst}

- The basic parameters controlling fuel clad deformation and ballooning are:

- Stress,

- temperature and

- creep strength, which is affected by oxidation, grain size and anisotropy.

- Burst leads to release of noble gases, iodine, caesium and other species released by the fuel (source term)

- Burst is facilitated by Hydrogen 


\section{Effect of Decay Heat}

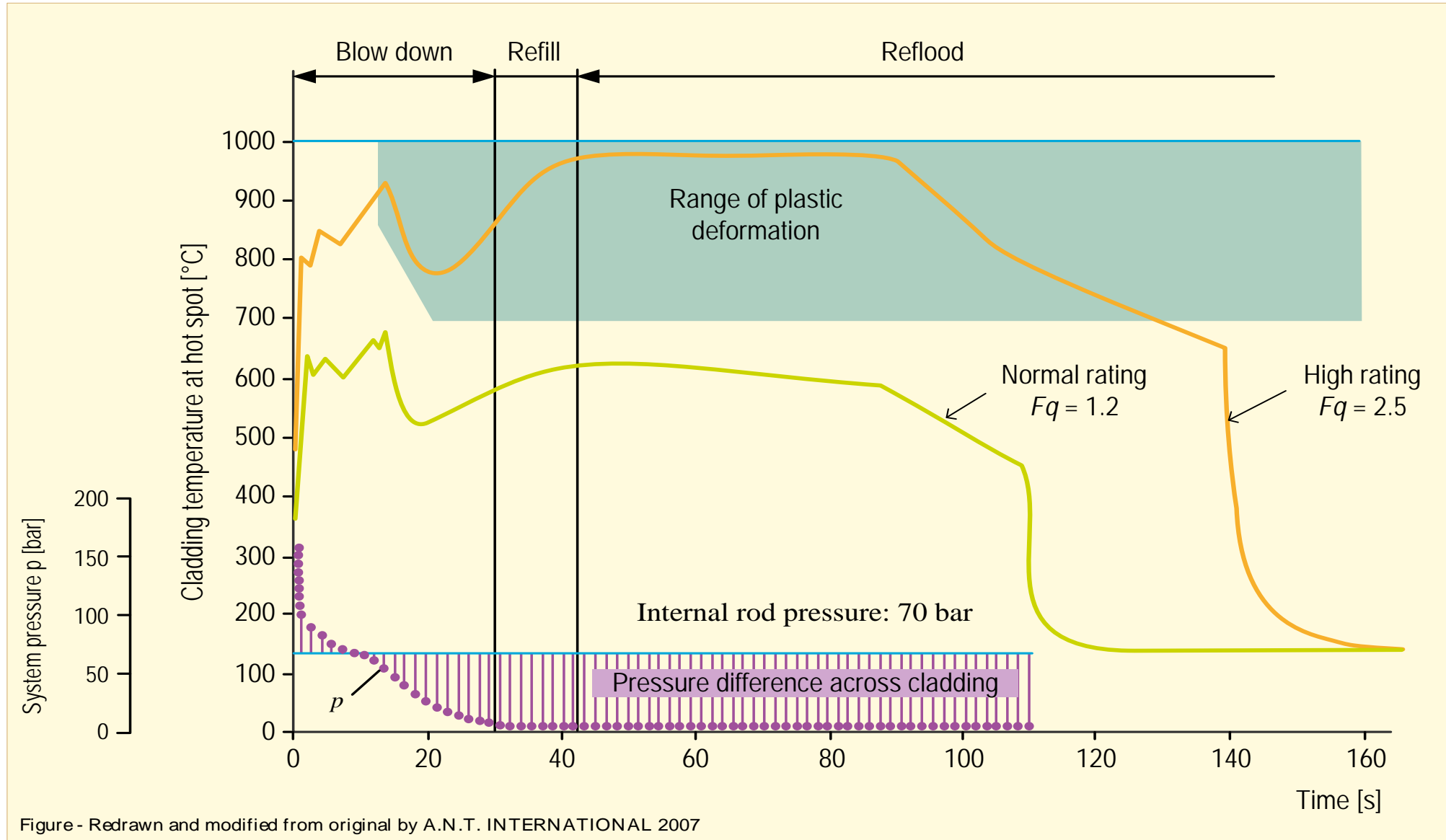

[Rudling and Patterson

2012\} 


\section{Zr-O phase diagram}

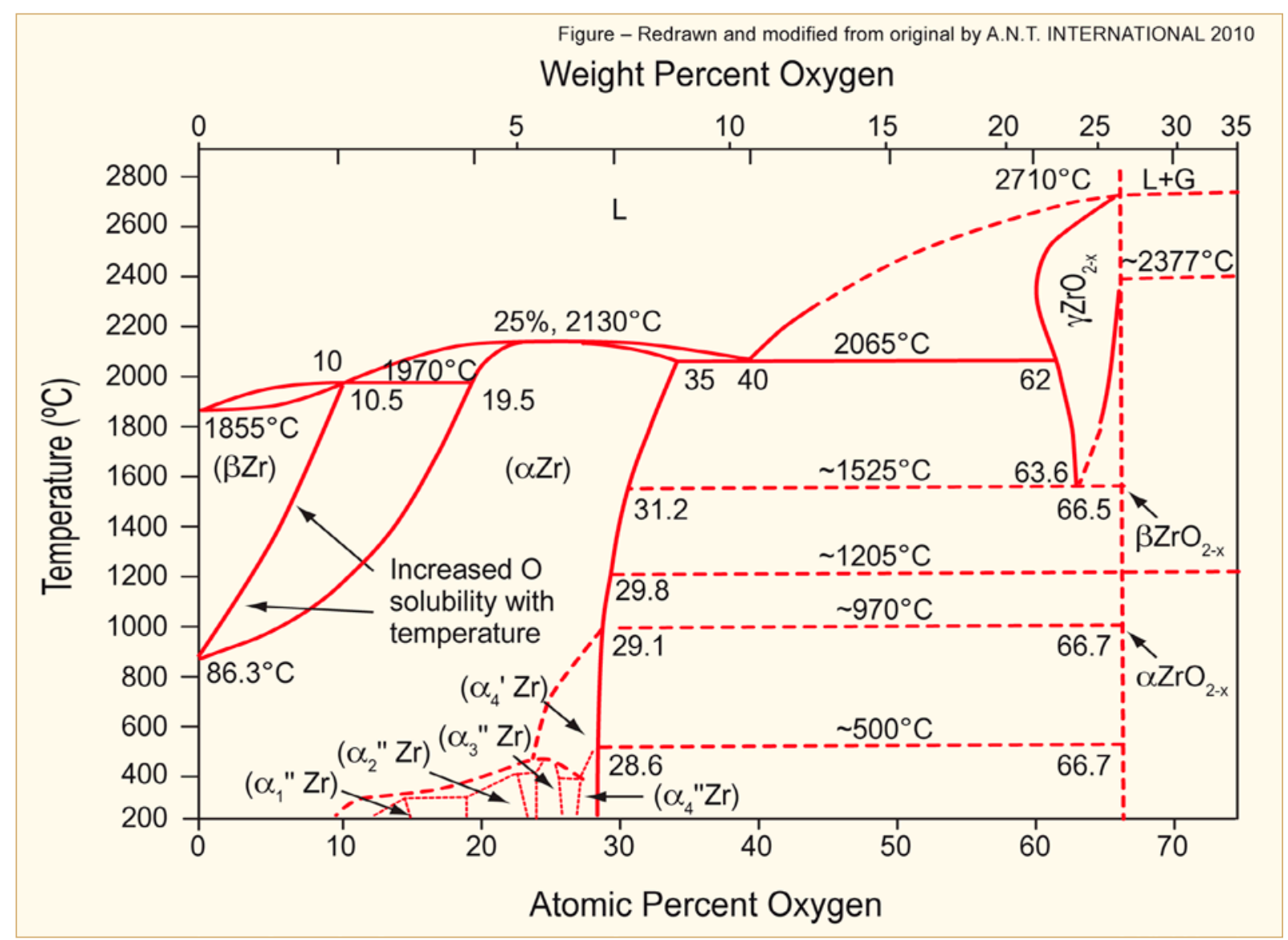

[Abriata et al, 1986]

[Rudling and Patterson

2012\} 


\section{In-vessel Severe Accident Progression}

- Thermal-hydraulic and fuel rod degradation

- Hydrogen generation

- Degradation of core structure

- In-vessel fuel-coolant interaction

- Oxide/metal separation

- In-vessel debris formation

- RPV failure $w /$ or w/o high pressure melt ejection 


\section{Design of Fukushima-Daiichi-1 Provides Primary Containment Around Vessel}

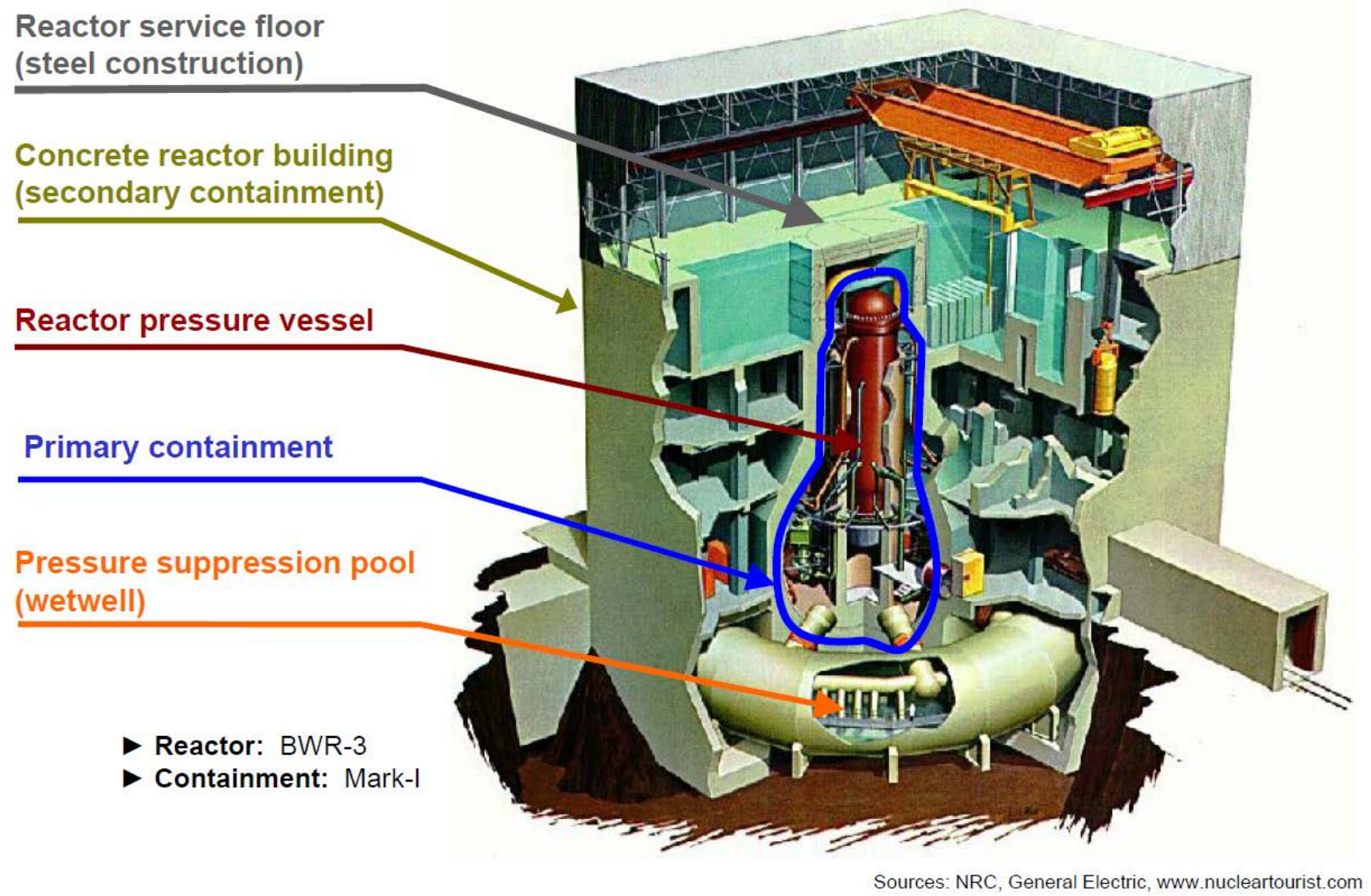




\section{Range of Melt Progression Phenomena Affects Vessel Failure Mode and Timing For All Reactor Designs}

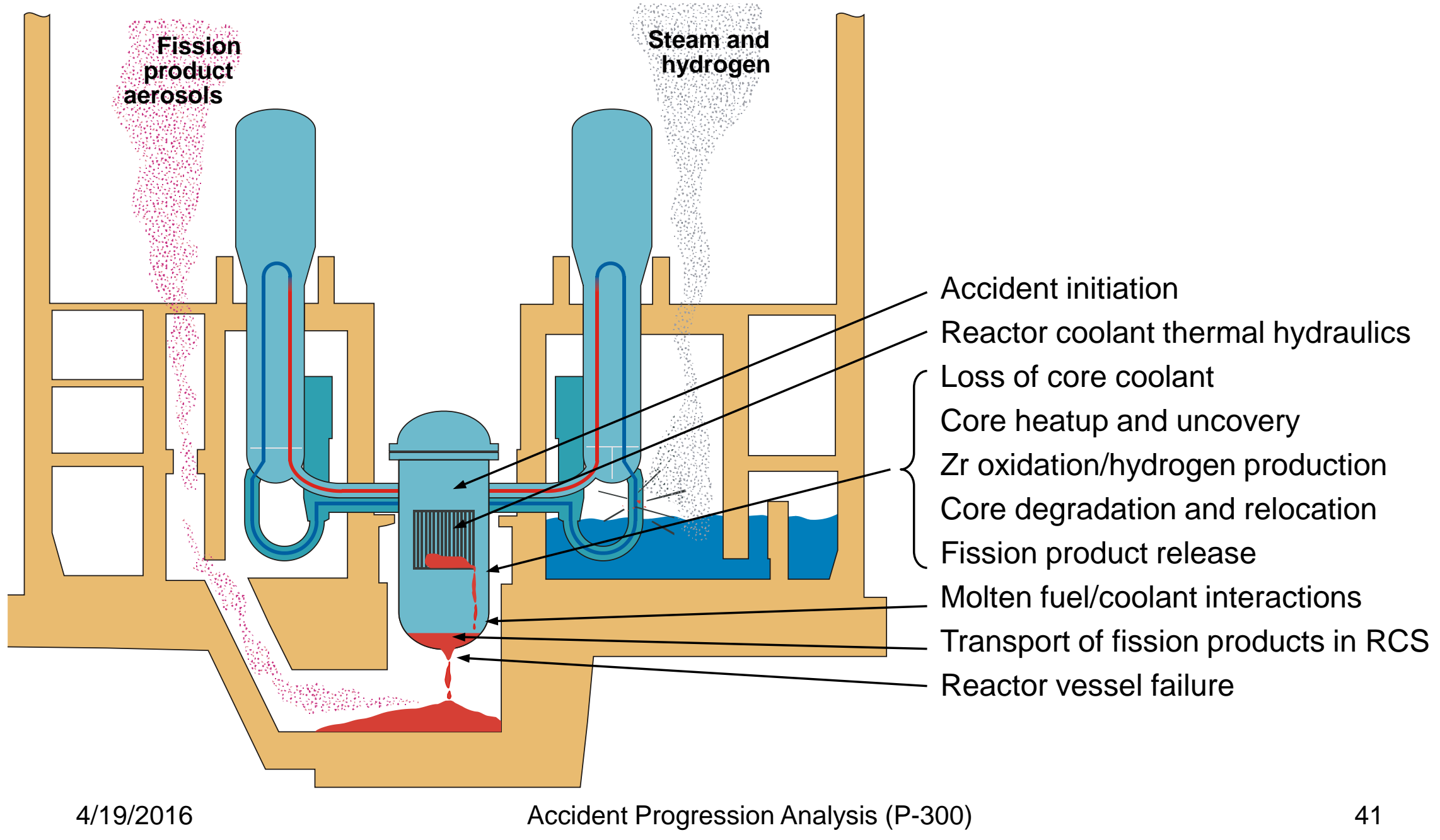




\section{BWR Vessels Also Penetrated by CRD Assemblies and Drain Line}

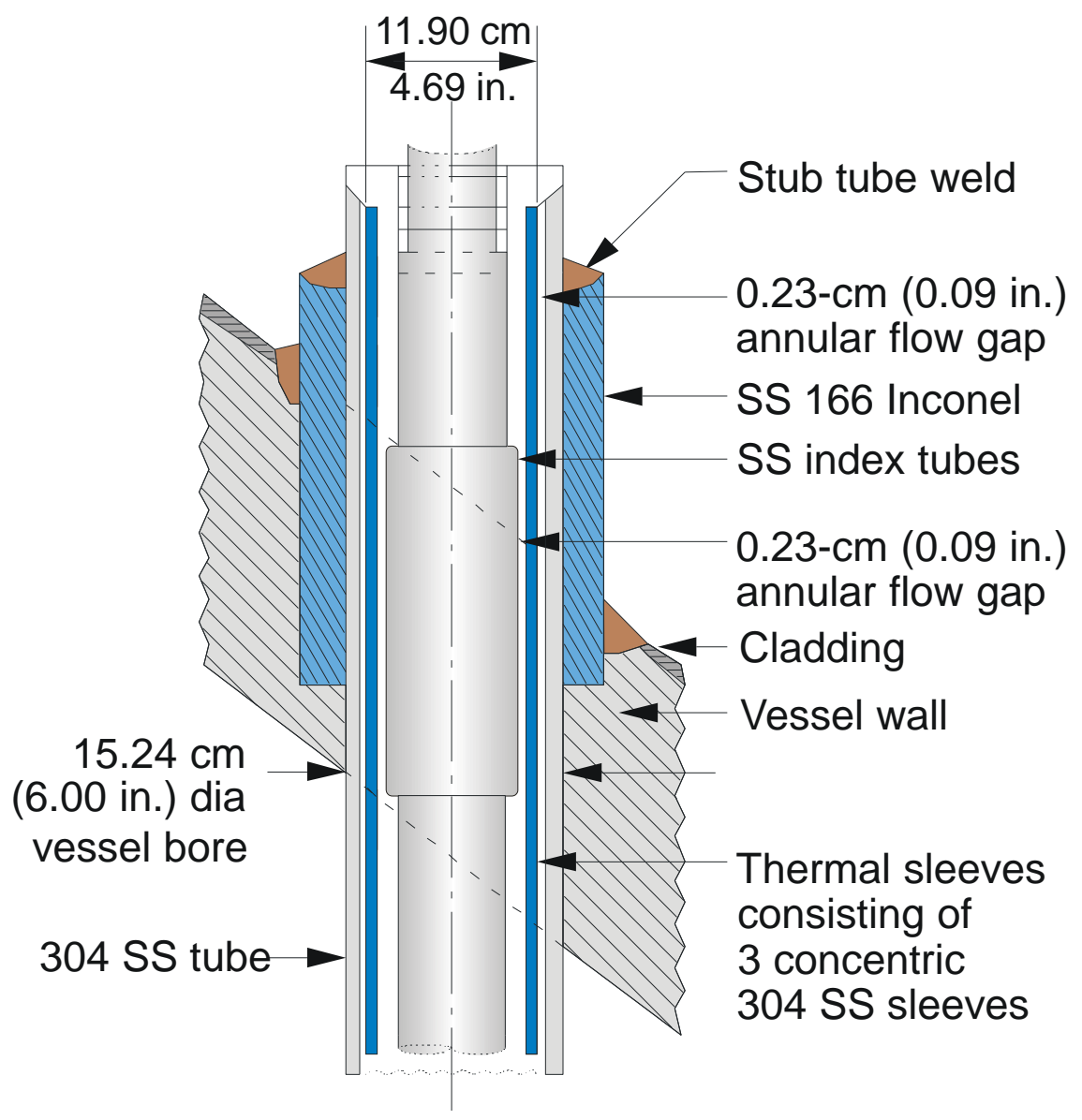

Typical GE CRD Assembly Penetration

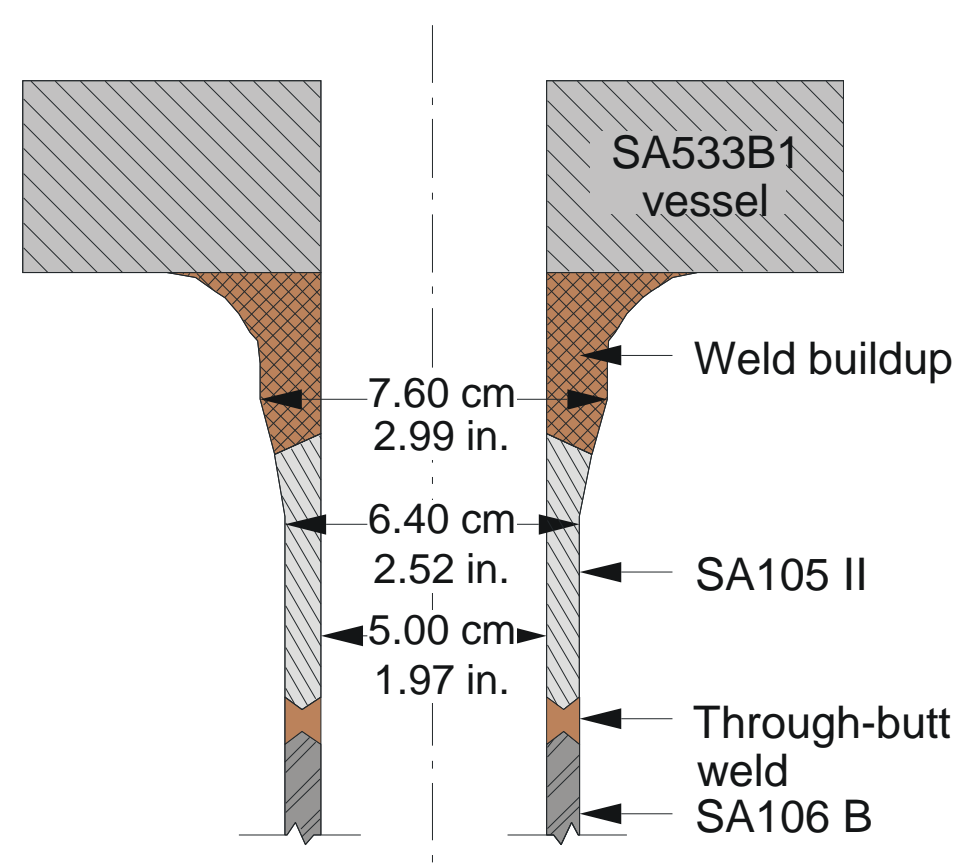

Typical GE Drain Line Nozzle Penetration 


\section{Design}

\section{Insulation, Supports, and Cavities for Lower Heads Differ}

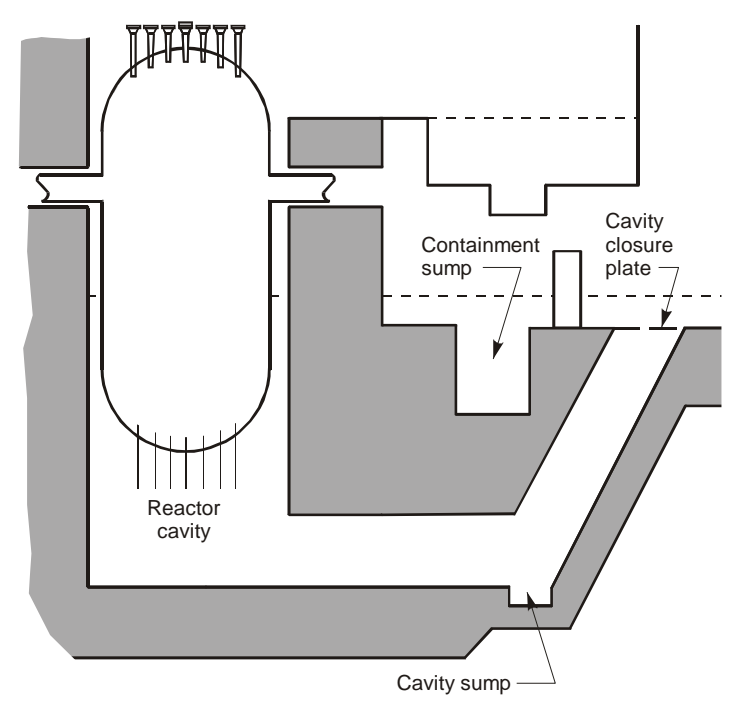

(a) W

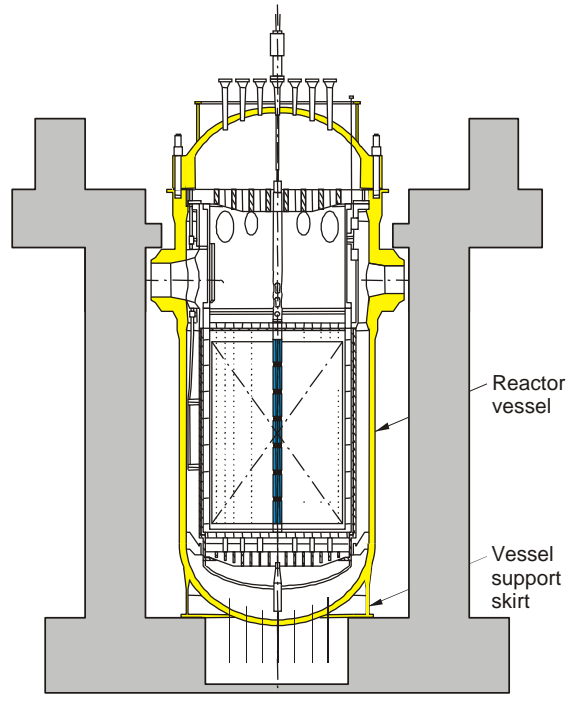

(b) B\&W

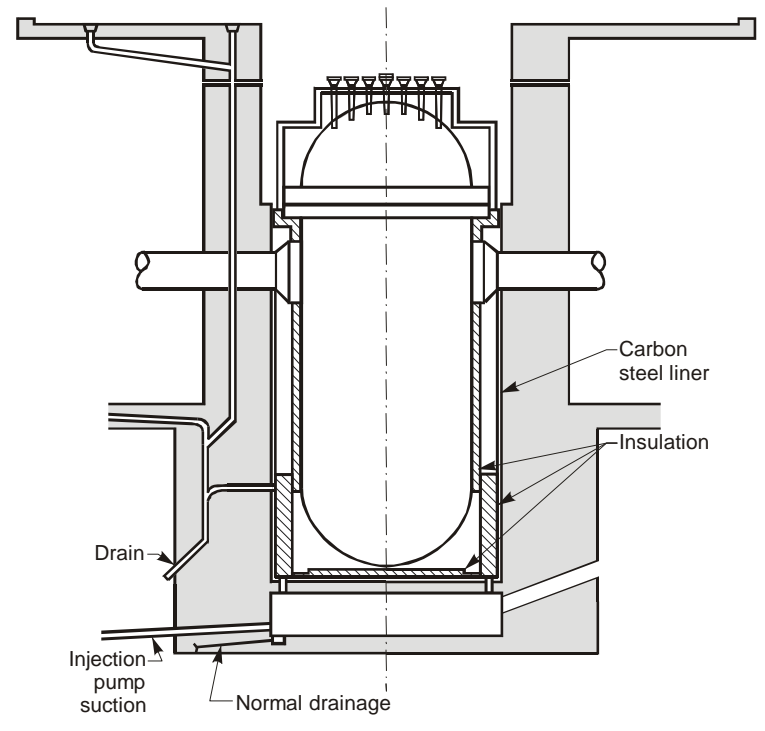

(c) CE 


\section{In-vessel Steam Explosion Issues}

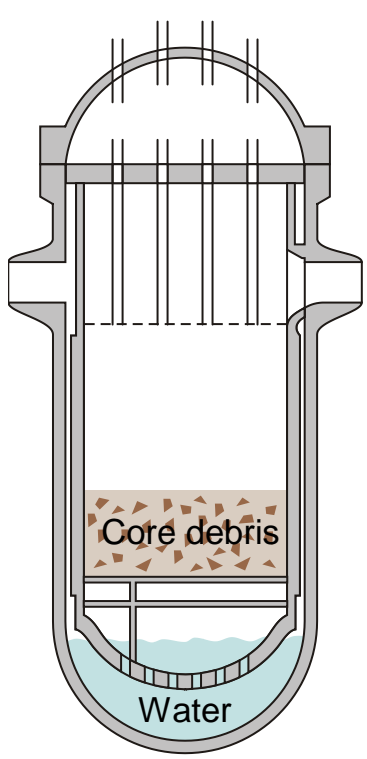

A. Initial separated configuration

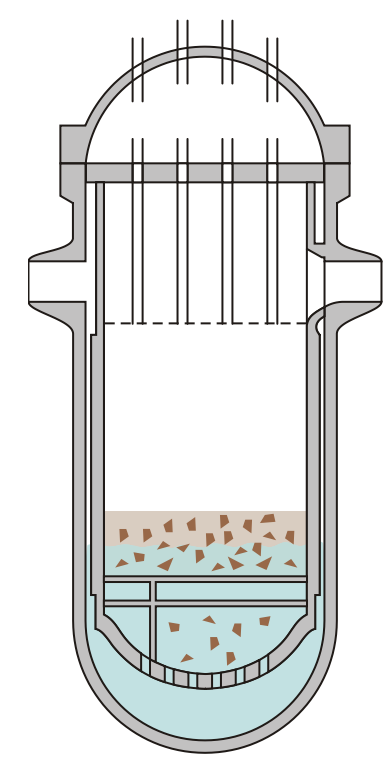

B. Relocation and instantaneous mixing

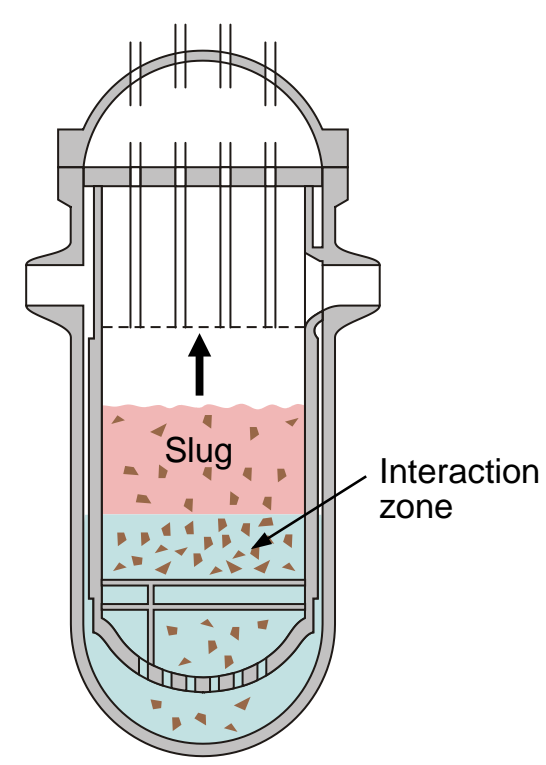

C. Sustained energy transfer and slug acceleration

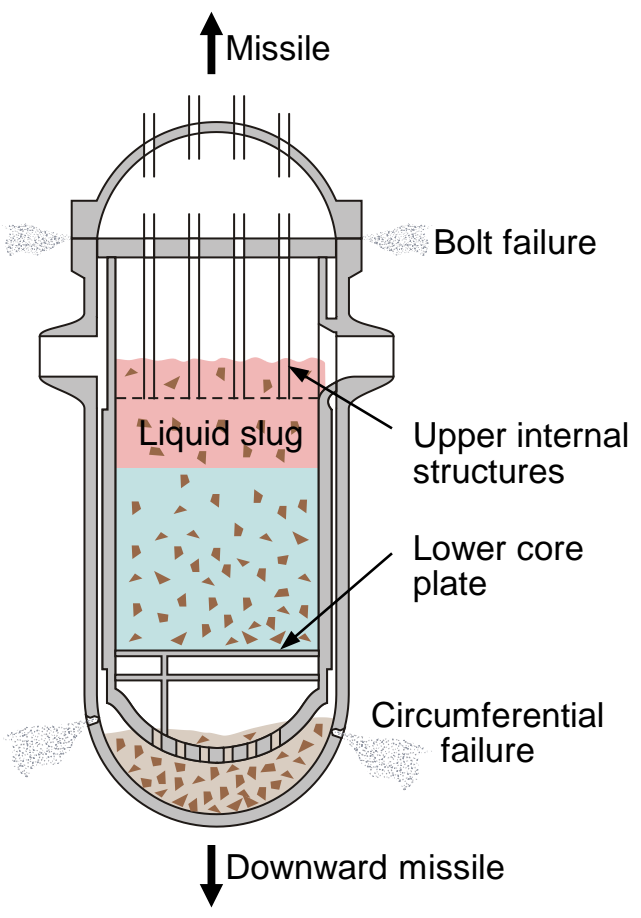

D. Slug impact

- Will in-vessel fuel/water interactions cause energetic reactions?

- Are such reactions sufficient to accelerate a slug that fails the vessel and/or create a missile that causes early containment failure? 


\section{Additional Data obtained since NUREG- 1150 Evaluations}

- Issues so controversial at time NUREG-1150 completed, expert panel refused to address.

- SNL staff internally developed distribution based on opinions expressed by Steam Explosion Review Group (SERG) in NUREG-1116.

- More recent experimental results indicate:

- At low pressure [<0.1 MPa (14.7 psi)], limited fuel mass expected to participate in energetic $\mathrm{FCl}$

- At higher pressures [> $1 \mathrm{MPa}$ (147 psi)], explosion difficult to trigger

- All eleven SERG-2 experts estimated low probabilities for energetic invessel steam explosion 


\section{In-vessel Core Debris Coolability}

- Initial conditions for stabilization are subject to the uncertainties of in-vessel melt progression

- Event progression through RPV failure represents the largest source of uncertainty for SA mitigation
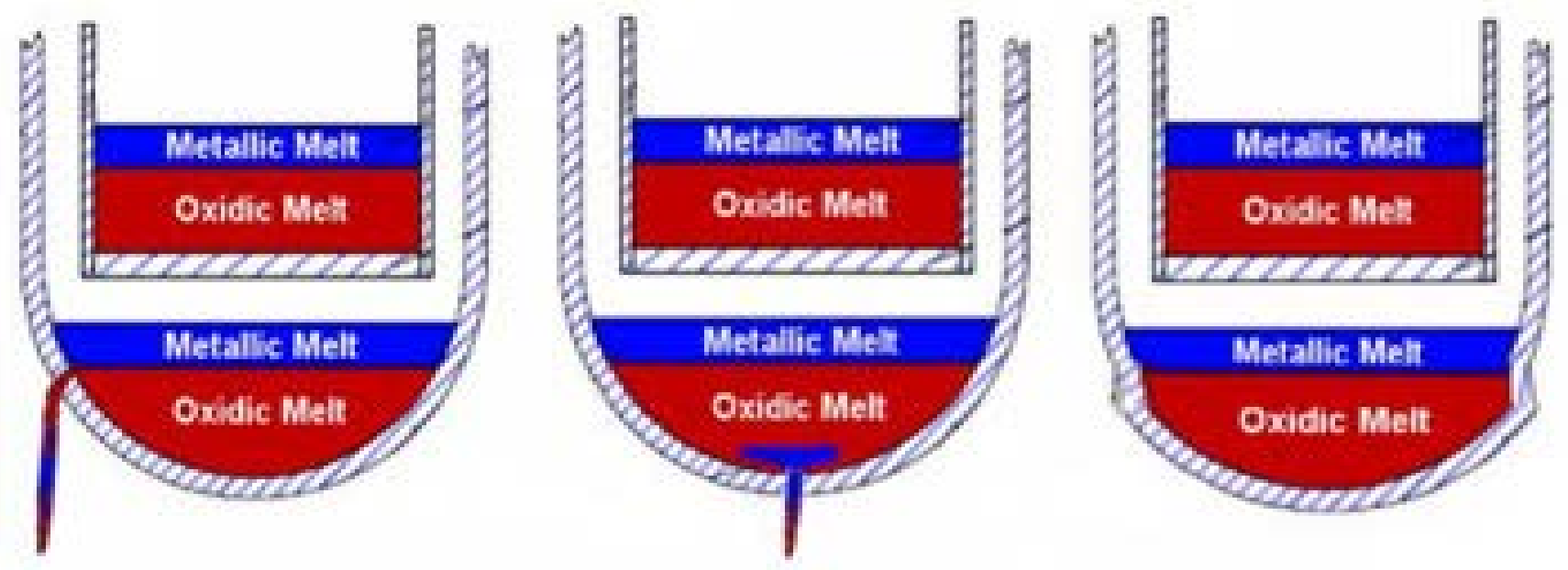


\section{Large Uncertainties Associated with Early Methods for Quantifying Vessel Lower Head Failure Potential}

- Codes typically assumed early penetration failure (with subsequent depressurization) or global vessel failure based on temperature criterion

- NUREG-1150 developed aggregate distributions derived from uncertainty models provided by three experts

- Several cases considered (varied pressure, availability of upper head injection, and accumulator injection)

- Expert review based on calculation results, TMI-2 data, and severe fuel damage test data

- Wide variation in expert opinion

- Singled out as area with major uncertainty in Special Committee Review for NUREG-1150 due to importance of vessel failure mode and timing on subsequent accident progression. 


\section{Several research programs provide data and improved tools for predicting vessel failure.}

\begin{tabular}{|c|c|c|c|c|}
\hline Program & Focus & Heat Loads & Vessel & Pressure \\
\hline $\begin{array}{l}\text { NRC Lower } \\
\text { Head Failure } \\
\text { Program (INL) }\end{array}$ & $\begin{array}{l}\text { Models and } \\
\text { material data for } \\
\text { evaluating vessel } \\
\text { and penetration } \\
\text { failure }\end{array}$ & $\begin{array}{l}\text { Wide range of } \\
\text { well-defined } \\
\text { localized and } \\
\text { global heat } \\
\text { loads }\end{array}$ & $\begin{array}{l}\text { Wide range (with } \\
\text { and without } \\
\text { penetrations) }\end{array}$ & $\begin{array}{l}\text { Wide range } \\
(0.1 \text { to } 15 \mathrm{MPa} / \\
14.5-2175 \mathrm{psi})\end{array}$ \\
\hline $\begin{array}{l}\text { OECD TMI-2 } \\
\text { Vessel } \\
\text { Investigation } \\
\text { Program }\end{array}$ & $\begin{array}{l}\text { Data to assess } \\
\text { tools for predicting } \\
\text { vessel and } \\
\text { penetration failure }\end{array}$ & $\begin{array}{l}\text { Localized and } \\
\text { global heat } \\
\text { loads (but not } \\
\text { well defined) }\end{array}$ & $\begin{array}{l}\text { B\&W PWR } \\
\text { SS-lined SA533 } \\
\text { vessel with } \\
\text { penetrations }\end{array}$ & $\begin{array}{l}\text { High } \\
(3-15 \mathrm{MPa} / \\
435-2175 \mathrm{psi})\end{array}$ \\
\hline $\begin{array}{l}\text { NRC and } \\
\text { OECD Lower } \\
\text { Head Failure } \\
\text { Tests (SNL) }\end{array}$ & $\begin{array}{l}\text { Failure data for } \\
\text { well-defined heat } \\
\text { loads }\end{array}$ & $\begin{array}{l}\text { Localized and } \\
\text { global heat } \\
\text { loads }\end{array}$ & $\begin{array}{l}1 / 5^{\text {th }} \text { scale SA533 } \\
\text { (with and without } \\
\text { penetrations); OLHF } \\
-1 / 2 \text { scale wall }\end{array}$ & $\begin{array}{l}\text { High } \\
(2-10 \mathrm{MPa} / \\
30-1450 \mathrm{psi})\end{array}$ \\
\hline
\end{tabular}




\section{INL Lower Head Failure Program First Comprehensive Study of Vessel Failure Mechanisms}
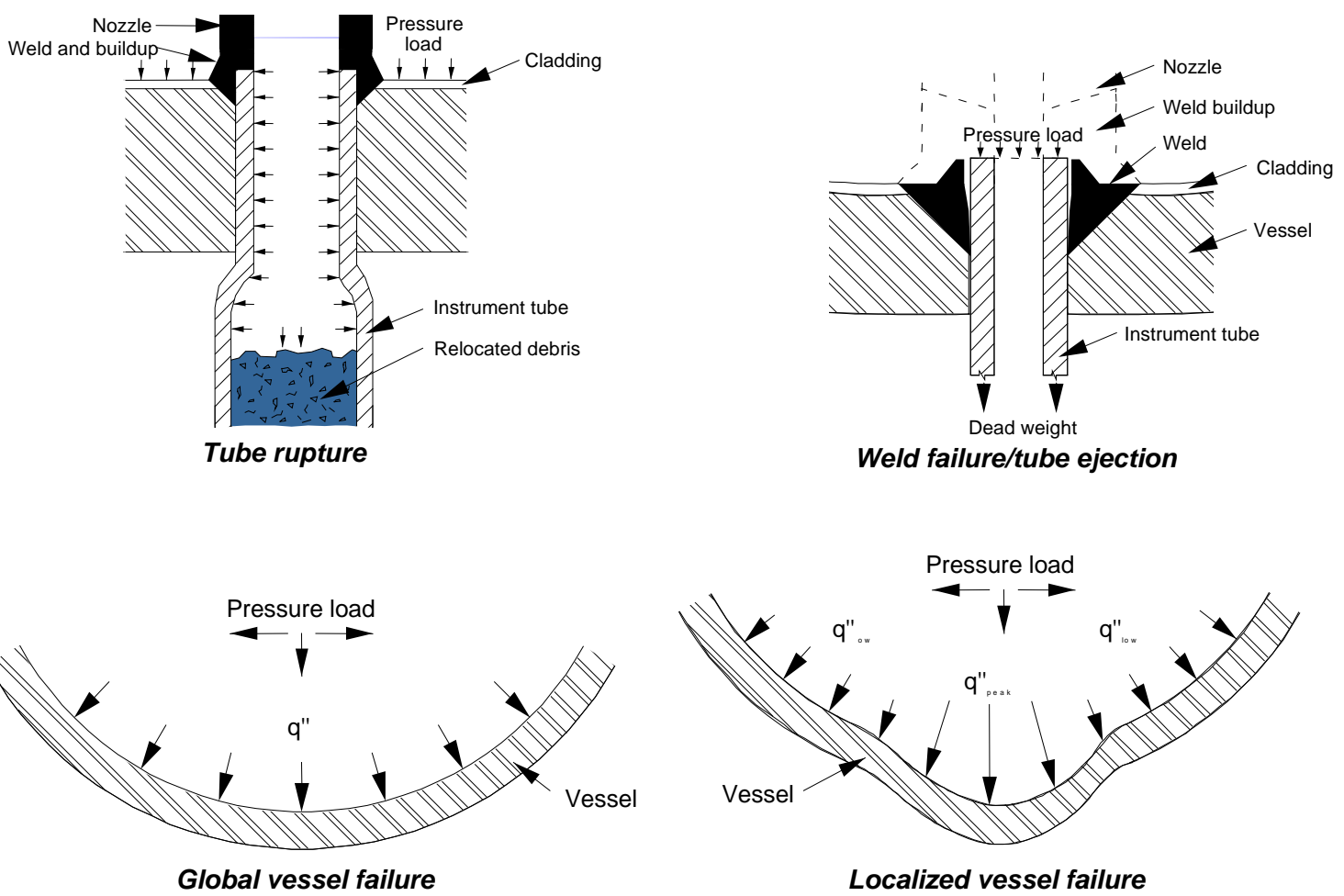

- Identified and developed models for each failure mechanism

- Obtained high temperature creep and tensile data for vessel and penetration materials

- Applied methods to obtain insights for range of accident conditions and reactor designs 


\section{Vessel Failure}

\section{High-temperature Tensile and Creep Data Obtained for Vessel and Penetration Materials}

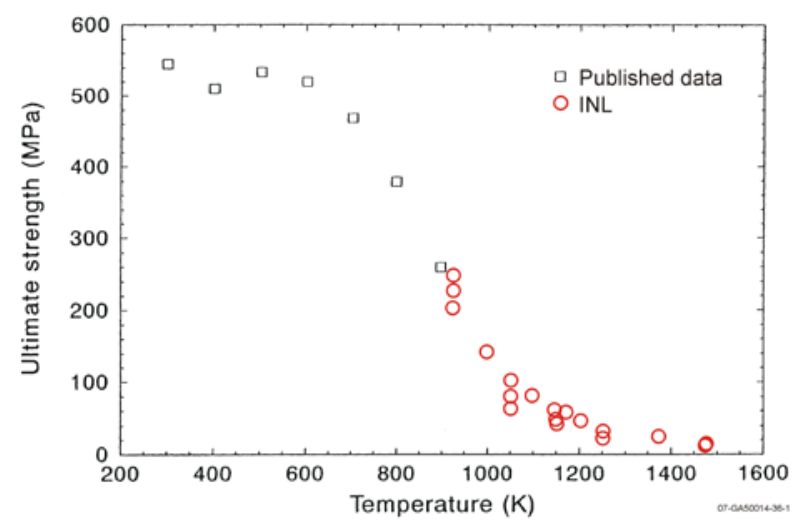

- Data for penetration materials (SS304, Inconel 600 and SA105/106) also available

- For SA533B1:

- Significant reduction in SA533B1 yield strength at temperatures above $1000 \mathrm{~K}$

- Stress versus time to rupture only moderately sensitive to phase transformation

- Higher temperature thermal diffusivity and thermal expansion data smaller than extrapolated published values

- Calculations needed to assess impact of new data!
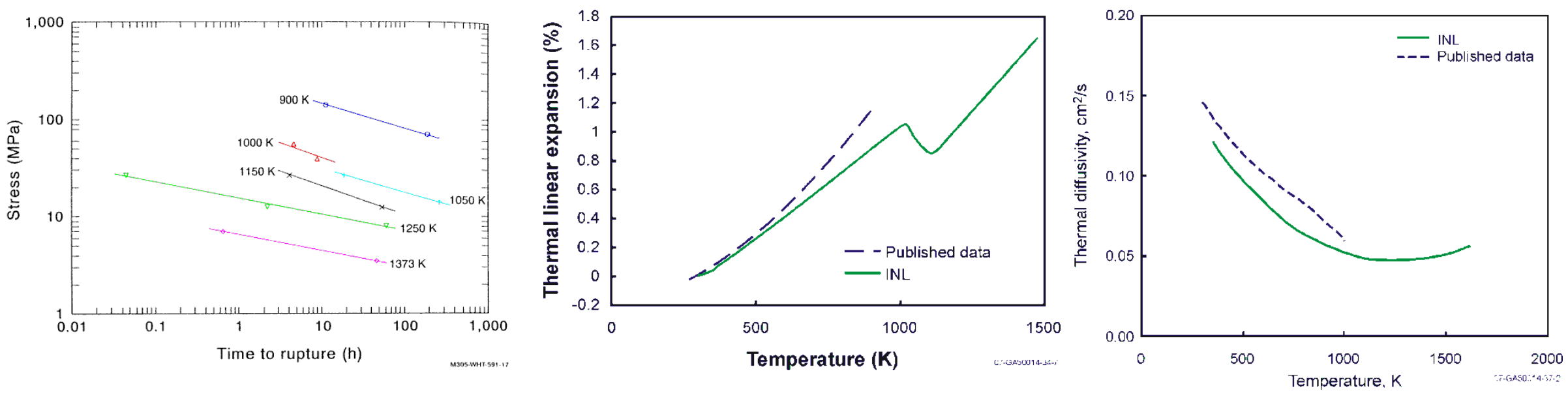


\section{Summary}

- Research results suggest energetic in-vessel steam explosions not important from risk perspective

- Recent assessments and experiments provide key insights about potential for other failure modes:

- Importance of RCS pressure and relocated debris mass, composition, decay heat distribution and melt fraction, and vessel material and fabrication

- Experimental data and analyses suggest localized and global vessel failures more likely than penetration failures at high pressures 


\section{Debris Heat Loads Impact Quantification of Several Events}

- Debris heat loads impact mode and timing of vessel failure and potential for containment failure.

- Information needed to address key questions:

- What type of debris endstates may occur?

- How does debris endstate affect vessel heat loads?

- What phenomena affect debris coolability? 


\section{Debris Heat Load Considered by NUREG-1150 Experts Evaluating Vessel Failure Mode}

- Three experts asked to evaluate several cases (medium to high pressure, with and without injection)

- Available code calculations, TMI-2 post-accident examinations, and severe fuel damage tests used to derive

- mass ejection rate

- melt temperature

- oxidation fraction of released melt

- molten fraction of released melt

- Wide variation in expert opinion (due to limited data). 


\section{Debris Endstate Configurations Key in Assessing Vessel Response}

Molten pool

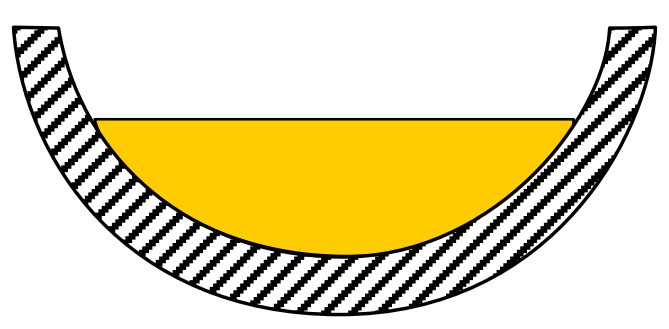

Homogeneous
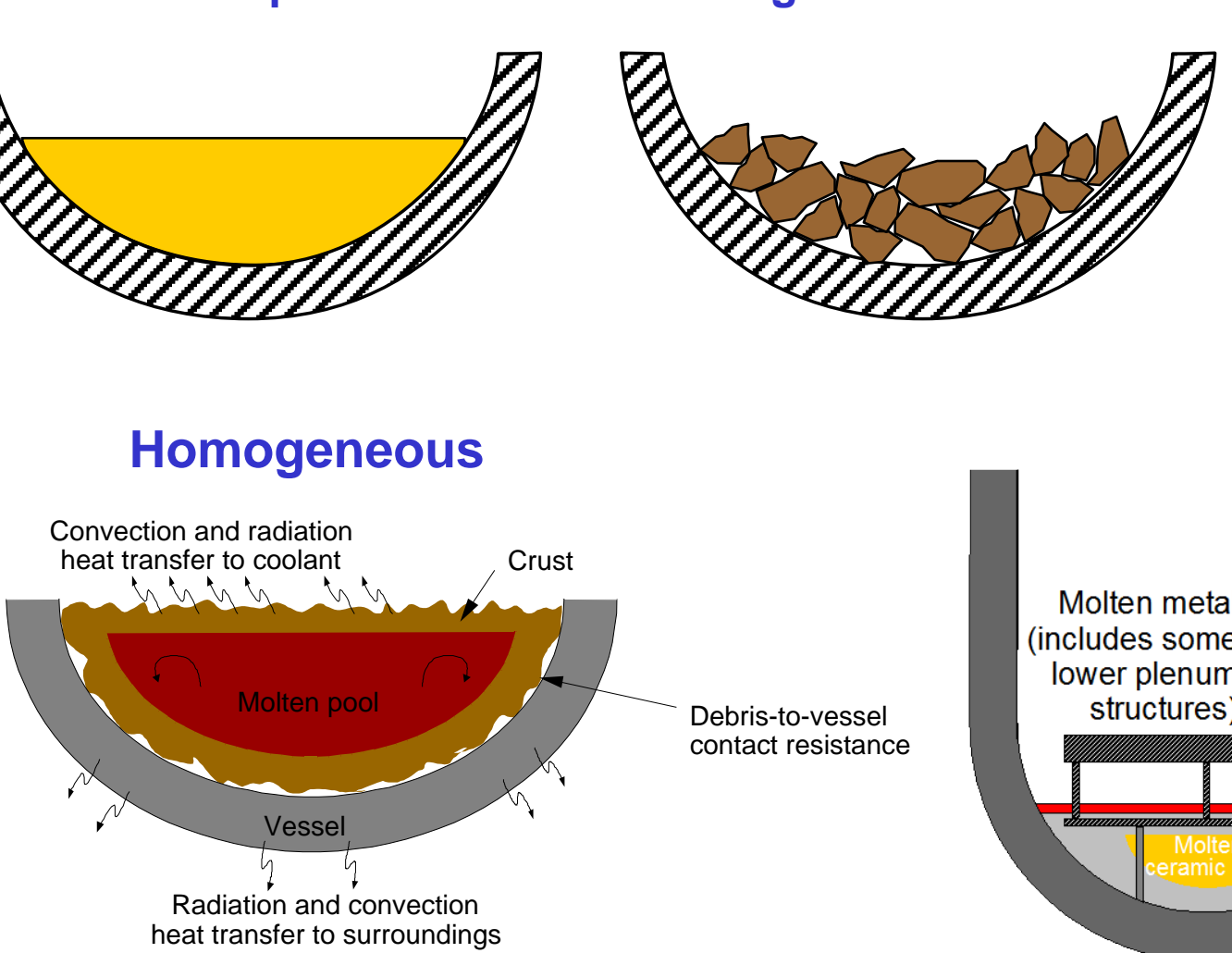
heat transfer to surroundings
Debris-to-vessel contact resistance

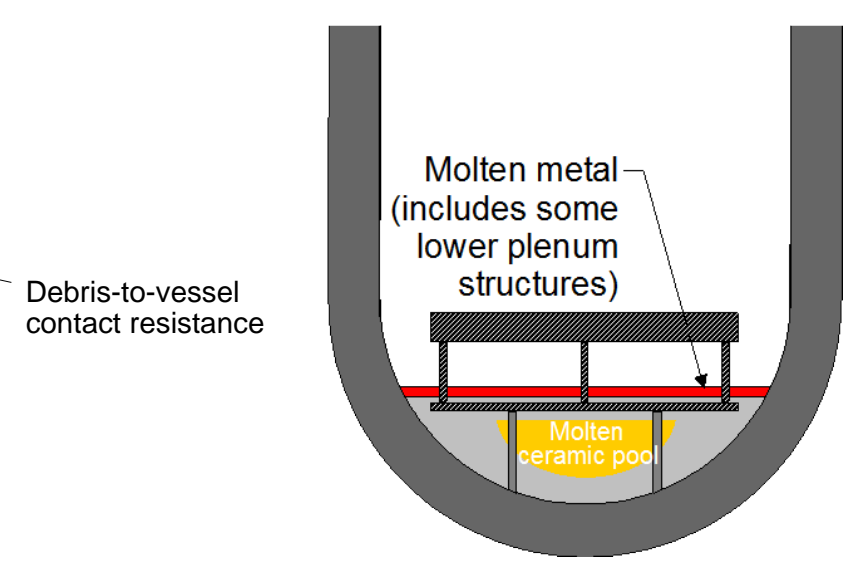

Stratified

Molten pool beneath fragmented rubble

Fragmented rubble

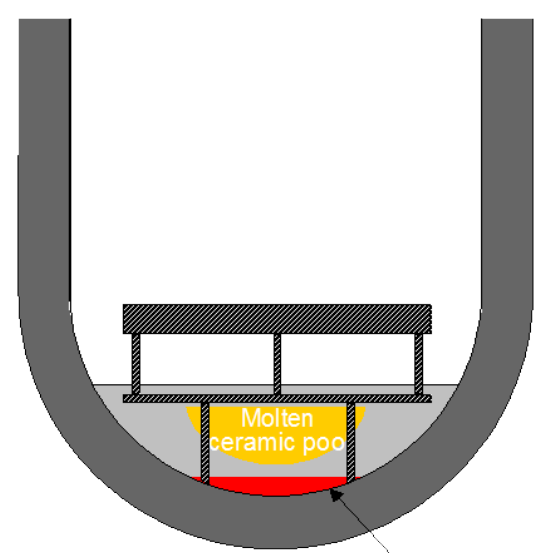

Molten metal (includes dissolved uranium in unoxidized zircaloy) 
Debris Heat Loads

\section{Enhanced Cooling Possible As Relocated Core Material Solidifies}

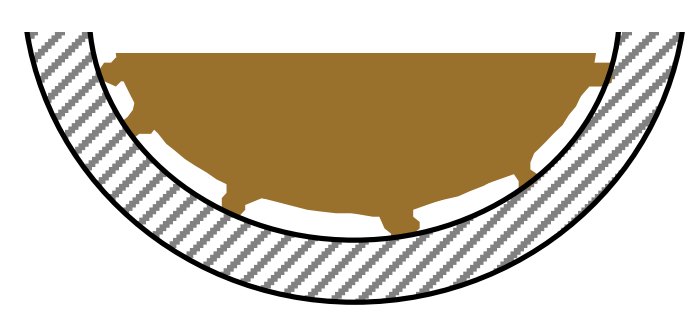

Intermittent

debris-to-vessel gap

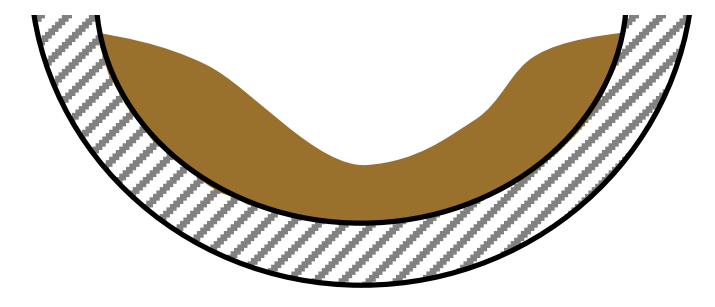

Enhanced upper surface corium surface area

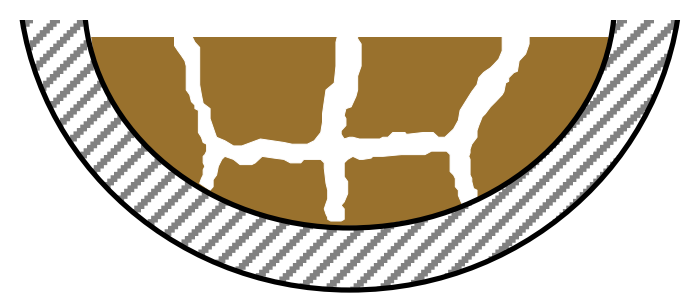

Interconnected corium cracks 


\section{Wide Range of Investigations Provide Insights about Heat Load from Relocated Corium}

\begin{tabular}{|c|c|c|c|c|c|}
\hline \multirow[t]{2}{*}{ Program } & \multirow[t]{2}{*}{ Insight } & \multicolumn{3}{|c|}{ Materials } & \multirow[t]{2}{*}{ Pressure } \\
\hline & & Corium & Vessel & Coolant & \\
\hline $\begin{array}{l}\text { RRC/OECD } \\
\text { RASPLAV }\end{array}$ & $\begin{array}{l}\text { Natural convection heat } \\
\text { fluxes, corium } \\
\text { stratification }\end{array}$ & $\begin{array}{l}\mathrm{UO}_{2} \\
\mathrm{ZrO}_{2}, \mathrm{Zr} \\
\mathrm{C}, \mathrm{FeO} \\
\mathrm{LaO}\end{array}$ & $\begin{array}{l}\text { W/Ta } \\
\text { protected } \\
\text { graphite in } \\
\text { slice geometry }\end{array}$ & None & $\begin{array}{l}\text { Low } \\
(0.1 \mathrm{MPa} / \\
14.7 \mathrm{psi})\end{array}$ \\
\hline $\begin{array}{l}\text { JRC/ISPRA } \\
\text { FARO }\end{array}$ & $\begin{array}{l}\text { Melt/water interactions, } \\
\text { debris cooling, } \\
\text { morphology, } \\
\text { interactions with } \\
\text { structures }\end{array}$ & $\begin{array}{l}\mathrm{UO}_{2}, \\
\mathrm{ZrO}_{2}, \mathrm{Zr}\end{array}$ & Flat plate & Water & $\begin{array}{l}\text { High } \\
\text { (0.5 to } 5 \mathrm{MPa} / \\
72.5-725 \mathrm{psi})\end{array}$ \\
\hline $\begin{array}{l}\text { OECD TMI-2 } \\
\text { Vessel } \\
\text { Investigation } \\
\text { Program }\end{array}$ & $\begin{array}{l}\text { Debris cooling, } \\
\text { morphology, and } \\
\text { interactions with } \\
\text { structures }\end{array}$ & $\begin{array}{l}\mathrm{UO}_{2} \\
\mathrm{ZrO}_{2} \\
\mathrm{FeO}_{2}, \mathrm{Ag} \\
\mathrm{SS}-304\end{array}$ & $\begin{array}{l}\text { SS-lined } \\
\text { carbon steel } \\
\text { vessel with } \\
\text { penetrations }\end{array}$ & Water & $\begin{array}{l}\text { High } \\
\text { (3-15 MPa / } \\
435-2175 \text { psi) }\end{array}$ \\
\hline
\end{tabular}




\section{FARO Provides Insights about Relocating Debris Initial Condition, Morphology, and Heat Transfer}

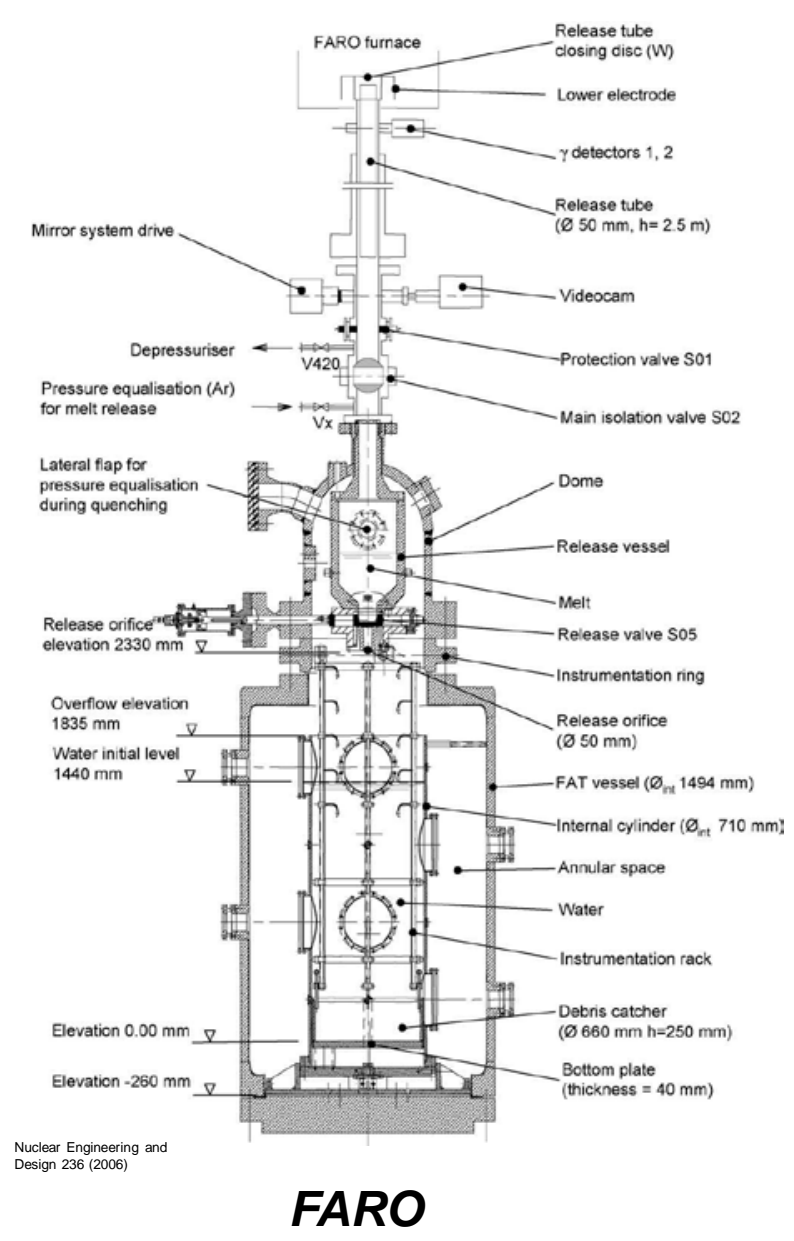

$4 / 19 / 2016$

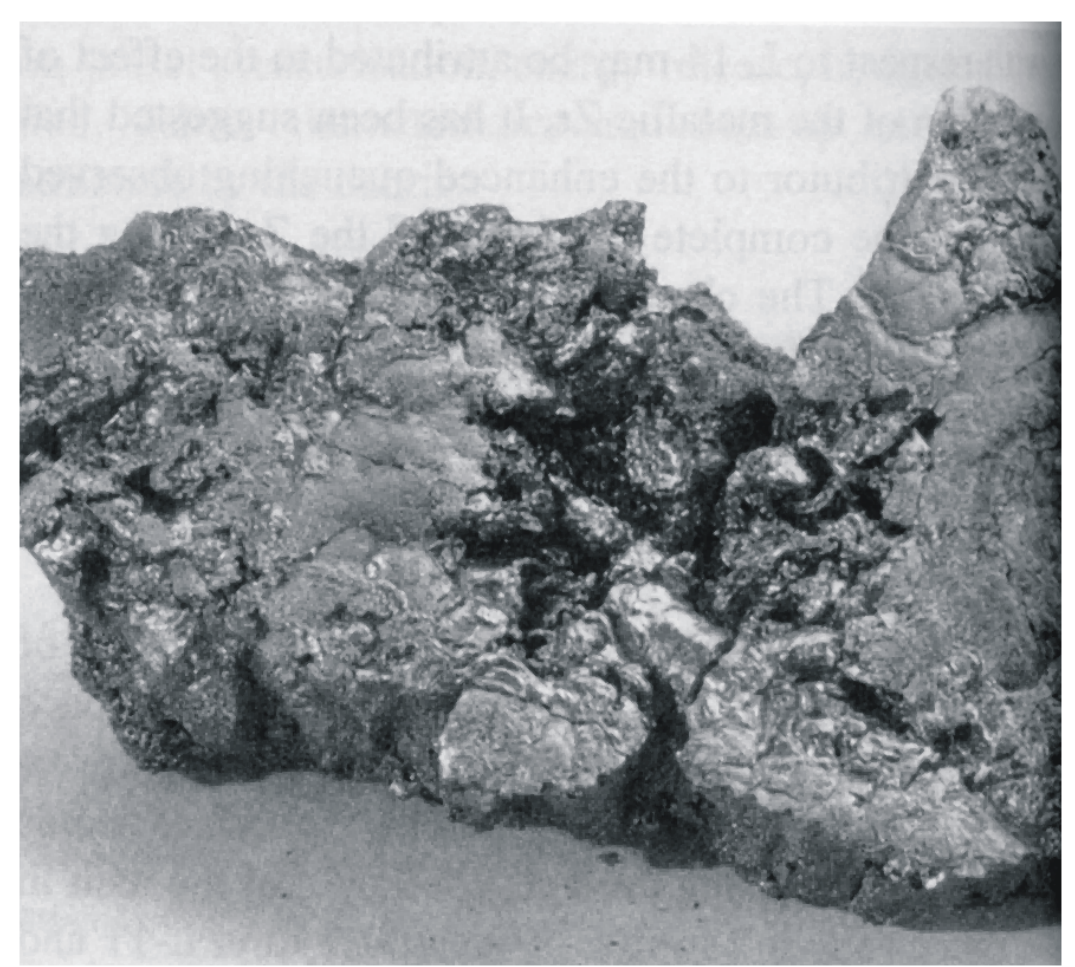

- Furrows observed in relocated debris

- Intermittent contact between relocated debris and test plate Accident Progression Analysis (P-300) 


\section{RASPLAV provides insights about stratification in relocated molten corium materials}
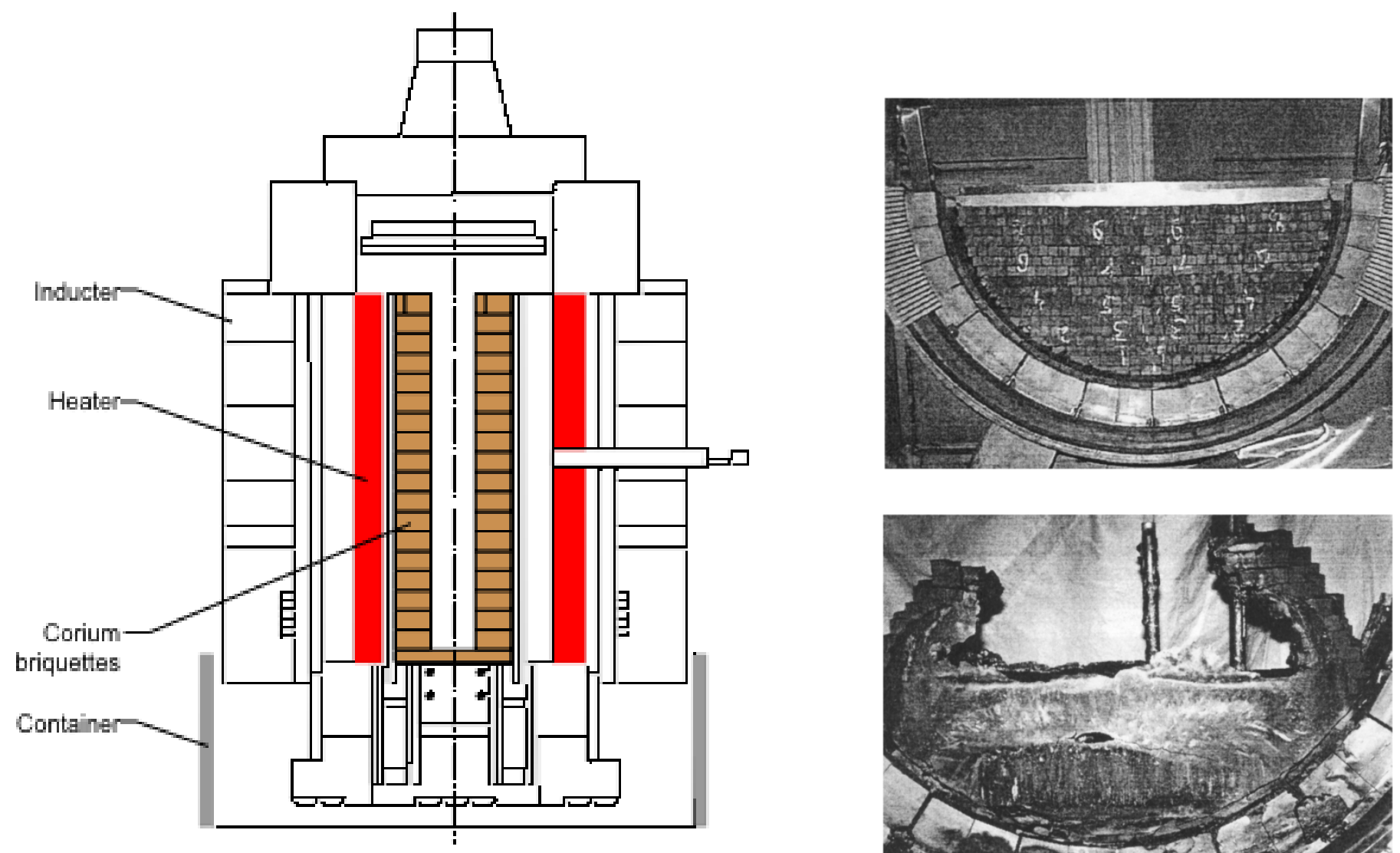

Before

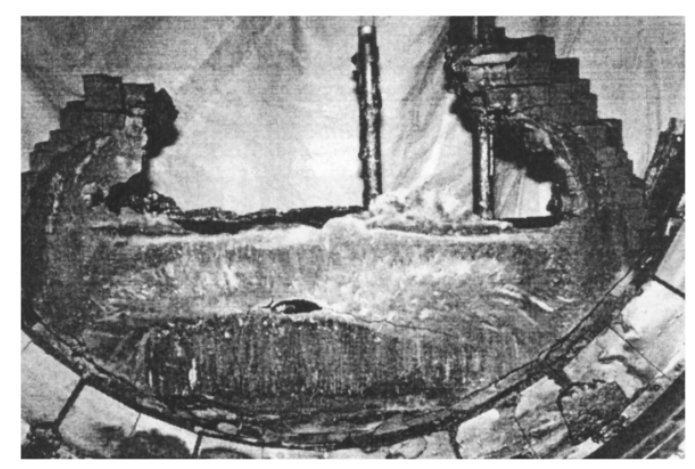

After

Stratification dependent on presence of carbon and fraction of unoxidized zirconium (AW-200-2 used C-22 with 81.8 wt $\% \mathrm{UO}_{2}, 5.0 \mathrm{wt} \% \mathrm{ZrO}_{2}, 13.2 \mathrm{wt} \% \mathrm{Zr}$, and $0.3 \mathrm{wt} \% \mathrm{C}$ ) 


\section{Summary}

- Experimental data suggest range of debris endstates possible

- Data insufficient to select one bounding configuration

- Data suggest melt progression scenario dependent

- Additional research needed to assess potential for various configurations to occur and heat transfer conditions associated with various configurations

- Experimental data provide insights related to heat transfer from various configurations

- Gaps, cracks, and increased upper surface area enhance ceramic melt coolability 


\section{Several mechanisms available to reduce potential for vessel failure}

- External Reactor Vessel Cooling (ERVC)

- Enhanced vessel/insulation arrangement

- Enhanced vessel coatings

- RCS depressurization

- Intentional

- Unintentional 


\section{Requirements for Successful External Reactor Vessel Cooling}

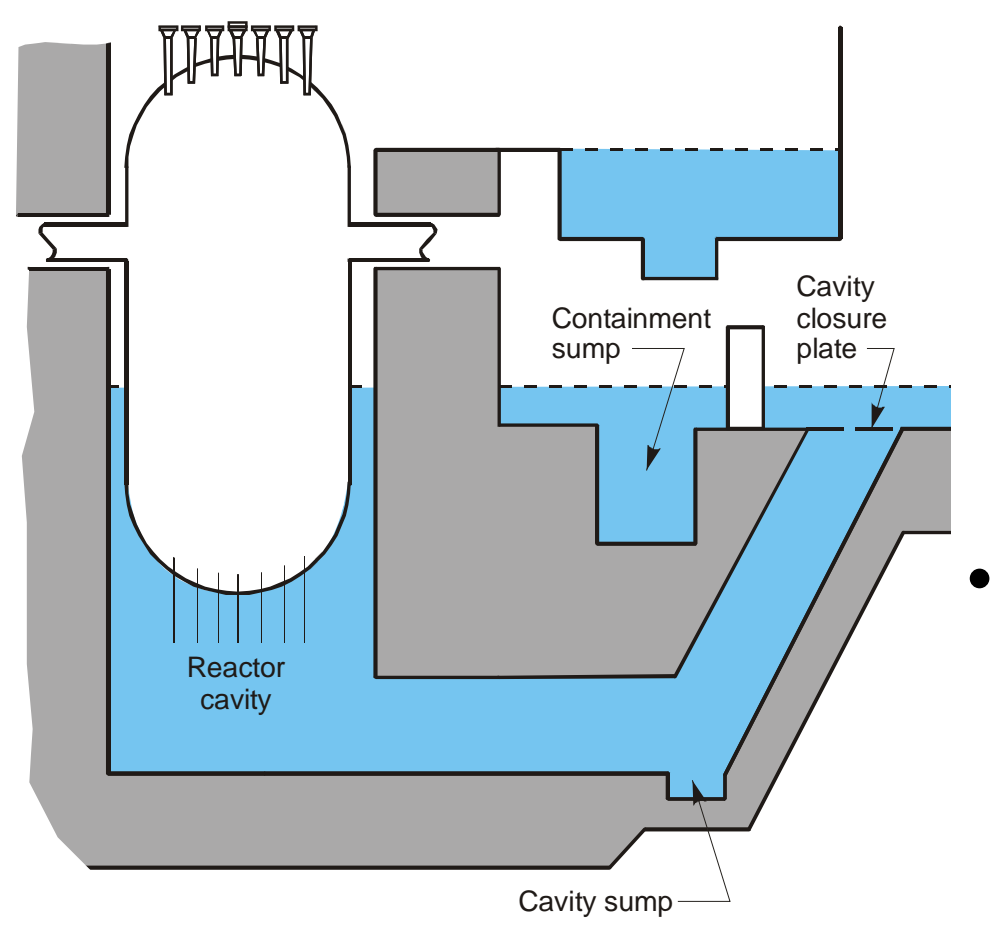

- Water must quickly cover lower vessel external surfaces

- Flooding must occur prior to melt relocation

- Sufficient coolant ingress and steam egress

- Insulation must be designed to withstand forces associated with ERVC

Heat flux to vessel must be less than heat removed from the vessel

- Often translated to vessel heat flux must be less than Critical Heat Flux (CHF) for nucleate boiling on vessel outer surface

- CHF dependent on angle, surface treatment, geometry(penetrations, junctions, insulation) and water height 


\section{External Reactor Vessel Cooling (ERVC) Proposed or Used for Several Plants}

- In many Individual Plant Examinations (IPEs), cavity flooding assumed to preclude vessel failure and reduce event consequences

- Westinghouse vessels (Zion, Byron, etc.) penetrated by instrumentation tubes that travel through reactor cavity

- CE vessels (Palisades, etc.) without lower head instrumentation tubes

- All four generic vendor Severe Accident Management Guidelines (SAMGs) invoke ERVC, although extent of reliance varies in plantspecific SAMGs

- Finnish safety authorities approved ERVC as an Accident Management strategy for Loviisa plant (modified to enhance ERVC)

- Proposed for many advanced reactor designs, such as Westinghouse AP600, AP1000, and the Korean APR1400. 


\section{Various Approaches used to Investigate ERVC}

SULTAN

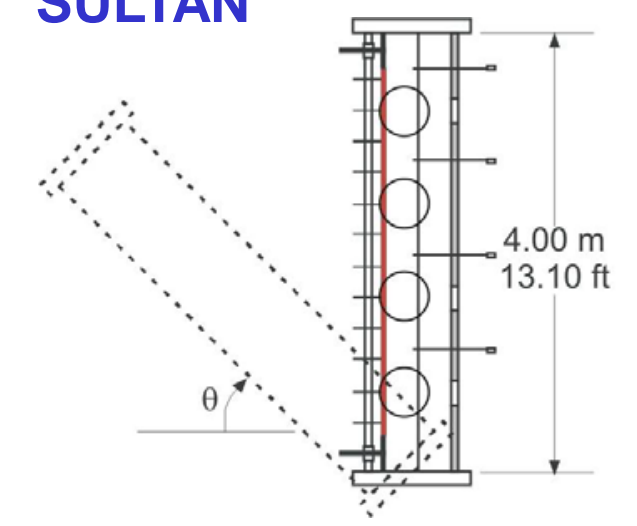

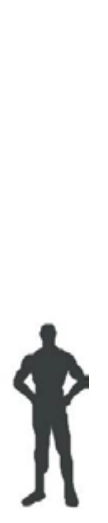

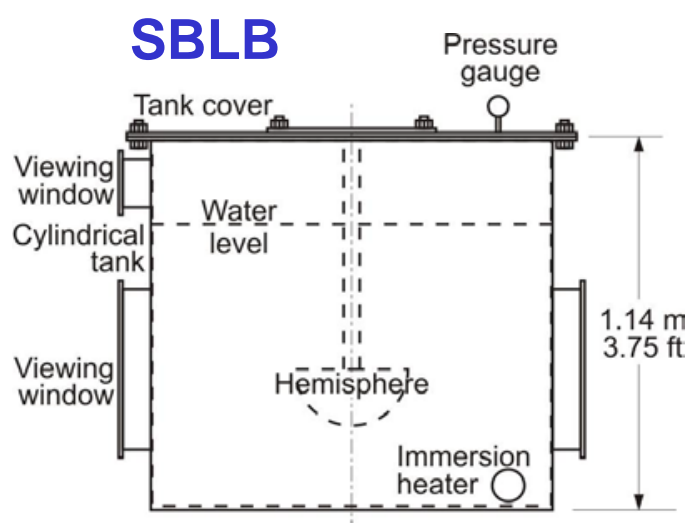

\begin{tabular}{|c|c|c|c|}
\hline Program & Description & $\begin{array}{l}\text { Subcooling } \\
\left({ }^{\circ} \mathrm{C}\right)\end{array}$ & $\begin{array}{l}\text { Critical Heat Flux } \\
\left(\mathrm{kW} / \mathrm{m}^{2}\right)\end{array}$ \\
\hline UCSB ULPU & $\begin{array}{l}\text { SS heated 2D full-scale slice } \\
{[2 \mathrm{~m}[6.6 \mathrm{~m}] \text { outer radius] }}\end{array}$ & $\begin{array}{c}0-14 \\
\left(32-57^{\circ} \mathrm{F}\right)\end{array}$ & $\begin{array}{c}\sim 500 \text { to } 1500 \\
(\sim 1.59 \mathrm{E} 5 \text { to } 4.76 \mathrm{E} 5 \\
\left.\text { Btu/hr-ft }{ }^{2}\right)\end{array}$ \\
\hline $\begin{array}{l}\text { CEA } \\
\text { SULTAN }\end{array}$ & $\begin{array}{l}\text { SS electrical heating of a flat } \\
\text { plate }[15 \mathrm{~cm}(49.2 \mathrm{ft}) \text { wide/ } \\
4 \mathrm{~m}(13 \mathrm{ft}) \text { long }]\end{array}$ & $\begin{array}{c}0-50 \\
\left(32-122{ }^{\circ} \mathrm{F}\right)\end{array}$ & $\begin{array}{c}\sim 500 \text { to } 1500 \\
(\sim 1.59 \mathrm{E} 5 \text { to } 4.76 \mathrm{E} 5 \\
\left.\text { Btu/hr-ft }{ }^{2}\right)\end{array}$ \\
\hline $\begin{array}{l}\text { Penn State } \\
\text { SBLB }\end{array}$ & $\begin{array}{l}\text { Quench and SS heated } \\
\text { hemisphere [0.31 } \mathrm{m}(1.0 \mathrm{ft}) \mathrm{OD}]\end{array}$ & $\begin{array}{c}0-10 \\
\left(32-50^{\circ} \mathrm{F}\right)\end{array}$ & $\begin{array}{c}\sim 400 \text { to } 2000 \\
(\sim 1.27 \mathrm{E} 5 \text { to } 6.34 \mathrm{E} 5 \\
\left.\text { Btu/hr-ft }{ }^{2}\right)\end{array}$ \\
\hline
\end{tabular}

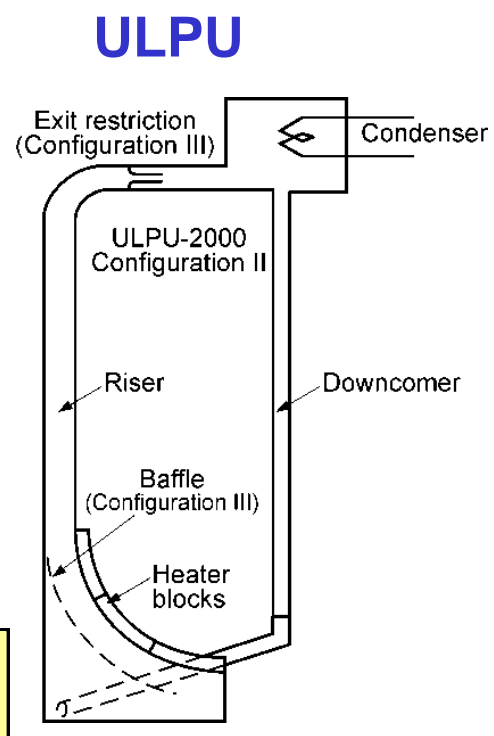




\section{Mitigating High Pressure Scenarios}

- Progression of core damage under high pressure presents unique challenges

- Steam generator tube rupture (bype risk)

- Hot leg/surgeline failure

- Safety valve failure to close

- RCP seal leakage

- High pressure melt ejection

- Direct containment heating

- Mechanisms to prevent by design

- Primary depressurization system

- Lower core power density

- Minimize head penetrations

- Minimize pathways to upper containment

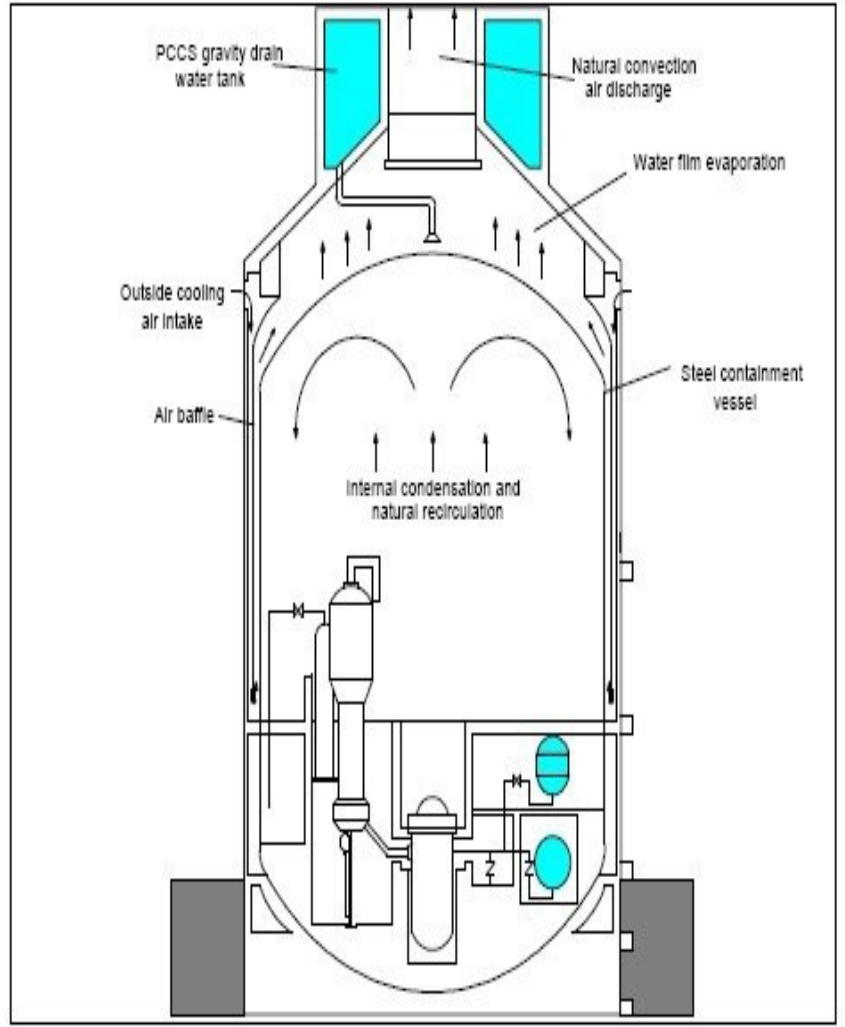

AP1000 Passive containment cooling system 


\section{SCDAP/RELAP5 calculations suggest induced RCS piping failure prior to significant core relocation.}

- Calculations performed for wide spectrum of SBLOCAs assuming unflawed steam generator tubes

- Wide spectrum of plants (Zion, Surry, Calvert Cliffs, Arkansas Nuclear One) analyzed

- Results suggest

- natural circulation promotes hot leg or surge line failure before core relocation

- RCS depressurizes and accumulators discharge prior to vessel failure

- small amounts of steel and zirconium relocate

- $\mathrm{H}_{2}$ generation consistent with $20-60 \% \mathrm{Zr}$ oxidation 


\section{Summary}

- External Vessel Reactor Cooling (ERVC) may prevent vessel failure

- Plant-specific evaluations needed to assure timing of flooding, sufficient water ingress, and steam egress.

- Methods available to enhance ERVC.

- Several RCS depressurization mechanisms offer potential for accident mitigation:

- RCP seal leakage

- Induced RCS piping failures

- Safety valve failing open

- Intentional PORV depressurization. 


\section{Case Study: AP1000}

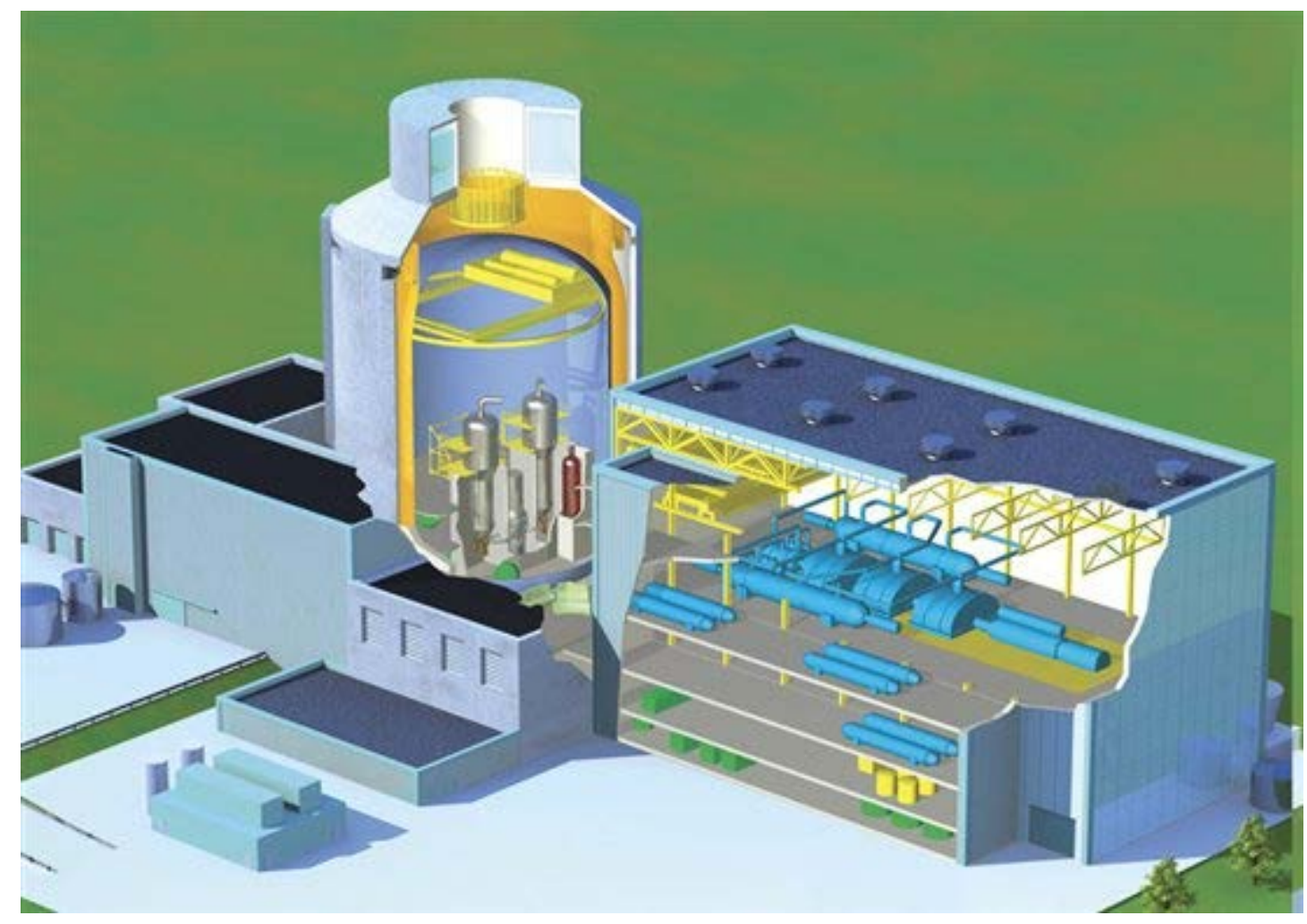

Westinghouse Advanced PWR 1000 MWe (AP1000) focused on simplicity

- Heavily reliant on passive, rather than active, safety systems

- Reduced outages and maintenance 


\section{ERVC Central to Westinghouse AP1000 Severe Accident Treatment}

The AP $1000^{\mathrm{TM}}$ is designed to mitigate a postulated severe accident such as core melt. In this event the AP1000 operator can flood the reactor cavity space immediately surrounding the reactor vessel with water to submerge the reactor vessel. The cooling is sufficient to prevent molten core debris in the lower head from melting the steel vessel wall and spilling into the containment. These water storage tanks hold enough water to cool the containment vessel for seventy two hours. 


\section{AP1000 Relies on Design Simplicity and Passive Cooling}

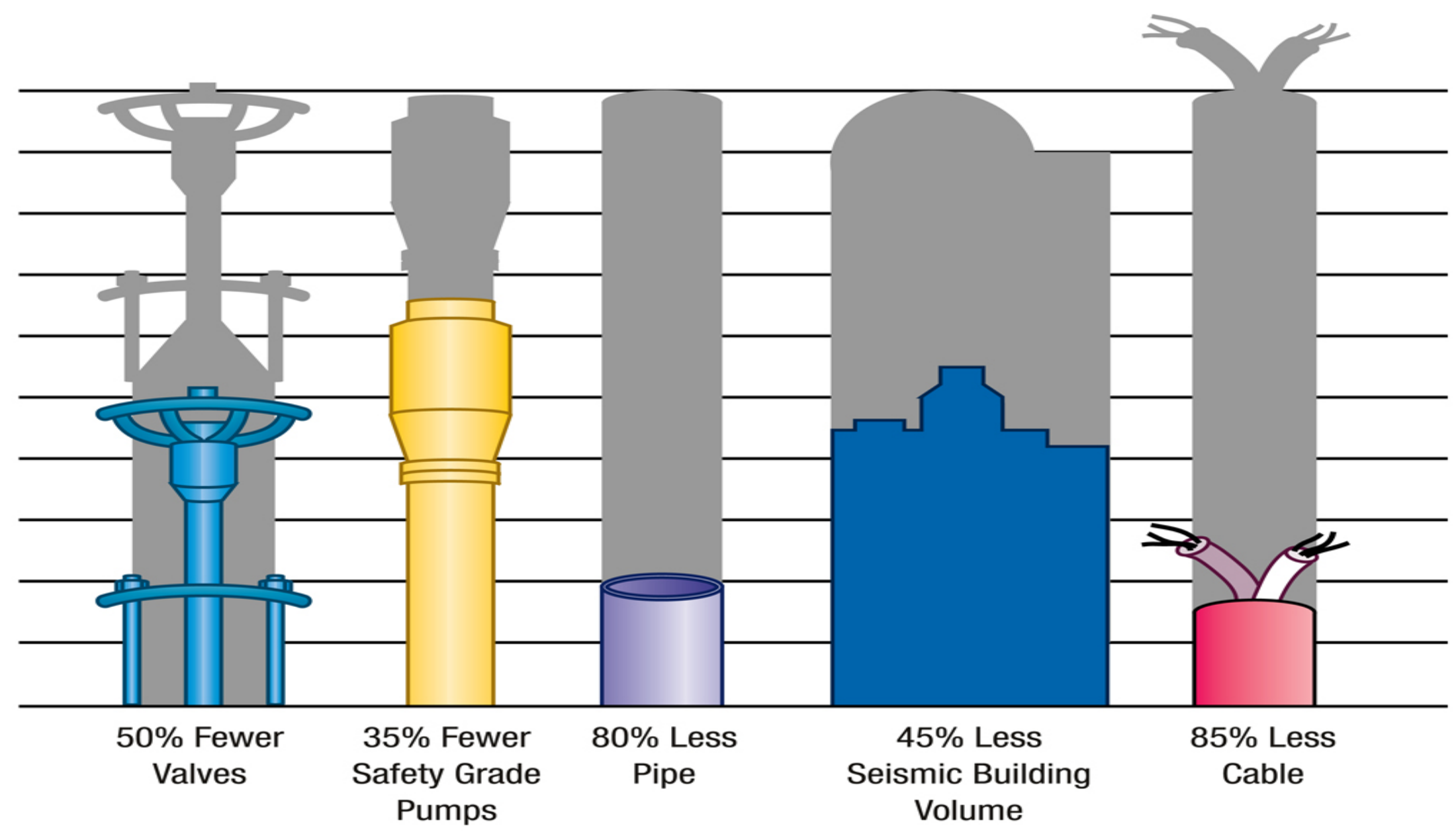




\section{Study Questions}

- What key parameters may influence vessel integrity during a severe accident?

- Why is vessel failure mode and timing important in assessing the risk associated with an accident sequence?

- Name several vessel failure modes.

- Name two mechanisms for RCS depressurization.

- Describe ERVC and factors that may influence its success.

- Draw several possible configurations for relocated core materials. Show where peak heat fluxes will occur and describe why they will occur at these locations. 


\section{References}

\section{In-Vessel Steam Explosion}

- S. Basu and T. Ginsberg, A Reassessment of the Potential for an Alpha-Model Containment Failure and a Review of the Current Understanding of Broader Fuel-Coolant Interaction Issues, NUREG1524, 1995.

- OECD Nuclear Energy Agency and Center for Risk Studies and Safety (UCSB), Proceedings of the CSNI Specialists Meeting on Fuel-Coolant Interactions, NUREG/CP-0127 (NEA/CSNI/R(93)8), January 1993.

- M. L. Corradini, "VAPOR Explosions: A Review of Experiments for Accident Analysis," Nuclear Safety, 32, No. 3, July - September 1991.

- D. F. Fletcher, "Steam Explosion Triggering: A Review of Theoretical and Experimental Investigations," Nuclear Engineering and Design, 155, 1995.

- J. H. Kim, et al., "A Study on Intermediate Scale Steam Explosion Experiments with Zirconia and Corium Melts," Transactions of the International Congress on Advanced Nuclear Power Plants (ICAPP), June 9-13, 2002, Hollywood, FL, USA 


\section{References (continued)}

\section{Vessel Failure}

- Fauske and Associates, Inc., Experiments to Address Lower Plenum Response under Severe Accident Conditions, EPRI TR-1033890V1, Project 3130-02, Final Report, April 1994.

- R. E. Henry, "Overview: Uncertainties Remaining in Severe Accident Phenomenology," OECD/NEA/CSNI Specialist Meeting on Severe Accident Management Implementation, June 12-14, 1995.

- T. Y. Chu, et al., Lower Head Failure Experiments and Analyses, NUREG/CR-5582, February 1999.

- L.L. Humphries, et al., OECD Lower Head Failure Project Final Report, OECD/NEA/CSNI/2 (2002) 27.

- B. R. Seghal, et al., "Assessment of Reactor Vessel Integrity (ARVI)," Nuclear Engineering and Design, 235 (2005) 213-232. 


\section{References (continued)}

\section{External Reactor Vessel Cooling}

- Cheung, F. B., et al., Critical Heat Flux (CHF) Phenomenon on a Downward Facing Curved Surface, NUREG/CR-6507, June 1997.

- Rougé, S., "SULTAN Test Facility for Large-Scale Vessel Coolability in Natural Convection at Low Pressure, "Nuclear Engineering and Design, 169, 1997, pp 185-195.

- Cheung, F. B., et al., Critical Heat Flux (CHF) Phenomenon on a Downward Facing Curved Surface: Effects of Thermal Insulation, NUREG/CR-5534, September 1998. 


\section{References (continued)}

\section{Debris Endstate}

- Papers presented at the OECD/NEA/CSNI Workshop on In-vessel Retention and Coolability, Garching, Germany, March 3-6, 1998.

- Papers presented at the OECD/CSNI Special Meeting on In-vessel Debris Coolability and Lower Head Integrity, Paris, France, November 1996.

- J. R. Wolf and J. L. Rempe, Integration Report, OECD-NEA-TMI-2 Vessel Investigation Project, TMI V(93) EG10, October 1993 (Also issued as NUREG/CR-6197, EGG-2734, March 1994).

- Magallon, D., "Characteristics of Corium Debris Bed Generated in Large-scale Fuel-Coolant Interaction Experiments," Nuclear Engineering and Design, 236, pp. 1998-2009, 2006. 


\section{References (continued)}

\section{RCS Depressurization - RCP Seal Leakage}

- R. G. Neve and H. W. Heiselmann, Cost/Benefit Analysis for Generic Issue 23: Reactor Coolant Pump Seal Failure, NUREG/CR-5167, April 1991. (See Appendix A, Letter from D. B. Rhodes to R. G. Neve, "Confirmation of Best Estimate Failure Models for Westinghouse RCP Seal during Station Blackout")

- T. A. Wheeler, Analysis of Core Damage Frequency: Expert Judgement Elicitation on Internal Events Issues, Volume 2, Part 1, NUREG/CR-4550 (SAND-2084), December 1990.

- T. Boardman, et al., Leak Rate Analysis of the Westinghouse Reactor Coolant Pump, NUREG/CR-4294, 85-ETEC-DRF-1714, Rockwell International Corporation, Canoga Park, CA, 1985.

- Ruger, C., BNL, Letter to Shaukat, S., K., NRC, October 5, 1995 (letter cited as reference in section of NUREG-1570 discussing seal LOCAs). 


\section{References (continued)}

\section{RCS Depressurization - Induced depressurization}

- D. L. Knudson and C. A. Dobbe, Assessment of the Potential for High Pressure Melt Ejection Resulting from a Surry Station Blackout Transient, NUREG/CR-5949, EGG-2689, Idaho National Engineering Laboratory, Idaho Falls, ID, 1993.

- M. M. Pilch, et al., The Probability of Containment Failure by Direct Containment Heating in Zion, NUREG/CR-6075, Supplement 1, December 1994.

- M. M. Pilch, et al., The Probability of Containment Failure by Direct Containment Heating in Surry, NUREG/CR-6109, May 1995.

- M. Pilch, et al., Resolution of the Direct Containment Heating Issue for all Westinghouse Plants with Large Dry Containments or Subatmospheric Containments, NUREG/CR-6338, February 1996. 


\title{
TMI Damage Implications for Fukushima and Status
}

\author{
Douglas Akers \\ Nuclear Physics \\ Idaho National Laboratory
}

$4 / 19 / 2016$ 


\section{Overview}

- TMI reactor accident core damage progression

- TMI reactor core damage and fuel relocation

- Core material melt behavior

- Relocation of fission products and core materials

- Damage to the lower head of the TMI reactor vessel

- RPV design differences between PWRs and BWRs

- Implications of the TMI accident for the Fukushima recovery

- Fukushima status

- Fukushima path forward and schedule

- Nuclear material accountability issues and TMI approach 


\section{TMI Core Damage Occurred Within 224 Minutes Including Core Relocation to RPV Lower Head}

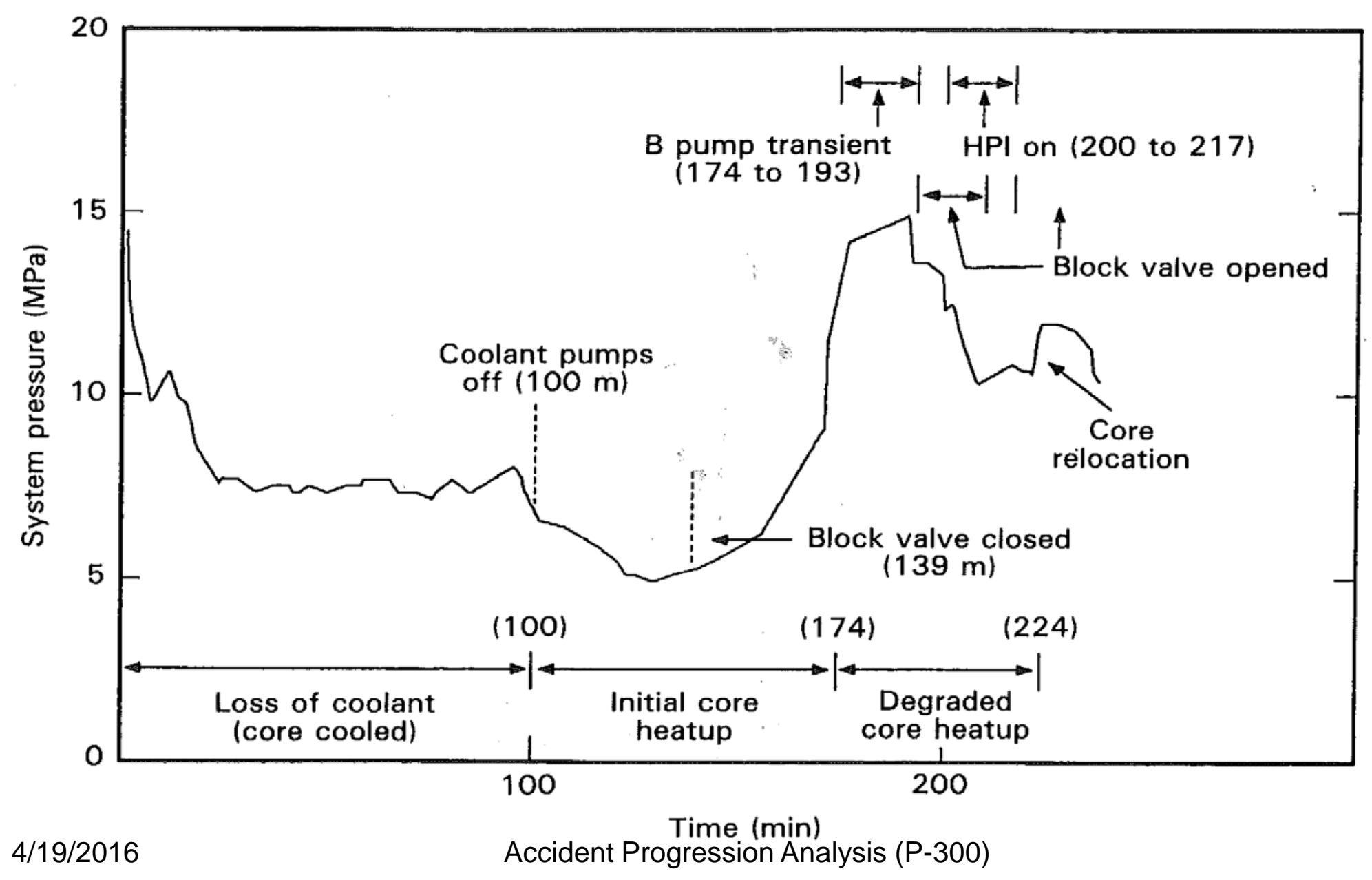




\section{Melt Behavior Defines Core Damage Progression}

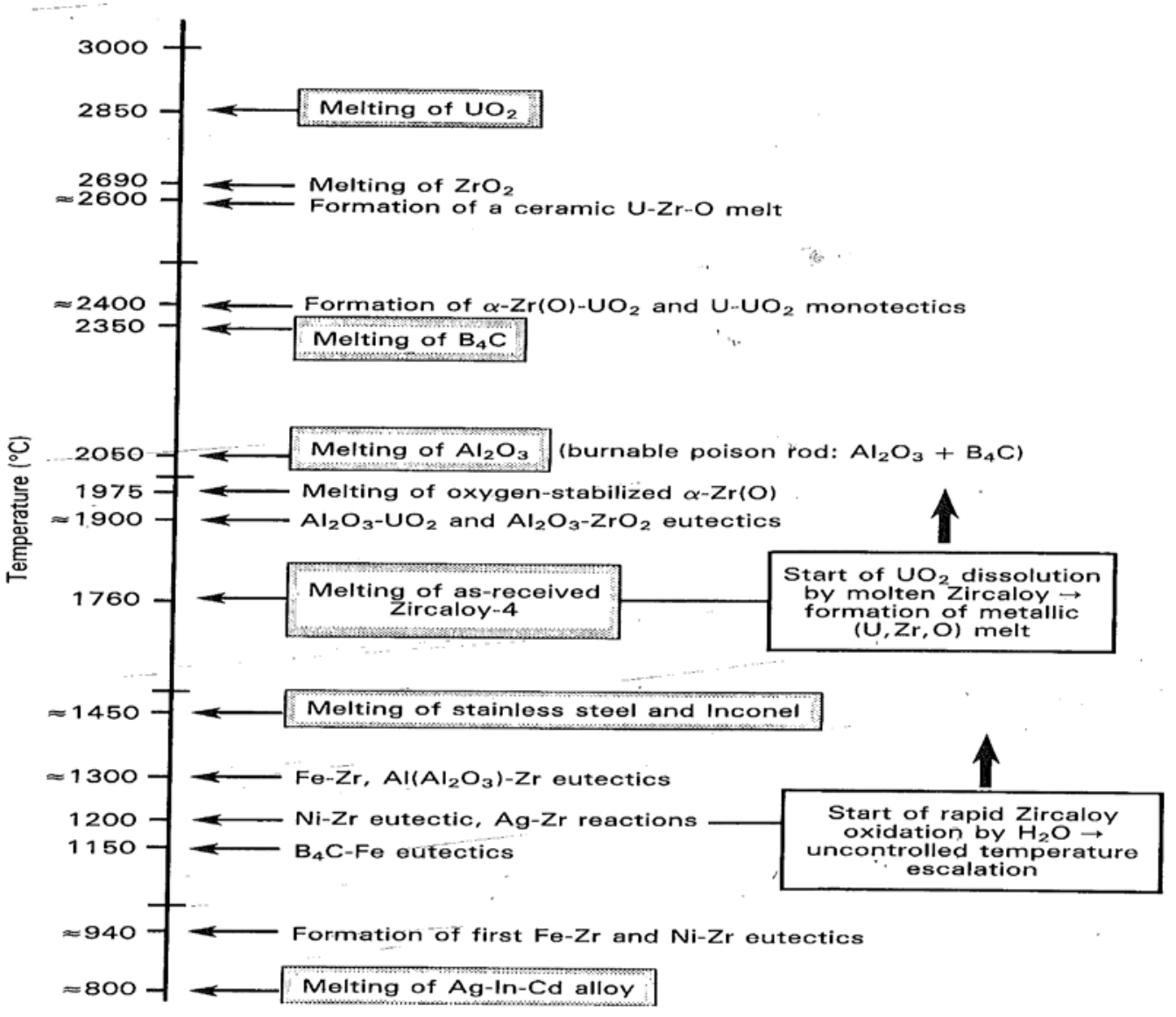




\section{Extensive Sampling and Coring Used to define Core damage and Materials/Fission Product Behaviqu rore Examinations included}

TMI-2 Core End-State Configuration

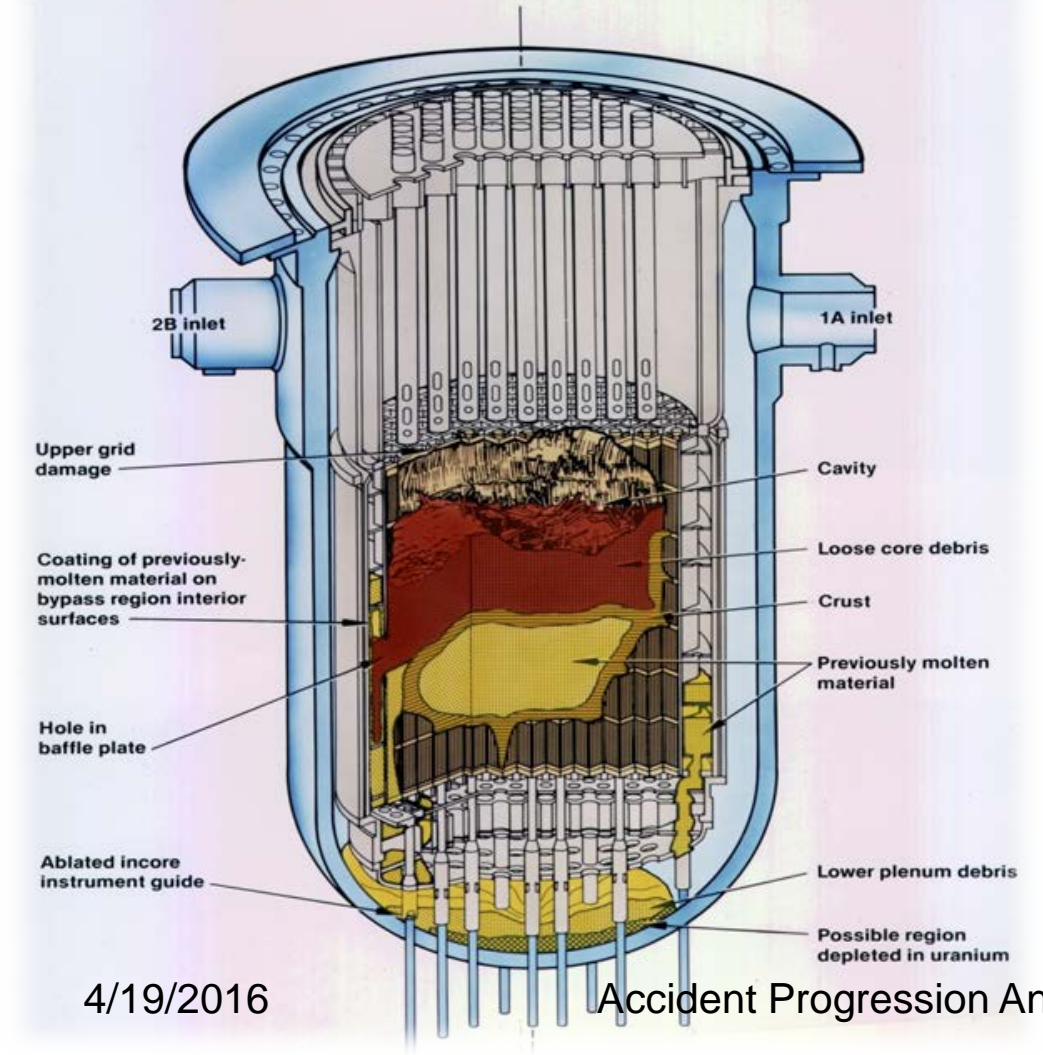

- Control rod leadscrews

- Upper RPV core debris

- Core bores

- lower RPV debris

- Fuel - $\left(\mathrm{UO}_{2}\right)$ and Zirconium Relocation

- Upper core debris - 26,000 kg

- Center core melt - 21000 kg

- Lower crust - $5400 \mathrm{~kg}$

- Partial fuel assemblies - $40000 \mathrm{~kg}$

- Core support assembly - 8900 kg

4/19/2016 


\section{Limited Damage to Reactor Pressure Vessel Above Fuel Assemblies}

Damage to Grid Above Fuel

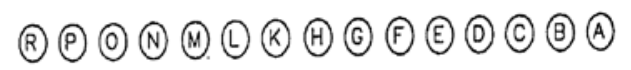

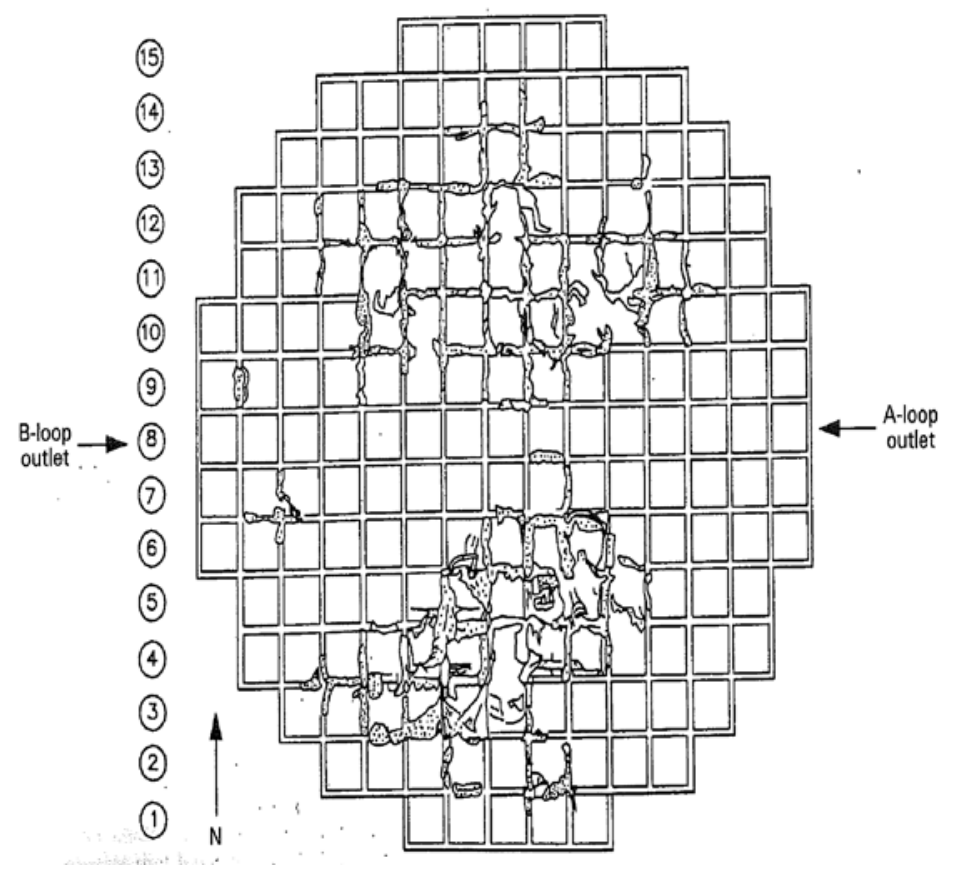

Damage to Fuel Assembly

End Fitting

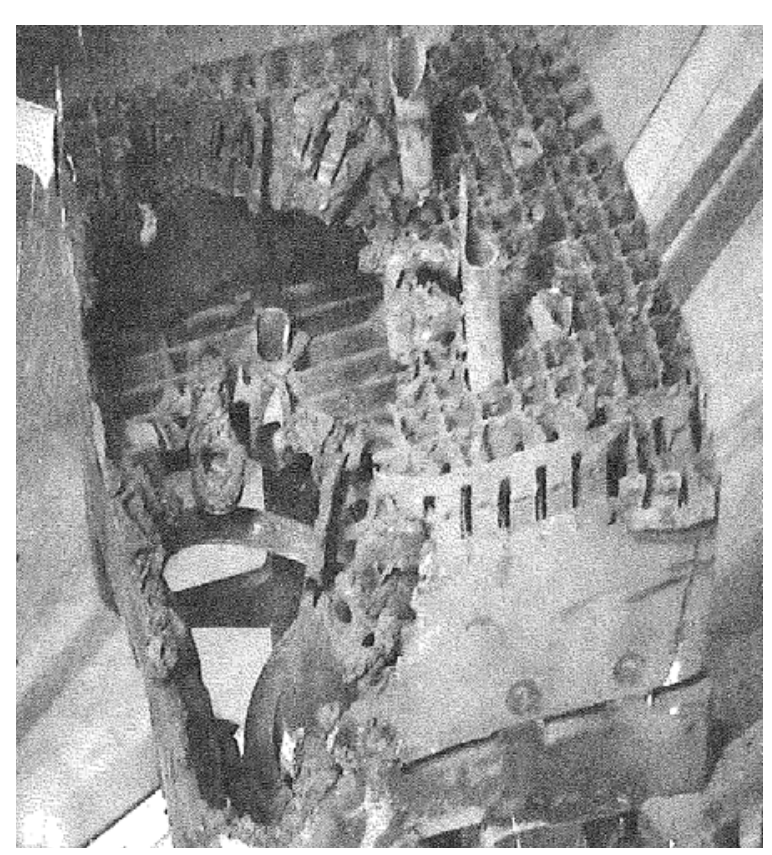




\section{$(\mathrm{U}, \mathrm{Zr}) \mathrm{O}_{2}$ Previously Melted Reactor Fuel -Highly Inert and Depleted of Volatile Fission Products}
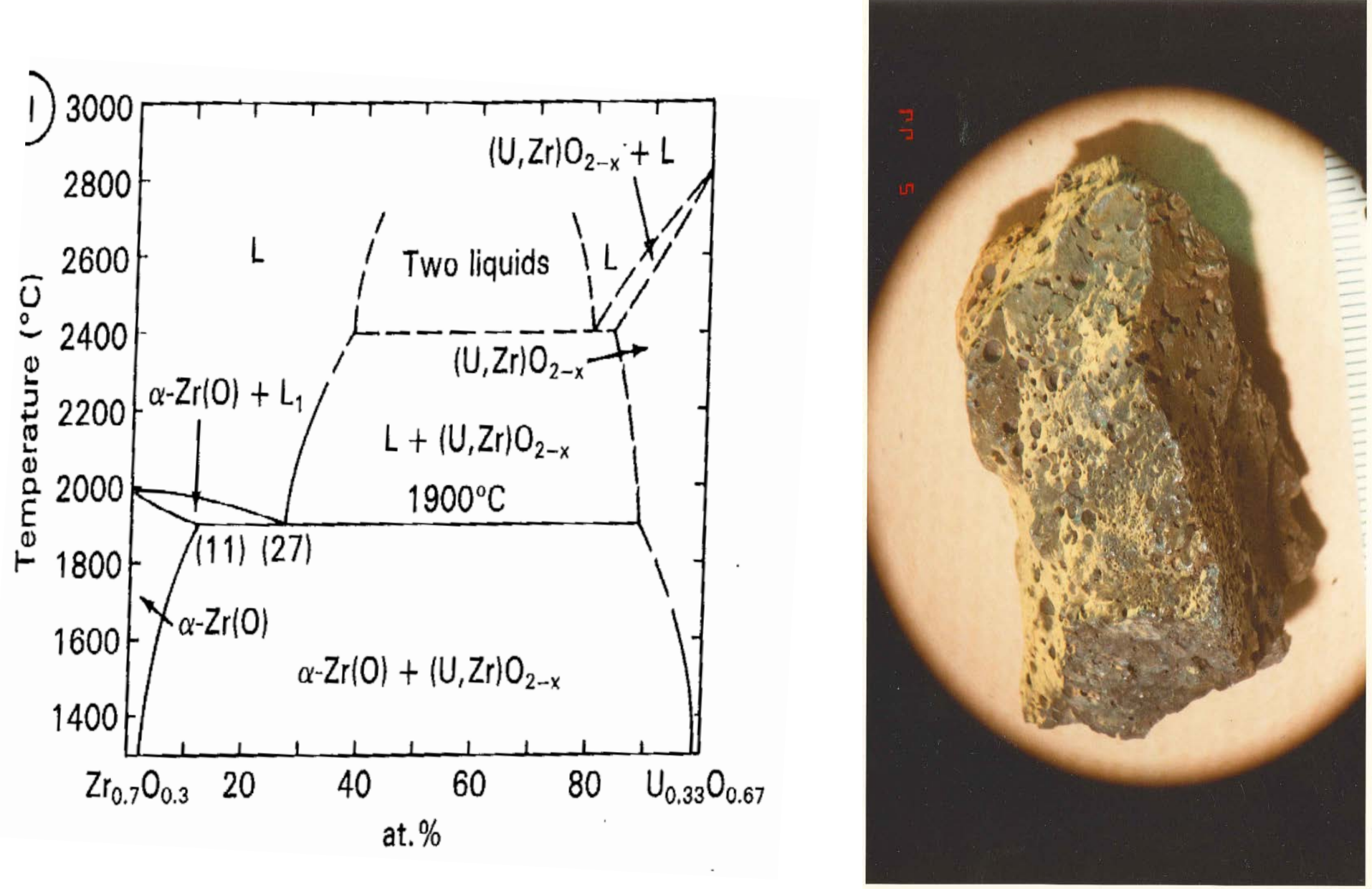


\section{$(\mathrm{U}, \mathrm{Zr}) \mathrm{O}_{2}$ Melted Reactor Fuel -Highly Inert and Similar Composition in Central Core and Lower Head}

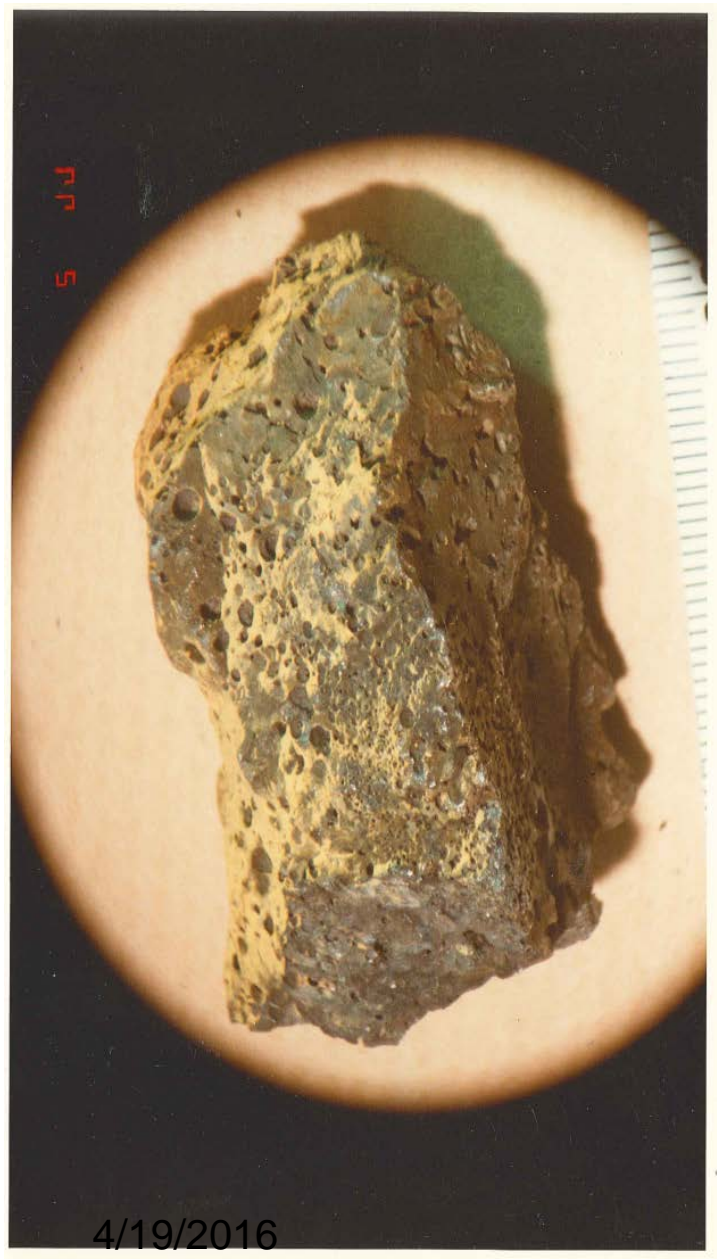

- Composition is primarily $\left(\mathrm{U}, \mathrm{ZrO}_{2}\right)$ nominally $69 \% \mathrm{U}, 26 \% \mathrm{Zr}$ and $4.6 \% \mathrm{O}$

- Density of debris ranges from $7-9 \mathrm{~g} / \mathrm{cm}^{3}$

- Nominally $<1 \%$ of volatiles inventory (e.g., ${ }^{134,137} \mathrm{Cs}$, radioiodine and noble gases)

- Dissolution of bulk specimens (>50 g) in some cases required multiple step processes and required days to complete dissolution 


\section{TMI Core Boring System (Modified Drilling System) to Break Up Debris}

Core bore head
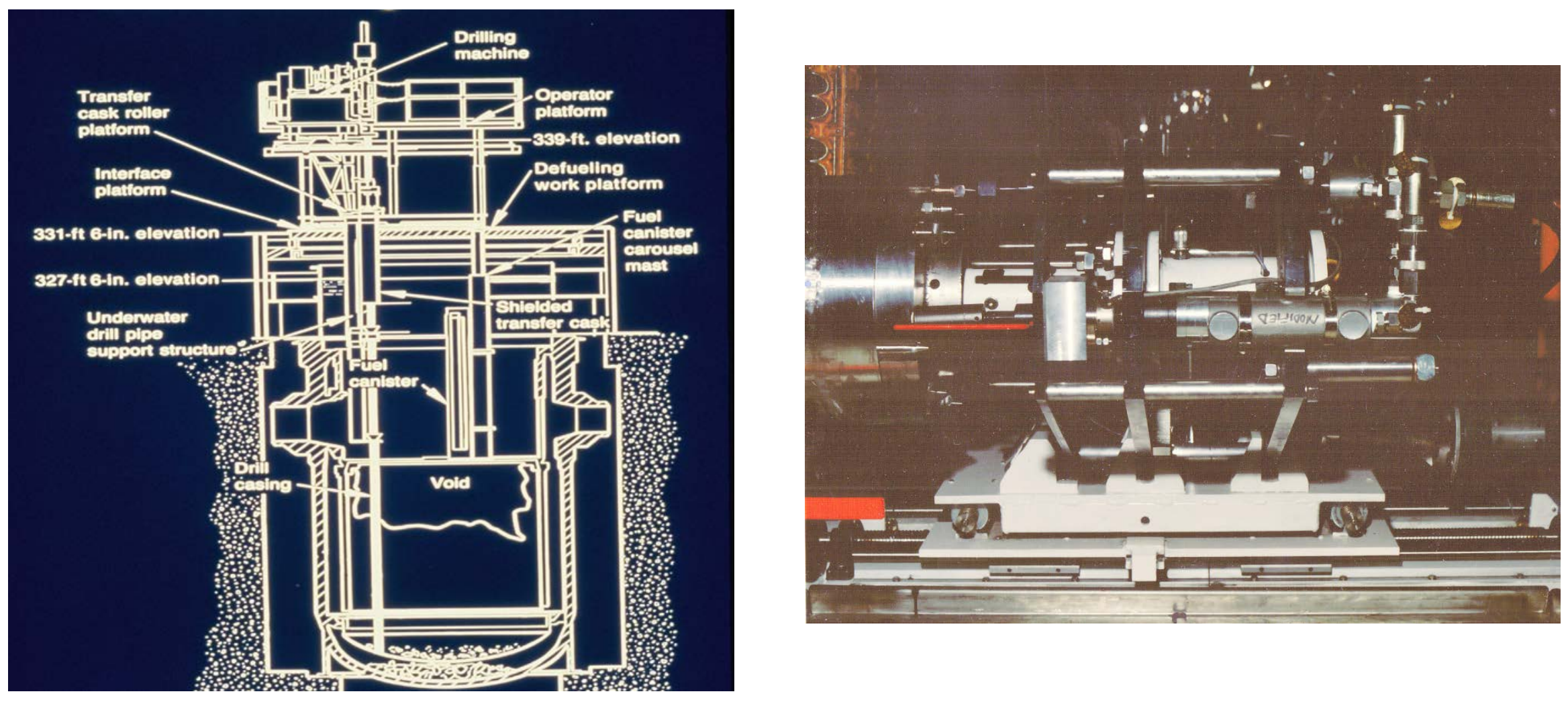


\section{Specialized Gamma Spectrometry System used to Reconstruct Fuel and Fission Product Relocation}

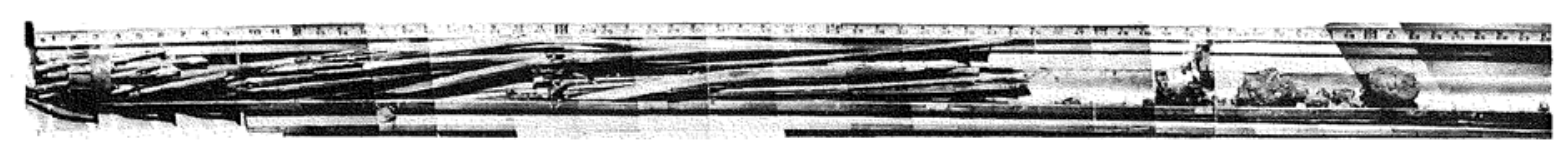

(a)
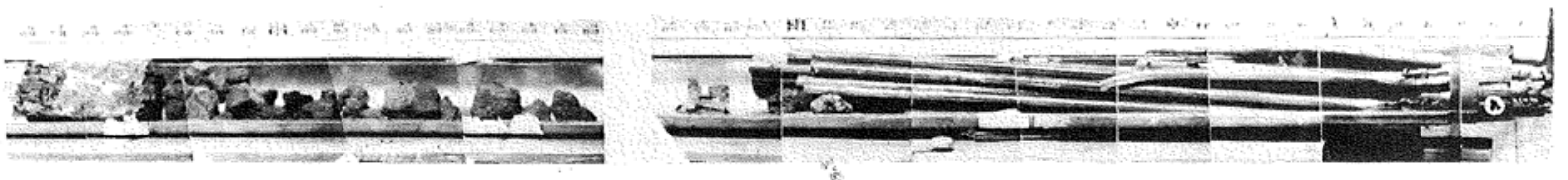

(b)

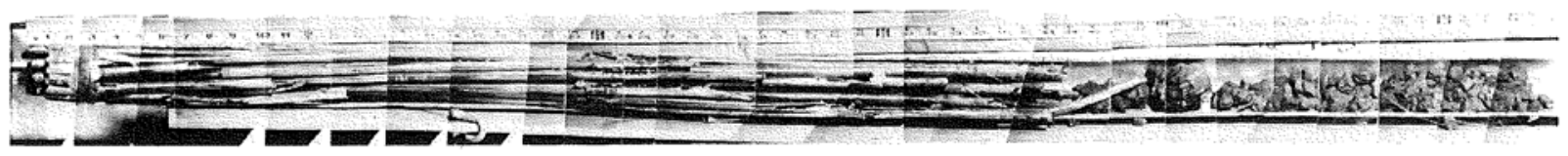

(c)

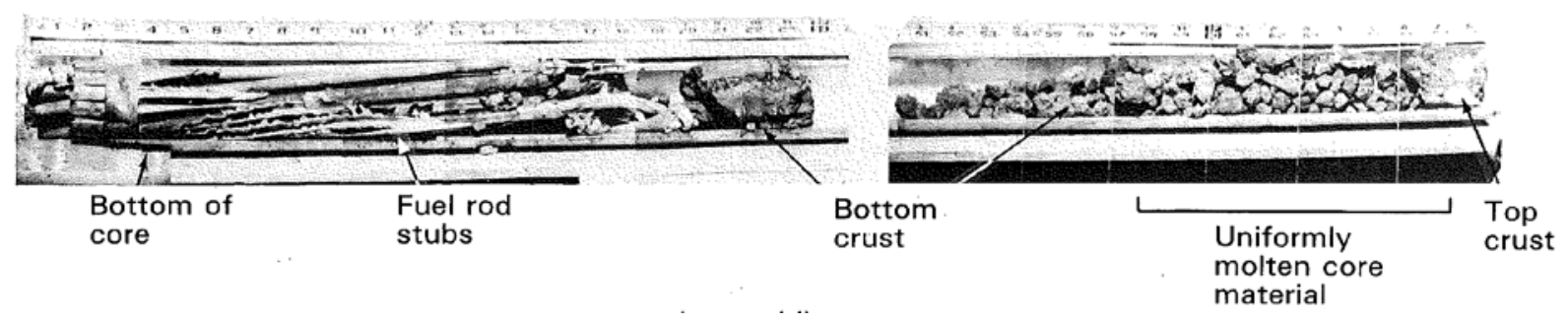




\section{Fission Product Release (e.g., ${ }^{137}$ Cs) from Prior molten Reactor Fuel Evaluated using Gamma Tomography System}

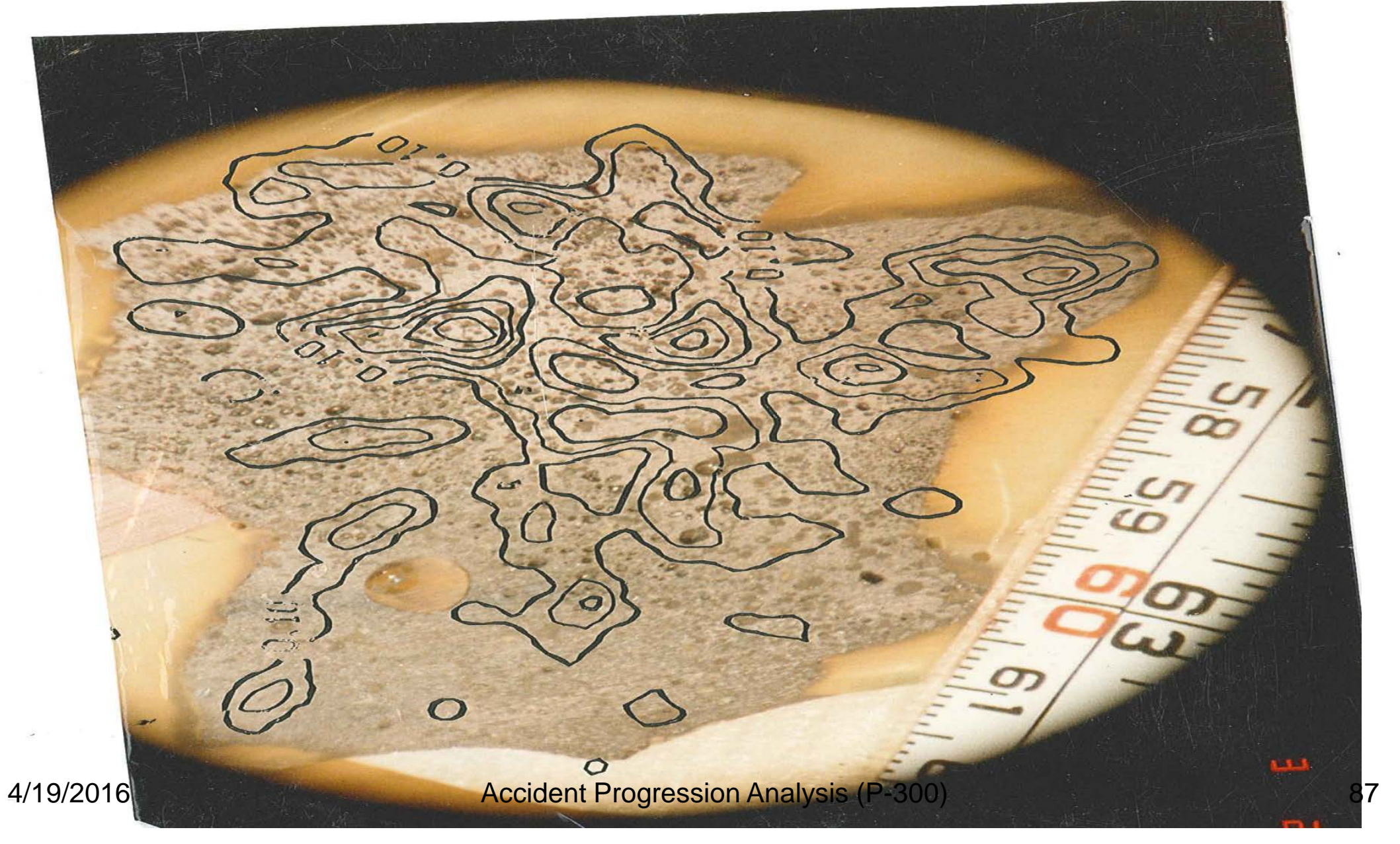




\section{Relatively Intact Fuel In Metal Layer Below Central Core}
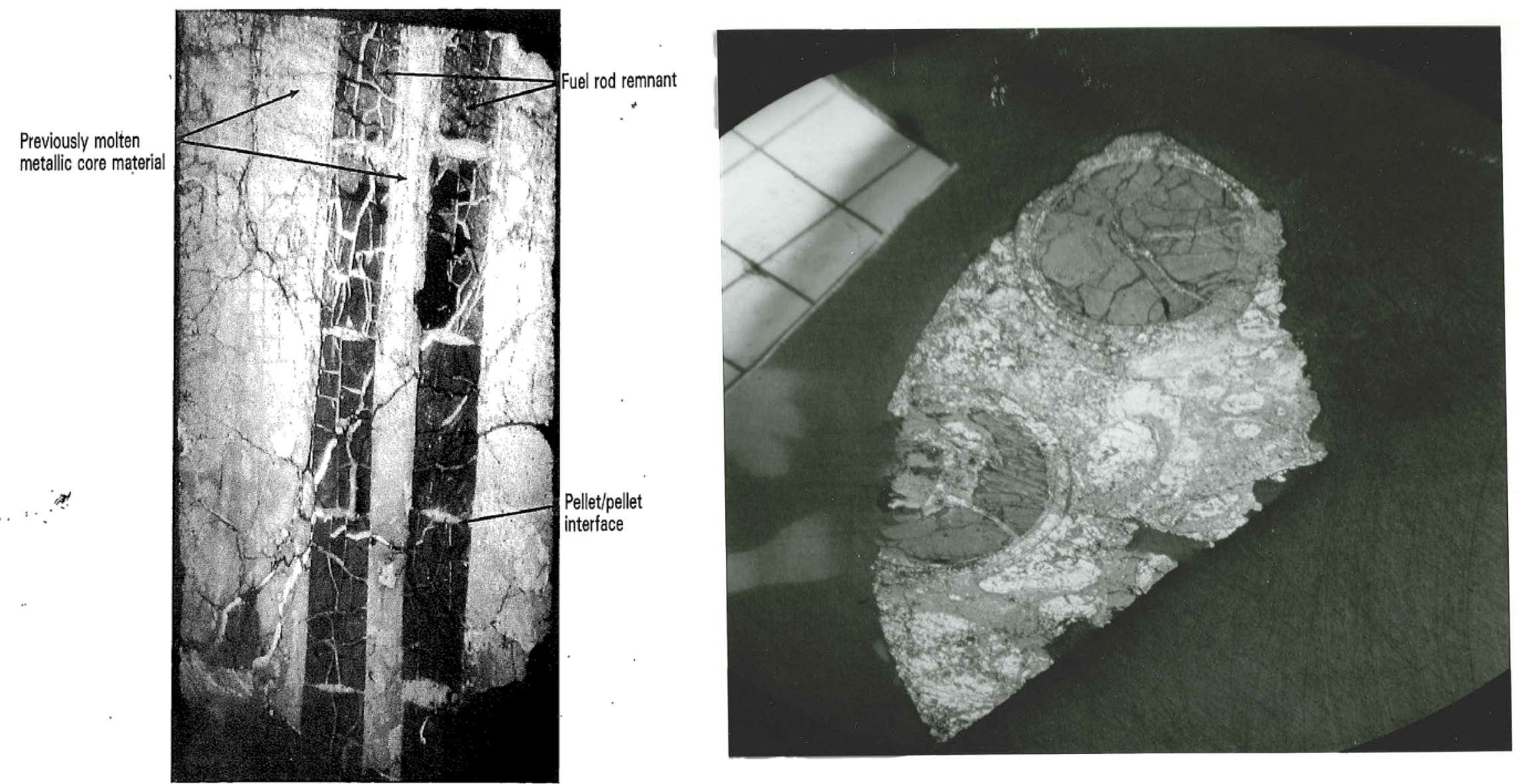


\section{$19000 \mathrm{~kg}$ of Fuel Melt On TMI RPV Lower Head}
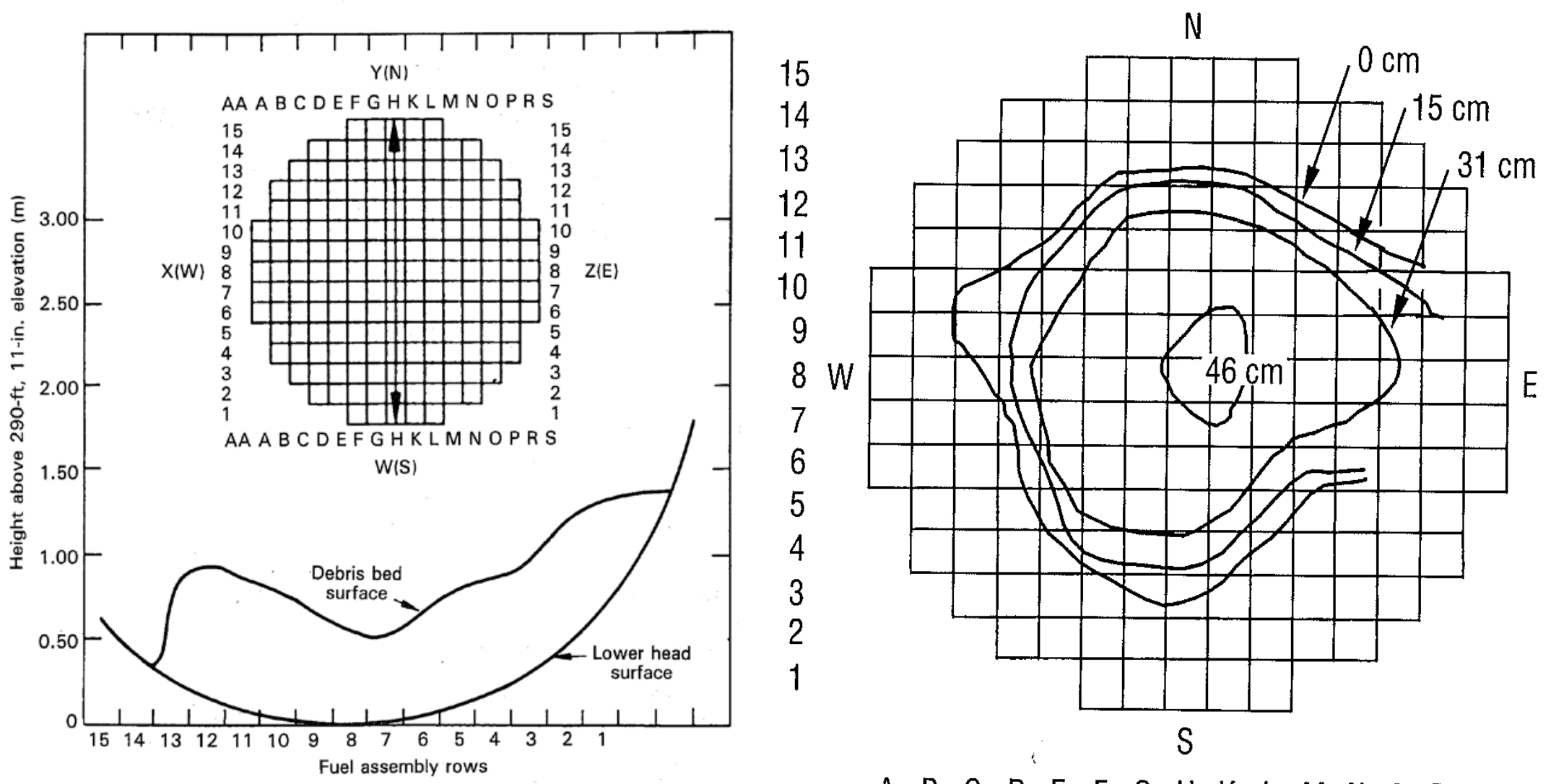

A B C D E F G HKL MNOPR

$4 / 19 / 2016$ 


\section{Burned off Incore Instrument Penetrations on Head Indicate Protection by Soldified Melt}

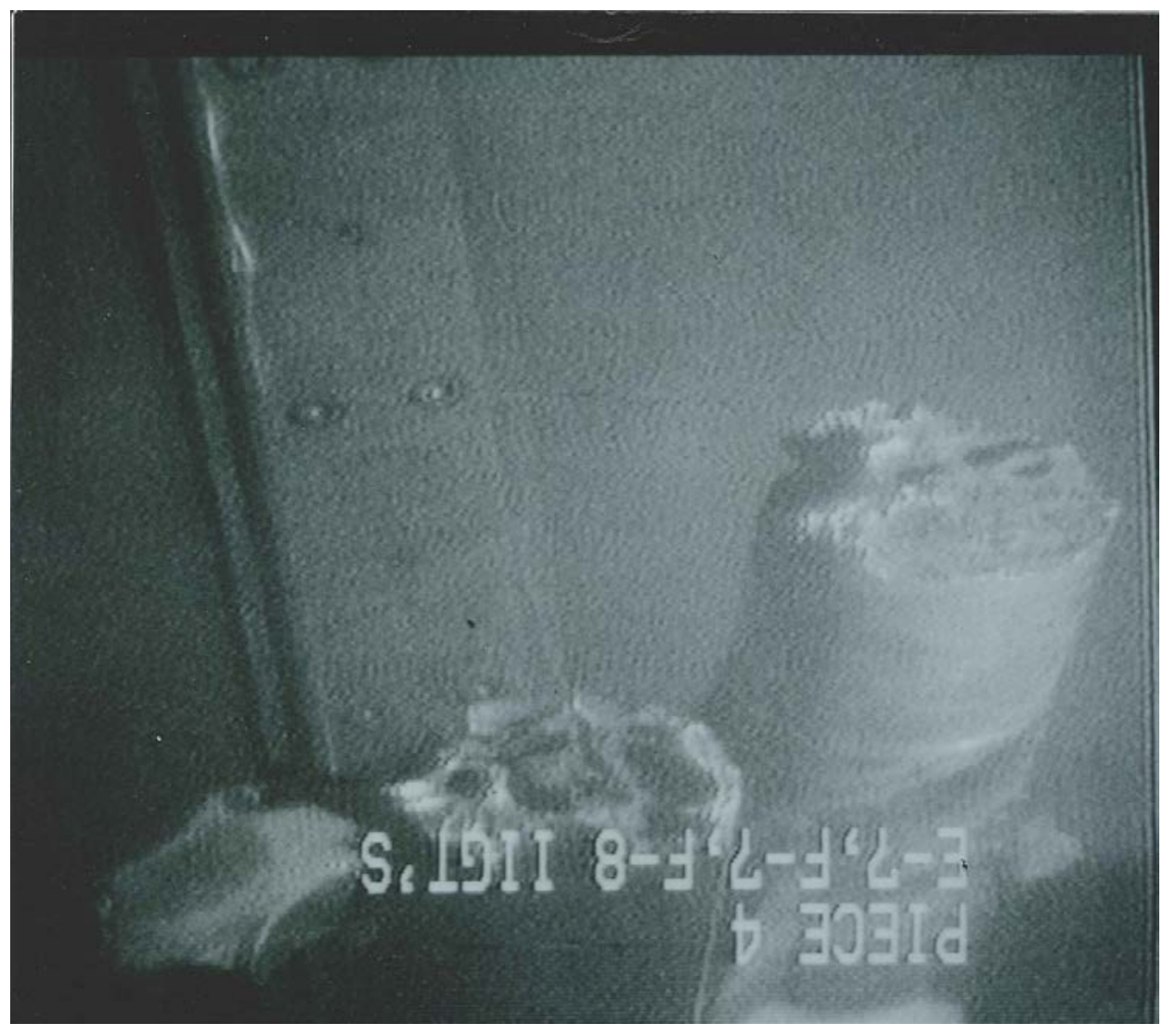




\section{TMI -2 Incore Nozzle Protected by Solidified Fuel Melt}

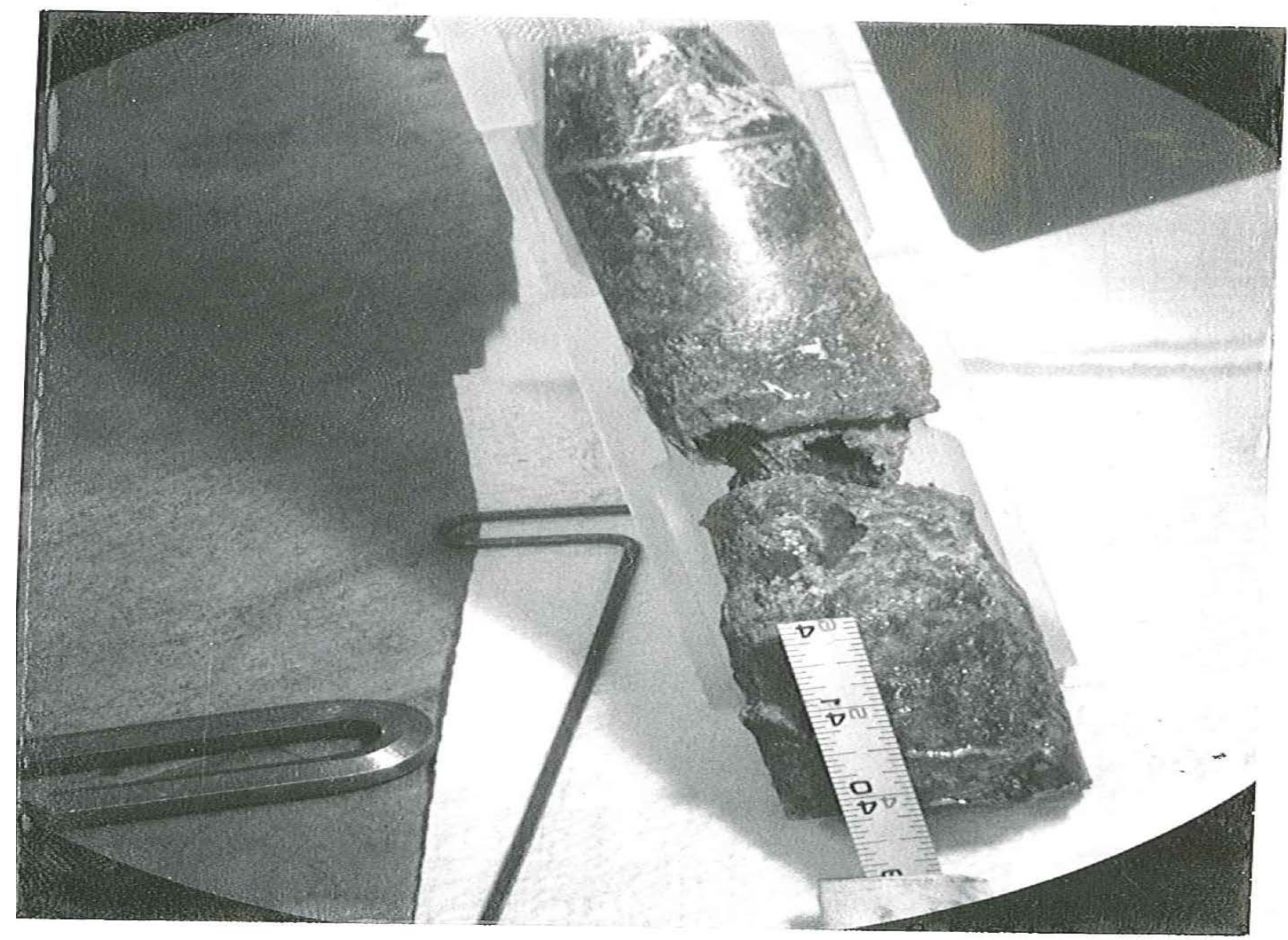




\section{Varying damage to Lower Head RPV Nozzles}

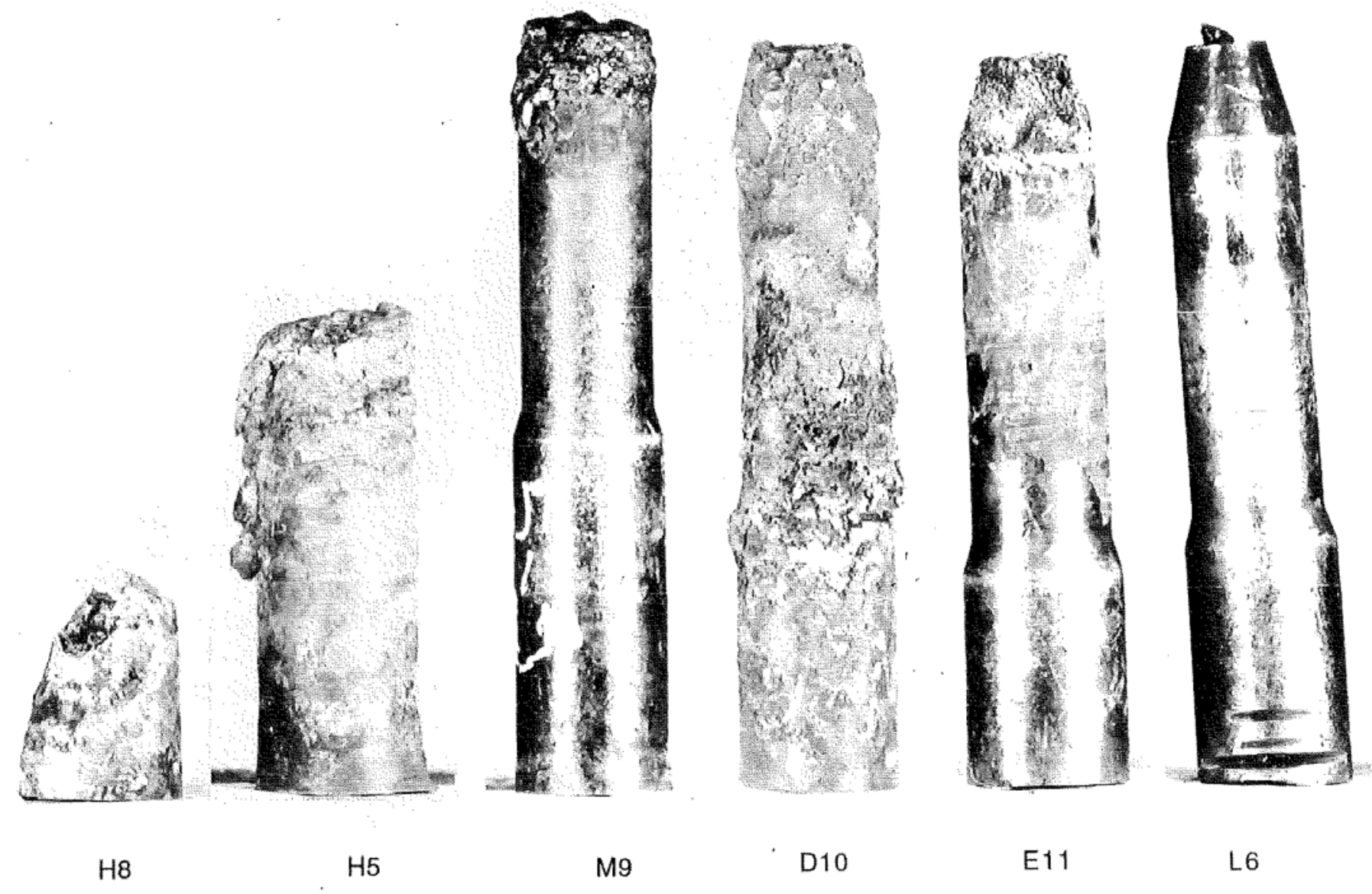




\section{Lower Head Boat Samples Indicate Max Temperature $<1100^{\circ} \mathrm{C}$}
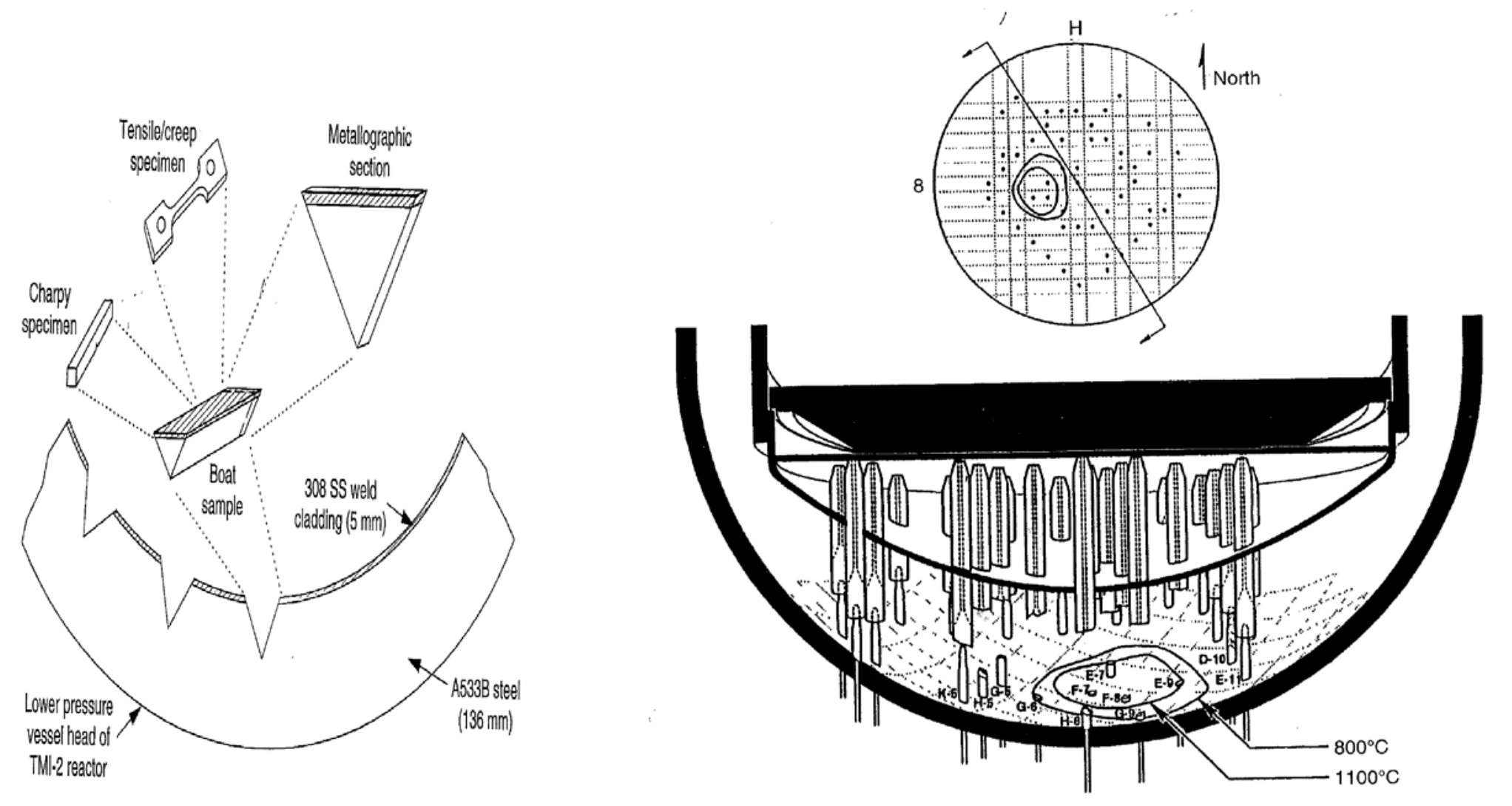


\section{BWR RPV Assembly More Massive Than PWR}

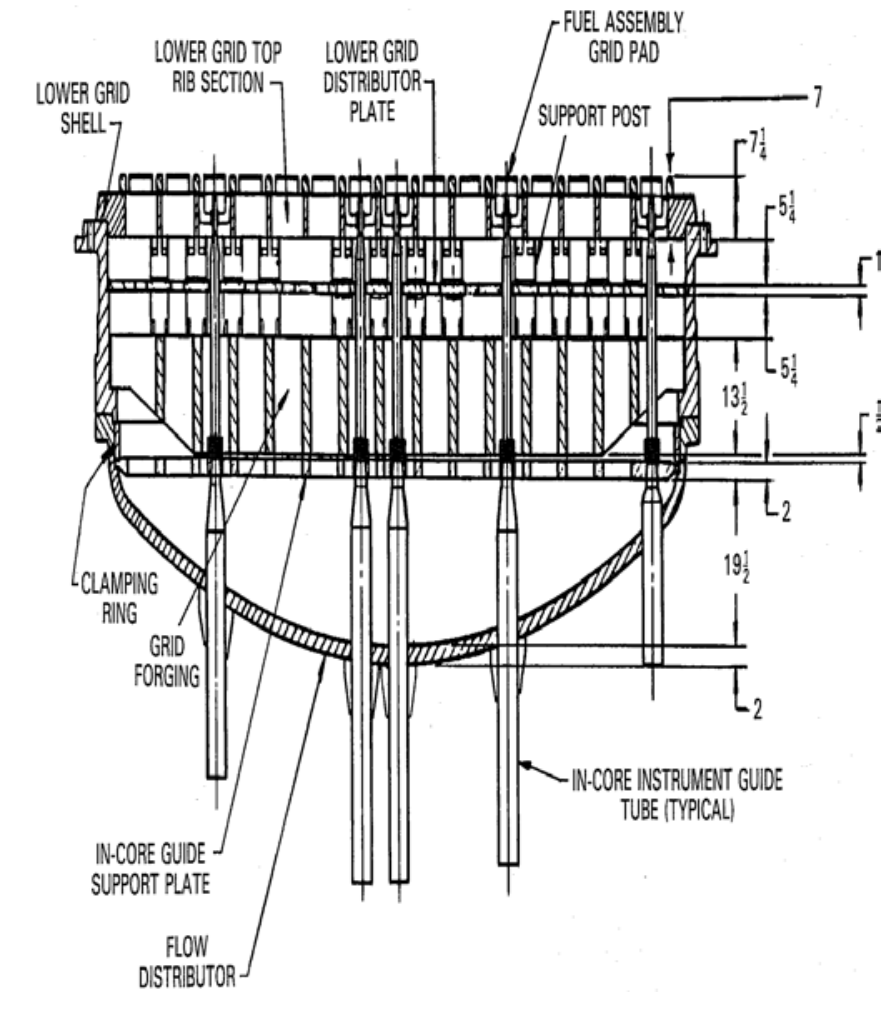

PWR Lower RPV Head

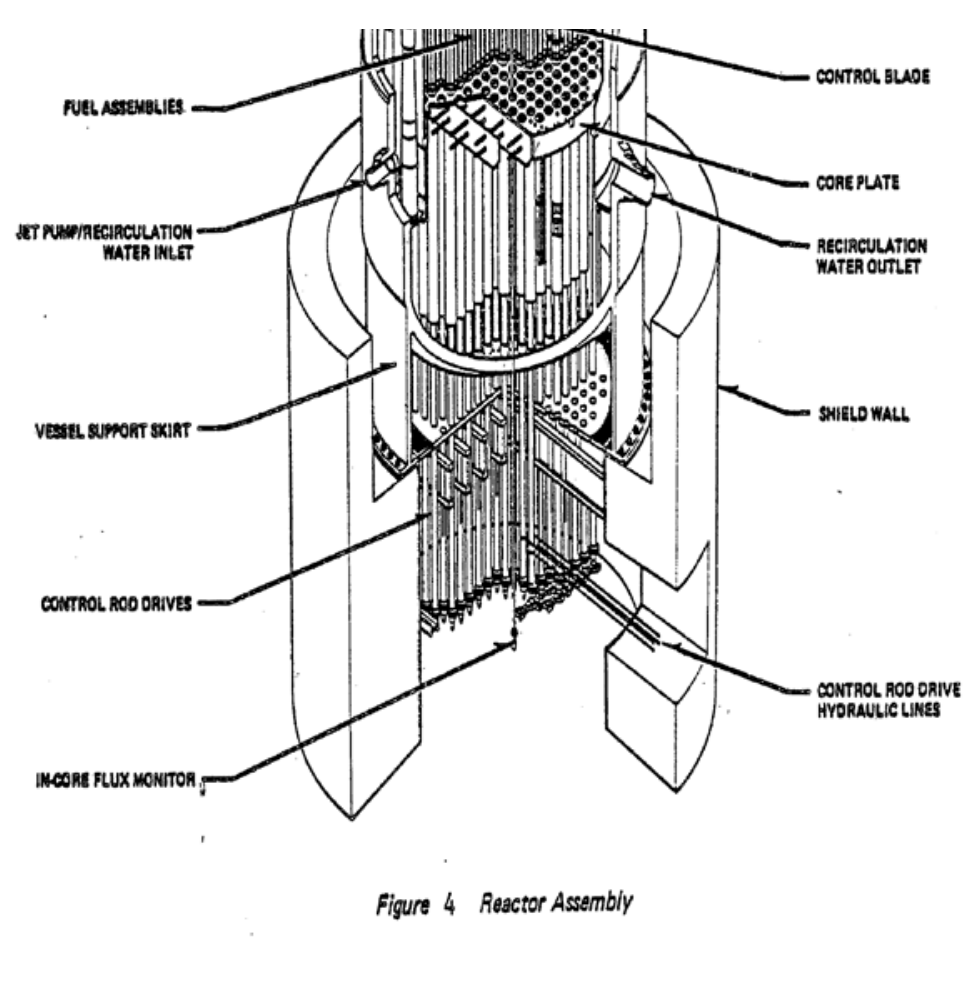

BWR Lower RPV Head
4/19/2016

Accident Progression Analysis (P-300) 


\section{Significant Relocation of Volatile Fission Products From the Reactor Vessel to the Containment with little Release to the Environment}

- Significant release of all highly volatility fission products where melting occurred - Approximately 50\% of noble gases, iodines and cesium radionuclides

- Medium volatility radionuclides ${ }^{125} \mathrm{Sb}$ and ${ }^{104} \mathrm{Ru}$ accumulated in metal layer below mid core location

- Low volatility ${ }^{144} \mathrm{Ce},{ }^{154} \mathrm{Eu}$ and ${ }^{155} \mathrm{Eu}$ fully retained in fuel

- Tc-99 releases also expected due to volatility and long half-life 


\section{${ }^{137}$ Cs Retained in RB water(47\%) and noble gases in containment (54\%)}

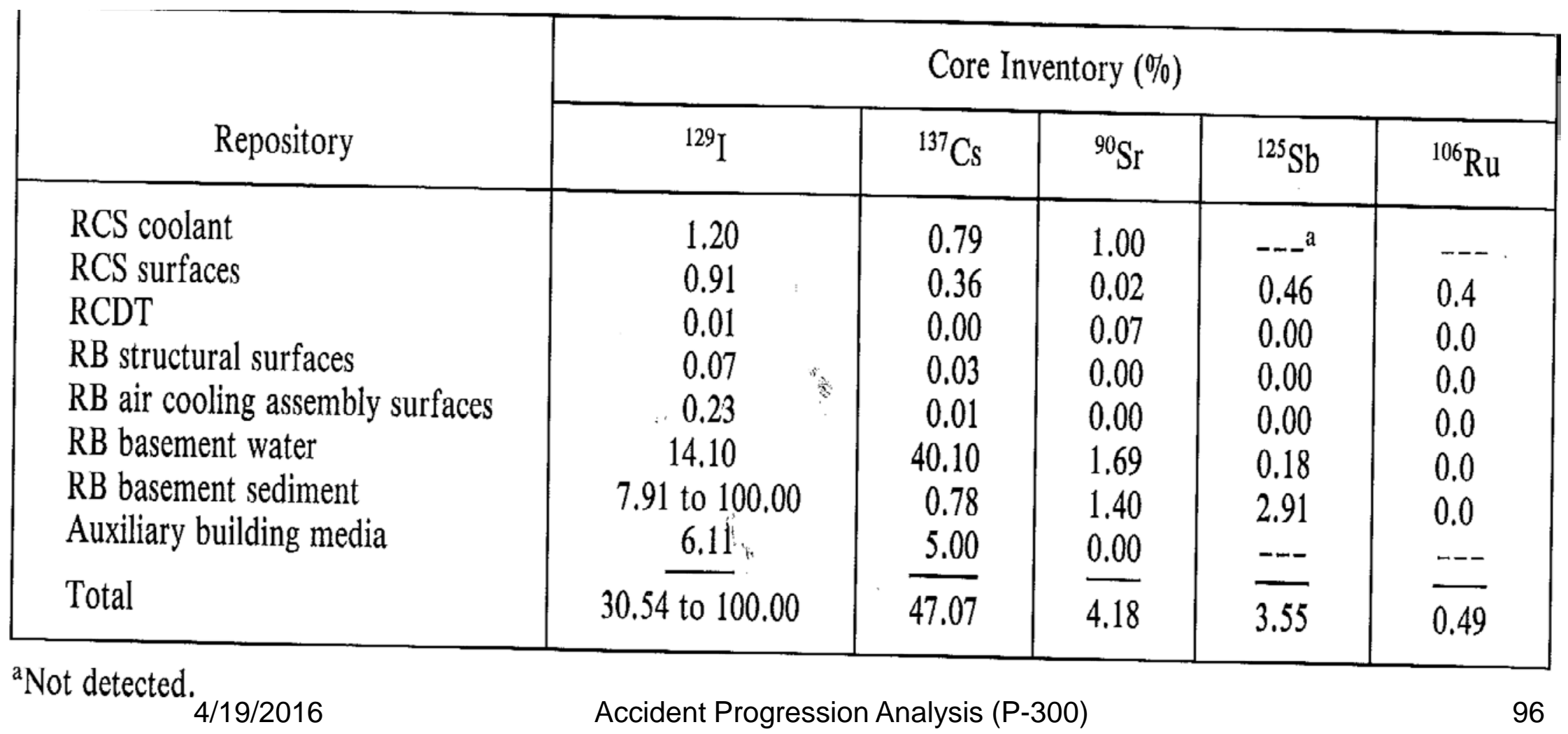




\section{Post Accident Fuel Distribution Outside the Reactor Core}

- Auxiliary and fuel handling buildings $<17 \mathrm{~kg}$

- Reactor building outside the RCS - $<75 \mathrm{~kg}$

- RCS outside the RV - $<133 \mathrm{~kg}$

- Primarily steam generator tube sheet

- Reactor vessel following defueling $<900 \mathrm{~kg}$

- Several techniques used for post accident defueling assessment

- Visual examination estimate $630 \mathrm{~kg}$

- Passive neutron measurement - $1332 \mathrm{~kg}$ 


\section{Recent View of Fukushima Daiichi (Units 1 to 4)}

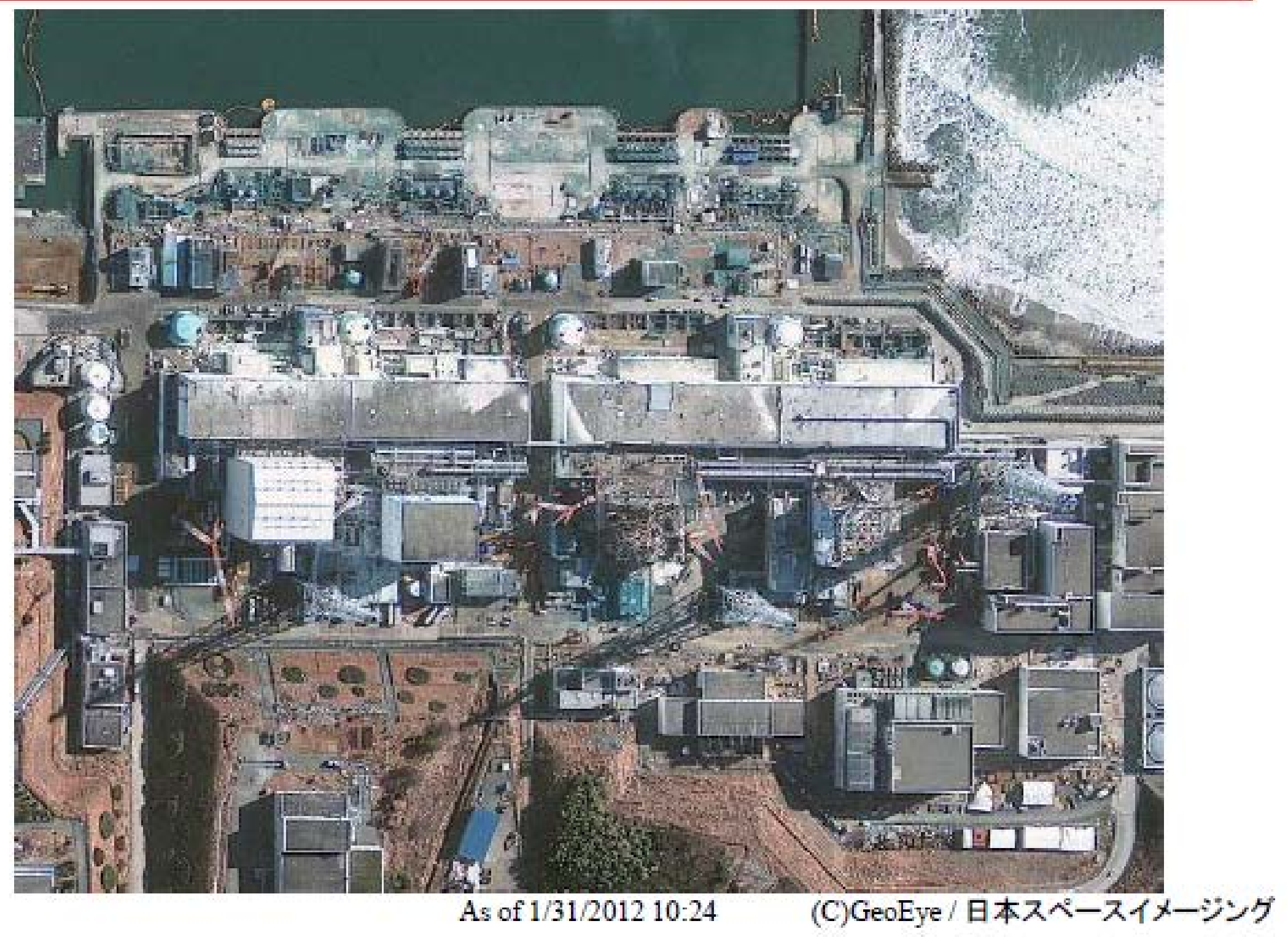




\section{Unit Specifications}

\begin{tabular}{|l|l|l|l|l|l|}
\hline Unit & $\begin{array}{l}\text { Output } \\
\text { (MW) }\end{array}$ & $\begin{array}{l}\text { Start of } \\
\text { Operation }\end{array}$ & $\begin{array}{l}\text { Reactor } \\
\text { Type }\end{array}$ & $\begin{array}{l}\text { Containment } \\
\text { Model }\end{array}$ & $\begin{array}{l}\text { General } \\
\text { Contractor }\end{array}$ \\
\hline 1 & 460 & $3 / 26 / 1971$ & BWR-3 & Mark I & GE \\
\hline 2 & 784 & $7 / 18 / 1974$ & BWR-4 & Mark I & $\begin{array}{l}\text { GE \& } \\
\text { Toshiba }\end{array}$ \\
\hline 3 & 784 & $3 / 27 / 1976$ & BWR-4 & Mark I & Toshiba \\
\hline 4 & 784 & $10 / 12 / 1978$ & BWR-4 & Mark I & Hitachi \\
\hline 5 & 784 & $4 / 18 / 1978$ & BWR-4 & Mark I & Toshiba \\
\hline 6 & 1100 & $10 / 24 / 1979$ & BWR-5 & Mark II & $\begin{array}{l}\text { GE \& } \\
\text { Toshiba }\end{array}$ \\
\hline
\end{tabular}




\section{Contamination technology developm}

Challenge for development of macromolecule cesium collection material, soil exfoliation technology with solidification agent, etc.

Demonstration of areal decontamination at the model areas, totaling 221 ha in size with various components and various dose rate levels from 5 to over $100 \mathrm{mSv} / \mathrm{y}$, and decontamination technologies were carried out to provide valuable data for full scale decontamination work in the future.

Results of decontamination in Otto-zawa area in Okuma-machi

\begin{tabular}{|l|c|c|c|}
\hline & $\begin{array}{c}\text { Before } \\
\text { decontamination } \\
(\mu \mathrm{S} v / \mathrm{h})\end{array}$ & $\begin{array}{c}\text { After } \\
\text { decontamination } \\
(\mu \mathrm{S} v / \mathrm{h})\end{array}$ & $\begin{array}{c}\text { Reduction } \\
\text { rate }\end{array}$ \\
\hline Forest & 136.8 & 63.1 & $54 \%$ \\
\hline Farmland & 62.4 & 12.4 & $80 \%$ \\
\hline Housing site & 55.3 & 14.5 & $74 \%$ \\
\hline Road & 55.2 & 17.3 & $69 \%$ \\
\hline Road & 1125 & $32 \%$ \\
\hline
\end{tabular}

JAEA staff members talk face-to-face with parents and teachers, answering their questions on radiation and its health effects. 177 sessions have been held since July 2011, and a total of about 12,900 people joined.

WBC measurement for Fukushima pref. residents (A total of 18,600.persons have been measured and those who were estimated as more than $1 \mathrm{mSv}$ (a maximum of $2.8 \mathrm{mSv}$ ) are $0.07 \%$ of the whole.
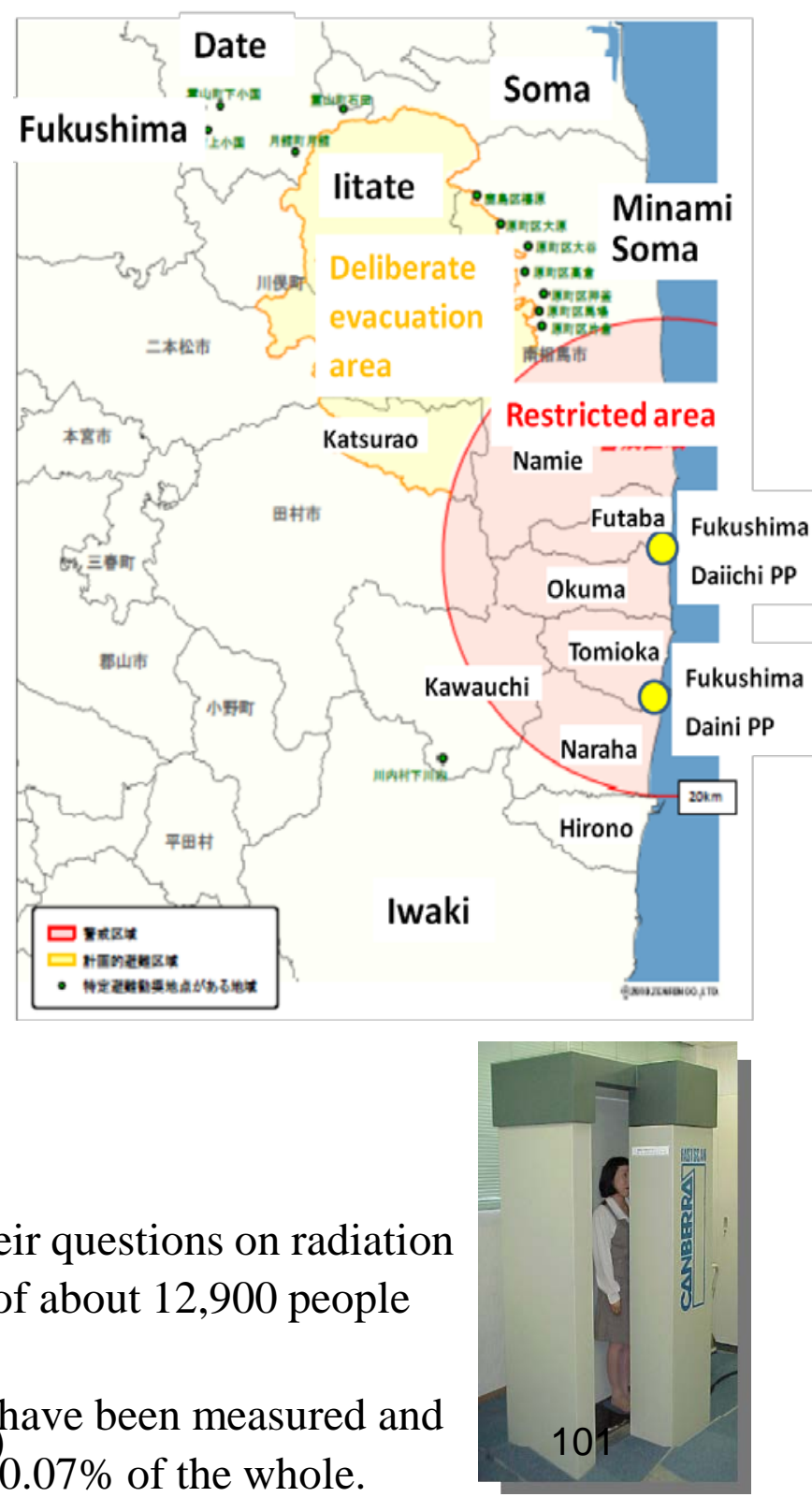

WBC 


\section{Overview of Circulating Water Cooling}

"Circulated cooling water injection" has been established to reuse the contaminated water in the buildings (accumulated water) for injection into the reactors (since 2011/6/27.)
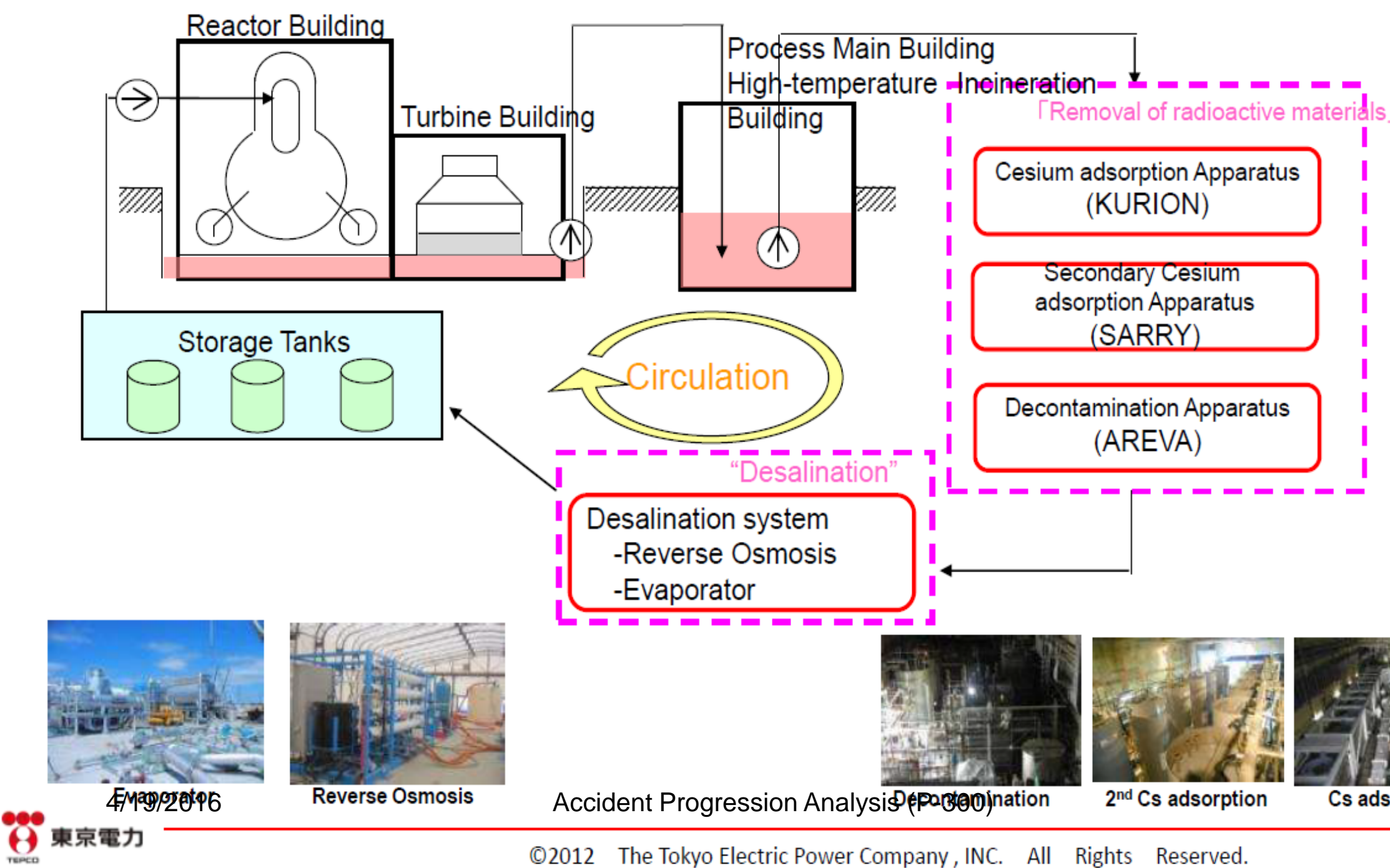

Accident Progression Analysi\$(eportegjnation
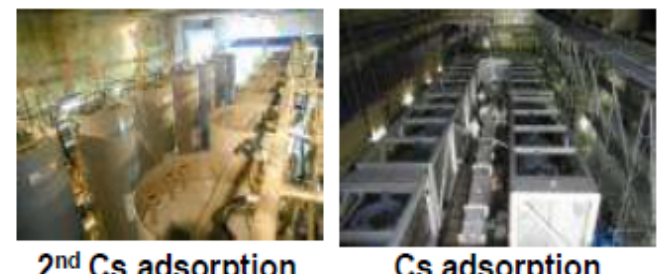

(C)2012 The Tokyo Electric Power Company, INC. All Rights Reserved. 


\section{Photos inside of PCV, Unit2 on Jan. $20^{\text {th }}$}
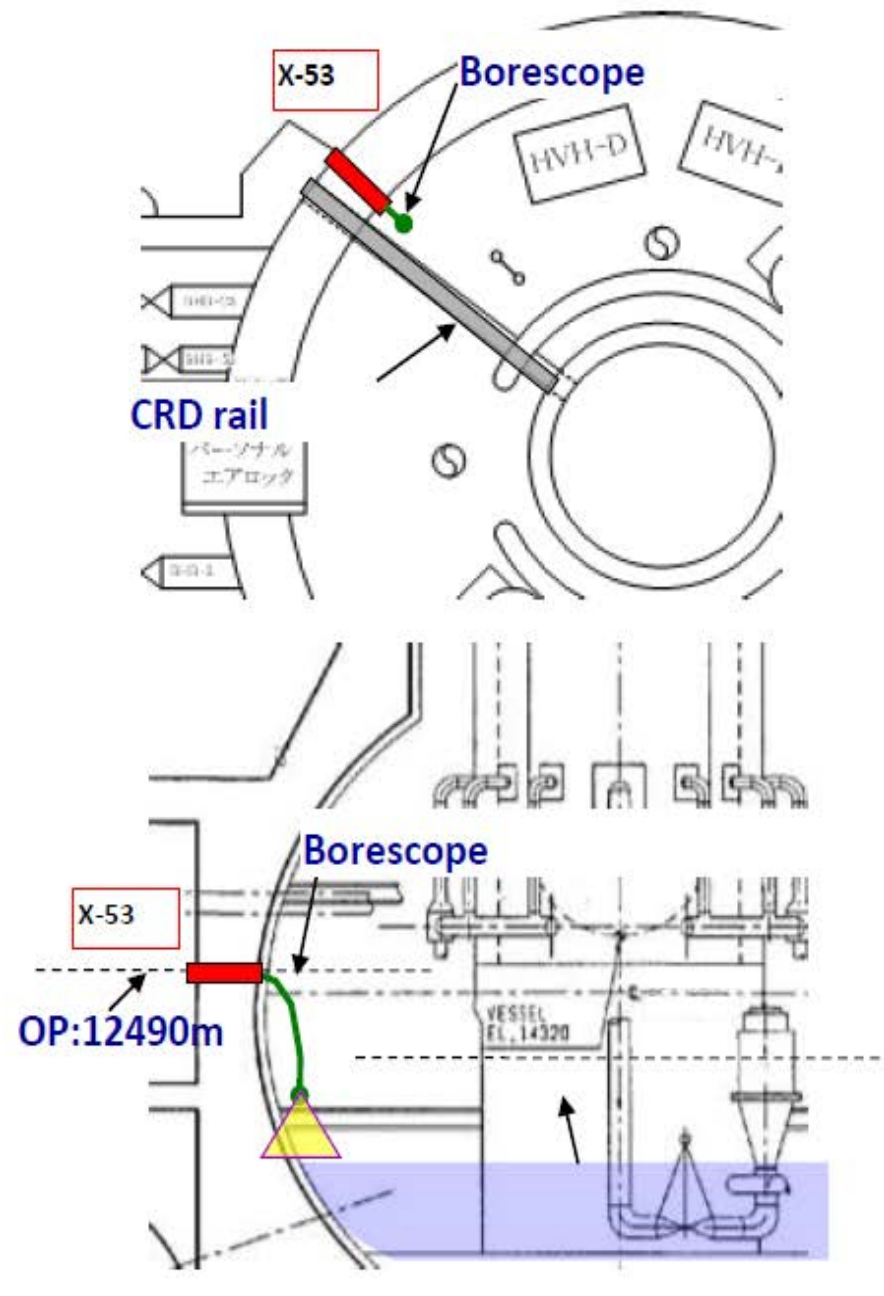

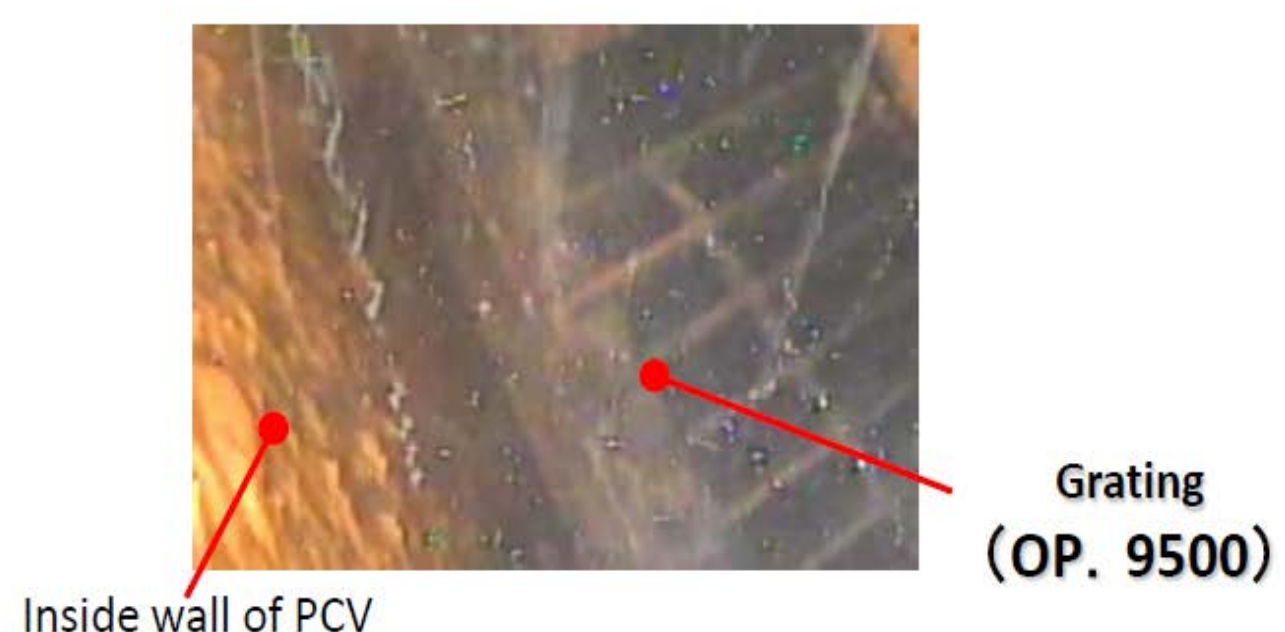

Inside wall of PCV

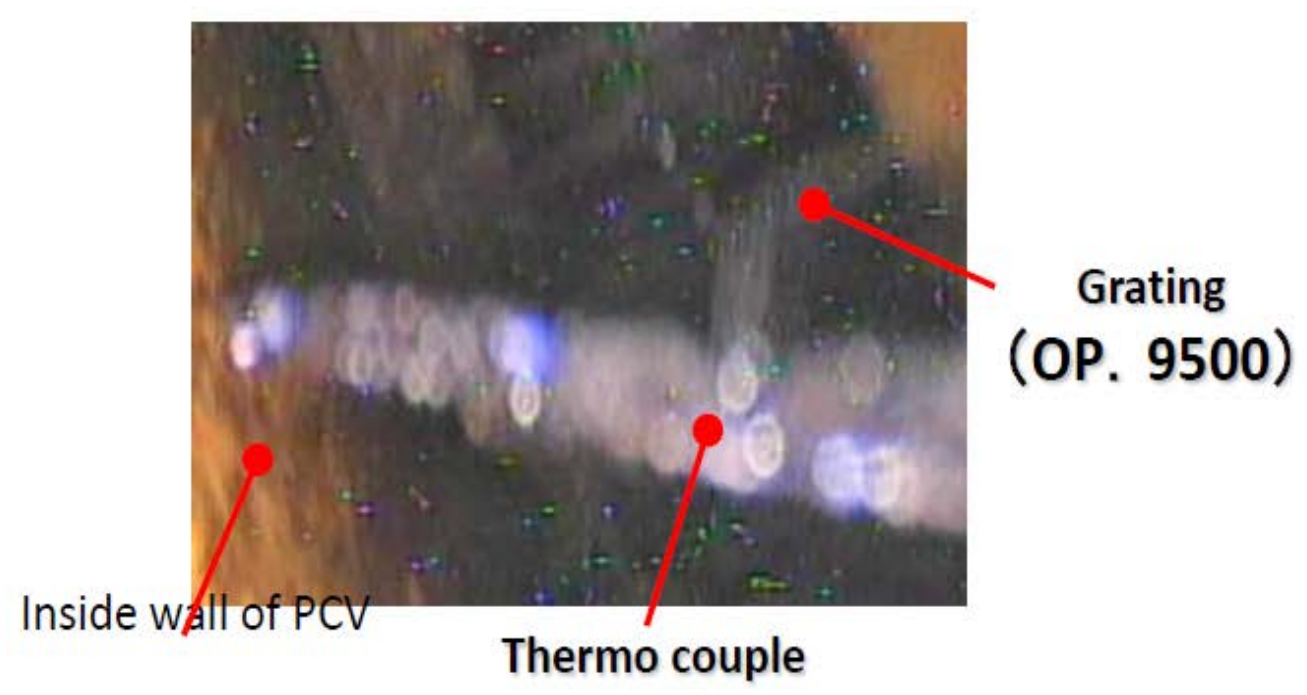

$4 / 19 / 2016$ : Shooting to this direction 80 柬京電力

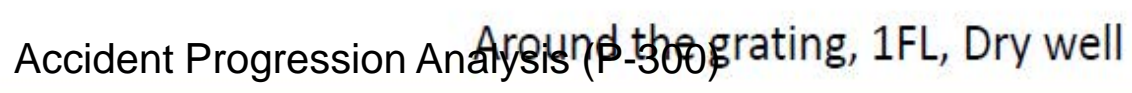

(C)2012 The Tokyo Electric Power Company, INC. All Rights Reserved. 


\section{Inside inspection of damaged PCV, Unit1 on Sep. $27^{\mathrm{h}}$}

Bottom surface (dry well)

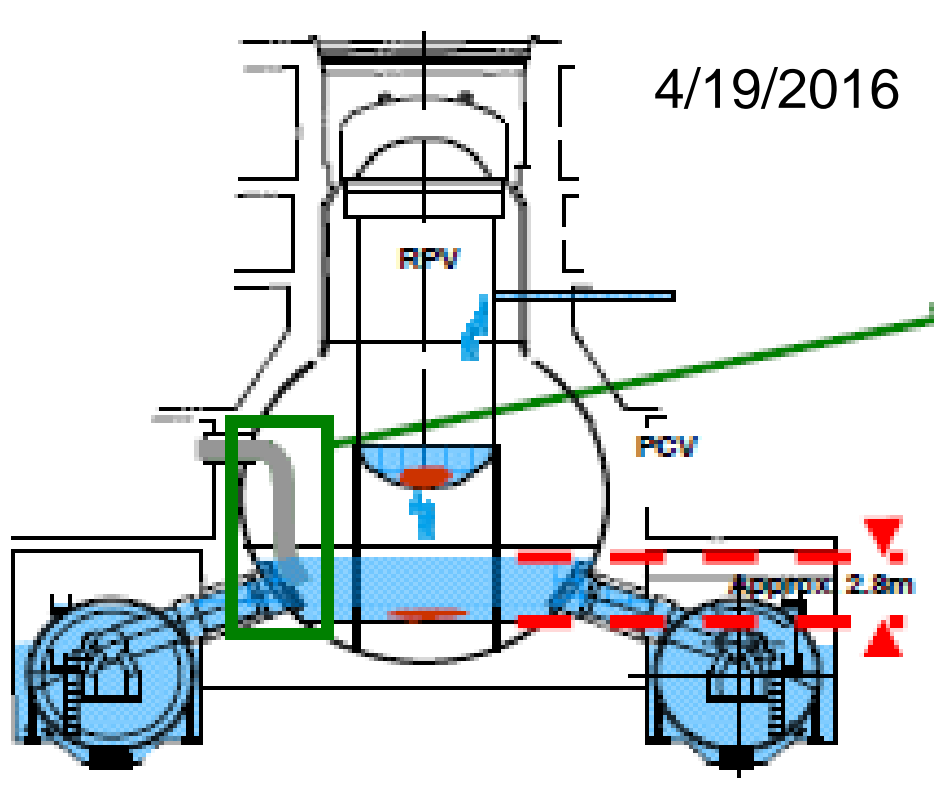

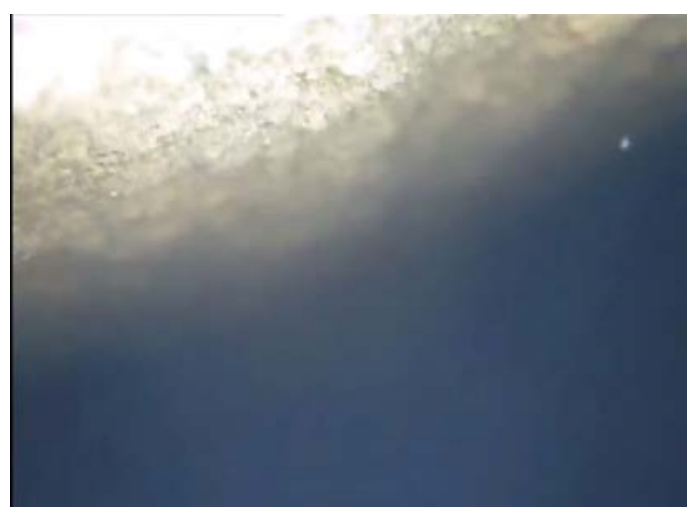

Surface on the deflector

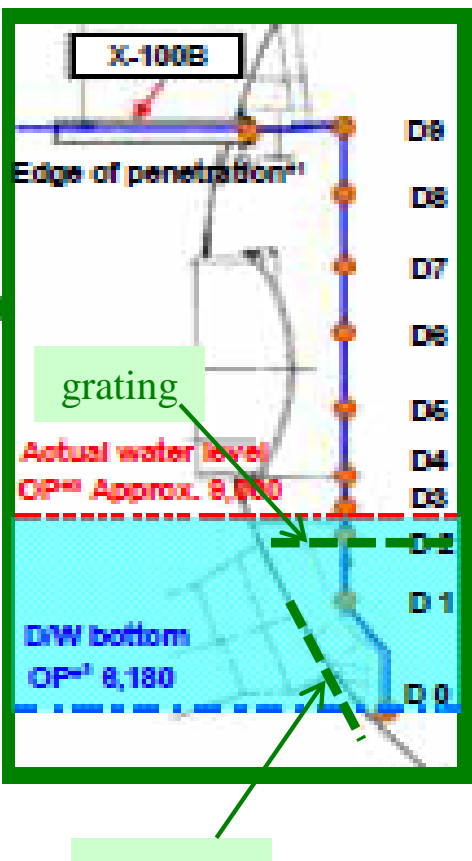

deflector

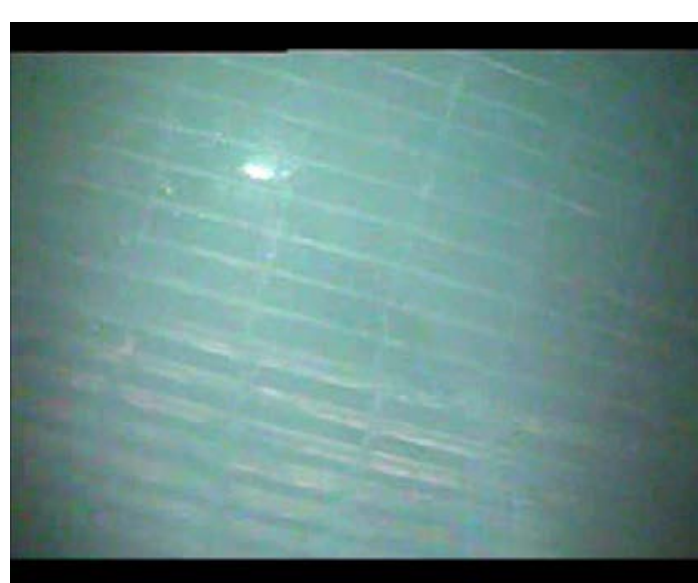

CCD camera inspection

\begin{tabular}{|c|c|c|}
\hline $\begin{array}{l}\text { Mesourement } \\
\text { point }\end{array}$ & $\begin{array}{c}\text { Dictanos from } \\
\text { the botiom of } \mathrm{DW} \text { - }\end{array}$ & $\begin{array}{c}\text { Padiation does } \\
\text { [Bwh] }\end{array}$ \\
\hline $\begin{array}{l}\text { This boloe of } \\
\text { menstration }\end{array}$ & 8.685 & Approe 11.1 \\
\hline $\mathrm{DS}$ & B.685 & 9.8 \\
\hline DE & Apprax 7,E:s & 9.0 \\
\hline $\mathrm{DT}$ & Approx. 8,800 & 9.2 \\
\hline DS & Apprax S,B: & 8.7 \\
\hline D5 & Apprax $4,8: 0$ & 8.9 \\
\hline D4 & Apprax 3,E:S & 6.2 \\
\hline Ds & Apprax 3,2 & 4.7 \\
\hline 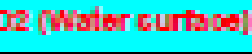 & Approw 2,500 & 0.5 \\
\hline D1 & $=$ & $=$ \\
\hline Do & 0 & $=$ \\
\hline
\end{tabular}




\section{Muon Model of Unit 1 Vessel and Core}

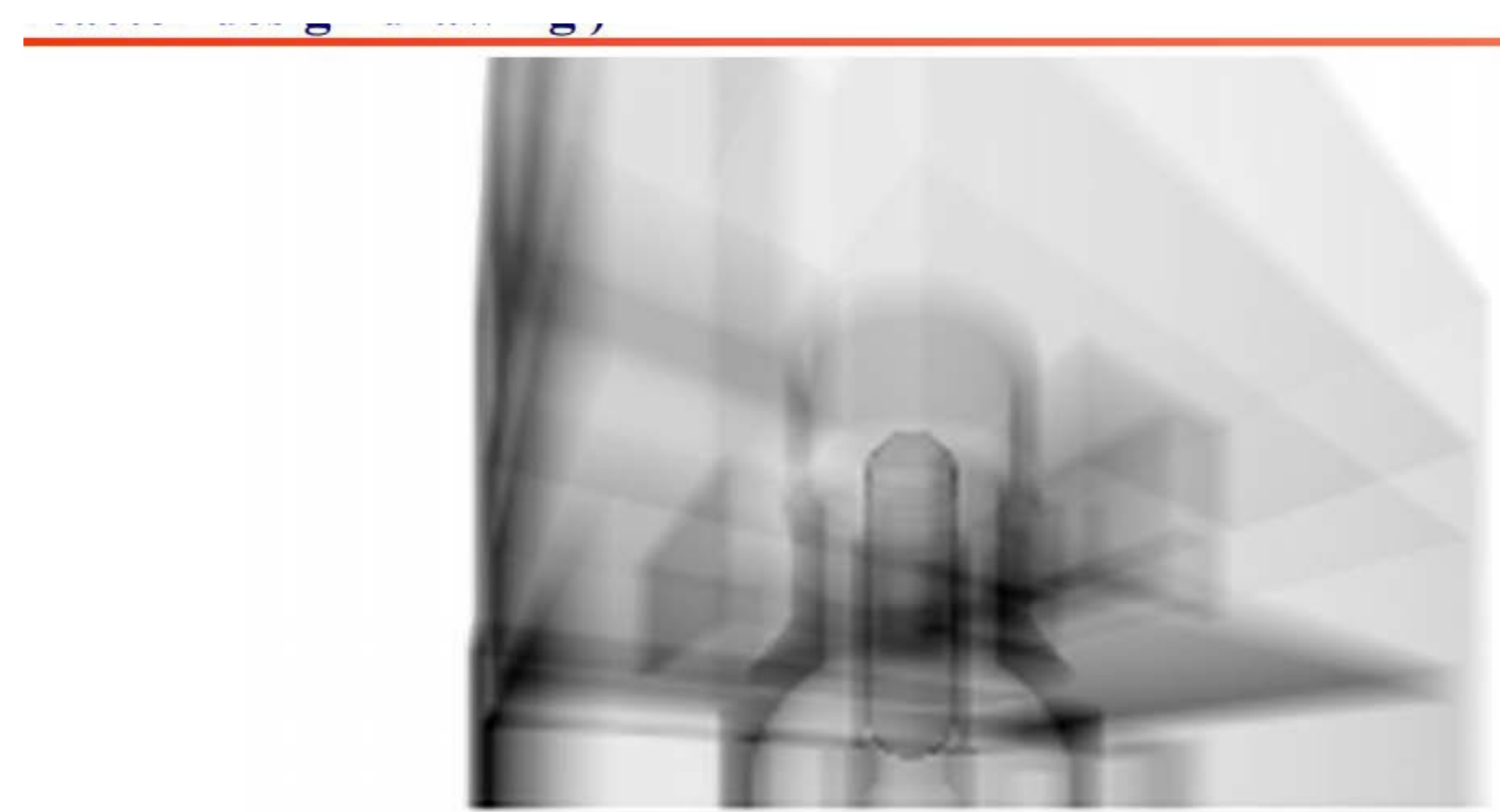

Density-length image from Detector-1 based on design drawing

Then the density of substances existing inside is higher, the more muon are absorbed. The Black part inside the reactor show: sactor core location. (Assuming fuel is not damaged)

Density-length is the multiplying structure density and length along with incidence path

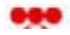

from the detector, which represents the extent of muon attenuation

Accident Progression Analysis (P-300) 


\section{Muon Imaging of Unit 1 Reactor - 26 days}

'. Results of twenty-six day measurement with detectors 1 and 2

The results gained from the detector 1 (North West side) do not identify fuel debris inside the reactor, while those from the detector 2 (North side) appear to show something exists inside.

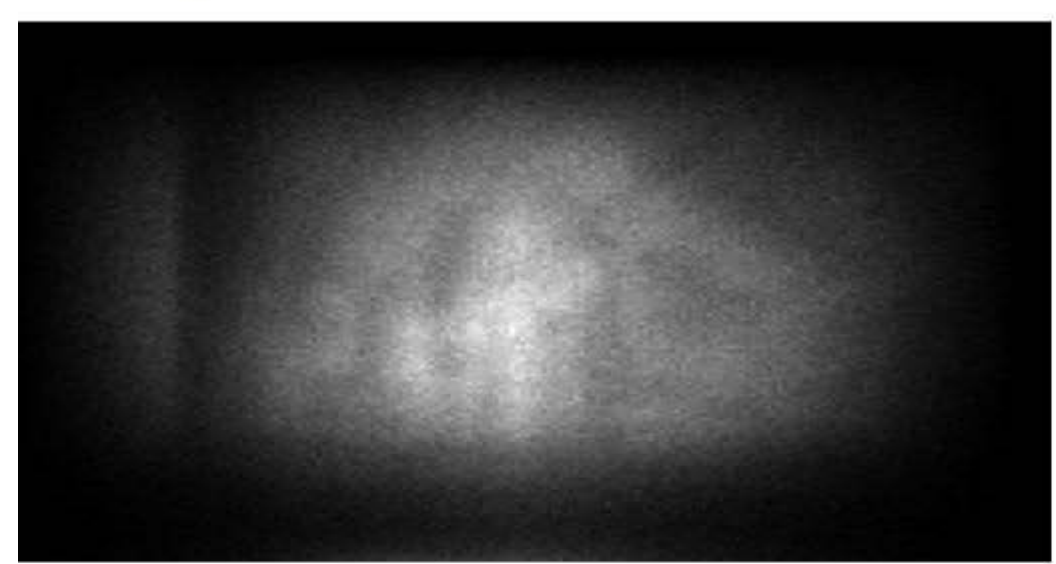

Figure 2. Measured image from the detector 1 (North west side)

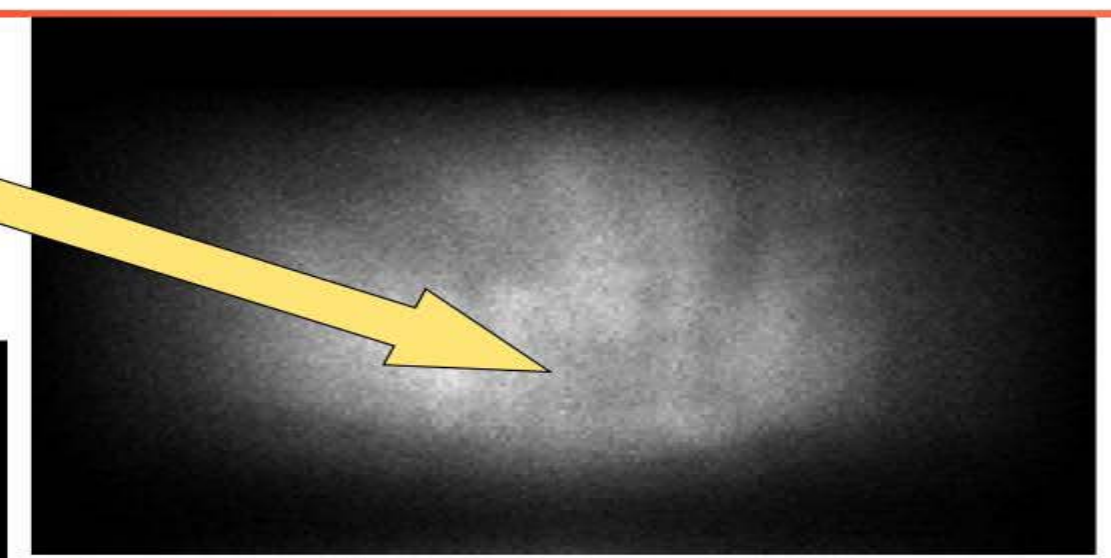

Figure 1. Measured image from the detector 2 (North side)

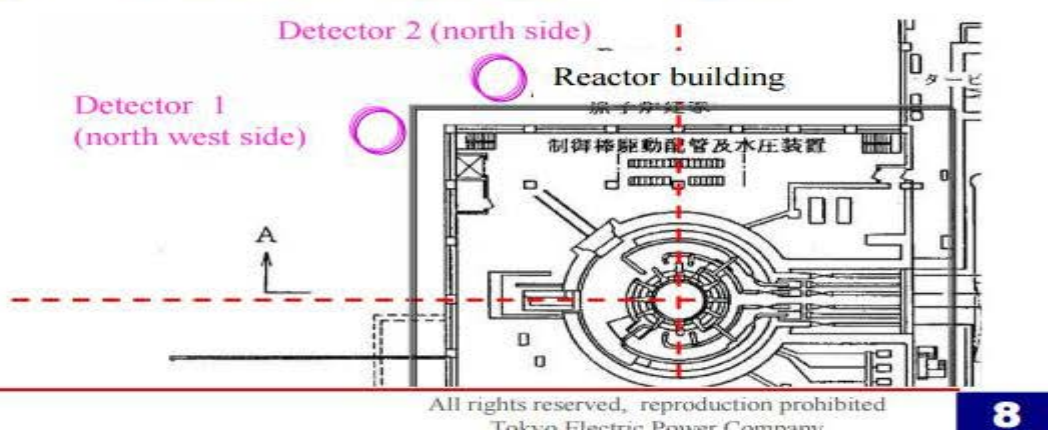




\section{Defueling Floor Radiation Fields -100 $\mathrm{R} / \mathrm{hr}$ Maximum (1 mSv = $100 \mathrm{mR}$ )}

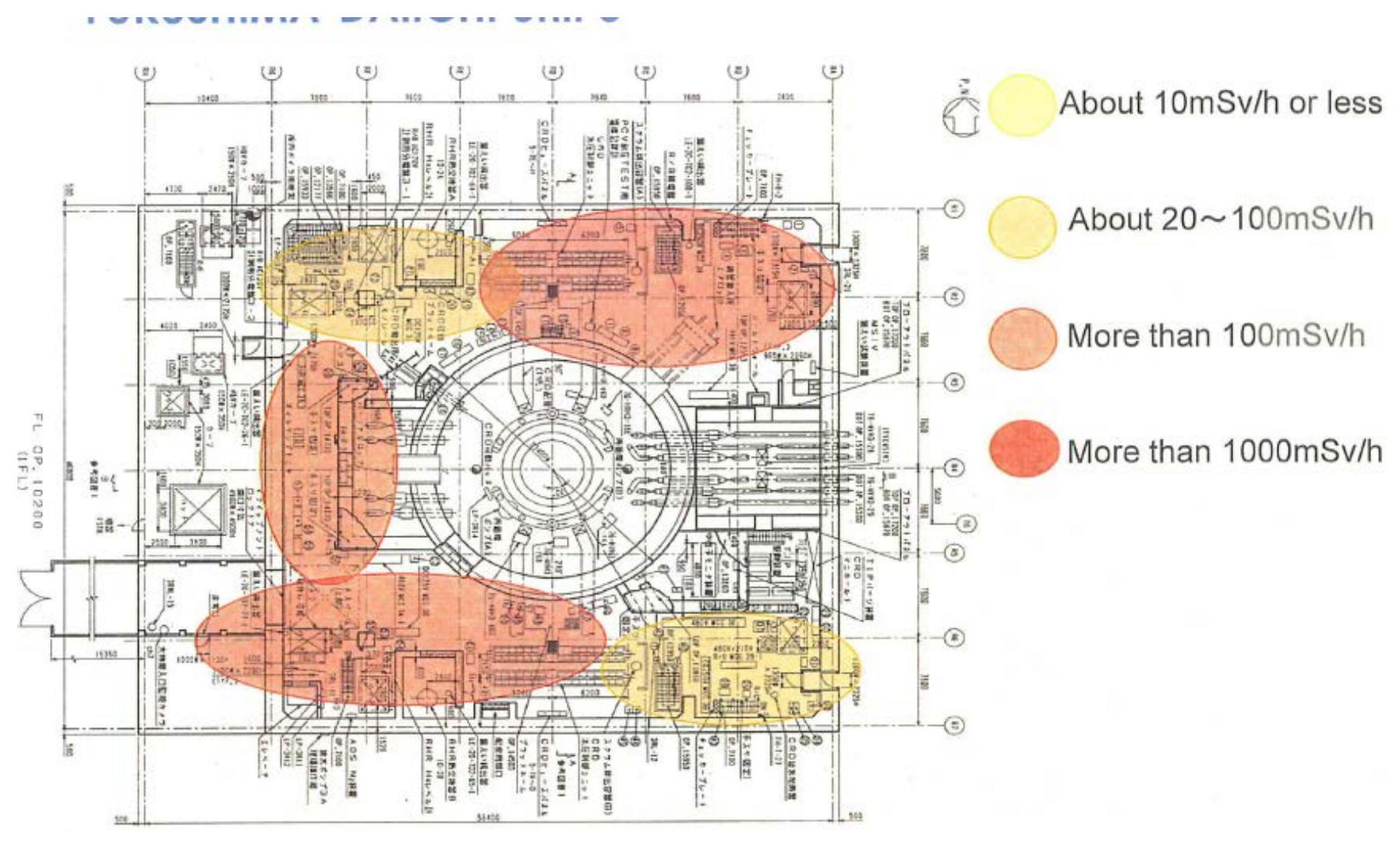




\section{Summary}

- TMI data provides a basis for understanding the Fukushima reactor accident

- Improvements in nuclear technology provided methods for characterizing the reactor accident

- Significant retention of core debris in the control rod assemblies is likely

- Direct measurement of relocated fuel material is possible 


\section{Phenomena Affecting Containment Integrity}

- Introduction

- Failure Analyses

- Phenomena

- Case Study and Problem

- Study Questions

- References 


\section{Objectives}

- Identify various containment failure modes and understand their likelihood for various accident scenarios.

- Identify and describe parameters affecting various challenges to containment integrity. 


\section{Ex-vessel Severe Accident Progression}

- Hydrogen Combustion

- Hydrogen Recombination/Burn

- Molten Core-Concrete Interaction

- Hydrogen/CO Generation

- Melt Spreading

- Steam/Hydrogen Transport

- Long-term Containment Heat Removal 


\section{Several Challenges to Containment Integrity}

- Pre-existing leaks

- Overpressure

- Dynamic pressure (shock wave)

- Internal missiles

- External missiles

- Basemat meltthrough

- Bypass

- Isolation failures
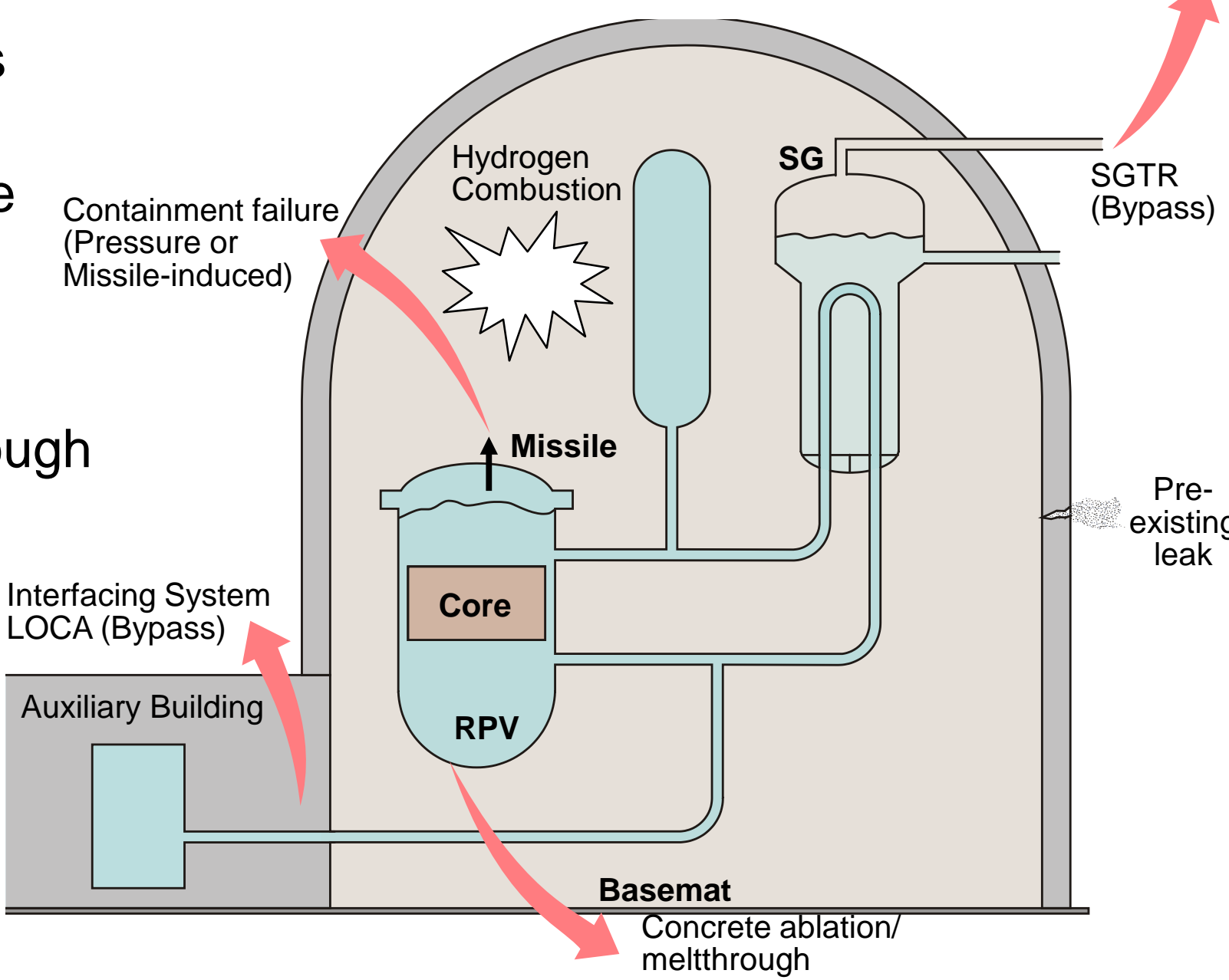


\section{Challenges Dominate at Different Time Periods}

\begin{tabular}{|l|l|l|}
\hline \multicolumn{2}{|c|}{ Time Regime } & \multicolumn{1}{c|}{ Challenge } \\
\hline \multirow{2}{*}{ Early } & Start of accident & pre-existing leak, isolation failure, bypass \\
\cline { 2 - 3 } & $\begin{array}{l}\text { At or soon after vessel } \\
\text { breach }\end{array}$ & $\begin{array}{l}\text { RCS blowdown, hydrogen combustion, bypass, steam } \\
\text { explosion, liner meltthrough }\end{array}$ \\
\hline $\begin{array}{l}\text { Late } \\
(>2 \text { hours after vessel breach) }\end{array}$ & $\begin{array}{l}\text { containment heat removal system failure, hydrogen } \\
\text { combustion, non-condensable gas generation, basemat } \\
\text { meltthrough }\end{array}$ \\
\hline
\end{tabular}




\section{Containment Failure addressed in NUREG-1150 Using Expert Elicitation}

- What is the probability distribution function for various challenges to the containment for various events?

- What is the pressure and temperature load distribution given that each challenge occurs?

- What is the conditional probability of each containment failure mode for given temperature and pressure loads? 
Failure Analyses

\section{NUREG-1150 Results Indicate BWR Early Containment Failures More Likely}

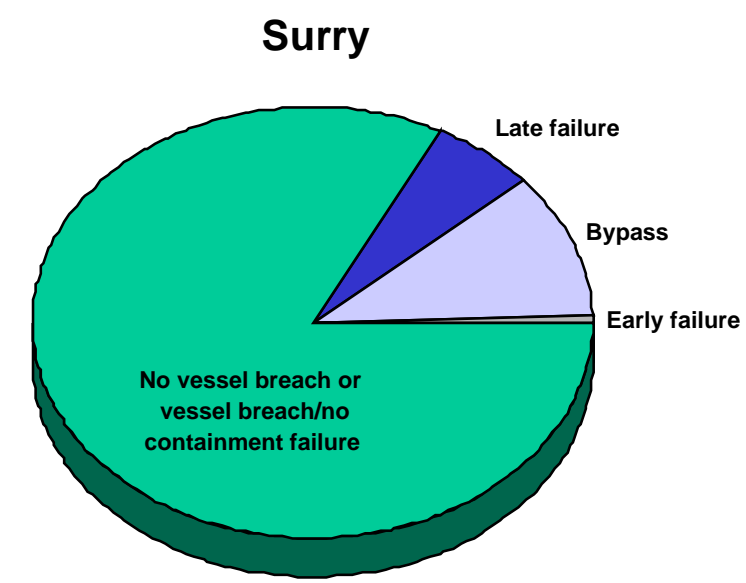

Peach Bottom

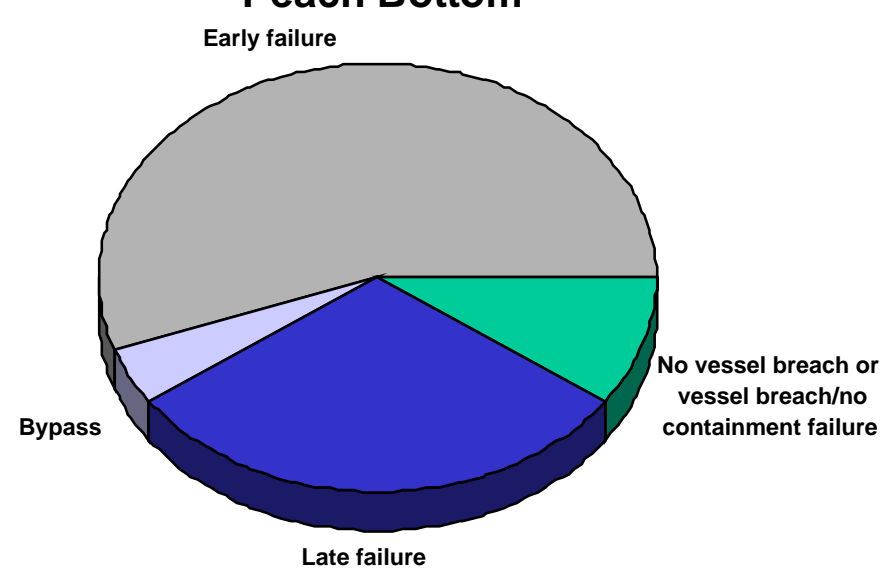

Zion

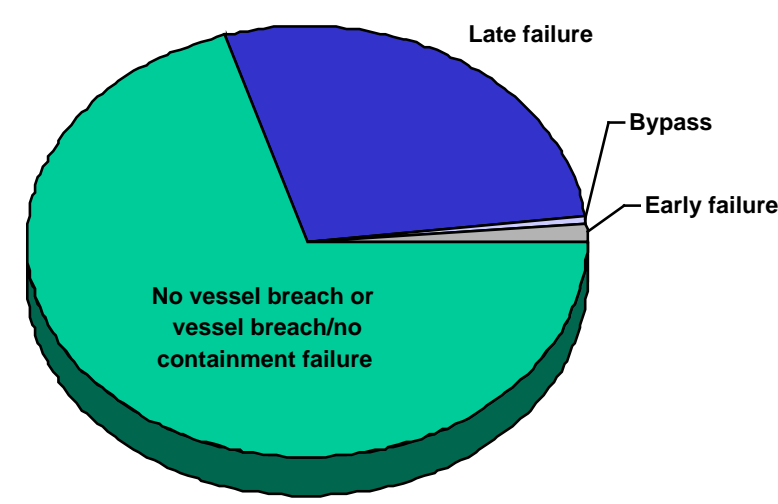

Sequoyah

Late failure

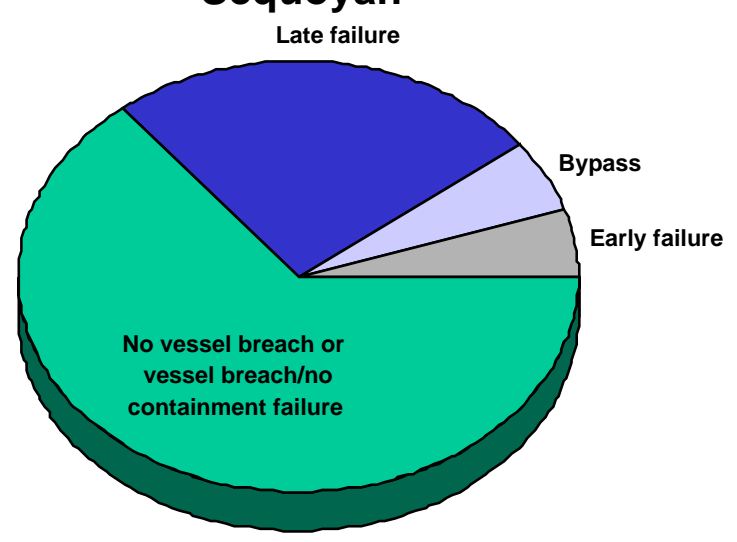

Grand Gulf

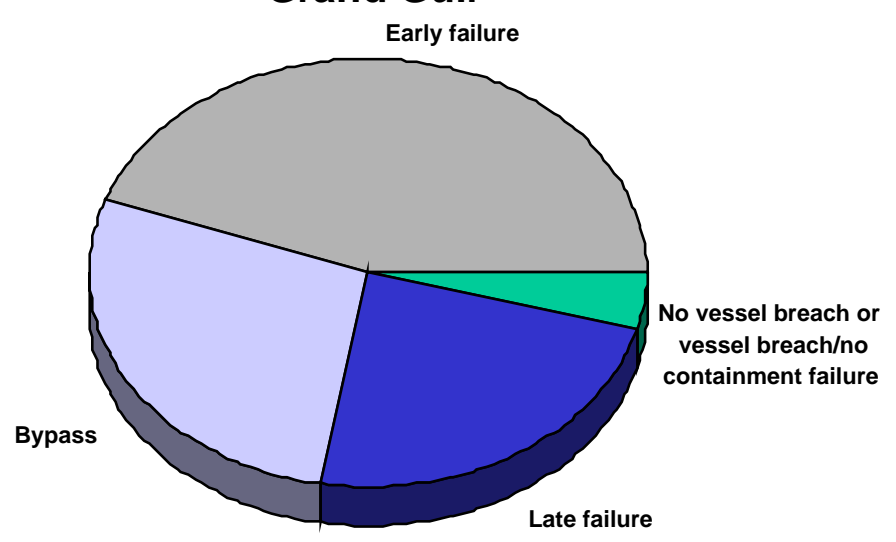

NUREG-1150 relative probability of containment failure modes from internal events 


\section{Individual Plant Examinations (IPEs) Suggest Late Failures Dominate}

- PWR containments less likely to experience early failures than smaller BWR containments

- Bypass probabilities higher in PWRs due to higher operating pressures and use of steam generators

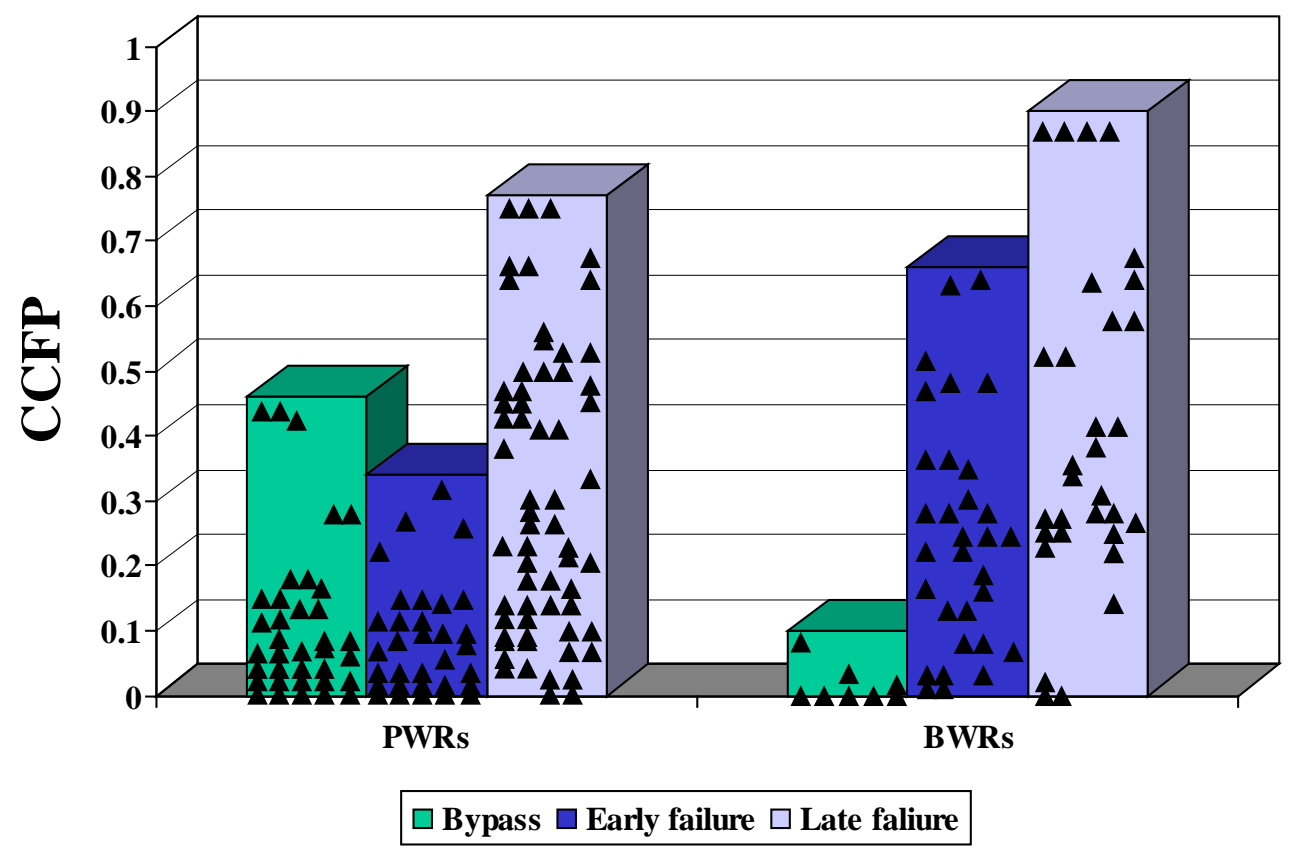

- Result variability due to differing containment features and analysis 


\section{Key Phenomena Challenging Containment Integrity}

- In-vessel steam explosions

- Ex-vessel steam explosions

- Direct containment heating (DCH)

- Molten core concrete interactions (MCCl)

- Hydrogen combustion

- Meltthrough 


\section{In-vessel Steam Explosion Issues}

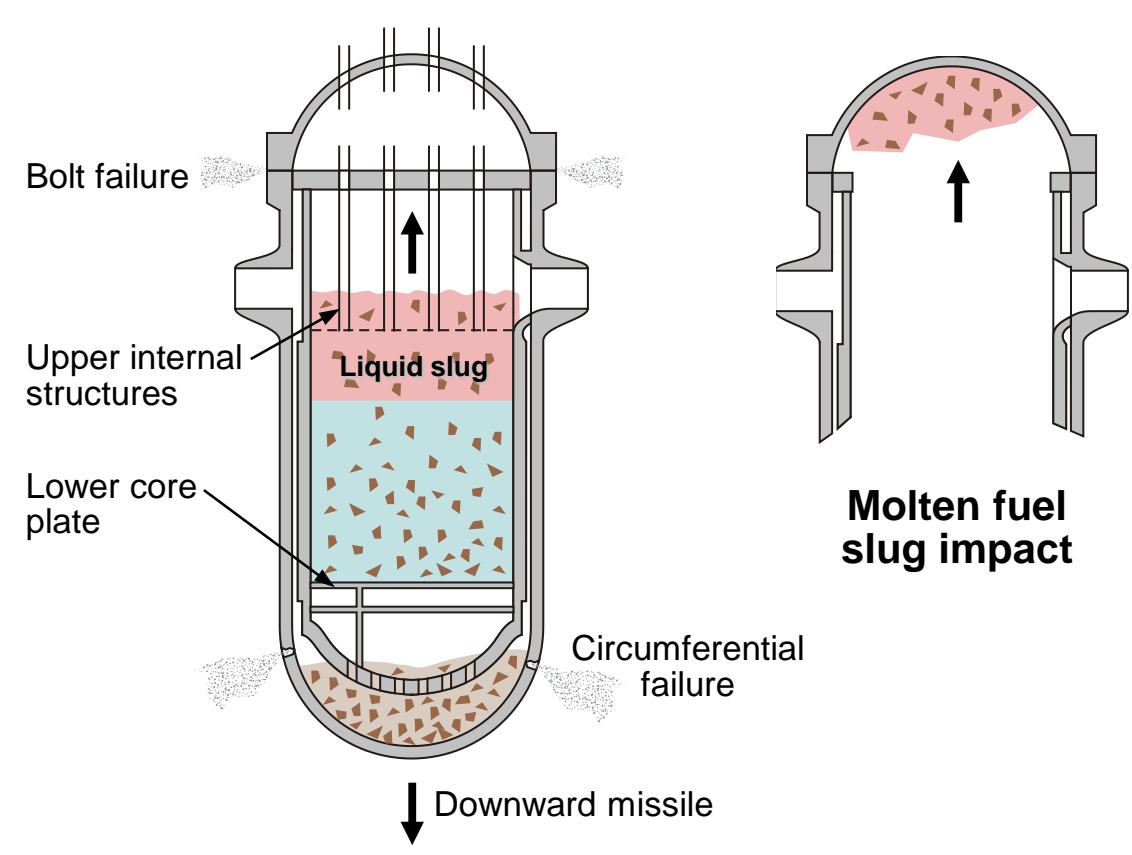

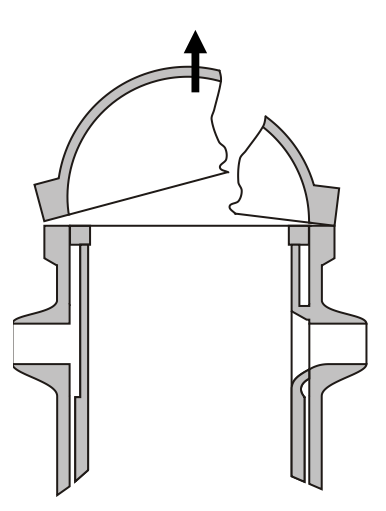

Generation of missiles

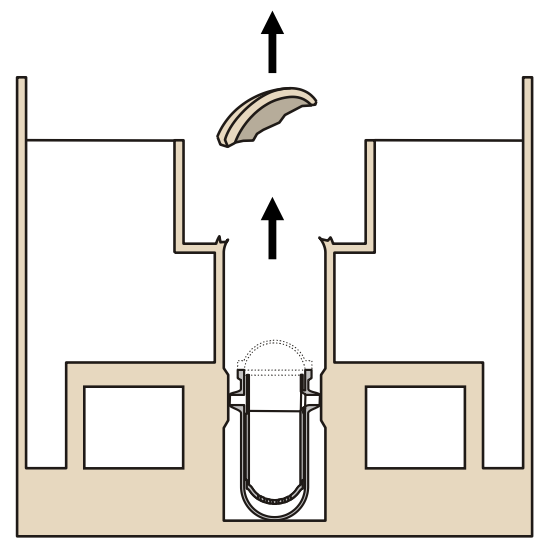

Missile impact at the containment shell

-Will in-vessel fuel/water interactions cause rapid energetic reactions?

- Are such reactions sufficient to accelerate a slug that fails vessel upper head and/or creates a missile that causes early $(\alpha)$ containment failure? 


\section{Ex-Vessel Steam Explosion Issues}
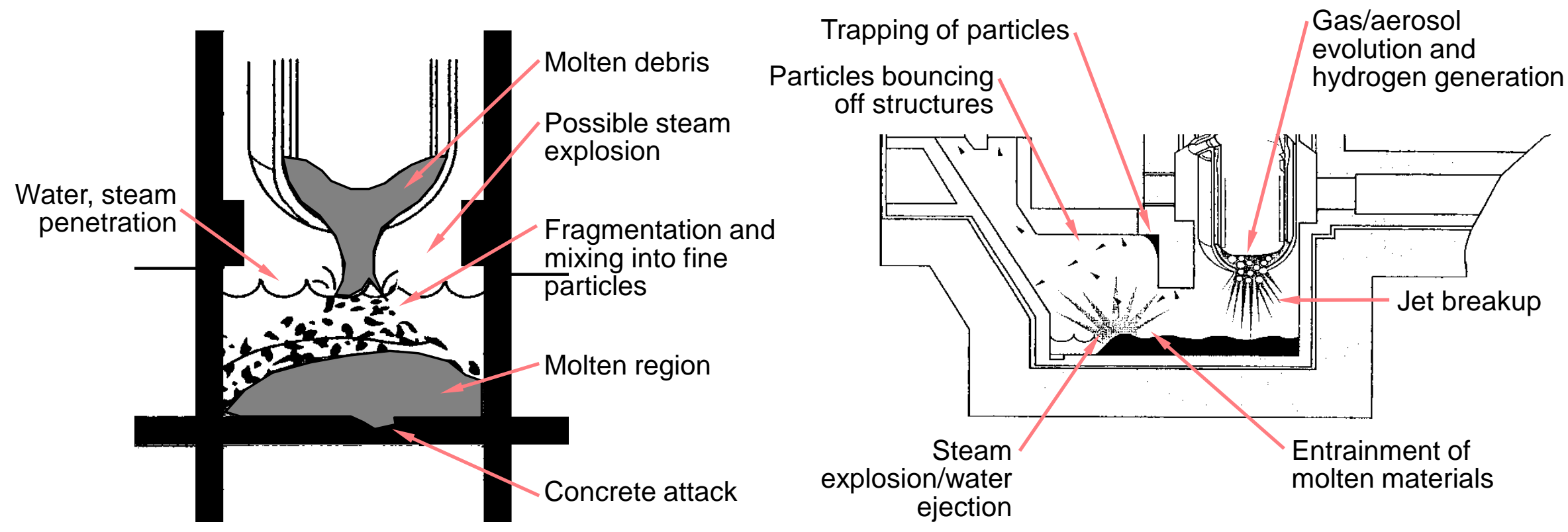

- Is sufficient water present in the reactor cavity or pedestal region for an energetic ex-vessel fuel/water reaction?

- Are such reactions sufficient to lead to containment failure? 


\section{NUREG-1150 Addresses SEs using Sensitivity Studies}

- Issues so controversial at time NUREG-1150 completed, expert panel refused to address.

- SNL staff internally developed distribution based on opinions expressed by SERG (NUREG-1116).

- Sensitivity studies performed assuming PDF derived by "averaging" published frequency estimates from diverse group of representative researchers. 


\section{Recent Experimental Data Provides Key Insights about Steam Explosions}

\begin{tabular}{|c|c|c|c|c|c|c|}
\hline $\begin{array}{l}\text { Facilityl } \\
\text { Location }\end{array}$ & $\begin{array}{l}\text { Pheonomena } \\
\text { Investigated }\end{array}$ & $\begin{array}{l}\text { Test Section } \\
\text { Diameter }\end{array}$ & $\begin{array}{c}\text { Melt Jet } \\
\text { Diameter }(\mathrm{mm})\end{array}$ & Water Depth & System Pressure & $\begin{array}{l}\text { Melt Composition } \\
\text { and Mass }\end{array}$ \\
\hline $\begin{array}{l}\text { FAROI } \\
\text { ISPRA }\end{array}$ & $\begin{array}{l}\text { Integral tests } \\
\text { investigating } \\
\text { premixing, } \\
\text { quenching, } \\
\text { propagation, and } \\
\mathrm{FCl} \text { energetics }\end{array}$ & $\begin{array}{l}700 \mathrm{~mm} \\
(27.6 \mathrm{in} .)\end{array}$ & $\begin{array}{l}100 \mathrm{~mm} \\
(4.0 \mathrm{in} .)\end{array}$ & $\begin{array}{c}0.1-5.0 \mathrm{~m} \\
(0.3-1.4 \mathrm{ft})\end{array}$ & $\begin{array}{c}0.1-5.0 \mathrm{MPa} \\
(15-730 \mathrm{psi})\end{array}$ & $\begin{array}{l}\mathrm{UO}_{2}-\mathrm{ZrO}_{2} \\
(\mathrm{w} / \text { and } \mathrm{w} / \mathrm{o} \mathrm{Zr} \& \mathrm{SS}) \\
18-250 \mathrm{~kg} \\
(40-550 \mathrm{lb})\end{array}$ \\
\hline $\begin{array}{l}\text { KROTOSI } \\
\text { ISPRA }\end{array}$ & $\begin{array}{l}\text { Smaller scale tests } \\
\text { investigating } \\
\text { premixing, } \\
\text { quenching, } \\
\text { propagation, and } \\
\mathrm{FCl} \text { energetics }\end{array}$ & $\begin{array}{l}95-200 \mathrm{~mm} \\
(3.7-7.9 \mathrm{in} .)\end{array}$ & $\begin{array}{l}30-50 \mathrm{~mm} \\
(1.2-2.0 \mathrm{in})\end{array}$ & $\begin{array}{l}1.0 \mathrm{~m} \\
(3.3 \mathrm{ft})\end{array}$ & $\begin{array}{c}0.1-1.0 \mathrm{MPa} \\
(15-150 \mathrm{psi})\end{array}$ & $\begin{array}{l}\mathrm{UO}_{2}-\mathrm{ZrO}_{2} \\
\mathrm{Al}_{2} \mathrm{O}_{3} \\
1.4-6.0 \mathrm{~kg} \\
(3.1-13 \mathrm{lb})\end{array}$ \\
\hline $\begin{array}{l}\text { TROII } \\
\text { KAERI }\end{array}$ & $\begin{array}{l}\text { Integral tests } \\
\text { investigating } \\
\text { premixing, } \\
\text { quenching, } \\
\text { propagation, and } \\
\mathrm{FCl} \text { energetics }\end{array}$ & $\begin{array}{l}600 \mathrm{~mm} \\
(24.0 \mathrm{in} .)\end{array}$ & $\begin{array}{l}\sim 38 \text { to } 50 \mathrm{~mm} \\
(\sim 1.5-2.0 \mathrm{in} .)\end{array}$ & $\begin{array}{l}0.67 \mathrm{~m} \\
(2.2 \mathrm{ft})\end{array}$ & $\begin{array}{l}0.1 \text { to } 2.0 \mathrm{MPa} \\
(15.0-290 \mathrm{psi})\end{array}$ & $\begin{array}{l}\mathrm{ZrO}_{2} \text { and } \mathrm{UO}_{2}-\mathrm{ZrO}_{2} \\
5 \text { to } 14 \mathrm{~kg} \\
(11-30 \mathrm{lb})\end{array}$ \\
\hline
\end{tabular}




\section{Experimental Data Provides Key Insights about Steam Explosions (continued)}

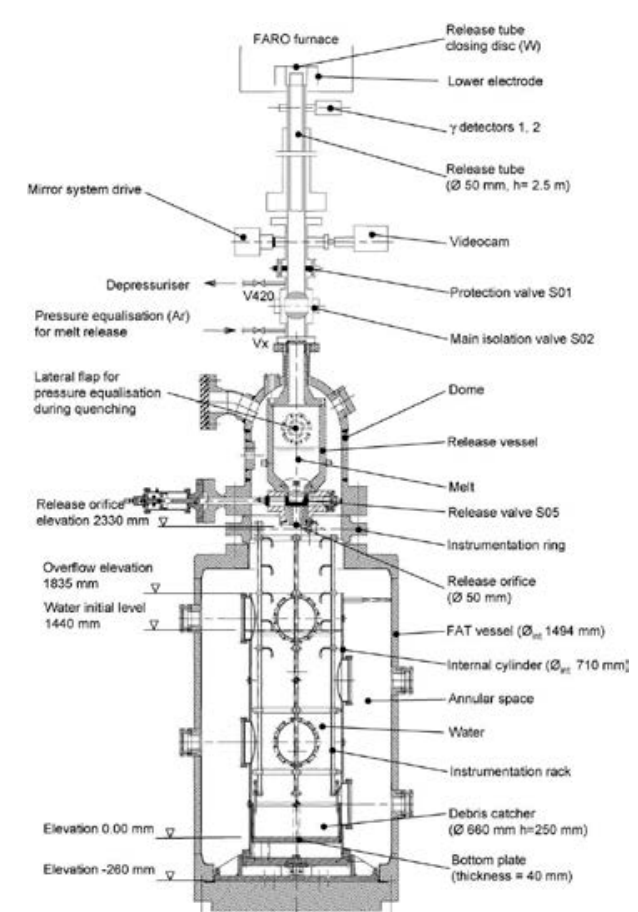

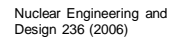

FARO

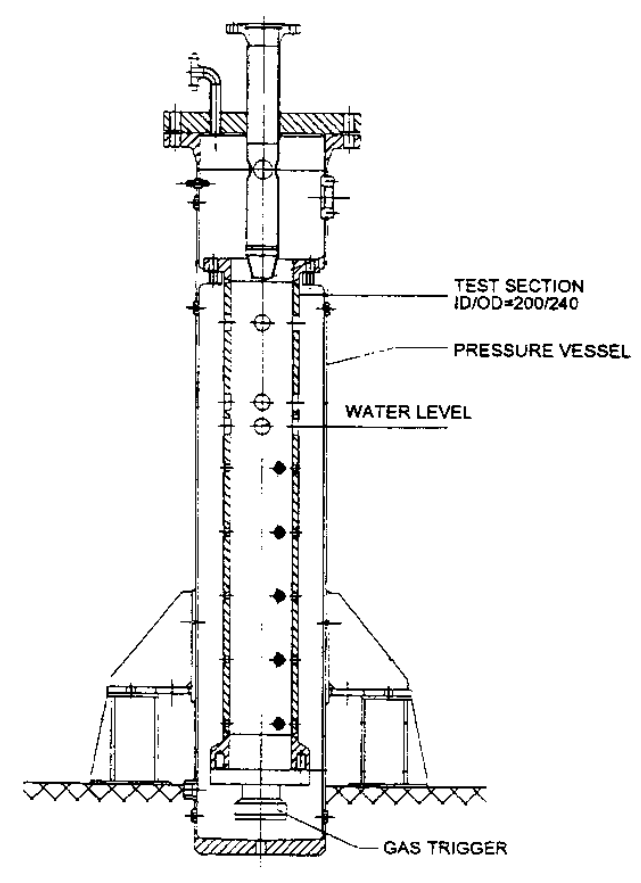

KRYTOS

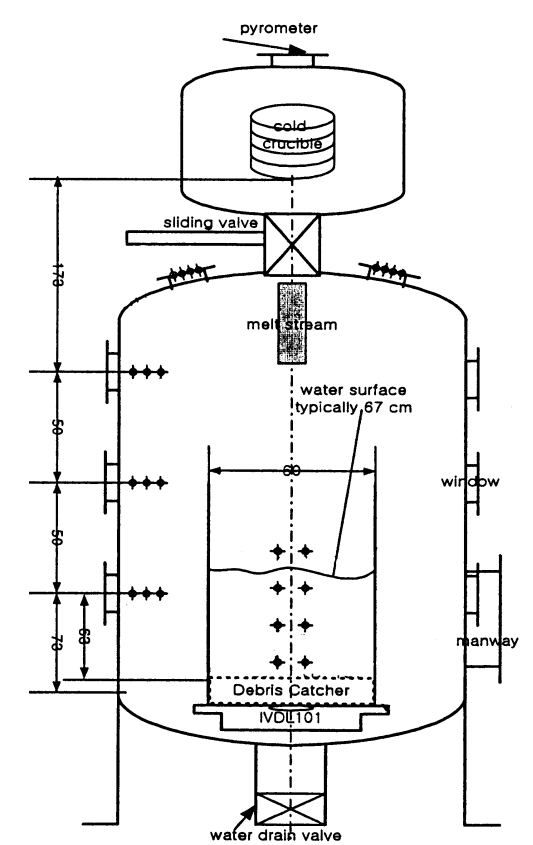

TROI 


\section{Prototypic Large-scale FARO Data Suggest Steam Explosions Less Likely}

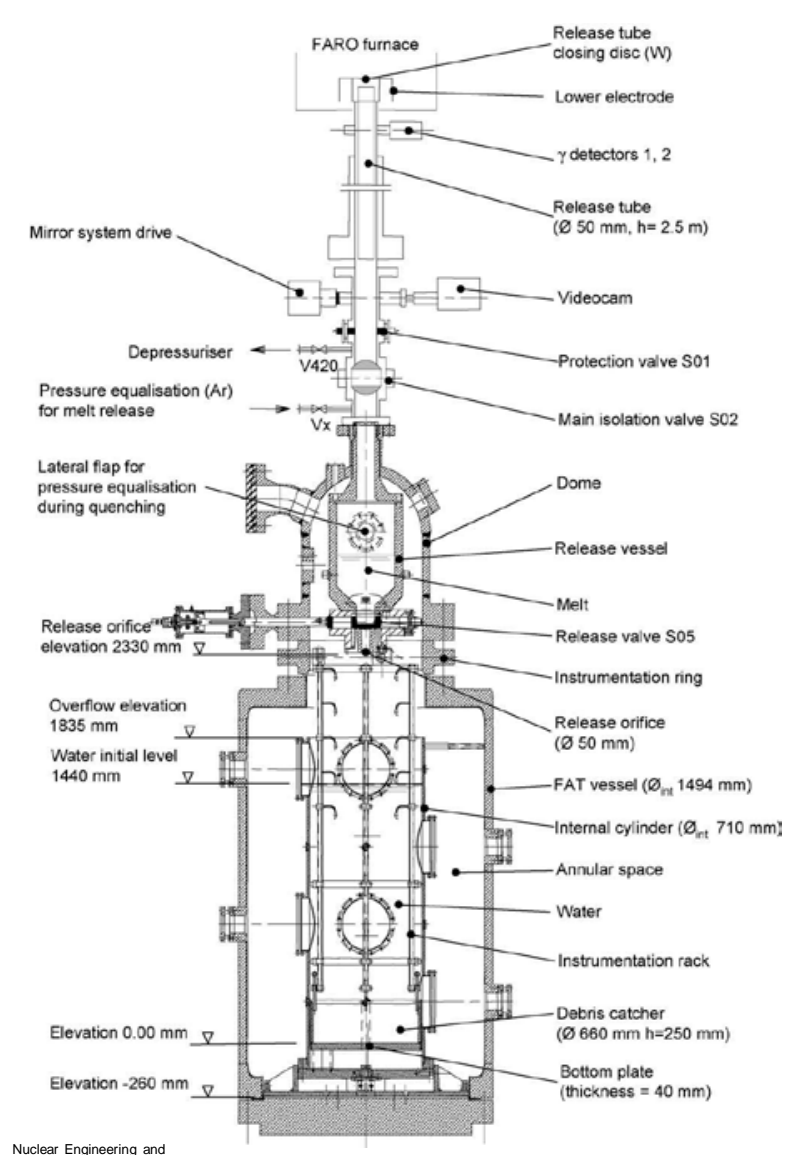

- In tests with $\mathrm{UO}_{2}, \mathrm{ZrO}_{2}$, and $\mathrm{Zr}$, complete fragmentation occurred

- In tests with $\mathrm{UO}_{2}$ and $\mathrm{ZrO}_{2}$, relocated materials consisted of a "cake" with an overlying layer of fragmented debris

- Mean particle size of fragmented debris ranged from 3.4 to $4.8 \mathrm{~mm}$ (0.13 to $0.19 \mathrm{in}$.)

- No energetic steam explosions observed in tests simulating in-vessel conditions. 


\section{Key Parameters for Evaluating Ex-Vessel Steam Explosion Potential}

- Sequence

- Melt composition (amount of unoxidized metals)

- Melt mass and energy

- Melt pour area, rate, and geometry

- Water availability

- Containment design

- Cavity or pedestal geometry

- Potential for shock wave transmission

- Water availability 


\section{Recent Findings Suggest Lower Probability for Steam Explosions}

- Experimental results indicate:

- At low pressure (0.1 MPa/15 psia), limited fuel mass participates

- At higher pressures ( >1 MPa/150 psia), difficult to trigger

- Debris composition affects ability to trigger spontaneous SE

- All eleven SERG-2 experts estimated low probabilities for $\alpha$ mode failure

- Low conversion energy

- Lower explosivity of corium

- Intervening structures

- Nine of eleven SERG-2 experts declared issue of $\alpha$-mode failure induced by steam explosion resolved from risk perspective

- OECD-sponsored SERENA program designed to compare various SE models with data from FARO, KROTOS, and TROI. 


\section{Direct Containment Heating (DCH) Issues}

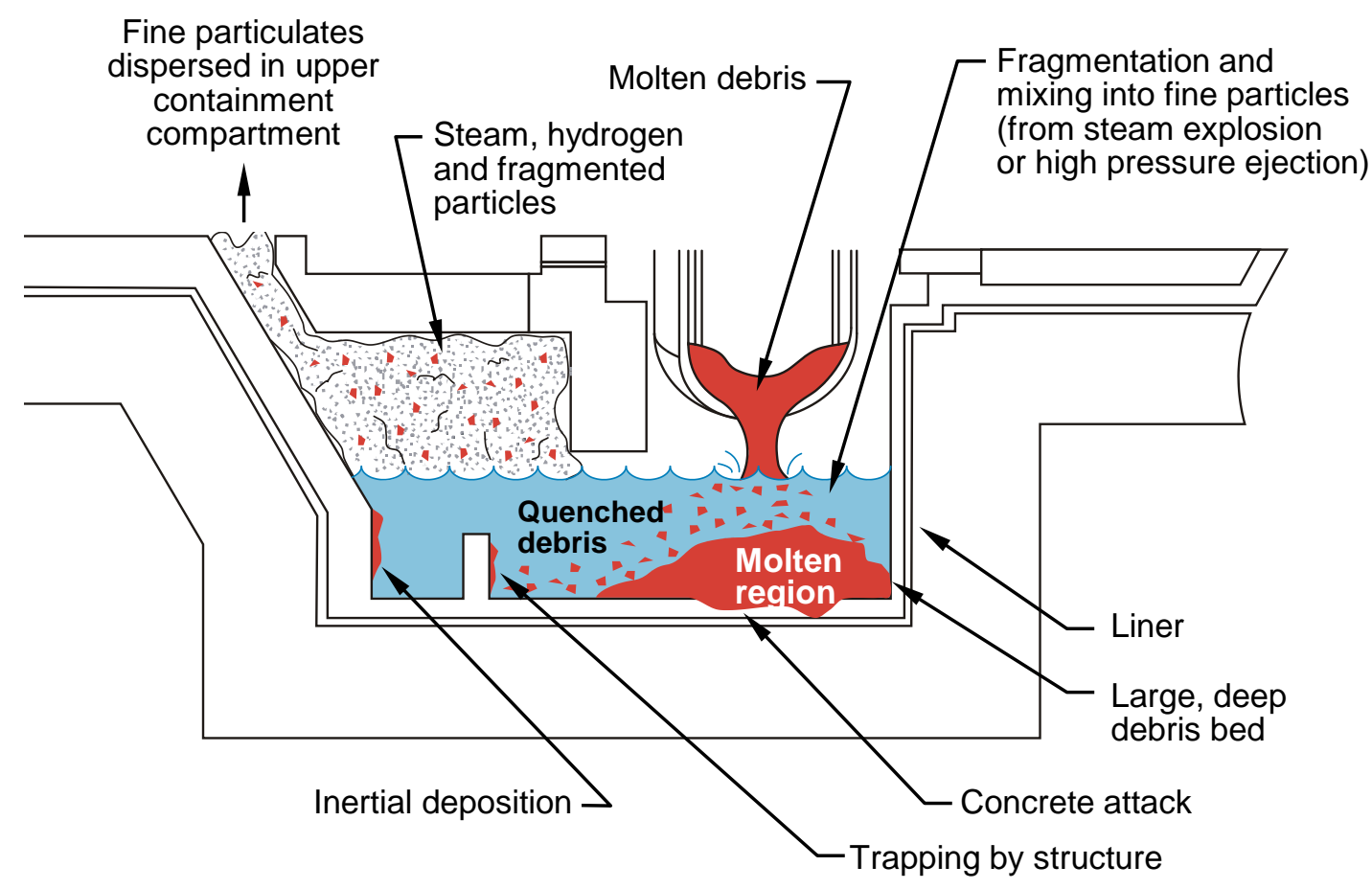

- Is sufficient melt entrained as vessel depressurizes?

- Does sufficient heat transfer, oxidation, and/or hydrogen combustion occur to threaten containment integrity? 


\section{Unique Experimental Facilities Provide Insights About Potential for DCH}

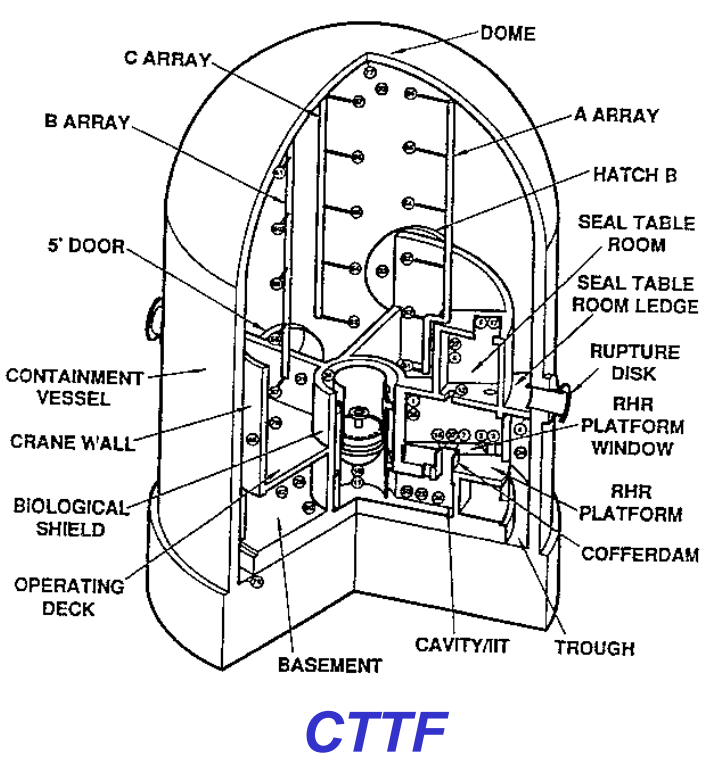

Facility capabilities allowed measurement of :

- Pressure load

- Hydrogen distribution and combustion

- Containment compartment geometry effect

- Post-test debris distribution

- Effectiveness of safety equipment

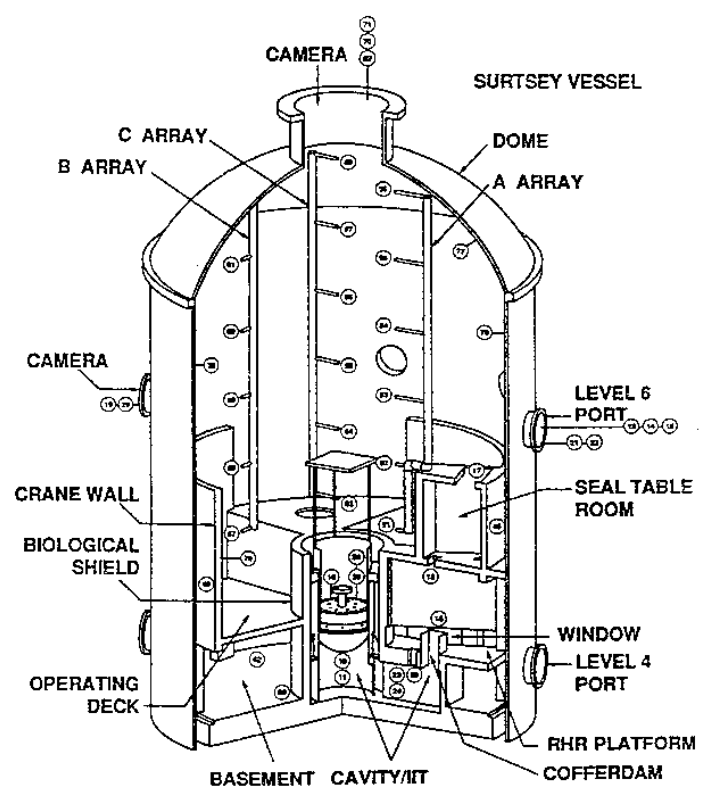

SURTSEY 


\section{Key Parameters for Evaluating DCH Potential}

- Sequence

- Melt composition (amount of unoxidized metals)

- Melt mass

- Vessel pressure and failure area

- Water availability (via containment sprays, etc.)

- Containment design

- Subcompartment configuration

- Cavity flow paths

- Water availability (flooded height) 


\section{Recent results suggest very low potential for DCH in large dry or subatmospheric containments.}
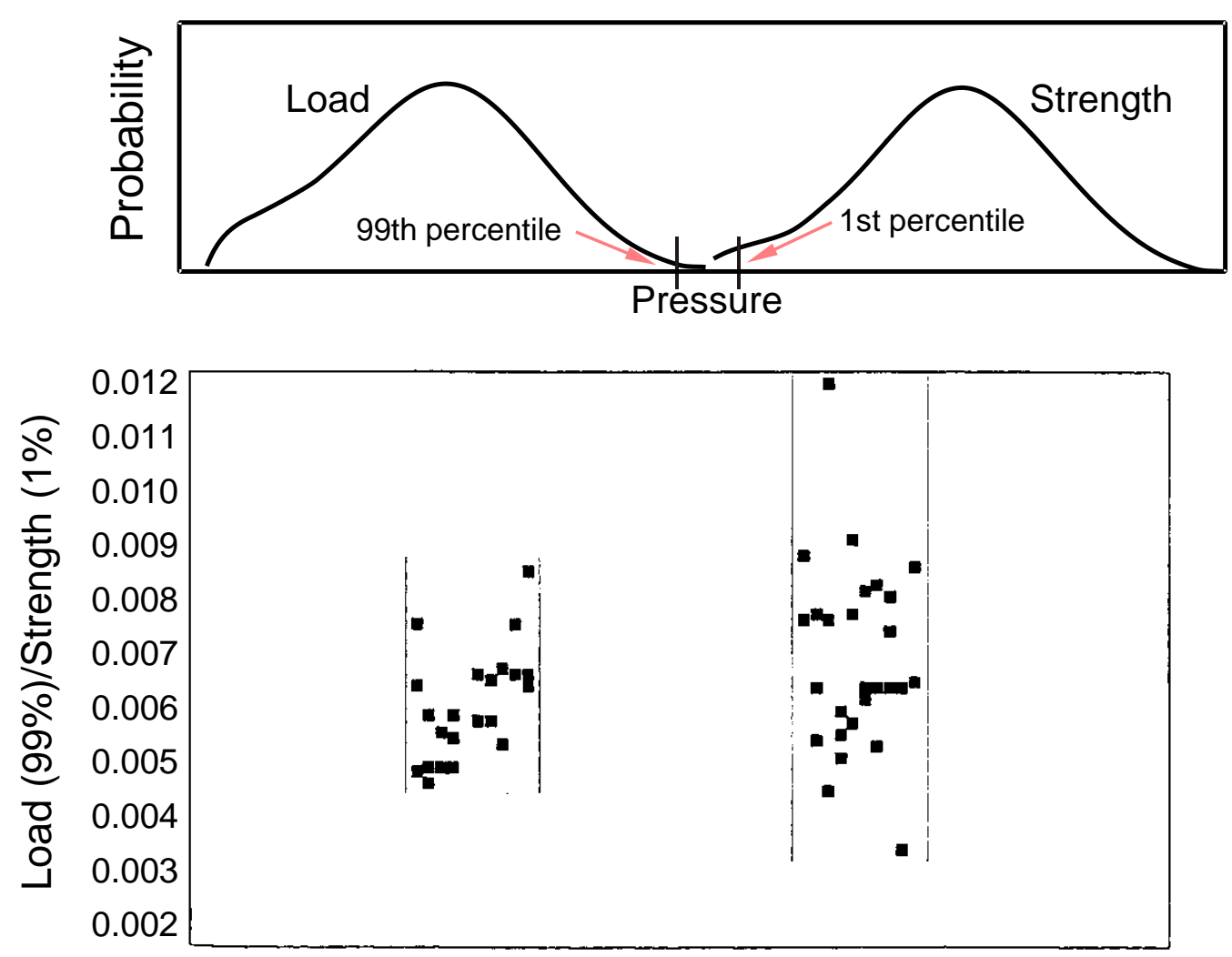

Scenario $\mathrm{V}$
Scenario VI
- Compartmentalization (CCFP < 0.01 for most $W$ plants)

- Higher potential for induced RCS depressurization (lower likelihood for HPME)

- Realistic initial melt conditions based on SCDAP/RELAP5 calculations (smaller melt mass, less unoxidized metallics) 


\section{Molten Core Concrete Interaction (MCCl) Issues}

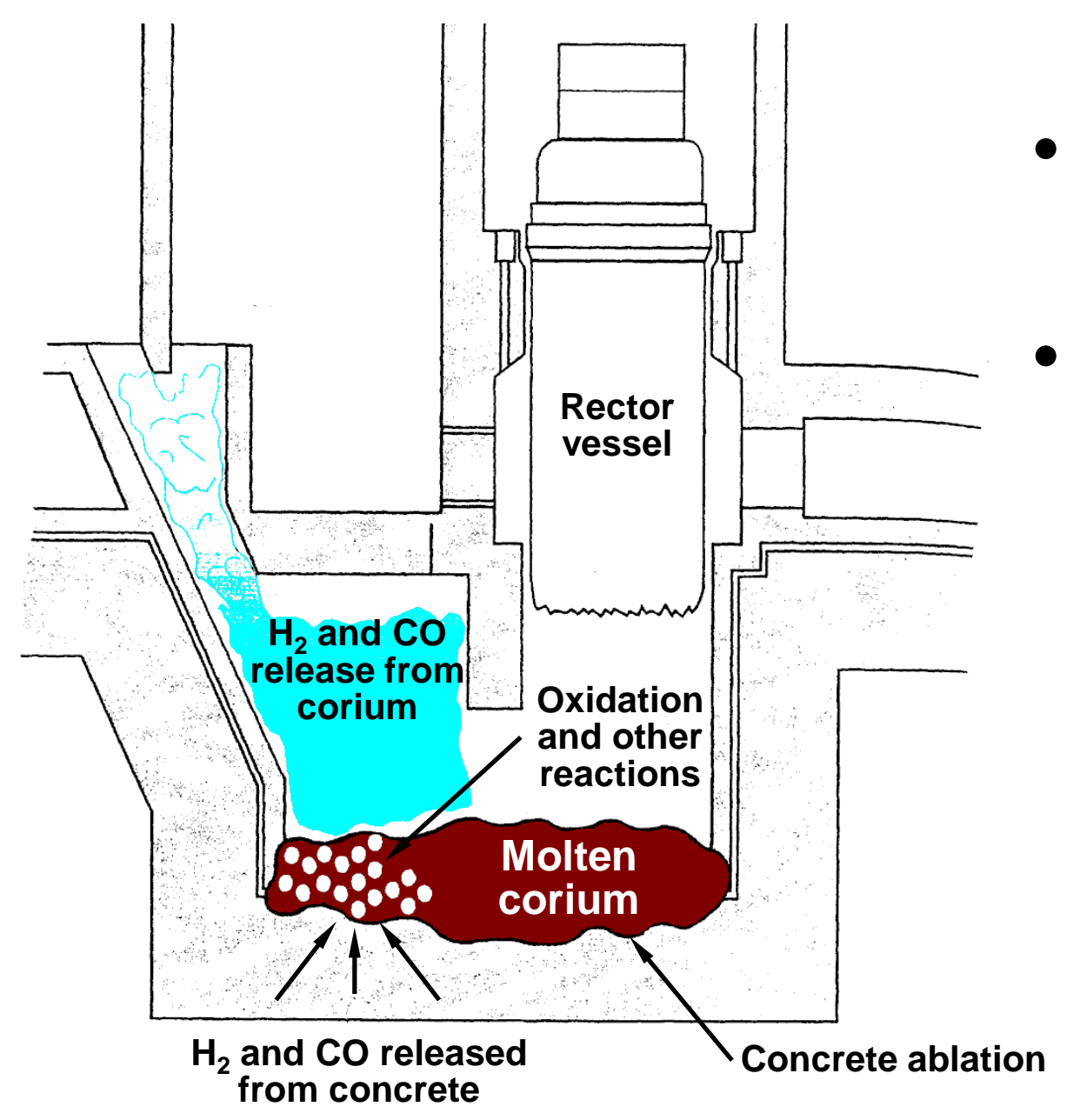

- Is corium released from the vessel coolable?

- If not, does MCCI lead to:

- combustible and/or noncondensible gas release?

- radioactive and/or nonradioactive aerosol release?

- basemat meltthrough/failure 


\section{MACE Tests Provide Key MCCI Insights}

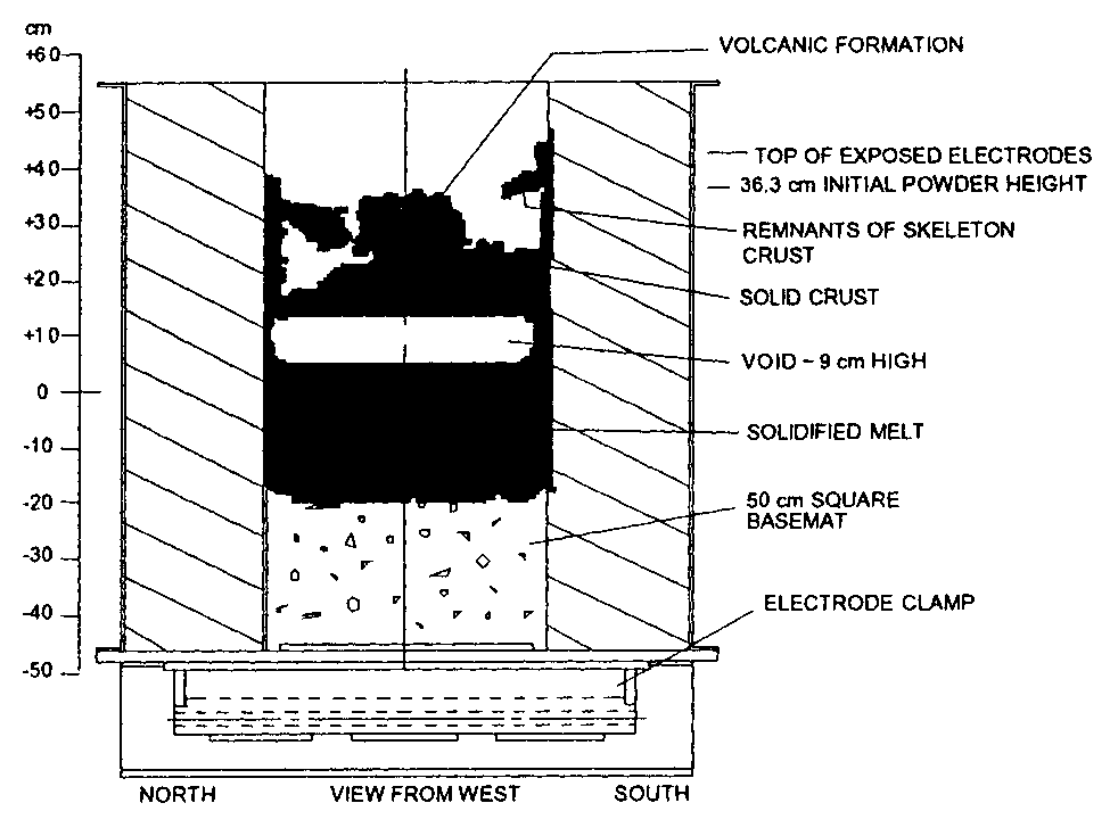

- Large scale, prototypic tests:

- 100 to $2000 \mathrm{~kg}$ (220 to $4400 \mathrm{lbs}$ ) prototypic corium

$-30 \mathrm{~cm} \times 30 \mathrm{~cm}$ to $120 \mathrm{~cm} \mathrm{x} 120 \mathrm{~cm}$ $(1 \mathrm{ft} \times 1 \mathrm{ft}$ to $4 \mathrm{ft} \times 4 \mathrm{ft})$ concrete basemat area

- $\mathrm{UO}_{2}, \mathrm{ZrO}_{2}$, and $\mathrm{Zr}$ corium materials heated up to $2350 \mathrm{~K}\left(3770^{\circ} \mathrm{F}\right)$

- Electrodes to simulate decay heat

- Water added after corium melts

- Observed:

- High initial heat transfer from corium

- Significantly lower heat removal after crust forms on upper surface

- Voiding in corium region beneath crust

- Pool swelling followed by eruptions enhances heat removal.

- CEA-sponsored VULCANO underway (with $\sim 30-50 \mathrm{~kg}$ prototypic materials) 


\section{Several Factors Influence $\mathrm{MCCl}$}

- Containment design dependent

- Type of concrete (limestone quickly ablates isotropically and generates more gases than basalt-based/silica-rich concrete)

- Basemat thickness

- Cavity size and geometry

- Sequence dependent

- Melt mass released

- Melt composition

- Melt configuration (coolability)

- Presence of water 


\section{Concrete Composition Affects Gas Generation}

\begin{tabular}{|l|c|c|c|}
\hline \multicolumn{4}{|c|}{ Typical chemical composition (wt.\%) } \\
\hline Oxide & $\begin{array}{c}\text { Basaltic } \\
\text { Concrete }\end{array}$ & $\begin{array}{c}\text { Limestone } \\
\text { Concrete }\end{array}$ & $\begin{array}{c}\text { Limestone/Common } \\
\text { Sand Concrete }\end{array}$ \\
\hline $\mathrm{SiO}_{2}$ & 54.73 & 3.60 & 35.70 \\
\hline $\mathrm{CaO}$ & 8.80 & 45.40 & 31.20 \\
\hline $\mathrm{Al}_{2} \mathrm{O}_{3}$ & 8.30 & 1.60 & 3.60 \\
\hline $\mathrm{MgO}$ & 6.20 & 5.67 & 0.48 \\
\hline $\mathrm{Fe}_{2} \mathrm{O}_{3}$ & 6.25 & 1.20 & 1.44 \\
\hline $\mathrm{K}_{2} \mathrm{O}$ & 5.38 & 0.68 & 1.22 \\
\hline $\mathrm{TiO}_{2}$ & 1.05 & 0.12 & 0.18 \\
\hline $\mathrm{Na}_{2} \mathrm{O}$ & 1.80 & 0.08 & 0.82 \\
\hline $\mathrm{MnO}^{2} \mathrm{O}$ & - & 0.01 & 0.03 \\
\hline $\mathrm{Cr}_{2} \mathrm{O}_{3}$ & - & 0.004 & 0.014 \\
\hline $\mathrm{H}_{2} \mathrm{O}$ & 5.00 & 4.10 & 4.80 \\
\hline $\mathrm{CO}_{2}$ & 1.50 & 35.70 & 22.00 \\
\hline
\end{tabular}
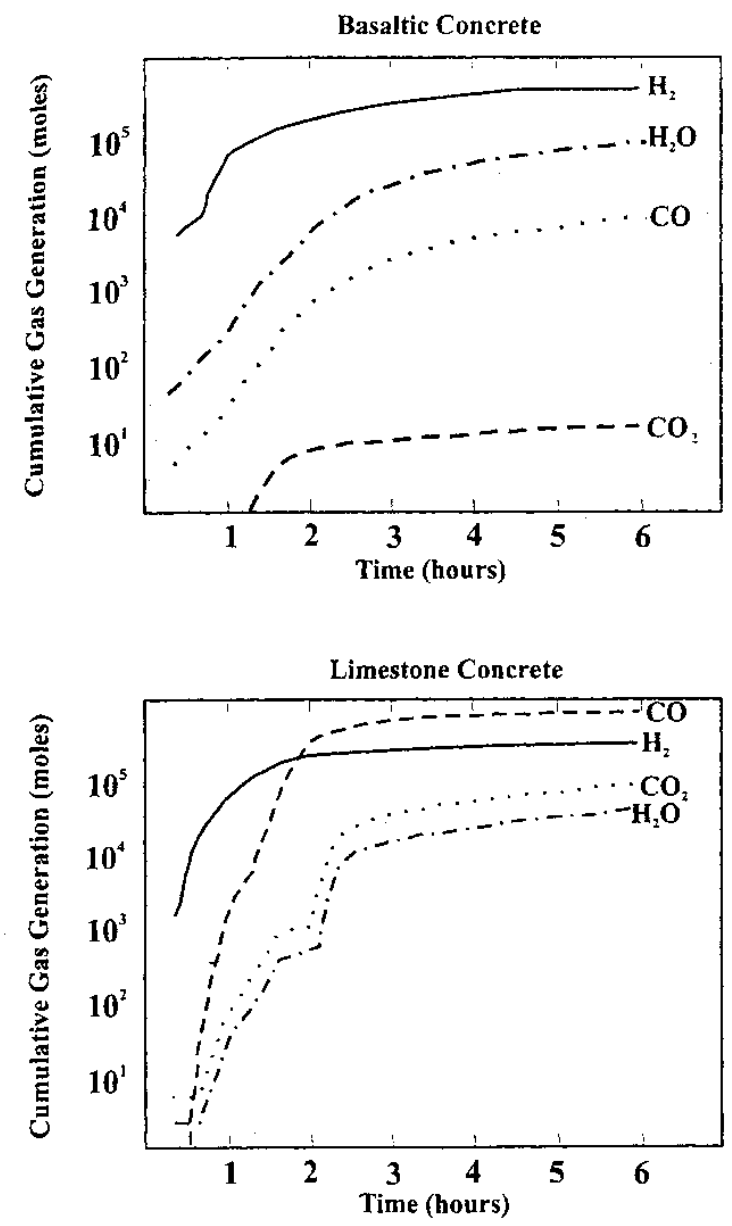

Limestone concrete ablates more rapidly and generates more gases 


\section{Presence of Water Does Not Guarantee Coolability}

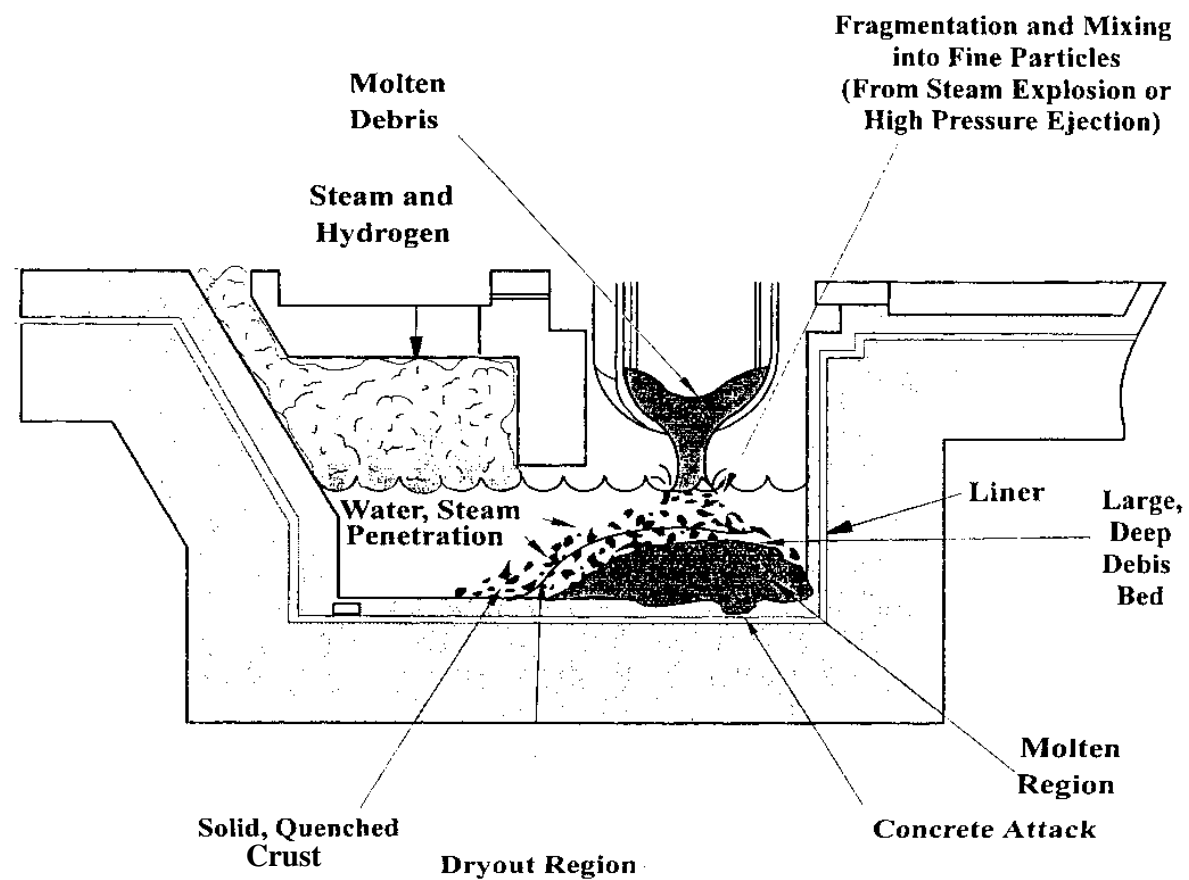

Water can cool released gases and retain some released fission products 


\section{EPR Relies on Large Spreading Area to Guarantee Coolability}

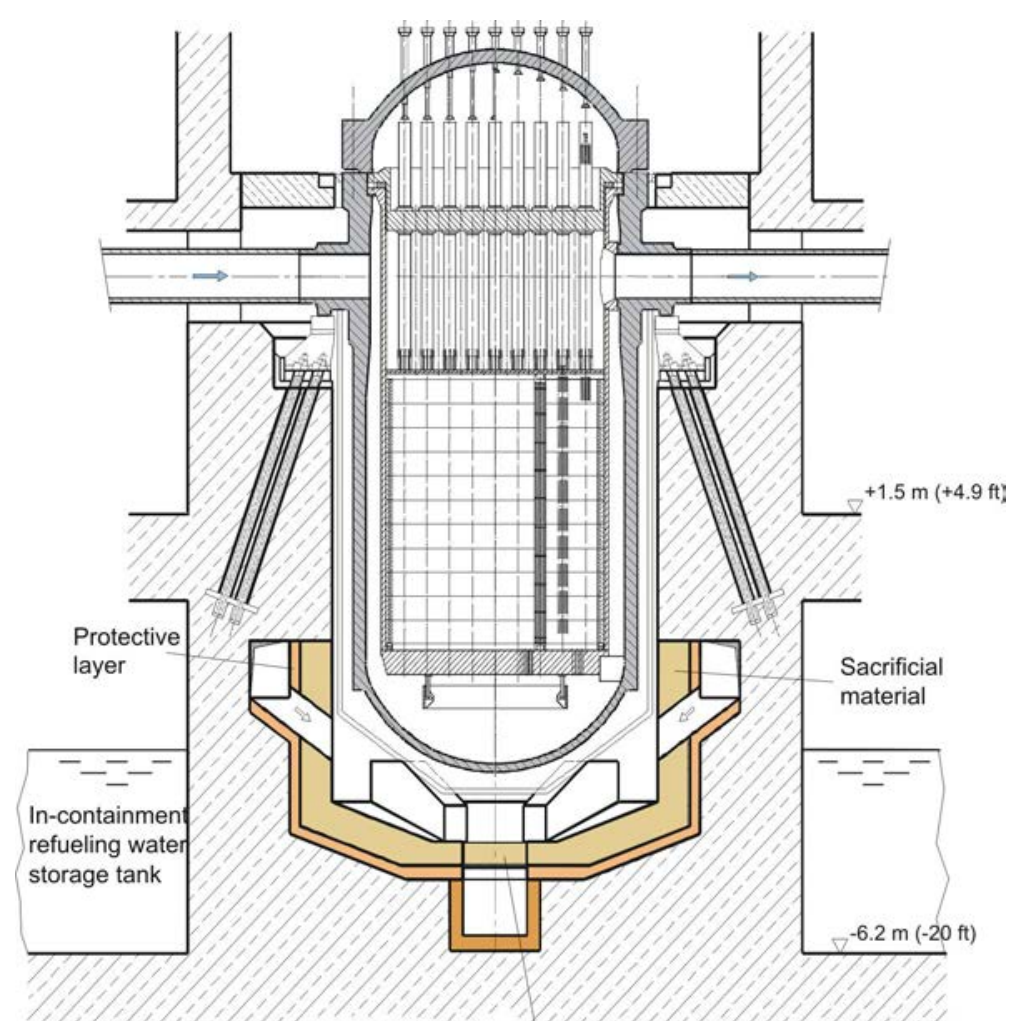

$-7.8 \mathrm{~m}(-25 \mathrm{ft})$

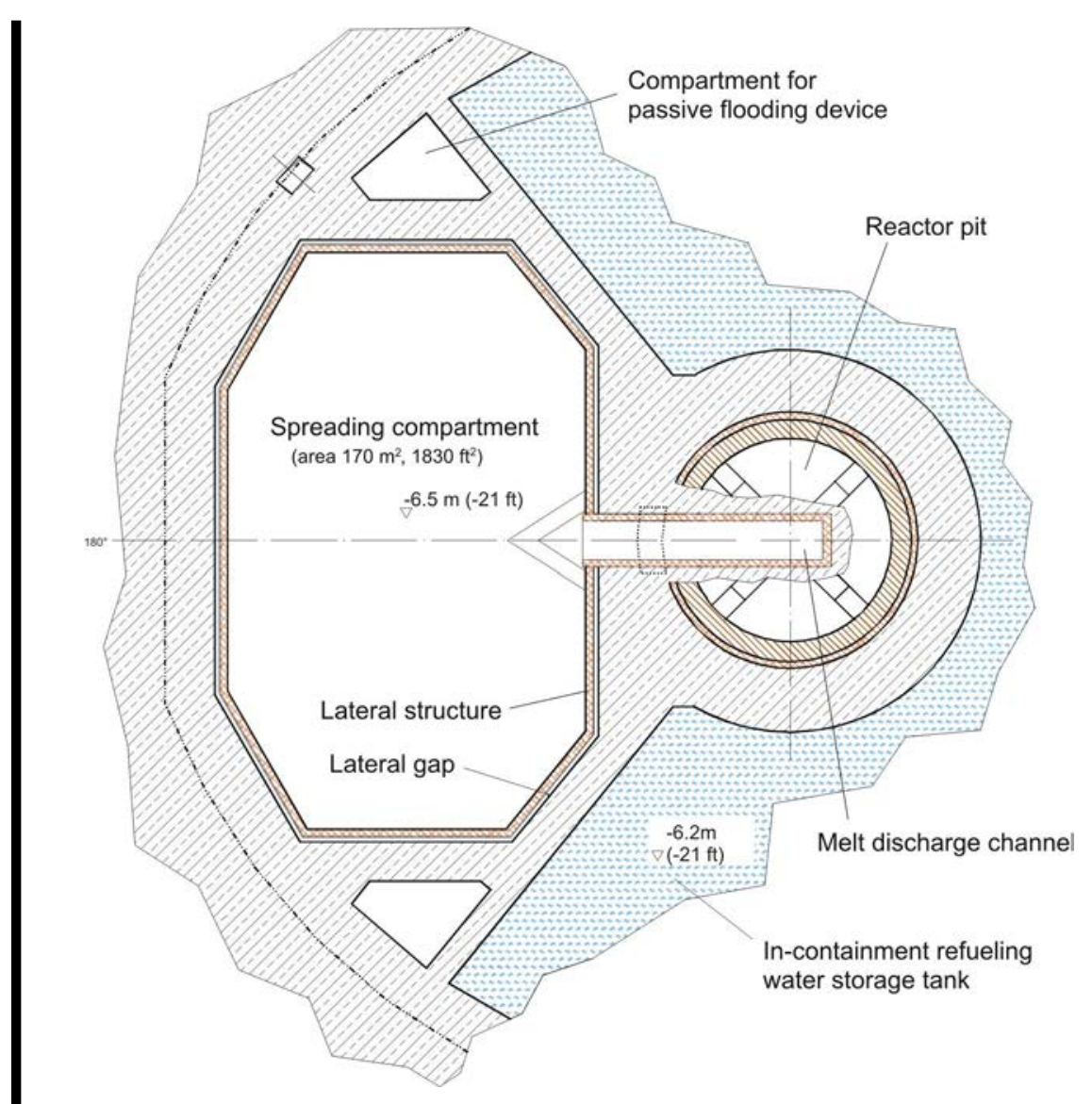

Spreading Area

Reactor Cavity 


\section{Incorporating $\mathrm{MCCl}$ Benefits in Event Mitigation Strategy - EPR Example}

- Refractory layer ensures melt discharge from cavity only occurs at the gate

- Admixture of concrete constituents during $\mathrm{MCCl}$ conditions melt to facilitate spreading

- Heavy and light oxides fully miscible - oxide layer eventually rises above metallic layer

- Metals react with $\mathrm{H}_{2} \mathrm{O}$ and $\mathrm{CO}_{2}$ with $\mathrm{H}_{2}$ and $\mathrm{CO}$ as products

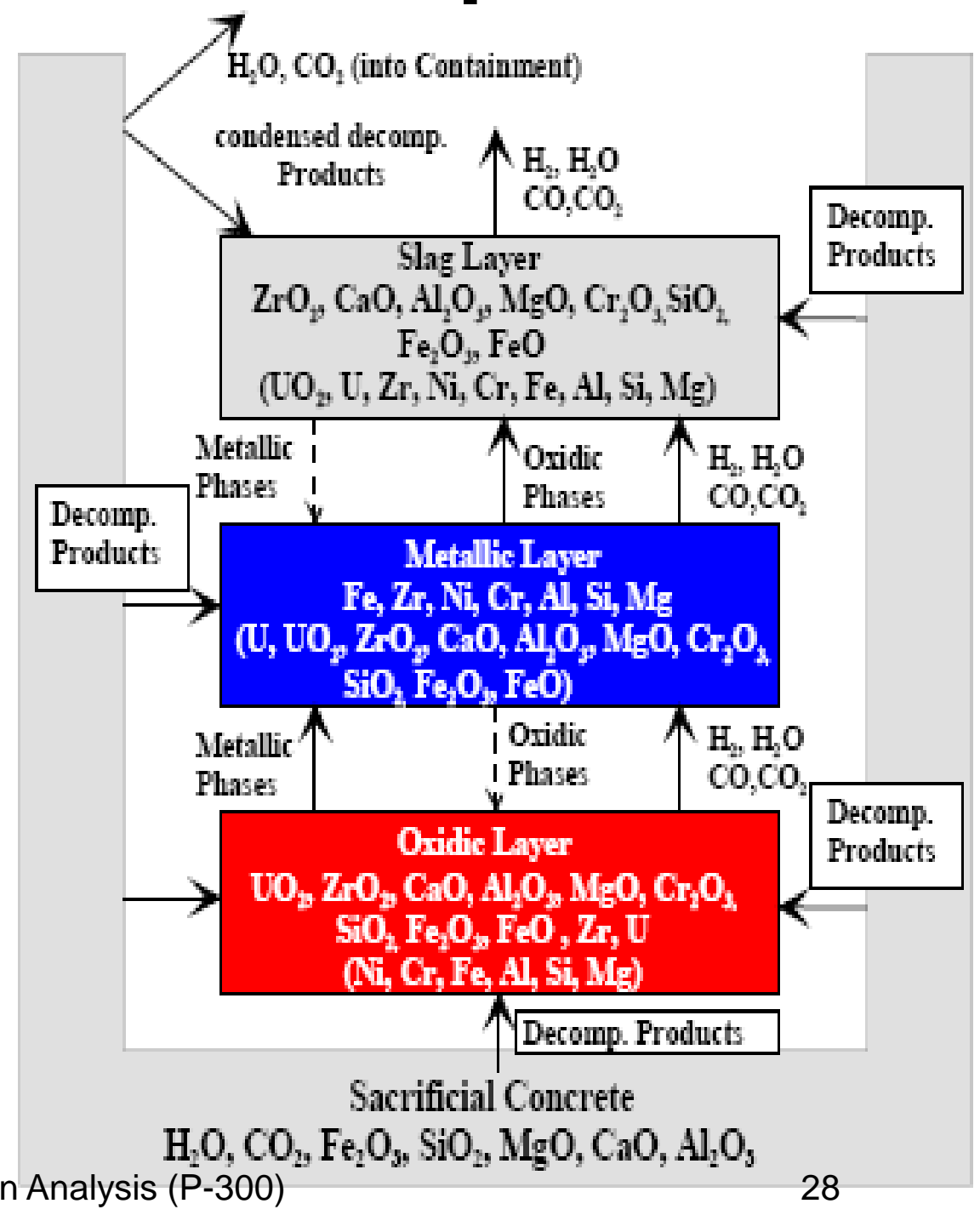




\section{Hydrogen Combustion Issues}

$2 \mathrm{H}_{2}+\mathrm{O}_{2} \rightarrow 2 \mathrm{H}_{2} \mathrm{O}+57.8 \mathrm{kcal} / \mathrm{mole}_{2}$ consumed (229 Btu /mole $\mathrm{H}_{2}$ consumed)

- Under what conditions will hydrogen combustion occur?

- Are pressure loads associated with hydrogen combustion sufficient to threaten containment integrity? 


\section{Hydrogen ignition significantly increased TMI-2 containment pressure}

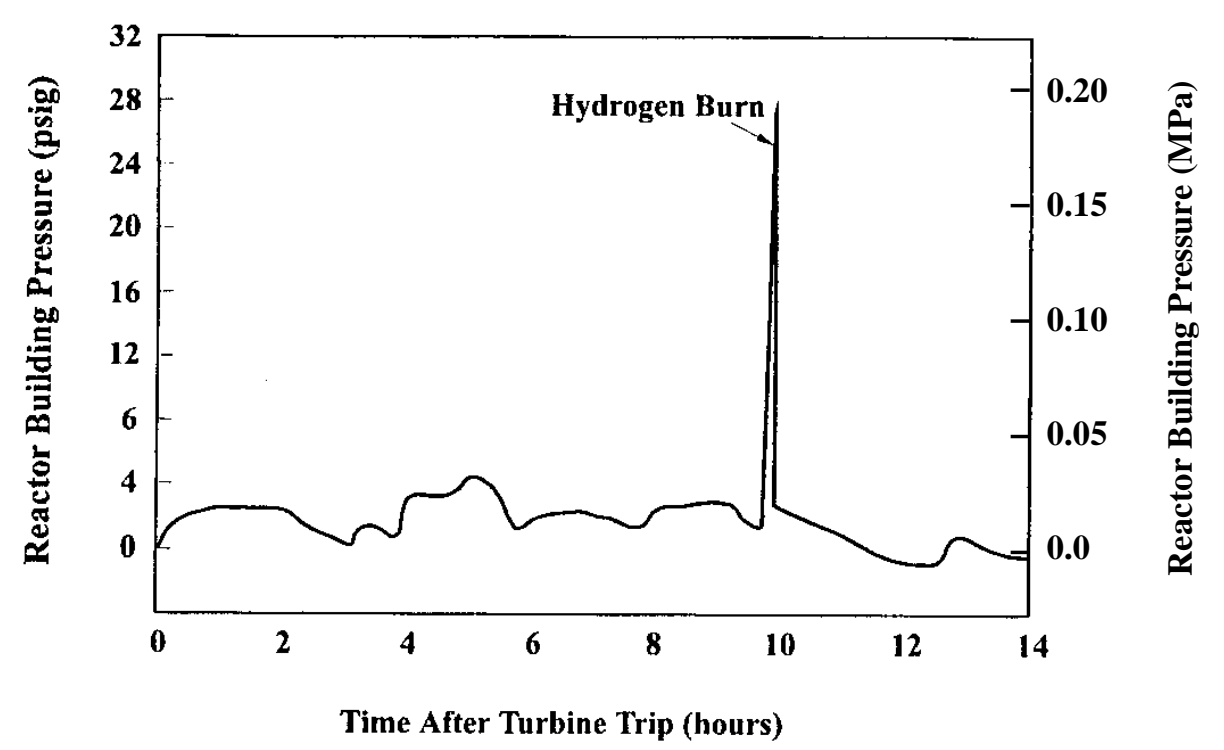

- During core heatup, between 270 to $370 \mathrm{~kg}\left(600\right.$ to $\left.820 \mathrm{lb}_{\mathrm{m}}\right)$ hydrogen released through PORVs ( $40 \%$ of zirconium oxidized)

- Pressure rise corresponds to complete combustion of approximately 8\% hydrogen atmosphere

- Concerns exist about the integrity of containments with smaller net free volumes or smaller design pressures exposed to similar threats 


\section{Two Types of Combustion}

- Deflagration waves

- requires low energy ignition source

- requires $\left[\mathrm{H}_{2}\right]>4$ vol\% and $\left[\mathrm{H}_{2} \mathrm{O}\right]<60$ vol\%.

- travel subsonically $(<35 \mathrm{~m} / \mathrm{s}$ or $<120 \mathrm{ft} / \mathrm{s}$ )

- heat unburned gases to temperatures high enough for chemical reactions to occur

- produce quasi-static containment loads

- Detonation waves

- requires high energy ignition source

- requires $\left[\mathrm{H}_{2}\right]>18$ vol\%

- travel supersonically (at least $2200 \mathrm{~m} / \mathrm{s}$ or $7200 \mathrm{ft} / \mathrm{s}$ )

- heat unburned gases by compression

- produce dynamic or impulsive containment loads in addition to static loads (can generate missiles and challenge containment steel shell). 


\section{Shapiro and Moffette Diagram Depicts Hydrogen: Air: Steam Flammability Limits}

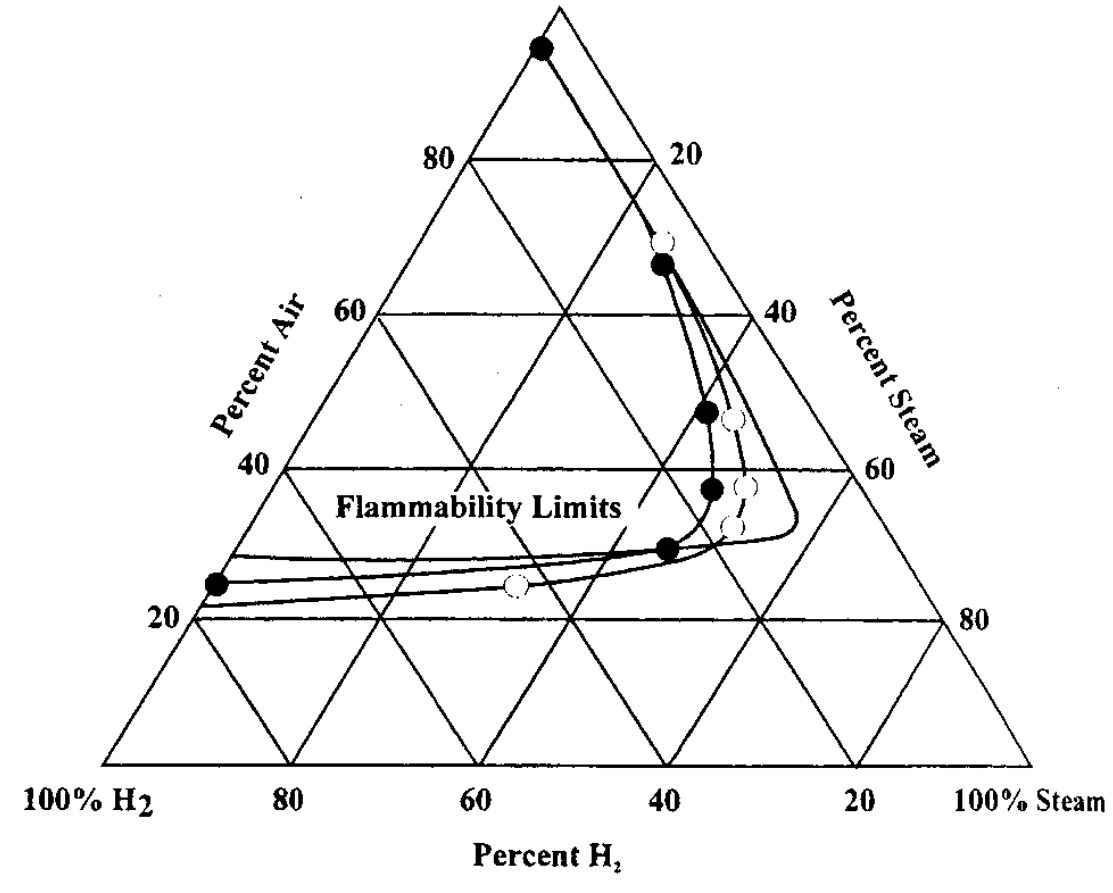

Flammability Limits

$-68^{\circ} \mathrm{F}-187^{\circ} \mathrm{F}$ at $15 \mathrm{psia}\left(20-86^{\circ} \mathrm{C}\right.$ at $\left.0.1 \mathrm{MPa}\right)$

$300^{\circ} \mathrm{F}-0$ psia $\left(150^{\circ} \mathrm{C}\right.$ at $\left.0.1 \mathrm{MPa}\right)$

( $300^{\circ} \mathrm{F}-100$ psia $\left(150^{\circ} \mathrm{C}\right.$ at $\left.892 \mathrm{kPa}\right)$
Limits vary with:

- pressure

- temperature

- $\quad$ presence of steam or other diluents.

Mixture non-flammable if:

- $\left[\mathrm{H}_{2}\right]<4$ vol\%,

- $\left[\mathrm{O}_{2}\right]<5$ vol\%, or

- $\left[\mathrm{H}_{2} \mathrm{O}\right]>60$ vol\% 


\section{RUT Experimental Data Provides Insights about Hydrogen Ignition}

- Series of tests with dynamic hydrogen injection and spark ignition

- Up to $480 \mathrm{~m}^{3}\left(17,000 \mathrm{ft}^{3}\right)$

- 0.6-1.0 kg/s (1.3 - $2.0 \mathrm{lb} / \mathrm{s})$ and 0.1-0.2 $\mathrm{kg} / \mathrm{s}(0.2-0.4 \mathrm{lb} / \mathrm{s}) \mathrm{H}_{2}$ injection

- Ignition made by electric spark operating at 0.1 and $1 \mathrm{~Hz}$.

- Ignition observed to depend most on:

- Distance between injection and ignition point

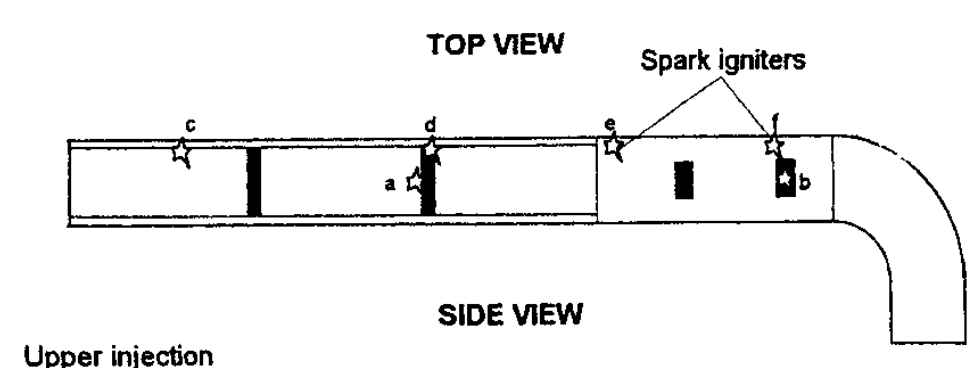

- Mean $\mathrm{H}_{2}$ concentration

- Results used to optimize number and location of igniters and develop $\mathrm{H}_{2}$ combustion criteria

$-\sigma$ criterion to estimate risk of flame acceleration

$-7 \lambda$ criterion to assess non-occurrence of DDT 


\section{Localized Effects May Be Important}

- Higher concentrations of hydrogen

- near release points

- under ceilings or dome due to density stratification,

- near steam removal locations, such as ice condensers, suppression pools, and fan coolers

- within smaller volume compartments

- Equipment susceptible to high pressure or temperature

- Ignition sources

- structures / regions at higher temperature

- electrical equipment sparks 


\section{CFR50.44 Hydrogen Control Requirements Instituted after TMI-2}

- All BWR Mark I and Mark II containments must be inerted during normal operation

- Deliberate ignition required in BWR Mark III and PWR ice condenser containments 


\section{BWR Mark I Liner or Shell Meltthrough Issues}

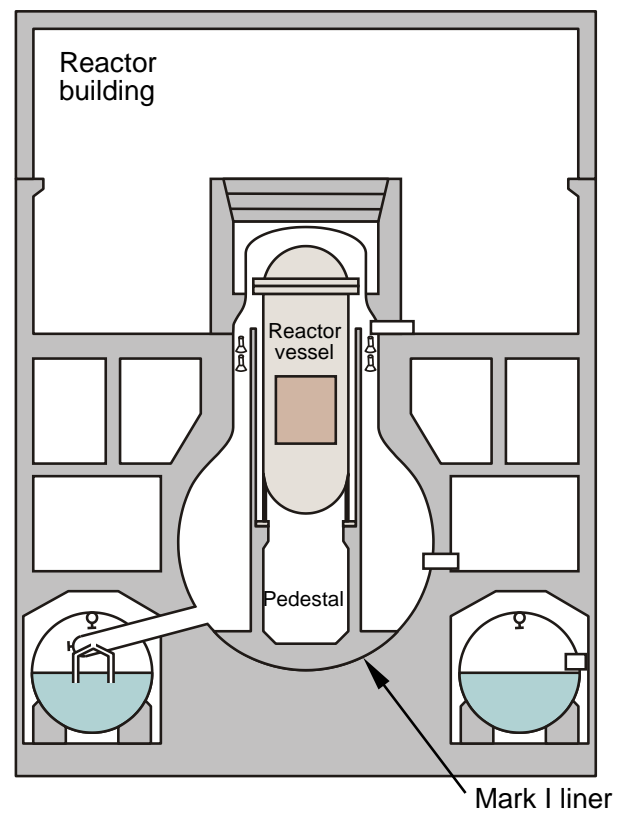

- Is sufficient melt released?

- Does melt contact carbon steel Mark I liner/shell?

- Is heat load from melt sufficient to fail Mark I liner/shell? 


\section{Several Factors Influence Melt-Through}

- Design dependent

- Pedestal door, drywell floor, sump, and downcomer entrance size and geometry

- Sequence dependent

- Melt mass released

- Melt composition

- Melt superheat

- RCS pressure

- Presence of water 


\section{Mark I Liner Failure Studies Led to Several Actions to Reduce Contribution Potential for Liner Meltthrough}

- Mark I Liner failure studies grouped cases by key parameters affecting liner failure

- Pressure

- Drywell Flooding

- Vessel Failure Mode

- Studies recommended several actions to

- Improve success for vessel depressurization

- Revised procedures

- Improve success for drywell flooding

- Availability of alternate water sources to drywell spray header

- Revised criteria for initiation of containment sprays

- Improved diesel pump and spray nozzle designs 


\section{Case Study: DCH in Westinghouse Plants with Large Dry Containments or Subatmospheric Containments}




\section{DCH Resolution Methodology}

\section{Resolution Criterion:}

For events with core damage, threat of early containment failure due to $\mathrm{DCH} \leq 0.1$

\section{Procedure:}

- Analyze several splinter scenarios to envelop conditions for release (melt mass, composition, vessel pressure, etc.)

- Predict containment pressurization pdf.

- Estimate CCFP using plant specific containment fragility curve (from IPEs).

- If CCFP > 0.01 (screening criterion), perform more detailed evaluation, considering probabilities of HPME and/or more refined containment load/strength analysis. 


\section{DCH resolution study assumed IPE containment fragility curves}

Pressure (MPa)

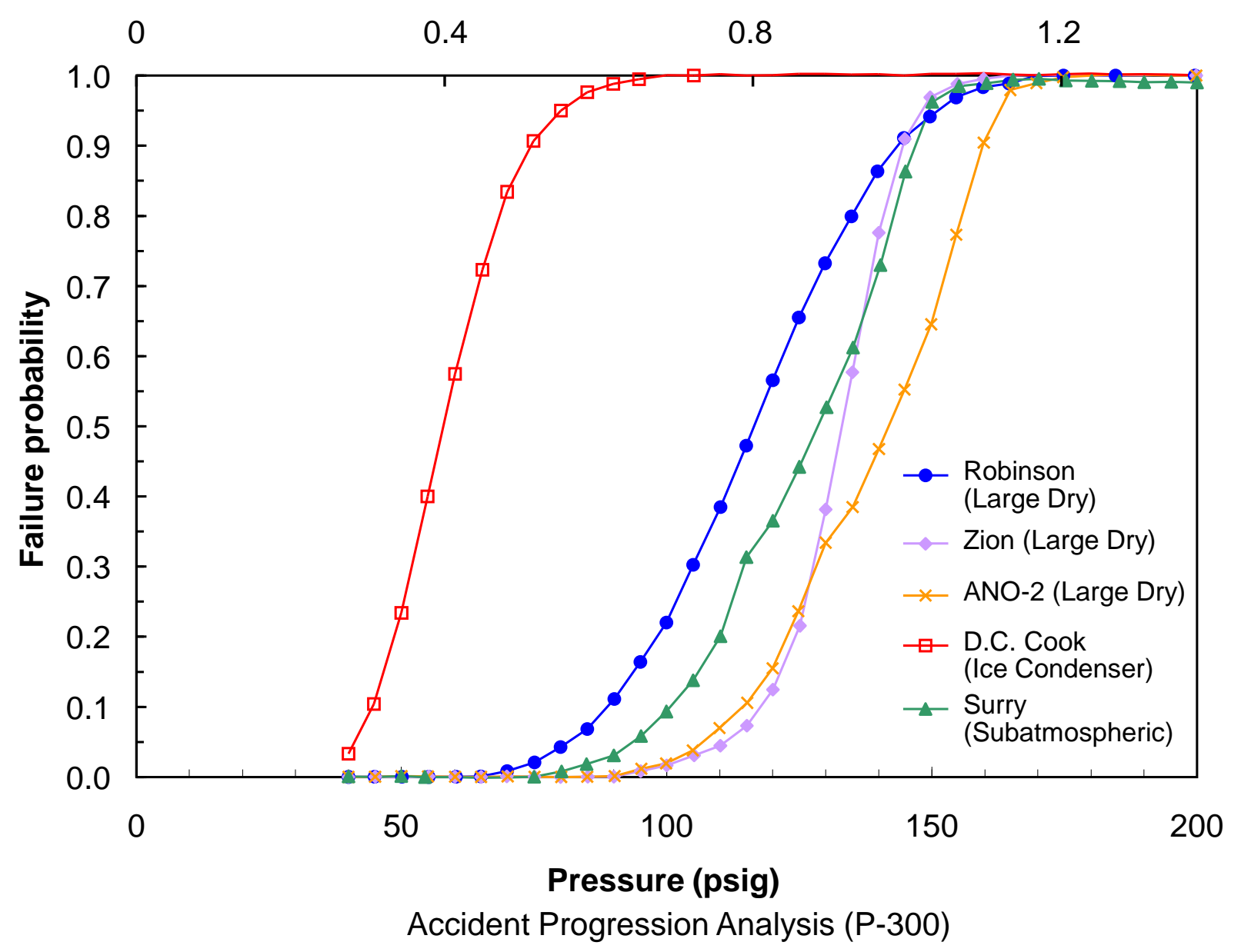




\section{Mean CCFP $<0.01$ for all Westinghouse Large Dry and Subatmospheric Containments}
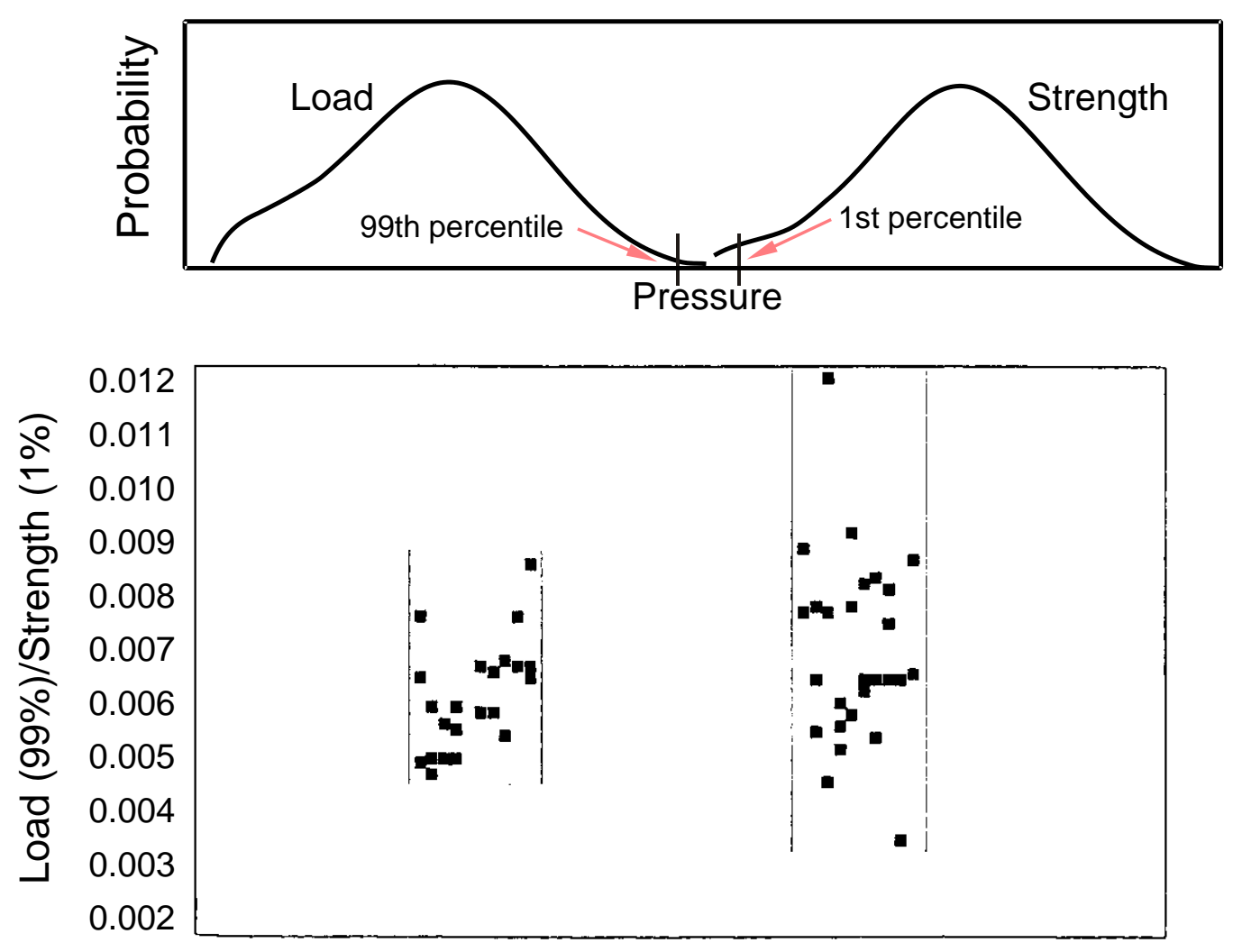

Scenario V
- No intersections of load distributions with fragility distributions for most plants $(\mathrm{CCFP} \sim 0)$.

- Finite, but negligible, intersection predicted for H.B. Robinson (broad containment fragility distribution and dome transport characteristics). 


\section{Problem: How would DCH analysis change if a Mark I containment were considered?}

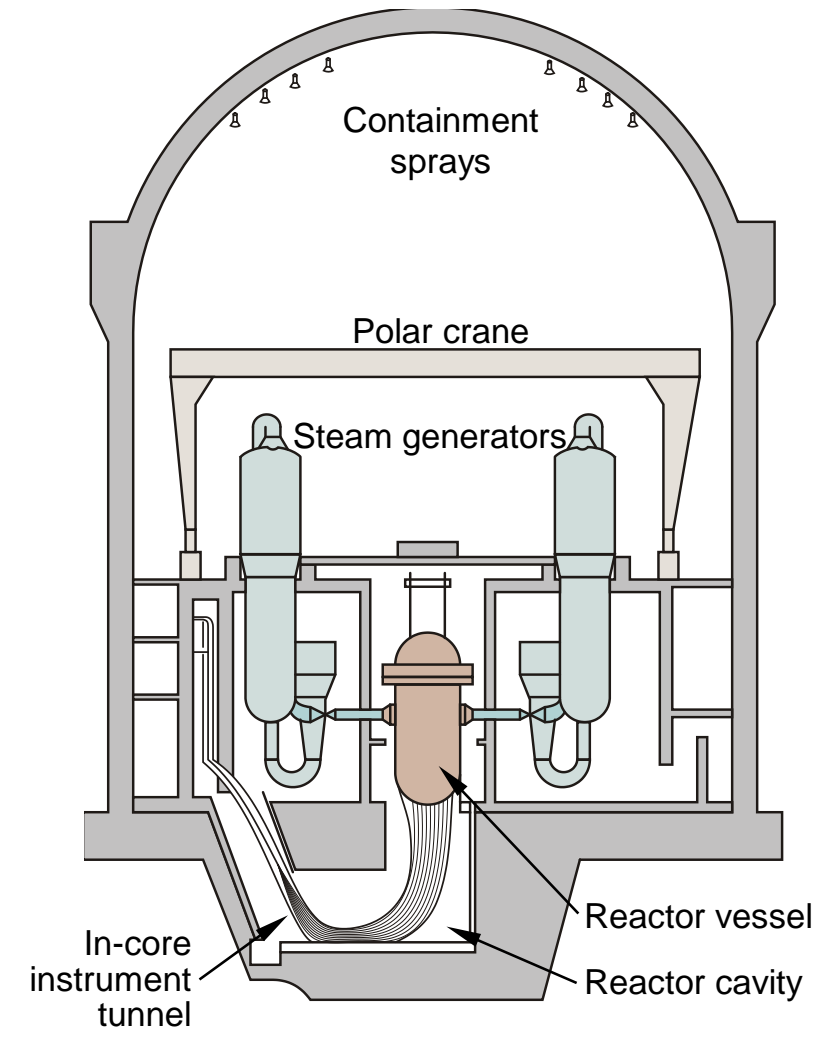

Large dry

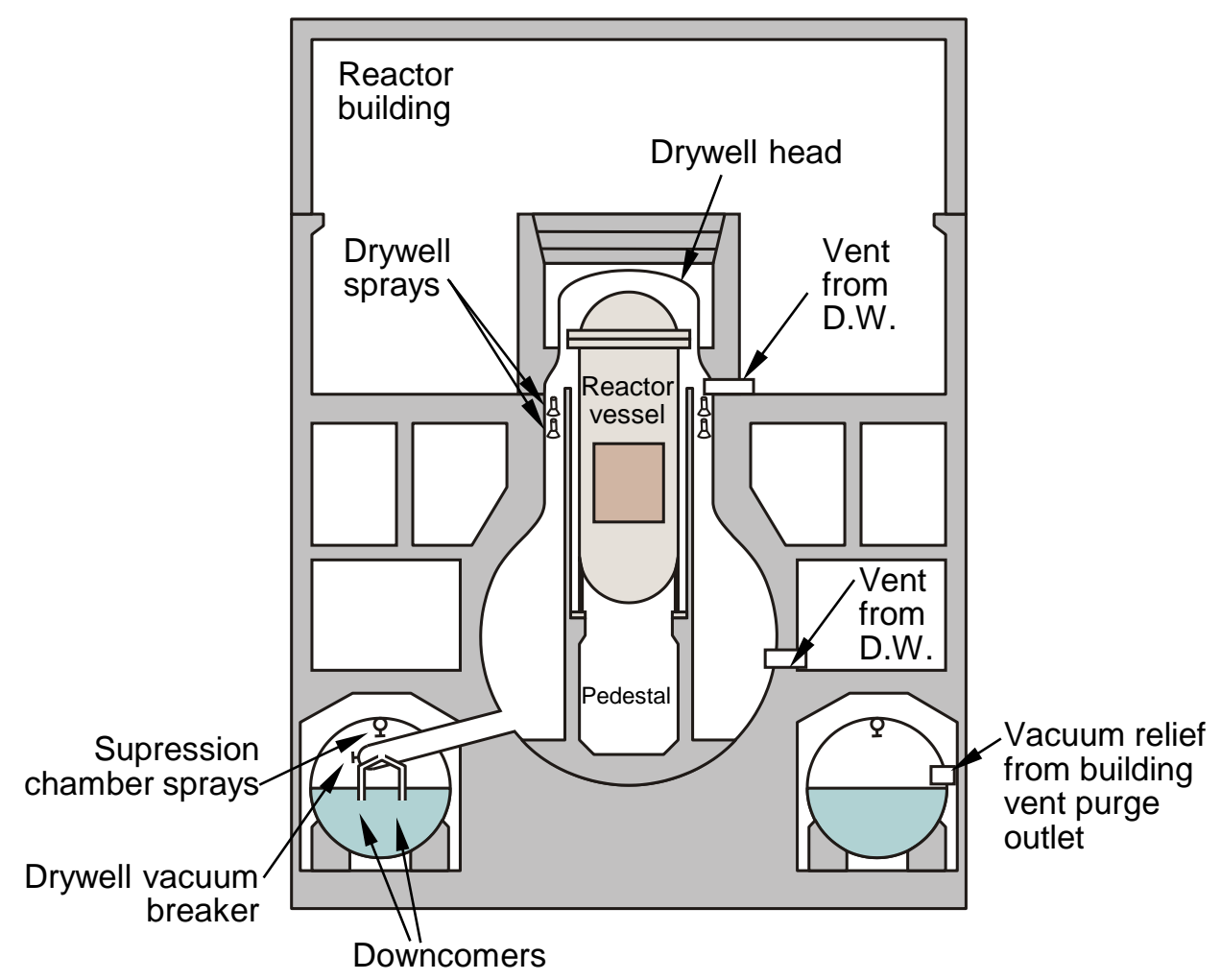

Mark I 


\section{Problem: How would EPR containment integrity evaluations differ?}

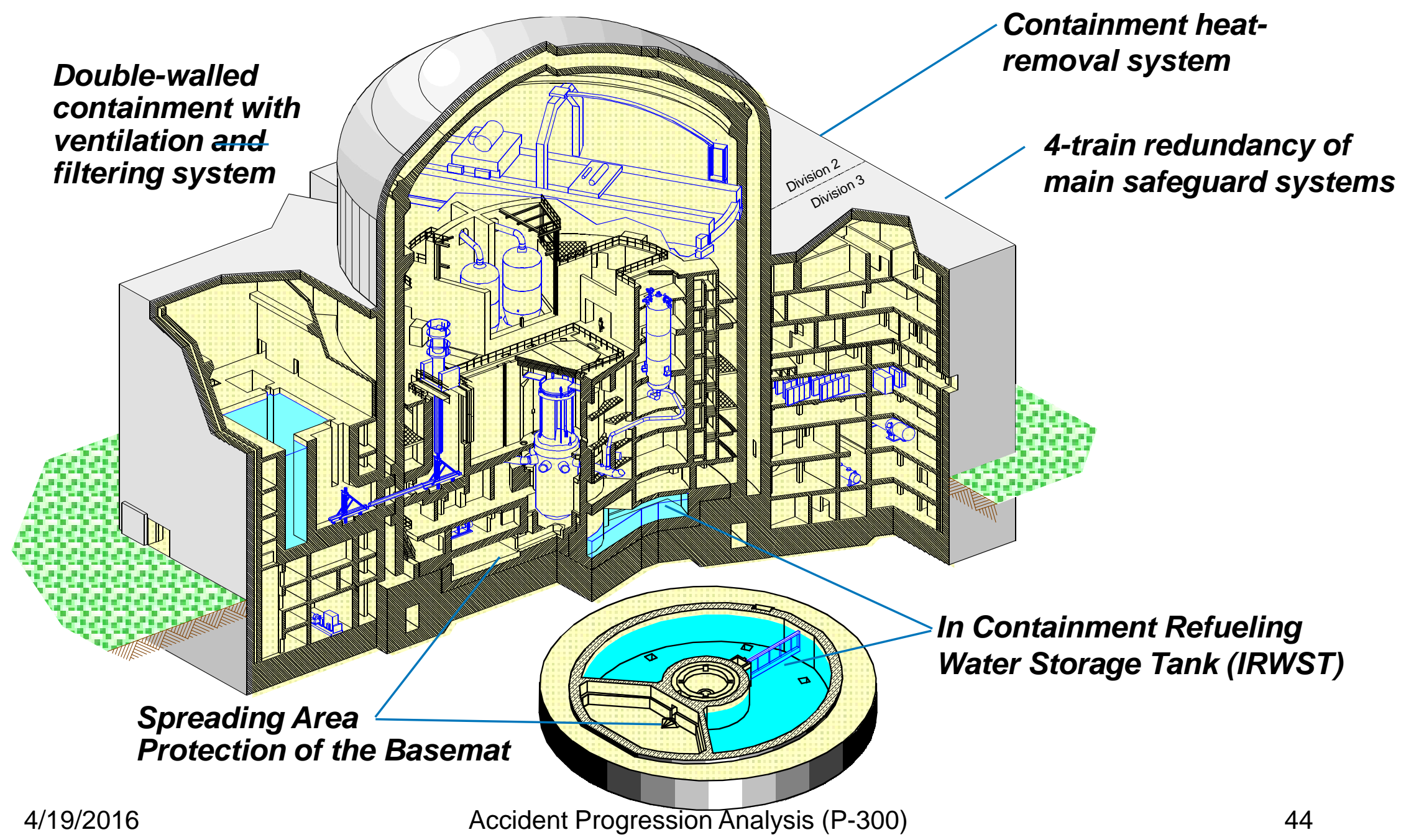




\section{Study Questions}

- Why is containment failure timing important in assessing the risk associated with an accident sequence?

- State the time period when the following challenges to containment integrity dominate.

- Steam explosions

- Direct containment heating

- Molten core concrete interactions

- Hydrogen combustion

- Meltthrough/impingement

- What are key sequence and containment design parameters for evaluating the above challenges to containment integrity? 


\section{References}

\section{General}

- General Individual Plant Examination Program: Perspectives on Reactor Safety and Plant Performance, Final Report, NUREG-1560, December 1997.

\section{In-Vessel and Ex-Vessel Steam Explosions}

- S. Basu and T. Ginsberg, A Reassessment of the Potential for an Alpha-Model Containment Failure and a Review of the Current Understanding of Broader Fuel-Coolant Interaction Issues, NUREG-1524, 1995.

- S. Basu and T. P. Speis, "An Overview of Fuel-Coolant Interactions $(\mathrm{FCl})$ Research at NRC," presented at the 23rd Water Reactor Safety Information Meeting, October 23-25, 1995, Bethesda, Maryland.

- OECD Nuclear Energy Agency and Center for Risk Studies and Safety (UCSB), Proceedings of the CSNI Specialists Meeting on Fuel-Coolant Interactions, NUREG/CP0127 (NEA/CSNI/R(93)8), January 1993.

- M. L. Corradini, "VAPOR Explosions: A Review of Experiments for Accident Analysis," Nuclear Safety, 32, No. 3, July - September 1991.

- D. F. Fletcher, "Steam Explosion Triggering: A Review of Theoretical and Experimental Investigations," Nuclear Engineering and Design, 155, 1995.

- J.H. Song, et al., "Fuel Coolant Interaction Experiments in TROI using $\mathrm{UO}_{2} / \mathrm{ZrO}_{2}$ Mixture," Nuclear Engineering and Design, 222, 2003. 


\section{References}

\section{Direct Containment Heating (DCH)}

- M. M. Pilch, et al., The Probability of Containment Failure by Direct Containment Heating in Zion, NUREG/CR-6075, Supplement 1, December 1994.

- M. M. Pilch, et al., The Probability of Containment Failure by Direct Containment Heating in Surry, NUREG/CR-6109, May 1995.

- M. Pilch, et al., Resolution of the Direct Containment Heating Issue for all Westinghouse Plants with Large Dry Containments or Subatmospheric Containments, NUREG/CR-6338, February 1996.

- M. Pilch, et al., Resolution of the Direct Containment Heating Issue for Combustion Engineering Plants and Babcock \& Wilcox Plants, NUREG/CR-6475, November 1998.

- Assessment of the DCH Issue for Plants with Ice Condenser Containments, NUREG/CR-6427, April 2000. 


\section{References}

\section{DCH (continued)}

- T. K. Blanchat, et al., Experiments to Investigate Direct Containment Heating Phenomena with Scaled Models of the Surry Nuclear Power Plant, NUREG/CR-6152, June 1994.

- T. K. Blanchat, et al., Experiments to Investigate Direct Containment Heating Phenomena with Scaled Models of the Zion Nuclear Power Plant in the Surtsey Test Facility, NUREG/CR-6044, 1995.

- M. D. Allen, et al., Experiments to Investigate the Effects of 1:10 Scale Zion Structures on Direct Containment Heating (DCH) in the Surtsey Test Facility: The IET-1 and IET-1R Tests, SAND92-0255, 1992.

- D. C. Williams, "An Interpretation of the Results of Some Recent Direct Containment Heating (DCH) Experiments in the Surtsey Facility," presented at NURETH-5, September 21-24, 1992, Salt Lake City, Utah. 


\section{References}

\section{Molten Core Concrete Interactions}

- Papers presented at the Second OECD (NEA) CSNI Specialists Meeting on Molten Core Debris-Concrete Interactions, KfK 5108, NEA/CSNI/R(92)10, April 1-3, 1992.

- E. R. Copus and D. R. Bradley, Interaction of Hot Solid Core Debris with Concrete, NUREG/CR-4558, SAND85-1739, June 1986.

- $\quad$ R. K. Cole, et al., CORCON-Mod2: A Computer Program for Analysis of Molten-Core Concrete Interactions, NUREG/CR-3920, SAND84-1246, August 1984.

- M. T. Farmer, et al., "Results of MACE Core Coolability Experiments M0 and M1b," Proceedings of the 8th international Conference on Nuclear Engineering, April 2-6, 2000, Baltimore, MD.

- M. T. Farmer, S. Lomperski, and S. Basu, "Status of the Melt Coolability and Concrete Interaction Program (MCCl) at Argonne National Laboratory," Proceedings of the 2005 International Congress on Advances in Nuclear Power Plants (ICAPP '05), May 15-19, 2005, Seoul, South Korea.

- $\quad$ C. Journeau, J-F. Haquet, Pascal Piluso, J. -M. Bonnet, "Differences between Silica and Limestone Concretes that may affect their Interaction with Corium," Proceeding of the 2008 International Congress on Advances in Nuclear Power Plants (ICAPP '08), Anaheim, CA, June 8-12, 2008. 


\section{References}

\section{Mark I Liner Failure}

- T. G. Theofanous, et al; The Probability of Liner Failure in a Mark-I Containment, NUREG/CR-5423, August 1991.

- T. G. Theofanous, et al., The Probability of Mark-I Containment Failure by MeltAttack of the Liner, NUREG/CR-6025, November 1993.

\section{Hydrogen Combustion}

- A. L. Camp, et al., Light Water Reactor Hydrogen Manual, NUREG/CR-2726, SAND92-1137, August 1983.

- Technical Aspects of Hydrogen Control and Combustion in Severe Light Water Reactors Accidents, National Academy Press, Washington, D.C., 1987.

- S. B. Dorofeev, et al., Recent Experimental and Analytical Results on Hydrogen Combustion at RRC "Kurchatov Institute," presented at the 23rd Water Reactor Safety Information Meeting, October 23-25, 1995, Bethesda, Maryland.

- W. Breitung, et al., Flame Acceleration and Deflagration to Detonation Transition in Nuclear Safety, OECD Nuclear Energy Agency Report NEA/CSNI/R(2000)7, August 2000. 


\title{
Accident Progression Analysis (P-300)
}

\author{
6. CET Development
}

April 2016 


\section{Iind}

\section{Session Objectives}

- To Understand the basic steps and information needs in the CET development process 


\section{(intm}

\section{Level of Detail in CET Varies}

- CET models can be very simple or very complex

- WASH-1400, many IPE's only consist of 6 to 12 top events in event tree

- NUREG-1150 APET's comprised 75 to 125 top events

- Not displayed graphically 


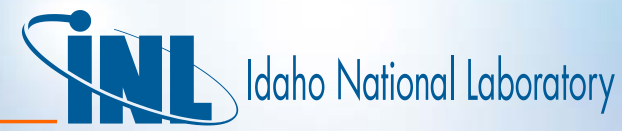

\section{CET Details Determined by Purpose of Level-2 Analysis}

- Is objective of Level-2 analysis to support Level-3 (i.e., generate source terms for health consequences)?

- Is objective of Level-2 limited to a containment analysis?

- Is objective to calculate LERF (i.e., Reg Guide 1.174)?

- Each of the above will yield different looking CET, Compare:

- NUREG-1150 APETs,

- IPE CETS,

- LERF CETs (NUREG/CR-6595) 


\section{CET Covers Multiple Phases}

- Either explicitly or implicitly CET needs to:

- Delineate boundary conditions (i.e., details of level-1 CD sequence, containment isolation, etc.)

- Update/establish status of containment systems (e.g., Recovery of AC power)

- Model progression of accident with respect to actual core damage and RPV/RCS failure

- Model resulting loads on containment structure

- Assign probability of release/source-term to each accident sequence 


\section{Level-2 Analysis Typically Represented as an} Event Tree

- Event trees appropriate modeling choice for chronological progression of a sequence of event

- Ideally, Level-2 analysis would be incorporated into expanded level-1 models (i.e., single integrated ET)

- Direct linking would better accommodate dependencies and obviate much manual manipulation of intermediate results

- Single integrated model, often not practical

- Level-2 analyst usually different from Level-1 analyst

- Modeling and bookkeeping requirements very extensive

- Large, integrated models more difficult to quantify and review 


\section{Potential CET Top Event Sources}

- NUREG-1560 (IPE Insights Report) provides a good overview on likely containment failure mechanisms for all containment types

- Specific IPEs could be utilized

- NUREG/CR-6595 outlines relatively simple CETs for use in estimating a screening LERF

- Standardized Plant Analysis Risk (SPAR) model program developed CETs for several PWR plants 


\section{Containment Failure Categories}

- Bypass Events

- Vessel failure not required for release

- Event V or Interfacing System LOCA (ISLOCA)

- SGTRs

- Largely determined by level-1 CD sequence information

- Early Failures

- Early - usually in relation to the timing of vessel failure (i.e., before, during or shortly after vessel failure)

- Typically within a few hours of the start of core damage

- Late Failures

- Several hours after vessel failure 


\section{Containment Failure}

- If containment is not bypassed, need to assess the likelihood and mode of containment failure

- Containment failure mechanisms are scenario dependent

- Mode of RPV failure has major impact on magnitude of containment challenges

- e.g., Does RPV fail while RCS is at high pressure or low pressure? 


\section{Analyze Containment Loads}

- Many challenges need to be considered

- Internal pressure rises (usually considered "static")

- High temperatures

- Thermo-mechanical erosion of concrete structures (molten core concrete interaction)

- localized dynamic loads (e.g. shock waves and internally generated missiles)

- Analyses often distinguish between catastrophic failures and leaks

- Location of failure is also important

- e.g., wetwell versus drywell 


\section{Loads Can be Characterized at Different Levels of Detail}

- A series of specific "small" estimates can be made, or a single estimate of the total pressure

- What is the pressure?

- Add the pressure from a number of contributors

- Initial pressure

- Pressure from DCH

- Pressure from steam explosion

- Pressure from hydrogen combustion

- etc.

- Both approaches have been used 


\section{Estimate Challenges to Containment Integrity (for example)}

- Hydrogen generation and combustion

- Fuel-coolant interactions (steam explosions)

- Melt/debris ejection following RV failure (DCH)

- Debris bed coolability and core-concrete interaction

- Shell melt-through failure in Mark-I containments

- Long-term overpressure

- Basemat melt-through

- Each phenomena depends on accident progression characteristics and containment design 


\section{Early Containment Failures}

- Early containment failure mechanisms include:

- direct contact of the core debris with steel containments

- rapid pressure and temperature loads

- hydrogen combustion

- missiles generated by fuel-coolant interactions (sometimes referred to as steam explosions or alpha-mode failures)

- containment isolation failures

- sometimes include containment venting (depending on when vents are opened) 


\section{Late Containment Failures}

- Late containment failures include:

- gradual pressure and temperature increases

- hydrogen combustion

- basemat melt-through by core debris

- sometimes include containment venting (depending on when vents are opened) 


\section{CET Endstate Defines Source Term}

- Primary purpose of CET

- Frequency and characteristics of source term

- Possibly as simple as large and early (LERF)

- Possibly very complex

- Amount of radioactive material released

- Start and end time of release

- Energy of release

- Location (elevation) of release 


\section{CET End-State Descriptions Vary}

- For example, common output forms include:

- Large Early Release Frequency (LERF)

- Large early containment failure plus bypass

- Containment Failure (CF) Mode Descriptions

- Accident Progression Bins

- Often segregated into:

- Early CF, Late CF and Containment Bypass

- Source Term Descriptions

- For input to a Level-3 (Consequence) analysis 


\section{CET Provides Needed Source Term Information}

- Specific information needed determined by the source term analysis method

- Example: SEQSOR (Sequoyah NUREG-1150)

- Simple, fast-running parametric code that extrapolates and interpolates results from more detailed mechanistic codes and expert judgement

- Early and late radioactive release fractions calculated for nine isotope classes (comprising 60 radionuclides)

- Information needed by SEQSOR organized into a 14-character Accident Progression Bin (APB) vector 


\section{SEQSOR Input (APB Vector)}

1 Time of containment failure

2 Period in which sprays operate

3 Occurrence of $\mathrm{CCl}$

$4 \quad R C S$ press before $V B$

5 Mode of VB

6 SGTR

7 Amount of core available for $\mathrm{CCl}$

8 Fraction of $\mathrm{Zr}$ oxidized in vessel

9 Fraction of core in HPME

10 Size or type of containment failure

11 \# of large holes in RCS after VB

12 Early ice condenser function

13 Late ice condenser function

14 Status of air return fans 


\section{Example: SEQSOR Characteristic 1 - Containment Failure Time}

A $V$-Dry Event $V$, releases not scrubbed by fire suppression sprays

B V-Wet Event $V$, releases scrubbed by fire suppression sprays

C CF-E Containment failure during core degradation

D CF-VB Containment failure at vessel breach

E CF-L Late containment failure (during initial CCl, nominally a few hours after VB)

$F \quad C F-V L \quad$ Very late containment failure (from 12 to 24 hours after VB

G NoCF No containment failure 


\section{Parametric Source Term Code}

- XSOR codes written specifically for NUREG-1150 plants

- Parametric Source Term (PST) code developed in 1996 under Accident Sequence Precursor (ASP) program

- PST developed to provide source terms for all U.S. PWRs

- Estimates source terms for 9 release classes comprising approximately 60 isotopes 


\section{PST Input Uses 10-Character Vector}

$1 \quad$ Containment Failure Mode

2 Status of Containment Heat Removal Systems

3 Occurrence of Core Concrete Interactions

$4 \quad$ RCS Pressure at Vessel Breach

$5 \quad$ Mode of Vessel Breach

$6 \quad$ Occurrence of SGTR

7 Presence of Water in Reactor Cavity

8 Amount of Oxidation in Vessel

9 Containment Failure Size

10 Core Damage Time 


\section{Example: PST Characteristic 1 - Containment Failure Mode}

\section{ID Definition}

A Containment bypass

B Containment not isolated

C Early containment failure (near time of vessel breach)

D Late containment failure

E No containment failure 


\section{Most Level-2 Analyses Involve a Mix of Supporting Information}

- Plant-specific code calculation

- MAAP, MELCOR, SCDAP/RELAP5

- Analyses from other prior PRAs or severe accident studies

- NUREG-1150, IPES

- Engineering analyses of specific issues

- Threat from hydrogen combustion

- Experimental data

- Debris coolability 


\begin{tabular}{|c|c|c|c|c|c|c|c|}
\hline Accident & Containment & Phenomena & & & & & \\
\hline Progression & Failure & or & & & & & \\
\hline Phase & Mode & Mechanism & Lg Dry & Ice Cond & Mark-I & Mark-II & Mark-III \\
\hline \multirow[t]{4}{*}{ Bypass } & ISLOCA & & Yes & Yes & Yes & Yes & Yes \\
\hline & SGTR & & Yes & Yes & No & No & No \\
\hline & Induced SGTR & & Yes & Yes & No & No & No \\
\hline & Induced Isol Cond tube failure & & No & No & BWR/2\&e3 & 3 No & No \\
\hline \multirow[t]{4}{*}{ CF before VB } & \multicolumn{2}{|c|}{ Isolation Failure (includes pre-existing leak) } & Yes & Yes & Yes & Yes & Yes \\
\hline & Venting & & No & No & Yes & Yes & Yes \\
\hline & Over Pressure & Steam & Yes & Yes & Yes & Yes & Yes \\
\hline & & H2 combustion & Yes & Yes (SBO) & inerted & inerted & Yes (SBO) \\
\hline \multicolumn{8}{|l|}{ CF at VB } \\
\hline \multirow[t]{4}{*}{ LP-RCS } & IVSE (FCl) & & Yes & Yes & Yes & Yes & Yes \\
\hline & EVSE (FCl) & & Yes & Yes & Yes & Yes & Yes \\
\hline & H2 combustion & & Yes & Yes & inerted & inerted & Yes \\
\hline & Liner (Shell) Melt-Thru & & No & No & Yes & No & No \\
\hline \multirow[t]{5}{*}{ HP-RCS } & IVSE (FCl) & & Yes & Yes & Yes & Yes & Yes \\
\hline & HPME (RPV blowdown) & $\mathrm{DCH}$ & Yes & Yes & Yes & Yes & Yes \\
\hline & & Steam & Yes & Yes & Yes & Yes & Yes \\
\hline & & H2 combustion & Yes & Yes (SBO) & inerted & inerted & Yes (SBO) \\
\hline & & Direct Impingement & Yes & Yes & No & Yes & Yes \\
\hline \multirow[t]{5}{*}{ CF after VB } & Venting & & No & No & Yes & Yes & Yes \\
\hline & Over Pressure $(\mathrm{CCl})$ & Steam & Yes & Yes & Yes & Yes & Yes \\
\hline & & Non-Cond. & Yes & Yes & Yes & Yes & Yes \\
\hline & & H2 combustion & Yes & Yes & Yes & Yes & Yes \\
\hline & Basemat melt-thru & & Yes & Yes & Yes & Yes & Yes \\
\hline
\end{tabular}




\section{7int}

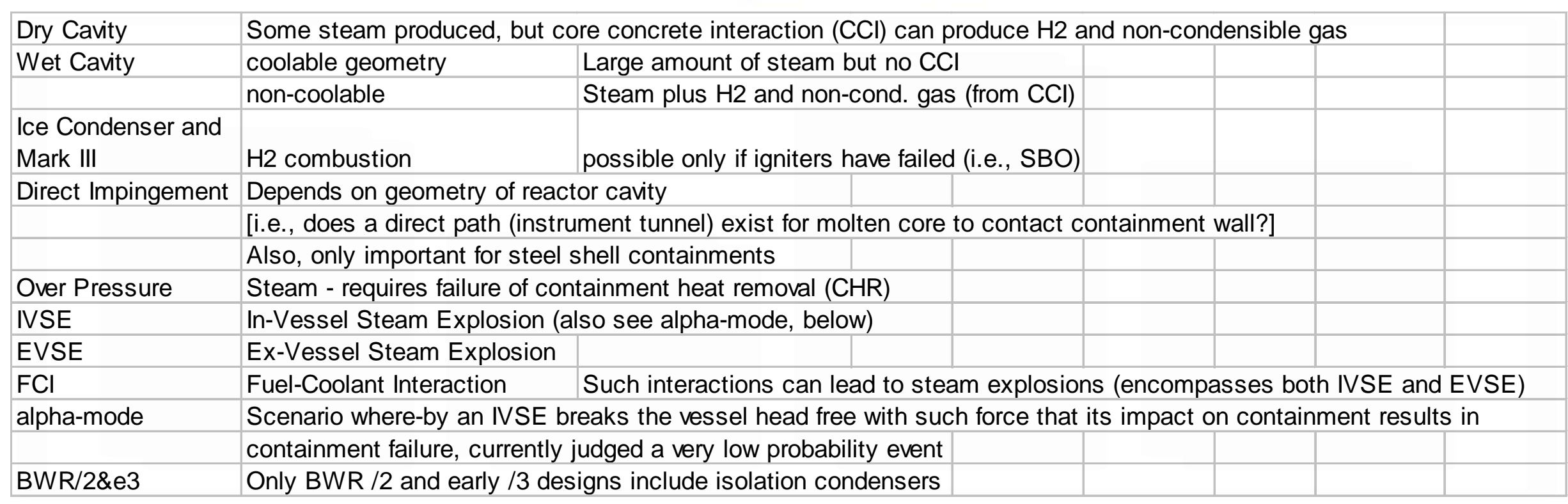




\title{
SPAR Level-2 Models (SAPHIRE ver. 7)
}

\author{
April 2016
}




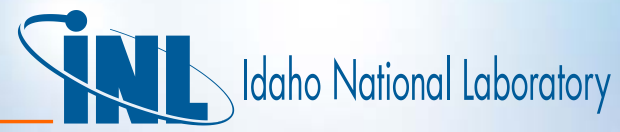

\section{Work Began July 2008}

- July 2008: Work began to develop integrated Level-1/Level-2 SPAR model using SAPHIRE ver. 7

- SOW specified three models

- Surry

- Peach Bottom

- Sequoyah 


\section{TII Idaho National laboratory}

\section{Level-2 Modeling Relies on Series of Event Trees Linked Together}

- Level-1 core damage sequences extended using Containment Systems Transfer Event Tree (CST-ET)

- Simple transfer from Level-1 ET (sometimes called Bridge Event Tree)

- CST-ET then transfers to Plant Damage State Event Tree (PDS-ET)

- Binning of CD sequences to PDSs provides detailed characteristics on each $C D$ sequence

- PDS becomes "Initiating Event" for level-2 portion of analysis

- Only PDS identifier and associated frequency are transferred to level-2 


\section{CST-ET Simple Transfer from CD ET}

- Objective is to capture dependencies between level-1 systems analysis and level-2 systems analysis

- Also referred to a Bridge Tree

- Level-1 SPAR models commonly use event tree transfers - this is just one more

- However, top event substitutions via logic rules need to be coordinated between level-1 event trees and CST-ET 


\section{CST-ET for Sequoyah}

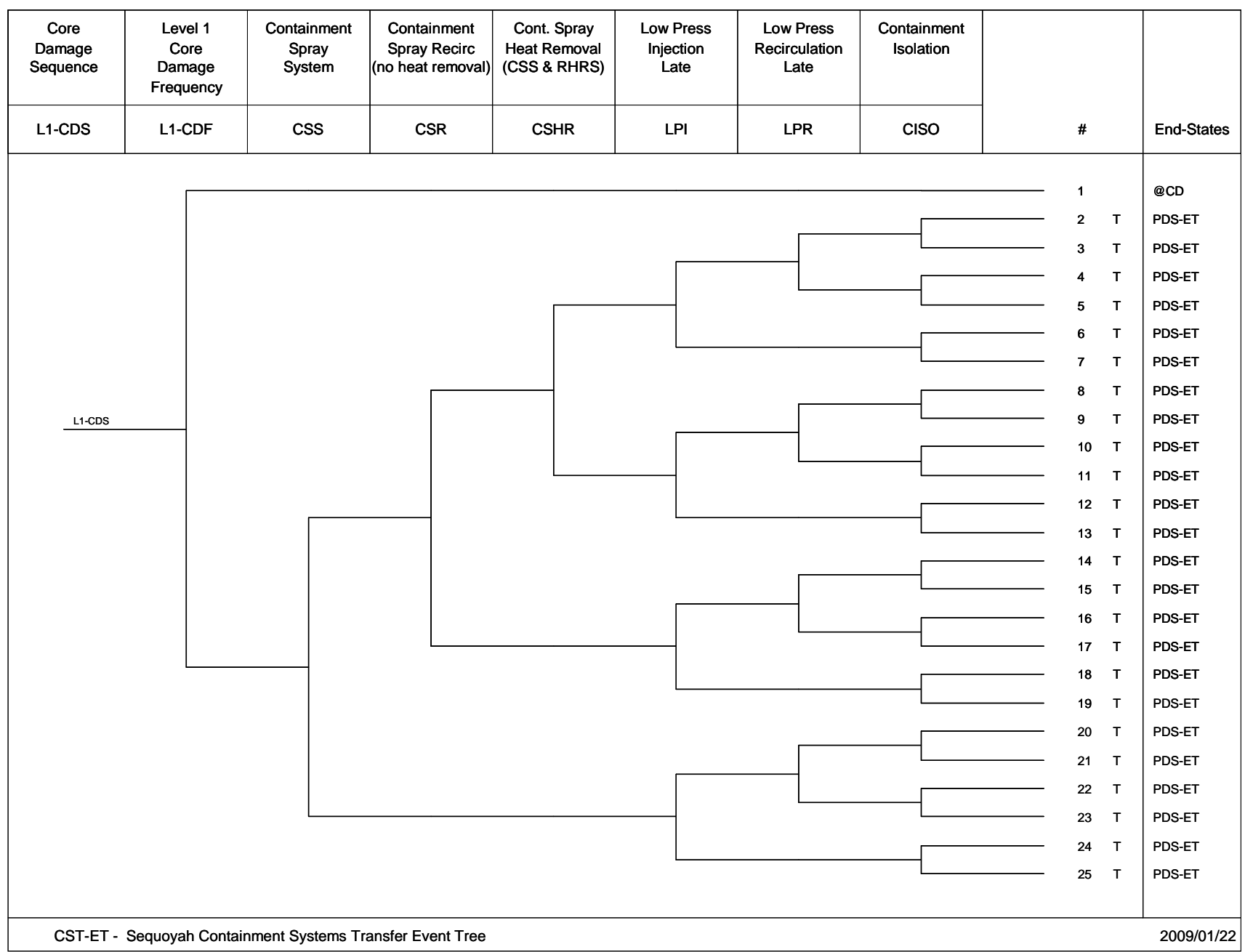




\section{TII Idaho National laboratory}

\section{CST-ET End States Transfer to PDS-ET}

- PDS-ET assigns each CD-containment systems sequence to one of the Plant Damage States

- PDS-ET logic rules search on combined level-1/CST-ET sequence logic

- Complete sequence logic carried through to PDS binning process

- Process relies on two types of SAPHIRE rules

- Logic rules for development of sequence logic

- Partitioning rules for generating PDS vector information 


\section{PDS Identifier Uses Vector Format}

- SAPHIRE capable of producing end-state information in two ways

- End state identified on event tree

- PDS-\#

- End state generated via "Partition" rules

- Partition rules used to produce PDS vector

- PDS captures 11 characteristics of CD sequence

- Each position of PDS vector associated with one of the 11 characteristics (top events on PDS-ET)

- PDS-ABCDEFGHIJK 
PDS Characteristics for Sequoyah

1. Containment isolation 7. Status of secondary Status side heat removal

2. Containment bypass 8. RCS pressure at CD status

3. Type of CD accident

9. Status of containment spray (CS)

4. Occurrence of SBO

5. Status of $A C$ power recovery

6. Occurrence of severe accident induced LOCA

10. Operation of CS for containment heat removal

11. Status of In-vessel injection before RPV fails 


\begin{tabular}{|c|c|c|c|c|c|c|c|c|c|c|c|c|c|}
\hline $\begin{array}{c}\text { Core } \\
\text { Damage } \\
\text { Sequence }\end{array}$ & $\begin{array}{c}\text { Containment } \\
\text { Isolation } \\
\text { Status } \\
1\end{array}$ & $\begin{array}{c}\text { Containment } \\
\text { Bypass } \\
2\end{array}$ & $\begin{array}{l}\text { Type } \\
\text { of } \\
\text { Accident } \\
3\end{array}$ & $\begin{array}{c}\text { Station } \\
\text { Blackout } \\
4\end{array}$ & $\begin{array}{c}A C \\
\text { Power } \\
\text { Recovery } \\
5\end{array}$ & $\begin{array}{c}\text { Consequential } \\
\text { LOCA } \\
6\end{array}$ & $\begin{array}{c}\text { Secondary } \\
\text { Heat } \\
\text { Removal } \\
7\end{array}$ & $\begin{array}{c}\text { RCS } \\
\text { Pressure } \\
\text { at } C D \\
8\end{array}$ & $\begin{array}{c}\text { CS Injection } \\
\text { or Recirc } \\
\text { w/o HR } \\
9\end{array}$ & $\begin{array}{l}\text { Containment } \\
\text { Heat Removal } \\
\text { via CS } \\
10\end{array}$ & $\begin{array}{c}\text { In-Vessel } \\
\text { Inject before } \\
\text { RPV fails } \\
11\end{array}$ & & \\
\hline $\cos$ & CONISOLAT & CONBYPASS & AOCIDENT & SBO & POWRECOV & CONSLOCA & SECHETREM & RCSPRESS & CONTSPRAY & CONHETREM & INVESSINJ & $\#$ & End-States \\
\hline
\end{tabular}

PDS Event Tree for Sequoyah

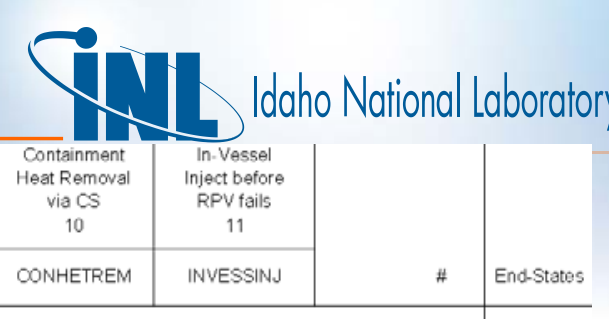

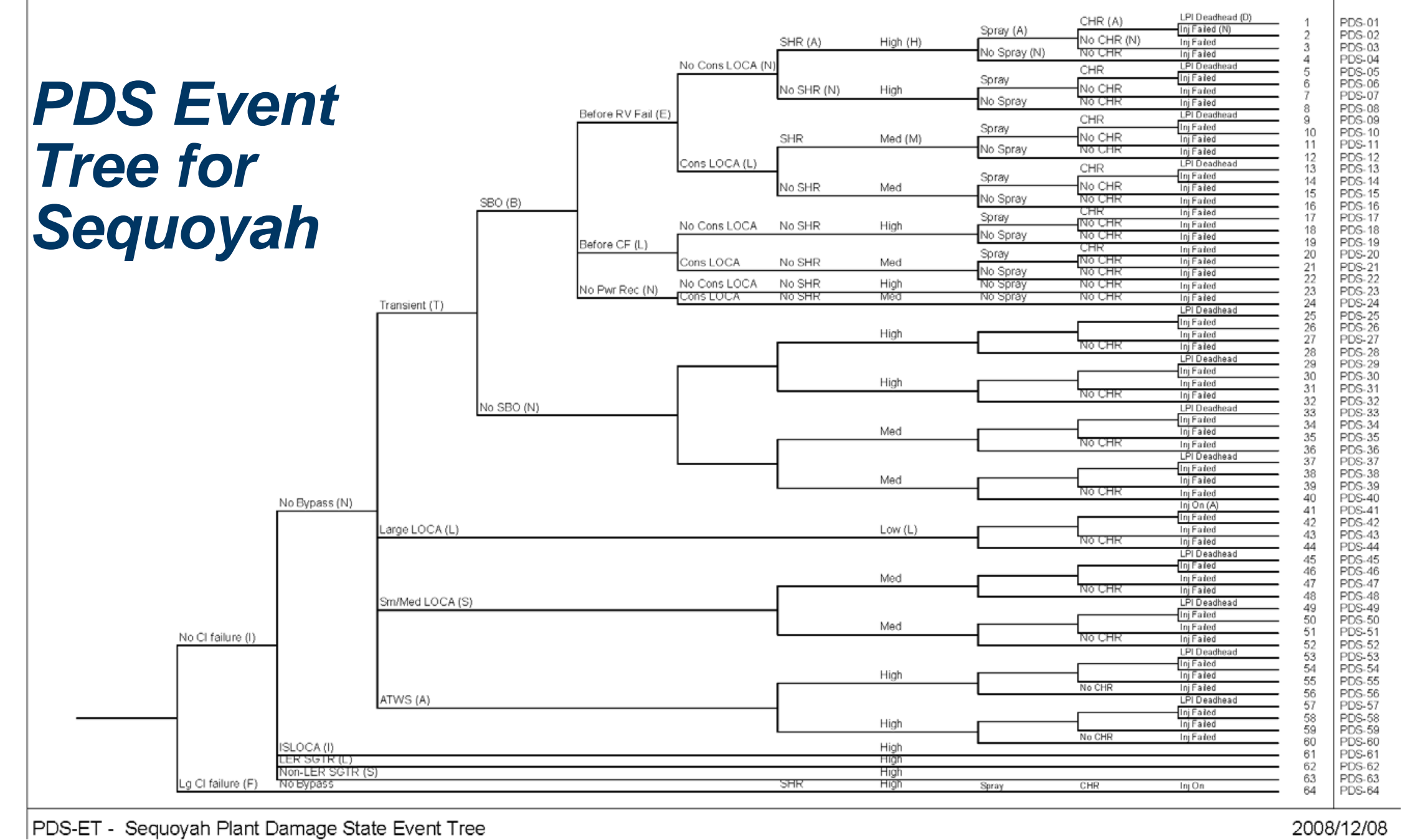




\section{PDS-ET Logic Rules Example}

I 2 - CONBYPASS

| Containment Bypass

| Branch[0] = No Bypass

| Branch[1] = ISLOCA

| Branch[2] = Large Early Release SGTR

| Branch[3] = No-LER SGTR

| if ISLOCA initiating event

if init(IE-ISL-HPI) + init(IE-ISL-LPI) + init(IE-ISL-RHR) then /CONBYPASS = skip(CONBYPASS);

CONBYPASS[1] = DE-ISLOCA; | set DE to 1.0

CONBYPASS[2] = skip(CONBYPASS);

CONBYPASS[3] = skip(CONBYPASS);

| SGTR but no LER

elsif init(IE-SGTR) * /FW * /SGI * (ISSC-SGTR + ISSC1) then

/CONBYPASS = skip(CONBYPASS);

CONBYPASS[1] = skip(CONBYPASS);

CONBYPASS[2] = skip(CONBYPASS);

CONBYPASS[3] = DE-NLR-SGTR; | set DE to 1.0
| SGTR with LER

elsif init(IE-SGTR) then

/CONBYPASS = skip(CONBYPASS);

CONBYPASS[1] = skip(CONBYPASS);

CONBYPASS[2] = DE-LER-SGTR; | set DE to 1.0

CONBYPASS[3] = skip(CONBYPASS);

| Default to No-Bypass

else

ICONBYPASS = DE-N-NOBYPASS;

| complimented, so set to zero

CONBYPASS[1] = skip(CONBYPASS);

CONBYPASS[2] = skip(CONBYPASS);

CONBYPASS[3] = skip(CONBYPASS);

endif 


\section{PDS Serves as an Intermediate Calculation Point}

- PDS-ET Logic Directs Sequence Freq to Appropriate End-State

- Process referred to as Binning

- PDS-ET end states only identified with a number (e.g., PDS-23, PDS-41)

- PDS will be the start of the severe accident analysis

- i.e., will be the "initiating" event for the containment analysis

- Containment Event Tree (CET) is the "real" level-2 PRA

- (NUREG-1150 used the name APET - Accident Progression Event Tree, a much more detailed CET) 


\section{PDS Vector Generated Via Partitioning}

- SAPHIRE term used to describe process of allocating sequence cut sets using rules

- Partitioning can be done on the sequence cut-sets or on sequence logic (as was done for SPAR)

- SAPHIRE allows partitioning rules to construct the PDS vector

- Partitioning generates an alternate version of the event tree endstate

- E.g., PDS-35 E PDS-INTNZLAMANZ 


\section{PDS Vector Partitioning Example}

| 2

I CONBYPASS - Containment Bypass

| Branch[0] $=$ No Bypass $(\mathrm{N})$

| Branch[1] = ISLOCA (I)

| Branch[2] = Large Early Release SGTR (L)

| Branch[3] = SGTR but not a Large Early Release (S)

I

| Define Partition Macros (PM) for top event parameters

PM-NO-BYPASS = SYSTEM $(/ D E-N-$ NOBYPASS);

PM-ISLOCA = SYSTEM(DE-ISLOCA);

PM-LER-SGTR = SYSTEM(DE-LERSGTR);

PM-SGTR = SYSTEM(DE-NLR-SGTR);
If PM-NO-BYPASS then

GlobalPartition = "PDS-?N";

Elsif PM-ISLOCA then

GlobalPartition = "PDS-?l";

Elsif PM-LER-SGTR then

GlobalPartition = "PDS-?L";

Elsif PM-SGTR then

GlobalPartition = "PDS-?S";

Else

GlobalPartition = "PDS-?Z"; 


\section{(int}

\section{PDS Results for Sequoyah}

$\begin{array}{ccc}\text { PDS } \# & \text { PDS Vector } & \text { Frequency } \\ \text { SBO } & & \\ \text { PDS-08 } & \text { PDS-INTBENNHNNN } & 3.80 \mathrm{E}-06 \\ \text { PDS-16 } & \text { PDS-INTBELNMNNN } & 1.48 \mathrm{E}-06 \\ \text { PDS-19 } & \text { PDS-INTBLNNHNNN } & 1.09 \mathrm{E}-06 \\ \text { PDS-22 } & \text { PDS-INTBLLNMNNN } & 3.57 \mathrm{E}-07 \\ \text { PDS-23 } & \text { PDS-INTBNNNHNNN } & 9.69 \mathrm{E}-07 \\ \text { PDS-24 } & \text { PDS-INTBNLNMNNN } & 4.10 \mathrm{E}-07 \\ \text { SBO Subtotal } & 8.10 \mathrm{E}-06 \\ \text { Trans } & & \\ \text { PDS-25 } & \text { PDS-INTNZNAHAAD } & 2.25 \mathrm{E}-10 \\ \text { PDS-26 } & \text { PDS-INTNZNAHAAN } & 4.19 \mathrm{E}-07 \\ \text { PDS-27 } & \text { PDS-INTNZNAHANZ } & 1.40 \mathrm{E}-07 \\ \text { PDS-28 } & \text { PDS-INTNZNAHNNN } & 3.68 \mathrm{E}-11 \\ \text { PDS-29 } & \text { PDS-INTNZNNHAAD } & 1.84 \mathrm{E}-07 \\ \text { PDS-30 } & \text { PDS-INTNZNNHAAN } & 9.97 \mathrm{E}-09 \\ \text { PDS-31 } & \text { PDS-INTNZNNHANZ } & 9.73 \mathrm{E}-08 \\ \text { PDS-32 } & \text { PDS-INTNZNNHNNN } & 0.00 \mathrm{E}+00 \\ \text { PDS-33 } & \text { PDS-INTNZLAMAAD } & 2.76 \mathrm{E}-08 \\ \text { PDS-34 } & \text { PDS-INTNZLAMAAN } & 1.01 \mathrm{E}-06 \\ \text { PDS-35 } & \text { PDS-INTNZLAMANZ } & 2.98 \mathrm{E}-05 \\ \text { PDS-36 } & \text { PDS-INTNZLAMNNN } & 7.27 \mathrm{E}-09 \\ \text { PDS-37 } & \text { PDS-INTNZLNMAAD } & 0.00 \mathrm{E}+00 \\ \text { PDS-38 } & \text { PDS-INTNZLNMAAN } & 3.06 \mathrm{E}-11 \\ \text { PDS-39 } & \text { PDS-INTNZLNMANZ } & 1.04 \mathrm{E}-09 \\ \text { Transient } & \text { Subtotal } & 3.17 \mathrm{E}-05\end{array}$

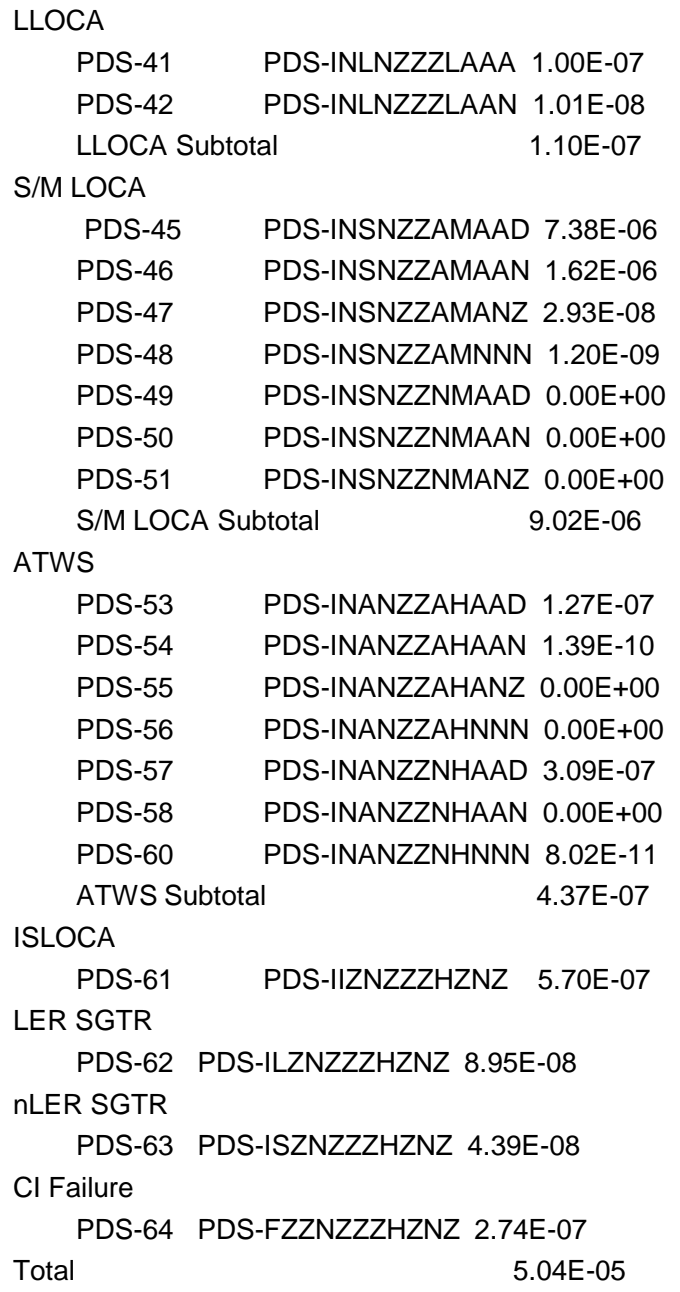




\section{Each PDS Vector Becomes an IE}

- SAPHIRE converts each PDS vector into an Initiating Event

- SAPHIRE automatically generates a "dummy" event tree with PDS name

- This is directed by the user in the Partitioning Rules

- PDS vector ET then transfers to CET for actual severe accident (i.e., level-2) analysis

- Note: PDSs are just core damage sequences with additional descriptive information on details of the accident 
- Containment Event Tree models the response of the Reactor Pressure Vessel (RPV) and containment to the Core Damage Sequence (CDS)

- Mode and severity of RPV failure affects challenge to containment structure

- CET logic rules query status of plant systems and then assign appropriate probabilities to various phenomena in severe accident progression

- PDS vector contains information on status of plant systems 


\section{CET Top Events}

CONBYPAS - Status of Containment Bypass

RCSFAIL - Mode of Induced RCS failure

SGTRPATH - Path of release from SGTR

INVCOOL - Status of core debris cooling in-vessel

CF-EARLY - Mode of Early

Cont. Failure
RS-EARLY - Early status of Recirc. Spray

EXVCOOL - Status of core debris cooling ex-vessel

CONHETRE - Status of Cont. Heat Removal

CF-LATE - Mode of Late Cont. Failure 


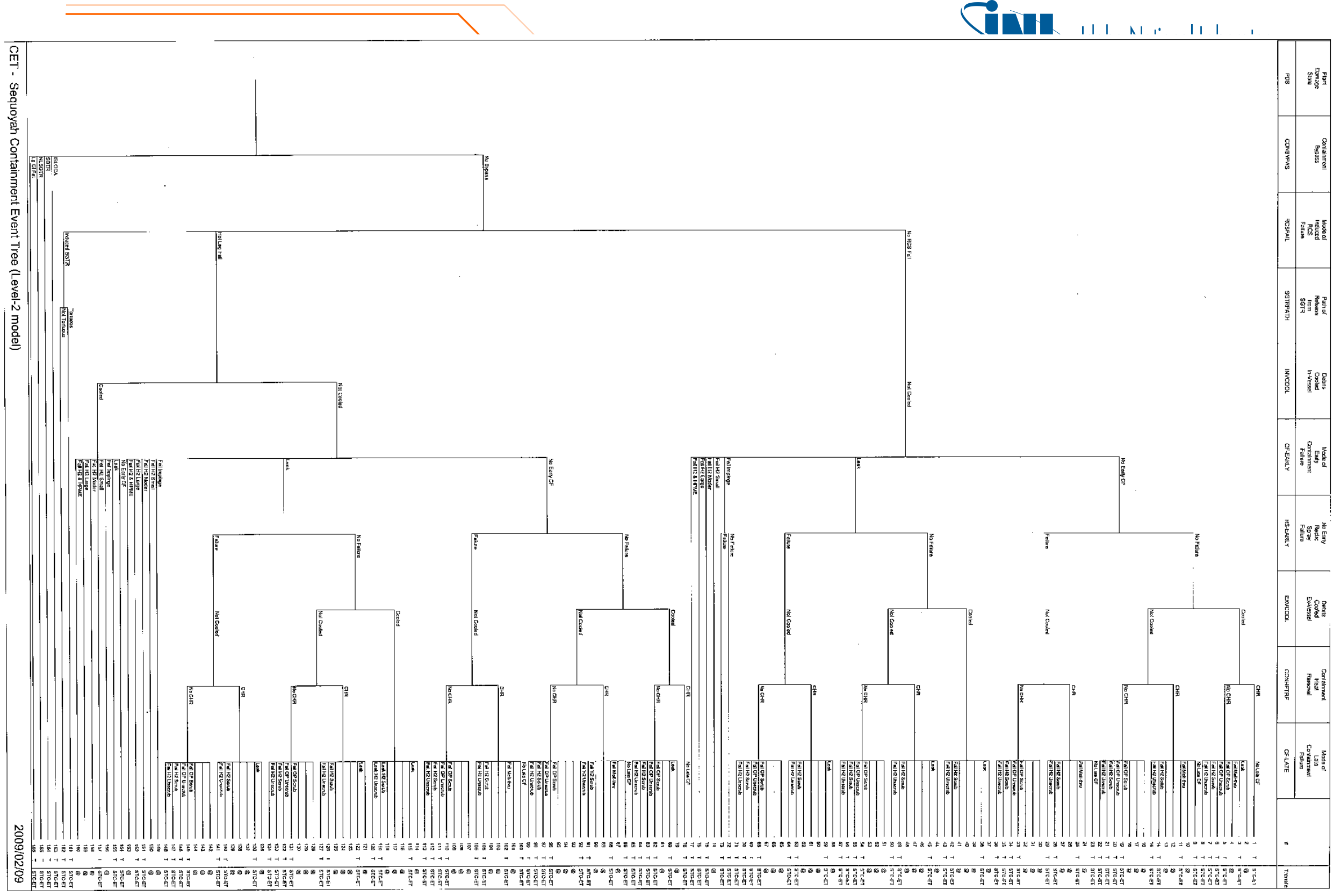




\section{CET End States Transfer to STC-ET}

- Source Term Category Event Tree (STC-ET) sorts the CET sequences into release categories

- Direct event tree transfer

- Logic rules in STC-ET used to query CET top event logic 


\section{STC-ET Assigns Release Category to Each CET Sequence}




\section{STC-ET Collects Sequence Frequencies}

\begin{tabular}{|l|l|l|}
\hline Release Category & Description & Frequency \\
\hline REL-LER & Large Early & $4.76 \mathrm{E}-06$ \\
\hline REL-MER & Medium Early & $3.03 \mathrm{E}-06$ \\
\hline REL-SER & Small Early & $0 \mathrm{E}+00$ \\
\hline REL-LLR & Large Late & $1.14 \mathrm{E}-05$ \\
\hline REL-MLR & Medium Late & $1.46 \mathrm{E}-05$ \\
\hline REL-SLR & Small Late & $6.40 \mathrm{E}-06$ \\
\hline REL-LK & Leak & $1.27 \mathrm{E}-07$ \\
\hline REL-NO & No Release & $1.00 \mathrm{E}-05$ \\
\hline Total & & $5.03 \mathrm{E}-05$ \\
\hline
\end{tabular}




\section{Severe Accident Simulation Codes}

- Introduction

- Codes - SCDAP/RELAP5, MELCOR, MAAP MAAP

- Case Studies

- Methods

- Study Questions

- References 


\section{Objectives}

- Identify various methods used in the US for modeling severe accident progression.

- Understand what phenomena are modeled by each method.

- Understand differences in modeling approaches that may impact code predictions. 


\section{Code Design Philosophies Differ}

\begin{tabular}{|l|l|l|}
\hline \multicolumn{1}{|c|}{ Method } & \multicolumn{1}{|c|}{ Developer/Sponsor } & \multicolumn{1}{c|}{ Design Philosophy } \\
\hline $\begin{array}{l}\text { SCDAP/RELAP5 } \\
\text { SCDAP/RELAP5-3D }\end{array}$ & $\begin{array}{l}\text { ISL/NRC/United States } \\
\text { INL/DOE }\end{array}$ & $\begin{array}{l}\text { Detailed mechanistic models } \\
\text { Limited to RCS } \\
\text { Limited user parameters }\end{array}$ \\
\hline MELCOR & SNL/NRC/ United States & $\begin{array}{l}\text { Simplified or mechanistic models (depending on phenomena) } \\
\text { Integrated RCS and containment analysis } \\
\text { Extensive user parameters }\end{array}$ \\
\hline MAAP & $\begin{array}{l}\text { FAI / EPRI/ United } \\
\text { States }\end{array}$ & $\begin{array}{l}\text { Simplified, parametric models } \\
\text { Integral RCS and containment analysis } \\
\text { Extensive user parameters } \\
\text { Separate versions for each reactor type (BWR, PWR, etc.) }\end{array}$ \\
\hline ICARE/ASTEC & IPSN/CEA/France & $\begin{array}{l}\text { Detailed models } \\
\text { Limited to RCS } \\
\text { Limited user parameters }\end{array}$ \\
\hline ATHLET-CD & GRS/Germany & $\begin{array}{l}\text { Detailed models } \\
\text { Limited to RCS } \\
\text { Limited user parameters }\end{array}$ \\
\hline $\begin{array}{l}\text { IMPACT } \\
\text { SAMPSON }\end{array}$ & NUPEC / METI/Japan & $\begin{array}{l}\text { Detailed models } \\
\text { Integral RCS and containment analysis }\end{array}$ \\
\hline
\end{tabular}

Presentation focuses on US severe accident analysis codes. 


\section{Approximate Accident Phenomena Covered by U.S. Severe Accident Computer Codes}

Integrated Codes

\begin{tabular}{|c|}
\hline MAAP \\
\hline MACCS \\
\hline MELCOR \\
\hline
\end{tabular}

Detailed Mechanistic Codes

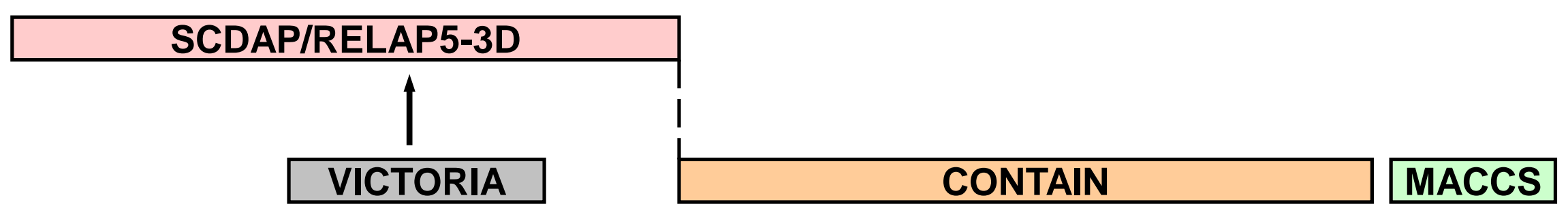

\begin{tabular}{|c|c|c|c|c|c|c|c|c|c|c|}
\hline $\begin{array}{c}\text { Thermal } \\
\text { hydraulics }\end{array}$ & $\begin{array}{l}\text { Core } \\
\text { melting }\end{array}$ & $\begin{array}{l}\text { Release } \\
\text { from fuel }\end{array}$ & $\begin{array}{l}\text { Transport } \\
\text { in RCS }\end{array}$ & $\begin{array}{l}\text { RCS } \\
\text { failure }\end{array}$ & $\begin{array}{l}\text { Concrete } \\
\text { interactions }\end{array}$ & $\begin{array}{c}\text { Release } \\
\text { from } \\
\text { debris }\end{array}$ & $\begin{array}{l}\text { Transport in } \\
\text { containment }\end{array}$ & $\begin{array}{l}\text { Containment } \\
\text { loads }\end{array}$ & $\begin{array}{l}\text { Containment } \\
\text { performance c }\end{array}$ & $\begin{array}{c}\text { Off-site } \\
\text { consequences }\end{array}$ \\
\hline
\end{tabular}

\section{Accident Progression Phenomena}




\section{Codes}

\section{SCDAPIRELAP5-3D ${ }^{\odot}$ Embodies Understanding of Severe Accident Processes}

Model Development and Assessment Based on Data from:

- DFIXR

- PHEBUS
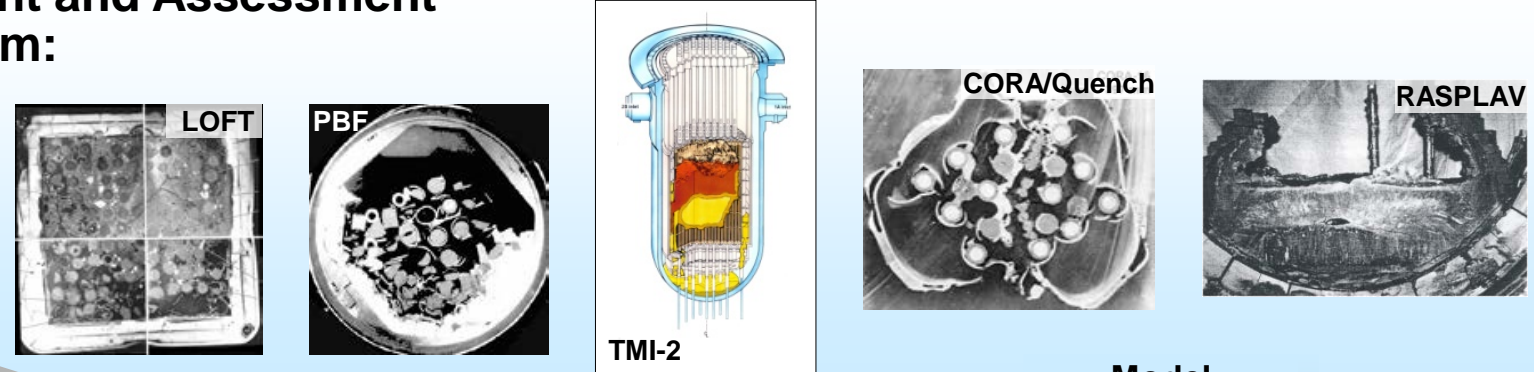

Experiments and Analyses

Model

Development and Assessment

\section{SCDAP/RELAP5-3D ${ }^{\odot}$}

Severe Accident Resolution (DCH, SGTR)

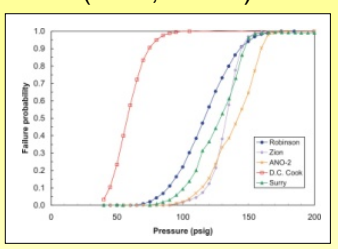

Severe Accident Mitigation Strategies (Depressurization, Water Addition)

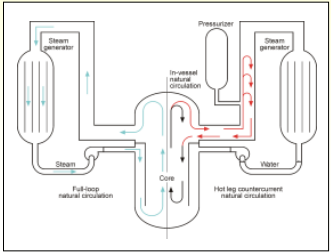

ALWR Evaluations (AP600, APR 1400,EPR, SBWR)
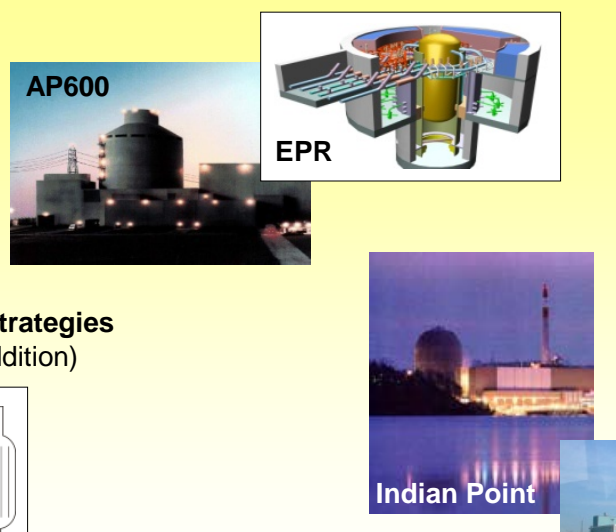

\section{Existing LWRs}

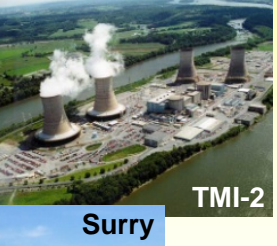

Applications

LWR

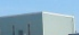

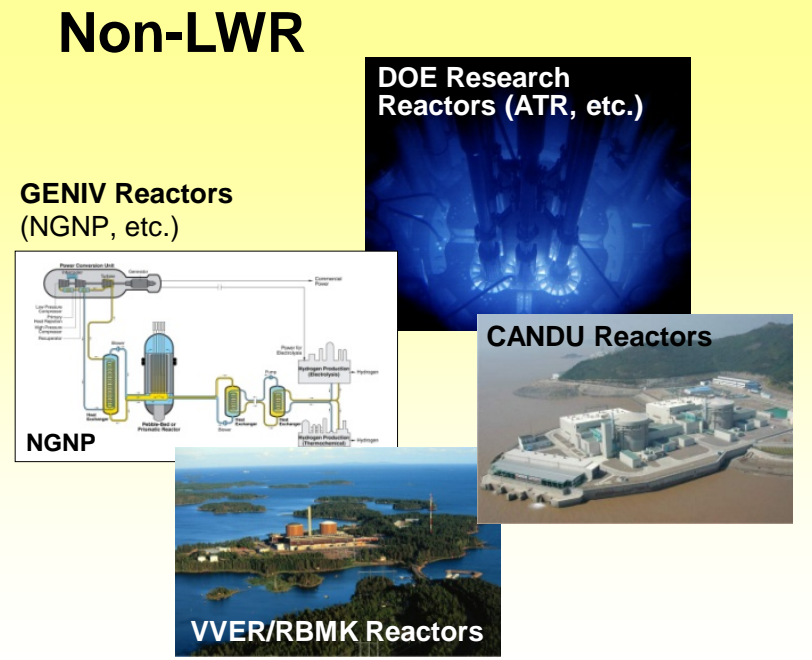




\section{SCDAP/RELAP5-3D ${ }^{\odot}$ Provides Mechanistic Severe Accident Modeling Tool}

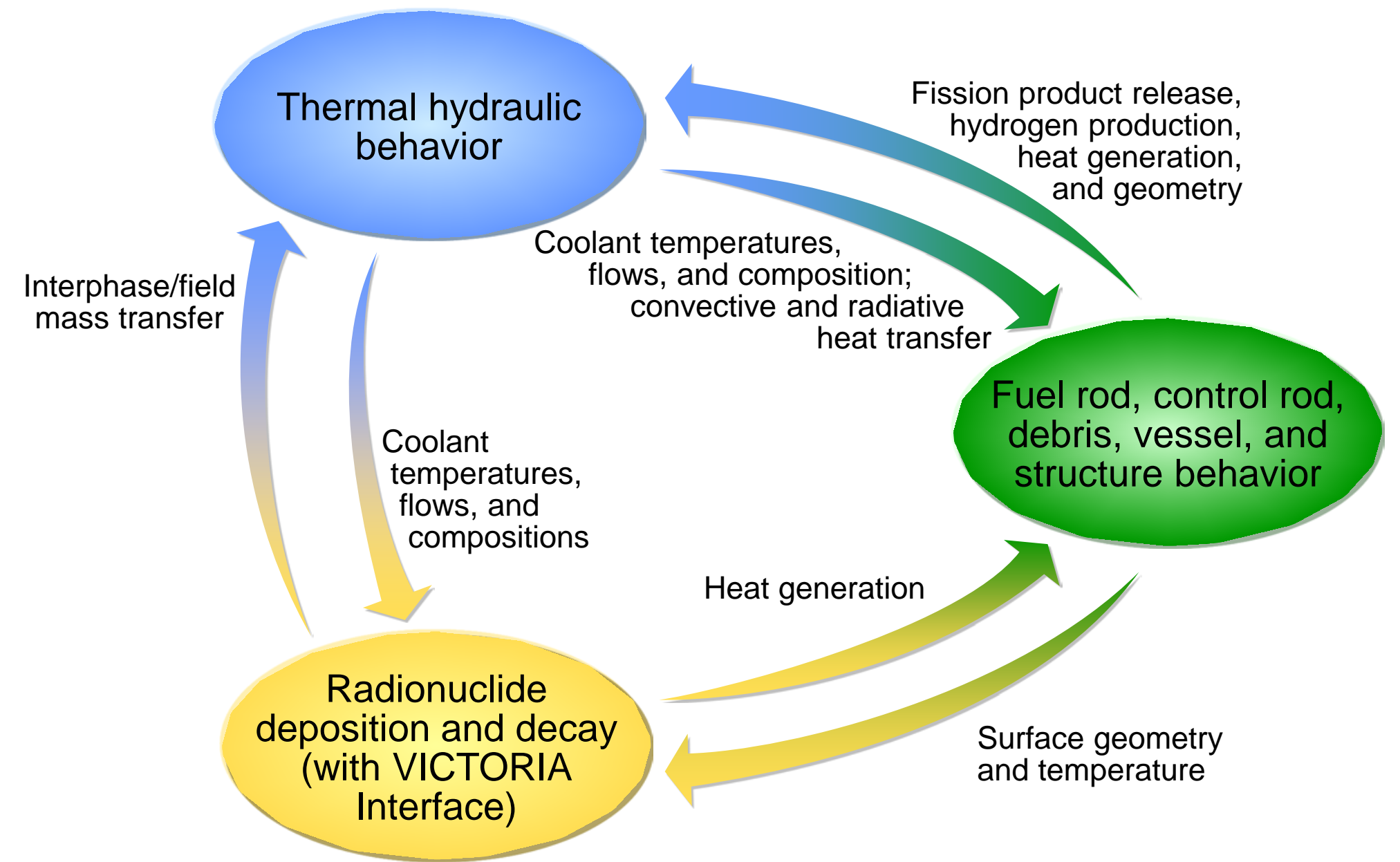




\section{PVM linkage provides options not available with other analysis tools}

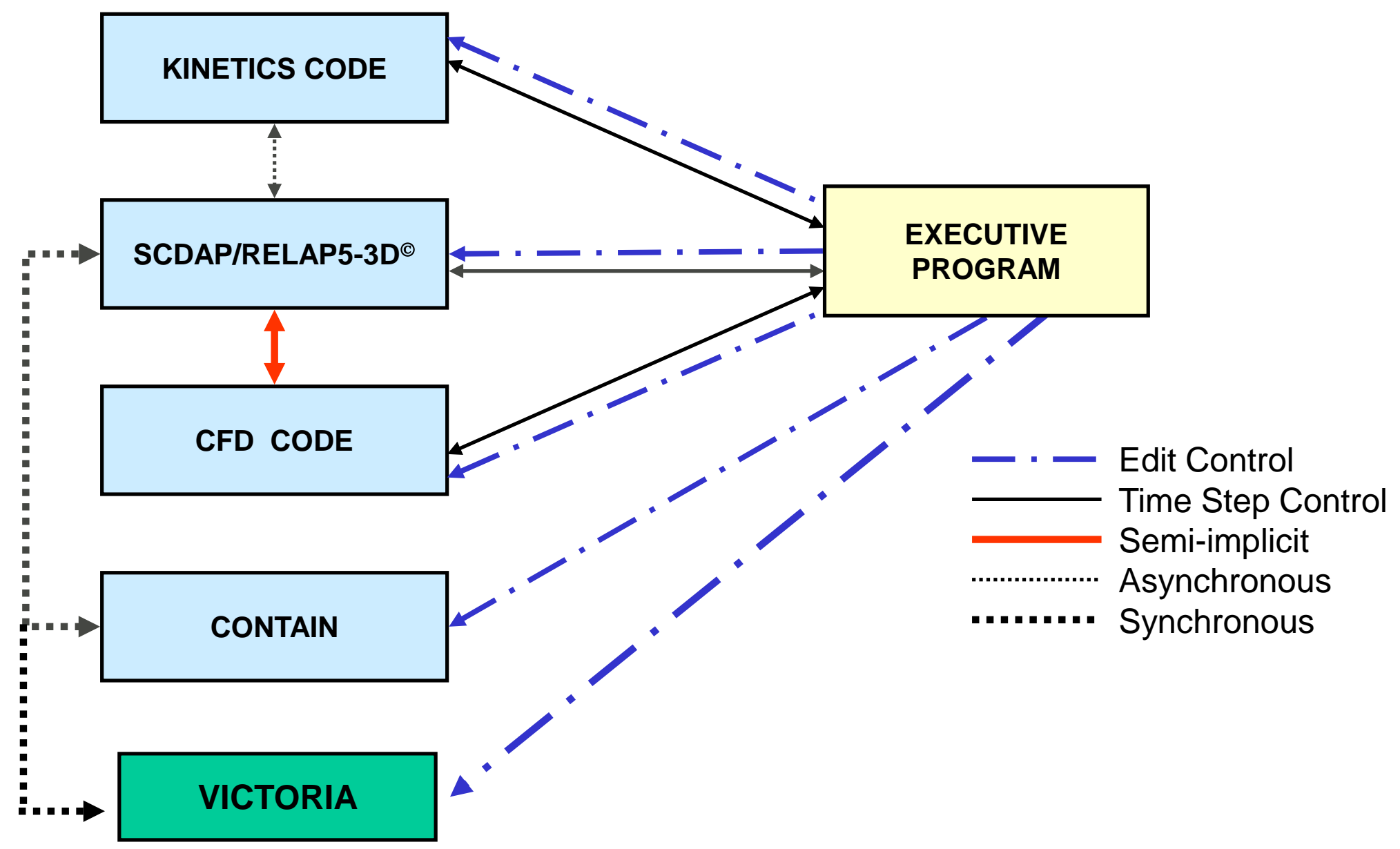




\section{CONTAIN provides mechanistic containment analyses tool.}

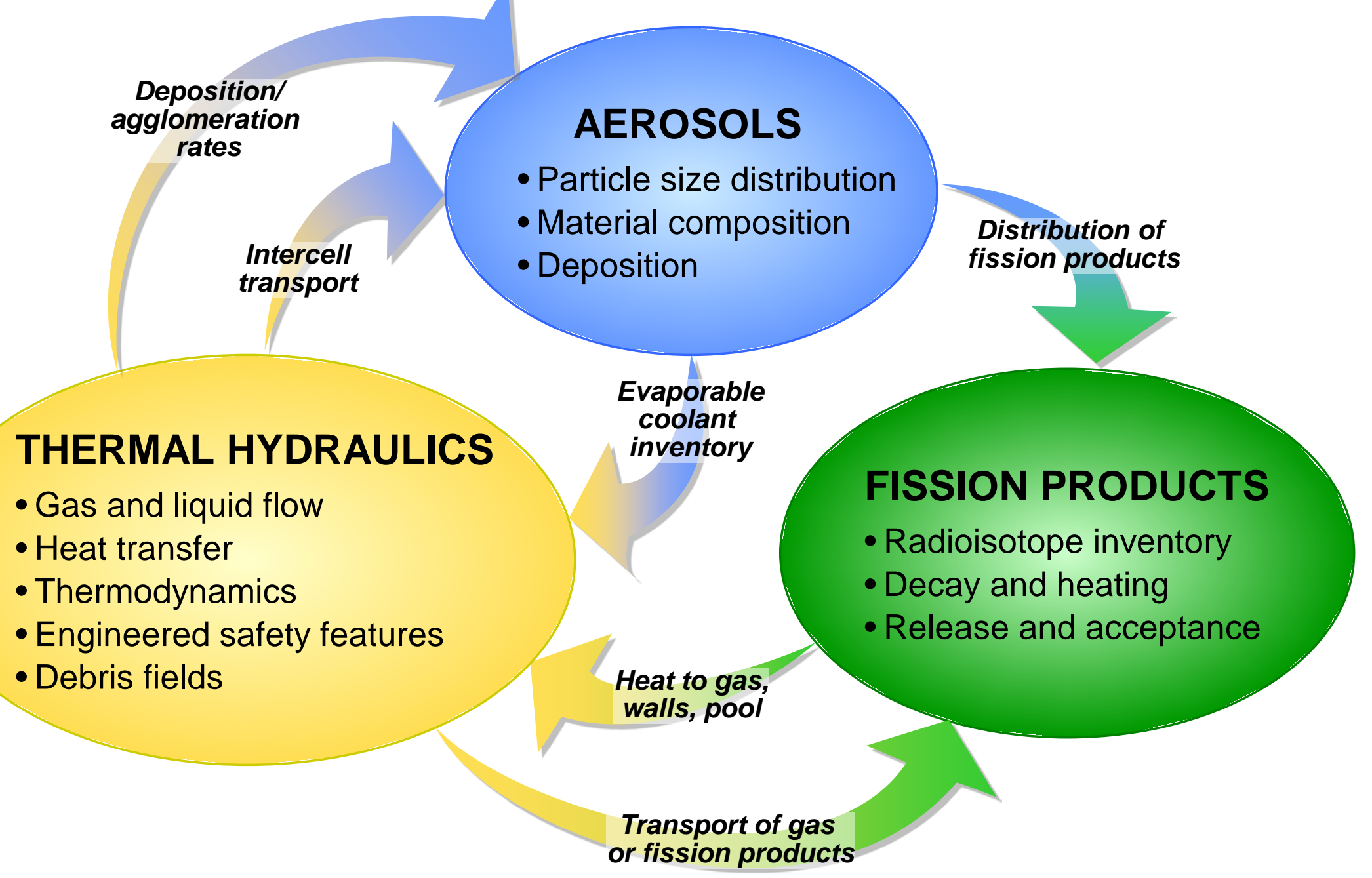




\section{MELCOR Code Physics Description}

- MELCOR is a fully integrated, engineering-level computer code that models the progression of severe accidents in light water reactor nuclear power plants

- MELCOR is being developed at Sandia National Laboratories for the U.S. Nuclear

Regulatory Commission as a second-generation plant risk assessment tool.

- A broad spectrum of severe accident phenomena in both boiling and pressurized water reactors is treated in MELCOR in a unified framework

- Reactor plant systems and their response to off-normal or accident conditions include:

$\checkmark$ Thermal-hydraulic response of the primary reactor coolant system, the reactor cavity, the containment, and the confinement buildings,

$\checkmark$ Core uncovering (loss of coolant), fuel heat-up, cladding oxidation, fuel degradation (loss of rod geometry), and core material melting and relocation,

$\checkmark$ Heat-up of reactor vessel lower head from relocated fuel materials and the thermal and mechanical loading and failure of the vessel lower head, and transfer of core materials to the reactor vessel cavity,

$\checkmark$ Core-concrete attack and ensuing aerosol generation,

$\checkmark$ In-vessel and ex-vessel hydrogen production, transport, and combustion,

$\checkmark$ Fission product release (aerosol and vapor), transport, and deposition,

Behavior of radioactive aerosols in the reactor containment building, including scrubbing in water pools, and aerosol mechanics in the containment atmosphere such as particle agglomeration and gravitational settling, and,

$\checkmark$ Impact of engineered safety features on thermal-hydraulic and radionuclide behavior 
Codes

\section{MELCOR Modeling Approach}

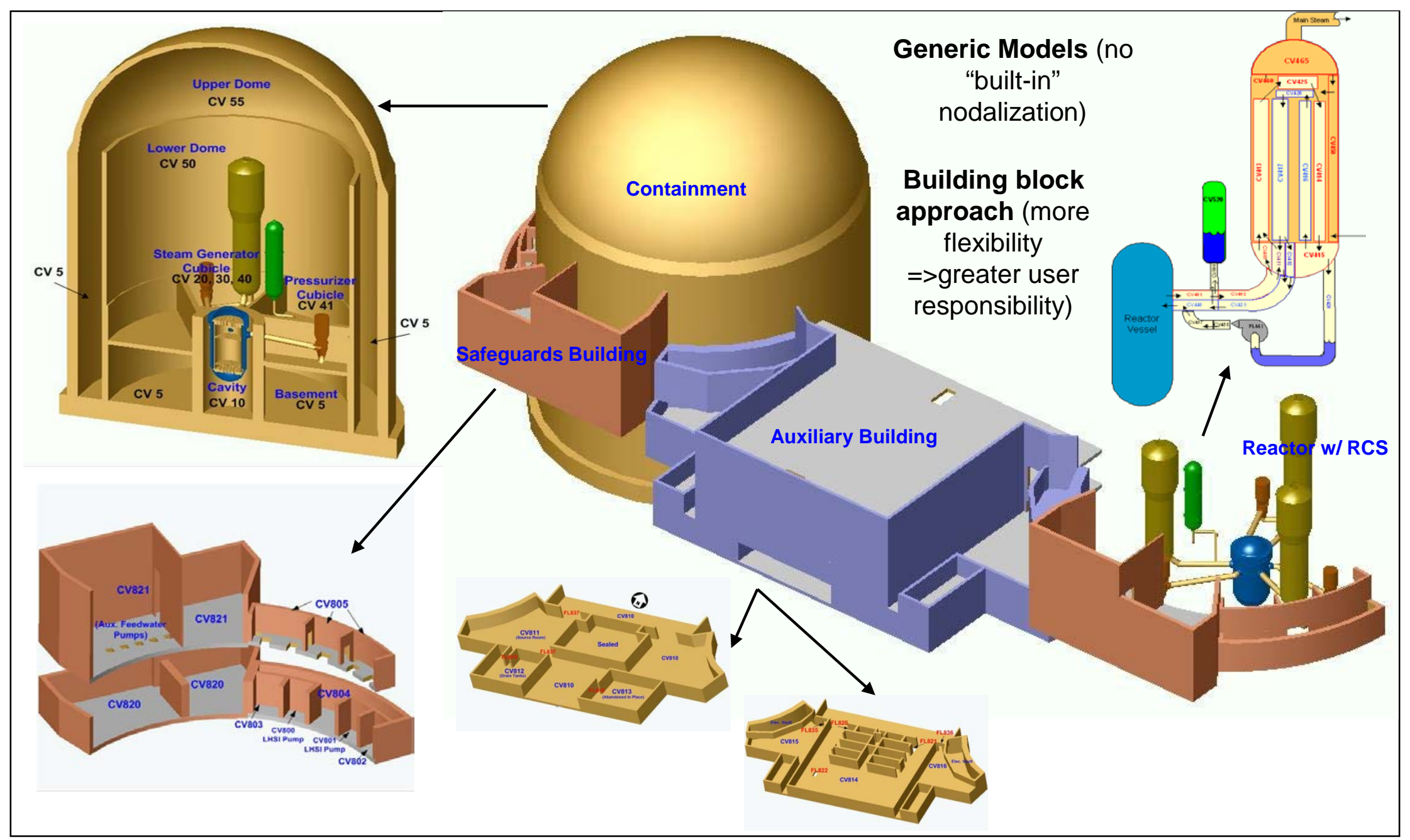


Codes

\section{MELCOR User Interface}
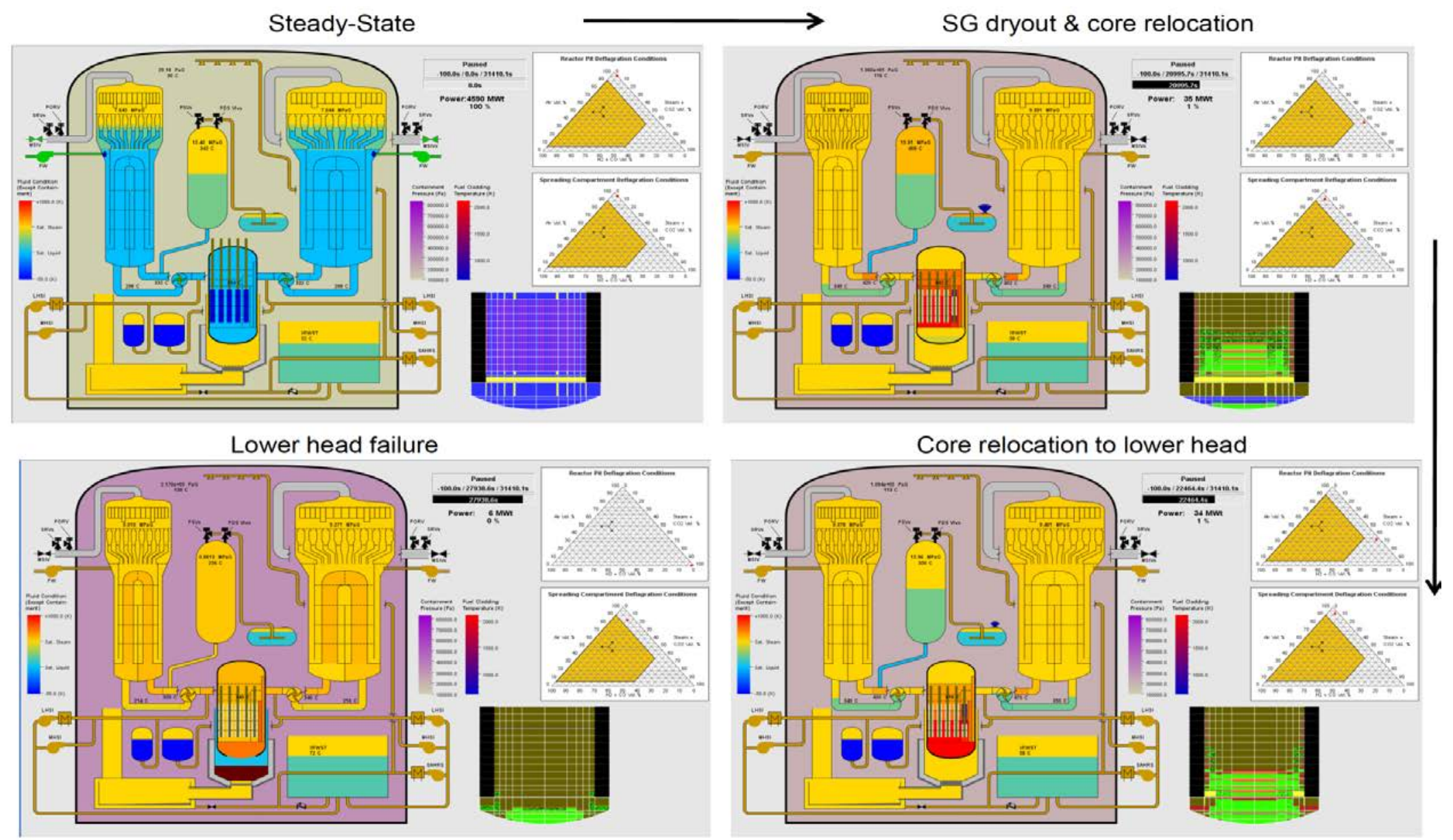

$4 / 19 / 16$

Accident Progression Analysis (P-300) 


\section{MELCOR Models Fission Facilities}

- A six equation non-equilibrium fluid flow model for fluid flow in a facility by using control volumes, flow paths, and heat structures

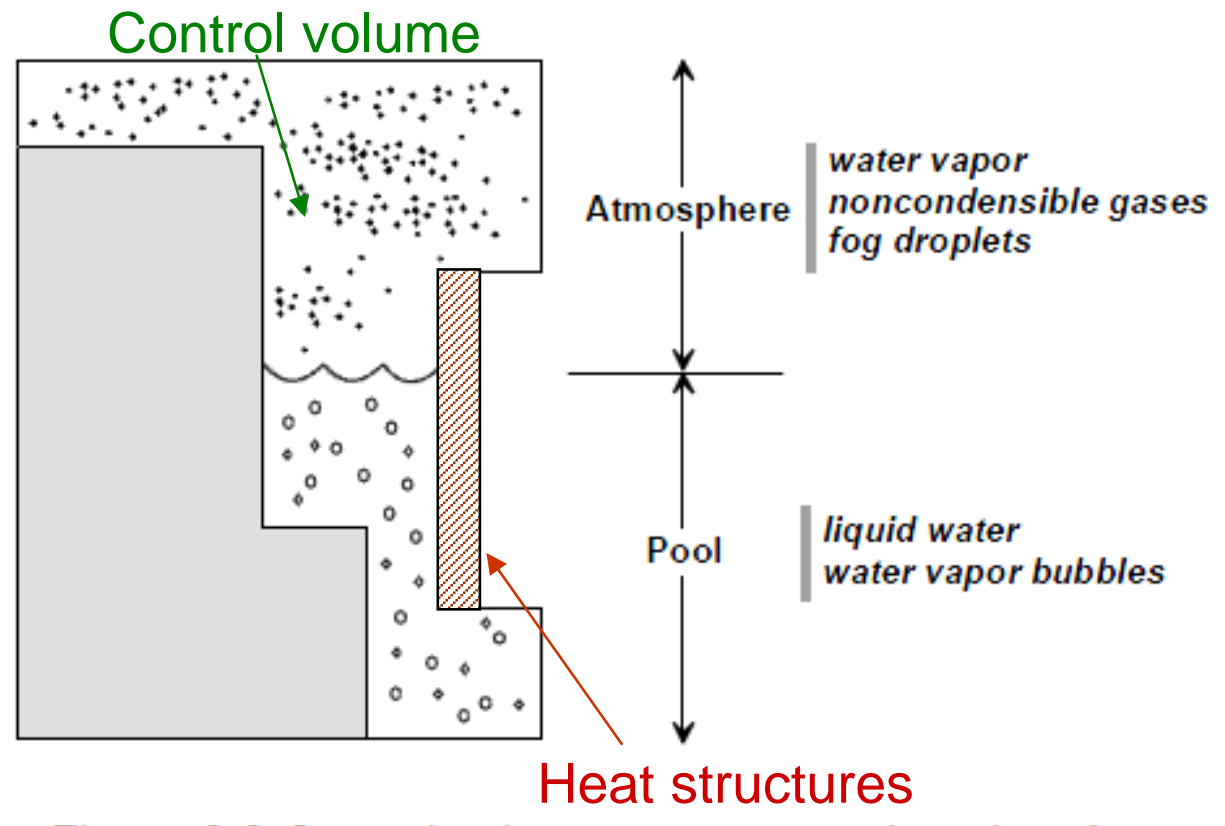

Figure 2.3 Control volume contents and pool surface
- Multiple flow paths can connect any two control volumes. Height of flow path determines time dependent phase of flow entering or leaving the flow path

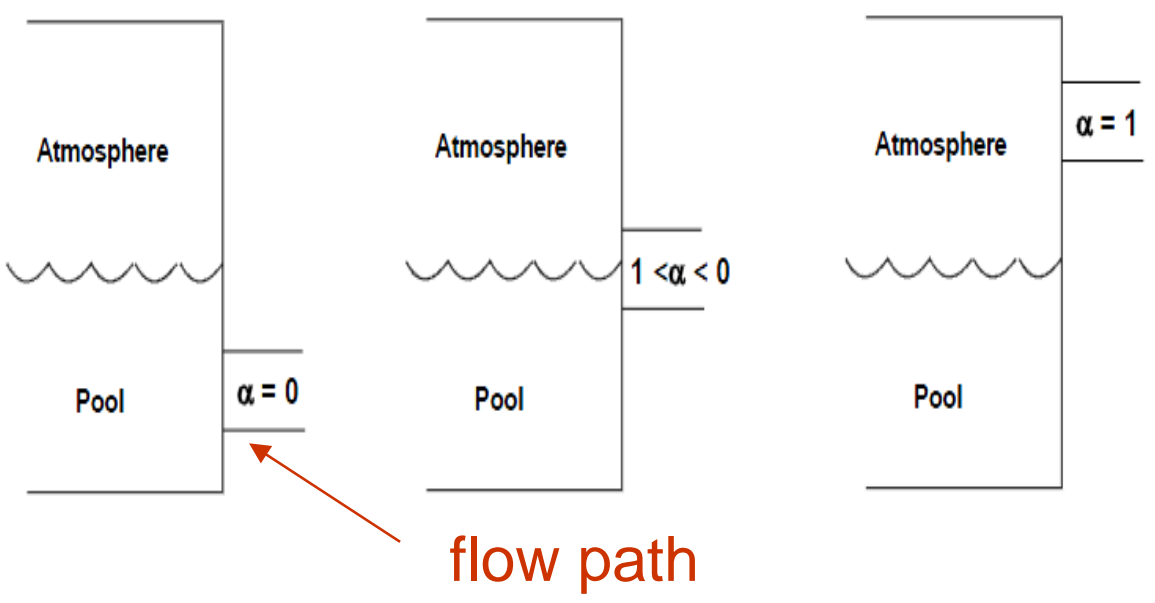

- Heat structures for walls, piping, vessels, etc. with pool and atmosphere natural, force convective heat transfer (pool includes boiling heat transfer)

- Aerosols and fission products are transported both in the vapor and liquid phases. $4 / 19 / 16$ 


\section{MELCOR Models Fission Facilities (cont.)}

A core model for fuel/cladding response

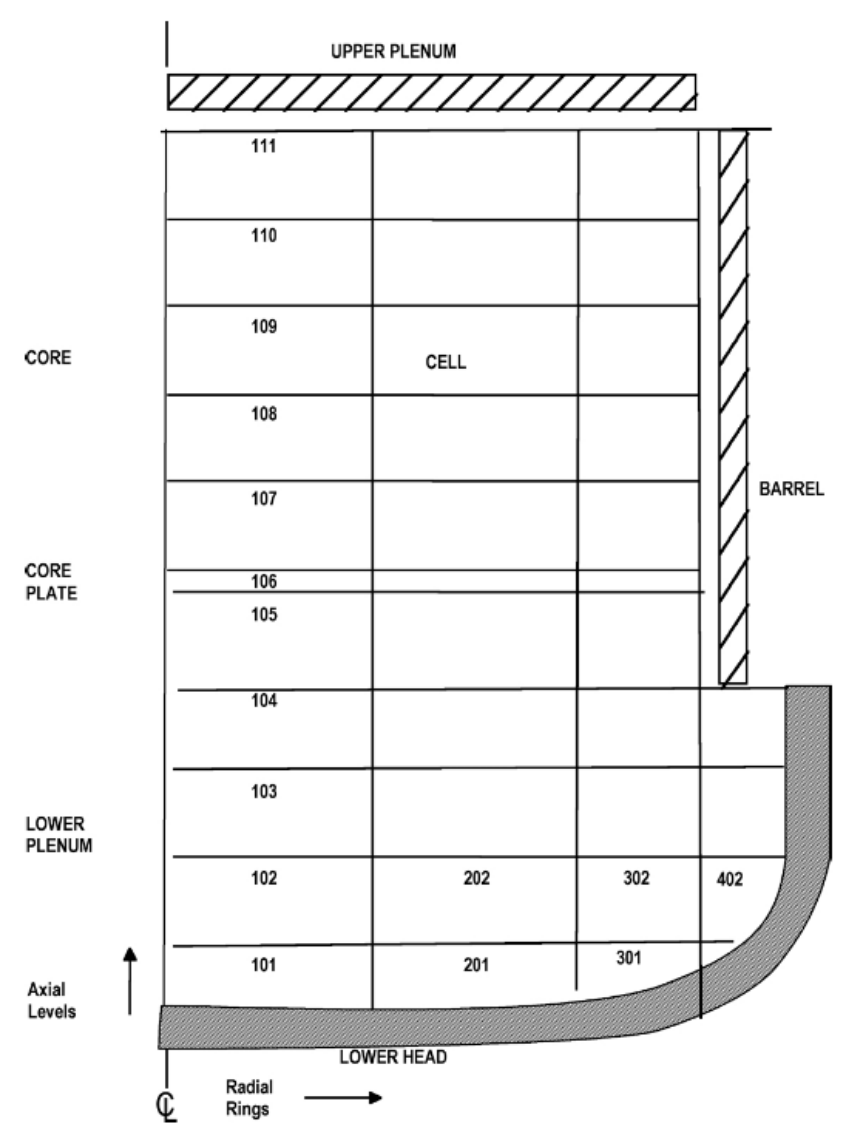

A cavity model for debris concrete reactions (dry well below RPV)

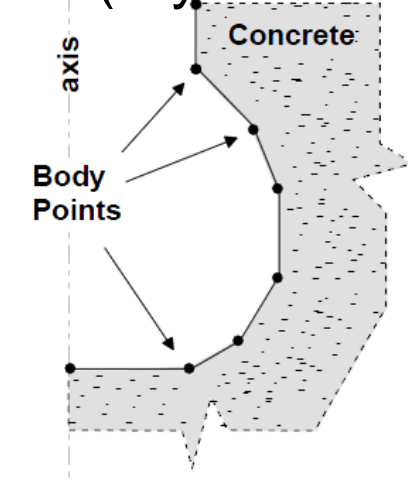

(a) Cavity Geometry

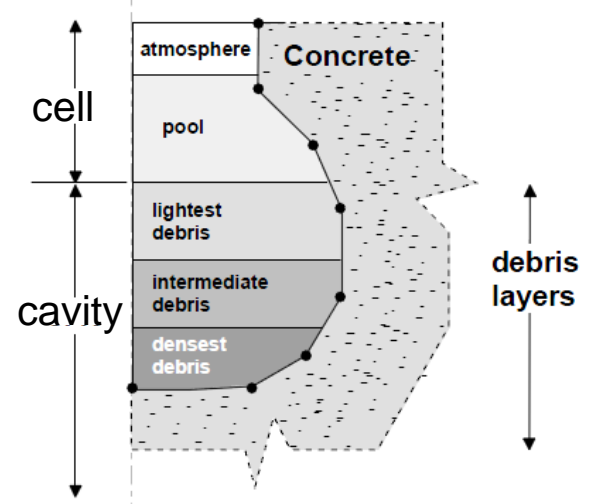

(b) Cavity Contents and Boundary Conditions 


\section{MELCOR Models Fission Releases and Transport}

- Radionuclide releases can occur from the core fuel, from the fuel-cladding gap, and from material in the cavity

- Three options are currently available for the release of radionuclides from the core fuel component; the CORSOR, CORSOR-M or CORSOR-Booth

- Cesium release fraction, $f$, at time $t$ is calculated from an approximate solution of Fick's law assuming spherical fuel grains

- Release of the radionuclides in the fuel-cladding gap (initial inventory plus masses from fuel release) occurs on cladding failure. Cladding failure is assumed to occur if either a temperature criterion is exceeded or if the intact cladding geometry has been lost due to candling or oxidation

- For release of radionuclides from the cavity due to core-concrete interactions, the VANESA model has been implemented in MELCOR coupled to the CORCON model

- The condensation and evaporation of fission product vapors to and from heat structures, pool surfaces, and aerosols is evaluated by the same $4 / 19 / 16$

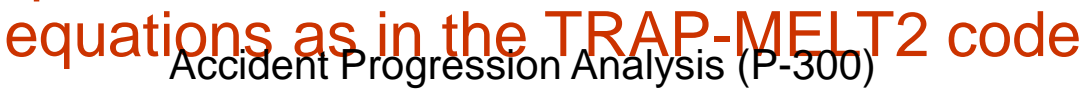




\section{MELCOR Models Fission Releases and Transport (cont.)}

- The MELCOR calculation of changes in aerosol distribution and location within a plant considers the following general processes:

- Aerosol phenomenological sources from other packages, such as release from fuel rods or during core-concrete interactions, and/or arbitrary userspecified sources;

- Condensation and evaporation of water and fission products to and from aerosol particles;

- Particle agglomeration (or coagulation), whereby two particles collide and form one larger particle;

- Particle deposition onto surfaces or settling through flow paths into lower control volumes;

- Advection of aerosols between control volumes by bulk fluid flows

- Removal of aerosol particles by Engineered Safety Features (ESFs), such as filter trapping, pool scrubbing, and spray washout 


\section{MELCOR Models Fission Releases and Transport (cont.)}

- Fission Product Chemistry effects can be simulated in MELCOR through the use of class reactions and class transfers.

- The class reaction process uses a first-order reaction equation with forward and reverse paths.

- The class transfer process, which can change the material class or location of a radionuclide mass, can be used to simulate fast chemical reactions.

- With these two processes, phenomena including adsorption, chemisorption, water chemistry, and chemical reactions can be simulated

This reaction can be simulated by the RN package by the following sequential class reactions and transfers:

\begin{tabular}{|l|l|}
\hline $\mathrm{Csl}(\mathrm{g}) \rightarrow \mathrm{Csl}(\mathrm{ad})$ & rate constant for adsorption is supplied through input \\
\hline $\mathrm{Csl}(\mathrm{ad}) \rightarrow \mathrm{CsOH}(\mathrm{ad})+H I(s)$ & $\begin{array}{l}\text { instantaneous and complete transfer between classes } \\
\text { when water is present. Note that the water mass is } \\
\text { not included in the model; water mass is not } \\
\text { explicitly conserved. }\end{array}$ \\
\hline $\mathrm{CsOH}(\mathrm{g}) \rightarrow \mathrm{CsOH}(\mathrm{ad})$ & $\begin{array}{l}\text { rate constant for adsorption supplied or condensation } \\
\text { limited }\end{array}$ \\
\hline $\mathrm{CsOH}(\mathrm{ad}) \rightarrow \mathrm{CsOH}(g)$ & reaction with zero rate constant below $T_{1}$ \\
\cline { 2 - 2 } & positive value or instantaneous above $T_{1}$ \\
\hline $\mathrm{HI}(\mathrm{s}) \leftrightarrow H \mathrm{HI}(\mathrm{g})$ & controlled by condensation/evaporation \\
\hline
\end{tabular}




\section{A MELCOR Model of a BWR that includes Reactor Building, Plus All}

Emergency Cooling Systems was used for analyzing Fukushima Unit 1

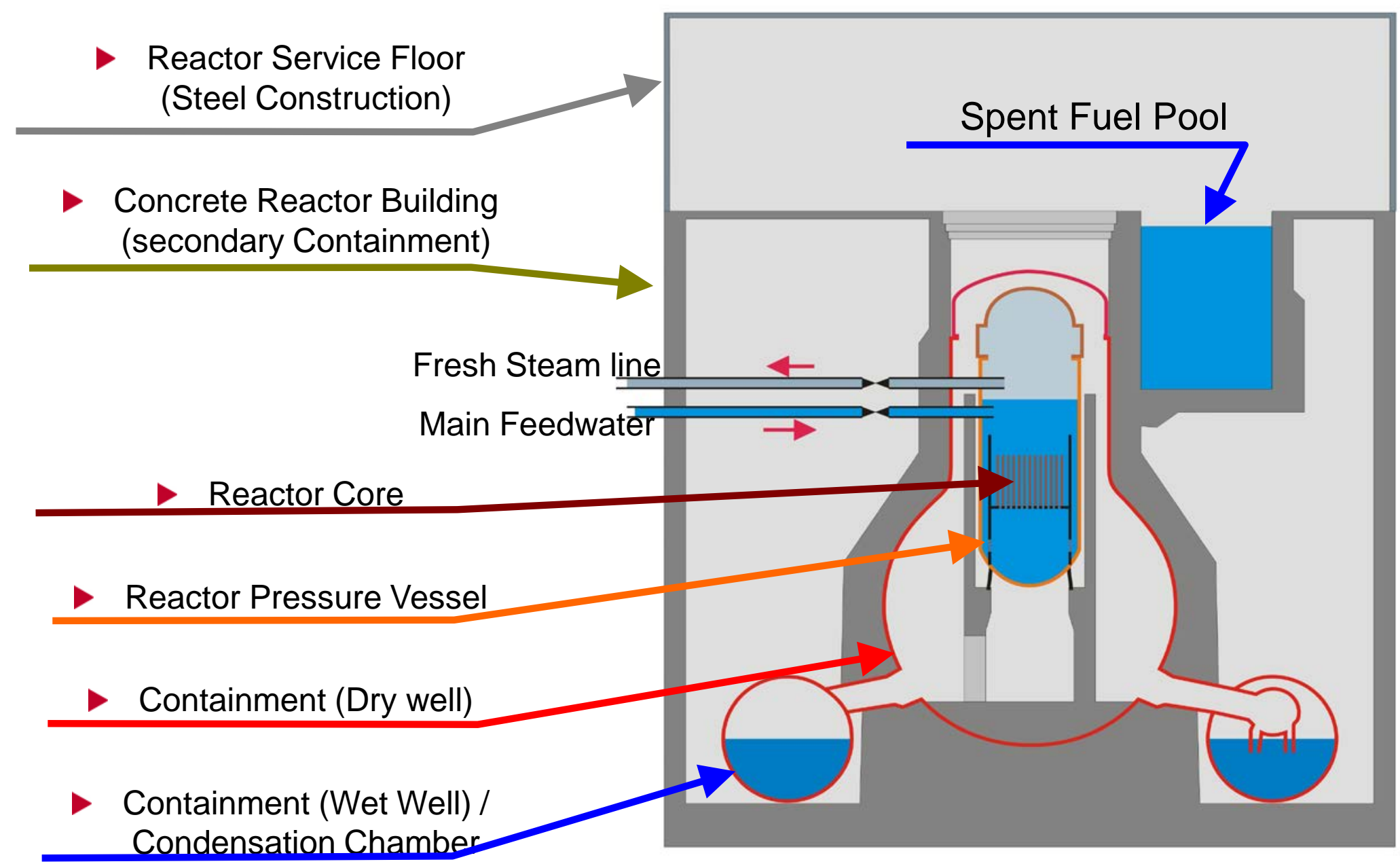




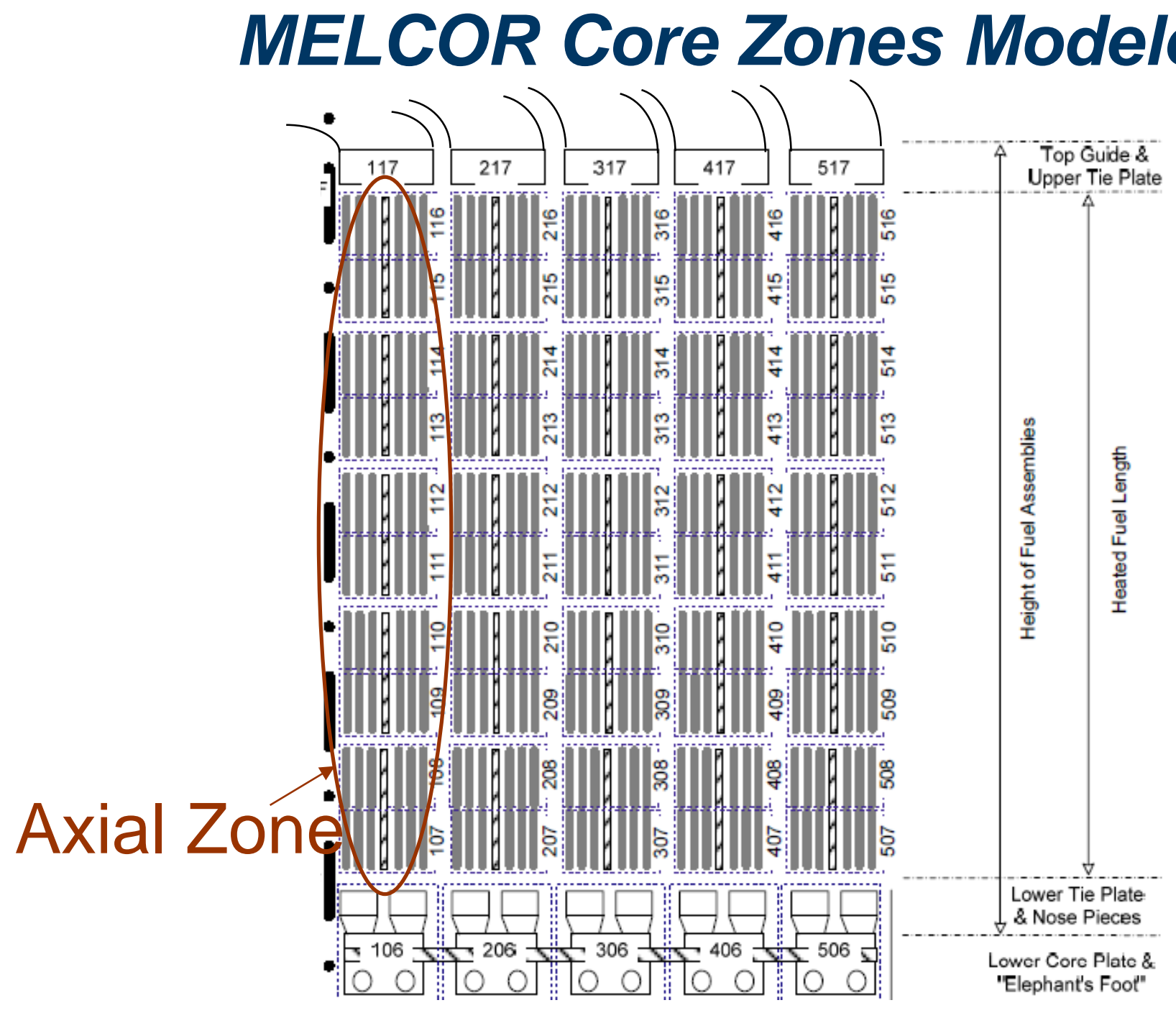




\section{Fukushima Unit 1 Schematic of Predicted Core Damage

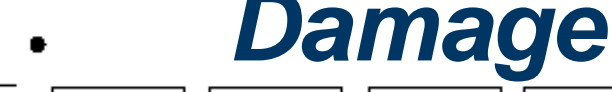

Time $=45 \mathrm{hrs}$
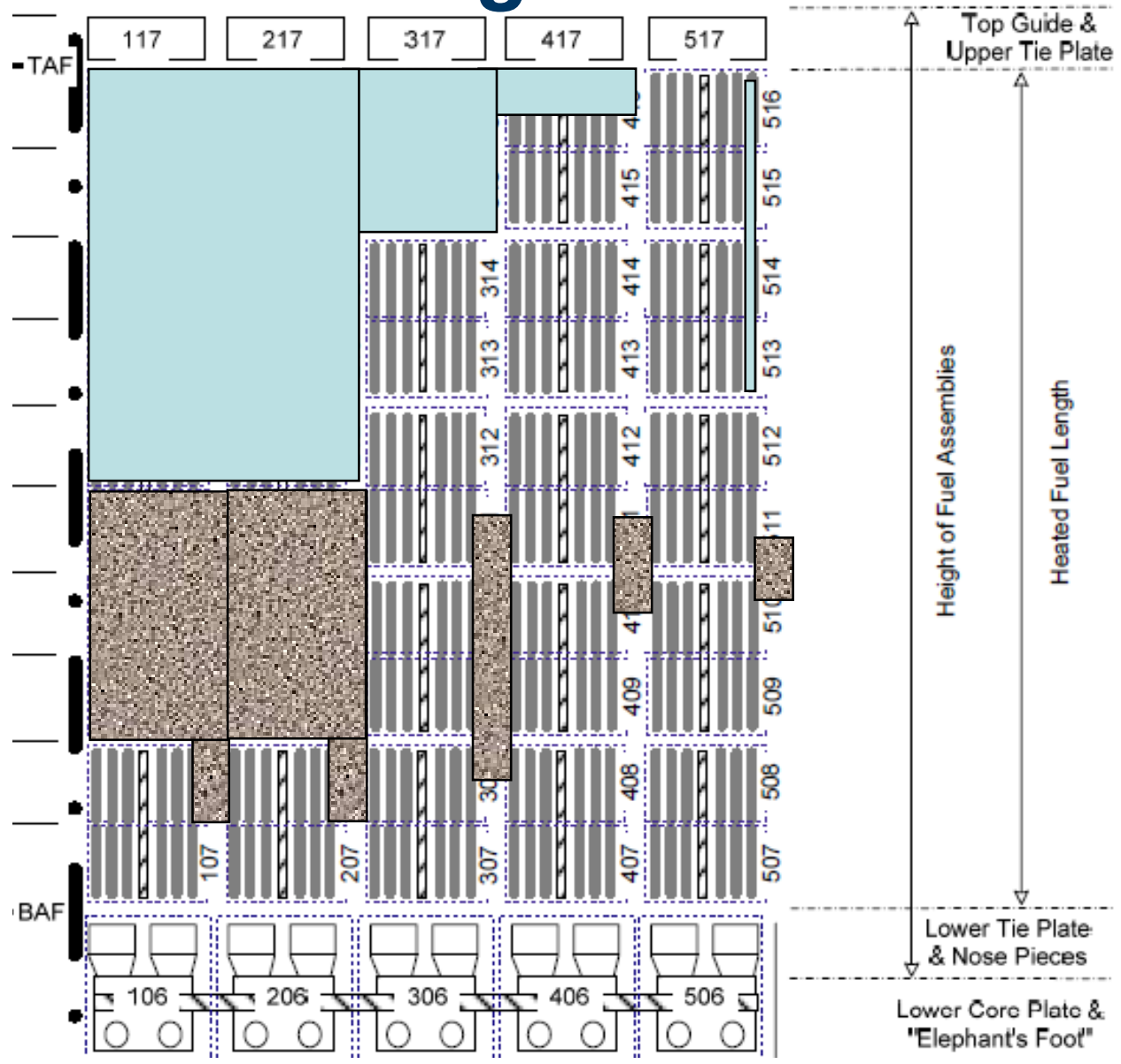


\section{Fukushima Unit 1 MELCOR Calculated/Defined RPV Water Injection Rate-SAND2012-6173}

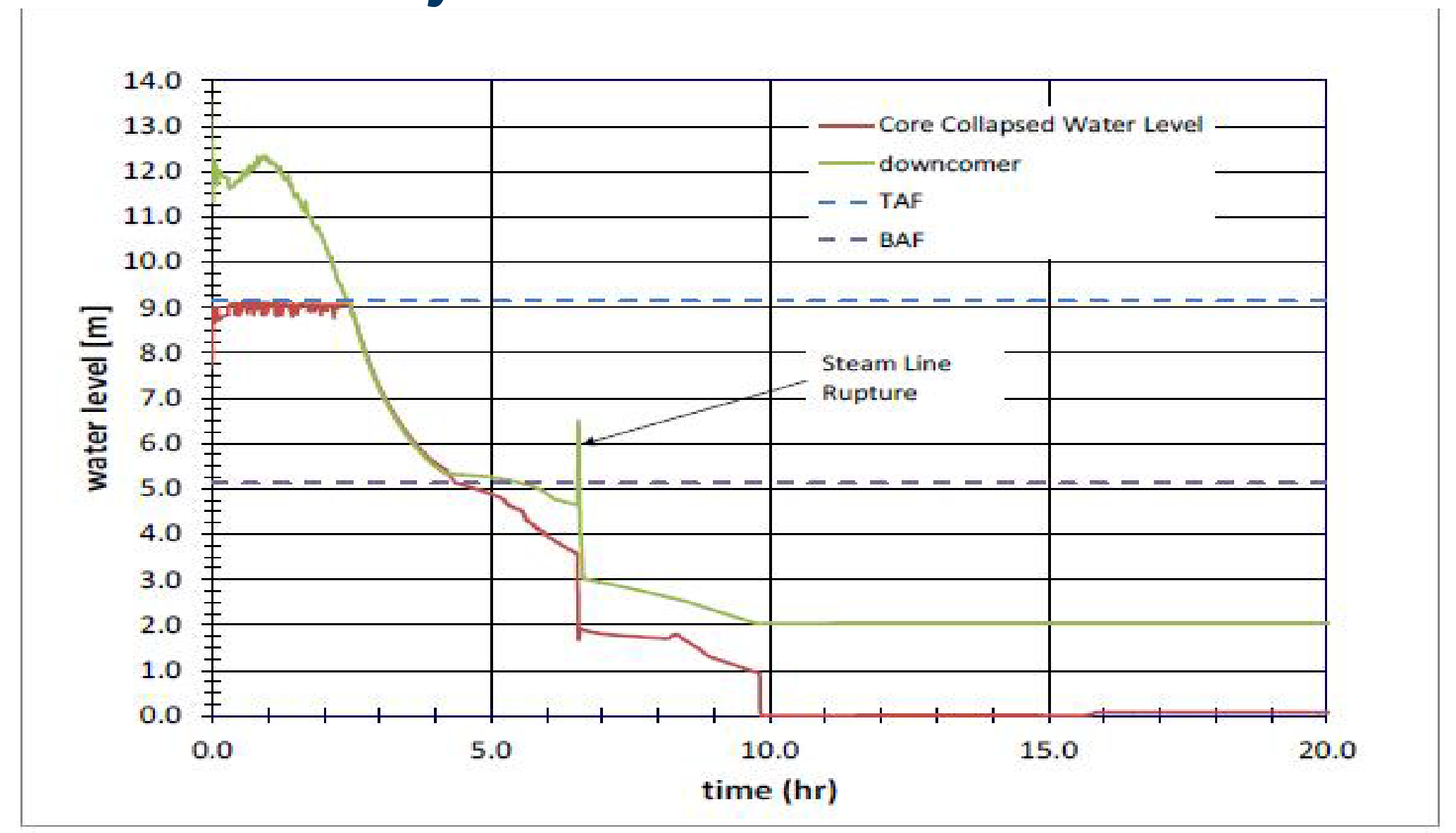




\section{Fukushima Unit 1 Fuel Temperatures - SAND2012-6173}

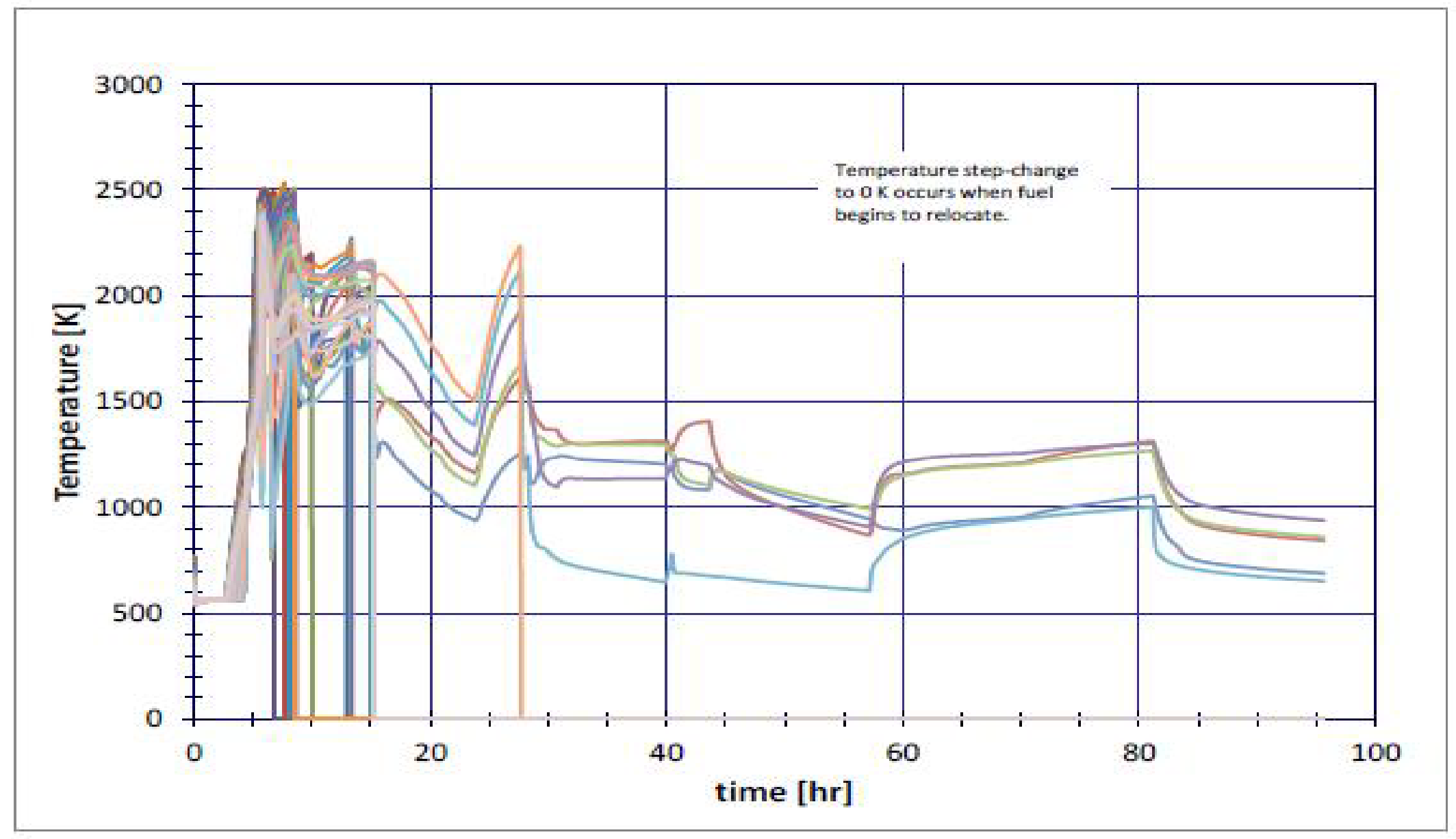




\section{Fukushima Unit 1 Hydrogen Generation from}

Cladding Stainless Steel and B4C -SAND20126173

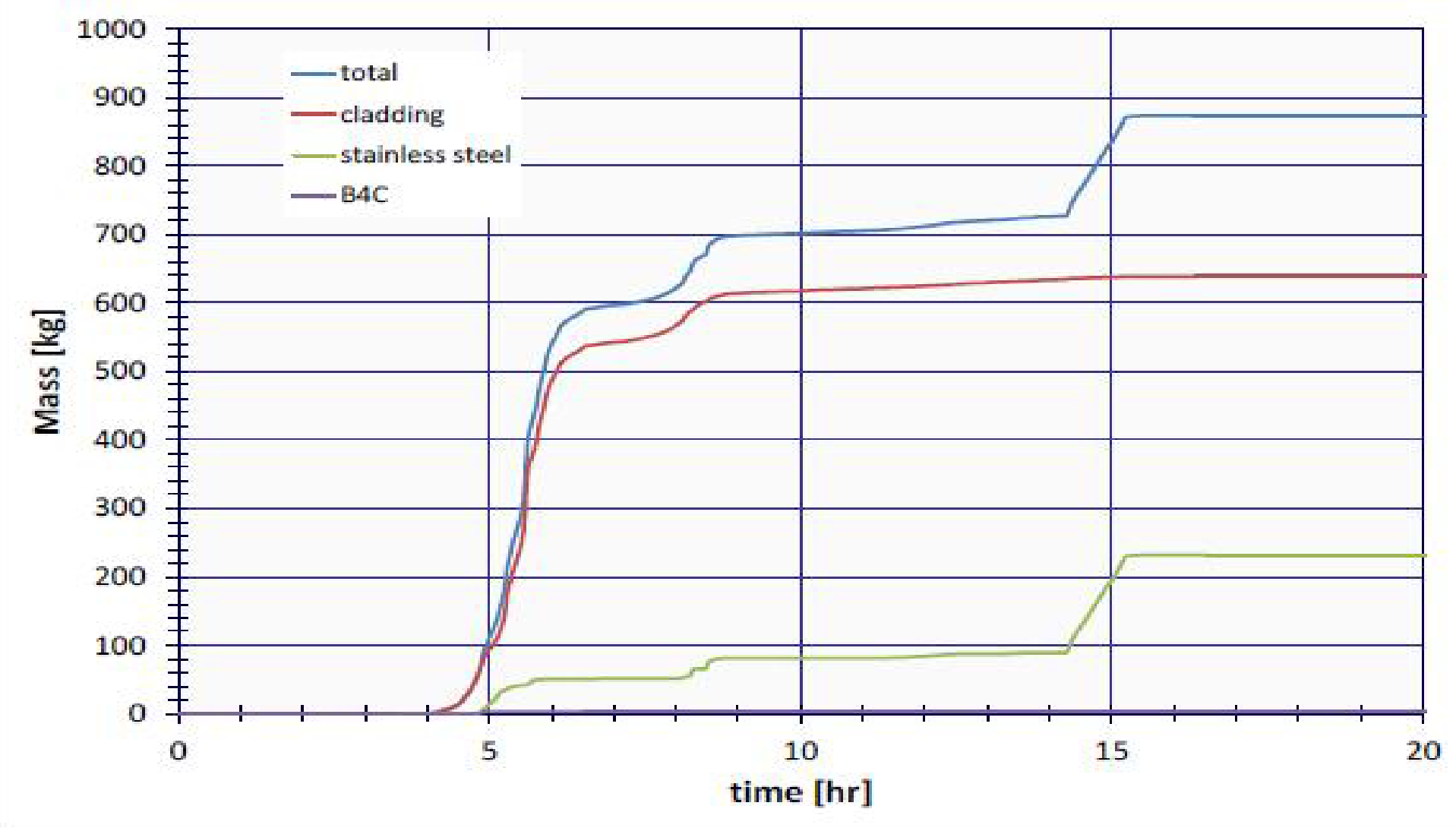




\section{Fukushima Unit 1 Lower Head Fuel Temperatures -SAND2012-6173}

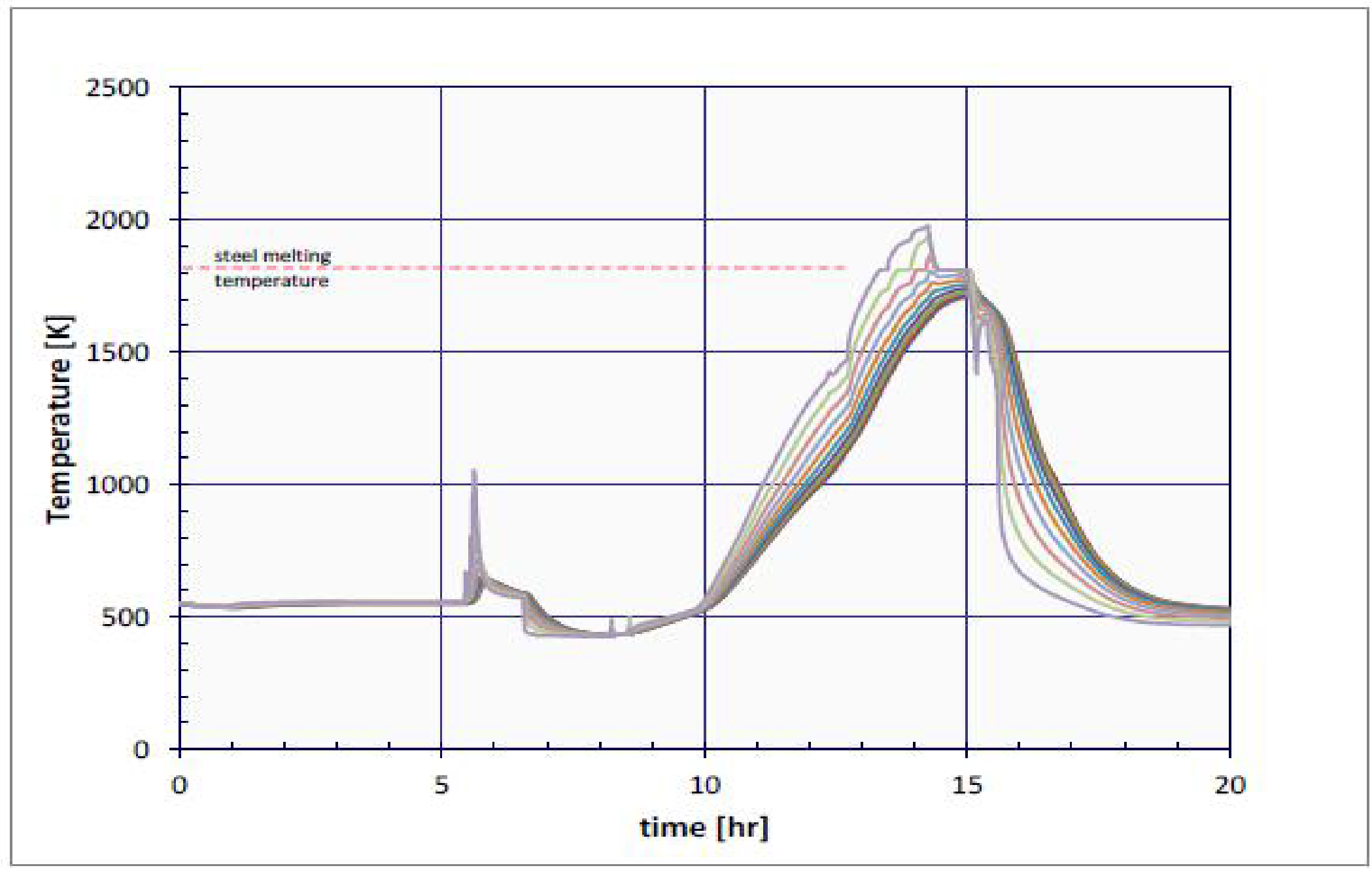




\section{Fukushima Unit 1 Accumulation of Fuel in Lower Plenum 139,000 kg on concrete - SAND2012-6173}

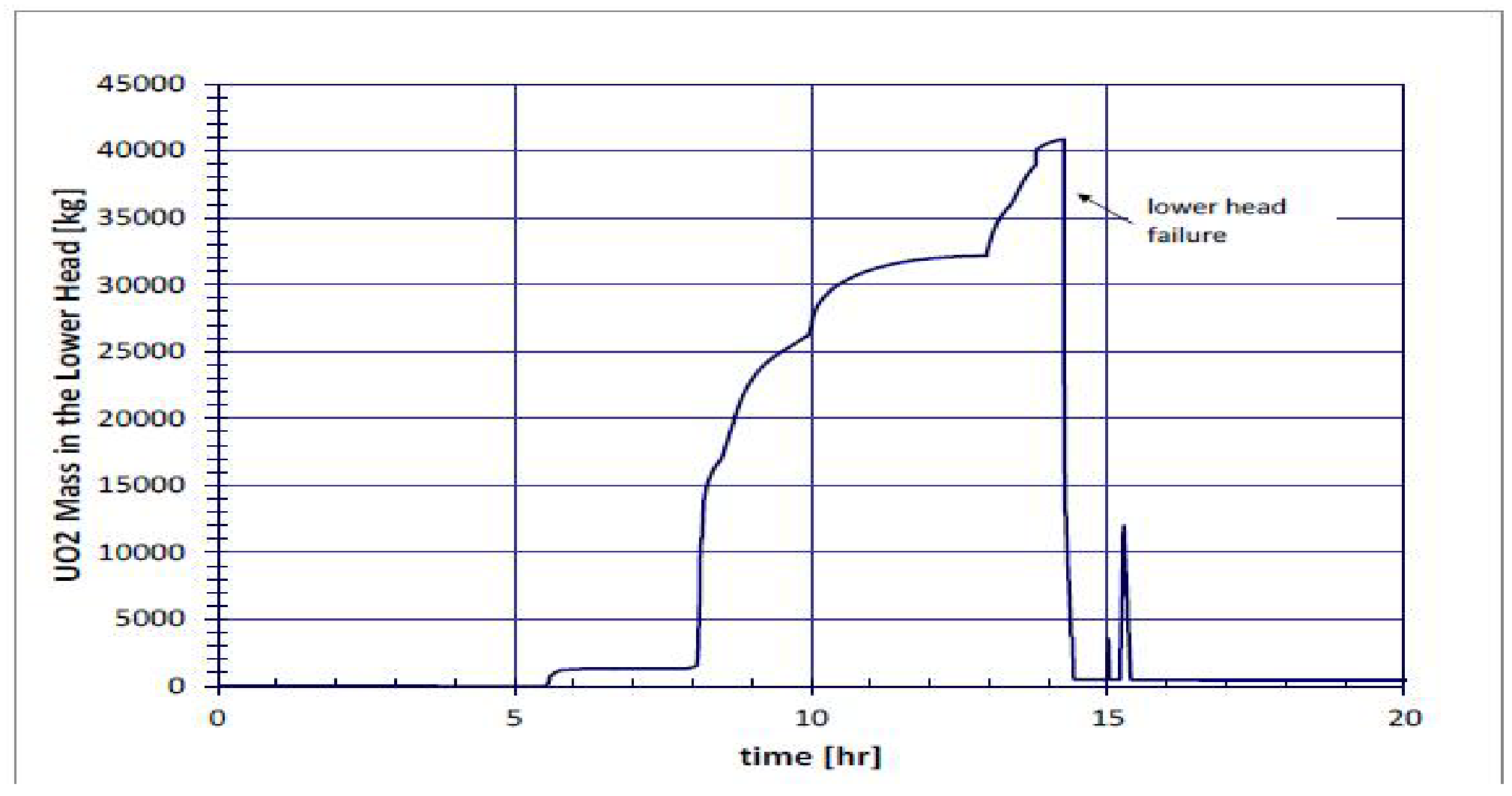




\section{Fukushima Unit 1 Fuel Relocation -SAND2012- 6173}

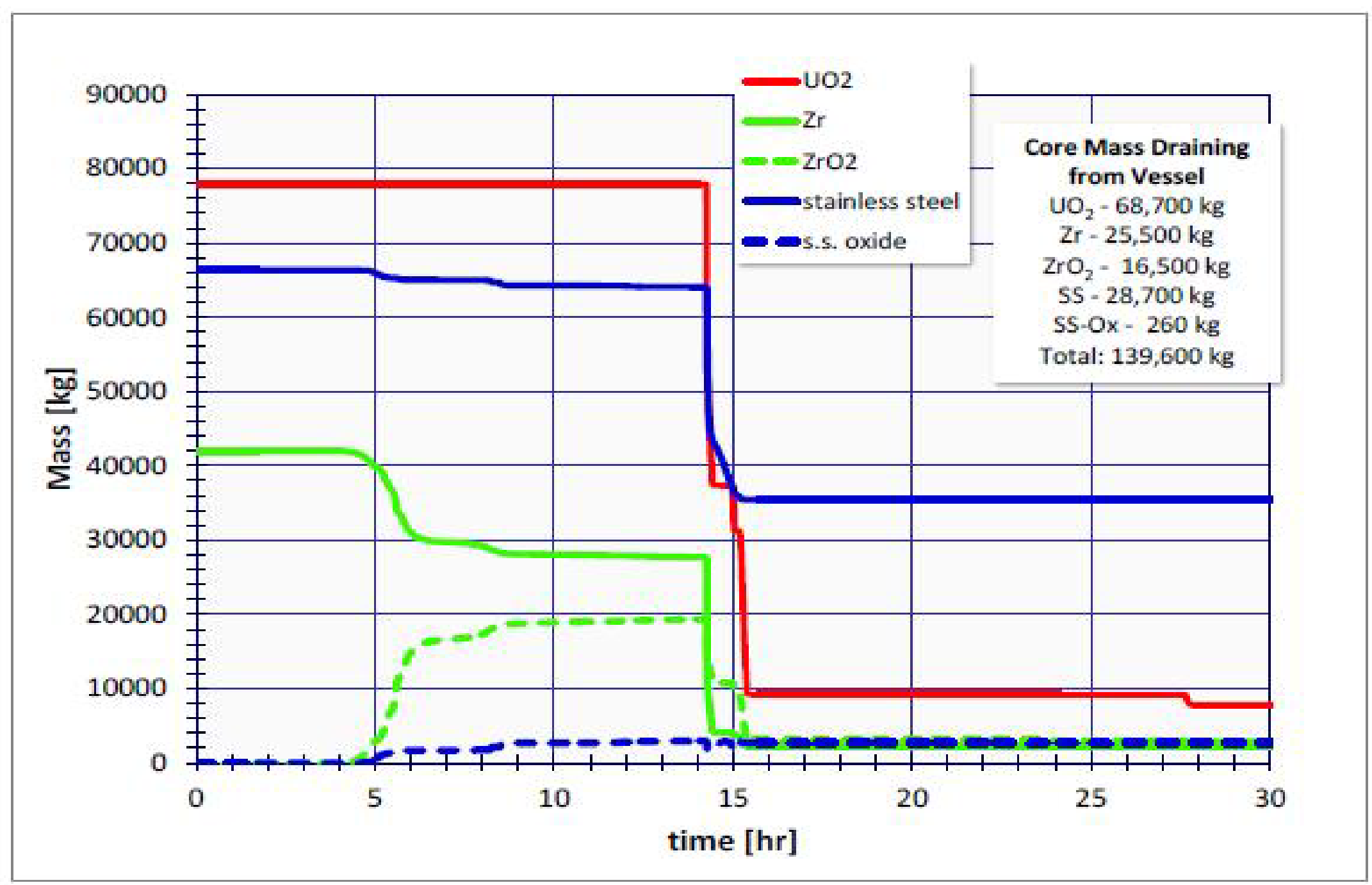




\section{Fukushima Unit 1 Core Condition -SAND2012- 6173}

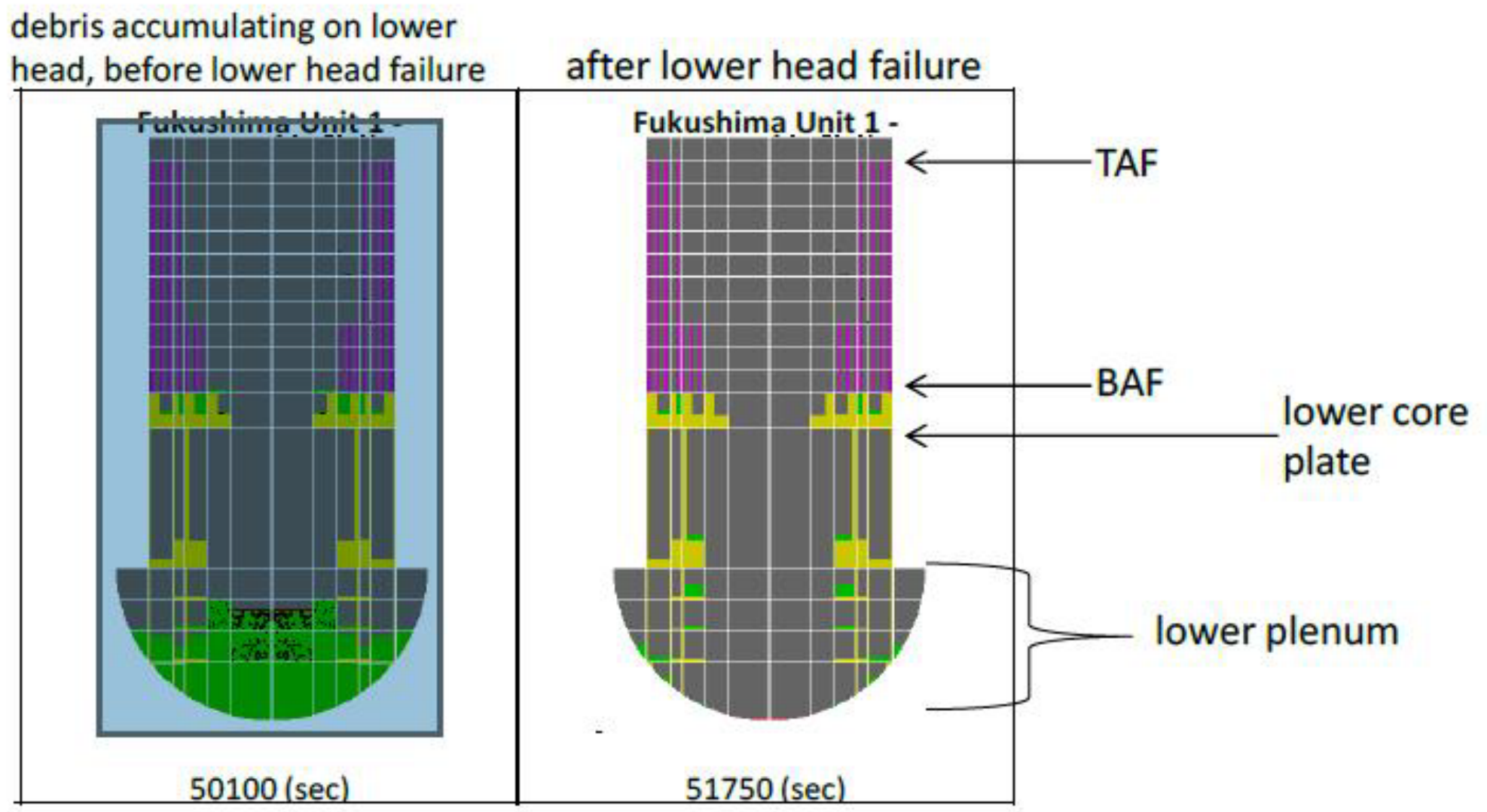




\section{Fukushima Unit 1 MCCI Interaction-SAND2012- 6173}

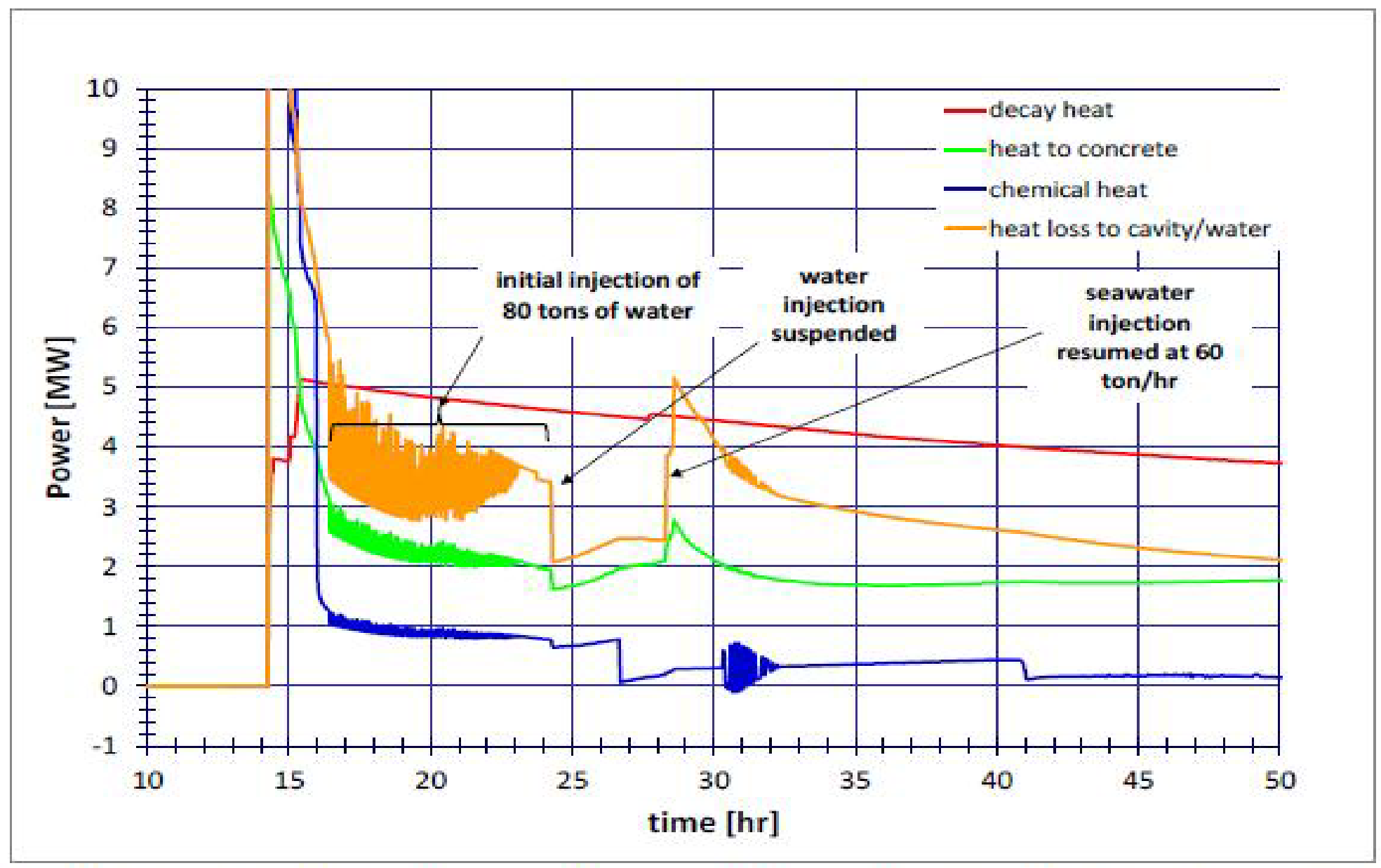




\section{Fukushima Unit 1 MCCI Products-SAND2012- 6173}

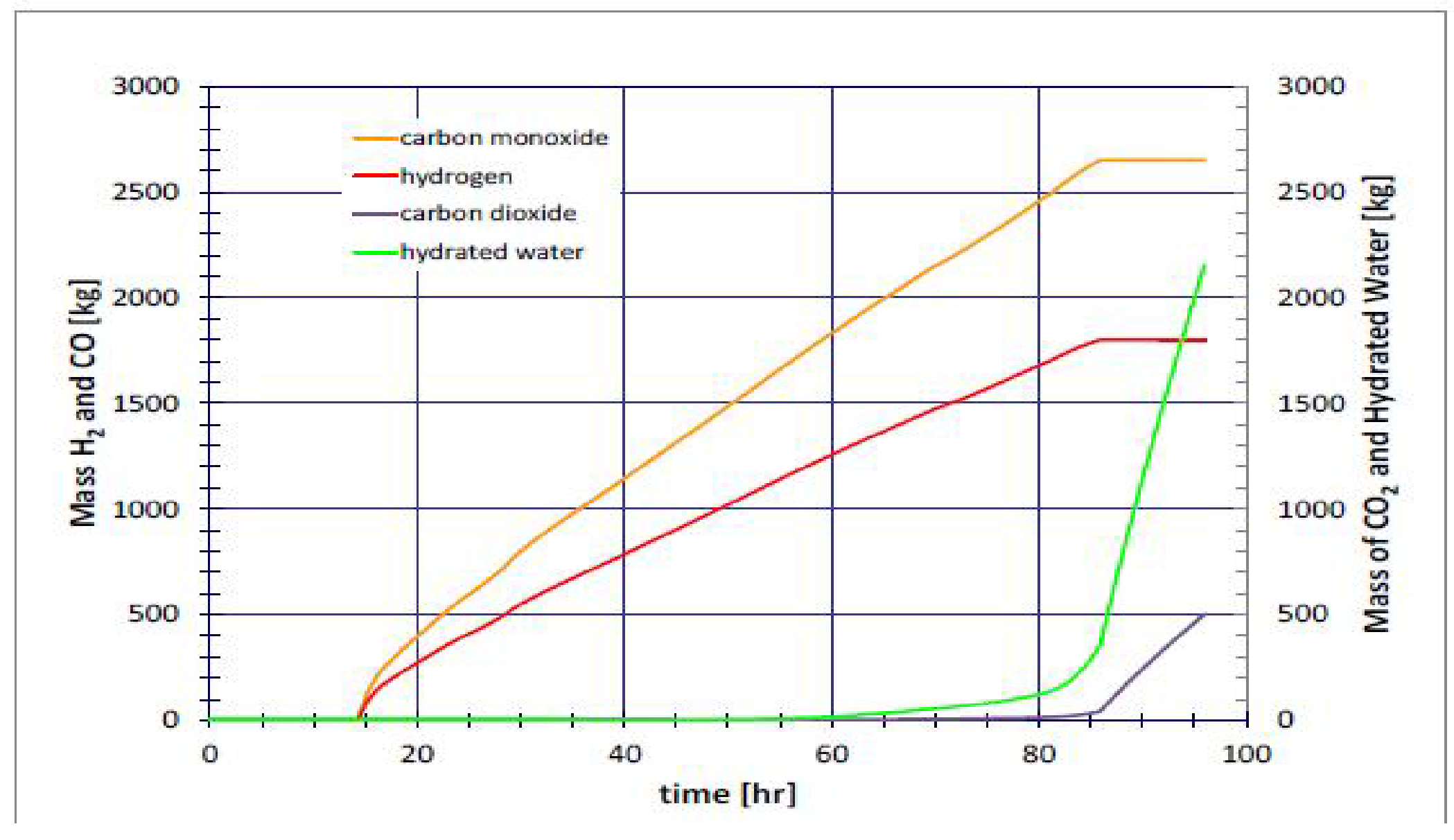




\section{Fukushima Unit $1 \mathrm{MCCl}$ and other hydrogen production -SAND2012-6173}

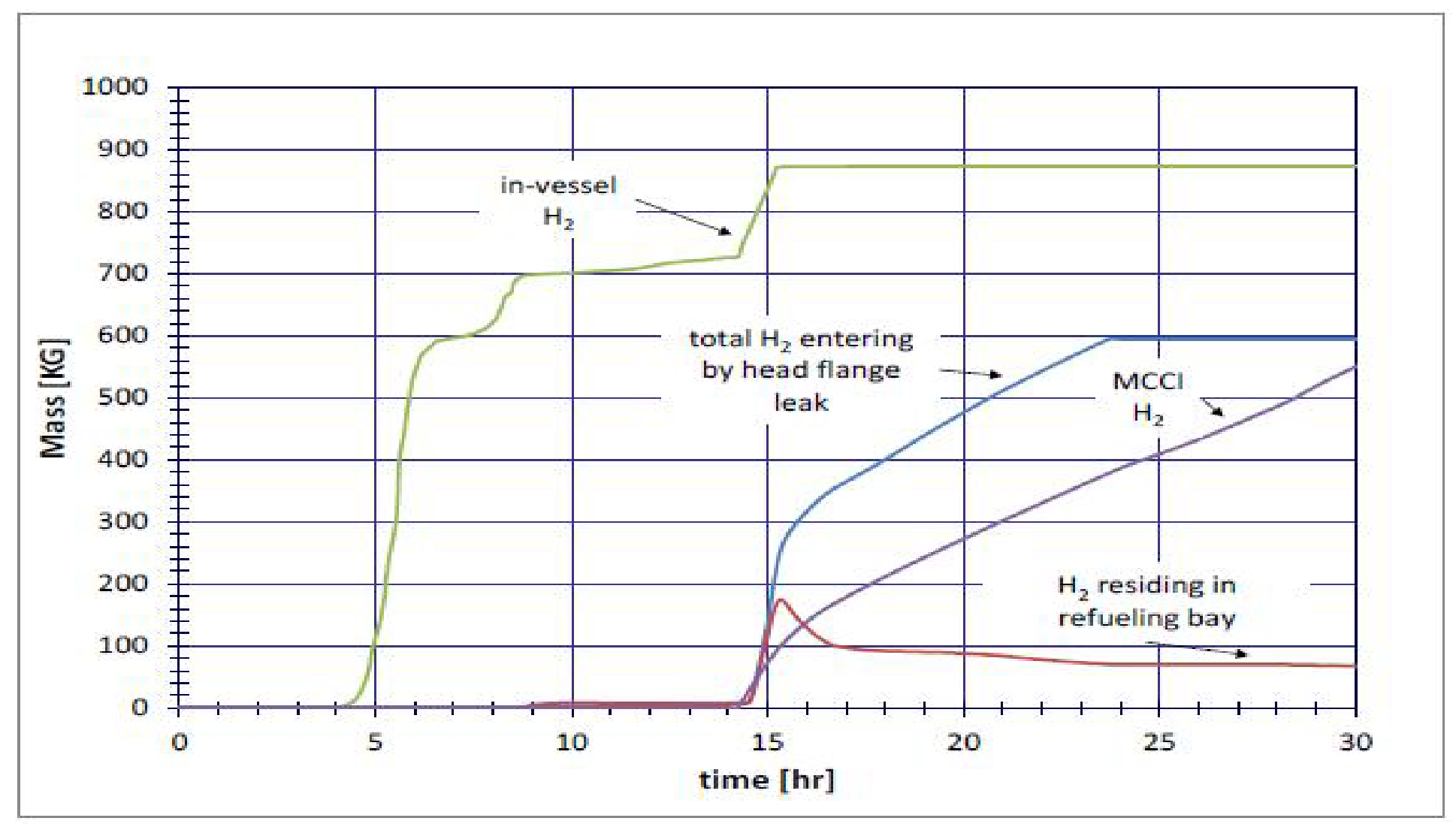




\section{Fukushima Unit 1 Csl Most Retained in Suppression pool with at 1-2\% Release- SAND2012-6173}

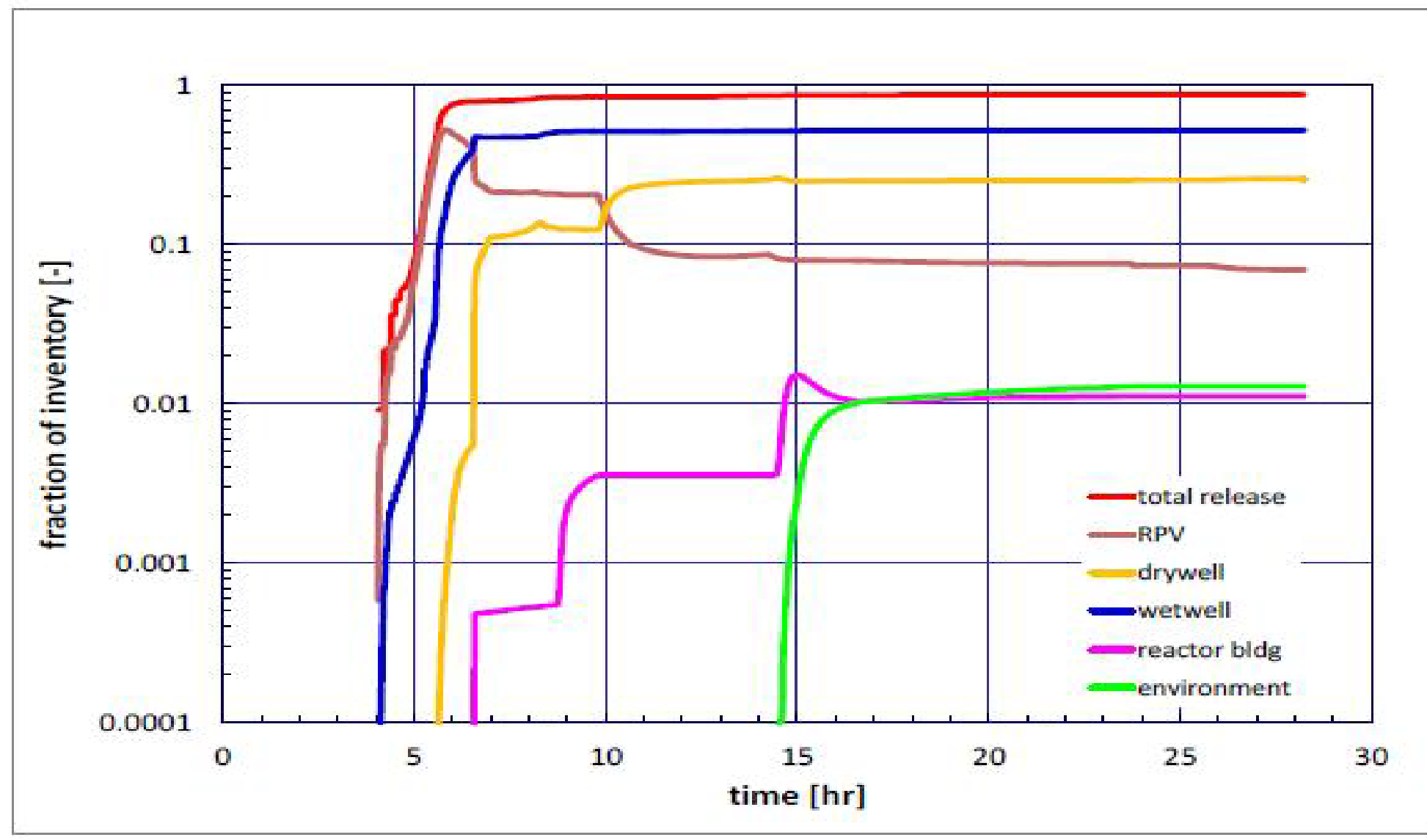




\section{Fukushima Unit 2 Significant Fuel Melt - SAND2012-6173}

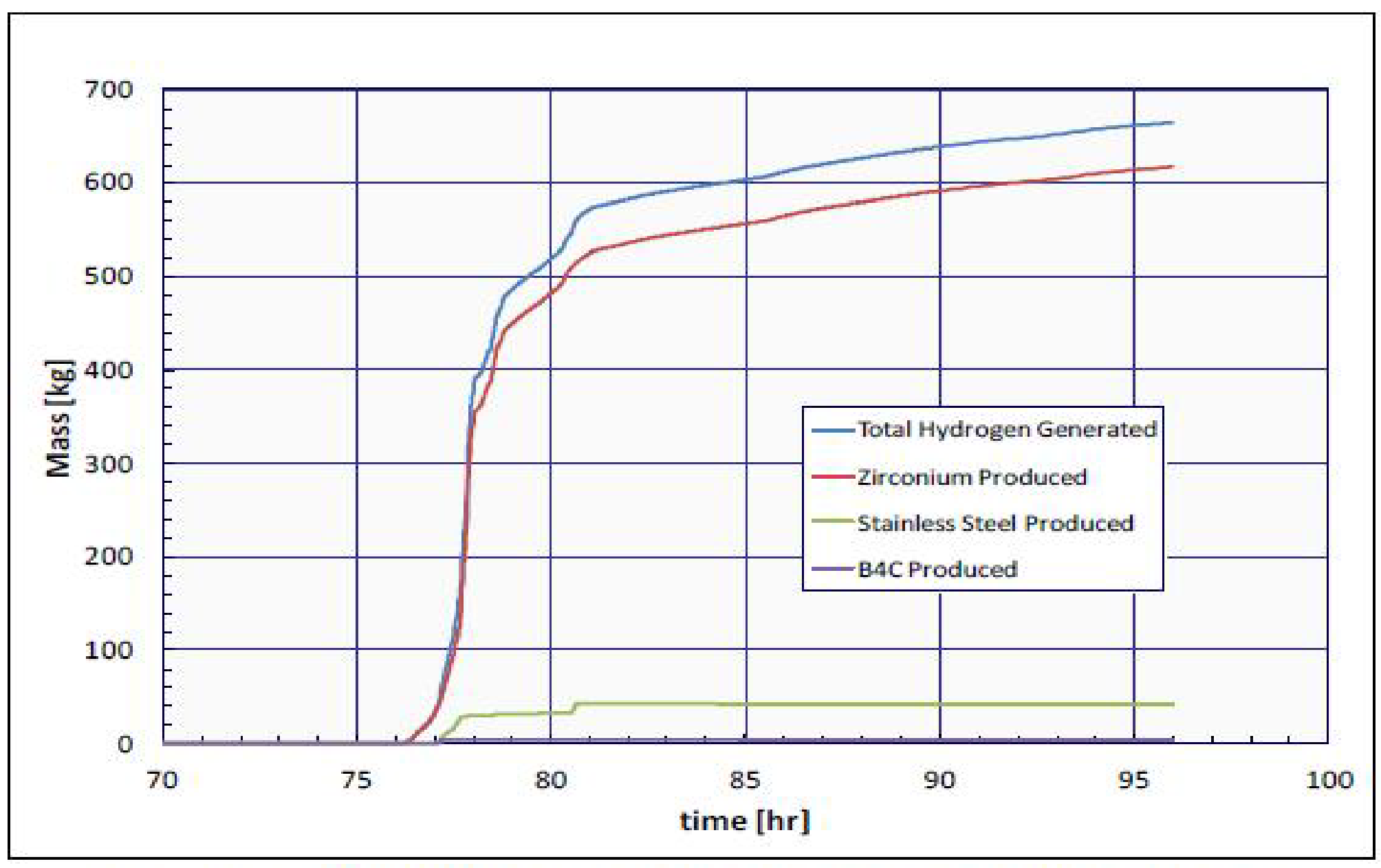




\section{Fukushima Unit 2 Significant Fuel Damage and Fission Product Release -SAND2012-6173}

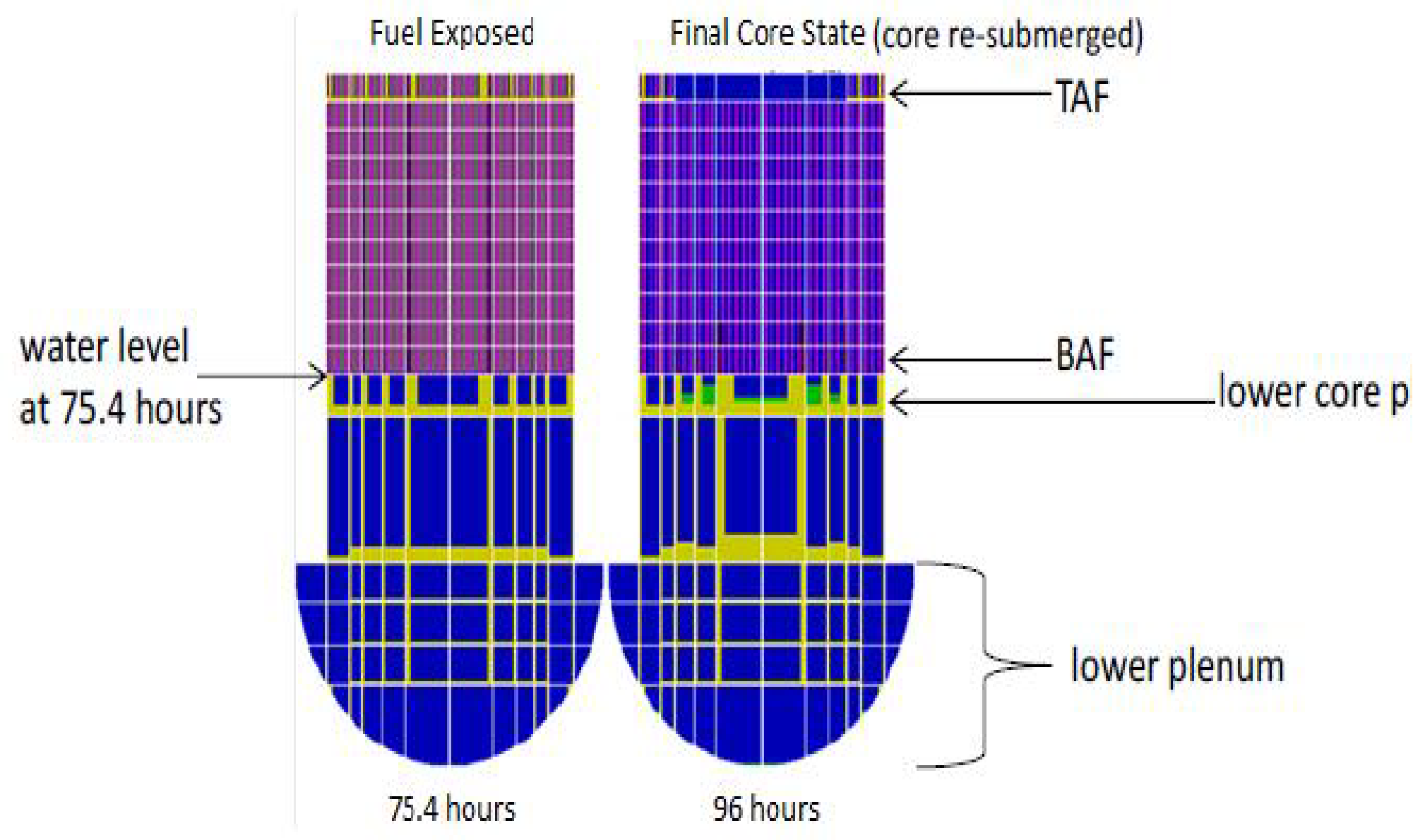




\section{Fukushima Unit 3 hydrogen production little damage to fuel -SAND2012-6173}

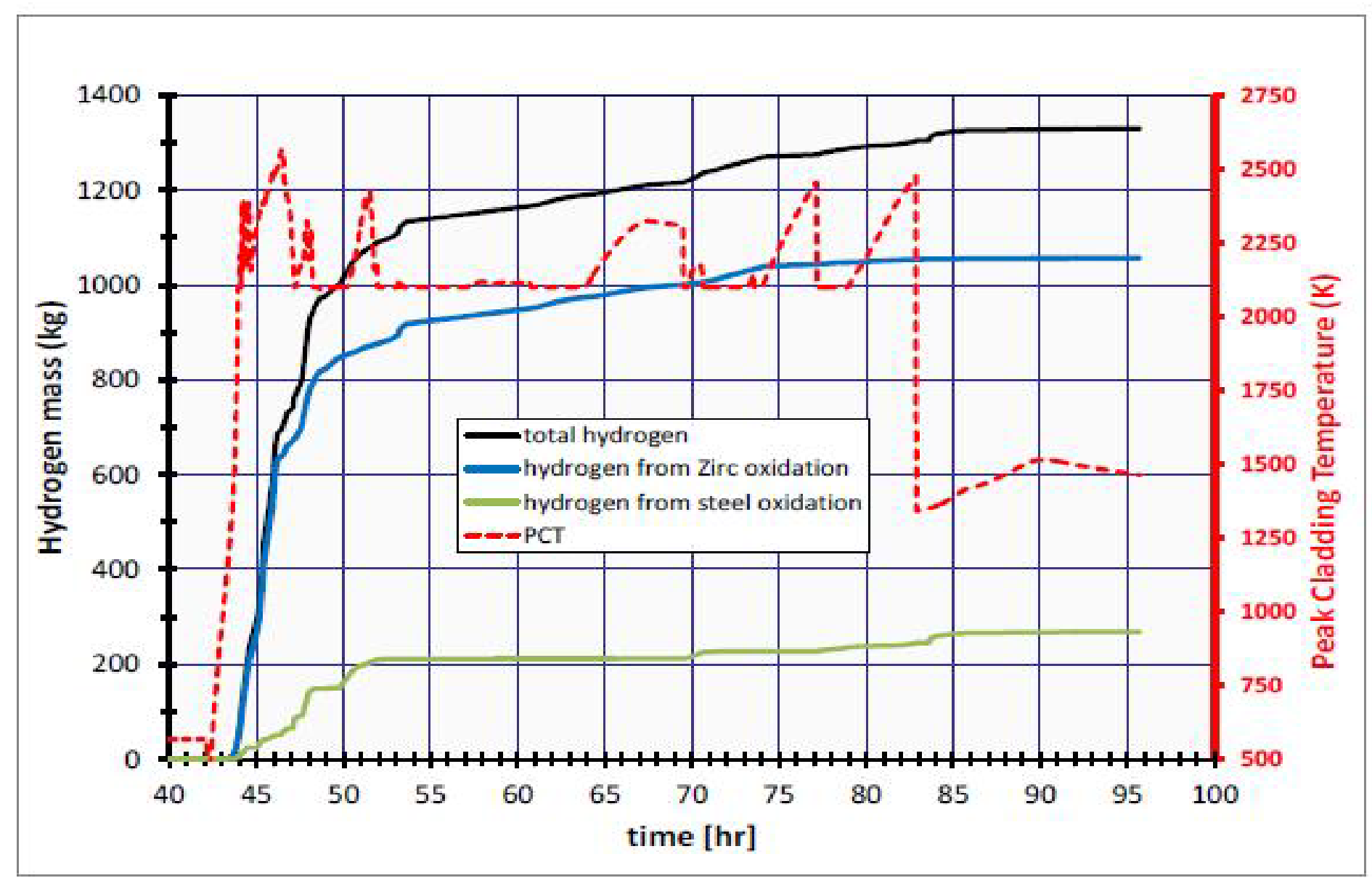




\section{Fukushima Unit 3 Fuel Retained in the RPV retained damage $58 \%$ of Noble Gases Released -SAND2012-6173}

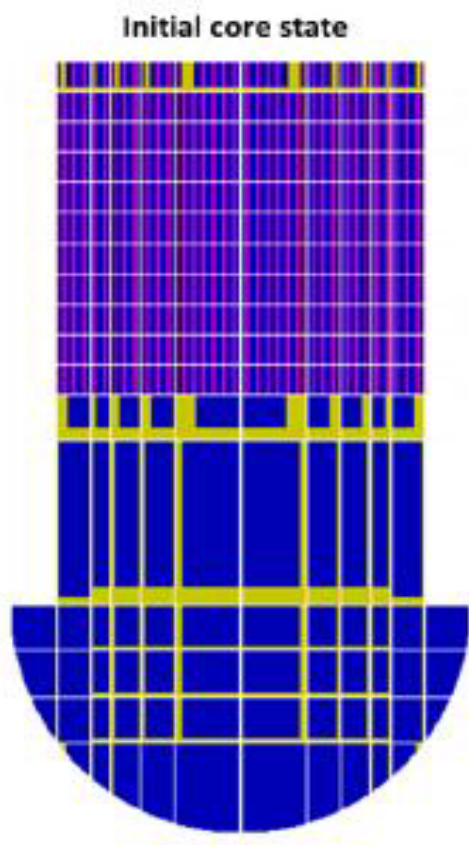

0 to $\mathbf{4 2}$ hours

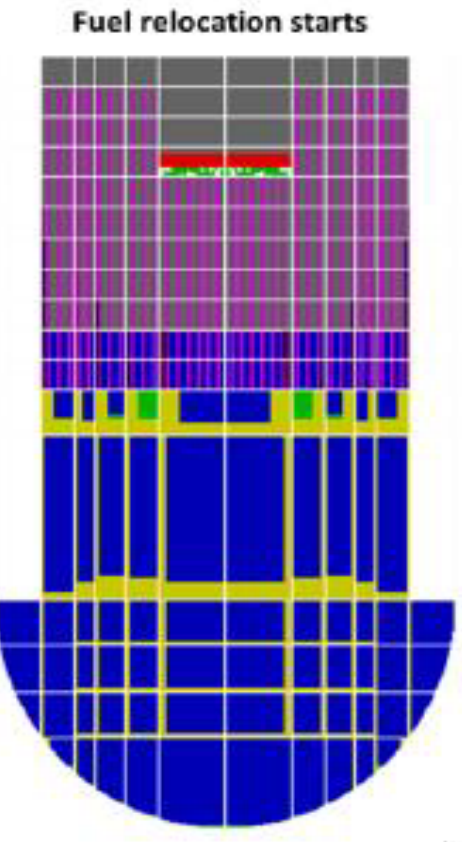

46.5 hours

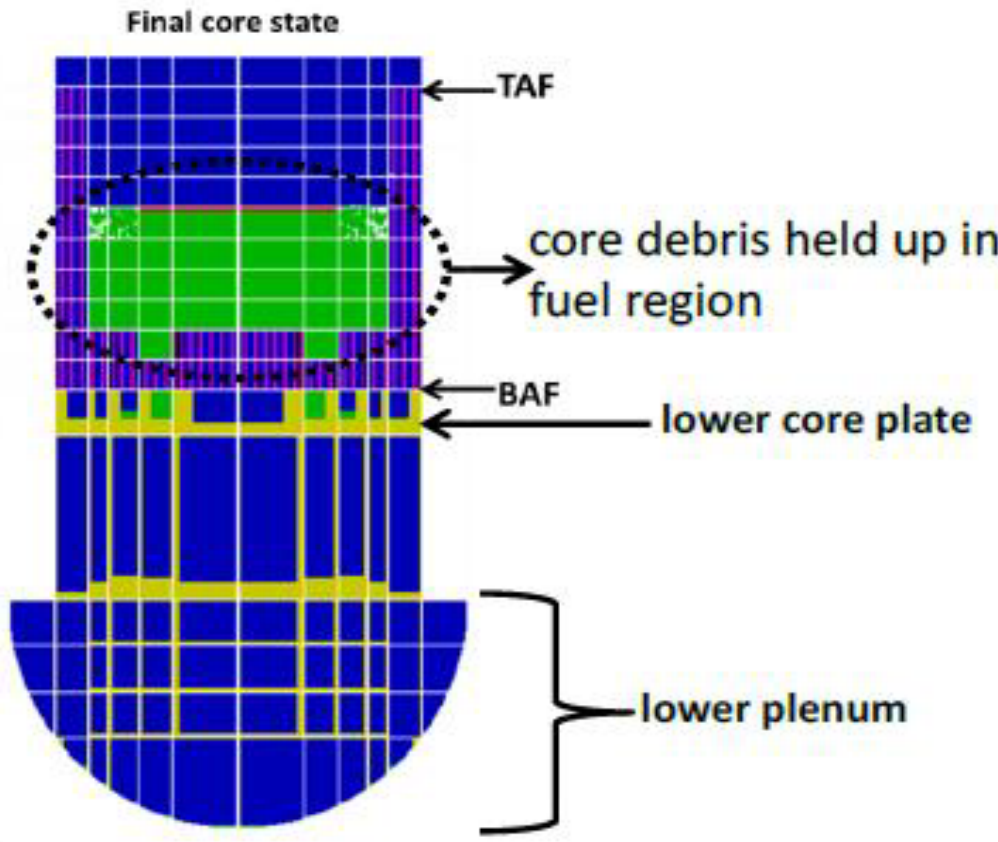

96 hours 


\section{MELCOR Role Evolving}

- Original role for PRAs required simpler, fast-running code

- Uncertainties assessed through sensitivity studies

- Substantial user flexibility allowed for parametric studies

- Recent role uses more detailed models

- NRC consolidating to one code

- Assessments against more detailed codes used to determine required model complexity

- More mechanistic models implemented as necessary

- Recent role using more flexible modeling geometry

- More generic modeling without "built-in" nodalization

- Control volume approach used to define plant system

- Application NOT limited to LWR reactor accident analysis 


\section{MELCOR Modeling Improvements Assessed with Mechanistic Codes}

- CONTAIN for containment modeling (completed)

- SCDAP/RELAP5 for core and in-vessel degradation modeling (underway)

- RCS natural circulation

- TMI-like core melt progression

- plant sequence comparisons

- VICTORIA for fission product chemistry and transport models (planned)

- fission product speciation

- fission product deposition 


\section{Audit Tool in New Plant Design Certification}

- Severe accident response and source term

- Containment response to design basis accident
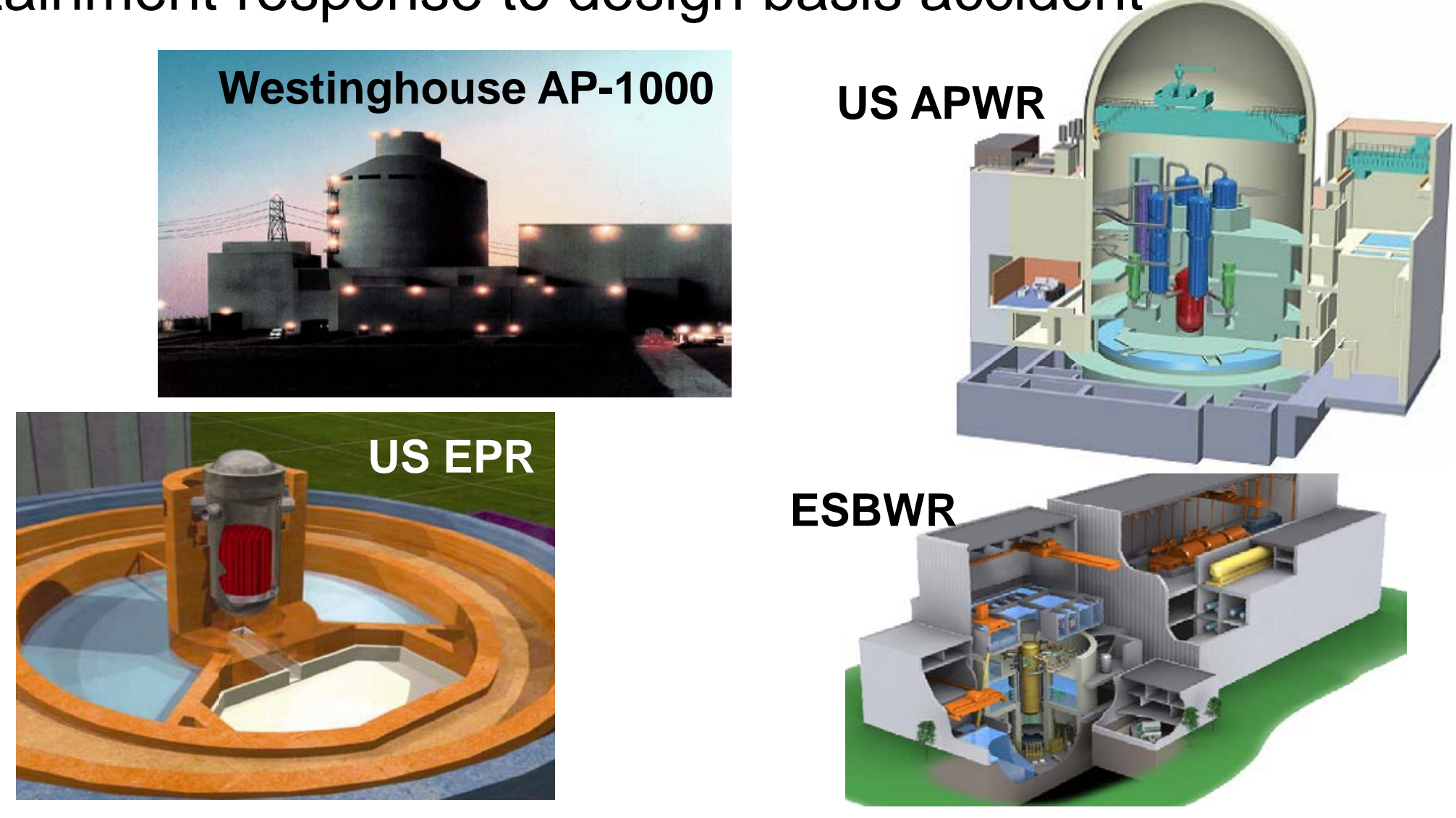


\section{MAAP Designed for Full-Plant Calculations}

- Developed \& used by industry for PRA and phenomenological studies

- Integrated RCS and containment analysis

- Control system/trip logic functions

- Lumped parameter models provide fast, global approximations

- Design specific versions (e.g., BWR, PWR) with relatively fixed thermal-hydraulic system representations

- Provides for free-form containment modeling

- Model validation against experimental data requires special models or versions. 


\section{MAAP Modeled Phenomena}

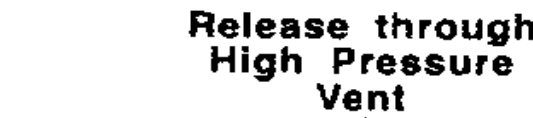

$\underset{\text { Pream \& }}{\mathrm{H}_{2}}$ From Core

Vent

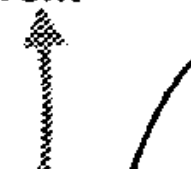

Primary System

Fluld Volume Change
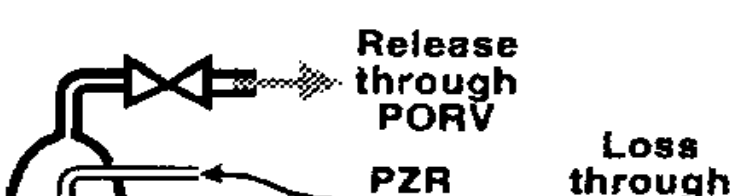

through

Break in SG Tube

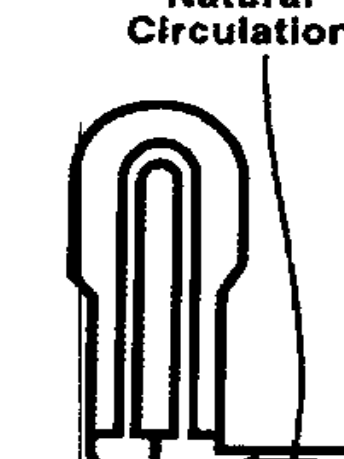

Heat Transfer to

Upper Plenum

Upper Head

Injection

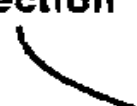

Condensation


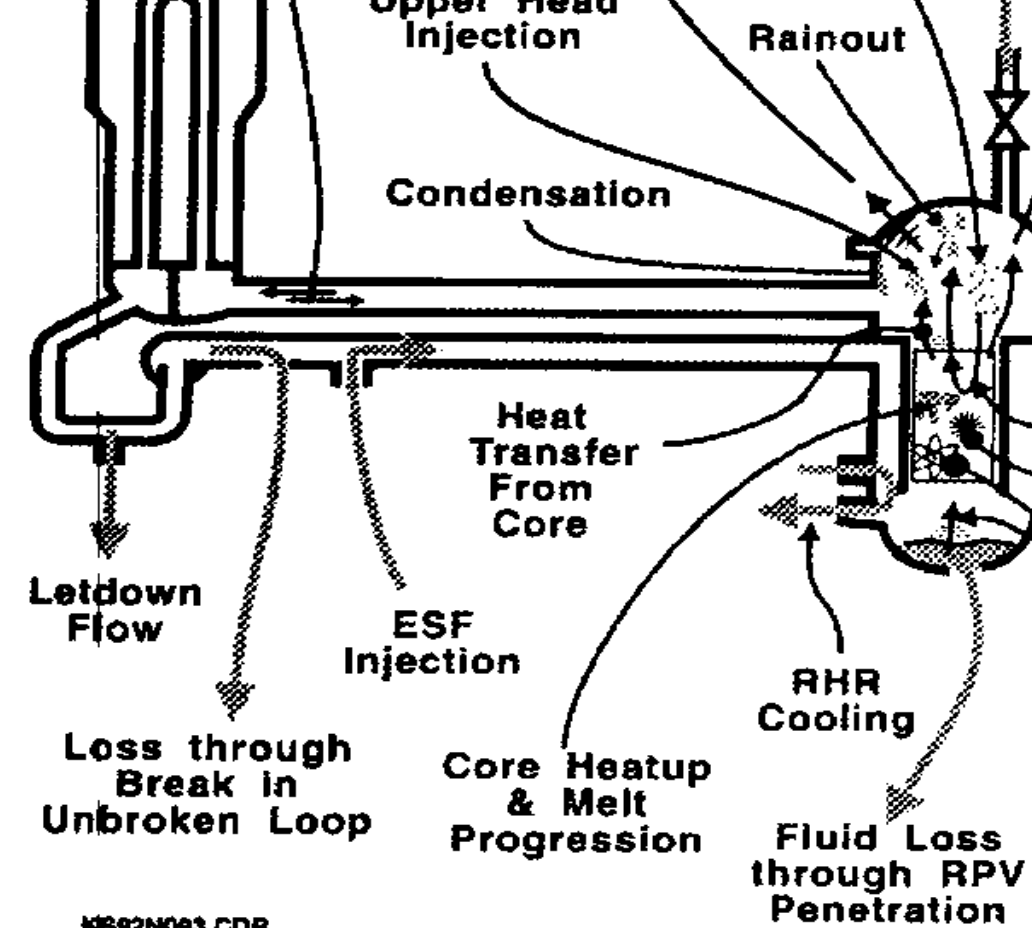

Heandos.CDR

Penetration

Heat Transfer

From Debris in

Lower Plenum

Natural

Circulation

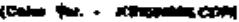




\section{Codes}

MAAP Modeled

Phenomena

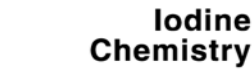

lodine

Flow through

Rupture Disk

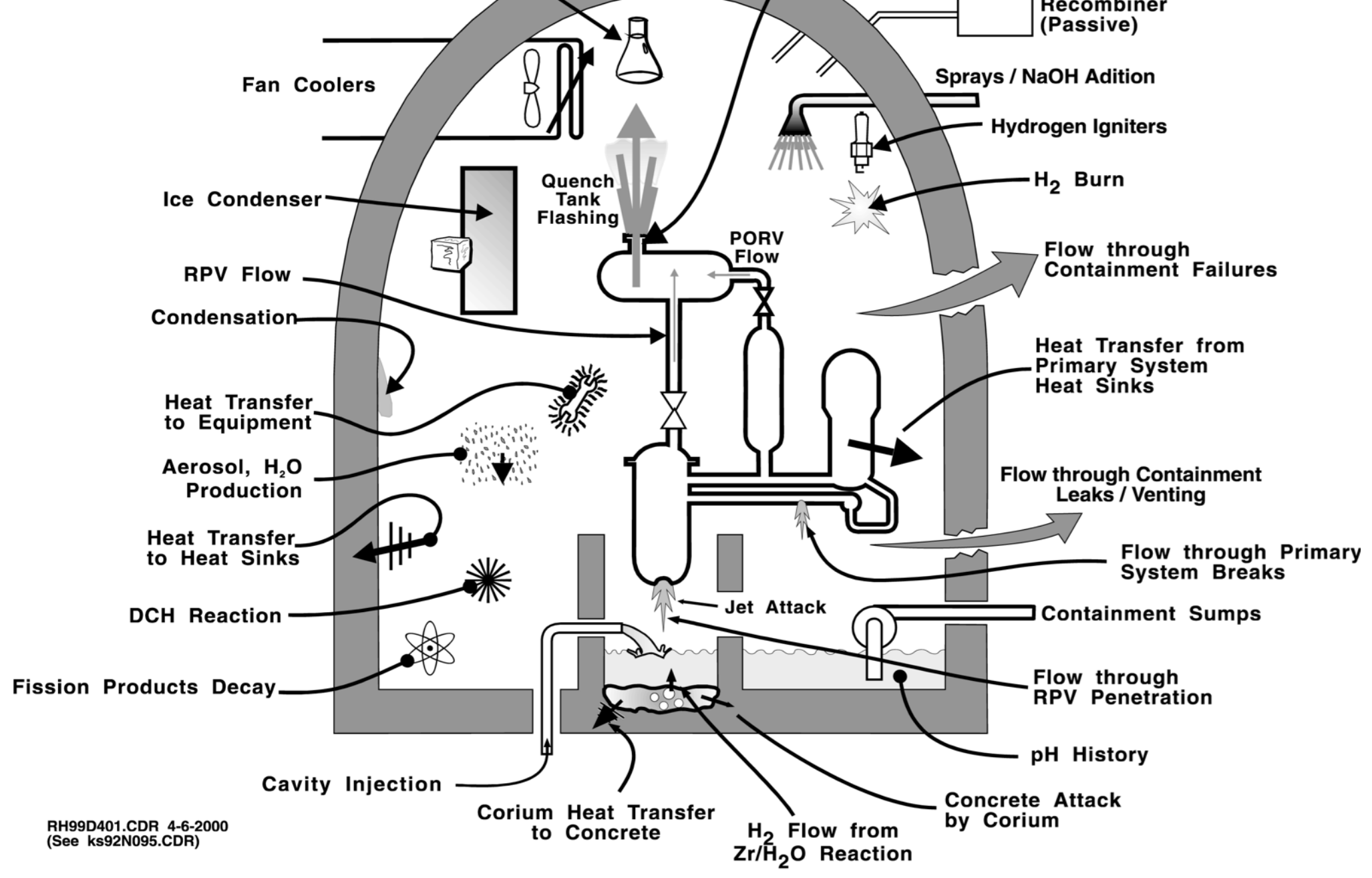




\section{Representative MAAP PWR Analysis Considers Gas Nodes, Heat Structures, and Water Nodes}

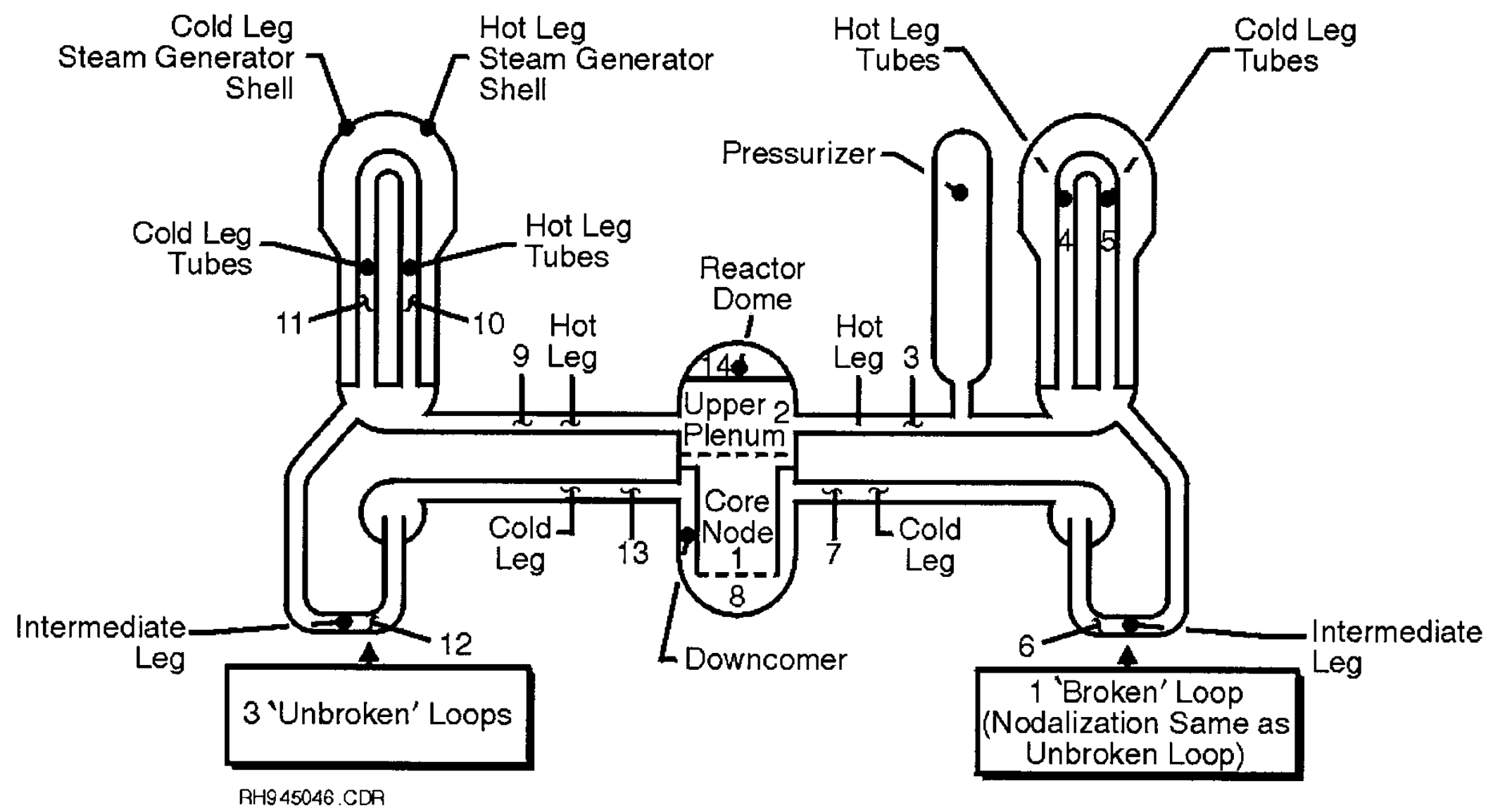




\section{MAAP4 Melt Progression Phenomena}
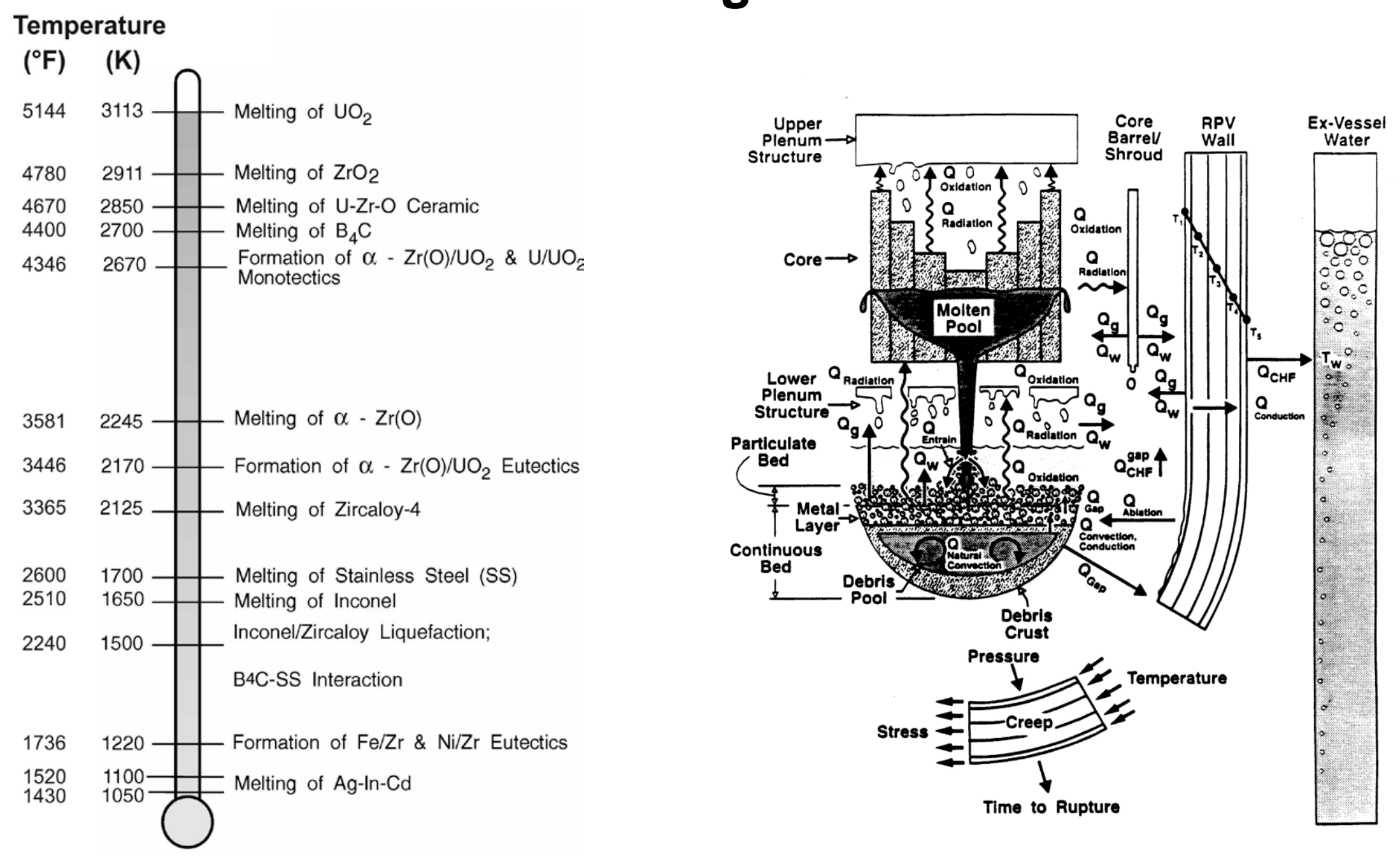


\section{MAAP Considers Unique BWR RCS Phenomena}

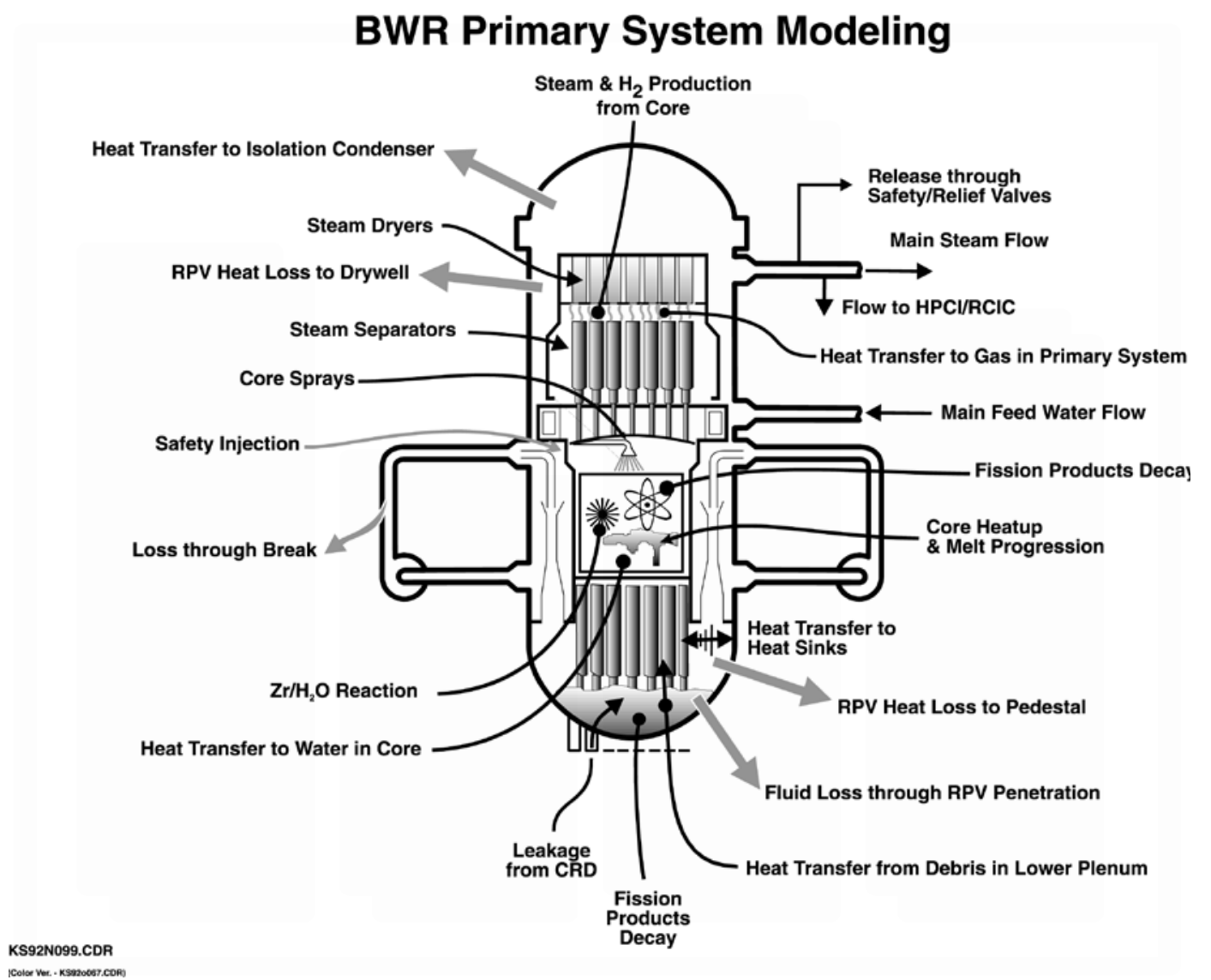




\section{MAAP Modeled BWR Containment Phenomena}

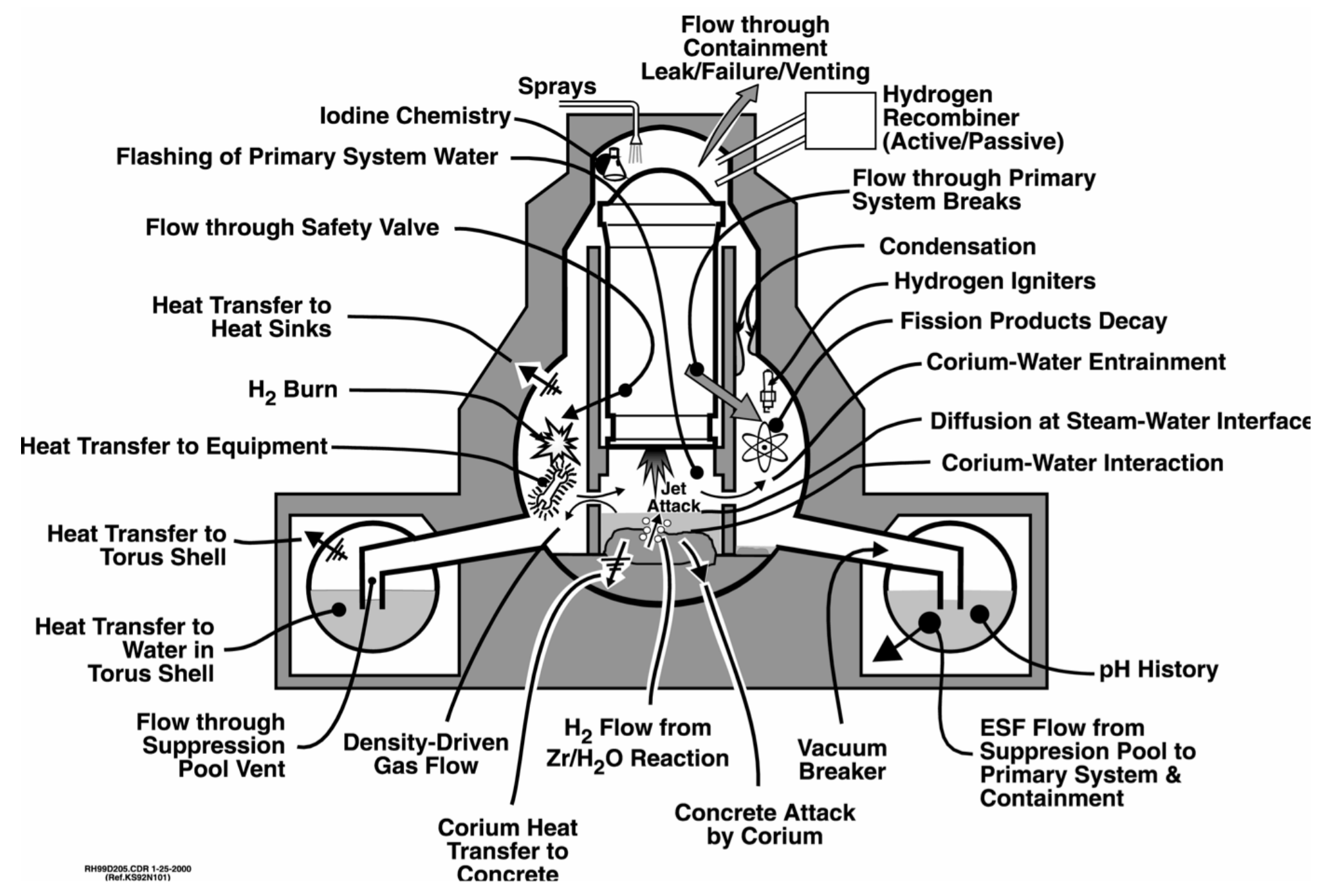




\section{Case Study 2: Comparison of Code Results for AP600 Analysis}




\section{Code Models and Assumptions Impact 3BE AP600 Analysis Results}

- 3BE transient initiated by large break at location that precludes reactor vessel reflood.

- Key assumptions affecting results:

\begin{tabular}{|l|l|l|l|}
\hline \multicolumn{1}{|c|}{ Phenomenon } & \multicolumn{1}{|c|}{ SCDAP/RELAP5-3D } & \multicolumn{1}{|c|}{ MAAP } & \multicolumn{1}{c|}{ MELCOR } \\
\hline $\begin{array}{l}\text { RCS } \\
\text { Depressurization } \\
\text { Model }\end{array}$ & $\begin{array}{l}\text { Ransom/Trapp critical } \\
\text { flow model (results } \\
\text { consistent with } \\
\text { ROSA/AP600 data) }\end{array}$ & $\begin{array}{l}\text { Single phase critical flow } \\
\text { model (unexplained mass } \\
\text { retained in RCS) }\end{array}$ & $\begin{array}{l}\text { Two-phase critical flow model } \\
\text { (with user supplied discharge } \\
\text { coefficients) }\end{array}$ \\
\hline Fuel melting & $\begin{array}{l}\text { At } 2870 \mathrm{~K} / 4710^{\circ} \mathrm{F} \text { due } \\
\text { to eutectic formation }\end{array}$ & $\begin{array}{l}\text { At } 3100 \mathrm{~K} / 5120^{\circ} \mathrm{F}\left(\mathrm{UO}_{2}\right. \\
\text { melting temperature) }\end{array}$ & At user-specified temperature. \\
\hline $\begin{array}{l}\text { Hydrogen } \\
\text { generation }\end{array}$ & $\begin{array}{l}\text { Throughout core } \\
\text { degradation }\end{array}$ & Until first relocation & Until cladding failure temperature. \\
\hline Relocation to vessel & $\begin{array}{l}\text { If crust cannot support } \\
\text { molten material }\end{array}$ & $\begin{array}{l}\text { When melting temperature } \\
\text { is predicted }\end{array}$ & $\begin{array}{l}\text { When fuel melting occurs, material } \\
\text { relocates to core plate and is } \\
\text { retained until core plate reaches } \\
\text { user-specified temperature. }\end{array}$ \\
\hline $\begin{array}{l}\text { Debris-to-vessel } \\
\text { heat transfer }\end{array}$ & $\begin{array}{l}\text { No enhanced debris } \\
\text { cooling (model } \\
\text { developed and data } \\
\text { now available) }\end{array}$ & $\begin{array}{l}\text { Enhanced cooling from } \\
\text { water in user-specified } \\
\text { gaps with user-specified } \\
\text { heat transfer }\end{array}$ & $\begin{array}{l}\text { No enhanced debris cooling } \\
\text { (model developed, and data now } \\
\text { available) }\end{array}$ \\
\hline
\end{tabular}




\section{Code Models and Assumptions Impact 3BE AP600 Analysis Results (continued)}

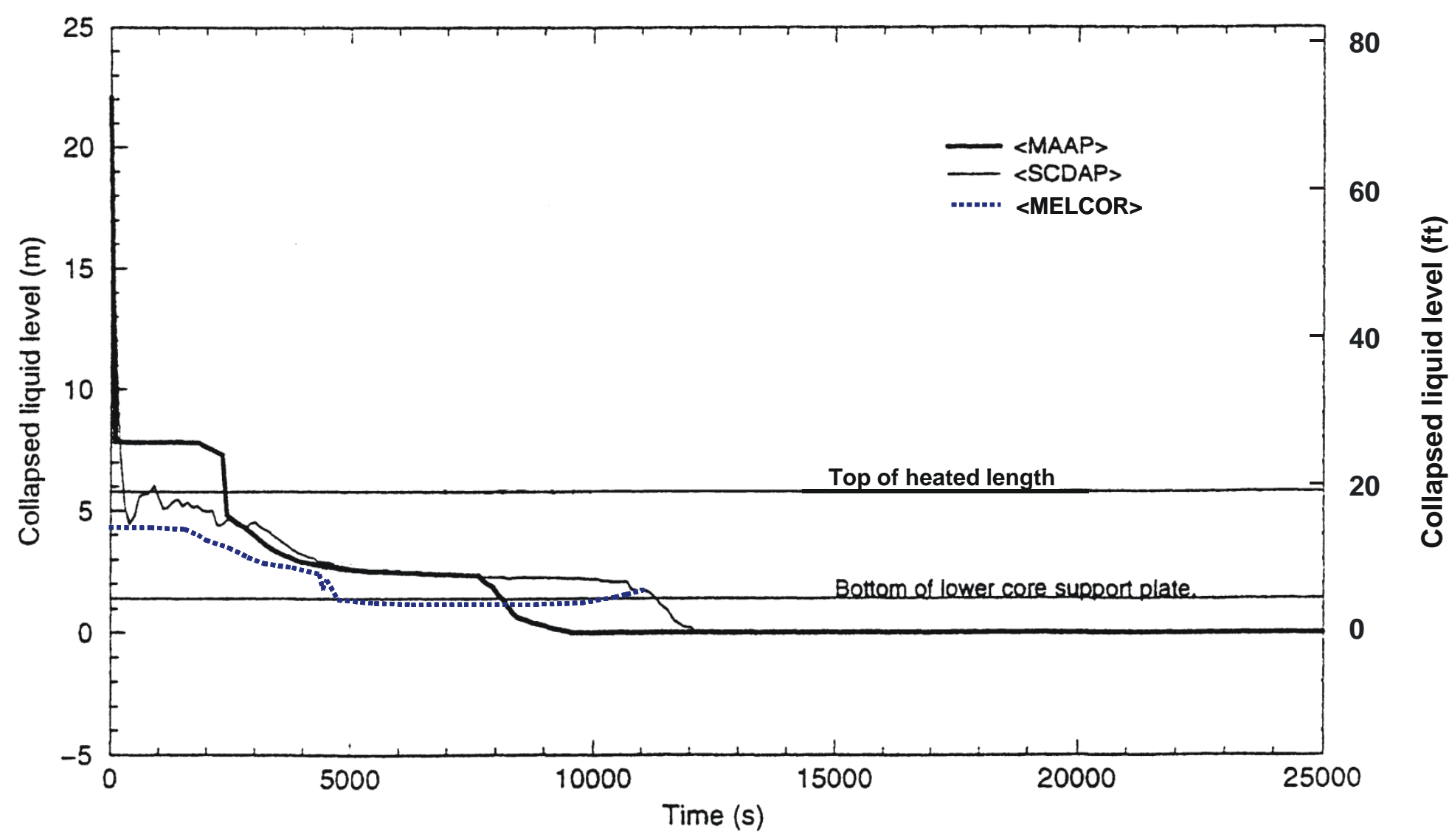

Unexplained additional coolant retained in RCS for MAAP calculation 


\section{Code Models and Assumptions Impact 3BE AP600 Analysis Results (continued)}

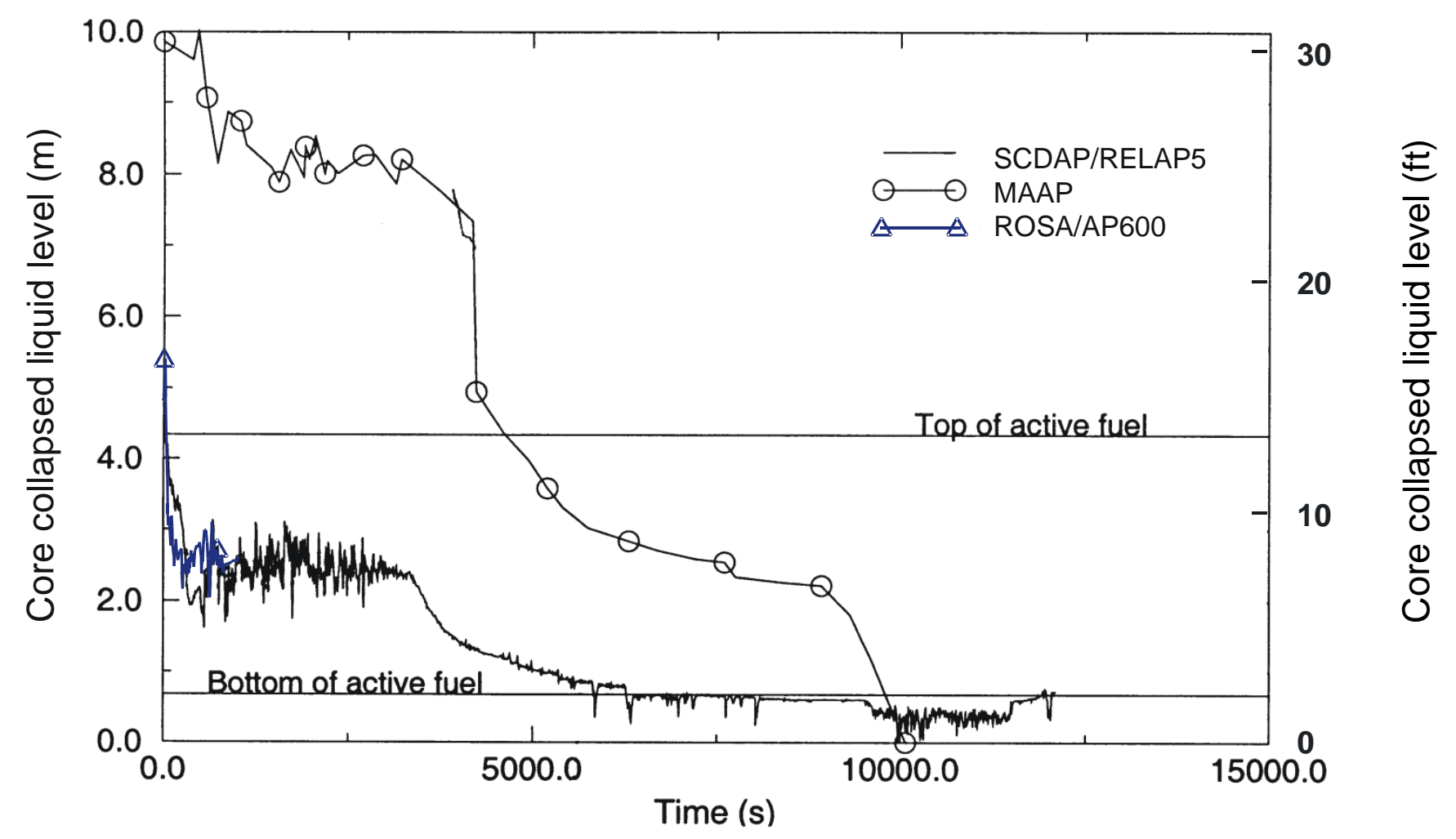

SCDAP/RELAP5-3D core uncovery consistent with ROSA/AP600 data. 


\section{Code Models and Assumptions Impact 3BE AP600 Analysis Results (continued)}

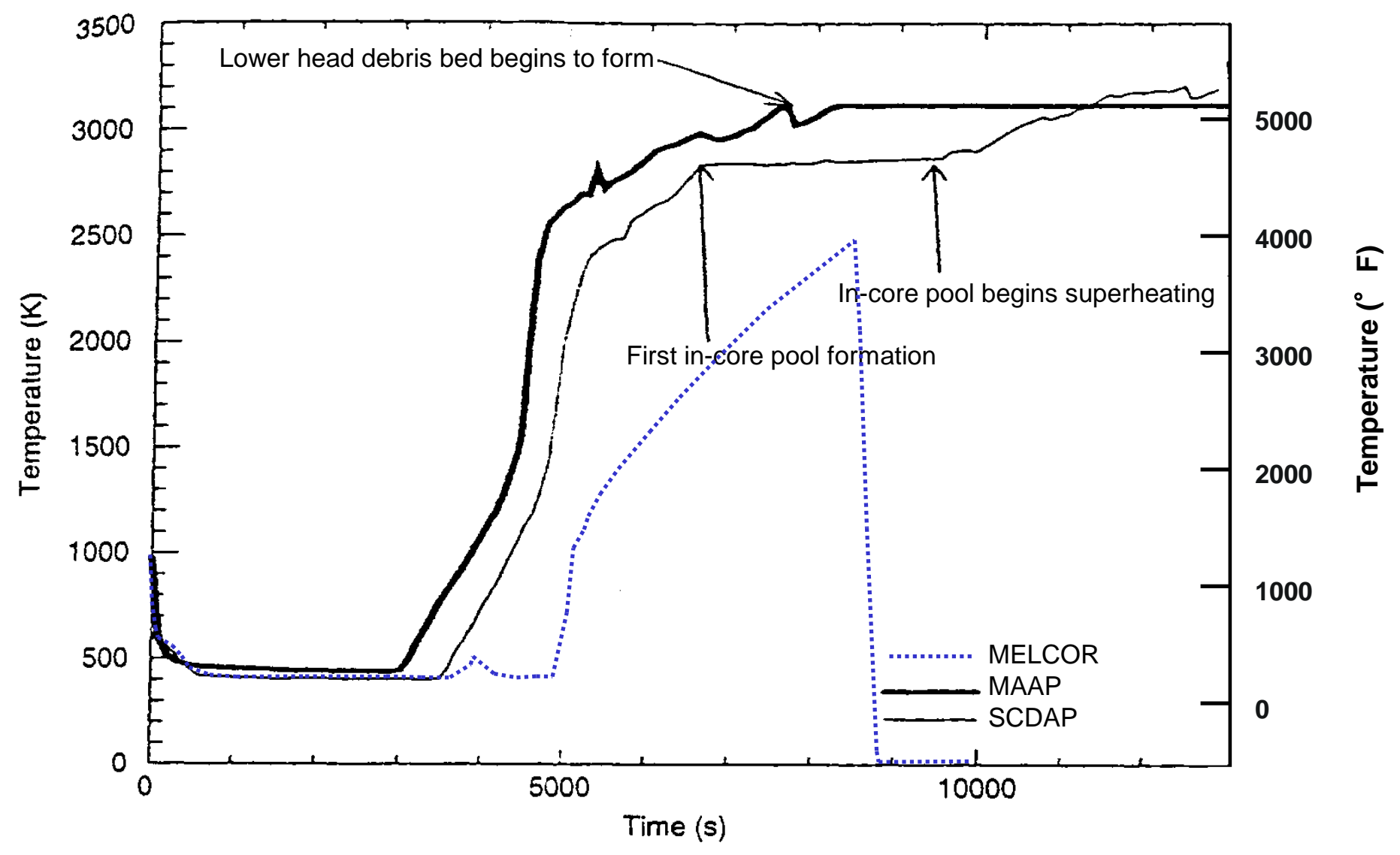

MELCOR shows delayed core heatup despite early core uncovery. 


\section{Code Models and Assumptions Impact 3BE AP600 Analysis Results (continued)}

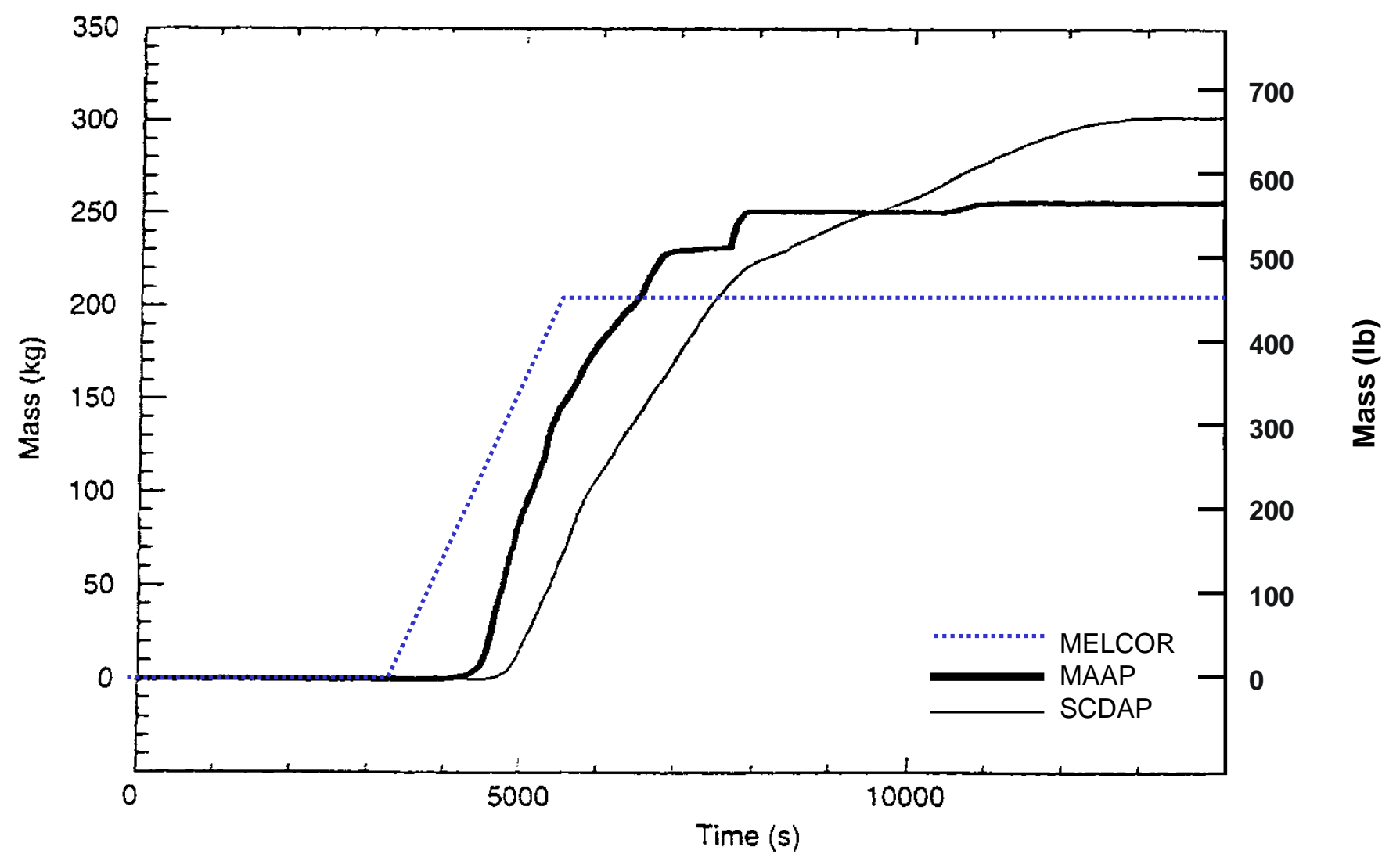

MAAP and MELCOR predict much lower total hydrogen generation. 


\section{Code Models and Assumptions Impact 3BE AP600 Analysis Results (continued)}

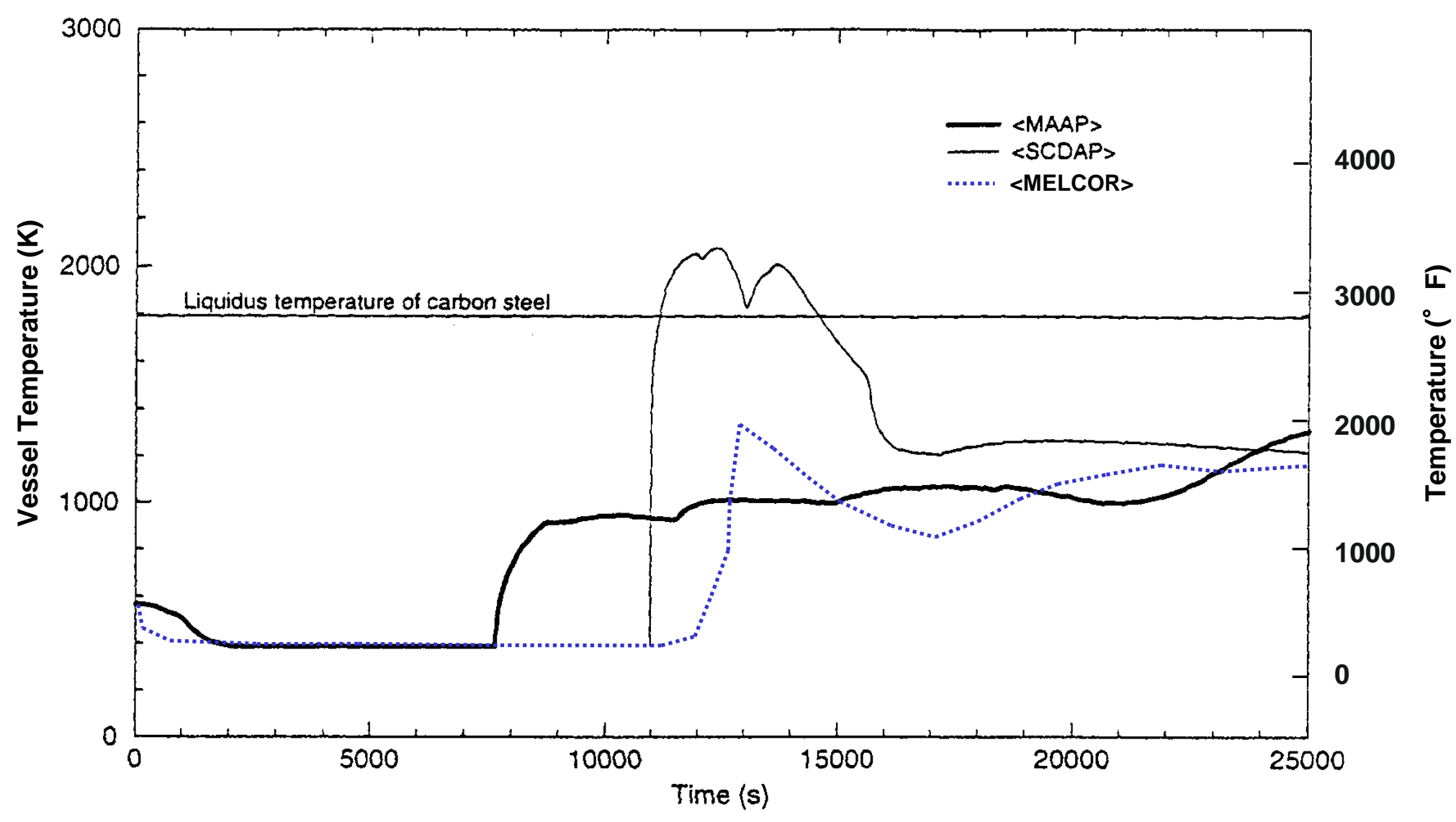

MELCOR and MAAP predict lower debris heat load on vessel wall 


\section{Summary and Discussion}

- Selection of mature US severe accident analysis codes available.

- Codes differ in modeling approaches

- Codes have undergone fairly extensive code-todata comparisons.

- Insights from code calculations have played a key role in resolving accident management issues

- Analysis reviews must consider impact of code modeling assumptions and approaches 


\section{Regulatory Considerations (SECY-93-087)}

- Hydrogen Control

- 10CFR50.44, "Combustible Gas Control for Nuclear Reactors"

- Capability to ensure a mixed atmosphere

- Maintain atmospheric concentration of hydrogen below $10 \%$ by volume

- Maintain containment integrity in the event of a deflagration

- Core Debris Coolability

- Provisions to spread and quench molten core debris

- Ensure that the environmental conditions (pressure and temperature) resulting from core-concrete interactions do not exceed established criteria

- Containment Performance

- Maintain role as a leak-tight barrier for 24 hours following core damage

- Post-24 hours, provide a barrier against uncontrolled fission product release

- Consideration of in-vessel and ex-vessel steam explosion

- High Pressure Melt Ejection

- Reliable depressurization system

- Features to decrease ejected debris in the upper containment 


\section{Methods \\ Uncertainty Convolution: Deterministic vs. Probabilistic}

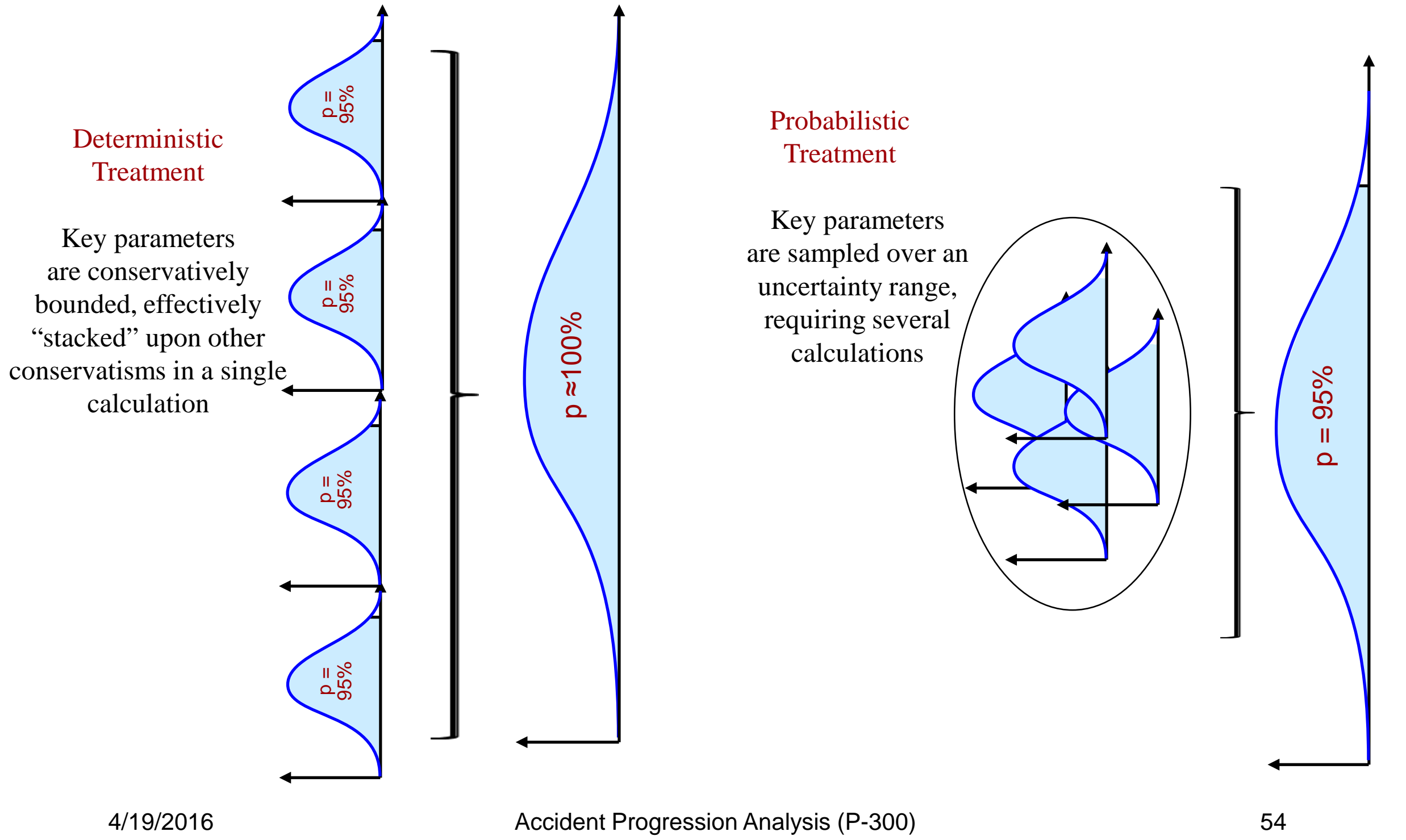




\section{Severe Accident Phenomena (EPR)}

- A selection of MAAP4 model parameters

- Perform numerous simulations from random sampling of model parameters

- Statistics can reveal limiting condition, important phenomena

\begin{tabular}{|c|c|c|}
\hline Description & Low Value & High Value \\
\hline \multicolumn{3}{|c|}{ HYDROGEN UNCERTAINTY PARAMETERS } \\
\hline $\mathrm{Zr}-\mathrm{H} 2 \mathrm{O}$ Oxidation Multiplier & 1.5 & 2.0 \\
\hline fraction of $\mathrm{Zr}$ oxidized to keep cladding intact & 0.0 & NA \\
\hline Cladding Melt Breakout Temperature & $2500 \mathrm{~K}$ & $3000 \mathrm{~K}$ \\
\hline Fuel Rod Collapse Temperature (i.e. L-M coef.) & 46 & 54 \\
\hline enable/disable the U-Zr-O eutectic model & NA & 1 \\
\hline Fuel Melt Temperature & $2500 \mathrm{~K}$ & $2800 \mathrm{~K}$ \\
\hline Control Rod Melt Temperature & $1500 \mathrm{~K}$ & $2500 \mathrm{~K}$ \\
\hline Melt relocation HTC & 0.0 & 0.15 \\
\hline Particulate debris size in lower plenum & 0.01 & 0.1 \\
\hline Porosity of fuel debris beds & 0.26 & 0.53 \\
\hline \multicolumn{3}{|c|}{ CORE DEBRIS COOLABILITY UNCERTAINTY PARAMETERS } \\
\hline Total Power (decay power) & $100 \%$ & $106 \%$ \\
\hline Initial radius of the local vessel failure & $0.005 \mathrm{~m}$ & $0.25 \mathrm{~m}$ \\
\hline Lower head damage fraction for failure & 0 & 1 \\
\hline corium friction coefficient & 0.001 & 0.1 \\
\hline Flat Plate CHF Kutateladze \# & 0.2 & 0.3 \\
\hline Steaming rate $(\mathrm{kg} / \mathrm{s})$ & 13 & 17 \\
\hline Emissivities & 0.7 & 1.0 \\
\hline
\end{tabular}


Methods

\section{CGCS Analysis: Tolerance Limit of H2 Concentration}

- Licensing limit is $10 \%$

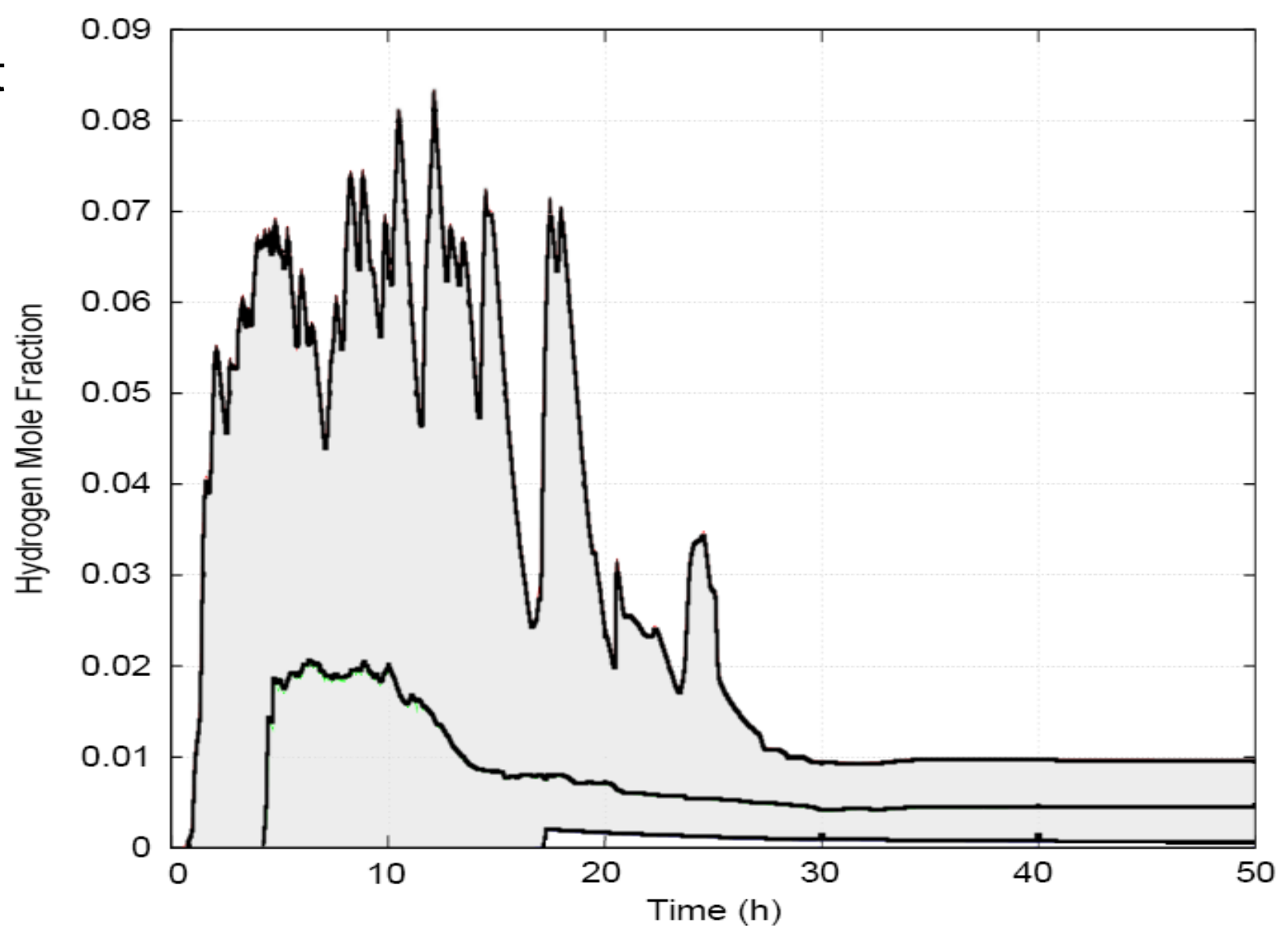




\section{Study Questions}

- Name U.S.-developed codes used in severe accident analysis

- What phenomena are considered in each severe accident analysis code?

- Discuss differences in code modeling approaches that may impact code predictions

- List some key questions to ask when reviewing an analysis 


\section{Code References}

- M. L. Corradini, et al., SCDAP/RELAP5 Independent Peer Review, Los Alamos National Laboratory, LA-12381, January 1993.

- E. W. Coryell, et al., "The Development and Application of SCDAP-3D," Tenth International Conference on Nuclear Engineering, April 14-18, 2002, Arlington, VA, USA

- L. J. Siefken, et al., SCDAP/RELAP5/MOD3.3 Code Manuals, Volumes 1-5, NUREG/CR-6150, INEL-96/0422, Rev. 2, January 2001, (http://www.nrc.gov/RES/SCDAP/nrc.html).

- L. J. Siefken, et al., SCDAP/RELAP5-3D ${ }^{\odot}$ Code Manuals, Volumes 1-5, INEELEXT-01-00917, July 2001, (also see http:www.inel.gov/relap5 or www.inel.gov/relap/scdap).

- D. L. Knudson, et al., SCDAP/RELAP5 Evaluation of the Potential for Steam Generator Tube Ruptures as a Result of Severe Accidents in Operating Pressurized Water Reactors, INEEL/EXT-98-00286, Rev 1, September 1998.

- K. K. Murata, et al., Code Manual for CONTAIN 2.0: A Computer Code for Nuclear Rector Containment Analysis, NUREG/CR-6533, SAND97-1735, Sandia National Laboratories, December 1997. 


\section{Code References (continued)}

- W. Weaver, et al., "A generic semi-implicit coupling methodology for use in RELAP5-3D," Nuclear Engineering and Design, 211, pp. 13-26, 2002.

- "MELCOR Project Status NRC Severe Accident Code Consolidation," presented at USNRC CSARP-2001 Meeting, May 7-9, 2001, Bethesda, Maryland.

- MELCOR 1.8.6 User's Manual and MELCOR 1.8.6 Reference Manual, NUREG/CR-6119, Volumes 1 - 3, (http: www. melcor.sandia.gov).

- B. E. Boyack, et al., MELCOR Peer Review, Los Alamos National Laboratory, LA-12240, March 1992.

- $\quad$ R. O. Gaurtt, "MELCOR 1.8.5 Simulation of TMI-2 Phase 2 with an Enhanced 2-Dimensional In-Vessel Natural Circulating Model," Tenth International Conference on Nuclear Engineering (ICONE 10), April 14-18, 2002, Arlington, VA.

- $\quad$ K. Ross, "MELCOR TMI-2 Assessment," MCAP Meeting, September 20, 2007. 


\section{Code References (continued)}

- MAAP4 User's Manual, Fauske and Associates, (http:www.maap4.com).

- Fauske and Associates, Inc., MAAP4-Modular Accident Analysis Program for LWR Power Plants, Vol. 3, Benchmarking, prepared for Electric Power Research Institute, May 1994.

- MAAP User's Group Meeting Presentations and Meeting Minutes, October 7-9, 1998, FAI Technical Report TR-111240-V1, December 1998.

- $\quad$ Revised Accident Source Terms: NUREG-1465 vs MAAP 4.0.2, FAI Technical Bulletin No. 1295-1 (http://www.fauske.com/Download/Nuclear/TechBulletins/tb1295-1.pdf).

- K. Vierow et al., "Severe accident analysis of a PWR station blackout with the MELCOR, MAAP4 and SCDAP/RELAP5 codes," Nuclear Engineering and Design 234, pp.129-145, 2004.

- OECD/NEA Group of Experts, SOAR on Containment Thermalhydraulics and Hydrogen Distribution, NEA-CSNI-R-99-16, June 1999. 


\section{Code References (continued)}

- K. A. Smith, Multi-Processor Based Simulation of Degraded Core and Containment Responses, PhD Thesis, The Pennsylvania State University, December 1992.

- F. Fichot, et al., ICARE/CATHARE: A Computer Code for Analysis of Severe Accidents in LWRs. ICARE2 V3mod0: Description of Physical Models, NT SEMAR 98/123, DRS/SEMAR/LECTA, 1998.

- H. Ujita, et al., "Development of Severe Accident Analysis Code SAMPSON in IMPACT Project," J. Nucl. Sci. and Tech., 36 (11), 1999.

- $\quad$ K. Trambauer, "Coupling Methode of Thermal-hydraulic Models with Core Degradation Models in ATHLET- CD," Sixth International Conference on Nuclear Engineering (ICONE6), San Diego, CA, May 1998.

- Martin, R.P., Bingham, M.W., et al., "AREVA NP's severe accident safety issue resolution methodology for the U.S. EPR," Proceedings of the 2008 International Congress on Advances in Nuclear Power Plants, Anaheim, CA, USA, 2008. 


\section{Tier 2 NRC Recommendations}

-Spent fuel pool makeup capability (Recommendation 7.2,

7.3, 7.4, and 7.5)

-Emergency preparedness regulatory actions

(Recommendation 9.3)

- Other External Hazards Reevaluation (tornados, hurricanes, drought, etc.)(additional Issue) 


\section{Tier 3 NRC Recommendations}

Potential enhancements to the capability to prevent or mitigate seismically-induce fires and floods (long-term evaluation) (Recommendation 3)

-Reliable hardened vents for other containment designs

-(long-term evaluation) (Recommendation 5.2)

- Hydrogen control and mitigation inside containment or in other buildings

-(longterm evaluation) (Recommendation 6)

-Emergency preparedness enhancements for prolonged station blackout and multiunit events

-(dependent on availability of critical skill sets) (Recommendation 9.1/9.2) 


\section{Tier 3 NRC Recommendations}

-Emergency Response Data System capability (related to long-term evaluation Recommendation 10) (Recommendation 9.3)

-Additional emergency preparedness topics for prolonged station blackout and multiunit events (long-term evaluation) (Recommendation 10)

-Emergency preparedness topics for decision-making, radiation monitoring, and public education (longterm evaluation) (Recommendation 11)

-Reactor Oversight Process modifications to reflect the recommended defenseindepth framework (dependent on Recommendation 1) (Recommendation 12.1) -Staff training on severe accidents and resident inspector training on severe accident management guidelines (dependent on Recommendation 8) (Recommendation 12.2)

-Basis of emergency planning zone size (additional issue)

- Prestaging of potassium iodide beyond 10 miles (additional issue)

-Ten-year confirmation of seismic and flooding hazards (dependent on

Recommendation 2.1) (Recommendation 2.2)

-Transfer of spent fuel to dry cask storage (additional issue) 


\section{Radionuclide Release and Transport}

- Introduction

- Characterization

- Phenomena

- Quantification

- Study Questions

- References 


\section{Objectives}

- Identify and understand factors affecting radionuclide release and transport during a severe accident.

- Identify and describe differences between various methods and approaches used to estimate severe accident releases. 


\section{Inventory Characterized in Terms of Decay Rates}

One curie $(\mathrm{Ci})$ of material undergoes radioactive decay at $3.7 \times 10^{10} \mathrm{dps}$

- 1 Becquerel $(\mathrm{Bq})=1 \mathrm{dps}$, or

$-1 \mathrm{Ci}=3.7 \times 10^{10} \mathrm{~Bq}$ 


\section{Categories of Fission Product Inventory}

- Volatile

- Gases and evaporated elements (e.g., I, Cs, and Br)

- Transport dominated by diffusion

- Semi-volatile

- Liquids and aerosols, elements susceptible to evaporation

- Rates influences by chemistry and temperature

- Transport dominated by evaporation-driven mass transfer

- Non-volatile

- Solids and aerosols

- May become volatile only at very high temperatures

- Non-radioactive

- Solids, liquids, or gases

- Inert vs. chemically reactive 


\section{Fission Product Yields Vary Based on Source and Burnup}

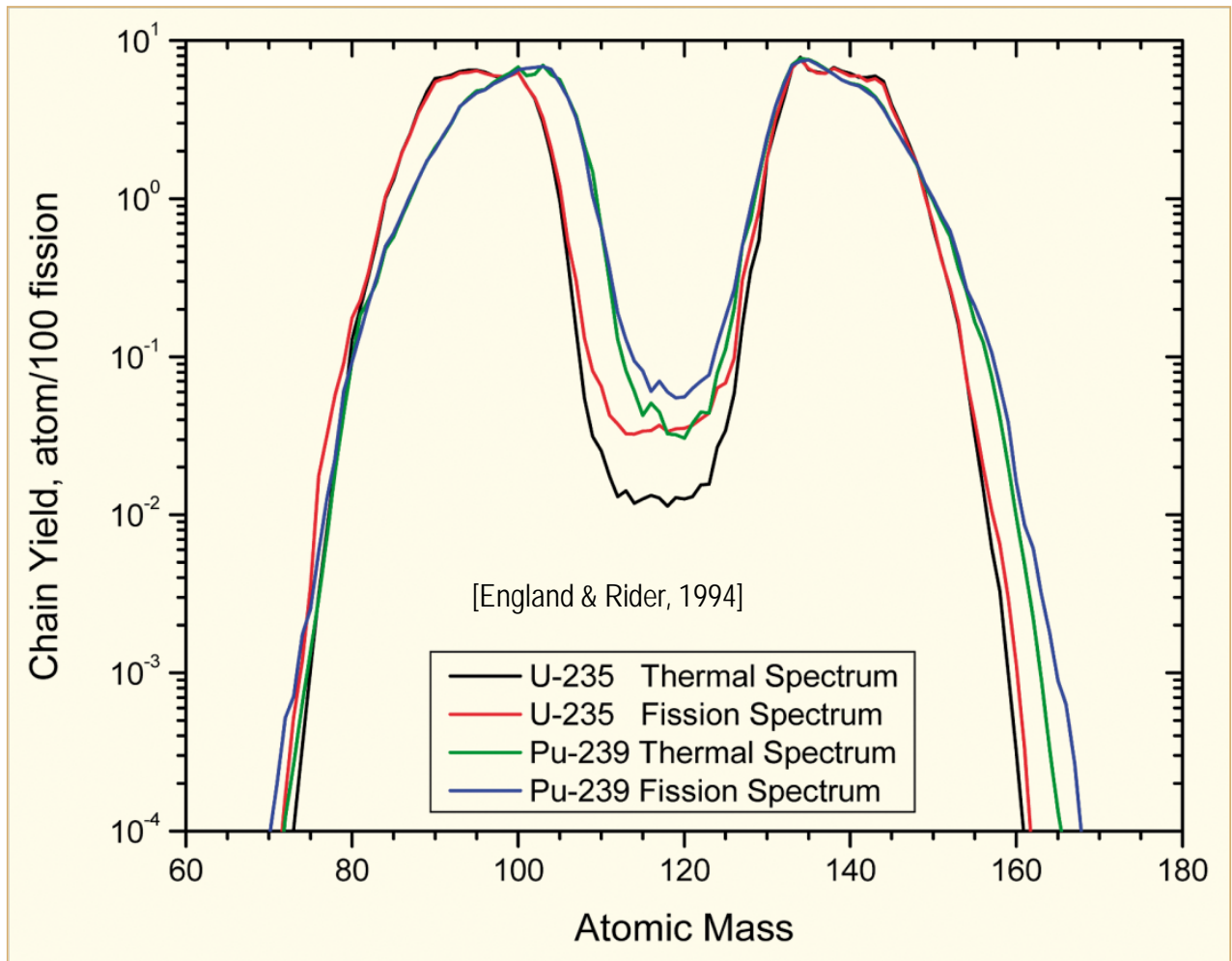

- Wide range of elements produced by fission

- Probabilistic process with "light" and "heavy" distributions

- Yields vary significantly by atomic mass and slightly by the fissile nuclide and neutron energy

- Cumulative production rate is $\sim 0.1 \%$ per GWd/MTU 


\section{Most Volatile Radionuclides Reside in Reactor Core}

\begin{tabular}{|l|c|c|}
\hline \multirow{2}{*}{\multicolumn{1}{|c|}{ Location }} & \multicolumn{2}{c|}{ Inventory, Ci } \\
\cline { 2 - 3 } & $\begin{array}{c}\text { Noble Gases } \\
\text { (Xe, Kr) }\end{array}$ & Iodine (I) \\
\hline Core & $\begin{array}{c}4.0 \mathrm{E}+8 \\
(1.48 \mathrm{E}+19 \mathrm{~Bq})\end{array}$ & $\begin{array}{c}7.5 \mathrm{E}+8 \\
(2.775 \mathrm{E}+19 \mathrm{~Bq})\end{array}$ \\
\hline Gap between $\mathrm{UO}_{2}$ fuel and Zr cladding & $3.0 \mathrm{E}+7$ & $1.4 \mathrm{E}+7$ \\
& $(1.11 \mathrm{E}+18 \mathrm{~Bq})$ & $(6.29 \mathrm{E}+17 \mathrm{~Bq})$ \\
\hline Spent fuel storage pool & $1.0 \mathrm{E}+6$ & $5.0 \mathrm{E}+5$ \\
& $(3.7 \mathrm{E}+16 \mathrm{~Bq})$ & $(5.18 \mathrm{E}+15 \mathrm{~Bq})$ \\
\hline Primary coolant ${ }^{3}$ & $1.0 \mathrm{E}+4$ & $6.0 \mathrm{E}+2$ \\
& $(3.7 \mathrm{E}+14 \mathrm{~Bq})$ & $(2.22 \mathrm{E}+13 \mathrm{~Bq})$ \\
\hline
\end{tabular}

${ }^{3}$ Nominal value, varies depending on fuel leakage. 


\section{Average Annual Plant Release Considerably Lower than Accident Releases}

\begin{tabular}{|l|c|c|}
\hline & Noble Gases, Ci & lodine, $\mathbf{C i}$ \\
\hline Average annual reactor release (1975-1979) & $\begin{array}{c}1.00 \\
(3.7 \mathrm{E}+10 \mathrm{~Bq})\end{array}$ & $\begin{array}{c}0.13 \\
(4.81 \mathrm{E}+9 \mathrm{~Bq})\end{array}$ \\
\hline TMI-2 accident (March 1979) & $\begin{array}{c}2.50 \mathrm{E}+6 \\
(9.25 \mathrm{E}+16 \mathrm{~Bq})\end{array}$ & $\begin{array}{c}15 \\
(5.55 \mathrm{E}+11 \mathrm{~Bq})\end{array}$ \\
\hline Chernobyl accident (April 1986) & $1.90 \mathrm{E}+8$ & $4.5 \mathrm{E}+7$ \\
& $(7.03 \mathrm{E}+18 \mathrm{~Bq})$ & $(1.665 \mathrm{E}+18 \mathrm{~Bq})$ \\
\hline
\end{tabular}




\section{Radionuclide Inventory Time-Dependent}

$$
d A_{i}(t) / d t=-\Lambda_{i}(t) A_{i}(t)+Q_{n}(t)
$$

where

$\Lambda_{\mathrm{i}}(\mathrm{t})$ - fractional loss rate due to deposition, decay, leakage, sprays, etc.

$A_{i}(t)$ - activity of species, $i$,

$\mathrm{Q}_{\mathrm{n}}(\mathrm{t})$ - activity source rate due to fuel release, $\mathrm{MCCl}$, contribution entering from another volume, etc. 


\section{Radionuclide Inventory Grouped by Chemical Properties and Volatility}

\begin{tabular}{|c|c|c|c|c|}
\hline $\begin{array}{l}\text { Group } \\
\text { Number }^{1}\end{array}$ & Release Class & Volatility & Isotopes & $\begin{array}{l}\text { Group Total } \\
(\mathrm{Ci})^{2}\end{array}$ \\
\hline 1 & Noble Gases & Inert & $\mathrm{Kr}-85, \mathrm{Kr} 85 \mathrm{~m}, \mathrm{Kr}-87, \mathrm{Kr}-88, \mathrm{Xe}-133, \mathrm{Xe}-135$ & $\begin{array}{c}3.84 \mathrm{E}+08 \\
(1.4208 \mathrm{E}+19 \mathrm{~Bq})\end{array}$ \\
\hline 2 & Halogens & \multirow[t]{3}{*}{ Volatile } & $\mathrm{I}-131, \mathrm{I}-132, \mathrm{I}-133, \mathrm{I}-134, \mathrm{I}-135$ & $\begin{array}{c}7.71 \mathrm{E}+08 \\
(2.8527 \mathrm{E}+19 \mathrm{~Bq})\end{array}$ \\
\hline 3 & Alkali Metals & & Cs-134, Cs-136, Cs-137, Rb-86 & $\begin{array}{c}2.18 \mathrm{E}+07 \\
(8.066 \mathrm{E}+17 \mathrm{~Bq})\end{array}$ \\
\hline 4 & Tellurium & & Sb-127, Sb-129, Te-127, Te-127m, Te-129, Te-129m, Te-131m, Te-132 & $\begin{array}{c}2.13 \mathrm{E}+08 \\
(7.881 \mathrm{E}+18 \mathrm{~Bq})\end{array}$ \\
\hline 5 & Strontium & \multirow[t]{5}{*}{ Non-volatile } & Sr-89, Sr-90, Sr-91, Sr-92 & $\begin{array}{c}3.57 \mathrm{E}+08 \\
(1.3209 \mathrm{E}+19 \mathrm{~Bq})\end{array}$ \\
\hline 6 & Noble Metals & & $\begin{array}{l}\text { Co-58, Co-60, Mo-99, Rh-105, Ru-103, Ru-103, Ru-105, } \\
\text { Tc-99m }\end{array}$ & $\begin{array}{c}5.94 \mathrm{E}+08 \\
(2.1978 \mathrm{E}+19 \mathrm{~Bq})\end{array}$ \\
\hline 7 & Lanthanides & & $\begin{array}{l}\text { Am-241, Cm-242, Cm-244, La-140, La-141, La-142, Nb-95, Nd-147, } \\
\text { Pr-143, Y-90, Y-91, Y-92, Y-93, Zr-95, Zr-97 }\end{array}$ & $\begin{array}{c}1.54 \mathrm{E}+09 \\
(5.698 \mathrm{E}+19 \mathrm{~Bq})\end{array}$ \\
\hline 8 & $\begin{array}{l}\text { Corium } \\
\text { (Cerium) }\end{array}$ & & Ce-141, Ce-143, Ce-144, Np-239, Pu-238, Pu-239, Pu-240, Pu-241 & $\begin{array}{c}2.15 \mathrm{E}+09 \\
(7.955 \mathrm{E}+19 \mathrm{~Bq})\end{array}$ \\
\hline 9 & Barium & & Ba-139, Вa-140, & $\begin{array}{c}3.38 \mathrm{E}+08 \\
(1.2506 \mathrm{E}+19 \mathrm{~Bq})\end{array}$ \\
\hline
\end{tabular}

${ }^{1}$ Group definitions vary in different approaches.

${ }^{2}$ For representative large (3300 MWt) LWR 30 minutes after shutdown. 


\section{Group Release Tied to Fuel Temperature}

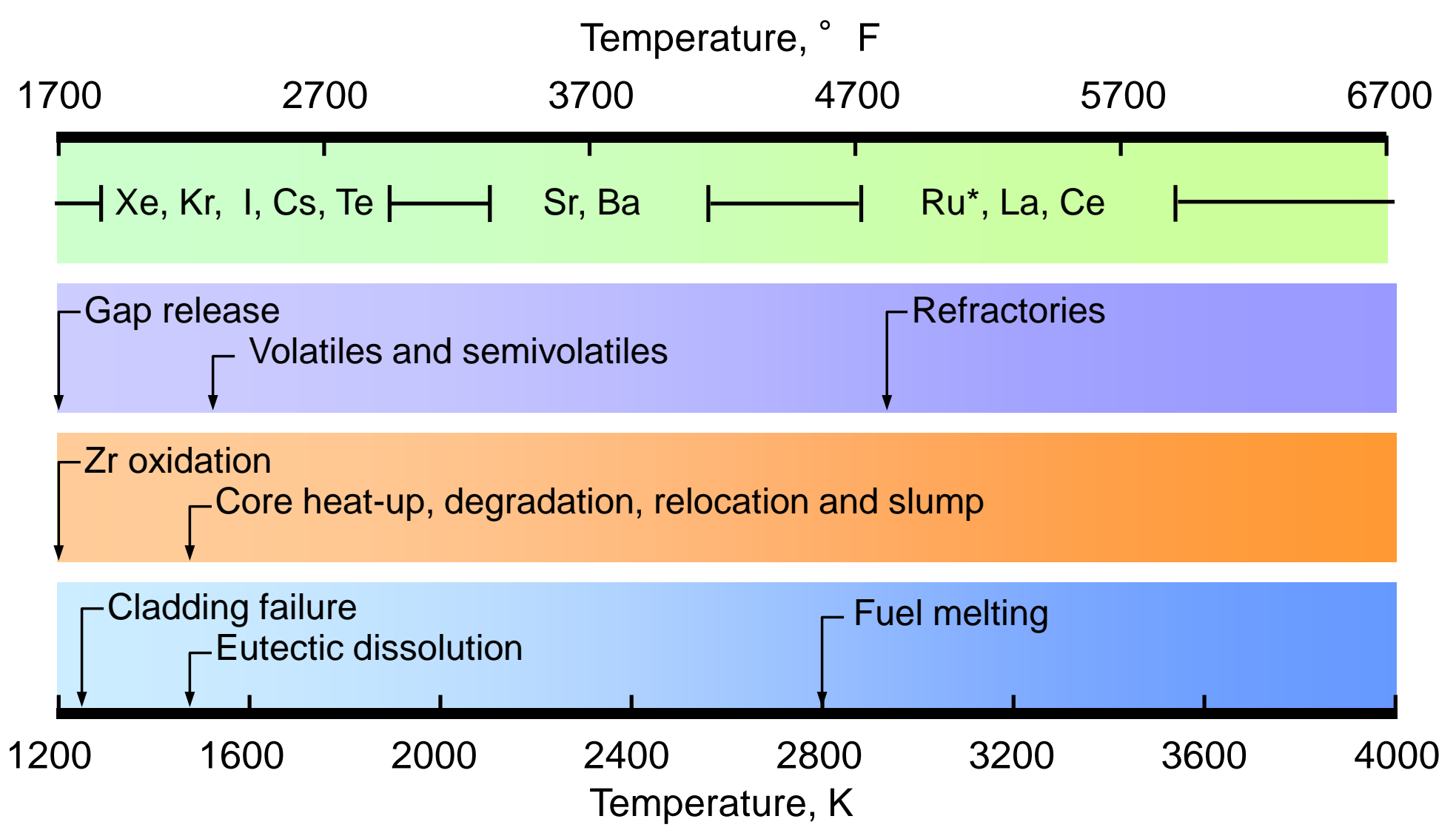

*In highly oxidizing environment, Ru is volatile 


\section{Radiological Impact of Isotopes Differ- Overall Exposure of 600 Rem or 6 Sv Considered Potentially Fatal}

Early Bone Marrow Dose 24 hour exposure

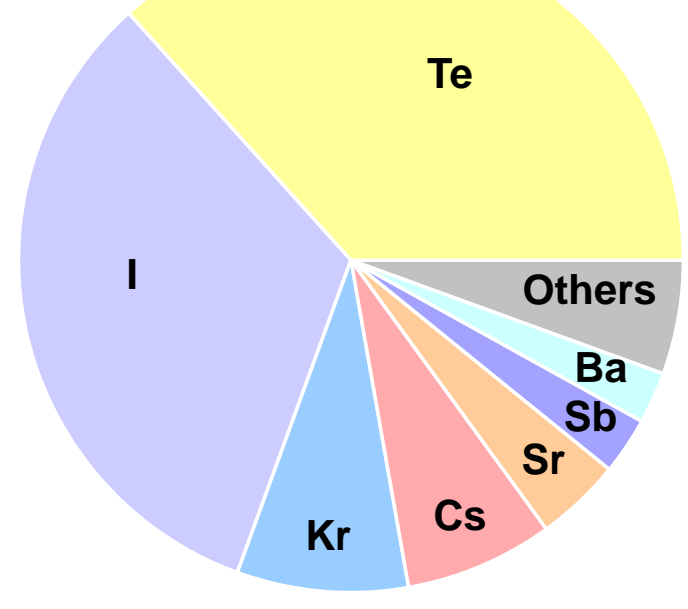

Early Lung Dose

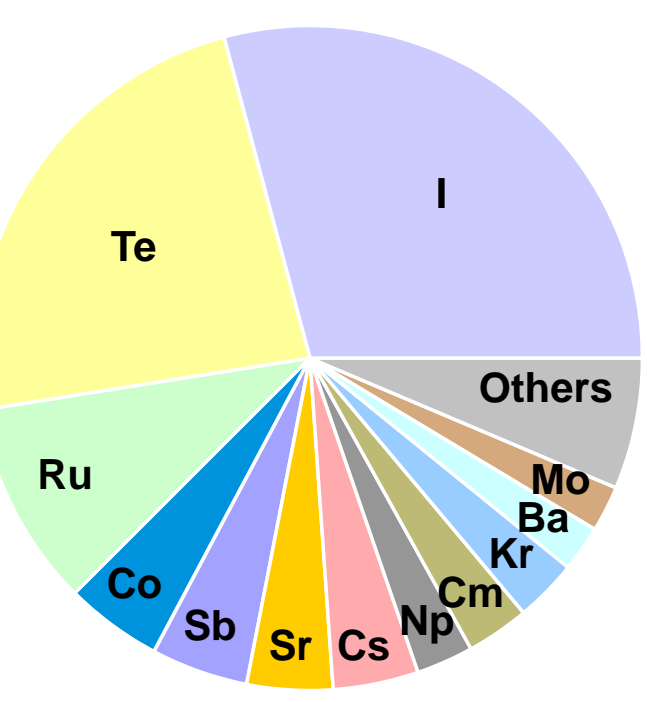

Total Latent Cancer deaths

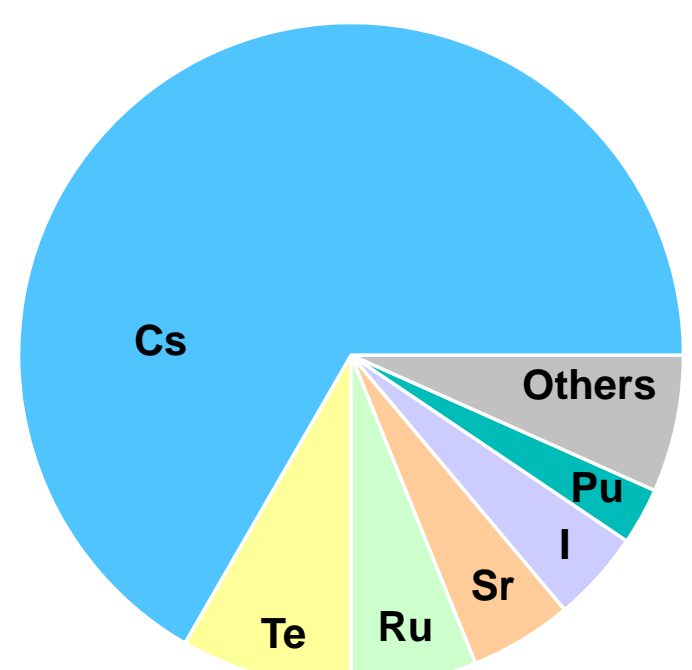




\section{Representative Isotope Used to Characterize Group Decay}

\begin{tabular}{|c|l|c|c|c|}
\hline $\begin{array}{c}\text { Group } \\
\text { Number }\end{array}$ & Release Class & $\begin{array}{c}\text { Representative } \\
\text { Isotope }\end{array}$ & $\begin{array}{c}\text { Half-life } \\
\text { (days) }\end{array}$ & Daughter \\
\hline 1 & Noble Gases & $\mathrm{Kr}-88$ & $1.18 \mathrm{E}-01$ & $\mathrm{Br}-88$ \\
\hline 2 & Halogens & $\mathrm{I}-131$ & $8.04 \mathrm{E}+00$ & $\mathrm{Te}-131$ \\
\hline 3 & Alkali Metals & $\mathrm{Cs}-134$ & $7.53 \mathrm{E}+02$ & \\
\hline 4 & Tellurium & $\mathrm{Te}-132$ & $3.21 \mathrm{E}+00$ & $\mathrm{Sb}-132$ \\
\hline 5 & Strontium & Sr-90 & $1.06 \mathrm{E}+04$ & $\mathrm{Rb}-90$ \\
\hline 6 & Noble Metals & $\mathrm{Co}-60$ & $1.93 \mathrm{E}+03$ & $\mathrm{Fe}-60$ \\
\hline 7 & Lanthanides & $\mathrm{Am}-241$ & $1.58 \mathrm{E}+05$ & $\mathrm{Pu}-241$ \\
\hline 8 & $\begin{array}{l}\text { Corium } \\
\text { (Cerium) }\end{array}$ & $\mathrm{Ce}-143$ & $1.38 \mathrm{E}+00$ & $\mathrm{Pr}-143$ \\
\hline 9 & Barium & $\mathrm{Ba}-140$ & $1.28 \mathrm{E}+01$ & $\mathrm{Cs}-140$ \\
\hline
\end{tabular}




\section{Sources and Losses Present in each Location along Release Path}

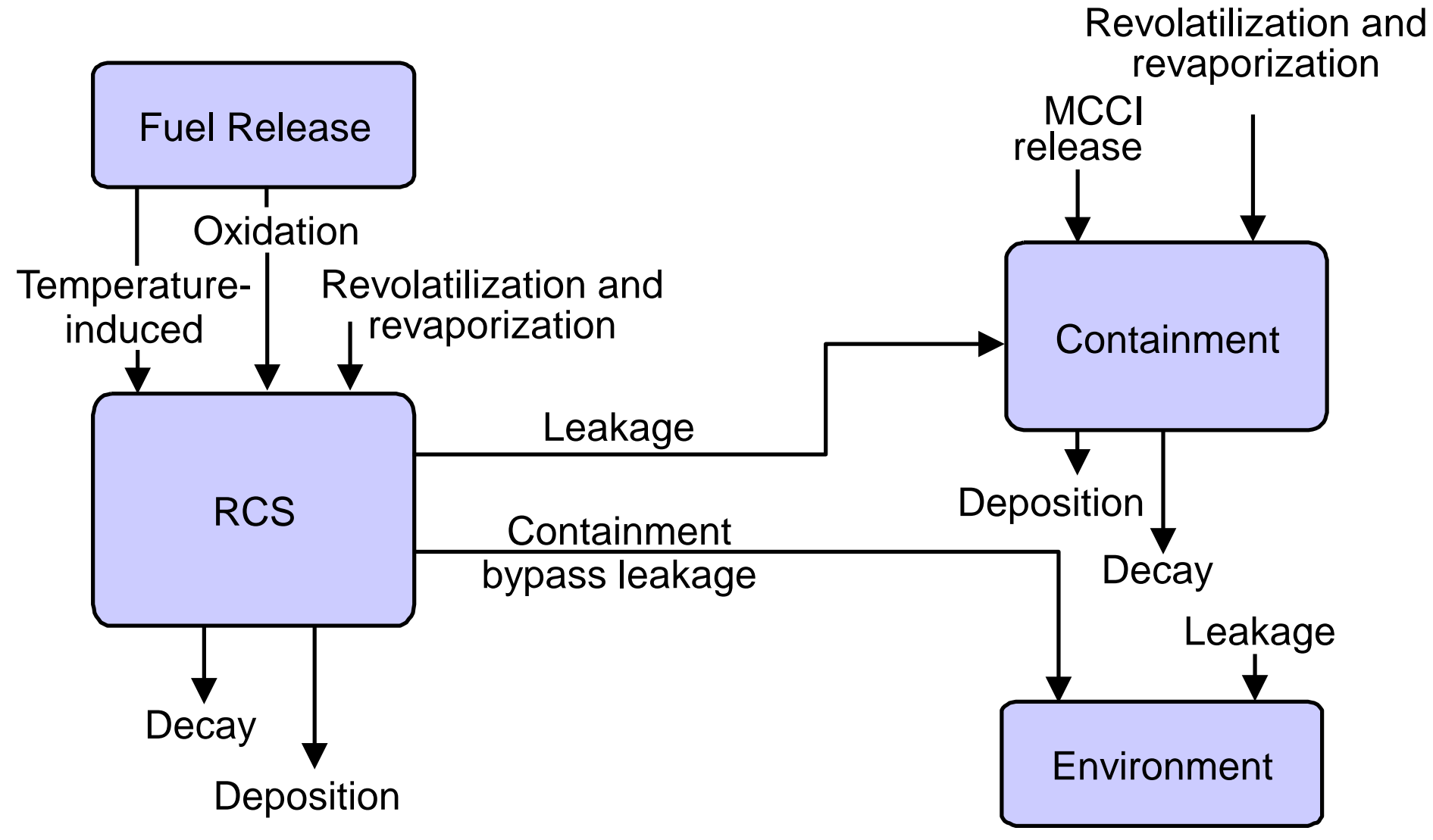




\section{AP1000 Radionuclide Containment}

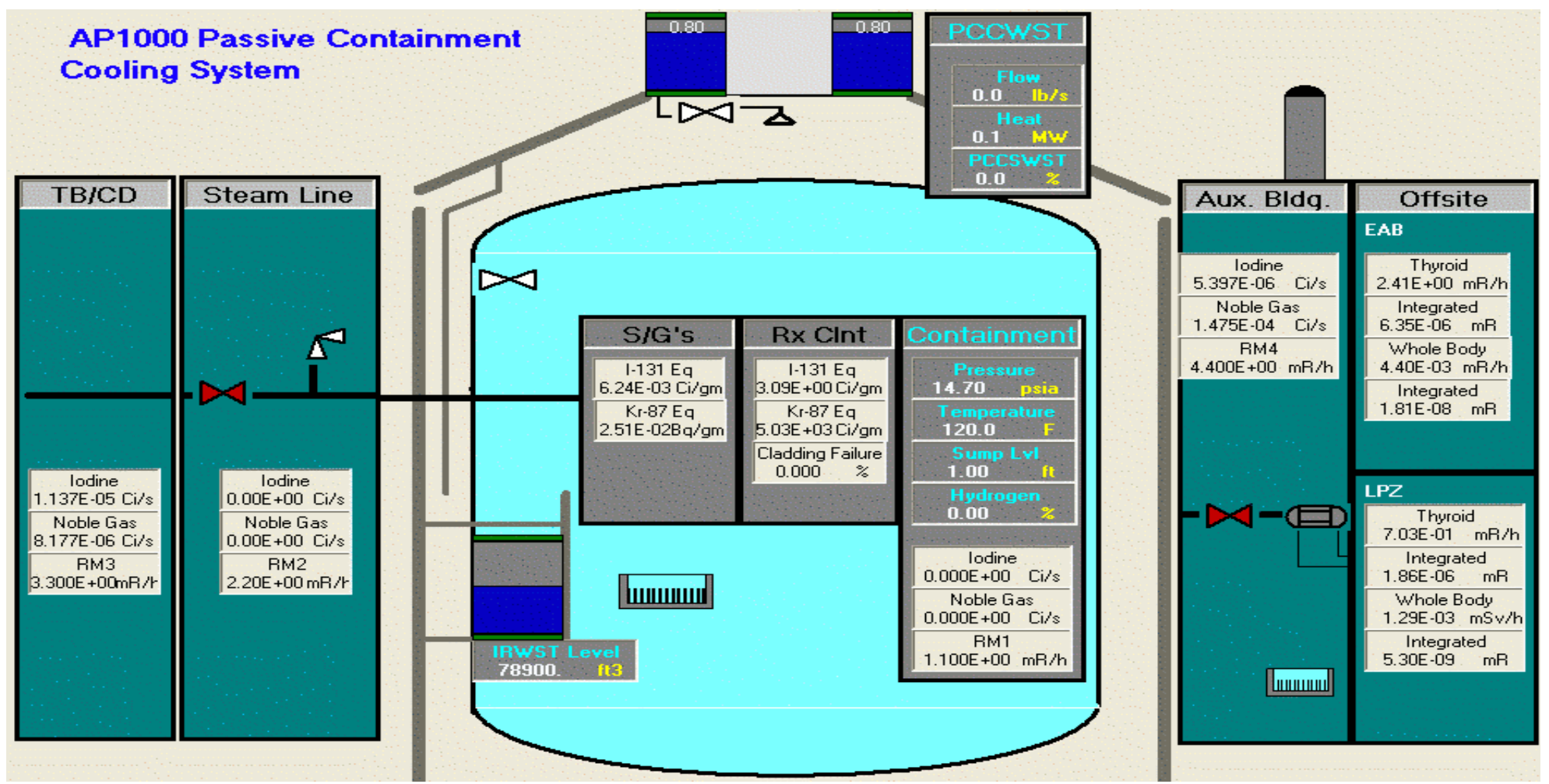




\section{Several Factors Affect Release and Transport}

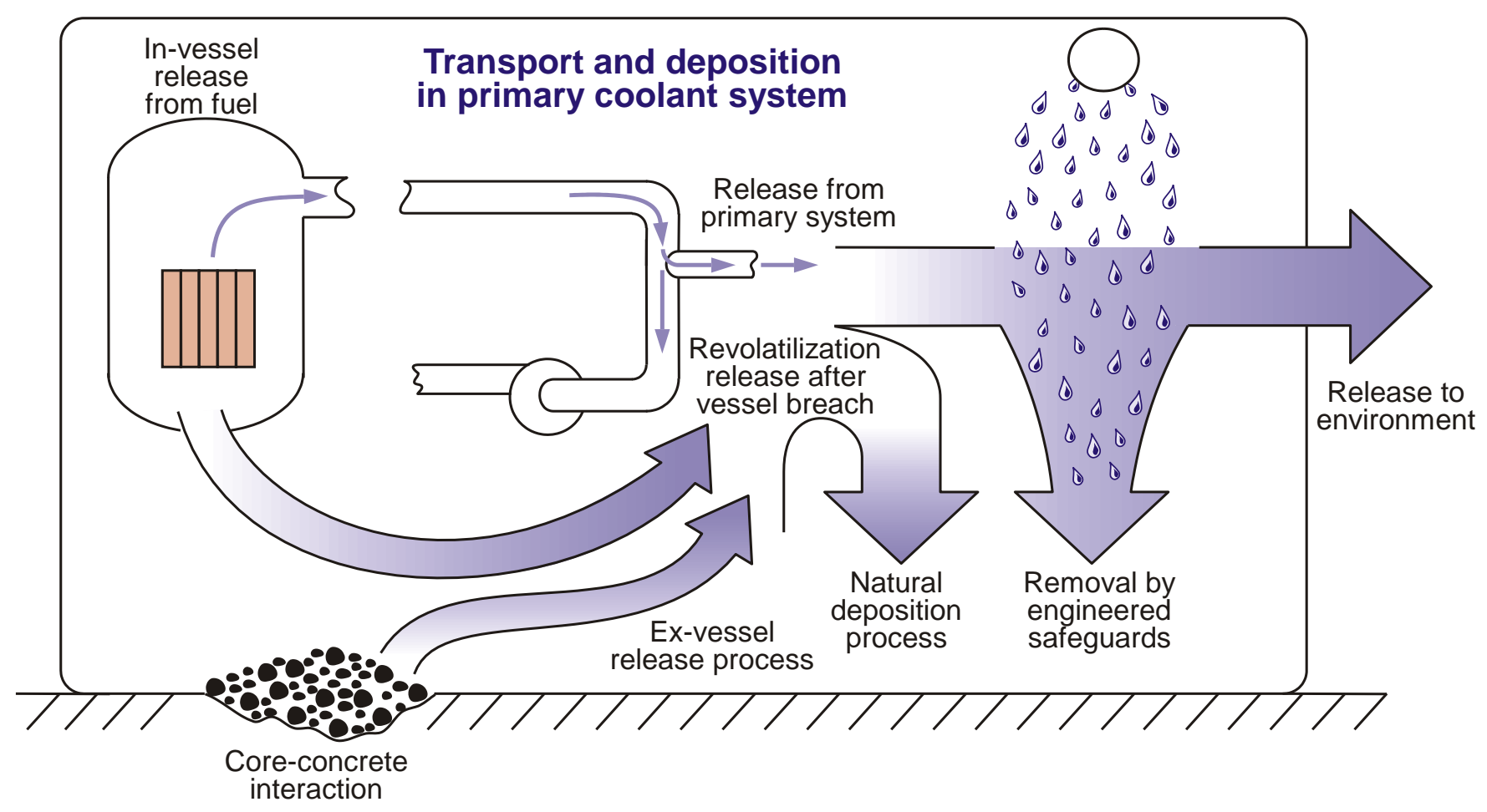

- Sequence dependent

- Timing

- Duration

- Energy

- Pressure
- Plant design dependent

- Pathway (barriers, configuration, surface area, etc.)

- Safety systems 


\section{Plant Features Significantly Reduce Release}

\begin{tabular}{|l|l|}
\hline \multicolumn{1}{|c|}{ Design Feature } & \multicolumn{1}{c|}{ Decontamination Factor ${ }^{1}$} \\
\hline Containment Sprays & 100 to 1000 \\
\hline Ice Condensers & 1 to 20 with ice present \\
\hline Suppression pools & 1 to 4000 \\
\hline Overlying water layers & 1 to 4000 \\
\hline
\end{tabular}

${ }^{1}$ Ratio of inlet to outlet concentrations. 


\section{Containment Sprays Rapidly Reduce Release}

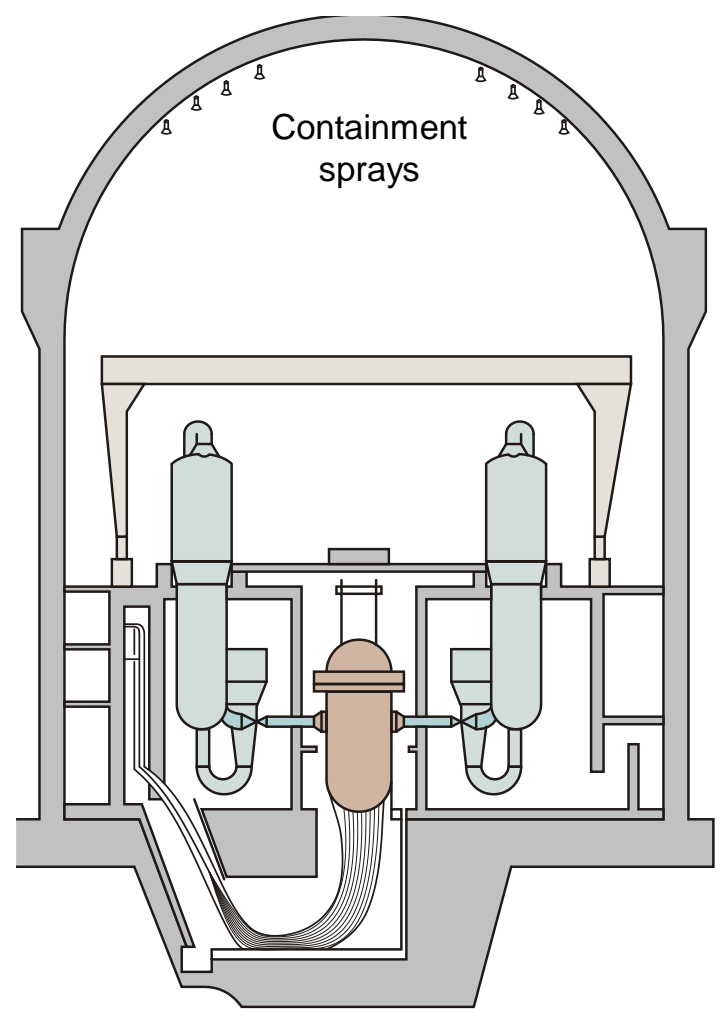

- Sprays reduce airborne concentration of aerosols and vapors in containment.

- Sprays may reduce airborne concentrations by order of magnitude in 15-20 minutes. 


\section{Ice Condensers Significantly Reduce Radioactive Release}

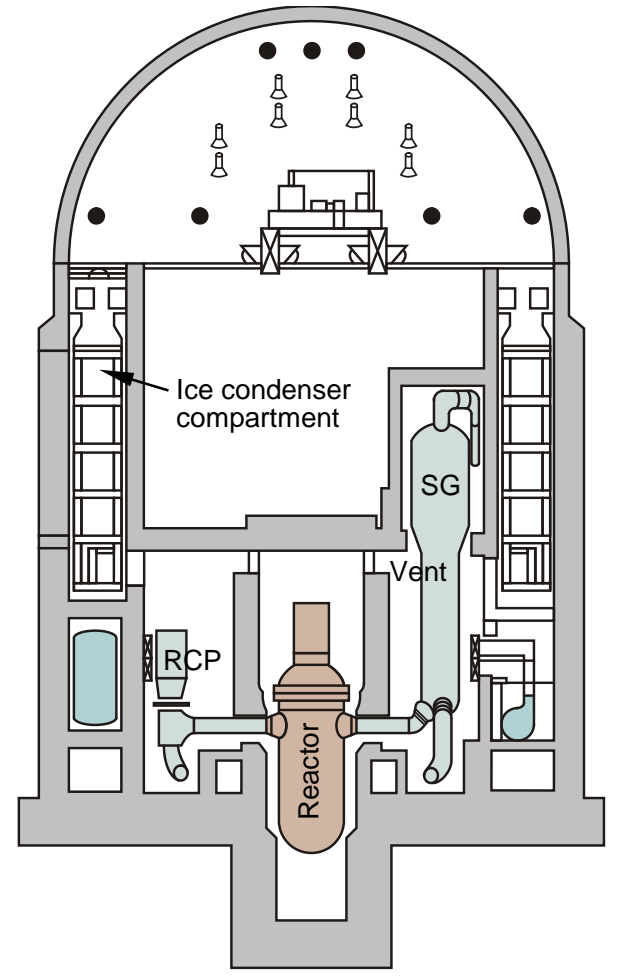

- Retain radioactive aerosols and vapors.

- Typical decontamination factors of 1 to 20 with a median of 3 .

- Decontamination factor sensitive to steam and hydrogen fraction of gas that flows through them. 


\section{BWR Suppression Pools Offer Significant Reduction}

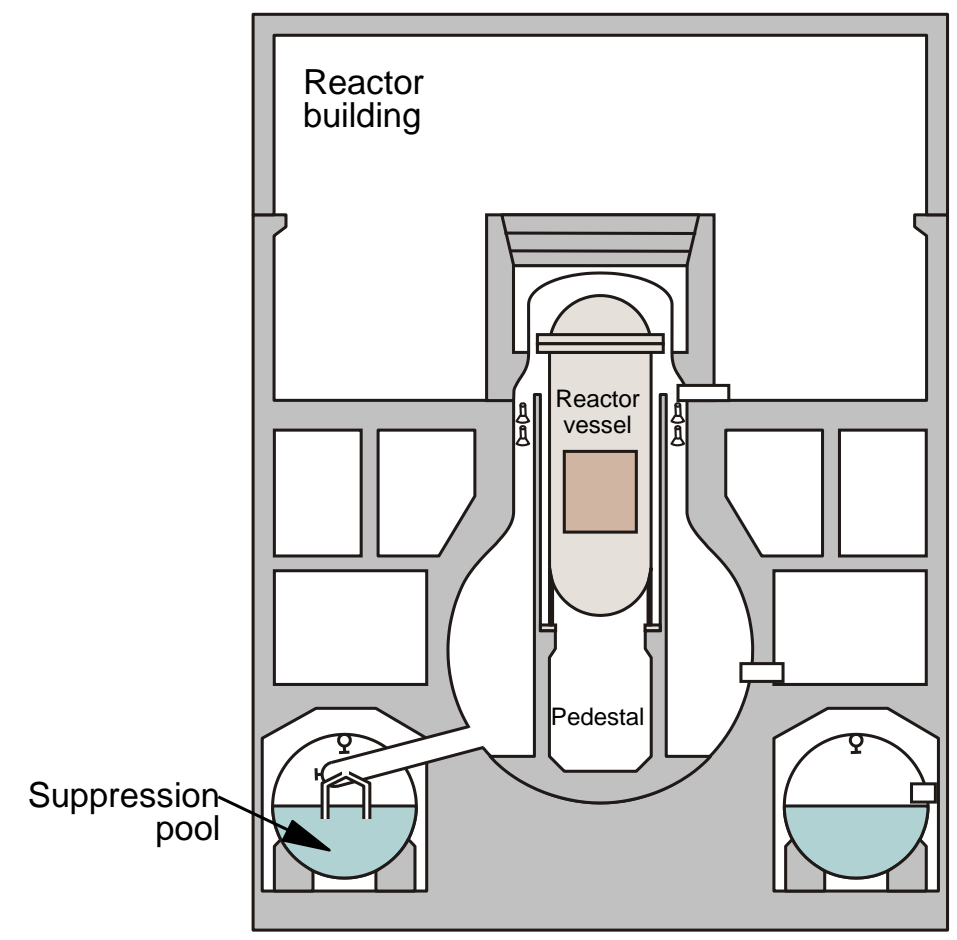

- Suppression pool water retains soluble vapors and aerosols.

- RSS (WASH-1400) assumed DF of 100 for subcooled pools and 1.0 for saturated pools.

- NUREG-1150 assumed DF between 1 and 4000 with a median value of 80 .

- Suppression pool scrubbing primary reason that likelihood of early BWR fatalities is much lower in NUREG-1150.

- If suppression pool pH not maintained by chemical additives, lower $\mathrm{pH}$ may occur that promotes $\mathrm{I}_{2}$ formation and vaporization (if heated) at later time periods. 


\section{Several Methods Available for Estimating Severe Accident Release}

- Detailed methods

- MELCOR

- SCDAP/RELAP5/VICTORIA/CONTAIN

- MAAP

- Less-detailed methods

- TID

- XSOR

- Parametric Source Term (PST)

- Alternate Approach (Revised Source Term, RST, or Alternate Source Term from NUREG-1465) 


\section{Source Terms Initially Based on TID-14844}

- Based on a postulated core melt accident and 1962 understanding of fission product behavior.

- As codified in Reg. Guides 1.3 and 1.4, assumed source term consists of an instantaneous release of:

- $100 \%$ of core inventory of noble gases

- $50 \%$ of core inventory of iodine

- half assumed to subsequently deposit on containment surfaces

- 91\% elemental, $5 \%$ particulate, and $4 \%$ organic

- Assumed source term affected the site selection process and the design of engineered safety features, such as containment isolation valves, containment sprays, and filtration systems. 


\section{NUREG-1150 Release and Transport Estimated with XSOR Codes}

- Developed for five NUREG-1150 plants

- Doesn't consider knowledge gained from severe accident research since1990.

- XSOR method decomposed source term into release fractions for various time periods and release barriers and quantified release fractions using expert opinion

- Approach is time-consuming.

- Approach isn't reproducible. 


\section{NUREG-1465 Proposes More Realistic Source Term}

- Developed more realistic source term for regulating future LWRS and for evaluating proposed changes to existing plants

- Considers chemical and physical form

- Provides safety and cost benefits

- Releases based on severe accident research and range of PWR and BWR STCP, MAAP, and MELCOR calculations

- Comparisons with MELCOR comparisons suggest considerable margin between RST and best-estimate MELCOR predictions.

- Proposes time-dependent releases grouped into five phases:

- DBA source term considers coolant, gap, and early-in-vessel releases

- Severe accident source term considers coolant, gap, early invessel, ex-vessel, and late ex-vessel releases

- Implementation requires revised Part 20 dose methodology (TEDE criterion) and evaluate dose for accident's "worst two hour interval."

- Codified in Regulatory Guide 1.183 


\section{NUREG-1465 provides Time-dependent Releases}

\begin{tabular}{|l|c|c|c|c|}
\hline \multirow{2}{*}{} & \multicolumn{4}{|c|}{ PWR LOCA Release (fraction of core inventory) } \\
\cline { 2 - 5 } & $\begin{array}{c}\text { Gap and } \\
\text { Coolant }\end{array}$ & Early In-vessel & Ex-Vessel & $\begin{array}{c}\text { Late } \\
\text { Ex-vessel }\end{array}$ \\
\hline Duration, hours & 0.5 & 1.3 & 2.0 & 10.0 \\
\hline Noble gases & 0.05 & 0.95 & 0 & 0 \\
\hline Halogens & 0.05 & 0.35 & 0.25 & 0.01 \\
\hline Alkali metals & 0.05 & 0.25 & 0.35 & 0.01 \\
\hline Tellurium group & 0 & 0.05 & 0.25 & 0.005 \\
\hline Barium, strontium & 0 & 0.02 & 0.1 & 0 \\
\hline Noble Metals & 0 & 0.0025 & 0.0025 & 0 \\
\hline Lanthanides & 0 & 0.0002 & 0.005 & 0 \\
\hline Cerium group & 0 & 0.0005 & 0.005 & 0 \\
\hline
\end{tabular}

\footnotetext{
${ }^{1}$ If coolant $\mathrm{pH}$ greater than or equal to 7 , then $95 \%$ particulate, $\sim 5 \%$ elemental and $\sim 0.15 \%$ organic.
} 


\section{Pilot plant applications demonstrate that RST reduces regulatory requirements and enhances safety}

- Time-dependent source term allows:

- delayed automatic isolation function for containment isolation valves

- increased allowable containment and/or penetration leakage rates

- Realistic iodine chemical species allows:

- relaxation of charcoal filtration system requirements

- relaxation of control room habitability requirements

- requirements for post-accident $\mathrm{pH}$ control of iodine particulates dissolved in water (to prevent elemental iodine formation). 


\section{SOARCA}

- NRC-sponsored State of the Art Reactor Consequences Analysis

- Realistic estimates of the potential public health effects from a severe accident

- Health effects from previous accidents often overstated in early phases

- Propensity to apply excessive conservatism in analyses

- Apply understanding developed from relatively recent research programs to better assess reactor accident consequences

- Better source term estimates

- Credit accident management

- Credit plant features

- Better software and computer systems 


\section{Study Questions}

-What contributes to and reduces radioactivity release during a severe accident?

- What characteristics are important in assessing radionuclide transport?

- Name several factors (and plant features) affecting radioactivity release and transport.

- Name several methods available for estimating severe accident releases.

- Define and describe differences between the RST and the TID source term. 


\section{References for Additional Reading}

- J.J. DiNunno, et.al, "Calculation of Distance Factors for Power and Test Reactors," Technical Information Document (TID)-14844, U.S. Atomic Energy Commission, 1962.

- U.S. Nuclear Regulatory Commission, "Assumptions Used for Evaluating the Potential Consequences of a Loss of Coolant Accident for Boiling Water Reactors," Regulatory Guide 1.3, Rev. 2, 1974.

- U.S. Nuclear Regulatory Commission, "Assumptions Used for Evaluating the Potential Radiological Consequences of a Loss of Coolant Accident for Pressurized Water Reactors" Regulatory Guide 1.4, Rev. 2, June 1974.

- U.S. Nuclear Regulatory Commission, Severe Accident Risks: An Assessment for Five U.S. Nuclear Power Plants, NUREG-1150, December 1990.

- J. L. Rempe, M. Cebull, and B. G. Gilbert, PST User's Guide, INEL/96-0308, September 1996.

- Procedures for Conducting Probabilistic Safety Assessments of Nuclear Power Plants (Level 2), IAEA Safety Series No. 50-P-8, 1995.

- $\quad$ L. Soffer, et al., Accident Source Terms for Light-Water Nuclear Power Plants, Final Report, NUREG-1465, February 1995.

- H. P. Nourbakhsh, Estimates of Radionuclide Release Characteristics into Containment under Severe Accidents, NUREG-CR-5747, Nov. 1993. 


\section{References for Additional Reading (continued)}

- $\quad$ Papers presented in the session, "Radiological Analysis Utilizing Revised Accident Source Terms," at the American Nuclear Society Meeting, Washington, D.C., Trans. Am. Nucl. Soc., 75, 1996, p. 308-315.

- Papers presented in the session, "Implementation of the New Source Term at Operating Plants," at the American Nuclear Society Meeting, Albuquerque, NM, Trans. Am. Nucl. Soc. 77, 1997 p. 304-308.

- $\quad$ L. J. Callan, EDO, "Results of the Revised (NUREG-1465) Source Term Rebaselining for Operating Reactors," SECY-98-154, June 30, 1998.

- J. H. Schaperow and J. Y. Lee, "Implementation of the Revised Source Term at U.S. Operating Reactors," presented at the U.S. WRSIM,October 27, 1999.

- H. P. Nourbakhsh, "Historical Perspectives and Insights on Reactor Consequence Analyses," attachment to letter from W. J. Shack, Chairman, US NRC, to R. W. Borchardt, Executive Director for Operations, US NRC, Nov. 14, 2008.

- $\quad$ E. C. Beam, R. A. Lorenz, and C. F. Weber, lodine Evolution and pH Control, NUREG/CR-5950, October 1992. 


\section{Accident Progression Analysis (P-300)}

9. PRA Integration and Quantification 


\section{Session Objectives}

- To understand the details of how the different phases of a PRA are linked to each other

- Level-1 output = Core Damage

- Segregation of CD sequences into Plant Damage States

- PDSs used as input (initiator) to Level-2

- Propagation of uncertainties 


\section{Outline}

- Integration of Level-1 and Level-2

- Uncertainty

- Level-2 Results 


\section{Level-1/2 PRA Integration}

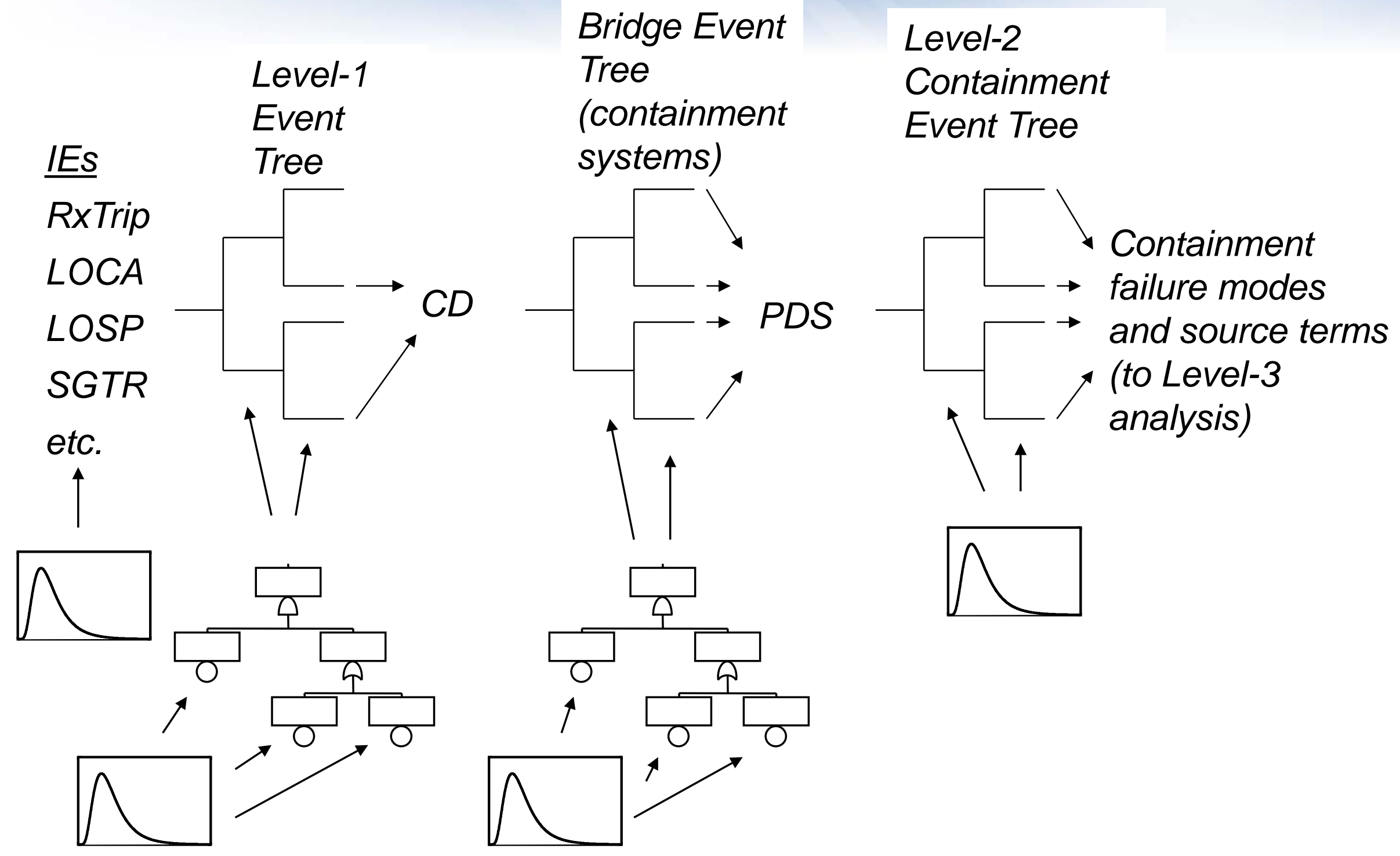




\section{Level-1/Level-2 Analysis Approach}

- Assignment of core damage (CD) sequences into appropriate plant damage state (PDS) bins

- Assessment of challenges associated with each PDS bin (typically using computer codes)

- Characterization of the containment's capacity to withstand the identified challenges (i.e., fragility)

- Combining the uncertainties associated with the previous two analyses to estimate probability of containment failure (for a given PDS)

- Combining the uncertainties associated with CD frequency with those associated with conditional containment failure probabilities to estimate containment failure frequency 


\section{Level-1 CD Sequences Mapped Into PDSs}

- Core Damage vs. no CD, does not provide enough information for Level-2 analysis

- CD sequences extended to include systems and events that mitigate consequences of core damage

- Containment spray and cooling systems

- Need to ensure dependencies accounted for

- SBO failing ECCS would also fail containment systems

- PDS are more detailed description of core damage sequence 


\section{Bridge Event Tree Maps CD Into PDS}

- Sometimes called "binning" of CD sequences

- Bridge Tree typically straightforward extension/expansion of Level-1 event trees

- Extends consideration beyond core damage

- Determines status of containment systems

- Every core damage sequence propagated through bridge tree 


\section{Example Bridge (or Binning) Event Tree}

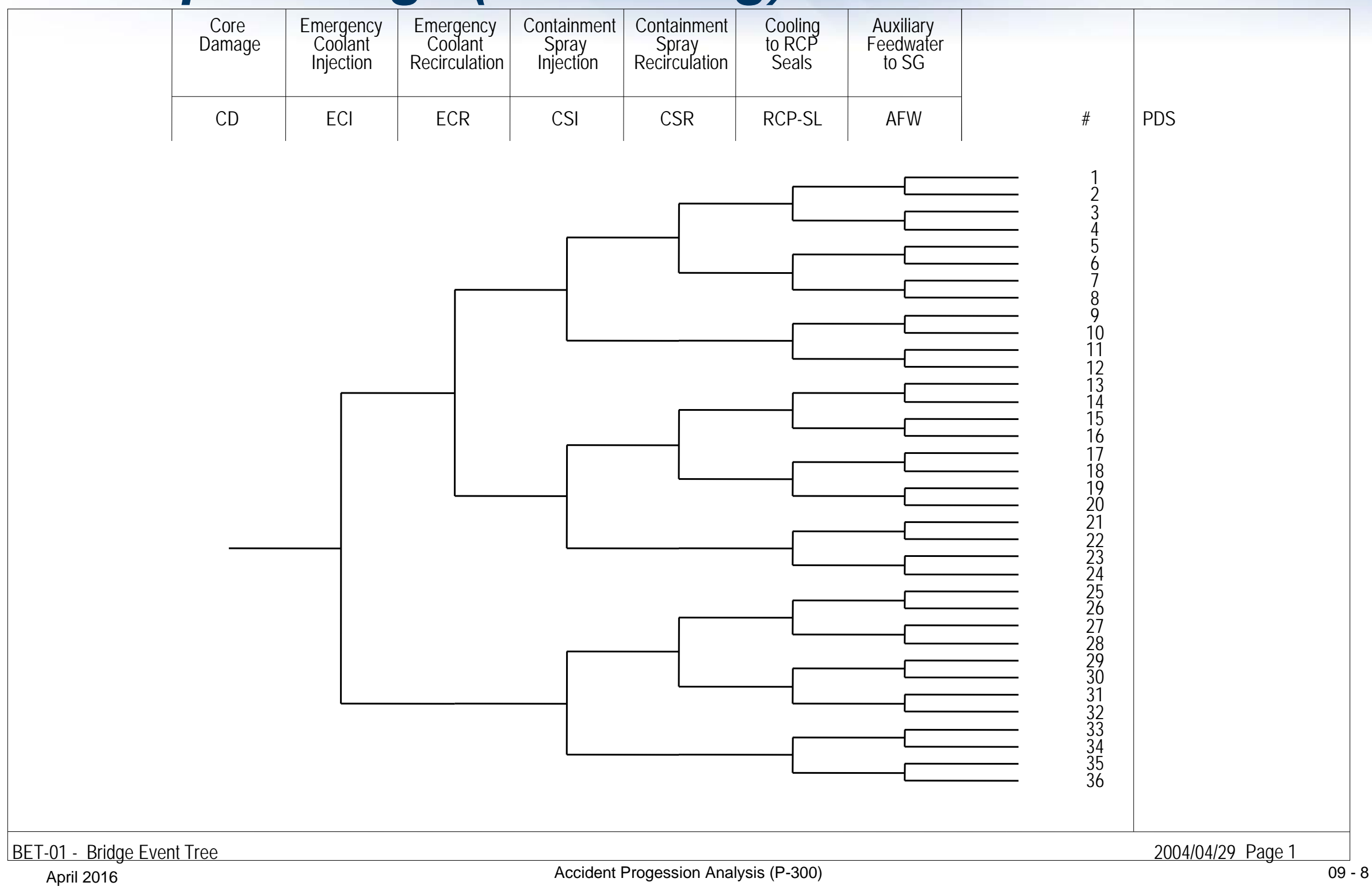




\section{Each CD Cut Set Unique}

- Each cut set represents a unique set of events (e.g., component failures, human actions) that is expected to lead to CD (e.g., UTAF)

- Individual cut sets generated from the same CD sequence can produce different impacts on containment response

- e.g., LOCA \& ECCS failure: ECCS can fail from different causes

- ECCS components can fail (implying containment systems are nominally operable)

- Loss of all ac power can fail ECCS (implying containment systems are NOT operable) 


\section{Each CD Cut Set Assigned to PDS}

- To accommodate different impacts on Level-2 analysis, each CD cut set explicitly mapped into a PDS (sometimes referred to as binning)

- Two approaches to binning Level-1 cut sets into PDSs

- Two step process (often performed using "If-Then" rules)

1 - assign PDS vector identifier to each CS

2 - map CS into PDS based on best match of vector

- One step process (often manually performed)

- Directly bin each CS into a PDS (this process does not necessarily need the vector framework) 


\section{Simple Binning Example}

- PWR core damage sequence

- Small LOCA with failure of ECCS (ignore other issues for sake of simplicity)

- Cut set \#1: Small LOCA with ECCS pump fails

- Cut set \#2: Small LOCA with loss of all AC power

$$
\begin{array}{r}
\mathrm{S}_{2} \mathrm{D}=\mathrm{IE}-\mathrm{S}_{2}{ }^{*} \mathrm{ECCS}-\mathrm{Pump}-\mathrm{F}+ \\
{\mathrm{IE}-\mathrm{S}_{2}}_{2}{ }^{*} \text { LOSP } \\
\text { * EAC-F. }
\end{array}
$$




\section{Simple PDS Scheme for PWR (Status of ...)}

\begin{tabular}{|c|c|c|}
\hline 1 & $R C S$ integrity at start of $C D$ & $\begin{array}{l}\text { I - Intact } \\
\text { S - Small hole }\end{array}$ \\
\hline 2 & ECCS & $\begin{array}{l}\text { A - Available } \\
\text { U - Unavailable }\end{array}$ \\
\hline 3 & CHR & $\begin{array}{l}\text { A - Available } \\
\text { U - Unavailable }\end{array}$ \\
\hline 4 & AC Power & $\begin{array}{l}\text { A - Available } \\
\text { U - Unavailable }\end{array}$ \\
\hline 5 & RWST & $\begin{array}{l}\text { A - Available for injection } \\
\text { I - Injected into containment } \\
\text { U - Unavailable for injection }\end{array}$ \\
\hline 6 & Heat Removal from S/G & $\begin{array}{l}\text { A - Available } \\
\text { U - Unavailable }\end{array}$ \\
\hline 7 & RCP seal cooling & $\begin{array}{l}\text { A - Available } \\
\text { U - Unavailable }\end{array}$ \\
\hline 8 & Containment Fan Coolers & $\begin{array}{l}\text { A - Available } \\
U \text { - Unavailable }\end{array}$ \\
\hline
\end{tabular}




\section{Different PDS Vectors for CS\#1 and CS\#2}

\begin{tabular}{llllllll}
1 & 2 & 3 & 4 & 5 & 6 & 7 & 8 \\
$R C S$ & $E C C S$ & $C H R$ & $A C$ & $R W S T$ & $S / G$ & $R C P$ & Fans \\
& & & & & & seals & \\
\hline$S$ & $U$ & $A$ & $A$ & $A$ & $A$ & $U$ & $A$ \\
$S$ & $U$ & $U$ & $U$ & $A$ & $U^{*}$ & $U$ & $U$
\end{tabular}

- Frequency from cut sets \#1 and \#2, even though from the same core damage accident sequence, would likely be mapped into different Plant Damage States

- Mapping of core damage sequences into PDS not necessarily a one-to-one process 


\section{Each CS-Vector Then Matched to Most Appropriate PDS-Vector}

- Seldom is "fit" perfect

- Only a limited number of PDS ( 10-20)

- List of available PDSs dictated by available T/H resources

- Typically, each PDS has been analyzed using severe accident code (e.g., CONTAIN, MELCOR, MAAP)

- Code results needed to realistically model the accident progression of each PDS

- Strive for complete coverage of the spectrum of core damage sequences with significant contributions to total core damage frequency

- However might include low frequency sequences that result in high consequences (containment bypass) 
Each PDS Frequency Calculated (Analogous to a CDF Calculation)

- Uncertainty analysis (i.e., Monte Carlo or Latin Hypercube) generates probability histogram for each PDS

- Each PDS then used as input to (i.e., serves as the initiating event) the CET

- CET can be manually tailored for each PDS

- Each PDS associated with a unique CET

- Note that vector framework NOT necessary

- Single "general-purpose" CET can be modified during processing

- Incorporates various "If-Then" logic rules

- Vector framework not absolutely necessary but very useful 


\section{PDSs Are Level-2 "Initiating Events"}

- Each PDS (or PDS group) used as Level-2 IE

- Represent unique characteristics of core damage event

- Influence containment challenges

- Affect potential source term

- PDS contains relevant information needed to assess containment performance 


\section{Accident Progression Quantified Different Ways}

- Depends on level of detail in CET and in "initiating event" (i.e., plant damage state vector)

- Typically use conditional split-fractions/distributions for CET branch points

- Effectively "If-Then" statements

- Sometimes branch probability is a weighted average of different accident sequences

- Accounts for dependencies

- Requires detailed analysis of Level-1 sequences

- E.g., what portion of ECCS failures are caused by SBO (implies H2 igniters won't work) 


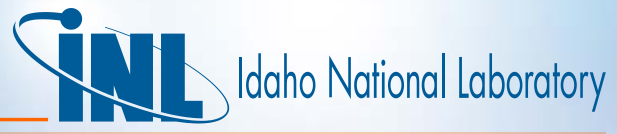

\section{Simple LERF Quantification Example}

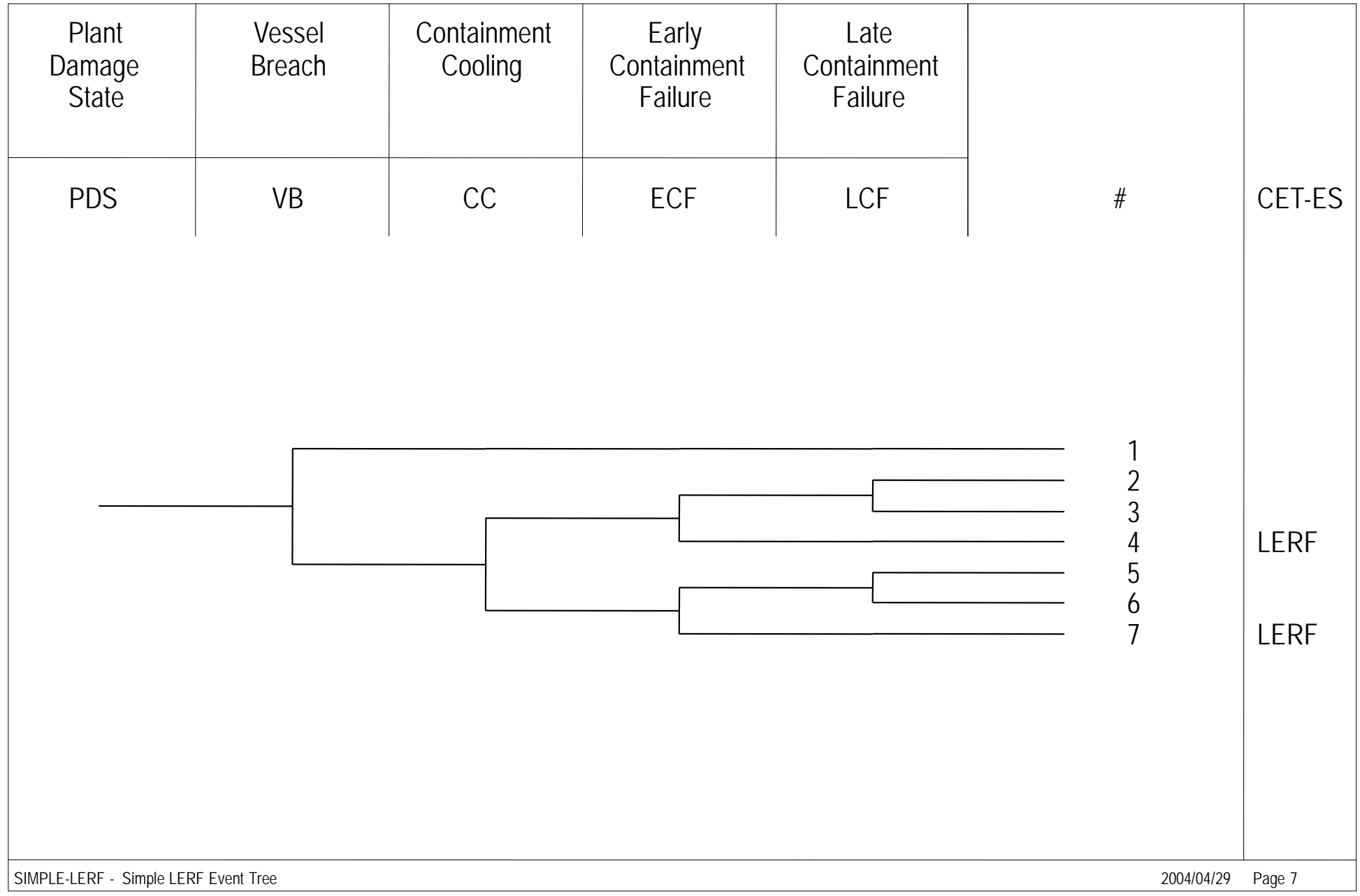




\section{Split Fractions for LERF-ET}

- S2D1 - Small LOCA with early failure of all injection

- Freq(S2D1) = 1E-4/yr

$-\operatorname{Pr}(\mathrm{VB} \mid \mathrm{S} 2 \mathrm{D} 1)=0.5$

$-\operatorname{Pr}(\mathrm{CC} \mid \mathrm{S} 2 \mathrm{D} 1)=0.2$

$-\operatorname{Pr}(E C F \mid V B, C C)=0.5$

$-\operatorname{Pr}(E C F \mid V B, / C C)=0.1$

Quantify LERF

What is conditional probability of LER given S2D1? 


\section{CET Output Organized}

- If analysis is limited to Level-2, output usually formatted for ease of presenting results on containment failure

- If supporting Level-3, then need detailed source term information

- Output also needs to adequately represent uncertainty in the analysis 


\section{Uncertainty}

- Uncertainty important in all PRA

- Level-2 results reflect uncertainty in Level-1 results and CET uncertainties

- Uncertainty expressed as a probability density function on the containment failure frequency (or source term release frequency)

- "Probability of Frequency" characterization

- Implies Bayesian techniques and interpretation 


\section{There are Different Interpretations of Probability}

- Classical

- Requires a statistical basis

- Generates confidence intervals only (not probability distributions)

- Bayesian

- Implies a degree of belief

- able to accommodate sparse data and engineering judgement

- Needed to produce and propagate probability distributions in a PRA (i.e., all PRAs employ Bayesian techniques and interpretations) 


\section{Uncertainty Often Classified by Type}

- Aleatory - Stochastic, random or tolerance uncertainty

- A product of the assumed model

- i.e., a binomial or Poisson process

- Can also include variability in boundary conditions

- Epistemic - State of knowledge, subjective or confidence uncertainty

- A produced by a lack of data

- Similar to a classical statistical confidence

- Bayesian interpretation is the degree of belief 


\section{Aleatory Uncertainties}

- Measure of randomness in process

- e.g., coin flip - sometimes heads, sometimes tails

- Note that this "randomness" could also be interpreted as variability in the boundary conditions of each coin flip

- Distribution is result of assumptions about the process (i.e., variability accommodated using the random process premise)

- Additional data does not necessarily reduce aleatory uncertainty

- Distribution is a function of parameter values (i.e., $\lambda$ 's), which are usually uncertain 


\section{Epistemic Uncertainties}

- Uncertainty in model parameters (i.e., uncertainty in our estimate of $\lambda$ )

- Distribution reflects data, relevant model predictions, engineering judgment

- As more data is accumulated, the uncertainty narrows

- Typically generated using Bayesian methods (covered in Probability and Statistics for PRA course)

- e.g., Bayesian update process 


\section{Idaho National Laboratory}

\section{Uncertainty Needs to be Propagated Through Entire PRA}

- Beginning with uncertainty on Level-1 initiating event frequencies

- Uncertainty in different input parameters represented in different ways

- lognormal, beta, gamma, uniform distributions

- Different types and sources of uncertainty need to be accounted for in the PRA results

- Be it core damage frequency, containment failure frequency or health risk 


\section{Simulation Techniques Used to Quantify Models}

- Analytical methods simply not feasible

- Monte Carlo or Latin Hypercube are currently the only practical approaches to propagating uncertainty

- Select random values from input parameter distributions, quantify model, repeat many times

- repeating mathematical "experiment" over and over produces a frequency histogram on the output

- Quantification done step-wise

- Distributions on intermediate results (e.g., CDF or PDS) are then inputs to subsequent steps 


\section{Example Monte Carlo Sampling (5 Samples) on input}

parameter $\lambda$

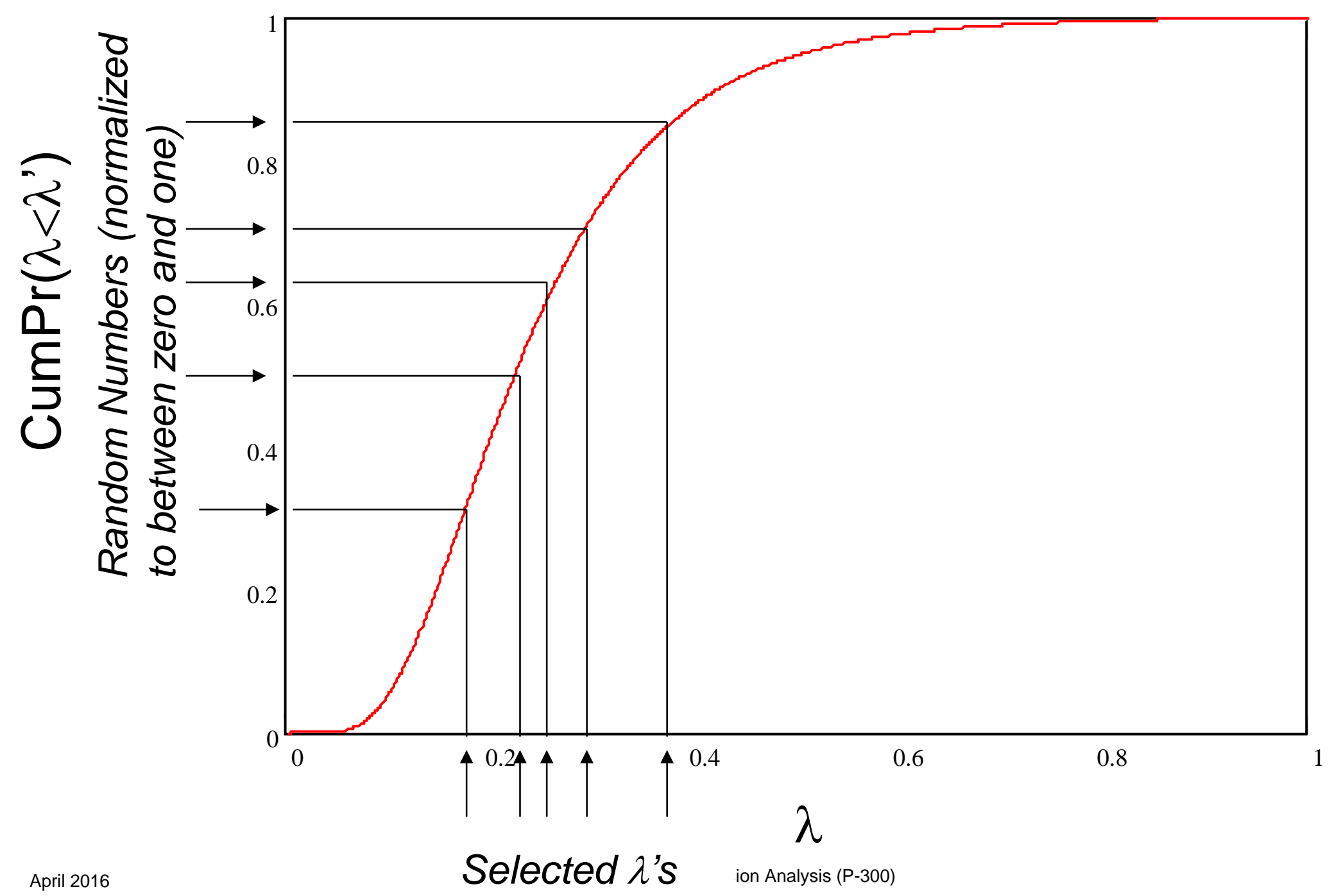


Latin Hypercube Sampling (one $\lambda$ selected from each equalprobability area)

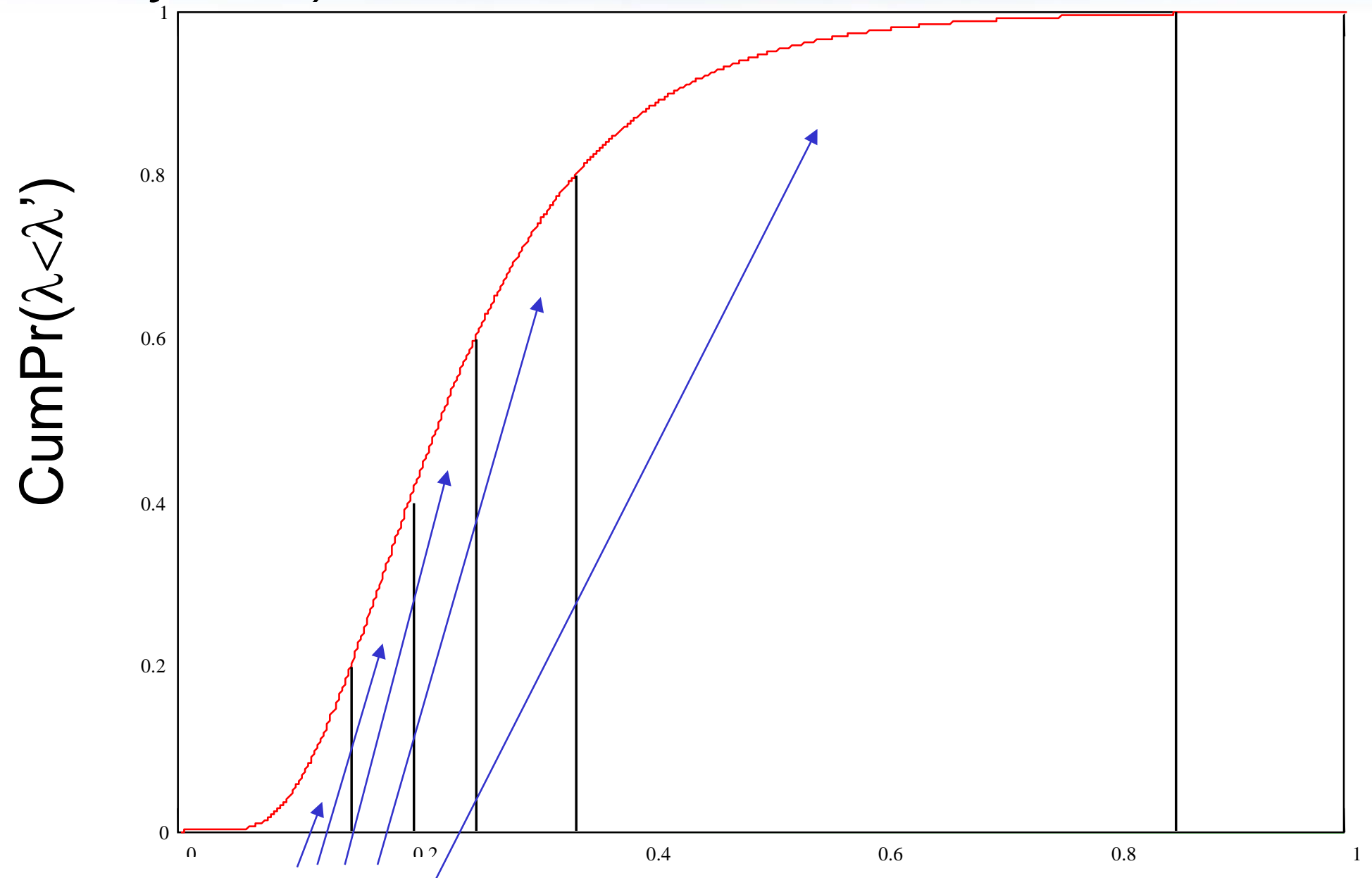

Equal probability regions 


\section{Propagation of Uncertainties}

- Simulation Process (either Monte Carlo or Latin Hypercube)

- Generates frequency histogram for Result $=f(X, Y)$ by sampling from distributions for $X$ and $Y$ re-calculating result for each of simulation samples

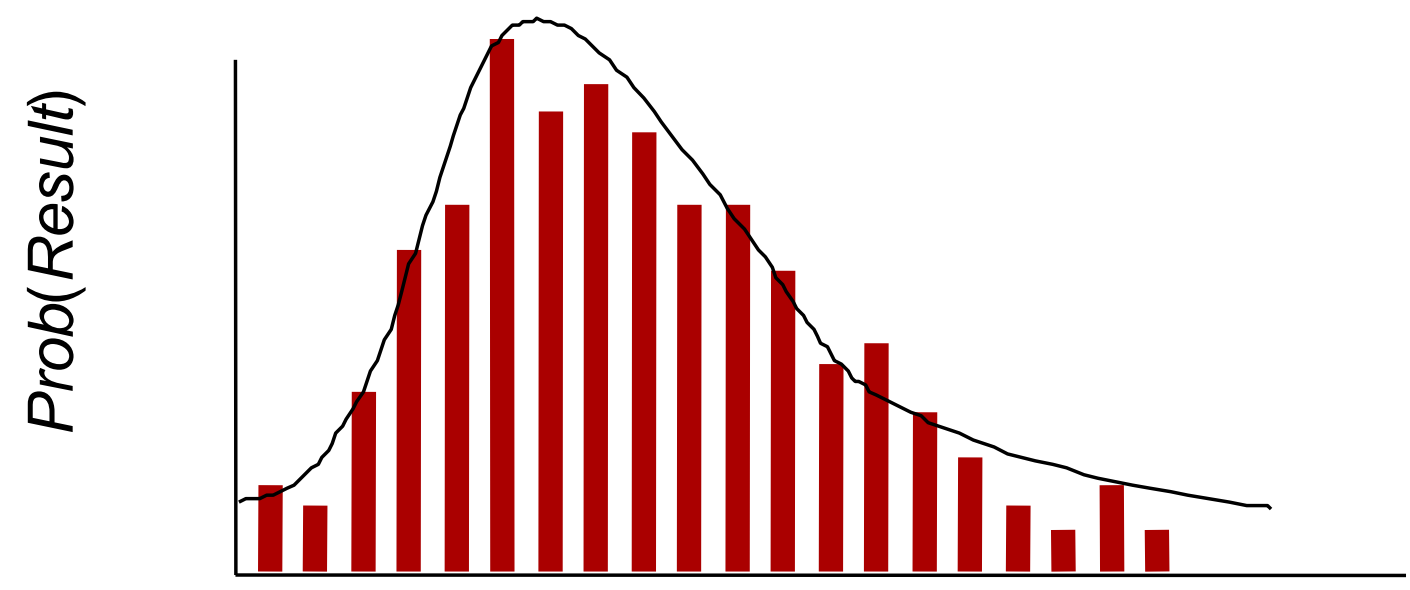

Result 


\section{Results Can Take Many Forms}

- Level-1 Results

- Core Damage Frequency or Plant Damage State Frequencies

- Level-2 Results

- Containment Failure Frequency, Conditional Containment Failure Probability, Large Early Release Frequency

- Level-3 Results

- Various health and financial consequence risk measures 


\section{CET Results for Each Accident Sequence Combined and Normalized}

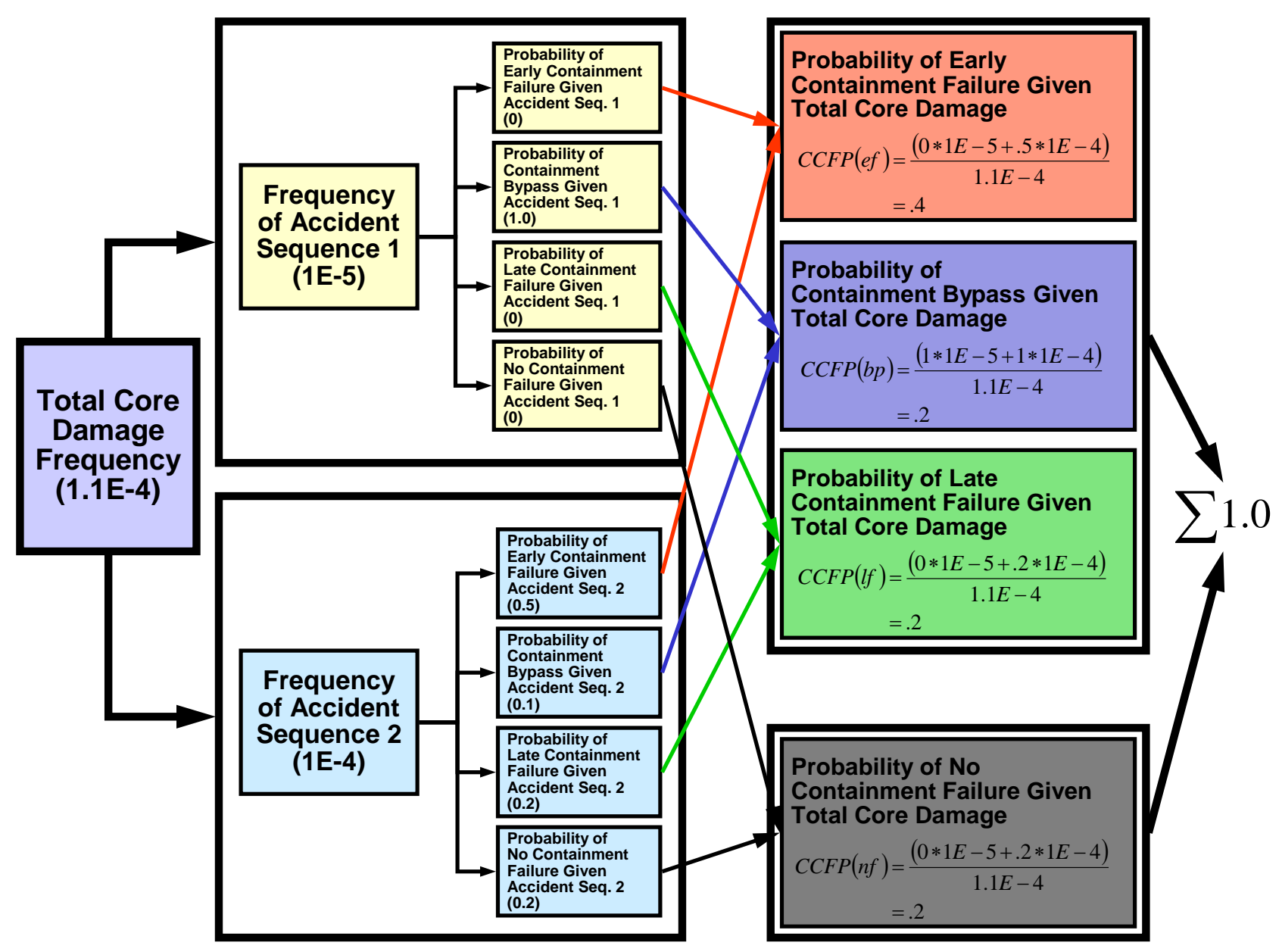




\section{Two Measures Typically Cited for Assessing Containment Performance}

Conditional Containment Failure Probability

$$
=\mathrm{CCFP}=\sum_{i=1}^{n} \frac{S_{i}}{C D F} C_{i}
$$

$$
=\mathrm{CFF}=\sum_{i=1}^{n} S_{i} C_{i}
$$

$S_{i}=$ frequency for accident sequence, $i$

$C_{i}=$ containment conditional failure probability given accident sequence, $i$

$n=$ total number of accident sequences 


\section{NUREG-1150 Presentation Bins}

- Vessel Breach (VB), early (during core damage) containment failure (CF)

- VB, alpha, early CF (at VB)

- VB > 200 psi, early CF (at VB)

- VB $<200$ psi, early CF (at VB)

- VB, late CF

- VB, basemat melt-thru, very late CF

- Bypass

- VB, no CF

- No VB, early CF (during core damage)

- No VB, no CF 


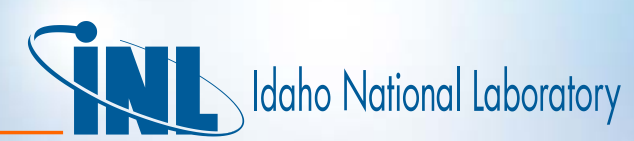

ACCIDENT

PROGRESSION

BIN

NUREG-1150

Sequoyah

Accident

Progression

Bin Results

for Summary

PDSs

(during CD)
VB, early CF

VB, alpha,

early CF (at VB)

$\mathrm{vB}>200 \mathrm{psi}$,

early CF (at VB)

$\mathrm{vB}<200$ psi, early CF (at VB)

VB, late $\mathrm{CF}$

VB, BMT,

very late $C F$

Bypass

VB, No CF

No VB, early $C F$ (during $\mathrm{CD}$ )

No VB
PLANT DAMAGE STATE

(Mean Core Damage Frequency)

Frequency

Weighted

$\begin{array}{cccccc}\text { LOSP } & \text { ATWS } & \text { Transients } & \text { LOCAs } & \text { Bypass } & \begin{array}{c}\text { Average } \\ \text { Averaghed }\end{array} \\ (1.38 \mathrm{E}-05) & (2.07 \mathrm{E}-06) & (2.32 \mathrm{E}-06) & (3.52 \mathrm{E}-05) & (2.39 \mathrm{E}-06) & (5.58 \mathrm{E}-05)\end{array}$

\begin{tabular}{|c|c|c|c|c|c|}
\hline 0.014 & 0.003 & & 0.002 & & 0.005 \\
\hline 0.002 & 0.003 & & 0.002 & & 0.002 \\
\hline 0.064 & 0.023 & 0.014 & 0.031 & & 0.035 \\
\hline 0.054 & 0.020 & 0.004 & 0.014 & & 0.023 \\
\hline 0.153 & 0.001 & & 0.001 & & 0.038 \\
\hline 0.065 & 0.151 & 0.039 & 0.260 & & 0.171 \\
\hline 0.001 & 0.134 & 0.006 & & 0.996 & 0.056 \\
\hline 0.200 & 0.471 & 0.137 & 0.301 & & 0.269 \\
\hline 0.038 & 0.001 & 0.005 & 0.002 & & 0.011 \\
\hline 0.384 & 0.171 & 0.785 & 0.367 & & 0.371 \\
\hline
\end{tabular}

$\mathrm{BMT}=$ Básemat Melthrough

$\mathrm{CF}=$ Containment Failure

Sequoyáh

$C D=$ Core Degradation 


\section{NUREG-1150 Results Indicate BWR Early Containment Failures More Likely}

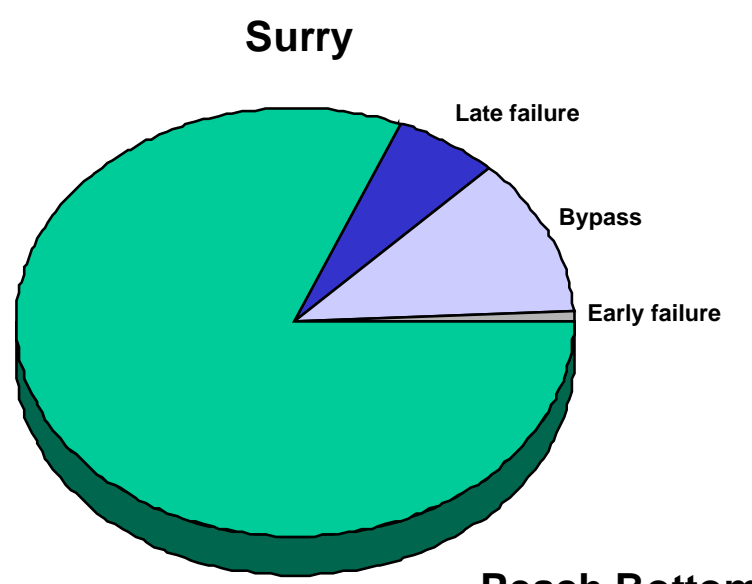

No vessel breach or vessel breach/no containment failure

Early failure
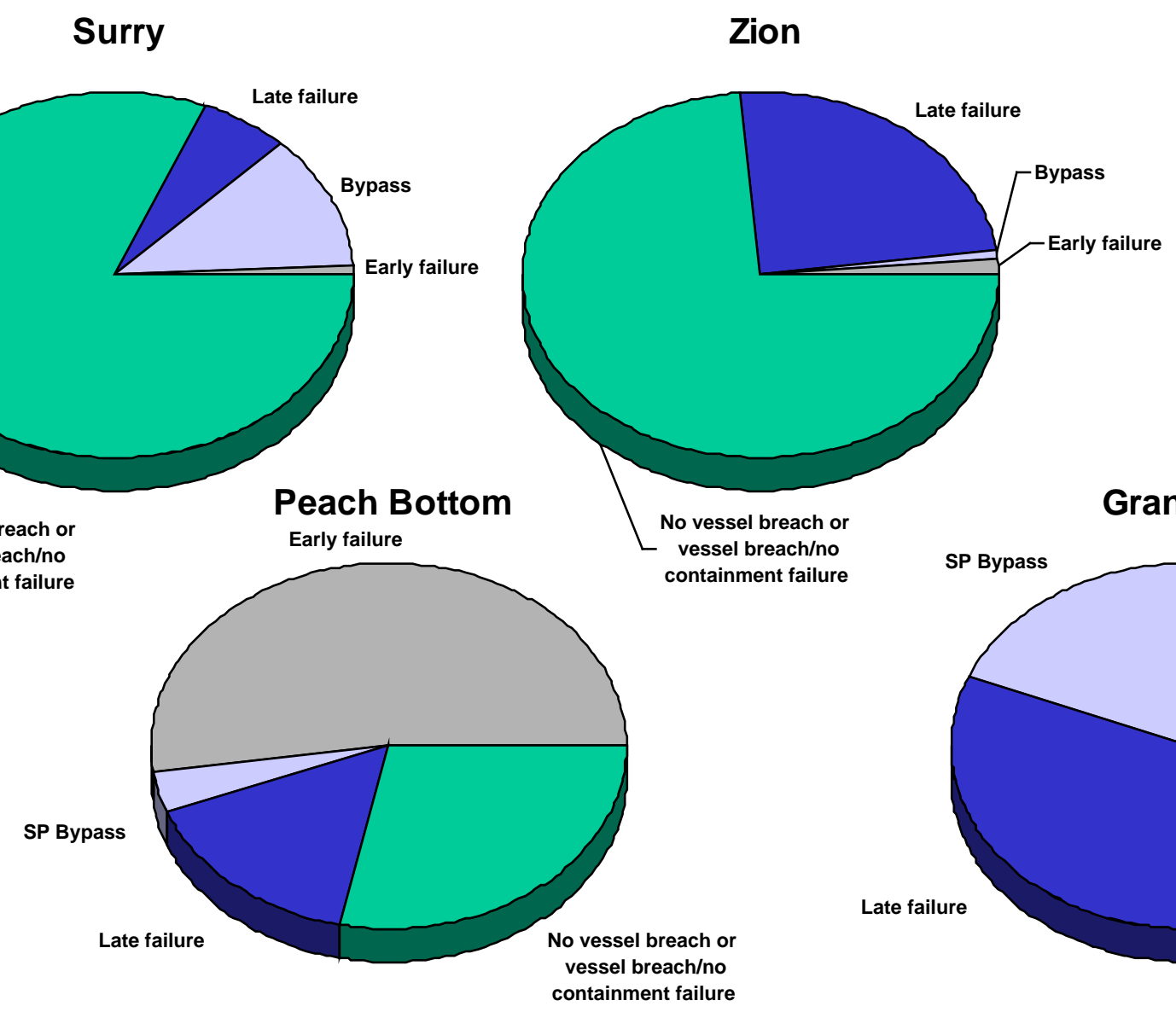

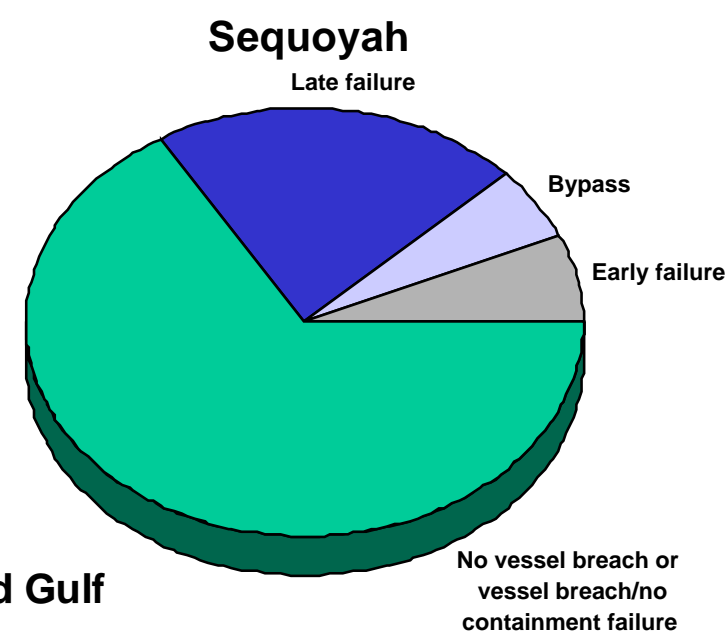

NUREG-1150 relative probability of containment failure modes from internal events 


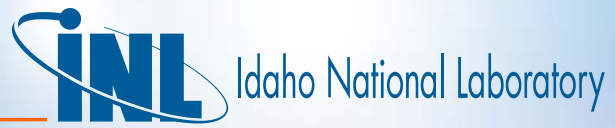

\section{IPEs Suggest that Late Failures Dominate in BWRs and PWRs}

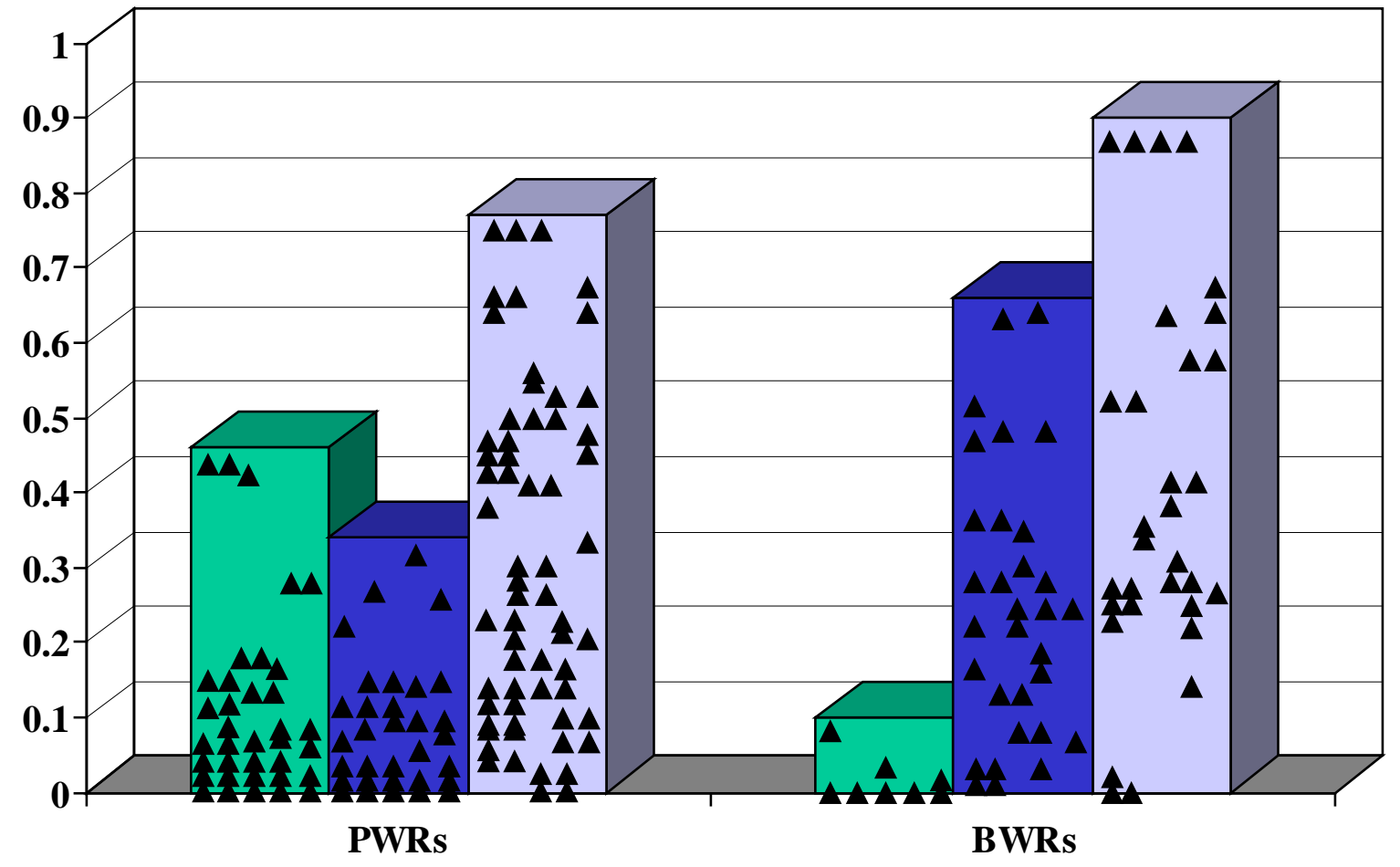

$\square$ Bypass $\square$ Early failure $\square$ Late faliure 


\section{TII Idaho National laboratory}

\section{General Insights From Containment Response Analyses}

- Large volumes of PWR containments are less likely to experience early structural failures than the smaller BWR pressure suppression containments.

- Probability of bypass is generally higher in PWRs because of higher operating pressures and use of steam generators

- Specific containment features as well as differing assumptions regarding containment loads lead to observed variability. 


\section{qint}

\section{Session Review}

- How are the Level-1 and Level-2 portions of a PRA linked?

- What are the two types of uncertainty?

- How is uncertainty propagated through the analysis? 


\section{Accident Progression Analysis (P-300)}

Example: Palisades IPE (Jan. 1993) 


\section{Example: Palisades IPE}

- Two-loop Combustion Engineering (CE) 2530 MWt (780 MWe) PWR

- Two steam generators (SGs)

- Four reactor coolant pumps (RCPs)

- Two power-operated relief valves (PORVs)

- Large dry pre-stressed concrete containment

- Reinforced concrete cylinder (post-tensioned in three directions) with 1/4-in. carbon steel liner

- Design basis capacity is 55 psig at 2830F

- Complete Level-2 PRA submitted as Individual Plant Examination (IPE) to NRC on January 29, 1993. 


\section{PALISADES NUCLEAR PLANT \\ GENERAL CONTAINMENT ARRANGEMENT}

\section{Idaho National Laboratory}

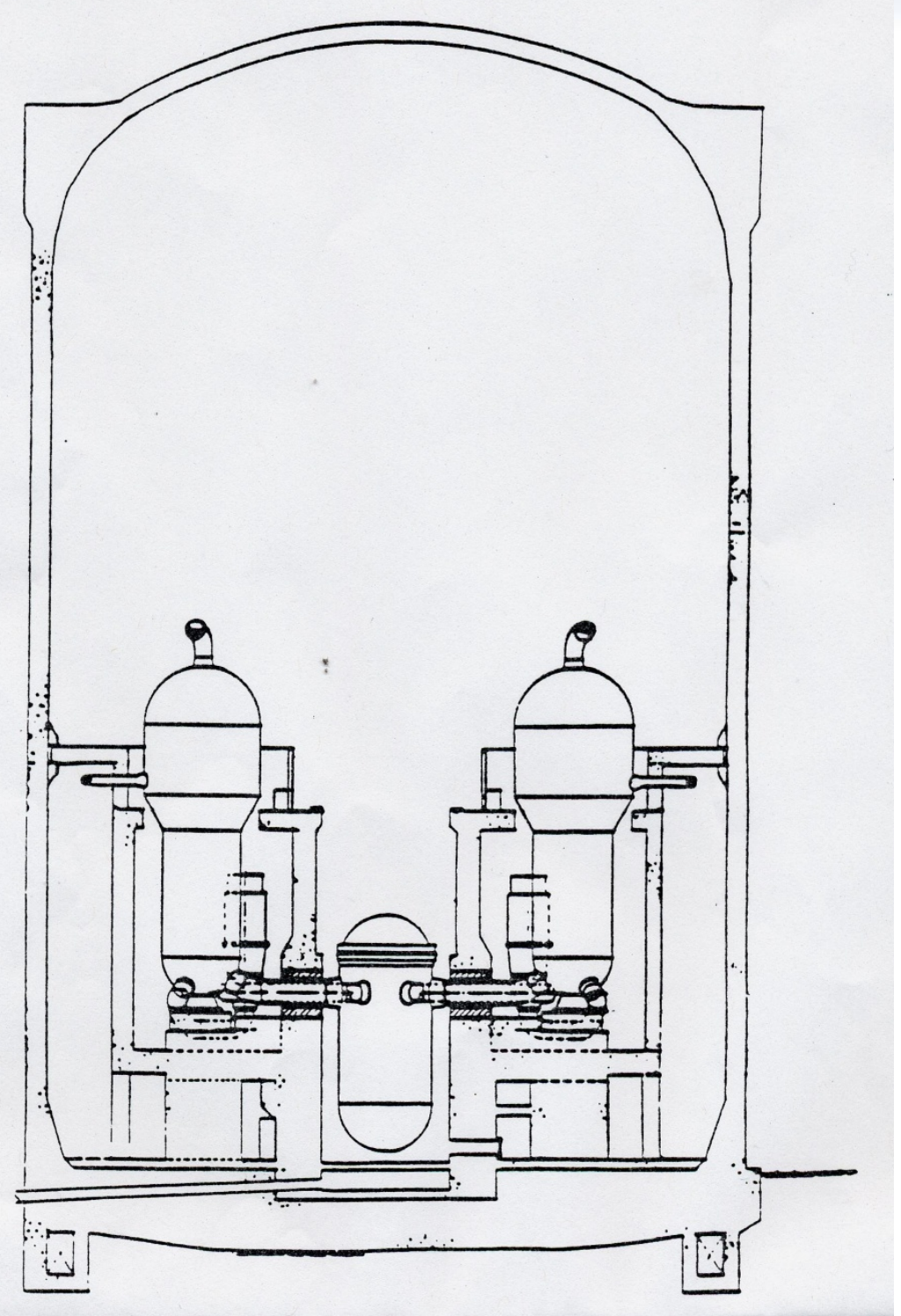




\section{Palisades Level-2 PRA Analysis Process}

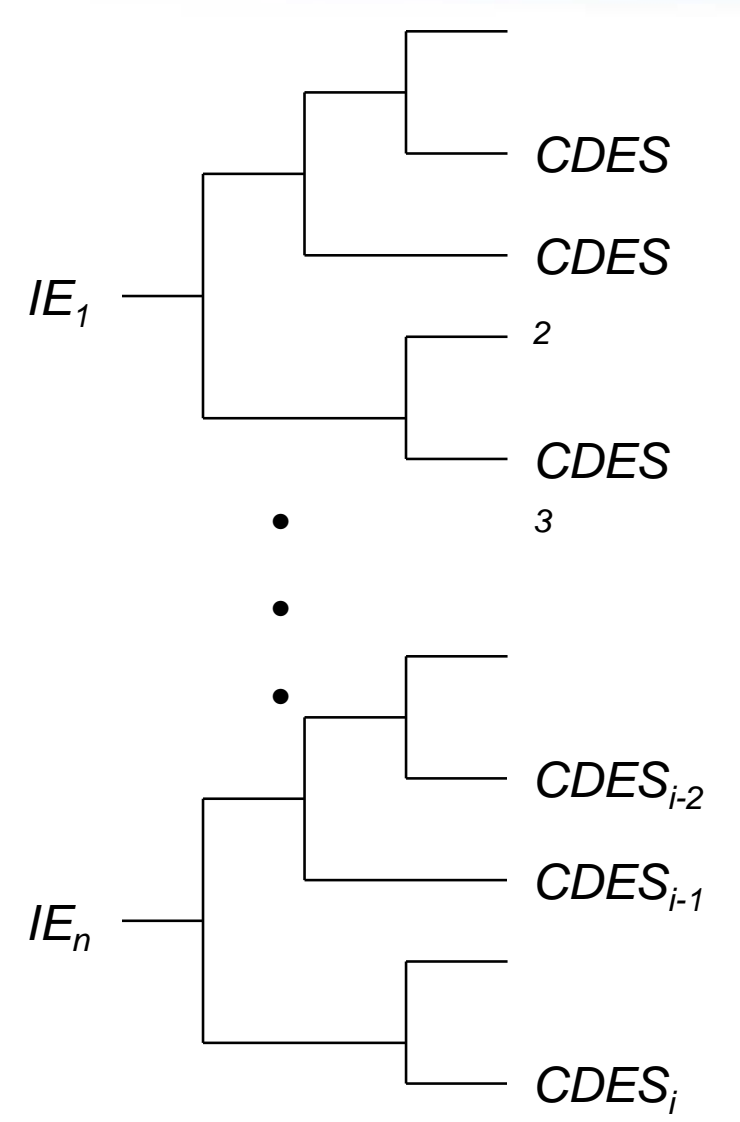

$\sum_{m=1}^{i} \operatorname{Pr}\left(C D E S_{m}\right)=C D F$

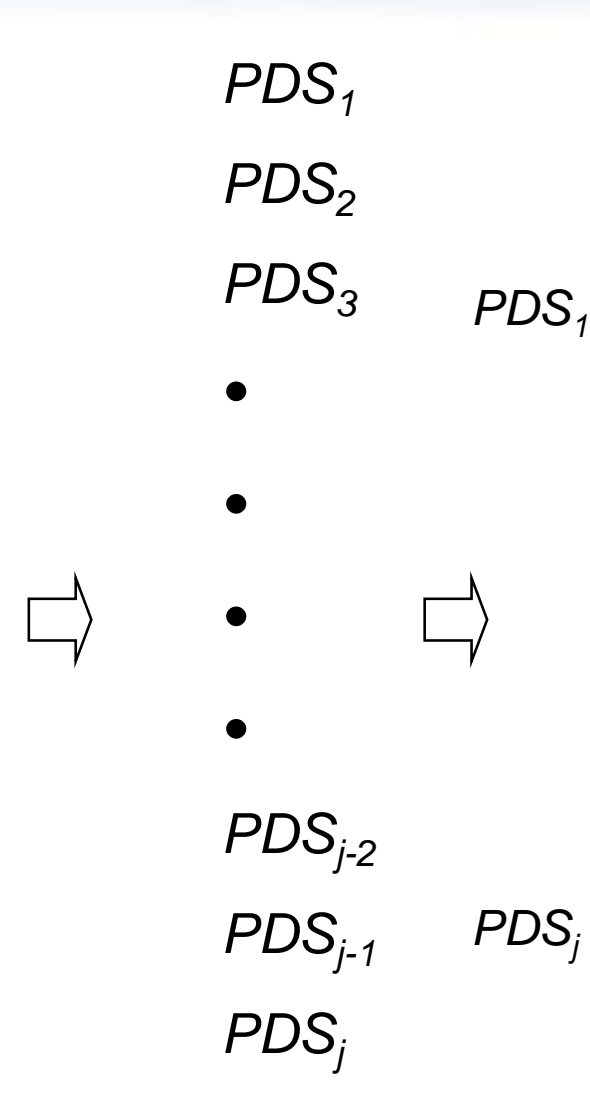

$\sum_{n=1}^{j} \operatorname{Pr}\left(P D S_{n}\right)=C D F$

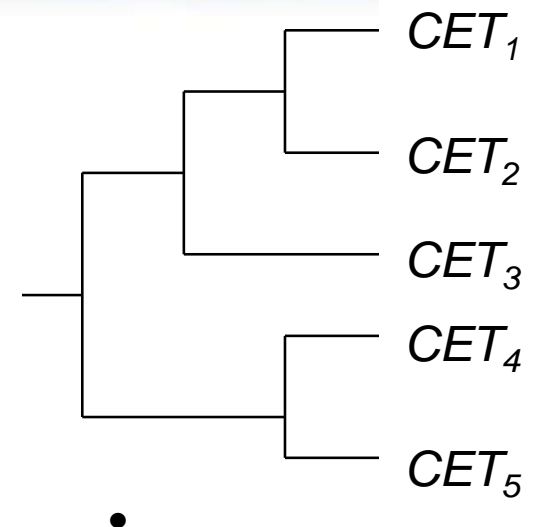

$R C_{1}$ $R C_{2}$ $R C_{3}$

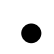
$R C_{r-2}$ $R C_{r-1}$ $R C_{r}$ 
Palisades IPE Used PDS Bridge Tree to Map CD Sequences Into PDS

- CET developed first, PDS-BT then developed to satisfy information needs of CET

- Total CDF conserved in binning to PDS's

- i.e., Total CDF $=\Sigma_{m=1, i}$ PDS $_{m}$

- PDS-BT incorporated as an extension of the Level-1 core damage event tree

- PDS-BT primarily used as a sorting mechanism

- Most branch choices dictated by previous events

- Presence of water in containment was exception (PDS-BT top event SII)

- In some CD sequences, operation of ECCS does not guarantee water in containment (i.e., ISLOCA, SGTR) 


\section{Palisades IPE PDS Characteristics}

\begin{tabular}{cl}
\hline \# Characteristic & Description \\
\hline 1 Initiator & $\begin{array}{l}\text { Affects potential for containment bypass, fission } \\
\text { product retention by the RCS, pressure of the RCS at } \\
\text { vessel failure, etc. }\end{array}$ \\
\hline 2 CD Time & $\begin{array}{l}\text { Time of fission product release and amount of warning } \\
\text { time for offsite protective actions. }\end{array}$ \\
\hline 3 Secondary & $\begin{array}{l}\text { Can affect late revaporization of fission products } \\
\text { Cooling }\end{array}$ \\
\hline retained in the RCS \\
PORV & $\begin{array}{l}\text { Affects } R C S \text { pressure during the core relocation/vessel } \\
\text { failure phase of a CD sequence }\end{array}$ \\
\hline 5 Containment & $\begin{array}{l}\text { Affect long term integrity of containment. Can affect } \\
\text { Systems } \\
\text { debris coolability, flammable gas behavior, fission } \\
\text { product releases }\end{array}$ \\
\hline
\end{tabular}




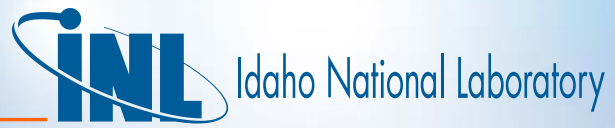

\section{Palisades IPE PDS Character \#1 (IE)}

A1 - Large LOCA ( $d>18$ in.)

A2 - Medium LOCA (2 in. $<d<18$ in.)

$B$ - Small LOCA (1/2 in. $<d<2$ in.)

C - Interfacing System LOCA

D - SGTR

$\mathrm{T}$ - Transient

Z - ATWS 


\section{Palisades IPE PDS Char. \#'s 2, 3 \& 4}

2 Core Damage Timing

E - Early CD

L - Late CD

3 Secondary Cooling

G - Secondary Cooling Available

$\mathrm{J}$ - No Secondary Cooling

4 Pressurizer PORV

M- PORV Available

$\mathrm{N}$ - PORV Unavailable 


\section{Palisades IPE PDS Char. \#5 (Cont. Sys.)}

P - Containment sprays and air coolers available

Q - Cont. sprays avail. and cont. air coolers NOT avail.

$\mathrm{R}$ - Only cont. air coolers avail., RWST contents in cont.

S - Only cont. air coolers avail., RWST contents NOT in cont.

$\mathrm{V}$ - No cont. systems avail., RWST contents in cont.

W - No cont. systems avail., RWST contents NOT in cont.

$X$ - Late (post VB) operation of only HPSI/LPSI 


\section{Palisades PDS's Grouped to Reduce Number of}

CET Analyses

- Initial development resulted in 392 possible PDS's

- IPE judged preemptive protective actions were unlikely

- All core damage timing assumed to be early

- Reduced number of possible PDS's to 196

- Illogical PDS's were also removed from the list (reduced number to 168)

- Truncation (at 1E-9) during the CD/PDS quantification further reduced the list to 70 PDS's

- Still too many PDS's

- PDS's collapsed on PORV availability

- For each remaining PDS PORV availability calculated by taking a weighted average (53 PDS's left) 


\section{Palisades IPE PDS Bridge Tree Top Events}

\begin{tabular}{ll}
\hline Heading & Description \\
\hline 2ND & AFW available to both steam generators \\
CSI & $\begin{array}{l}\text { Containment spray system available in injection } \\
\text { mode }\end{array}$ \\
CSR & $\begin{array}{l}\text { Containment spray system available in recirculation } \\
\text { mode }\end{array}$ \\
PRV & One pressurizer PORV available to depressurize \\
& RCS \\
SII & RWST water is in containment \\
FC & Containment air coolers available \\
SIL & Safety injection available after vessel failure
\end{tabular}




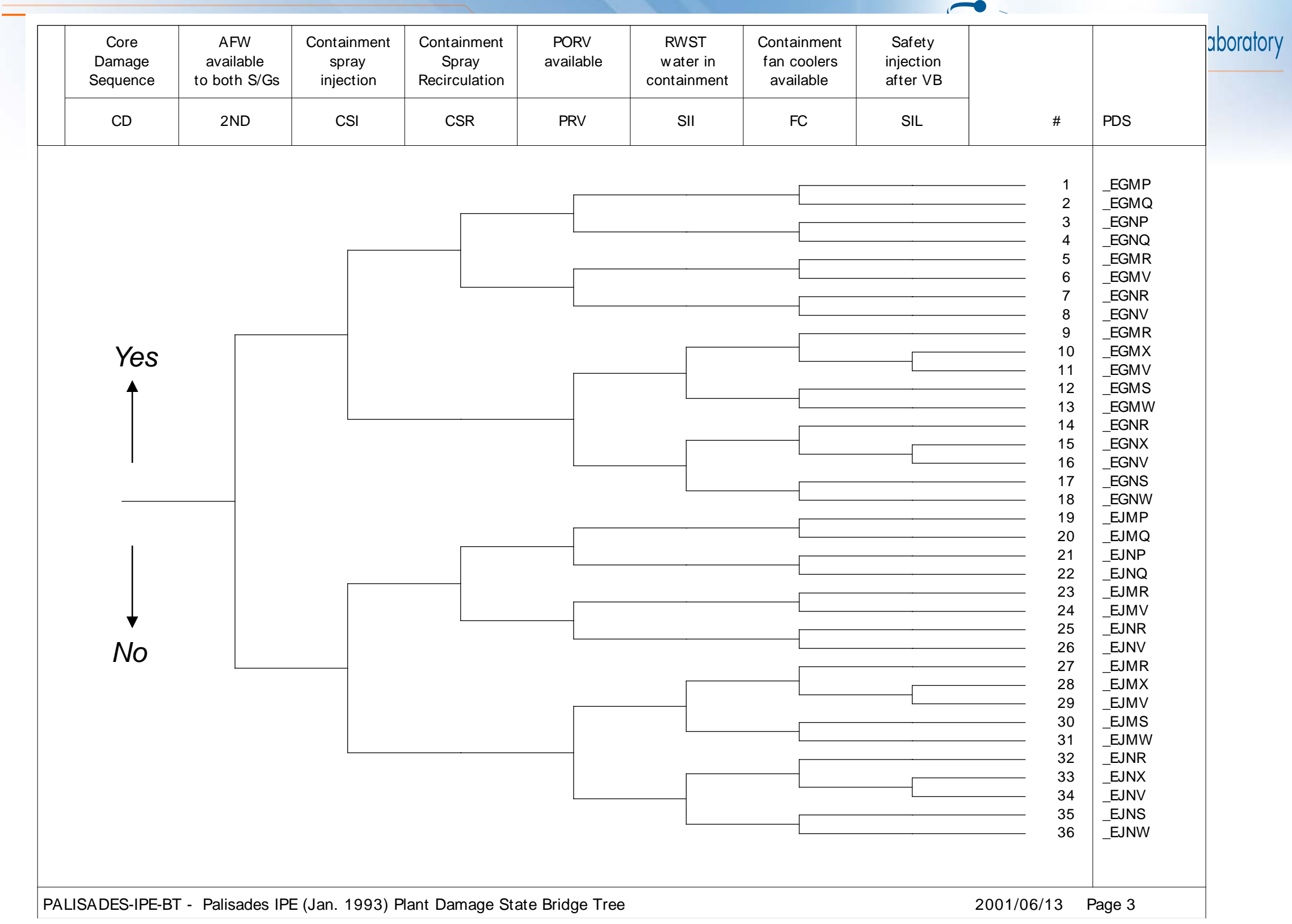


Top 18 PDSs from Palisades IPE

\begin{tabular}{|l|l|l|l|}
\hline PDS & Freq & PDS & Freq \\
\hline BEGP & $1.11 \mathrm{E}-5$ & BEGS & $7.22 \mathrm{E}-7$ \\
\hline TEJP & $9.40 \mathrm{E}-6$ & TEJQ & $3.70 \mathrm{E}-7$ \\
\hline TEJW & $9.02 \mathrm{E}-6$ & CEJW & $3.70 \mathrm{E}-7$ \\
\hline TEJV & $6.89 \mathrm{E}-6$ & A2EGR & $2.42 \mathrm{E}-7$ \\
\hline ZEGP & $4.20 \mathrm{E}-6$ & BEGV & $2.33 \mathrm{E}-7$ \\
\hline BEGR & $2.97 \mathrm{E}-6$ & TEJS & $3.32 \mathrm{E}-7$ \\
\hline TEJR & $2.42 \mathrm{E}-6$ & DEJR & $1.10 \mathrm{E}-7$ \\
\hline DEJP & $1.33 \mathrm{E}-6$ & A2EGP & $1.00 \mathrm{E}-7$ \\
\hline DEJS & $1.04 \mathrm{E}-6$ & A1EGR & $9.72 \mathrm{E}-8$ \\
\hline
\end{tabular}




\section{CET Top Event Quantification Focus on Probability of Containment Failure}

- Need to know how strong is the containment structure

- Need to identify the likely failure location

- Need to identify the size of any potential containment failure 


\section{Palisades IPE Containment Structural Response and Failure Characterization}

- Purpose

- To establish best estimate probabilistic measure of containment fragility

- Identify failure mode (i.e., leak or rupture) given a predicted failure due to quasi-static overpressure event

- Approach

- Two dimensional axi-symmetric finite element analysis of the total containment structure

- Provided detailed information on potential weak links (discontinuities)

- Detailed analyses of the weak links 


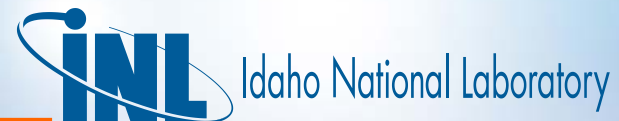

\section{Containment Structural Evaluation Comprised Two Parts}

- Palisades Finite Element Model (PFEM) mesh consisted of five major sections

- dome, ring girder, cylinder wall, basemat and soil

- Analysis performed by plant Engineer/Constructor (Bechtel)

- Leakage at major penetrations was evaluated using EPRI developed method (EPRI NP-6260-M)

- Penetrations less than 24-inches diameter were judged not to constitute a weak link in a concrete containment

- Electrical penetrations also judged to not be a concern (based on NUREG-1037 analysis) 


\section{Structural Evaluations Identified Potential Weak Links}

- Global Weak Links (failure = catastrophic rupture)

- Mid-Height Region of Cylindrical Wall

- Apex Region of the Dome

- Basemat-Cylindrical Wall Interface Region

- Local Weak Links (failure = minor loss of pressure)

- Access Openings (including seals)

- equipment hatch

- escape lock

- personnel air lock

- Large pipe penetrations 


\section{Containment Fragility Curve Combination of Fragility Curves for Each Weak Link}

- Fragility curve provides cumulative probability of containment failure as a function of internal pressure

- Seven weak link fragility curves combined into composite (total containment) fragility curve

$-\operatorname{PrF}(p)=1-\Pi_{i=1, n}\left[1-\operatorname{PrF}_{i}(p)\right]$

- where:

- $\operatorname{PrF}_{i}(p)=$ probability of failure mode $i$ at pressure $p$

- $\mathrm{n}=$ total number of failure modes

- Minimum median capacity of the Palisades containment at 95\% confidence level was determined to be

- 131 psig (0.90 MPa) or 2.38 times the design pressure of 55 psig 


\section{Palisades IPE CET Features}

- CET and PDS's developed together such that PDS's contain ONLY plant system information, and CET addresses ONLY effect of severe accident physical processes

- Plant system dependencies accounted for

- CET focused on containment performance and fission product release

- Single, general-form CET

- Consistent treatment of PDS's

- Consistent binning of CET endstates into source terms 


\section{Only Dominant PDS's Used in CET Analysis}

- Highest frequency PDS's analyzed until 99\% of total frequency has been included

- Highest 18 PDS contribute $99.16 \%$ of total frequency

- Comprises all PDS with frequency greater than 1E-7

- Most severe PDS frequency was increased to account for the missing $0.84 \%$ frequency

- Total core damage frequency of 5.12E-5/yr is preserved 


\section{Palisades IPE CET Top Events}

PDS - Plant Damage State

BYE - Early Cont. Bypass

CIS - Cont. Isolation

BYL - Late Cont. Bypass

RIV - Recovery after CD but before VB

UDD - Upward debris dispersal at VB

$\mathrm{CAE}$ - Early relocation of core debris to aux. bldg.

CIE - Cont. intact early
LVE - Large volatile fission product release early

$\mathrm{CAL}$ - Late relocation of core debris to aux. bldg.

CIL - Cont. intact late

$\mathrm{CCl}$ - Core concrete interaction resulting in large fission product release

LVL - Large volatile fission product release late 


\section{Pan}

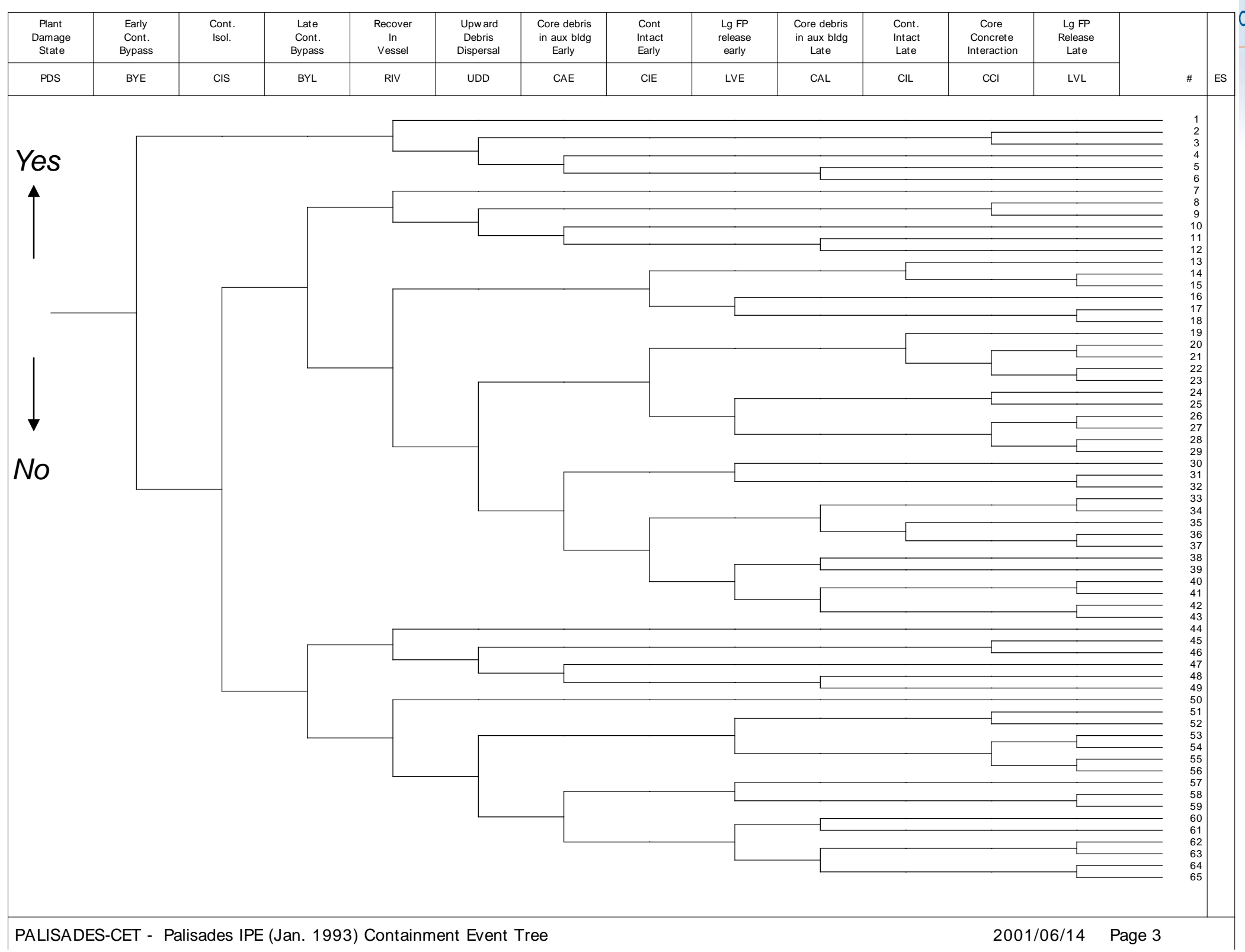




\section{CET Top Events Modeled Using Fault Trees}

- 93 pages of fault trees used to model 12 top events

- Comprising about a hundred basic events (4 groups)

- PDS dependent BEs ("house events")

- Recovery BEs

- Recovery of containment systems or S/G cooling

- Operator Action BEs

- Operator open PORV to depressurize RCS

- Phenomenological BEs

- 45 events

- Single event assigned different probabilities depending on context (boundary conditions) 


\section{CAE Top Event}

- Core debris enters Auxiliary building Early

- Early: soon after vessel failure

- Core debris enters the auxiliary building via ESF (sump) recirculation line

- Core debris falls to cavity floor, is not quenched and flows into sump via drain lines.

- Core debris falls to cavity floor, is quenched, but not in a coolable geometry

- Core debris reheats and flow into sump

- RV fails at high pressure causing catastrophic failure of cavity floor. 


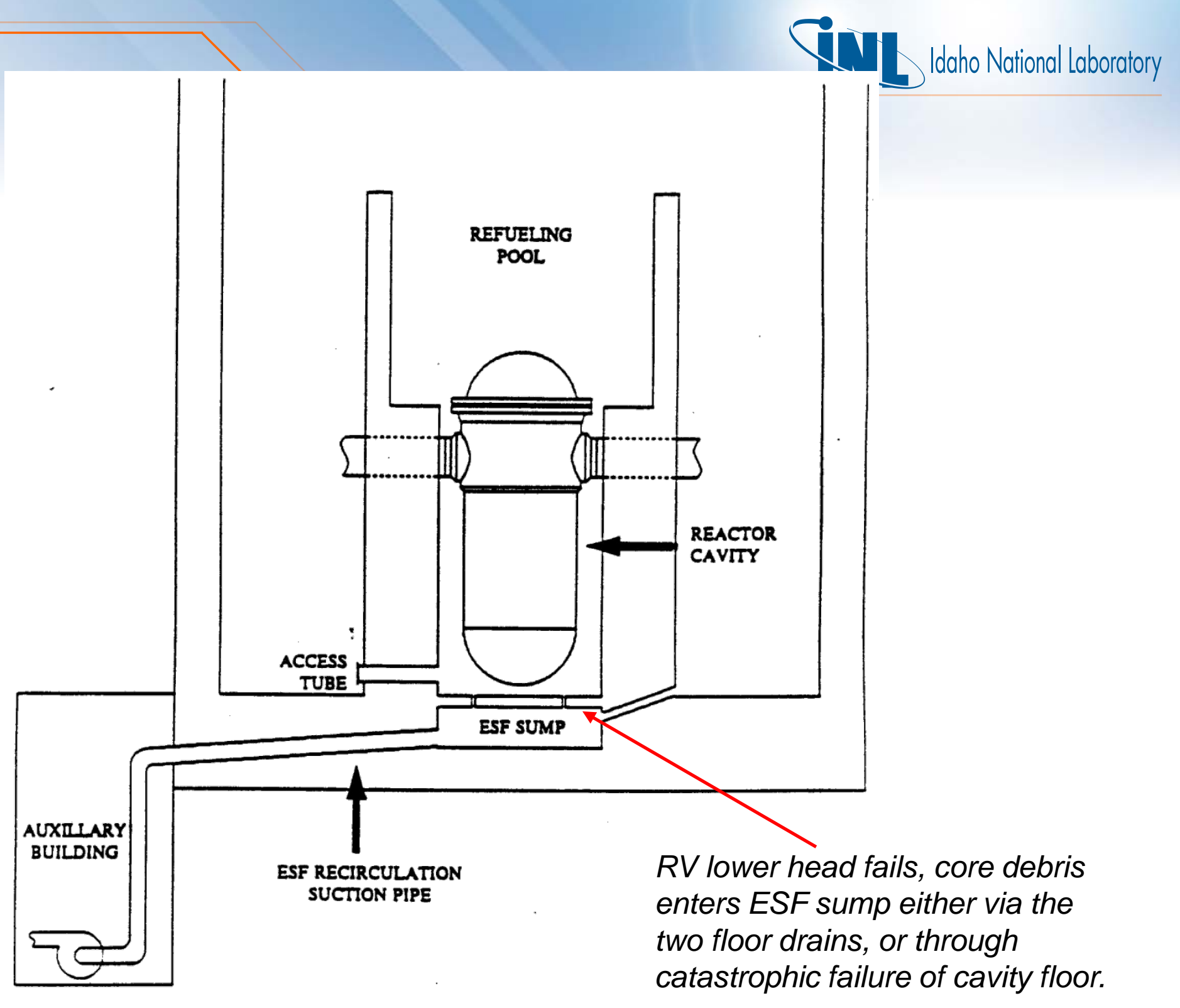

PALISADES REACTOR CAVITY-ENGINEERED SAFEGUARDS SUMP ARRANGEMENT 


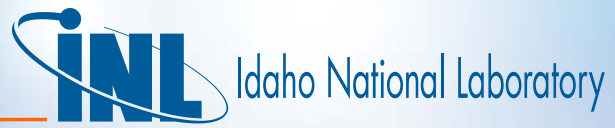

\section{CAE Top Event Fault Tree}

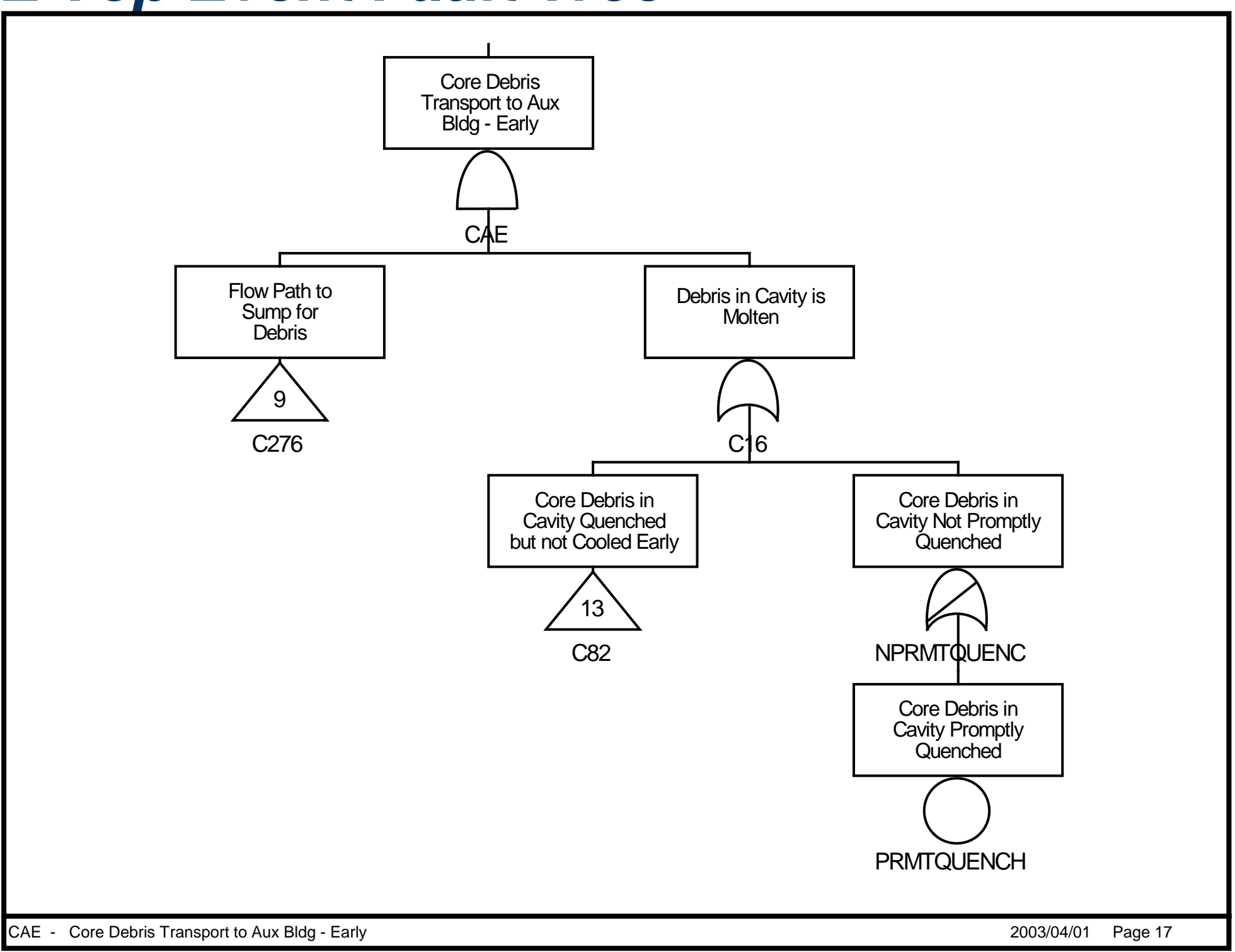




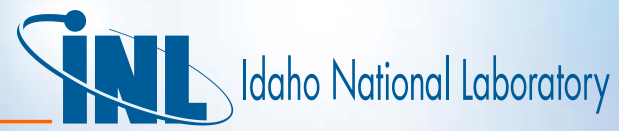

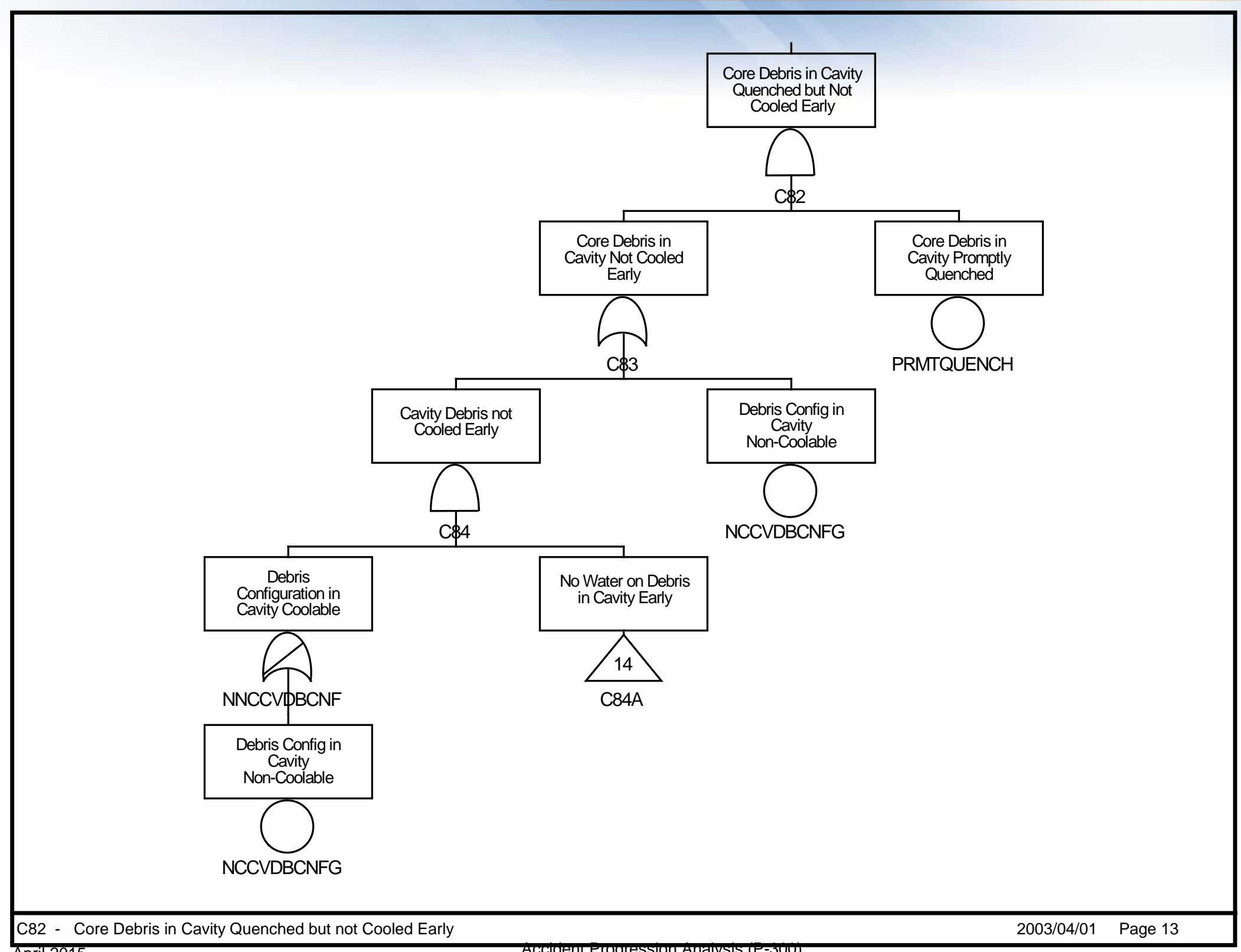




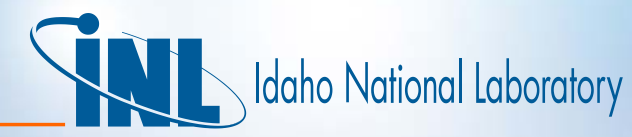

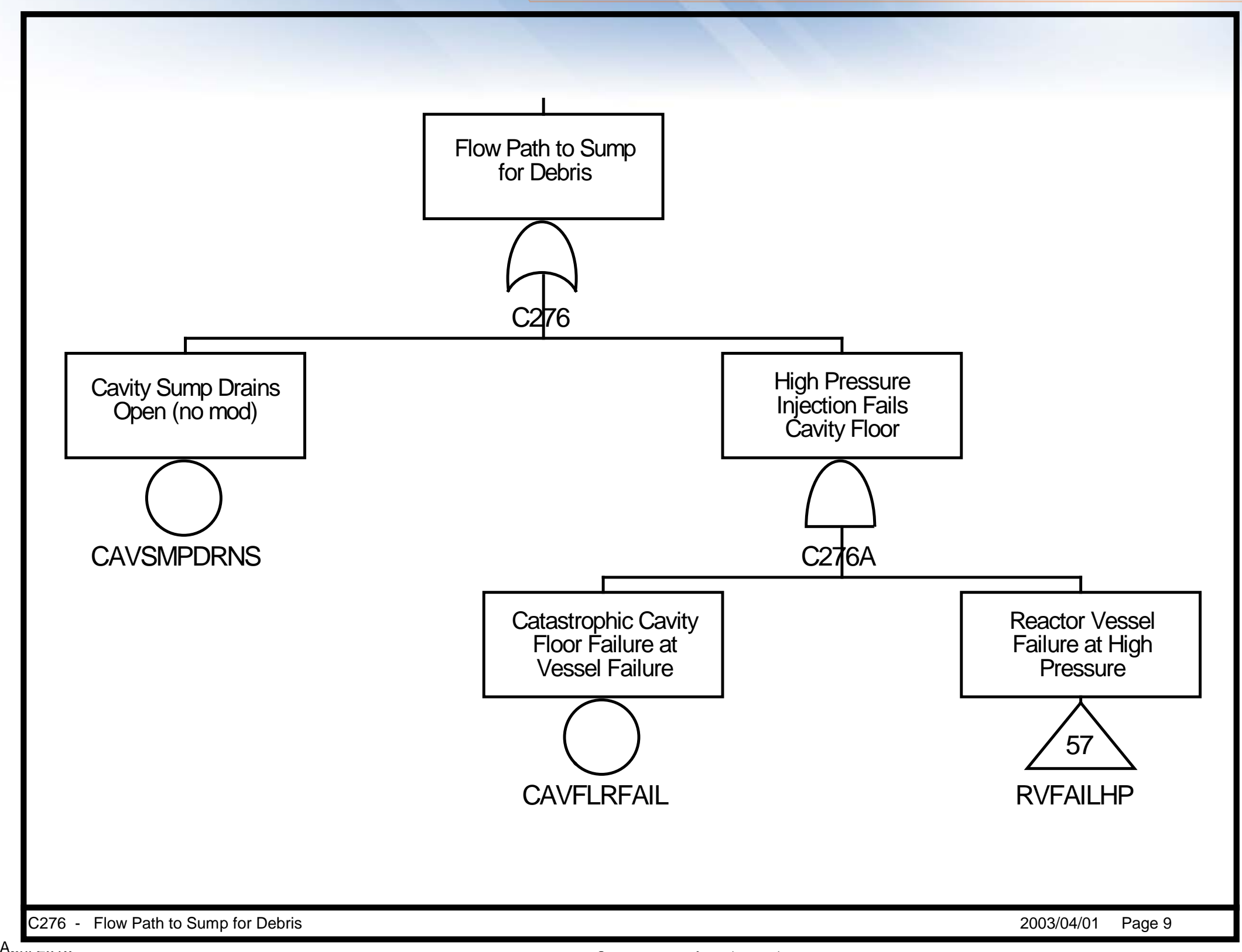




\section{CAVFLRFAIL - Cavity Floor Fails}

- Structural analysis estimates a failure pressure of 370 psid (2.55 MPa)

- Assumed to be a mean value

- Standard deviation of $10 \%$ assumed

- Analyses of Palisades severe accidents produced peak cavity pressure estimates for three class of PDS

- High, medium, and low RCS pressures 


\section{CAVFLRFAIL - Cavity Floor Failure Probability Estimate}

Probability of Cavity Floor Failure depends upon RCS Pressure (at time of RPV failure) - Estimated by convolution of peak cavity pressure distribution and floor failure pressure distribution.

\begin{tabular}{|l|l|l|l|}
\hline $\begin{array}{l}\text { RCS Pressure } \\
(\mathrm{MPa})\end{array}$ & $\begin{array}{l}\text { RCS Pressure } \\
\text { Class (at RPV } \\
\text { failure) }\end{array}$ & $\begin{array}{l}\text { Prob of Cavity } \\
\text { Floor Failure }\end{array}$ & Applicable PDS \\
\hline 17.0 & High & 0.53 & $\begin{array}{l}\text { T w/o creep } \\
\text { rupture }\end{array}$ \\
\hline 7.0 & Medium & 0.196 & B and D \\
\hline 3.0 & Low & $2.71 \mathrm{E}-3$ & $\begin{array}{l}\text { A1, A2, C, and T } \\
\text { w/ creep rupture }\end{array}$ \\
\hline
\end{tabular}




\section{Other BE Quantified in a Variety of Ways}

\begin{tabular}{|l|l|l|l|}
\hline Basic Event & Description & Comments & Prob. \\
\hline CVFLOODSYS & $\begin{array}{l}\text { RPV cavity } \\
\text { flooding system } \\
\text { fails }\end{array}$ & $\begin{array}{l}\text { passive system consisting of } \\
\text { drain lines and restricting } \\
\text { orifices to direct water into } \\
\text { cavity (engineering analysis) }\end{array}$ & $1.65 \mathrm{E}-2$ \\
\hline FLNGFAIL & $\begin{array}{l}\text { Reactor Cavity } \\
\text { Access Tube } \\
\text { Blind Flange } \\
\text { Failed by Debris }\end{array}$ & $\begin{array}{l}\text { Failure probability depends on } \\
\text { whether or not water is present } \\
\text { on opposite side of flange (PDS } \\
\text { dependent) }\end{array}$ & $\begin{array}{l}\text { (wet) } \\
\text { (wOT) }\end{array}$ \\
\hline HOTLEGFAIL & $\begin{array}{l}\text { Induced failure } \\
\text { (thermal creep) } \\
\text { of RCS Hot Leg }\end{array}$ & $\begin{array}{l}\text { CPMAAP analysis (RCS initially } \\
\text { intact, SRV not stuck open) }\end{array}$ & 0.402 \\
\hline
\end{tabular}




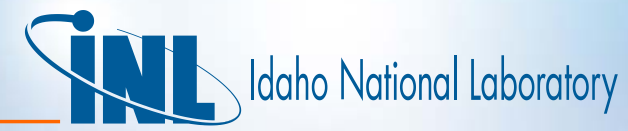

\section{BE Quantification (cont.)}

\begin{tabular}{|l|l|l|l|}
\hline Basic Event & Description & Comments & Prob. \\
\hline SEALLOCA & $\begin{array}{l}\text { Induced failure of } \\
\text { RCP seals }\end{array}$ & $\begin{array}{l}\text { Probability based on } \\
\text { CEOG tests }\end{array}$ & $1 \mathrm{E}-3$ \\
\hline VFTIMELONG & $\begin{array}{l}\text { Time to Vessel } \\
\text { Failure sufficiently } \\
\text { long to ensure low } \\
\text { RCS pressure when } \\
\text { lower RV head fails }\end{array}$ & $\begin{array}{l}\text { Various potential } \\
\text { failure mechanisms } \\
\text { analyzed along with } \\
\text { likelihood of } \\
\text { necessary conditions }\end{array}$ & $\begin{array}{l}\text { Depend on } \\
\text { RCS pressure } \\
\text { and whether } \\
\text { cavity is flooded } \\
\text { or dry (see next } \\
\text { slide) }\end{array}$ \\
\hline
\end{tabular}




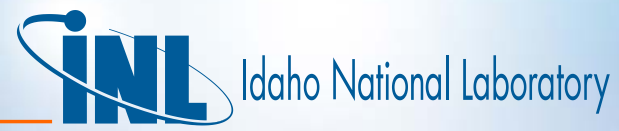

\section{VFTIMELONG - Probability Estimates}

\begin{tabular}{|l|l|l|}
\hline & \multicolumn{2}{|l|}{ Containment System Status } \\
\hline PDS Initiator & $\begin{array}{l}\text { P or Q } \\
\text { (Cavity Flooded) }\end{array}$ & $\begin{array}{l}\text { R, S, V or W } \\
\text { (Cavity Dry) }\end{array}$ \\
\hline A1 & 0.99 & 0.95 \\
A2 & 0.99 & 0.95 \\
B & 0.74 & 0.27 \\
C & 0.99 & 0.95 \\
D & 0.50 & 0.05 \\
T (w/ induced failure) & 0.75 & 0.56 \\
T (w/o induced failure) & 0.00 & 0.00 \\
\hline
\end{tabular}




\section{Values for each basic event documented for every PDS}

PDS DESCRIPTOB - TEIP COMPLETED BY:_RGChris=ie PDS_EROS $=9.400 E-06$ REVIEWED BY :

ZATE - $03 / 27 . \pm 2$ RDS DEPENDENT BASTC EVENTS -

$\begin{array}{lllll}\text { ISLOCA } & -\frac{0.0}{10} & \text { LBLOCA } & -0.0 & \text { MBLOCA } \\ \text { SBLOCA } & -\underline{0.0} & \text { SGTR } & -0.0 & \text { TRANSIENT }-1.0 \\ \text { CSP } & -0.0 & \text { CAC } & -0.0 & \text { SECONDCOOL }-1.0 \\ \text { SIRWT } & -1.0 & \text { SILATE } & -0.0 & \end{array}$

RECOVERY BASIC EYENTS -

$\begin{aligned} \text { CACRECOV } & =0.0 .0 \text { CSPRECOV }=\frac{0.0}{0.0} \text { SECCLLREOV }=\frac{0.0}{\text { CSPRECIV }}\end{aligned}$

OPERATOR ACTION BASIC WYEHTS -

OPDEPRESS $=0.0$

RHENOMENOLOGICAL BASIC BVENTS -

\begin{tabular}{|c|c|c|c|c|c|}
\hline $\mathrm{CF}$ & 0 & FLAMMGAS1 & 0.00 & PORVS & 5149 \\
\hline VFLRFAIL & $=$ & FLAMMGASZ & $=$ & PRMTRUENCH & 25 \\
\hline VITYFAIL & 0.0215 & FLNGFAIL & 0.005 & PZSRVFTC & 0.475 \\
\hline VSMPDRNS & 1.000 & FRACMSLBIC & 0.0002 & REVAPTMNG & 1.000 \\
\hline VT & 0.001 & FRACMSLBOC & 0.0001 & RLFVLVOPEN & 0.0 \\
\hline s & 0. & HOTLEGFAIL & 0.402 & SEALLOCA & 0.002 \\
\hline 1 & 20 & INVSLSTEXP & 0.0001 & SECVLVOPEN & 1.000 \\
\hline ICATKTMG2 & $=$ & INVS & 0.00792 & SGTUBE & 0.0034 \\
\hline (D) & 0.050 & MSLBPRESS & 0.00087 & SIFLOWPATH & 1.000 \\
\hline 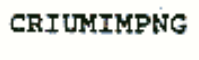 & $=$ & MSI & 0.050 & FTMSPIXE & 0.178 \\
\hline$P 1$ & 0. & MV504SPP & 2.000 & SURGEFAIL & 0.025 \\
\hline (2) & 50 & NATCONV & 0.500 & VFTIMELONG & 0.750 \\
\hline sys & 0.0165 & NCCVDBCNFG & 0.25 & VSSLHTXFR & 0.900 \\
\hline H & 0.00992 & NCUCDBCNFG & 0.050 & VSSLIMPNG & 0.001 \\
\hline . & & RESS & 0.730 & VSSLTHRUS & 0.00005 \\
\hline LS: & Q. & TENS & & & \\
\hline
\end{tabular}




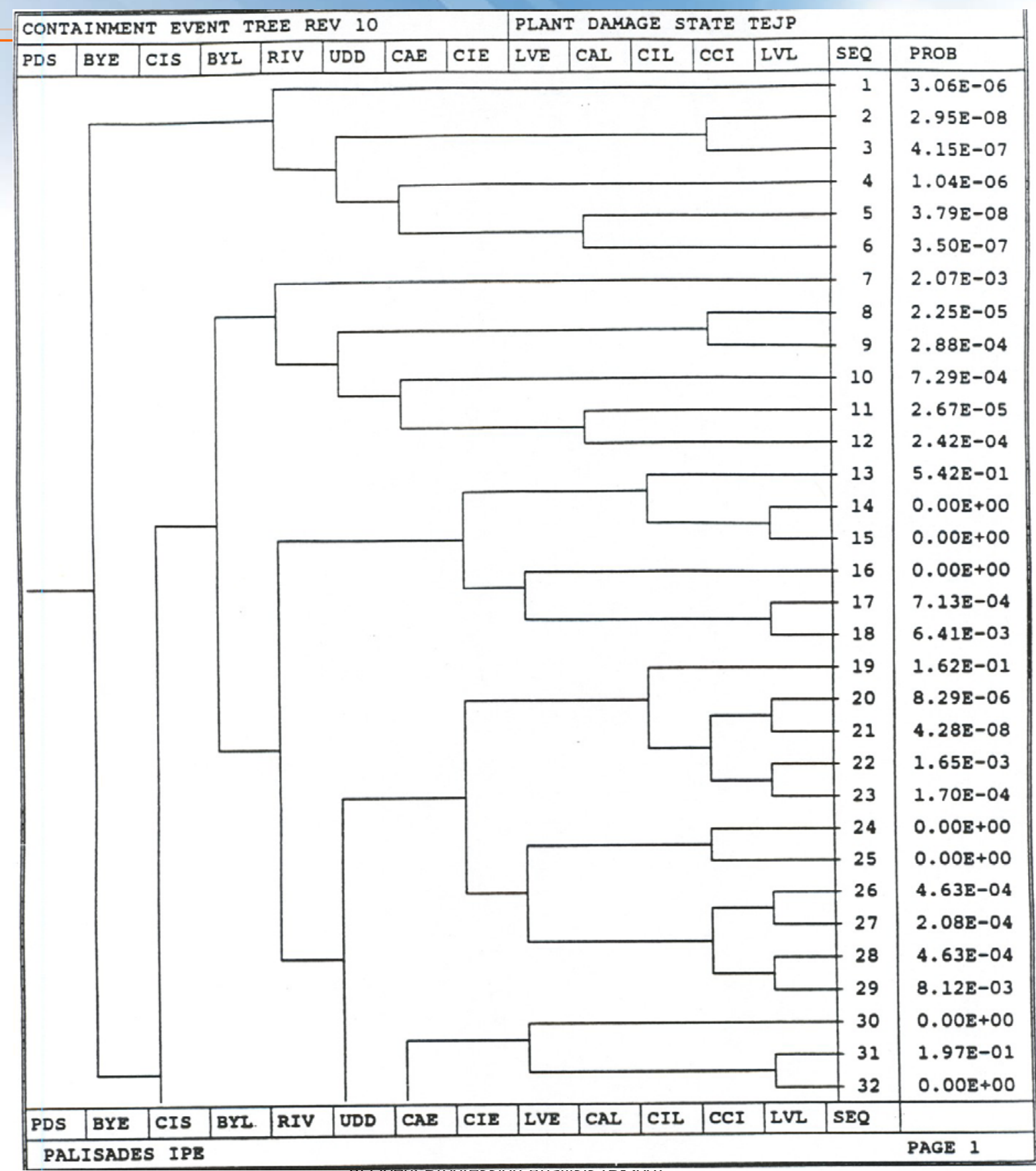

ho National Laboratory 


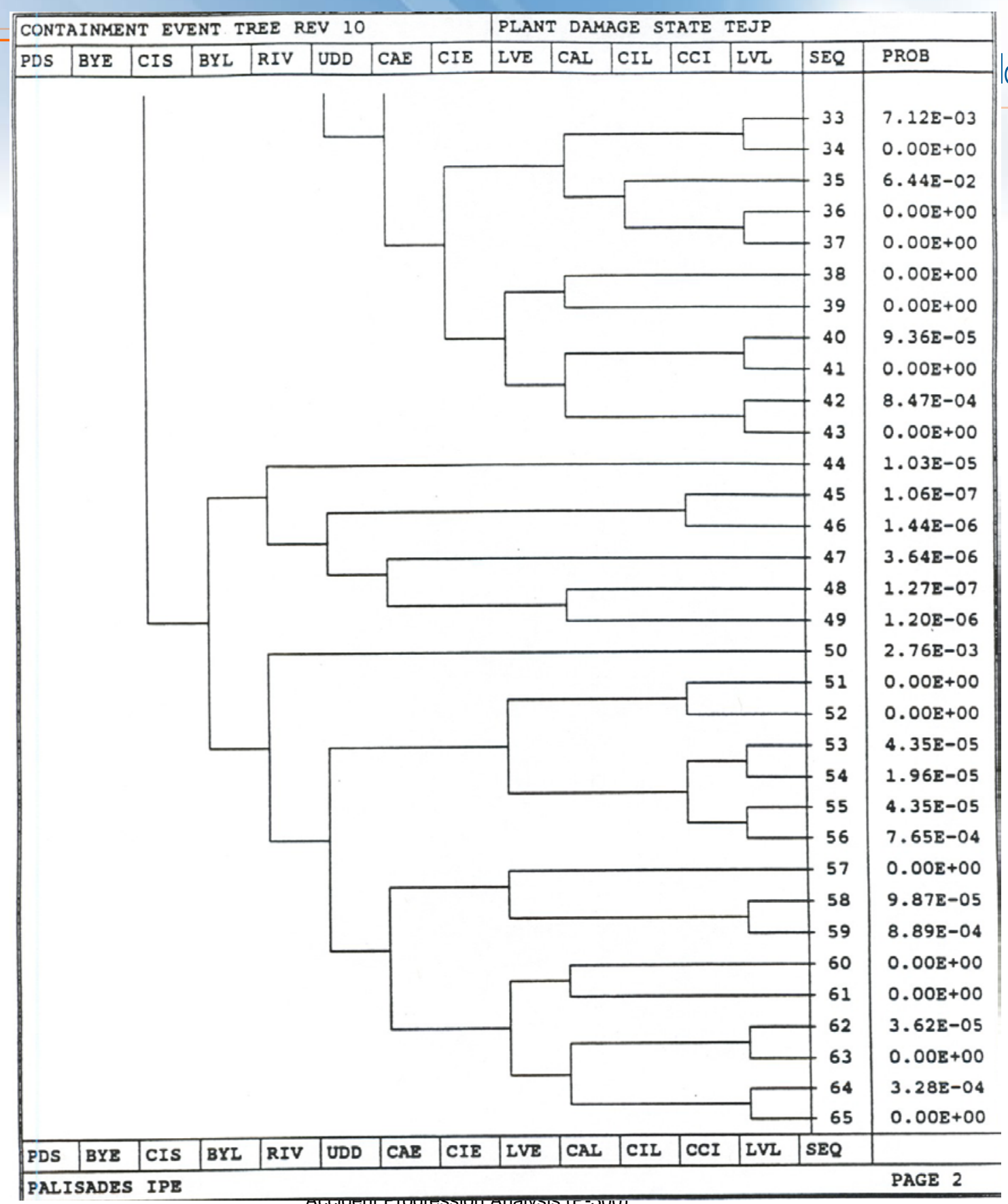

aho National Laboratory 


\section{CET Quantified for Each PDS (18)}

- For each PDS:

- CET basic events quantified

- CET fault trees quantified

- CET end states (65) quantified

- Generates a 18 x 65 matrix

- CET end state frequencies summed over 18 PDS

- Total frequency of each containment-state/source-term

- Source terms generated for each of the 65 CET end states

- CPMAAP (Consumers Power version of MAAP) 


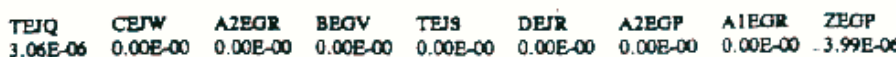

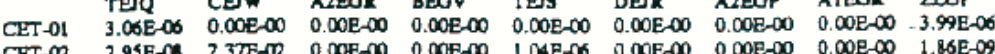

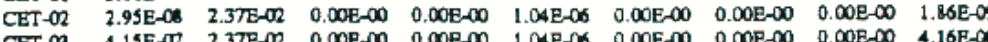
CET- -93 4.1SE-

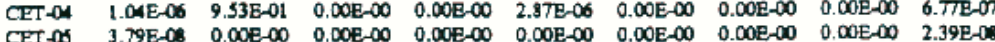

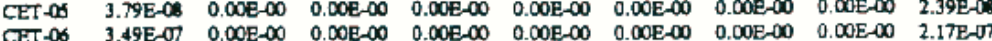

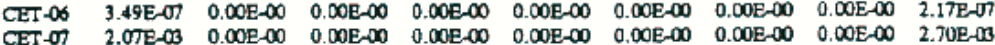
CET- 0 2.7.0.

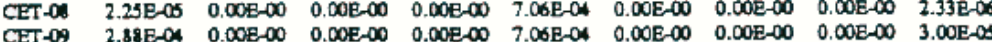

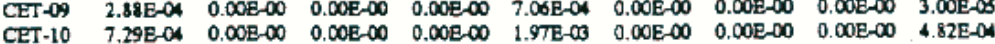

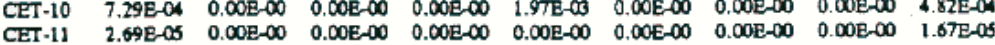

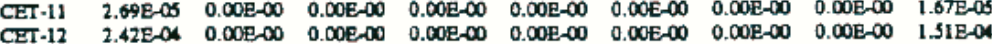

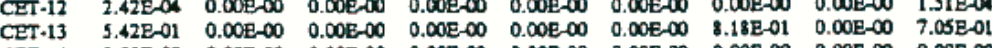

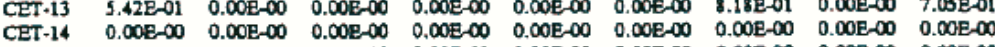

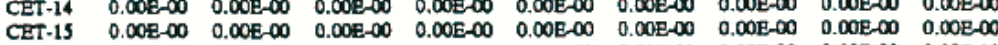
$\begin{array}{llllllllll}\text { CET } 16 & 0.00 E-\infty & 0.00 E-\infty & 0.00 E-\infty & 0.00 E-\infty & 0.00 E-\infty & 0.00 E-\infty & 0.00 E-\infty & 0.00 E-\infty & 0.00 E-\infty\end{array}$ $\begin{array}{llllllllll}\text { CET } 17 & 7.13 E-04 & 0.00 E-\infty & 0.00 E-00 & 0.00 E-00 & 0.00 E-00 & 0.00 E-\infty & 9.20 E-\infty & 0.00 E-\infty & 4.17 E-\infty\end{array}$ $\begin{array}{llllllllll}\text { CET-18 } & 6.41 \mathrm{E}-03 & 0.00 \mathrm{E}-\infty & 0.00 \mathrm{E}-00 & 0.00 \mathrm{E}-00 & 0.00 \mathrm{E}-0 & 0.00 \mathrm{E}-00 & 8.28 \mathrm{E}-03 & 0.00 \mathrm{E}-00 & 8.26 \mathrm{E}-03\end{array}$ $\begin{array}{llllllllll}\text { CET.19 } & 1.48 \mathrm{E}-01 & 0.00 \mathrm{E}-00 & 4.12 \mathrm{E}-02 & 0.00 \mathrm{E}-00 & 4.01 \mathrm{E}-01 & 7.83 \mathrm{E}-01 & 7.62 \mathrm{E}-03 & 0.00 \mathrm{E}-\infty & 9.34 \mathrm{E}-02\end{array}$

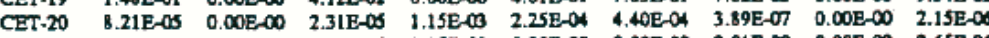
$\begin{array}{llllllllll}\text { CET-21 4.28E- } & 0.00 \mathrm{E}-\infty & 0.00 \mathrm{E}-\infty & 1.15 \mathrm{E}-03 & 0.00 \mathrm{E}-\infty & 0.00 \mathrm{E}-\infty & 2.01 \mathrm{E}-09 & 0.00 \mathrm{E}-\infty & 2.65 \mathrm{E}-\infty\end{array}$ $\begin{array}{llllllllll}C E T \cdot 22 & 1.63 \mathrm{E}-02 & 0.00 \mathrm{E}-00 & 4.60 \mathrm{E}-03 & 2.28 \mathrm{E}-01 & 4.48 \mathrm{E}-02 & 8.76 \mathrm{E}-02 & 7.74 \mathrm{E}-05 & 0.00 \mathrm{E}-00 & 4.27 \mathrm{E}-04\end{array}$

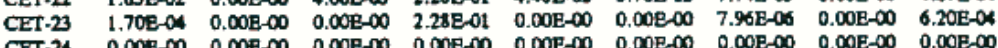

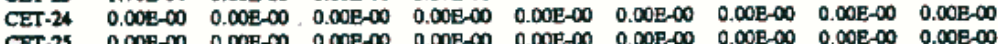

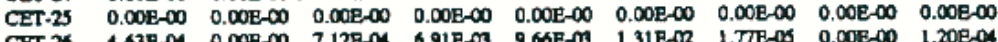

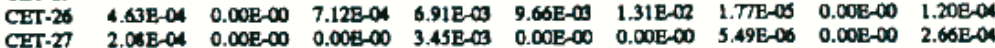

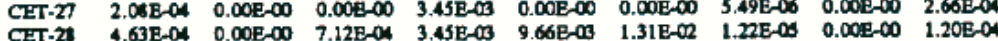
$\begin{array}{llllllllll}C E T-29 & 3.12 \mathrm{E}-03 & 0.00 \mathrm{E}-00 & 0.00 \mathrm{E}-00 & 3.45 \mathrm{E}-03 & 0.00 \mathrm{E}-00 & 0.00 \mathrm{E}-00 & 2.15 \mathrm{E}-04 & 0.00 \mathrm{E}-\infty & 4.32 \mathrm{E}-03\end{array}$ $\begin{array}{llllllllllll}C \text { CET-30 } & 0.00 \mathrm{E}-00 & 0.00 \mathrm{E}-00 & \mathbf{3} .15 \mathrm{E}-01 & 2.37 \mathrm{E}-01 & 2.37 \mathrm{E}-01 & 0.00 \mathrm{E}-00 & 0.00 \mathrm{E}-00 & 3.55 \mathrm{E}-01 & 0.00 \mathrm{E}-00\end{array}$

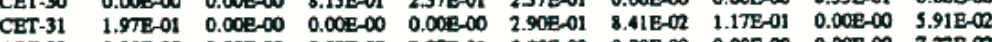
$\begin{array}{lllllllllll}\text { CET-32 } & 0.00 \mathrm{E}-\infty & 0.00 \mathrm{E}-00 & 0.00 \mathrm{E}-\infty & \mathbf{2} .37 \mathrm{E}-01 & 0.00 \mathrm{E}-\infty & 0.00 \mathrm{E}-00 & 0.00 \mathrm{E}-\infty & 0.00 \mathrm{E}-\infty & 7.22 \mathrm{E}-0\end{array}$ $\begin{array}{llllllllll}\text { CET-33 } & 7.16 \mathrm{E}-03 & 0.00 \mathrm{E}-00 & 1.32 \mathrm{E}-02 & 2.4 \mathrm{EE}-02 & 0.00 \mathrm{E}-00 & 1.37 \mathrm{E}-03 & 2.22 \mathrm{E}-03 & 1.38 \mathrm{E}-02 & 2.03 \mathrm{E}-0 \mathrm{3}\end{array}$

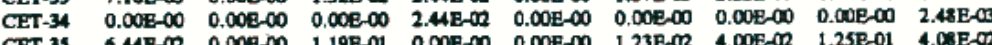

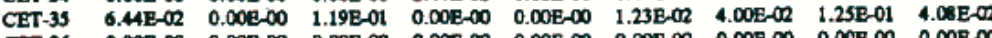
$\begin{array}{llllllllll}\text { CET-36 } & 0.00 E-00 & 0.00 E-D 0 & 0.00 E-00 & 0.00 E-10 & 0.00 E-\infty 0 & 0.00 E-00 & 0.00 E-\infty & 0.00 E-00 & 0.00 E-00\end{array}$ $\begin{array}{llllllllll}\text { CET-37 } & 0.00 \mathrm{E}-0 & 0.00 \mathrm{E}-00 & 0.00 \mathrm{E}-00 & 0.00 \mathrm{E}-0 & 0.00 \mathrm{E}-00 & 0.00 \mathrm{E}-00 & 0.00 \mathrm{E}-\infty & 0.00 \mathrm{E}-00 & 0.00 \mathrm{E}-\mathrm{D}\end{array}$

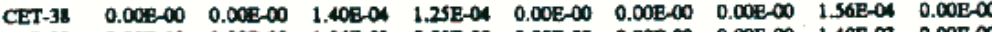
$\begin{array}{llllllllll}\text { CET-39 } & 0.00 \mathrm{E}-\infty & 0.00 \mathrm{E}-\infty & 1.26 \mathrm{E}-03 & 0.00 \mathrm{E}-\infty & 0.00 \mathrm{E}-00 & 0.00 \mathrm{E}-\infty & 0.00 \mathrm{E}-\infty & 1.40 \mathrm{E}-03 & 0.00 \mathrm{E}-\mathrm{O}\end{array}$

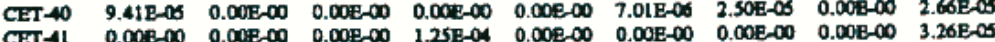
$\begin{array}{llllllllll}C E T A & 0.00 E-\infty & 0.00 E-\infty & 0.00 E-\infty & 1.25 E-04 & 0.00 E-\infty & 0.00 E-\infty & 0.00 E-\infty & 0.00 E-\infty & 3.26 E-05\end{array}$

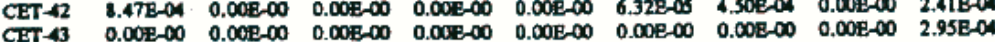

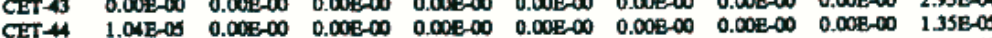

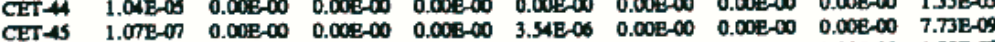
CET 46 1. CET $\rightarrow$ 17 CET 4 S

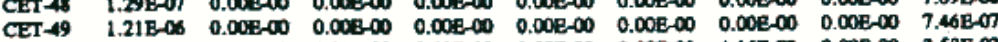

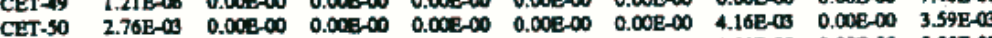

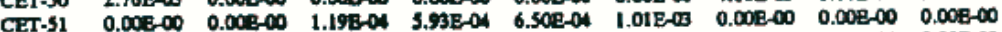

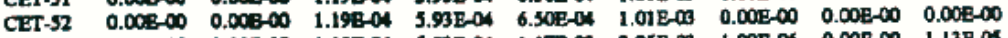

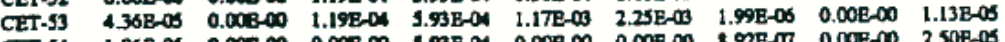

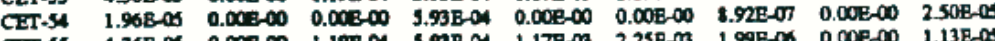

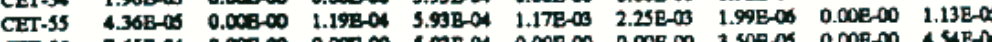

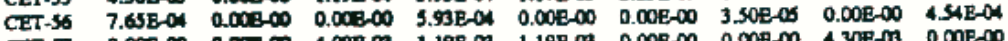

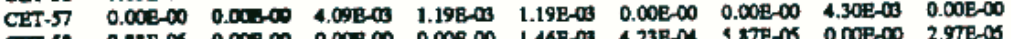

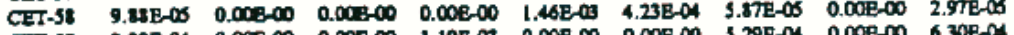
$\begin{array}{lllllllllll}C E T-59 & 8.89 \mathrm{E}-04 & 0.00 \mathrm{E}-00 & 0.006-00 & 1.19 \mathrm{E}-03 & 0.00 \mathrm{E}-00 & 0.00 \mathrm{E}-00 & 3.29 \mathrm{E}-04 & 0.00 \mathrm{E}-00 & 6.30 \mathrm{E}-\mathrm{A}\end{array}$

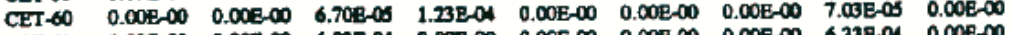

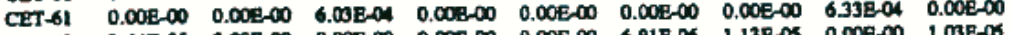

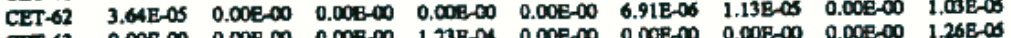
$\begin{array}{llllllllll}\text { CET-63 } & 0.00 E-00 & 0.00 E-\infty & 0.00 E-00 & 1.23 E-04 & 0.00 E-\infty & 0.00 E-00 & 0.00 E-00 & 0.00 E-00 & 1.26 \mathrm{E}-06\end{array}$

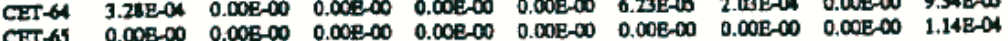
AprII $\angle U \perp \supset$

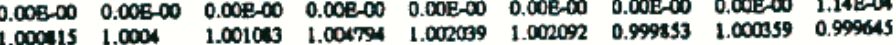

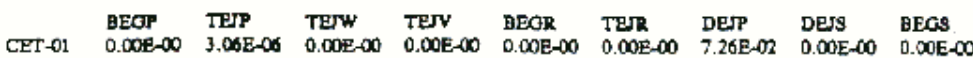

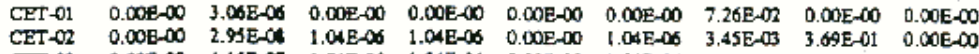

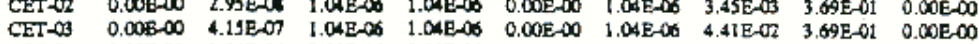

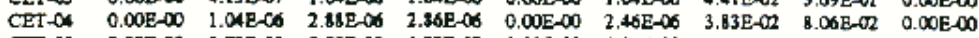

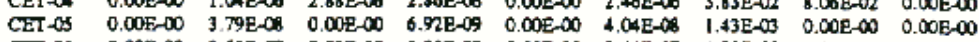

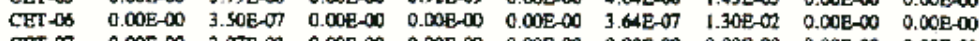

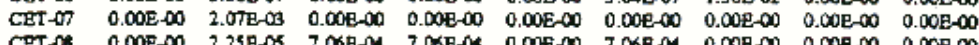

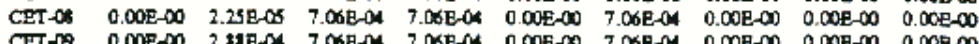

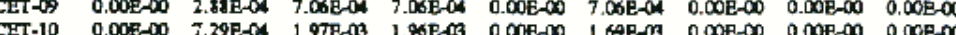

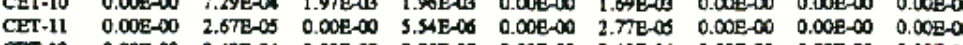
$\begin{array}{llllllllll}\text { CET }-12 & 0.00 E-\infty & 2.42 \mathrm{E}-04 & 0.00 \mathrm{E}-00 & 0.00 \mathrm{E}-\infty & 0.00 \mathrm{E}-\infty & 2.49 \mathrm{E}-04 & 0.00 \mathrm{E}-\infty & 0.00 \mathrm{E}-\infty & 0.00 \mathrm{E}-\infty\end{array}$

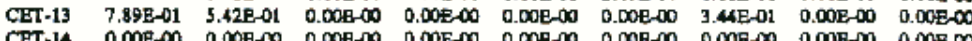

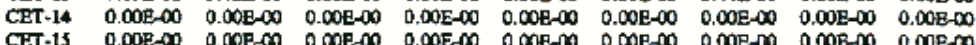

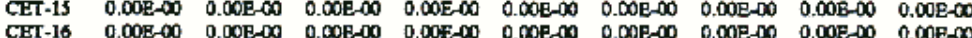
CET.17 2.48E- 24 7. $\begin{array}{llllllllll}C \text { CET-18 } & 4.72 \mathrm{E}-03 & 0.41 \mathrm{E}-03 & 0.00 \mathrm{E}-\infty & 0.00 \mathrm{E}-\infty & 0.00 \mathrm{E}-\infty & 0.00 \mathrm{E}-\infty & 1.59 \mathrm{E}-\mathrm{M} & 0.00 \mathrm{E}-\infty & 0.00 \mathrm{E}-\infty\end{array}$

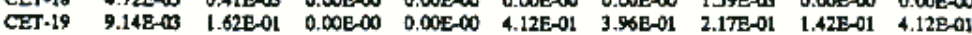

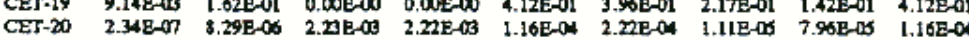

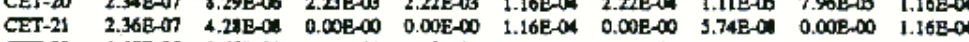
$\begin{array}{llllllllll}C E T-22 & 4.65 \mathrm{E}-0 \mathrm{~S} & 1.65 \mathrm{E}-03 & 4.44 \mathrm{E}-01 & 4.42 \mathrm{E}-01 & 2.30 \mathrm{E}-02 & 4.43 \mathrm{E}-02 & 2.21 \mathrm{E}-03 & 1.58 \mathrm{E}-03 & 2.30 \mathrm{E}-02\end{array}$ $\begin{array}{llllllllll}C E T-23 & 5.00 E-05 & 1.70 \mathrm{E}-04 & 0.00 \mathrm{E}-00 & 0.00 \mathrm{E}-00 & 2.30 \mathrm{E}-02 & 0.00 \mathrm{E}-00 & 2.27 \mathrm{E}-04 & 0.00 \mathrm{E}-00 & 2.30 \mathrm{E}-\mathrm{OP}\end{array}$ $\begin{array}{llllllllll}\text { CET-24 } & 0.00 \mathrm{E}-\infty & 0.00 \mathrm{E}-\infty & 0.00 \mathrm{E}-\infty & 0.00 \mathrm{E}-\infty & 0.00 \mathrm{E}-\infty & 0.00 \mathrm{E}-0 & 0.00 \mathrm{E}-\infty & 0.00 \mathrm{E}-00 & 0.00 \mathrm{E}-\infty\end{array}$ $\begin{array}{lllllllllll}\text { CET-25 } & 0.00 E-00 & 0.00 \mathrm{E}-00 & 0.00 \mathrm{E}-0 & 0.00 \mathrm{E}-\infty & 0.00 \mathrm{E}-00 & 0.00 \mathrm{E}-00 & 0.00 \mathrm{E}-00 & 0.00 \mathrm{E}-00 & 0.00 \mathrm{E}-00\end{array}$

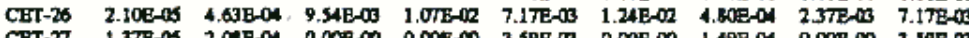

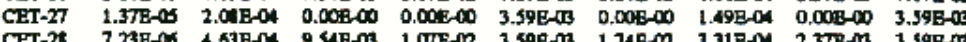

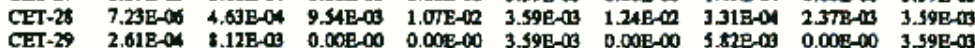

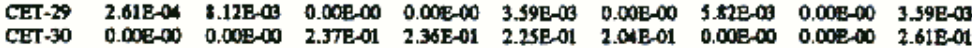

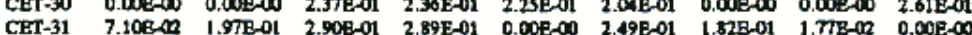

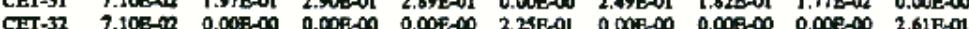

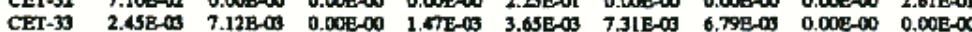
$\begin{array}{lllllllllll}\text { CET-34 2.45E- } 03 & 0.00 E-\infty & 0.00 E-\infty & 0.00 E-\infty & 3.65 \mathrm{E}-1 \mathrm{~S} & 0.00 \mathrm{E}-\infty & 0.00 \mathrm{E}-\infty & 0.00 \mathrm{E}-\infty & 0.00 \mathrm{E}-\infty\end{array}$ $\begin{array}{llllllllll}C E T-35 & 4.43 E-02 & 6.44 \mathrm{E}-02 & 0.00 \mathrm{E}-00 & 0.00 \mathrm{E}-\infty & 6.58 \mathrm{E}-02 & 6.53 \mathrm{E}-02 & 6.14 \mathrm{E}-02 & 0.00 \mathrm{E}-00 & 0.00 \mathrm{E}-00\end{array}$ $\begin{array}{lllllllllll}\text { CET-36 } & 0.00 E-\infty & 0.008-00 & 0.00 E-00 & 0.00 E-\infty & 0.00 E-00 & 0.00 E-\infty & 0.00 E-\infty & 0.00 E-\infty & 0.00 B-00\end{array}$

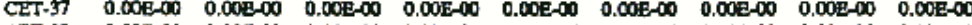

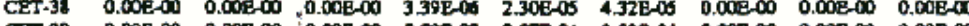

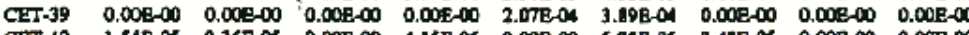

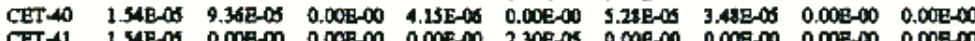

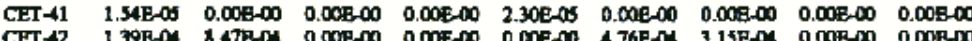
CETA2 1.39ECET-4 CET $-450.00 E-\infty)$

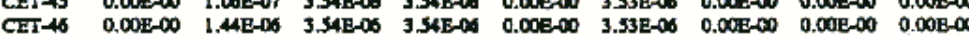

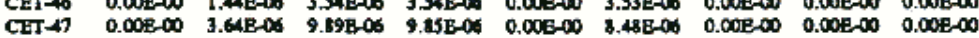

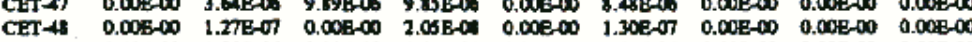

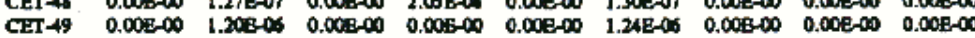

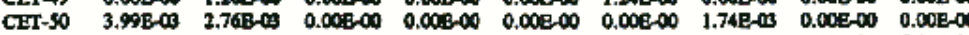

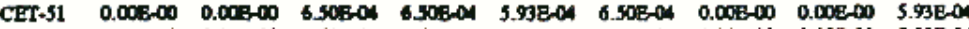

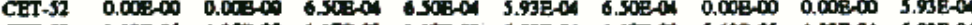

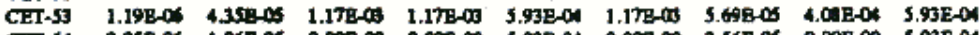

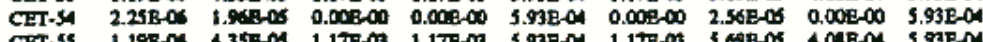

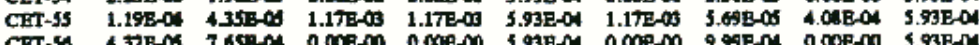

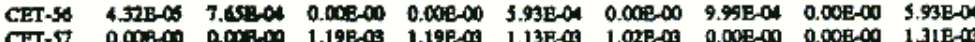
CET-S7 $0.00 \mathrm{E}$ CETS $6.73 \mathrm{E}-0$.

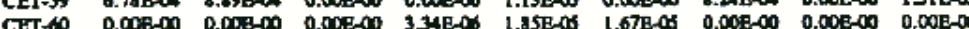

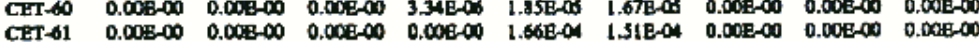

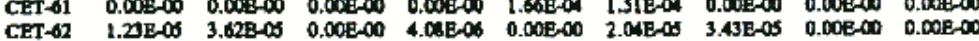

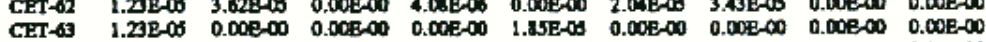

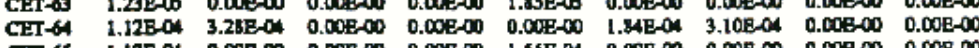

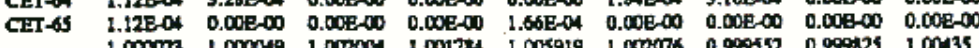




\begin{tabular}{|l|l|l|}
\hline $\begin{array}{l}\text { CET } \\
\text { ES }\end{array}$ & $\begin{array}{l}\text { Aggregated } \\
\text { Freq (lyr) }\end{array}$ & Important PDS Contributors \\
\hline 1 & $1.20 E-8$ & DEJP(100\%a) \\
2 & $8.47 E-7$ & DEJS(99\%) \\
3 & $8.53 E-7$ & DEJS(99\%) \\
4 & $4.18 E-7$ & CEJW(55\%) DEJS(44\%) \\
$10^{b}$ & $4.44 E-8$ & TEJW(39\%) TEJV(29\%) TEJP(15\%) TEJR(9\%) \\
18 & $1.54 E-7$ & BEGP(40\%) TEJP(36\%) ZEGP(22\%) \\
22 & $7.31 E-6$ & TEJW(53\%) TEJV(40\%) \\
23 & $1.43 E-7$ & BEGR(46\%) BEGV(36\%) BEGS(11\%) ZEGP(5\%) \\
26 & $2.29 E-7$ & TEJW(36\%) TEJV(30\%) TEJR(13\%) BEGR(7\%) \\
28 & $2.15 E-7$ & TEJW(39\%) TEJV(33\%) TEJR(14\%) BEGR(4\%) \\
29 & $1.18 E-7$ & TEJP(65\%) ZEGP(25\%) BEGR(4\%) \\
30 & $5.43 E-6$ & TEJW(36\%) TEJV(27\%) BEGR(14\%) TEJR(8\%) A2EGR(4\%) BEGS(4\%) \\
31 & $8.25 E-6$ & TEJW(30\%) TEJV(23\%) TEJP(22\%) BEGP(11\%) TEJR(7\%) ZEGP(3\%) \\
32 & $2.01 E-6$ & BEGP(40\%) BEGR(34\%) ZEGP(13\%) BEGS(10\% \\
33 & $1.54 E-7$ & TEJP(40\%) BEGP(20\%) TEJR(10\%) BEGR(8\%) TEJV(6\%) ZEGP(5\%) \\
$57^{c}$ & $2.73 E-8$ & TEJW(36\%) TEJV(27\%) BEGR(14\%) TEJR(8\%) \\
\hline total & $2.62 E-5$ & Sum of dominant CET ES \\
& $2.68 E-5$ & Total containment failure frequency \\
\hline
\end{tabular}
a. Contribution to ES frequency
b. Containment bypass
c. Containment isolation failure 


\section{NIIdoho Naional laboridory}

\section{Source Terms Calculated Using CPMAAP}

- 41 cases selected for CPMAAP analysis

- various combinations of PDS and CET-ES from list of dominant contributors to containment failure

- For example:

- DEJP-01 - SGTR with recovery in-vessel

- DEJS-02 - SGTR with stuck open secondary SRV, upward debris dispersal and $\mathrm{CCl}$ in upper containment

- CEJW-04 - ISLOCA outside containment

- TEJW-10 - Blackout with creep induced SGTR

- A1EGR-30 - LBLOCA with core to aux early and a large volatile release early

- BEGP-31 - SBLOCA with core to aux early and late revaporization form aux building and $\mathrm{CCl}$ in aux bldg 


\begin{tabular}{|c|c|c|}
\hline $\begin{array}{l}\text { CET } \\
\text { ES }\end{array}$ & $\begin{array}{l}\text { Aggregated } \\
\text { Freq (/yr) }\end{array}$ & Important PDS Contributors \\
\hline $\begin{array}{l}1 \\
2 \\
3 \\
4 \\
10^{\mathrm{b}} \\
18 \\
22 \\
23 \\
26 \\
28 \\
29 \\
30 \\
31 \\
32 \\
33 \\
57^{c}\end{array}$ & $\begin{array}{l}1.20 \mathrm{E}-8 \\
8.47 \mathrm{E}-7 \\
8.53 \mathrm{E}-7 \\
4.18 \mathrm{E}-7 \\
4.44 \mathrm{E}-8 \\
1.54 \mathrm{E}-7 \\
7.31 \mathrm{E}-6 \\
1.43 \mathrm{E}-7 \\
2.29 \mathrm{E}-7 \\
2.15 \mathrm{E}-7 \\
1.18 \mathrm{E}-7 \\
5.43 \mathrm{E}-6 \\
8.25 \mathrm{E}-6 \\
2.01 \mathrm{E}-6 \\
1.54 \mathrm{E}-7 \\
2.73 \mathrm{E}-8\end{array}$ & $\begin{array}{l}\text { DEJP(100\%a) } \\
\text { DEJS(99\%) } \\
\text { DEJS(99\%) } \\
\text { CEJW(55\%) DEJS(44\%) } \\
\text { TEJW(39\%) TEJV(29\%) TEJP(15\%) TEJR(9\%) } \\
\text { BEGP(40\%) TEJP(36\%) ZEGP(22\%) } \\
\text { TEJW(53\%) TEJV(40\%) } \\
\text { BEGR(46\%) BEGV(36\%) BEGS(11\%) ZEGP(5\%) } \\
\text { TEJW(36\%) TEJV(30\%) TEJR(13\%) BEGR(7\%) } \\
\text { TEJW(39\%) TEJV(33\%) TEJR(14\%) BEGR(4\%) } \\
\text { TEJP(65\%) ZEGP(25\%) BEGR(4\%) } \\
\text { TEJW(36\%) TEJV(27\%) BEGR(14\%) TEJR(8\%) A2EGR(4\%) BEGS(4\%) } \\
\text { TEJW(30\%) TEJV(23\%) TEJP(22\%) BEGP(11\%) TEJR(7\%) ZEGP(3\%) } \\
\text { BEGP(40\%) BEGR(34\%) ZEGP(13\%) BEGS(10\% } \\
\text { TEJP(40\%) BEGP(20\%) TEJR(10\%) BEGR(8\%) TEJV(6\%) ZEGP(5\%) } \\
\text { TEJW(36\%) TEJV(27\%) BEGR(14\%) TEJR(8\%) }\end{array}$ \\
\hline total & $\begin{array}{l}2.62 \mathrm{E}-5 \\
2.68 \mathrm{E}-5\end{array}$ & $\begin{array}{l}\text { Sum of dominant CET ES } \\
\text { Total containment failure frequency }\end{array}$ \\
\hline
\end{tabular}
a. Contribution to ES frequency
b. Containment bypass
c. Containment isolation failure 


\section{Calculated Source Terms from CPMAAP (examples)}

\begin{tabular}{|l|l|l|l|l|l|l|l|l|l|l|l|l|}
\hline PDS-ES & $\begin{array}{l}\text { Nob } \\
\text { el } \\
\text { Gas }\end{array}$ & I & Cs & Te & Sr & Mo & La & Ce & Ba & $\begin{array}{l}\text { Time } \\
\text { of } \\
\text { releas } \\
\text { e (hr) }\end{array}$ & $\begin{array}{l}\text { Warni } \\
\text { ng } \\
\text { Time } \\
\text { (hr) }\end{array}$ & $\begin{array}{l}\text { Relea } \\
\text { se } \\
\text { Durati } \\
\text { on } \\
\text { (hr) }\end{array}$ \\
\hline $\begin{array}{l}\text { DEJP- } \\
01\end{array}$ & 0.03 & 0.01 & 0.01 & $<1 \mathrm{E}-5$ & $6 \mathrm{E}-5$ & $3 \mathrm{E}-5$ & $4 \mathrm{E}-6$ & $1 \mathrm{E}-5$ & $6 \mathrm{E}-4$ & 25 & 3.6 & 2.0 \\
\hline $\begin{array}{l}\text { DEJS- } \\
\text { 22 }\end{array}$ & 0.97 & 0.30 & 0.29 & $1 \mathrm{E}-3$ & $1 \mathrm{E}-3$ & 0.04 & $3 \mathrm{E}-5$ & $1 \mathrm{E}-5$ & 0.01 & 27 & 5.7 & 2.0 \\
\hline $\begin{array}{l}\text { DEJS- } \\
\text { 03 }\end{array}$ & 0.97 & 0.30 & 0.29 & $1 \mathrm{E}-3$ & $1 \mathrm{E}-3$ & 0.04 & $3 \mathrm{E}-5$ & $1 \mathrm{E}-5$ & 0.01 & 27 & 5.7 & 2.0 \\
\hline $\begin{array}{l}\text { CEJW- } \\
\text { 04 }\end{array}$ & 1.0 & 0.92 & 0.92 & 0.45 & 0.03 & 0.25 & 0.01 & $4 \mathrm{E}-4$ & 0.10 & 1.3 & 0.9 & 2.0 \\
\hline $\begin{array}{l}\text { A2EGR- } \\
\text { 32 }\end{array}$ & 0.49 & 0.02 & 0.02 & $<1 \mathrm{E}-5$ & $2 \mathrm{E}-4$ & $8 \mathrm{E}-3$ & $<1 \mathrm{E}-5$ & $<1 \mathrm{E}-5$ & $2 \mathrm{E}-3$ & 4.0 & 3.0 & 1.0 \\
\hline
\end{tabular}

Typically, multiple PDSs selected for each ES/CPMAAP calculation with "worstcase" eventually selected to represent particular CET-ES. 


\title{
Accident Progression Analysis (P-300)
}

\author{
11. NUREG/CR-6595, Rev.1
}




\section{Session Objectives}

- To understand the simple LERF analysis approach developed under NRC sponsorship

- NUREG/CR-6595, Rev. 1, Oct. 2004

- An Approach for Estimating the Frequencies of Various Containment Failure Modes and Bypass Events 


\section{NUREG/CR-6595 Approach}

- Simplified approach to supplement Level-1 PRA used in risk-informed decision-making

- Relies upon Level-1 information to estimate containment failure frequencies

- Aimed at Regulatory Guide 1.174 acceptance guidelines

- Quick, approximate estimate of LERF for screening against 1.174 guidelines 


\section{Containment Failure Modes}

- Early structural failure

- Containment bypass

- Containment isolation failure

- Late structural failure

- Containment venting 


\section{LERF Models developed for PWRs and BWRs}

- PWRs with a large volume containment

- PWRs with an ice condenser containment

- BWRs with a Mark I containment

- BWRs with a Mark II containment

- BWRs with a Mark III containment 


\section{CET from NUREG/CR-6595 (LERF)}

- Focus is on early loss of containment integrity

- Includes 5 CETs:

- PWR large dry (and subatmospheric), and ice condenser containments

- BWR Mark-I, Mark-II and Mark-II containments

- Simplified, high-level models intended to provide reasonable, somewhat bounding estimates of LERF for most plants

- first step in scoping study for comparing plant-specific analysis to RG-1.174 acceptance criteria 


\section{LERF CET for PWR Large Dry Containment}

- Also encompasses subatmospheric containments

- Both rely on large volumes and relatively high design pressures to mitigate consequences

- Initiating Event is Core Damage (CD) - Frequency and characteristics of $C D$ sequences from Level-1 analysis

- Most split fractions determined from Level-1 PRA supplemented by additional analysis and information

- Generic estimates provided only for probability of early containment failure 


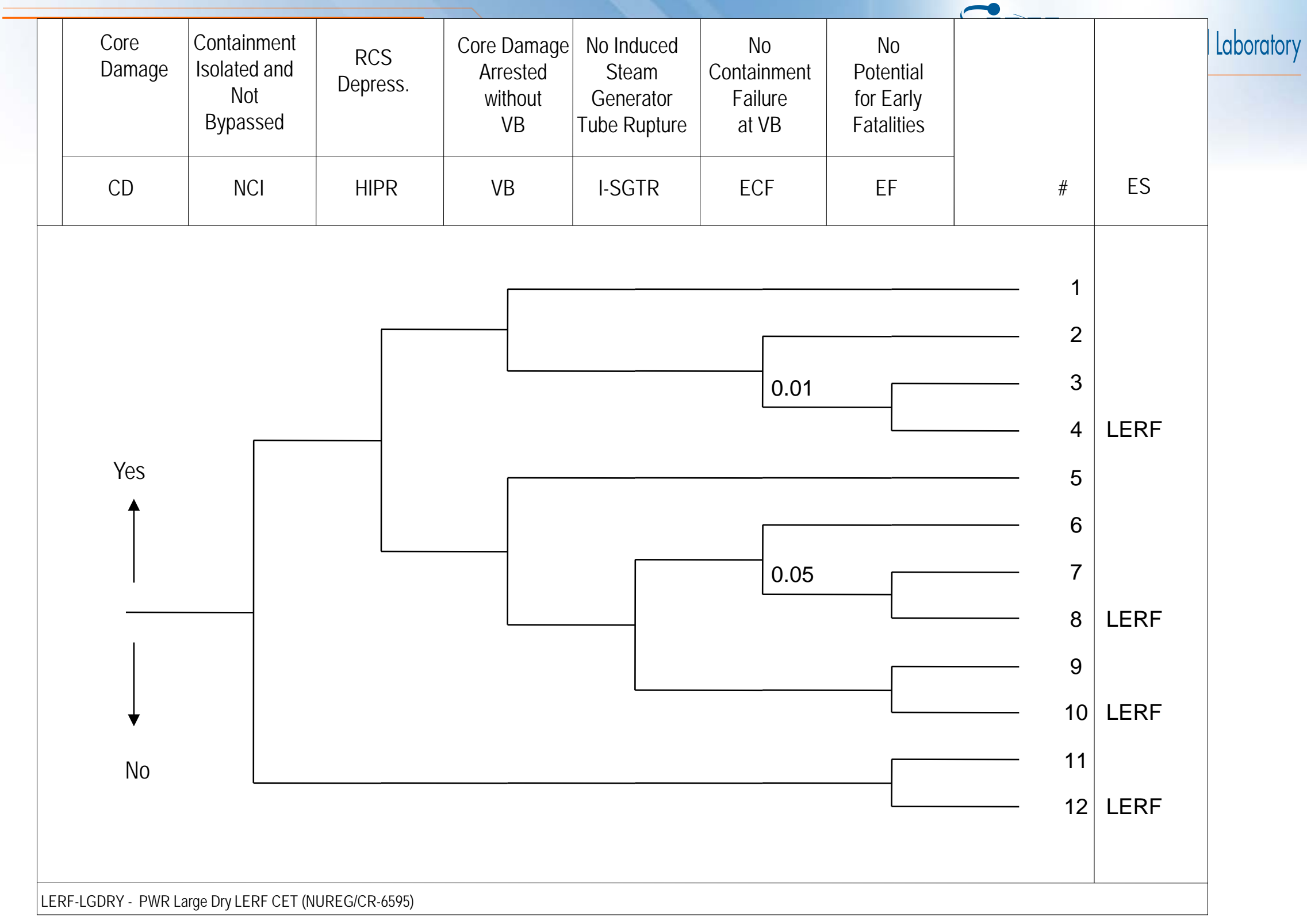




\section{$\mathrm{NCI}$ - No Containment Isolation (Nor Containment Bypass)}

- Includes:

- Failure of containment to isolate

- Interfacing system LOCA

- SGTR Initiating Event

- ATWS (pressure-)induced SGTR or RCS pipe failure

- Loss of containment heat removal

- i.e., containment failure before core damage

- Quantified using Level-1 information 


\section{HIPR - RCS Not Depressurized}

- Top event identifies pressure in reactor vessel at time of core damage (for subsequent evaluation of likelihood of containment failure)

- Dependent on

- Level-1 initiating event (i.e., small LOCA - RCS at high pressure, medium and large LOCAs - RCS at low pressure)

- Likelihood of operator initiating depressurization

- Likelihood of temperature-induced RCS pressure boundary failure after core damage 


\section{IIIt}

\section{VB - Vessel Breach}

- Addresses possibility of recovery of coolant injection after uncovery of top of active fuel (i.e., Level-1 CD state) but before vessel failure

- Recovery of electric power - typically based on probability of recovering offsite power (Level-1 analysis)

- Depressurization of RCS by operators - if low pressure systems are available 


\section{TII Idaho National laboratory}

\section{I-SGTR - Induced Steam Generator Tube Rupture}

- Creep failure (thermally induced) of SG tubes during core oxidation

- Depends on status of S/G secondary side

- Not likely if steam-side remains pressurized

- Typically assessed with plant-specific calculations that track relevant phenomena and compute creep damage to multiple RCS components to determine likely failure point

- Surge line, hot leg, S/G tube failures all possible 


\section{ECF - Early Containment Failure}

- Containment failure at vessel breach, depends on:

- RCS pressure

- Amount and temp. of core debris exiting vessel

- Size of hole in vessel

- Amount of water in cavity

- Configuration in cavity

- Operability of containment sprays

- Structural capacity of containment building

- In simplified treatment, only RCS pressure explicitly considered 


\section{ECF - Low Pressure RCS}

- ECF given Low Pressure Vessel Failure Includes:

- In-vessel steam explosion

- Rapid steam generation from core debris contacting water in the cavity

- Hydrogen combustion

- Conditional probability of ECF estimated at 0.01

- based on previous PRAs 


\section{ECF - High Pressure RCS}

- ECF given high pressure vessel failure Includes:

- High Pressure Melt Ejection (HPME)

- Direct Containment Heating (DCH)

- Hydrogen combustion

- In-vessel steam explosions (less likely compared to low pressure RCS case)

- Conditional probability of ECF estimated at 0.05

- based on previous PRA and research 


\section{EF - Early Fatalities}

- Given loss of containment integrity

- depends on magnitude and timing of radionuclide release

- Sequence-specific (timing of start of core damage, vessel failure)

- CET path specific (timing of containment failure)

- Plant/site-specific (timing of declaration of site emergency, initiation of evacuation, and time needed for evacuation) 


\section{(ind}

\section{Example Core Damage Sequence}

- Transient IE with failure of all secondary side cooling (AFW \& MFW), success of feed and bleed, but failure of recirculation from containment sump

- Sequence \#30 (see next slide)

- Sequence frequency = 1E-6/year 


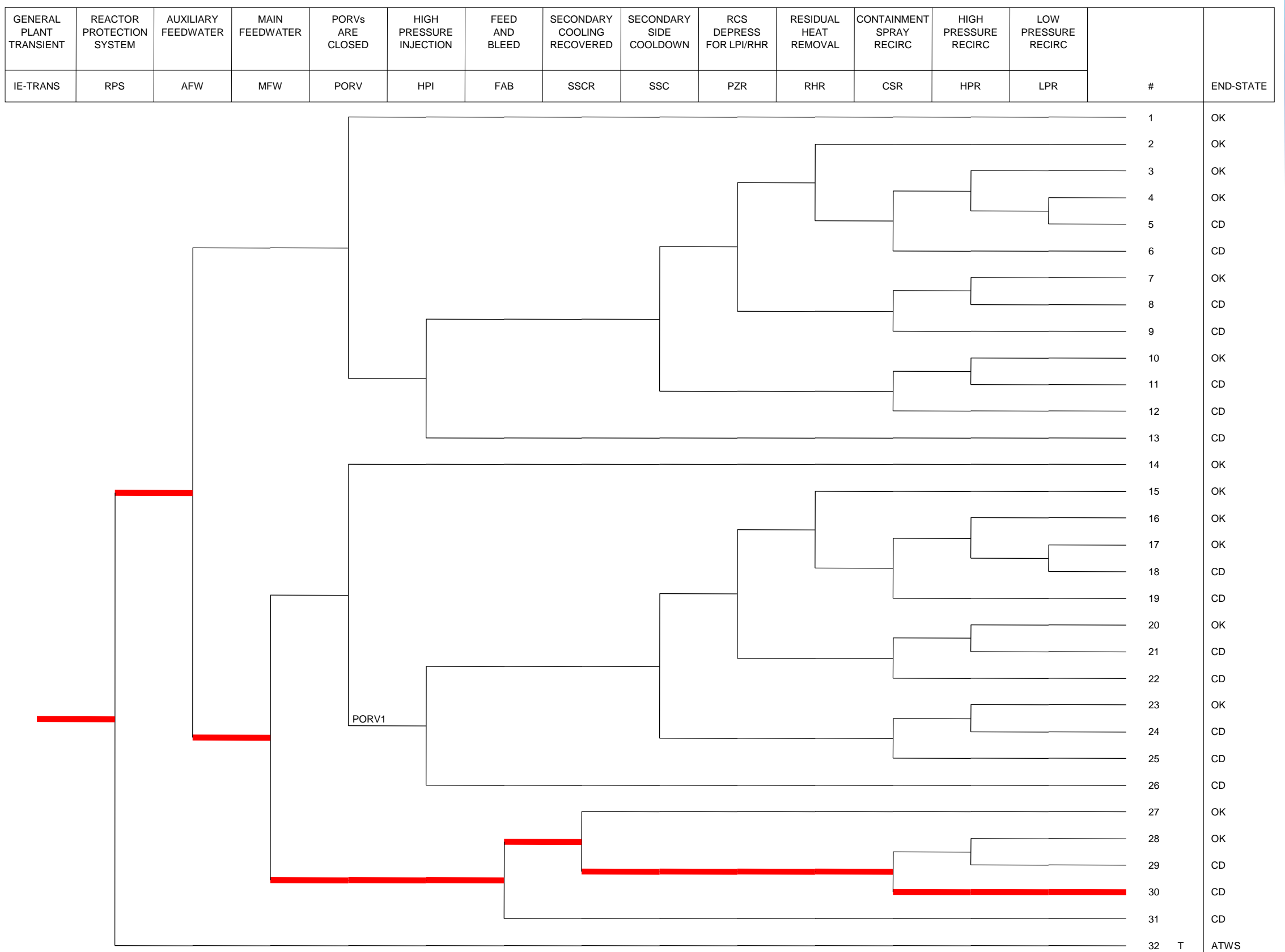




\section{Analyze CD Sequence for LERF}

Failure ID - Success event description

$\mathrm{NCl}$ - Containment isolated and not bypassed

HIPR - RCS depressurized

VB - Core damage arrested without vessel breach

I-SGTR - No induced steam generator tube rupture

ECF - No containment failure at vessel breach

EF - No potential for early fatalities 


\section{$\mathrm{NCl}$ - Containment Not-Isolated or Bypassed}

- Two issues to address

- Is initiating event a bypass

- Does containment isolation fail

- Transient - Not a bypass IE

- Containment Isolation

- Addressed by system model (fault tree)

- Signal to isolate containment (auto/manual)

- Hardware success

- Assume fault tree model yields $P_{\text {fail }}=0.01$ 


\section{HIPR - RCS Not Depressurized}

- Two considerations

- Effects of IE and subsequent plant response

- Transient - RCS at high pressure (at least initially)

- Subsequent plant response

- Secondary side cooling fails

- Feed and bleed cooling success

- RCS not depressurized

- Possible induced failure of reactor coolant pressure boundary (RCPB) 


\section{HIPR - RCS Remains at High Press.}

- Severe accident progression can induce a failure of the reactor coolant pressure boundary before CD

- In order of likelihood

- Surge line failure

- Hot leg failure

- Induced SGTR

- This event does NOT include I-SGTR (considered later)

- CD sequence determined, operator initiated, and induced surge line or hot let failures

- Addressed through T/H code calculations

- Assume analysis results in an induced RCS failure probability estimate of $25 \%$

- Therefore, $\mathrm{P}(\mathrm{HIPR})=0.75$ 


\section{VB - CD Not Arrested Before VB}

- System analysis issue

- Primarily for loss of offsite power sequences

- Recovering offsite power can recover coolant injection and/or core cooling

- Possibly recover (after start of CD) from hardware failures

- Non-safety coolant injection or core cooling options

- Assume probability of non-recovery $=0.9$ 


\section{I-SGTR - Induced SGTR}

- No secondary side cooling (secondary side depressurized) makes an ISGTR a concern

- SGTR can be either temperature-induced (creep) or pressureinduced (typically an ATWS issue)

- Dependent on state of SG tubes (flaws)

- Crack depth (\% through wall)

- Flaw size distributions vary greatly among plants and crack size difficult to determine

- Conditional probability of I-SGTR given HIPR (i.e., no other induced RCS failure or depressurization)

- I-SGTR is the worst case induced RCS failure

- Containment bypass

- Assume P(I-SGTR|HIPR) $=10 \%$ 


\section{ECF - Containment Failure at VB}

- Does containment structure survive loads resulting from vessel failure?

- Yes $=$ No large release

- No $=$ Potential for large release

- Depends on many factors

- Simplified (NUREG/CR-6595, Rev.1)

- Only depends on RCS pressure at VB

- Low Pressure RCS: ECF $=0.01$

- High Pressure RCS: ECF $=0.05$ 


\section{EF - Potential for Early Fatalities}

- Depends on magnitude and timing of release

- Typically comprises all early failures and bypass

- However, can discriminate on release size

- Threshold of greater than $2.5 \%$ to $10 \%$ iodine

- Requires estimation of source term

- Assume all early failures and bypass

- Split fraction $=1.0$ 


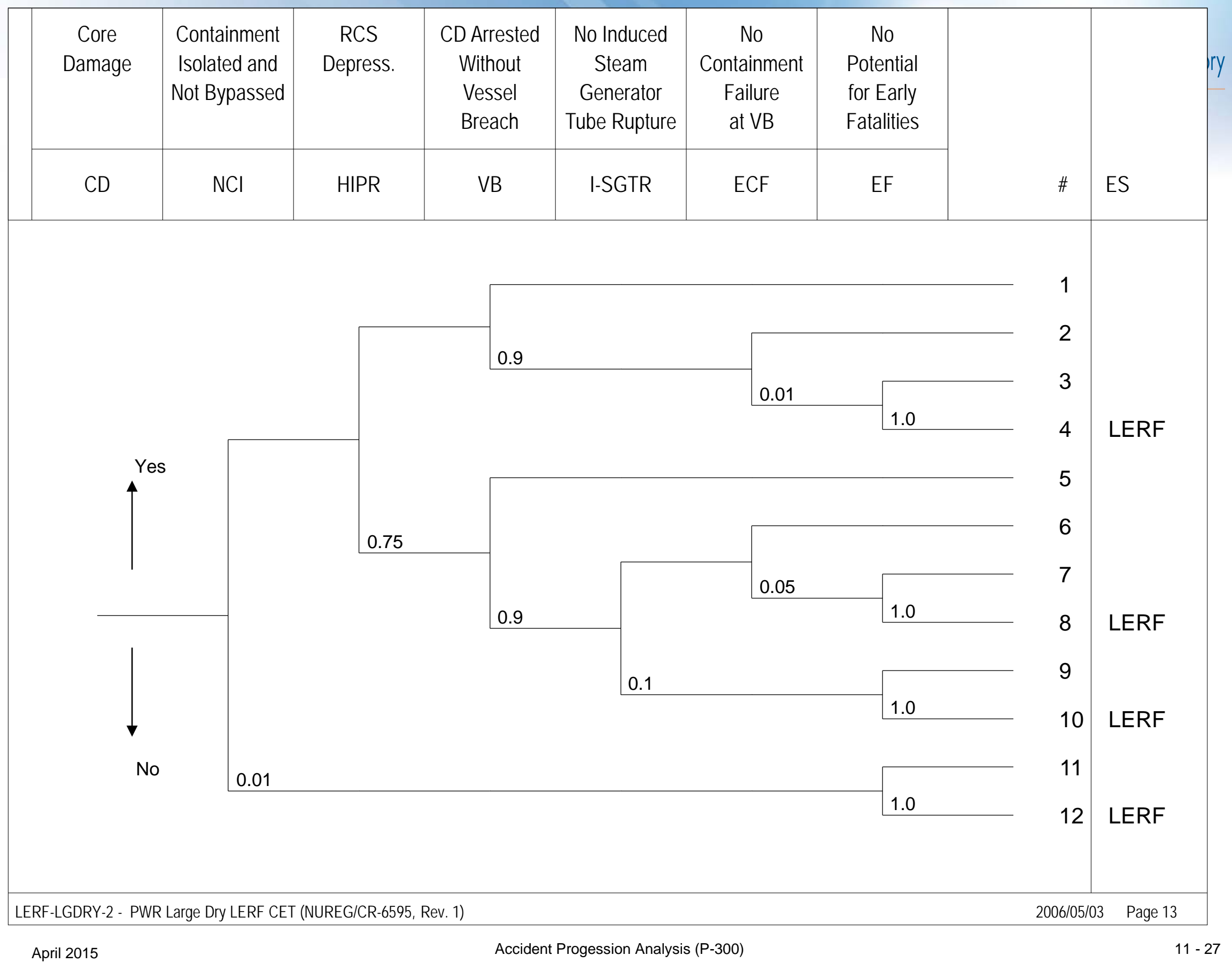




\section{LERF CET for PWR Ice Condenser Containment}

- Similar to that for large dry

- Additional top event for $\mathrm{H} 2$ igniters

- Initiating Event is Core Damage (CD) - Frequency and characteristics of $C D$ sequences from Level-1 analysis

- Most split fractions determined from Level-1 PRA supplemented by additional analysis and information

- Generic estimates provided only for probability of early containment failure 


\section{Most Top Events Same as Lg Dry}

- Core Damage

- Containment Isolated or Not Bypassed

- H2 Igniters - not in Lg Dry

- RCS Depressurized

- CD arrested before VB

- No I-SGTR

- No Cont. Failure at or before VB

- Treated differently from Lg Dry

- No Potential for Early Fatalities 


\section{H2 Igniters Operating Before TAF}

- Uncovering Top of Active Fuel results in oxidation of zircaloy clad releasing hydrogen

- Igniters require ac power

- Some plants might have dedicated backup power

- Igniters usually started manually

- Detailed system model - desired approach

- Availability of ac power and human action to actuate - reasonable approximation 


\section{Likelihood of Containment Failure Depends on Many Factors}

- RCS pressure

- Amount and temp of core debris exiting vessel

- Size of vessel failure

- Operability of containment sprays

- Operation of igniters

- Amount of ice at time of VB

- Amount of water in vessel cavity

- Configuration of cavity

- Structural strength of containment building 


\section{No Cont. Failure at or before VB}

- In simplified treatment only RCS pressure and igniters are explicitly accounted for

- If no Igniters and no VB then Prob. of $C F=0.04$

- i.e., prob. of CF before VB

- If igniters operating, no CF before VB

- If no igniters and

- VB at low pressure (non-DCH) then Prob. of CF $=0.97$

- VB at high pressure then Prob. of $\mathrm{CF}=1.0$ 


\section{No Cont. Failure at or before VB (cont.)}

- If igniters are operating, CF still possible from other causes

- VB at low pressure, prob. of CF $=0.01$

- In-vessel steam explosion

- Ex-vessel steam generation

- VB at high pressure, prob. of $\mathrm{CF}=0.05$

- HPME can result in direct impingement of corium on containment wall 


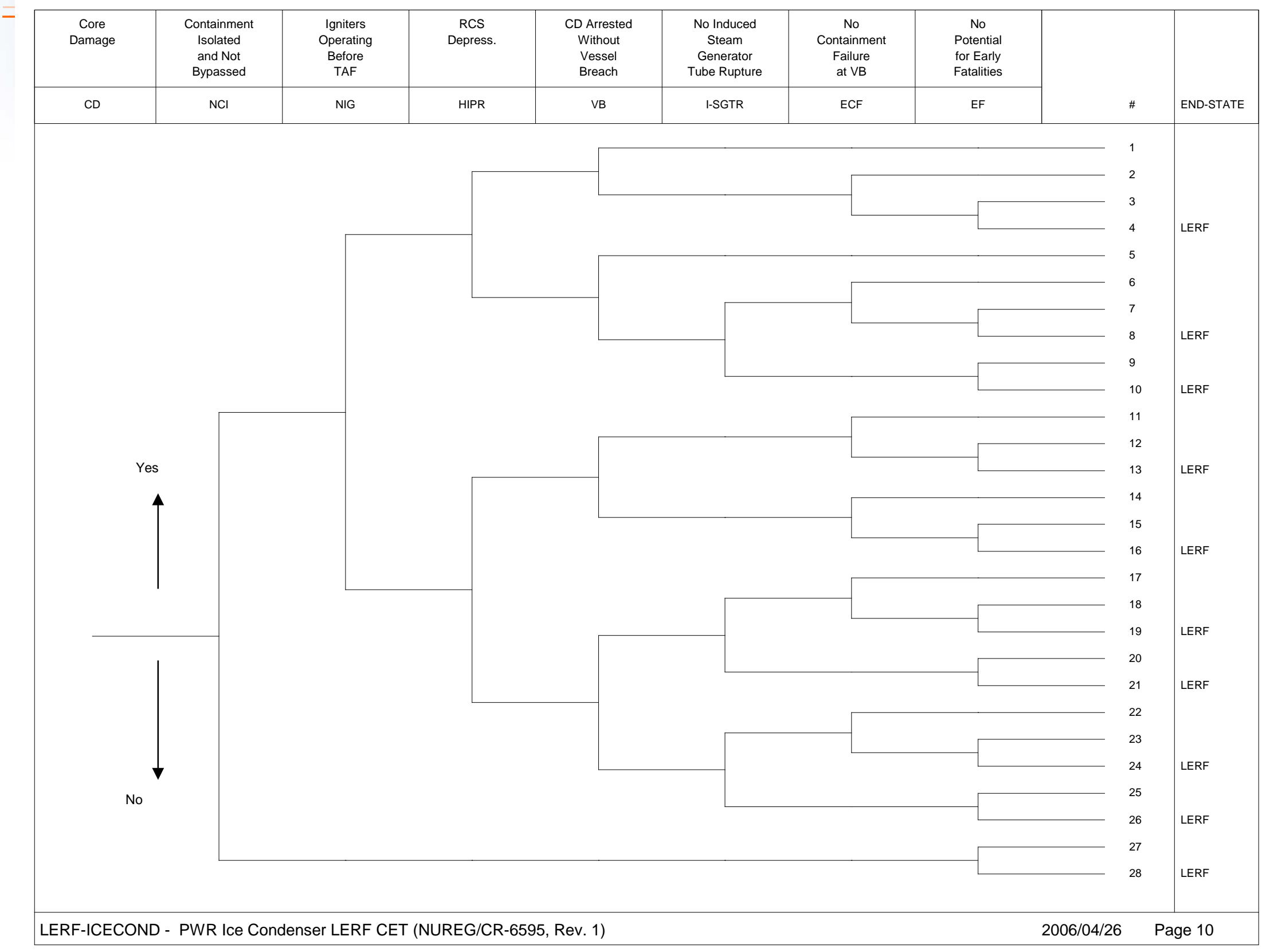




\section{PWR Late Containment Failure}

- To address accidents where evacuation not effective

- E.g., Seismic and high wind

- Considers only

- Core concrete interaction

- H2 combustion (Ice Condenser only)

- Basemat penetration not included

- Assumed to result in "small" release 


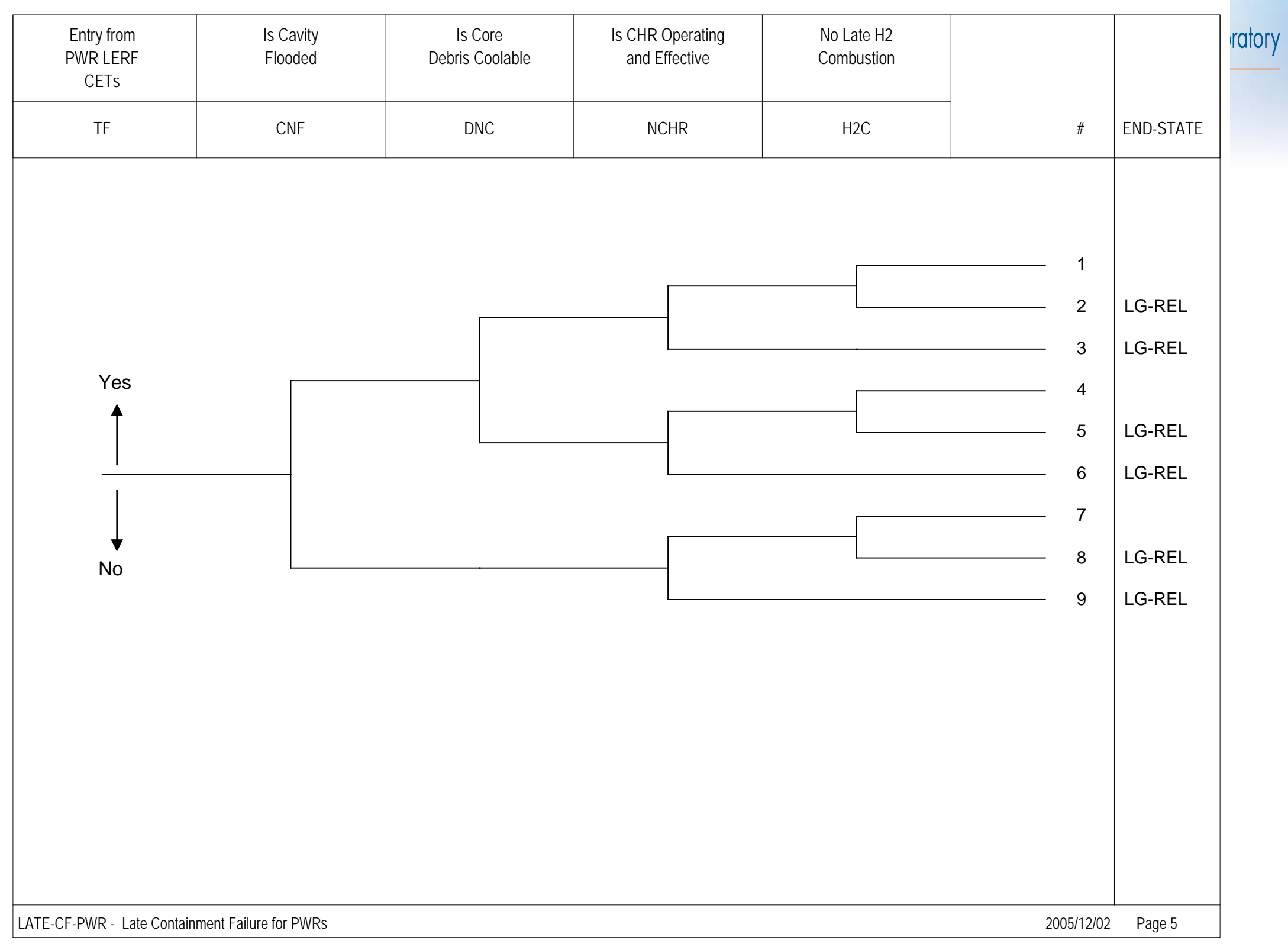




\section{Flooded Cavity}

- Core debris falling on a dry vs flooded cavity

- Flooded cavity produces steam

- Dry cavity results in core concrete interaction

- Produces noncondensibles

- Debris can be cooled in a flooded cavity if it is in a coolable geometry 


\section{Core Debris Coolable}

- Debris fragments (or forms very thin bed) then it is coolable - If coolable \& water available then steam is produced

- Not coolable or no water then $\mathrm{CCl}$ produces noncondensible and combustible gases 


\section{CHR Operating and Effective}

- Long-term operation of containment heat removal

- Containment sprays

- Two questions: Operating? Effective?

- If cavity is dry

- Then core concrete interaction produces noncondensible and combustible gases

- If CHR was operating, continued operation is questionable

- If cavity is flooded

- Is core debris coolable?

- Yes and CHR operating - then $\mathrm{CCl}$ does not occur and late CF prevented

- Yes but CHR not operating - then eventual CF probable

- No - then $\mathrm{CCl}$ occurs and CF probable 


\section{Late H2 Combustion}

- Applies only to Ice Condenser

- Are igniters available?

- Did H2 combustion occur early?

- If No and No

- Then CF (late H2 combustion) $=1.0$

- If igniters are available

- Then Late H2 Combustion $=0.0$ 


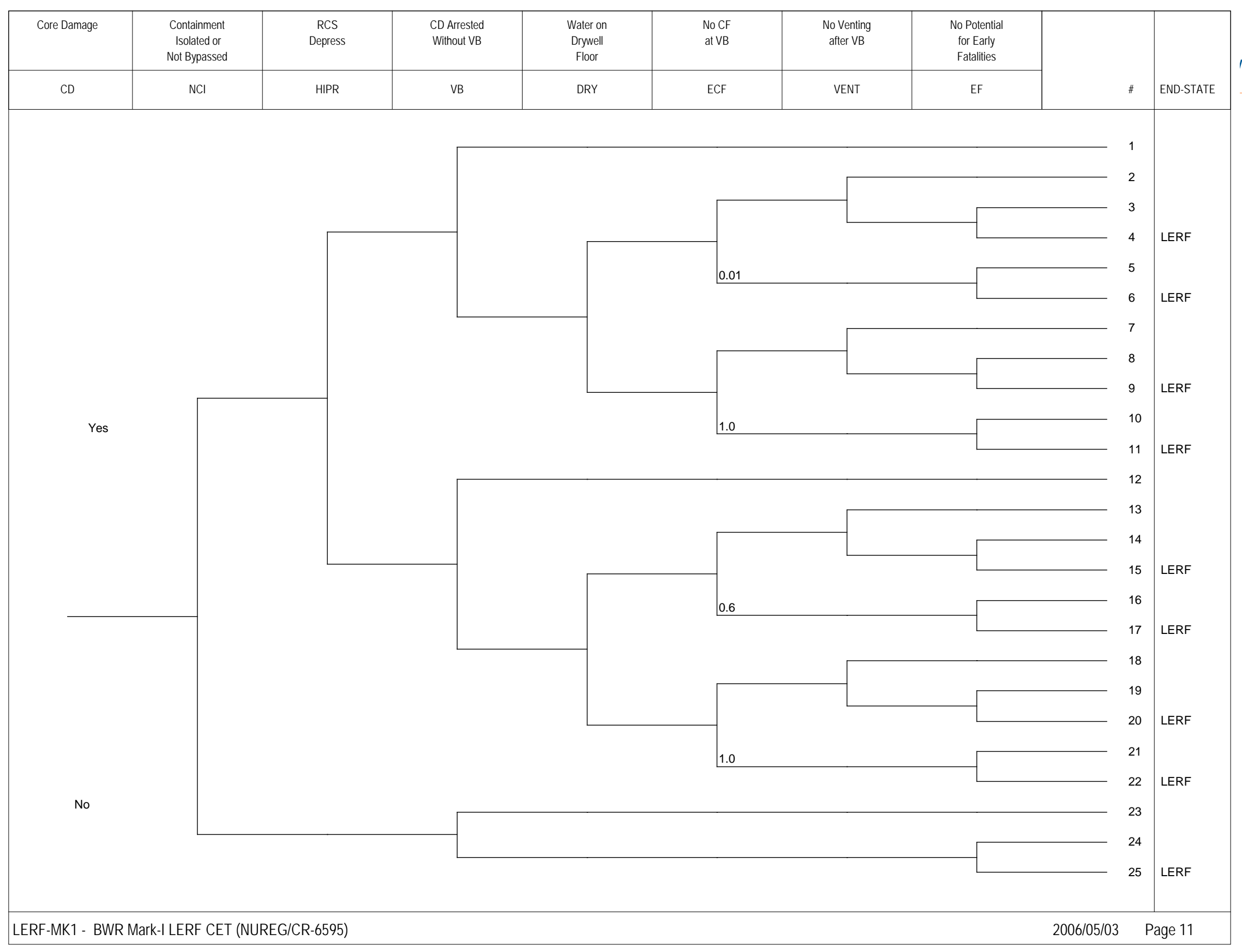




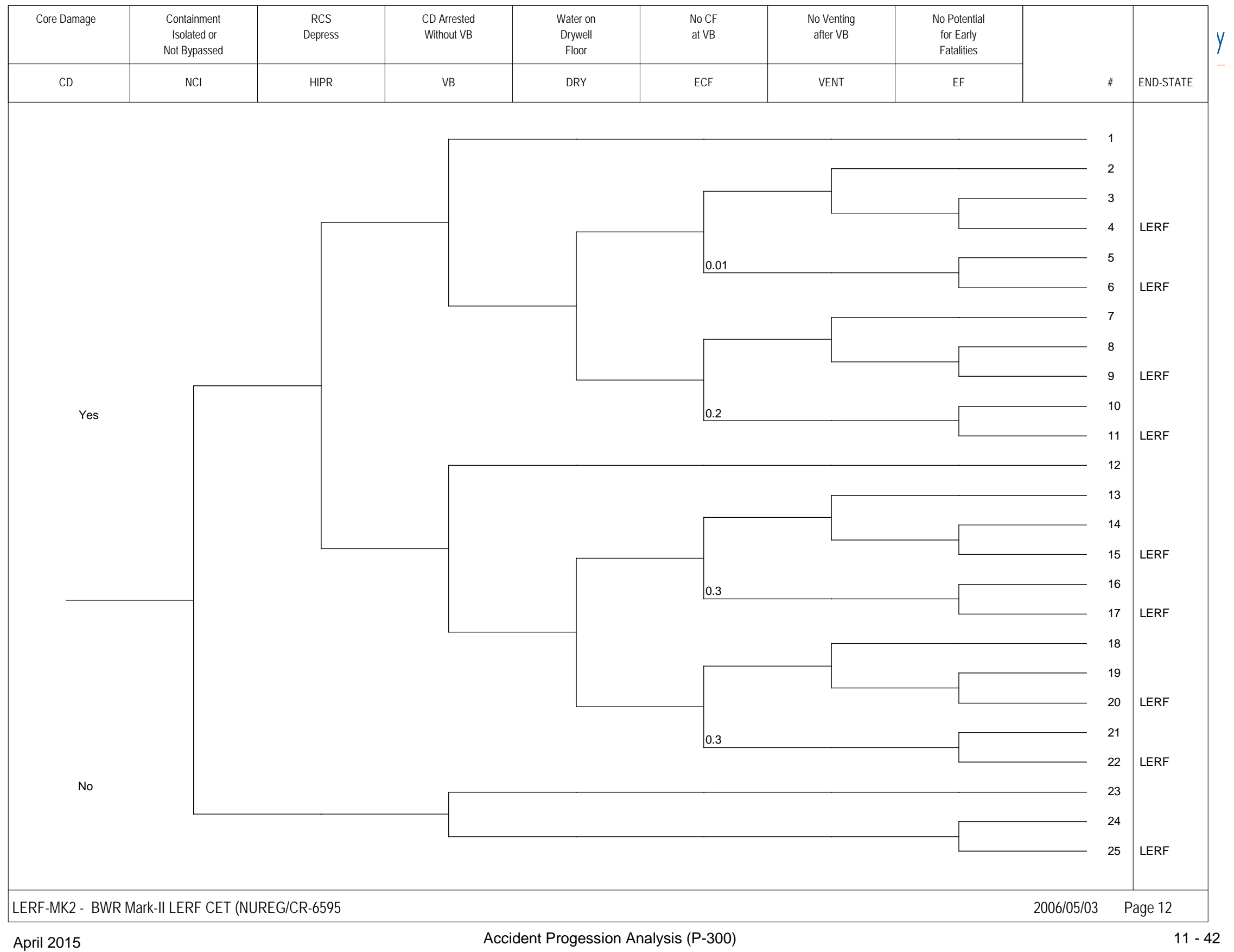




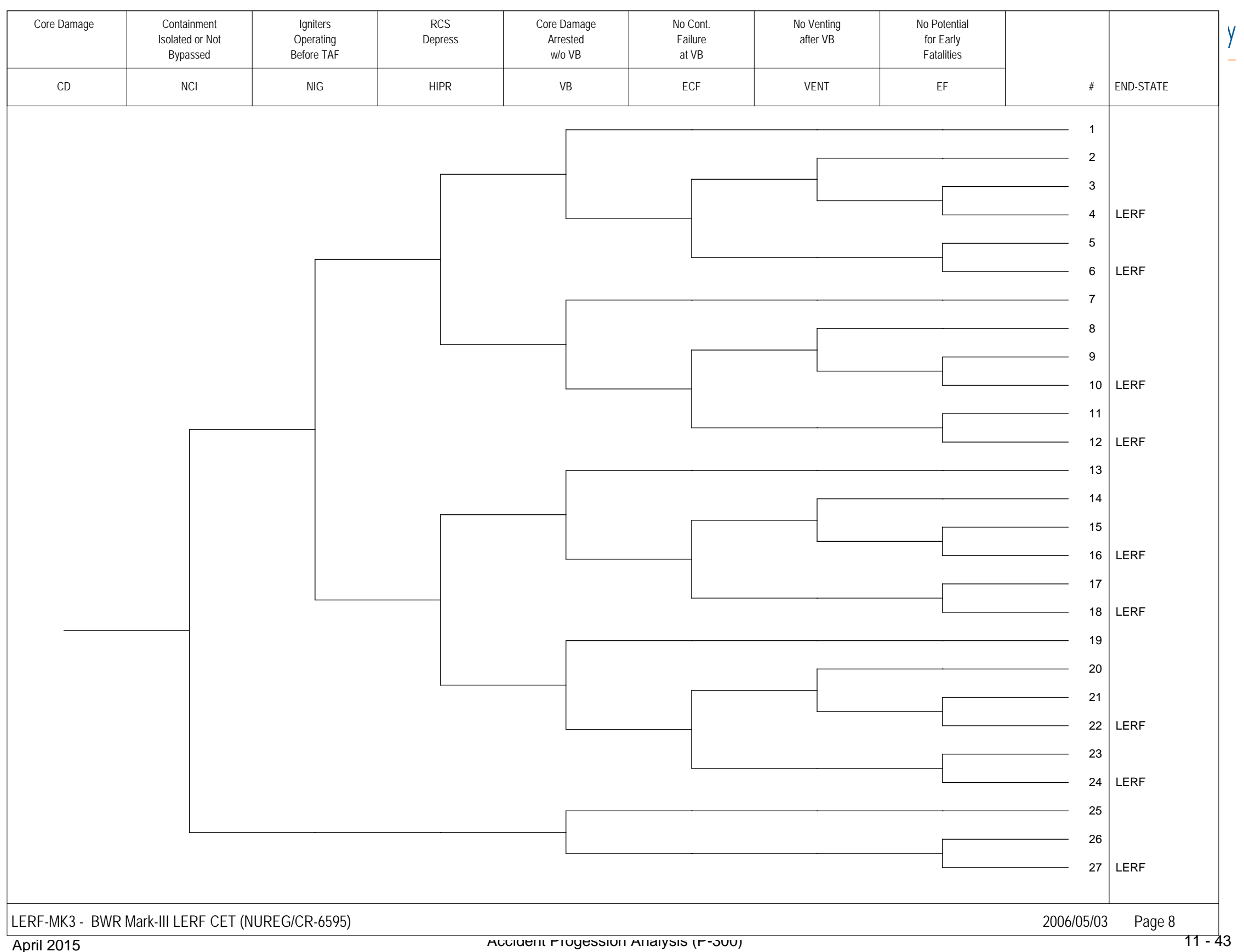




\title{
Accident Progression Analysis (P-300)
}

\author{
Review
}

April 2015 


\section{Review Questions}

1. Why do a level-2 Analysis?

2. What are the major events of interest in a level-2 analysis?

3. What severe accident progression issues are important to vessel failure probability?

4. What severe accident progression issues are important to containment failure probability?

5. What are the major LWR containment types? 


\section{Review Questions (cont.)}

6. What are some characteristics/design-features of each containment type (that are important from a severe accident analysis perspective)?

7. List the time frames of interest with respect to containment failure?

8. Each containment type incorporates a design feature to mitigate the hydrogen combustion failure mode. What are they? 